\title{
Dressings and topical agents for treating venous leg ulcers (Review)
}

Norman G, Westby MJ, Rithalia AD, Stubbs N, Soares MO, Dumville JC

Norman G, Westby MJ, Rithalia AD, Stubbs N, Soares MO, Dumville JC.

Dressings and topical agents for treating venous leg ulcers.

Cochrane Database of Systematic Reviews 2018, Issue 6. Art. No.: CD012583.

DOI: 10.1002/14651858.CD012583.pub2.

www.cochranelibrary.com 
TABLE OF CONTENTS

ABSTRACT

PLAIN LANGUAGE SUMMARY

SUMMARY OF FINDINGS

BACKGROUND

OBJECTIVES

METHODS

RESULTS

Figure 1.

Figure 2.

Figure 3.

Figure 4.

Figure 5.

Figure 6.

DISCUSSION

AUTHORS' CONCLUSIONS

ACKNOWLEDGEMENTS

REFERENCES

CHARACTERISTICS OF STUDIES

DATA AND ANALYSES

Analysis 1.1. Comparison 1 Direct evidence - included in base-case network, Outcome 1 Alginate vs nonadherent. ................

Analysis 1.2. Comparison 1 Direct evidence - included in base-case network, Outcome 2 Cadexomer iodine vs nonadherent. ....

Analysis 1.3. Comparison 1 Direct evidence - included in base-case network, Outcome 3 Film vs nonadherent.

Analysis 1.4. Comparison 1 Direct evidence - included in base-case network, Outcome 4 Foam vs nonadherent.

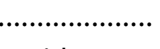

Analysis 1.5. Comparison 1 Direct evidence - included in base-case network, Outcome 5 Hyaluronic plus povidone vs nonadherent.

Analysis 1.6. Comparison 1 Direct evidence - included in base-case network, Outcome 6 Hydrocolloid vs non-adherent. ........ Analysis 1.7. Comparison 1 Direct evidence - included in base-case network, Outcome 7 Hydrofibre vs nonadherent. .............. Analysis 1.8. Comparison 1 Direct evidence - included in base-case network, Outcome 8 Hydrogel vs nonadherent. ................ Analysis 1.9. Comparison 1 Direct evidence - included in base-case network, Outcome 9 PMM vs nonadherent.

Analysis 1.10. Comparison 1 Direct evidence - included in base-case network, Outcome 10 SSD vs nonadherent. ..................... Analysis 1.11. Comparison 1 Direct evidence - included in base-case network, Outcome 11 Foam vs alginate. ........................ Analysis 1.12. Comparison 1 Direct evidence - included in base-case network, Outcome 12 Hydrocolloid vs alginate. .............. Analysis 1.13. Comparison 1 Direct evidence - included in base-case network, Outcome 13 Hydrofibre vs alginate. ................ Analysis 1.14. Comparison 1 Direct evidence - included in base-case network, Outcome 14 Paste bandage vs alginate. ........... Analysis 1.15. Comparison 1 Direct evidence - included in base-case network, Outcome 15 PMM vs alginate. .......................... Analysis 1.16. Comparison 1 Direct evidence - included in base-case network, Outcome 16 Gentian violet vs cadexomer iodine. Analysis 1.17. Comparison 1 Direct evidence - included in base-case network, Outcome 17 Hydrocolloid vs cadexomer iodine. . Analysis 1.18. Comparison 1 Direct evidence - included in base-case network, Outcome 18 Hydrocolloid vs foam. Analysis 1.19. Comparison 1 Direct evidence - included in base-case network, Outcome 19 lbuprofen foam vs foam. .............. Analysis 1.20. Comparison 1 Direct evidence - included in base-case network, Outcome 20 Octenidine vs foam. Analysis 1.21. Comparison 1 Direct evidence - included in base-case network, Outcome 21 Paste bandage vs foam. ................ Analysis 1.22. Comparison 1 Direct evidence - included in base-case network, Outcome 22 PMM vs foam. Analysis 1.23. Comparison 1 Direct evidence - included in base-case network, Outcome 23 PMM silver vs foam. ....................... Analysis 1.24. Comparison 1 Direct evidence - included in base-case network, Outcome 24 Silver vs foam. 
Analysis 2.1. Comparison 2 Direct evidence - not in base case network, in expanded base case, Outcome 1 Blood product vs emollient.

Analysis 2.2. Comparison 2 Direct evidence - not in base case network, in expanded base case, Outcome 2 Blood product vs hydrocolloid.

Analysis 2.3. Comparison 2 Direct evidence - not in base case network, in expanded base case, Outcome 3 Blood product vs hydrogel.

Analysis 2.4. Comparison 2 Direct evidence - not in base case network, in expanded base case, Outcome 4 Blood product vs saline gauze.

Analysis 2.5. Comparison 2 Direct evidence - not in base case network, in expanded base case, Outcome 5 Hyaluronic vs emollient cream.

Analysis 2.6. Comparison 2 Direct evidence - not in base case network, in expanded base case, Outcome 6 Growth factor vs hydrocolloid.

Analysis 2.7. Comparison 2 Direct evidence - not in base case network, in expanded base case, Outcome 7 Growth factor vs hydrogel.

Analysis 2.8. Comparison 2 Direct evidence - not in base case network, in expanded base case, Outcome 8 Growth factor vs nonadherent.

Analysis 2.9. Comparison 2 Direct evidence - not in base case network, in expanded base case, Outcome 9 SSD vs emollient. ....

Analysis 3.1. Comparison 3 Direct evidence - not in network, Outcome $1 \mathrm{~A}$. Pichinchensis vs alginate.

Analysis 3.2. Comparison 3 Direct evidence - not in network, Outcome 2 Non-adherent vs cellulose.

Analysis 3.3. Comparison 3 Direct evidence - not in network, Outcome 3 Phenytoin vs no treatment.

Analysis 3.4. Comparison 3 Direct evidence - not in network, Outcome 4 Cadexomer iodine vs standard treatment. .................

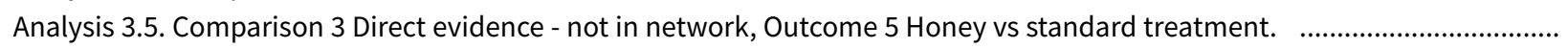

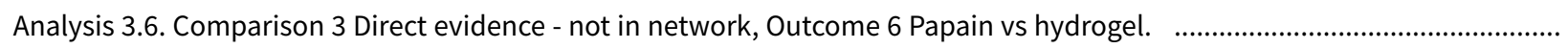

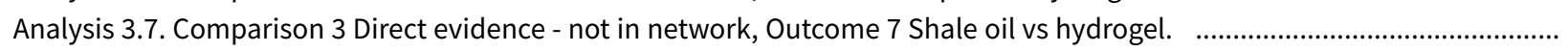

Analysis 3.8. Comparison 3 Direct evidence - not in network, Outcome 8 Tripeptide copper vs hydrogel. .................................

Analysis 3.9. Comparison 3 Direct evidence - not in network, Outcome 9 Hydrocolloid vs collagen.

Analysis 3.10. Comparison 3 Direct evidence - not in network, Outcome 10 Hydrocolloid vs dextranomer.

Analysis 3.11. Comparison 3 Direct evidence - not in network, Outcome 11 Hydrocolloid vs magnesium sulphate. .................

Analysis 3.12. Comparison 3 Direct evidence - not in network, Outcome 12 Hydrocolloid vs nonadherent or iodine. ................

Analysis 3.13. Comparison 3 Direct evidence - not in network, Outcome 13 Ozonated oil vs zinc oxide.

Analysis 3.14. Comparison 3 Direct evidence - not in network, Outcome 14 Cadexomer iodine vs dextranomer.

Analysis 3.15. Comparison 3 Direct evidence - not in network, Outcome 15 Silica gel fibre vs standard care. ............................

Analysis 3.16. Comparison 3 Direct evidence - not in network, Outcome 16 Silver vs non-silver.

Analysis 3.17. Comparison 3 Direct evidence - not in network, Outcome 17 Sulphadryl vs inactive powder. ............................

Analysis 3.18. Comparison 3 Direct evidence - not in network, Outcome 18 Tripeptide copper vs emollient cream. .................

Analysis 3.19. Comparison 3 Direct evidence - not in network, Outcome 19 Tripeptide copper vs SSD.

Figure 7.

Figure 8.

Figure 9.

Figure 10.

Figure 11.

Figure 12.

Figure 13.

Figure 14.

Figure 15.

Figure 16.

Figure 17.

Figure 18.

Figure 19.

Figure 20.

Figure 21. 


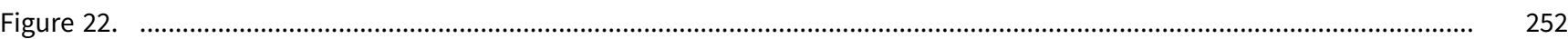

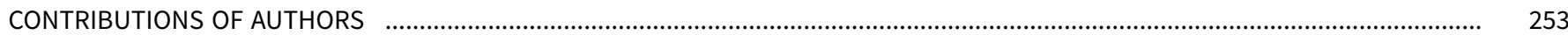

DECLARATIONS OF INTEREST

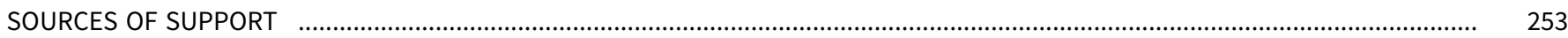

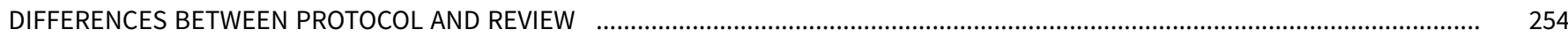

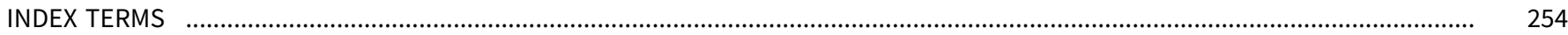


[Intervention Review]

\section{Dressings and topical agents for treating venous leg ulcers}

Gill Norman1a, Maggie J Westby ${ }^{1}$, Amber D Rithalia², Nikki Stubbs ${ }^{3}$, Marta O Soares ${ }^{4}$, Jo C Dumville ${ }^{1}$

1Division of Nursing, Midwifery and Social Work, School of Health Sciences, Faculty of Biology, Medicine and Health, University of Manchester, Manchester Academic Health Science Centre, Manchester, UK. 2 Independent Researcher, Leeds, UK. ${ }^{3}$ Leeds Community Healthcare NHS Trust, St Mary's Hospital, Leeds, UK. ${ }^{4}$ Centre for Health Economics, University of York, York, UK

aGill Norman and Maggie Westby contributed equally to this work, and should be considered as joint first authors.

Contact: Gill Norman, Division of Nursing, Midwifery and Social Work, School of Health Sciences, Faculty of Biology, Medicine and Health, University of Manchester, Manchester Academic Health Science Centre, Jean McFarlane Building, Oxford Road, Manchester, M13 9PL, UK.gill.norman@manchester.ac.uk.

Editorial group: Cochrane Wounds Group.

Publication status and date: New, published in Issue 6, 2018.

Citation: Norman G, Westby MJ, Rithalia AD, Stubbs N, Soares MO, Dumville JC. Dressings and topical agents for treating venous leg ulcers. Cochrane Database of Systematic Reviews 2018, Issue 6. Art. No.: CD012583. DOI: 10.1002/14651858.CD012583.pub2.

Copyright (c) 2018 The Cochrane Collaboration. Published by John Wiley \& Sons, Ltd.

\section{A B S T R A C T}

\section{Background}

Venous leg ulcers are open skin wounds on the lower leg which can be slow to heal, and are both painful and costly. The point prevalence of open venous leg ulcers in the UK is about 3 cases per 10,000 people, and many people experience recurrent episodes of prolonged ulceration. First-line treatment for venous leg ulcers is compression therapy, but a wide range of dressings and topical treatments are also used. This diversity of treatments makes evidence-based decision-making challenging, and a clear and current overview of all the evidence is required. This review is a network meta-analysis (NMA) which assesses the probability of complete ulcer healing associated with alternative dressings and topical agents.

\section{Objectives}

To assess the effects of (1) dressings and (2) topical agents for healing venous leg ulcers in any care setting and to rank treatments in order of effectiveness, with assessment of uncertainty and evidence quality.

\section{Search methods}

In March 2017 we searched the Cochrane Wounds Specialised Register; the Cochrane Central Register of Controlled Trials (CENTRAL); Ovid MEDLINE; Ovid MEDLINE (In-Process \& Other Non-Indexed Citations); Ovid Embase and EBSCO CINAHL Plus. We also scanned reference lists of relevant included studies as well as reviews, meta-analyses, guidelines and health technology reports to identify additional studies. There were no restrictions with respect to language, date of publication or study setting. We updated this search in March 2018; as a result several studies are awaiting classification.

\section{Selection criteria}

We included published or unpublished randomised controlled trials (RCTs) that enrolled adults with venous leg ulcers and compared the effects of at least one of the following interventions with any other intervention in the treatment of venous leg ulcers: any dressing, or any topical agent applied directly to an open venous leg ulcer and left in situ. We excluded from this review dressings attached to external devices such as negative pressure wound therapies, skin grafts, growth factors and other biological agents, larval therapy and treatments such as laser, heat or ultrasound. Studies were required to report complete wound healing to be eligible.

\section{Data collection and analysis}

Two review authors independently performed study selection, 'Risk of bias' assessment and data extraction. We conducted this NMA using frequentist meta-regression methods for the efficacy outcome; the probability of complete healing. We assumed that treatment effects 
were similar within dressings classes (e.g. hydrocolloid, foam). We present estimates of effect with their $95 \%$ confidence intervals (Cls) for individual treatments focusing on comparisons with widely used dressing classes, and we report ranking probabilities for each intervention (probability of being the best, second best, etc treatment). We assessed the certainty (quality) of the body of evidence using GRADE for each network comparison and for the network as whole.

\section{Main results}

We included 78 RCTs (7014 participants) in this review. Of these, 59 studies (5156 participants, 25 different interventions) were included in the NMA; resulting in 40 direct contrasts which informed 300 mixed-treatment contrasts.

The evidence for the network as a whole was of low certainty. This judgement was based on the sparsity of the network leading to imprecision and the general high risk of bias in the included studies. Sensitivity analyses also demonstrated instability in key aspects of the network and results are reported for the extended sensitivity analysis. Evidence for individual contrasts was mainly judged to be low or very low certainty.

The uncertainty was perpetuated when the results were considered by ranking the treatments in terms of the probability that they were the most effective for ulcer healing, with many treatments having similar, low, probabilities of being the best treatment. The two most highly-ranked treatments both had more than $50 \%$ probability of being the best (sucralfate and silver dressings). However, the data for sucralfate was from one small study, which means that this finding should be interpreted with caution. When exploring the data for silver and sucralfate compared with widely-used dressing classes, there was some evidence that silver dressings may increase the probability of venous leg ulcer healing, compared with nonadherent dressings: RR $2.43,95 \% \mathrm{Cl} 1.58$ to 3.74 (moderate-certainty evidence in the context of a low-certainty network). For all other combinations of these five interventions it was unclear whether the intervention increased the probability of healing; in each case this was low- or very low-certainty evidence as a consequence of one or more of imprecision, risk of bias and inconsistency.

\section{Authors' conclusions}

More research is needed to determine whether particular dressings or topical agents improve the probability of healing of venous leg ulcers. However, the NMA is uninformative regarding which interventions might best be included in a large trial, largely because of the low certainty of the whole network and of individual comparisons. The results of this NMA focus exclusively on complete healing; whilst this is of key importance to people living with venous leg ulcers, clinicians may wish to take into account other patient-important outcomes and factors such as patient preference and cost.

\section{PLAIN LANGUAGE S UMARY}

\section{Dressings and topical agents (gels, ointments and creams) for treating venous leg ulcers}

\section{What is the aim of this review?}

The aim of this review is to find out which dressings and topical agents (gels, ointments and creams) are most effective for treating a type of wound known as venous leg ulcers. These are long-term wounds in the lower leg caused by problems with blood flow back up the leg through the veins. Researchers from Cochrane found 78 relevant studies (randomised controlled trials) to answer this question. Randomised controlled trials are medical studies where patients are chosen at random to receive different treatments. This type of trial provides the most reliable evidence. We evaluated these studies using a method known as network meta-analysis (NMA), which allowed us to compare treatments across different studies and to rank them in terms of complete ulcer healing.

\section{Key messages}

We cannot be certain which dressings and topical agents are most effective for healing venous leg ulcers: over all studies there were not enough participants per treatment and there was high risk of bias; this means that many of the studies were conducted or reported in a way that means we cannot be sure if the results are accurate. The main treatment for venous leg ulcers is compression bandages or stockings and the choice of additional dressings or topical treatments should take into account the review findings and their uncertainty, alongside factors such as patient preference and cost.

\section{What was studied in the review?}

Venous leg ulcers are open wounds caused by poor blood flow through the veins of the lower leg. Increased pressure in the leg veins may cause damage to the skin and surrounding tissues, leading to an ulcer. Venous leg ulcers can be slow to heal and are painful and costly to treat. The main treatment is compression bandages or stockings but these are often combined with dressings (e.g. foam or nonadherent dressings) and topical creams, gels or ointments. We wished to know which of these additional treatments are most effective when it comes to ulcer healing.

\section{What are the main results of the review?}


We found 78 studies relevant to this question, dating from 1985 to 2016 . The studies involved 7014 participants (a majority were women, and average age ranged from 46 to 81 where reported). Our NMA included 59 studies (5156 participants) and compared 25 different treatments such as hydrocolloid and silver-impregnated dressings and a variety of creams and gels.

Silver dressings may increase the probability of venous leg ulcer healing compared with nonadherent dressings. However, in the light of the rest of the NMA evidence, we cannot be very confident about any conclusion, and the network as a whole represents low-certainty evidence. This was due to the small numbers of people involved across all included studies, the small number of studies focusing on each treatment, and the high risk of bias. We cannot therefore be certain which are the most effective treatments for venous leg ulcers, or even which treatments it would be best to compare in future trials.

\section{How up to date is this review?}

We searched for studies published up to March 2017. 
SUMMARY OF FINDINGS

Summary of findings for the main comparison. NMA evidence: proportion with complete healing

NMA evidence for base-case network: proportion with complete healing

Patient or population: people with venous leg ulcers

Intervention: dressing or topical agent

Comparator: alternative dressing or topical agent

Settings: hospital, community or care home, or combinations

\begin{tabular}{|c|c|c|c|c|c|}
\hline \multirow[t]{2}{*}{ Contrasts } & \multirow[t]{2}{*}{$\begin{array}{l}\text { Relative effect } \\
(95 \% \mathrm{CI})\end{array}$} & \multicolumn{2}{|c|}{$\begin{array}{l}\text { Anticipated absolute effects* }(95 \% \mathrm{Cl}) \text { - } \\
\text { from median of control groups in direct evidence }\end{array}$} & \multirow[t]{2}{*}{$\begin{array}{l}\text { Certainty of } \\
\text { the evidence } \\
\text { (GRADE) }\end{array}$} & \multirow[t]{2}{*}{ Comments } \\
\hline & & Median CGR & With intervention & & \\
\hline \multirow[t]{2}{*}{$\begin{array}{l}\text { Sucralfate versus } \\
\text { nonadherent }\end{array}$} & \multirow[t]{2}{*}{$\begin{array}{l}\text { RR } 6.80 \\
\text { (2.24 to } 20.7)\end{array}$} & 242 per 1000 & $\begin{array}{l}1000 \text { per } 1000 \\
(542 \text { to } 1000)\end{array}$ & \multirow[t]{2}{*}{$\begin{array}{l}\oplus \oplus \odot \ominus \\
\text { Lowa,b }\end{array}$} & \multirow{2}{*}{$\begin{array}{l}\text { Base-case: RR } 17.2 \\
\text { ( } 95 \% \mathrm{CI} 1.52 \text { to } 193) \text {. Large differences be- } \\
\text { tween base-case and extended base-case. } \\
\text { The calculated absolute effect for the inter- } \\
\text { vention is more than } 1000 \text { per } 1000 \text { for the } \\
\text { point estimate and its upper confidence lim- } \\
\text { it; and so the corresponding values for the ab- } \\
\text { solute risk difference are also approximated } \\
\text { by } 1000 \text { per } 1000 \text {. }\end{array}$} \\
\hline & & \multicolumn{2}{|c|}{$\begin{array}{l}1000 \text { more people healed per } 1000 \\
\text { (300 to } 1000 \text { more) }\end{array}$} & & \\
\hline \multirow[t]{3}{*}{$\begin{array}{l}\text { Sucralfate versus } \\
\text { foam }\end{array}$} & \multirow[t]{3}{*}{$\begin{array}{l}\text { RR } 5.94 \\
\text { (1.96 to } 18.0)\end{array}$} & 376 per 1000 & $\begin{array}{l}1000 \text { per } 1000 \\
(737 \text { to } 1000)\end{array}$ & \multirow[t]{3}{*}{$\begin{array}{l}\oplus \oplus \oplus \ominus \\
\text { Lowa,b }^{a}\end{array}$} & \multirow{2}{*}{$\begin{array}{l}\text { Base-case: } \mathrm{RR} 14.8 \\
\text { (95\% } \mathrm{Cl} 1.30 \text { to } 169 \text { ) } \\
\text { Large differences between base-case and ex- } \\
\text { tended base-case. }\end{array}$} \\
\hline & & \multicolumn{2}{|c|}{1000 more people healed per 1000} & & \\
\hline & & \multicolumn{2}{|c|}{ (361 to 1000 more) } & & $\begin{array}{l}\text { The calculated absolute effect for the inter- } \\
\text { vention is more than } 1000 \text { per } 1000 \text { for the } \\
\text { point estimate and its upper confidence lim- } \\
\text { it; and so the corresponding values for the ab- } \\
\text { solute risk difference are also approximated } \\
\text { by } 1000 \text { per } 1000 \text {. }\end{array}$ \\
\hline \multirow[t]{2}{*}{$\begin{array}{l}\text { Sucralfate versus } \\
\text { hydrocolloid }\end{array}$} & \multirow[t]{2}{*}{$\begin{array}{l}\text { RR } 6.51 \\
\text { (2.17 to } 19.6 \text { ) }\end{array}$} & 433 per 1000 & 1000 per 1000 (940 to 1000$)$ & \multirow[t]{2}{*}{$\begin{array}{l}\oplus \oplus \ominus \ominus \\
\text { Lowa,b }\end{array}$} & \multirow[t]{2}{*}{$\begin{array}{l}\text { Base-case: RR } 16.24 \\
(95 \% \mathrm{Cl} 1.43 \text { to } 185)\end{array}$} \\
\hline & & \multicolumn{2}{|c|}{1000 more people healed per 1000} & & \\
\hline
\end{tabular}




\begin{tabular}{|c|c|c|c|c|c|}
\hline & & (507 to $1000 \mathrm{r}$ & & & $\begin{array}{l}\text { Large differences between base-case and ex- } \\
\text { tended base-case } \\
\text { The calculated absolute effect for the inter- } \\
\text { vention is more than } 1000 \text { per } 1000 \text { for the } \\
\text { point estimate and its upper confidence lim- } \\
\text { it; and so the corresponding values for the ab- } \\
\text { solute risk difference are also approximated } \\
\text { by } 1000 \text { per } 1000 \text {. }\end{array}$ \\
\hline \multirow{2}{*}{$\begin{array}{l}\text { Silver versus } \\
\text { nonadherent }\end{array}$} & RR 2.43 & 242 per 1000 & 588 per 1000 (382 to 905$)$ & \multirow{2}{*}{$\begin{array}{l}\oplus \oplus \oplus \ominus \\
\text { Moderatea }\end{array}$} & \\
\hline & & \multicolumn{2}{|c|}{$\begin{array}{l}346 \text { more people healed per } 1000 \\
\text { (140 to } 663 \text { more) }\end{array}$} & & \\
\hline \multirow{2}{*}{$\begin{array}{l}\text { Silver versus } \\
\text { foam }\end{array}$} & \multirow{2}{*}{$\begin{array}{l}\text { RR } 2.12 \\
\text { (1.46 to } 3.07)\end{array}$} & 376 per 1000 & 797 per 1000 (549 to 1000$)$ & \multirow{2}{*}{$\begin{array}{l}\oplus \oplus \ominus \ominus \\
\text { Lowc }\end{array}$} & \multirow[t]{2}{*}{ Direct evidence: Analysis 1.24} \\
\hline & & \multicolumn{2}{|c|}{$\begin{array}{l}421 \text { more people healed per } 1000 \\
\text { (173 to } 786 \text { more) }\end{array}$} & & \\
\hline \multirow{3}{*}{$\begin{array}{l}\text { Silver versus } \\
\text { hydrocolloid }\end{array}$} & \multirow{3}{*}{$\begin{array}{l}\text { RR } 2.32 \\
\text { (1.58 to } 3.41)\end{array}$} & 433 per 1000 & 1000 per 1000 (684 to 1000$)$ & \multirow{3}{*}{$\begin{array}{l}\oplus \oplus \ominus \ominus \\
\text { Lowa,d }\end{array}$} & \\
\hline & & \multicolumn{2}{|c|}{567 more people healed per 1000} & & \\
\hline & & (251 to $1000 r$ & & & \\
\hline \multirow{2}{*}{$\begin{array}{l}\text { Sucralfate versus } \\
\text { silver }\end{array}$} & \multirow{2}{*}{$\begin{array}{l}\text { RR } 2.80 \\
\text { (0.88 to } 8.97 \text { ) }\end{array}$} & 81 per 1000 & 225 per 1000 (71 to 722 ) & \multirow{2}{*}{$\begin{array}{l}\oplus \ominus \ominus \ominus \\
\text { Very lowa,e }\end{array}$} & \multirow{2}{*}{$\begin{array}{l}\text { Base-case: RR } 6.99 \\
(95 \% \mathrm{Cl} 0.60 \text { to } 82.0) \\
\text { Large differences between base-case and ex- } \\
\text { tended base-case }\end{array}$} \\
\hline & & \multicolumn{2}{|c|}{$\begin{array}{l}145 \text { more people healed per } \mathbf{1 , 0 0 0} \\
\text { (10 fewer to } 642 \text { more) }\end{array}$} & & \\
\hline \multirow{2}{*}{$\begin{array}{l}\text { Foam versus } \\
\text { hydrocolloid }\end{array}$} & \multirow{2}{*}{$\begin{array}{l}\text { RR } 1.10 \\
\text { (0.93 to } 1.28 \text { ) }\end{array}$} & 433 per 1000 & 476 per 1000 ( 402 to 554 ) & \multirow{2}{*}{$\begin{array}{l}\oplus \Theta \Theta \Theta \\
\text { Very lowf,g,h }\end{array}$} & \multirow[t]{2}{*}{ Direct evidence: Analysis 1.18} \\
\hline & & \multicolumn{2}{|c|}{$\begin{array}{l}\mathbf{4 3} \text { more people healed per } 1000 \\
\text { (from } 31 \text { fewer to } 121 \text { more) }\end{array}$} & & \\
\hline \multirow{2}{*}{$\begin{array}{l}\text { Foam versus } \\
\text { nonadherent } \\
\text { dressing }\end{array}$} & \multirow{2}{*}{$\begin{array}{l}\text { RR } 1.15 \\
\text { (0.91 to } 1.44)\end{array}$} & 242 per 1000 & 278 per 1000 ( 220 to 348$)$ & \multirow{2}{*}{$\begin{array}{l}\oplus \oplus \ominus \ominus \\
\text { Lowa,h }\end{array}$} & \\
\hline & & \multicolumn{2}{|c|}{$\begin{array}{l}\mathbf{3 6} \text { more people healed per } 1000 \\
\text { (from } 22 \text { fewer to } 106 \text { more) }\end{array}$} & & \\
\hline
\end{tabular}




\section{B A C K G R O U N D}

\section{Description of the condition}

Venous leg ulcers are common and recurring complex wounds that heal by secondary intention (that is by the growth of new tissue rather than by primary closure). Problems with the leg veins (such as damage to the valves, or blockages) reduce the efficient return of blood to the heart and increase the pressure in the veins (Ghauri 2010), which may result in venous leg ulcers. The precise chain of events that links high venous pressures (chronic venous hypertension) with skin breakdown and a chronic wound is not fully understood (Coleridge Smith 1988; Valencia 2001).

Venous leg ulcers commonly occur on the gaiter region of the lower leg (from just below the ankle up to mid-calf). A venous leg ulcer is defined as any break in the skin that has either been present for longer than six weeks or occurs in a person with a history of venous leg ulceration. Differential diagnosis of the type of leg ulcer (i.e. the underlying cause) is made by taking a clinical history, physical examination, laboratory tests and haemodynamic assessment (RCN 2013; SIGN 2010). True venous ulcers are moist, shallow and irregularly shaped and lie wholly or partly within the gaiter area of the leg. Leg ulcers can be associated with venous disease in combination with vascular disease, which impairs arterial blood supply; in these instances they are said to have a 'mixed' aetiology (to have more than one cause). Open skin ulceration due solely to limb ischaemia from vascular disease is less common.

Accurate, current estimates of leg ulcer prevalence are hard to identify because most surveys do not differentiate between causes of leg ulceration, or do so per limb but not per person (Moffatt 2004; Srinivasaiah 2007; Vowden 2009b). Estimates of the prevalence of open leg ulceration (any cause) range from 4 to 48 cases per 10,000 (Graham 2003; Johnson 1995; Walker 2002), with the point prevalence of venous leg ulceration in Australian and European studies being between 10 per 10,000 and 30 per 10,000 (Nelzen 2008). A recent estimate suggests that venous ulceration has a point prevalence of 2.9 cases per 10,000 in the United Kingdom (UK), whilst mixed arterial/venous leg ulceration has a point prevalence of 1.1 per 10,000 (Hall 2014).

Venous disease is a chronic condition which can be characterised by periods of ulceration (i.e. an open wound) followed by healing and then recurrence. An early cross-sectional survey reported that half of current or recent ulcers had been open for up to nine months and that $35 \%$ of people with leg ulcers had experienced four or more episodes (Callam 1987b). This picture was supported by a subsequent cross-sectional study (Nelzen 1994). More recent analysis of almost 1200 people with venous leg ulcers documented a 24-week healing rate of $76 \%$ and a recurrence at one year of $17 \%$ (Gohel 2005).

Venous ulcers are painful, can be malodorous and prone to infection, and may severely affect people's mobility and quality of life. The presence of leg ulceration has been associated with pain, restriction of work and leisure activities, impaired mobility, sleep disturbance, reduced psychological well-being and social isolation (Herber 2007; Maddox 2012; Persoon 2004). In severe cases, ulceration can lead to limb amputation, although this may be more common in people with comorbid arterial insufficiency (Dumville 2009; Nelzen 1997; Valencia 2001). Recent research suggests that people with complex wounds, including those with venous leg ulcers, commonly see complete wound healing as the most important outcome to them (Cullum 2016; Madden 2014).

The financial cost of treating an unhealed leg ulcer in the UK has most recently been estimated at around GBP 1700 per year (price year 2012) (Ashby 2014). An earlier evaluation estimated the average cost of treating a venous leg ulcer in the UK (based on costs for material for dressing changes) as between EUR 814 and EUR 1994 and, in Sweden as lying between EUR 1332 and EUR 2585 (price year 2002), with higher costs associated with larger and more chronic wounds (Ragnarson 2005). In Bradford, UK, GBP 1.69 million was spent on dressings and compression bandages, and GBP 3.08 million on nursing time (estimates derived from resource use data for all wound types) during the financial year 2006 to 2007 (Vowden 2009a). Data from a German study, which estimated total costs including those classified as indirect or intangible costs, estimated mean annual costs of leg ulcers as EUR 9060 per patient (price year 2006). This figure is higher than other estimates because it includes non-health service costs to the patient and to society (Augustin 2012). These data are all derived from high-income countries and thus may not be a true reflection of costs elsewhere, which may be higher or lower.

\section{Description of the intervention}

The review includes all dressings and topical agents applied directly onto or into wounds and left in situ. This contrasts with products used to irrigate, wash or cleanse wounds and that are only in contact with wounds for a short period. First-line treatment for venous leg ulcers is compression therapy in the form of bandages, stockings or mechanical devices (Nelson 2014; O'Meara 2012). This application of external pressure around the lower leg assists venous return and reduces venous reflux (Woo 2013). We therefore anticipated that wound dressings would commonly be used in combination with compression therapy.

Dressings are widely used in wound care with the aim of protecting the wound and promoting healing by influencing the local wound environment (Bradley 1999), typically by physical means, such as thermal insulation, absorption of exudate and physical protection. Dressings may also have pharmacological, immunological or metabolic actions. Topical agents include hydrogel gels, ointments and creams that are placed in contact with the wound and left in situ.

\section{Dressings}

The classification of dressings usually depends on the key material used in their construction, and whether additional substances are added to the dressing. Several attributes of an ideal wound dressing have been described (BNF 2016), including the ability of the dressing to:

- absorb and contain exudate without leakage or strike-through, in order to maintain a wound that is moist but not macerated;

- achieve freedom from particulate contaminants or toxic chemicals left in the wound;

- provide thermal insulation, in order to maintain the optimum temperature for healing;

- allow permeability to water, but not bacteria;

- optimise the $\mathrm{pH}$ of the wound;

- minimise wound infection and avoid excessive slough; 
- avoid wound trauma on dressing removal;

- accommodate the need for frequent dressing changes;

- provide pain relief; and

- be comfortable.

There is a wide range of types of dressings available which may be used for treating wounds including venous leg ulcers; some of these and their properties are described below (BNF 2016). Impregnated dressings may have a range of bases, such as foams or alginates.

Absorbent dressings are applied directly to the wound and may be used as secondary absorbent layers in the management of heavily exuding wounds. Examples include Primapore (Smith \& Nephew); this can be lifted off at dressing removal, or removed by irrigation. Bonding to a secondary viscose pad increases absorbency. Examples include: Curasorb (Covidien), SeaSorb (Coloplast) and Sorbsan (Unomedical).

Capillary-action dressings consist of an absorbent core of hydrophilic fibres held between two low-adherent contact layers. Examples include: Advadraw (Advancis) and Vacutex (Protex).

Permeable film and membrane dressings are permeable to water vapour and oxygen, but not to water or micro-organisms. Examples include Tegaderm (3M) transparent film and OpSite (Smith \& Nephew).

Foam dressings contain hydrophilic polyurethane foam and are designed to absorb wound exudate and maintain a moist wound surface. There are a variety of versions and some include additional absorbent materials, such as viscose and acrylate fibres, or particles of superabsorbent polyacrylate, which are silicone-coated for non-traumatic removal. Examples include: Allevyn (Smith \& Nephew), Biatain (Coloplast) and Tegaderm (3M) foam adhesive and non-adhesive dressings.

Honey-impregnated dressings contain medical-grade honey that is purported to have antimicrobial and anti-inflammatory properties and can be used for acute or chronic wounds. Examples include: Medihoney (Medihoney) and Activon Tulle (Advancis).

Hydrocolloid dressings are usually composed of an absorbent hydrocolloid matrix on a vapour-permeable film or foam backing. Examples include: Granuflex (ConvaTec) and NU DERM (Systagenix). Fibrous alternatives that resemble alginates and are not occlusive have also been developed: Aquacel (ConvaTec).

lodine-impregnated dressings release free iodine, which is thought to act as a wound antiseptic when exposed to wound exudate. Examples include lodoflex (Smith \& Nephew) and lodozyme (Insense).

Low-adherence dressings and wound contact materials usually consist of cotton pads that are placed directly in contact with the wound. They can be non-medicated (e.g. paraffin gauze dressing, saline gauze dressing) or medicated (e.g. containing povidone iodine or chlorhexidine). Examples include paraffin gauze dressing, BP 1993 and Xeroform (Covidien) dressing - a nonadherent petrolatum blend with $3 \%$ bismuth tribromophenate on fine mesh gauze.

Odour-absorbent dressings contain charcoal and are used to absorb wound odour. Often this type of wound dressing is used in conjunction with a secondary dressing to improve absorbency. An example is CarboFLEX (ConvaTec).

Other antimicrobial dressings are composed of a gauze or lowadherent dressing impregnated with an ointment thought to have antimicrobial properties (e.g. chlorhexidine gauze dressing (Smith \& Nephew)). Alternatively, a dressing such as Cutimed Sorbact (BSN Medical) uses a hydrophobic layer to bind micro-organisms to the dressing surface, allowing them to be removed from the wound when the dressing is changed.

Protease-modulating matrix dressings alter the activity of proteolytic enzymes in chronic wounds. Examples include: Promogran (Systagenix).

Silver-impregnated dressings are used to treat infected wounds, as silver ions are thought to have antimicrobial properties. Silver versions of most dressing types are available, including silver impregnated dressings (e.g. silver hydrocolloid etc). Examples include: Acticoat (Smith \& Nephew) and Urgosorb Silver (Urgo).

Soft polymer dressings are composed of a soft silicone polymer held in a nonadherent layer; these are moderately absorbent. Examples include: Mepitel (Mölnlycke) and Urgotul (Urgo).

\section{Topical agents}

The following types of topical agents are considered as interventions in this review.

Cadexomer-iodine paste consists of a water-soluble, modified starch polymer containing iodine. It releases free iodine when exposed to wound exudate. The free iodine acts as an antiseptic on the wound surface, and the cadexomer absorbs wound exudate and encourages de-sloughing. Examples include: lodosorb (Smith \& Nephew) ointment and powder.

Collagenase-containing ointment is an enzymatic debriding ointment. Collagenase is thought to digest collagen in necrotic tissue and to contribute to granulation and epithelialisation (the final stage of wound healing).

Hydrogels consist of a starch polymer and up to $96 \%$ water. They can absorb wound exudate or rehydrate a wound depending on the wound moisture levels. Hydrogels are often considered to be dressings, but are also topical in nature. They are supplied in either flat sheets, an amorphous hydrogel or as beads. Examples include: ActiformCool (Activa) and Aquaflo (Covidien).

Topical phenytoin is thought to promote wound healing by a number of mechanisms, including stimulation of fibroblast proliferation, facilitation of collagen deposition and antibacterial activity.

Silver sulfadiazine cream is a topical antimicrobial cream that is used to treat and prevent infection in wounds by damaging bacterial cell membranes. Examples include Flamazine (Smith \& Nephew) and Silvadene (Pfizer).

We did not consider studies evaluating any products containing growth factors, platelet-rich plasma or other platelet-derived products and colony-stimulating factors. 


\section{How the intervention might work}

Animal experiments conducted over 40 years ago suggested that acute wounds heal more quickly when their surfaces are kept moist rather than left to dry and scab (Winter 1962; Winter 1963a; Winter 1963b). A moist environment is thought to provide optimal conditions for the cells involved in the healing process with faster revascularisation (Dyson 1992), and development of granulation tissue (Svensjö 2000), as well as allowing autolytic debridement (removal of dead tissue by natural processes), which is thought to be an important part of the healing pathway (Cardinal 2009).

The desire to maintain a moist wound environment is a key driver for the use of wound dressings and related topical agents. Whilst a moist environment at the wound site has been shown to aid the rate of epithelialisation in superficial wounds, excess moisture at the wound site can cause maceration (breakdown) of the surrounding skin (Cutting 2002), and it has also been suggested that dressings that permit fluid to accumulate might predispose wounds to infection (Hutchinson 1991). Wound treatments vary in their level of absorbency, so that a very wet wound can be treated with an absorbent dressing (such as a foam dressing) to draw excess moisture away and avoid skin damage, whilst a drier wound can be treated with a more occlusive dressing or a hydrogel to maintain a moist environment.

Some dressings are now also formulated with an 'active' ingredient (e.g. silver, honey or protease modulators).

\section{Why it is important to do this review}

Venous leg ulcers are a relatively common type of complex wound that have a negative impact on people's lives and incur high costs for health services and society. Leg ulcers are painful, sometimes malodorous, prone to infection, and may severely affect people's mobility and quality of life, and in severe cases, there is a risk of limb amputation. There are a number of treatments for venous leg ulcers, but many ulcers prove hard to heal, although healing is a key outcome for patients.

We conducted an open consultation with consumers to ask them which treatments for treating venous leg ulcers they would like to see considered. Respondents self-selected through their response to a short questionnaire posted on the Cochrane Wounds website and Facebook page. Although some identified compression as the main consideration, others mentioned specific types of dressings. These included many of the dressing types listed in Description of the intervention, including charcoal-containing (odour-absorbing) dressings, dressings designed to reduce formation and presence of biofilms (bacteria which grow on a surface to form a film of cells) and dressings with antimicrobial properties and debriding actions. Also specifically identified as being of interest was Unna's boot; a specialised dressing which consists of gauze wraps impregnated with zinc oxide and calamine, sometimes in combination with other agents.

The diversity of dressings and related materials available to health professionals for treating venous leg ulcers makes evidencebased decision-making difficult when determining the optimum treatment regimen for a particular patient (NICE 2016a). With increasingly sophisticated technology being applied to wound care, practitioners need to know the relative effectiveness and cost-effectiveness of these sometimes expensive dressings. Even where cost is not an issue, the most effective treatment may not be available (e.g. in some developing countries) or may be difficult or to use, so that information on the second and third best treatments is important too (Salanti 2011).

There are a number of existing or ongoing evidence syntheses on venous leg ulcer treatments, including Cochrane reviews of different types of dressings or topical treatments (Briggs 2012; O'Meara 2013; O'Meara 2014; O'Meara 2015; Ribeiro 2013; Ribeiro 2014; Westby 2016). There are also wider reviews of particular types of treatment for all wound types which include data on venous leg ulcers for treatments such as honey, silver, aloe Vera, and phenytoin (Dat 2012; Jull 2015; Shaw 2007; Vermeulen 2007). Other reviews on non-healing or chronic ulcers have also included a substantial number of relevant trials (Greer 2013; AHRQ 2013), and there are also older general reviews (e.g. Bouza 2005; O'Donnell 2006).

Guidance drawing on reviews available at the time has also been published (Robson 2006; SIGN 2010). The SIGN 2010 guideline recommended that low-adherent dressings be used routinely but that alternative dressings (hydrocolloids, alginates or hydrogels) may be considered to assist with pain, exudate and slough respectively. Earlier guidance (Robson 2006), recommended that maintaining a moist wound environment be prioritised in dressing choice. Most recently the UK National Institute for Health and Care Excellence (NICE) issued advice on the use of advanced and antimicrobial dressings for chronic wounds including venous leg ulcers (NICE 2016b). This updated the SIGN 2010 guidance to include the findings of the most recent systematic reviews.

However, despite the existence of high-quality recent systematic reviews, there is insufficient evidence to support the use of any particular type of advanced or antimicrobial dressing or treatment as the direct evidence is of low certainty and no network meta-analysis (NMA) has previously been undertaken in this area. Decision-makers currently have to consider the findings of a plethora of pairwise randomised controlled trials (RCTs) simultaneously and to make qualitative judgements across these in the face of uncertainty, when considering the evidence on dressing use.

NMA is the simultaneous comparison of linked, multiple, competing treatments in a single statistical regression model (Caldwell 2005; Lu 2004; Salanti 2008). NMA utilises evidence from both 'direct' (head-to-head or 'pairwise') comparisons (e.g. trials directly comparing treatments $A$ and $B$ ) and 'indirect' comparisons (e.g. the combination of trials comparing $A$ with $C$ and trials comparing $B$ with $\mathrm{C}$ ). If both direct and indirect estimates are available, they can be meta-analysed, preserving within-trial randomisation (Grant 2013; Thorlund 2012; Tu 2012).

Where there are relevant common comparators, NMA produces a set of effect estimates for each treatment linked into the network, relative to every other, whether or not they have been compared in head-to-head trials: thus, NMA is a method of obtaining estimates for comparisons for which there is no (direct) trial evidence. Even when direct evidence is available there may not be much of it, so pooling it with data from indirect comparisons generally gives more robust evidence and reduces uncertainty in the estimates of effect (Higgins 1996; Thorlund 2012). It is also possible to calculate the probability of one treatment being the best for a specific outcome, reflecting the precision surrounding the estimates (Caldwell 2014; Salanti 2011). 
A glossary of NMA terms is given in Appendix 1.

This review comprised a network meta-analysis (NMA) for the outcome of venous leg ulcer healing, for alternative dressings and topical agents for the treatment of venous leg ulcers. We drew on methods previously used in related work (Soares 2014; Westby 2017). The NMA was expected to enable us to determine which (if any) dressing or topical agent is the most effective for healing venous leg ulcers, taking into account direct and indirect evidence simultaneously. We also presented uncertainty around treatment estimates, and explored assumptions being made in the analysis.

\section{O B JECTIVES}

To assess the effects of (1) dressings and (2) topical agents for healing venous leg ulcers in any care setting and to rank treatments in order of effectiveness, with assessment of uncertainty and evidence quality.

\section{METHOD S}

\section{Criteria for considering studies for this review}

\section{Types of studies}

We included published and unpublished randomised controlled trials (RCTs), irrespective of language of report. We only included cross-over trials that reported outcome data at the end of the first treatment period and prior to cross-over. We excluded studies using quasi-random methods of allocation (such as alternation). We highlighted trials in which three or more interventions were randomised and included all relevant arms.

\section{Types of participants}

We included trials recruiting adults (aged at least 18 years) described as having venous leg ulcers, managed in any setting. We accepted study authors' definitions of venous leg ulcers. Where wounds were described only as "leg ulcers" without information as to aetiology, we assumed that they were venous in origin. Trials in which a minority of leg ulcers are described as having a mixed or arterial pathology were included provided that these were fewer than $25 \%$ of participants. Trials including other types of mixed wound populations were not included. We included participants at any stage of their treatment process - for example, participants with or without ulcers described as being hard to heal or clinically infected.

\section{Types of interventions}

The interventions evaluated are all those that can be directly applied as dressings or topical agents to open venous leg ulcers. We presented results for these interventions and included them in summary tables. In the context of a network of competing treatments, there are no 'comparators'. We used the term 'comparison' to mean two interventions compared in a single study and the term 'contrast' to mean two interventions compared across all studies with that comparison. A contrast may be represented by a single study, a simple direct meta-analysis or by the NMA.

We considered trials for which at least one of the interventions was (1) any dressing, including impregnated dressings or salinemoistened dressings or combination dressings*, or (2) any topical agent applied directly to an open venous leg ulcer and left in situ. The treatment of interest had to be the only systematic difference between treatment groups. We did not take into account secondary dressings. We also considered 'no dressing' as a valid intervention, where the wound is left open/covered only by compression bandaging.

* 'combination dressings' means two or more dressings applied sequentially over time (e.g. hydrocolloid for four weeks followed by alginate for four weeks), or a product containing two or more types of dressing material (e.g. a multilayer product comprising silicone polymer and hydrocolloid).

Some of the interventions we considered are as follows; we used the categories listed below as the basis for grouping the treatments used in individual studies:

- basic wound contact dressings (includes low-adherence (including paraffin gauze) or absorbent dressings (of any absorbency));

- saline-moistened gauze (all degrees of moistness);

- hydrogel dressing (includes hydrogel sheet or hydrogel application (amorphous) or sodium hyaluronate);

- vapour-permeable films and membranes (includes adhesive film (semi-permeable) or adhesive film with absorbent pad);

- soft polymer dressings (with/without absorbent pad or cellulose);

- hydrocolloid dressing (with/without adhesive border or matrix hydrocolloid);

- fibrous (spun) hydrocolloid;

- foam dressings (all absorbencies);

- alginate dressings;

- capillary action dressings;

- alginate dressing with charcoal;

- other charcoal-containing dressing;

- honey sheet dressing or topical honey;

- cadexomer lodine ointments;

- iodine-containing dressings;

- soft polymer dressing (with silver);

- hydrocolloid (with silver);

- foam dressings (with silver);

- alginate dressings (with silver);

- silver sulfadiazine (SSD) cream;

- protease-modulating matrix (PMM) dressings;

- collagenase-containing ointment;

- topical phenytoin;

- topical zinc oxide;

- no dressing (wound left exposed); and

- other treatments considered by the review team (with additional clinical advice where required) to be dressings or topical agents applied directly to the wound and left in situ.

The following interventions were excluded from evaluation: treatments in which dressings were attached to external devices such as negative pressure wound therapies, skin grafts, growth factor treatments, platelet gels and larval therapy. We also excluded interventions which, although topical, are not delivered as a physical presence (liquid or solid) on the wound surface such as oxygen, ultrasound, laser or radiant heat therapies. These treatments were considered to be outside the scope of a review 
focused on dressings and topical treatments used in place of dressings. Where studies compared an eligible with an ineligible intervention we included them if they usefully linked the network of studies evaluating two eligible treatments. Data from these linking studies were fully extracted and they were assessed for risk of bias. Studies which evaluated only one eligible intervention and did not perform this linking function were treated as excluded studies and are clearly identified in the list of excluded studies (Characteristics of excluded studies). Where studies used a placebo comparator for an eligible intervention, we included them and treated the placebo as being the vehicle used to deliver it; for example as an emollient cream, an inactive powder or a hydrogel. For example, a comparison of a cream containing an antibiotic with a placebo would be treated as a comparison of topical antibiotic with an emollient cream.

We grouped together dressings in the same class, for example, all hydrocolloid dressings were grouped together regardless of whether they were adhesive or non-adhesive (BNF 2016). This grouping was regardless of a particular brand's stated absorbency, size, concentration of active component or degree of moistness. Thus, where studies only compared two dressings from the same class (for example, two alginates or two foam dressings), we excluded them from the review as they contributed no information about the effectiveness of the class. We considered an impregnated dressing to be in a different class from a non-impregnated dressing. Judgements about whether particular dressings belonged to the same class were made on the basis of British National Formulary (BNF) classifications (BNF 2016), and clinical expert advice where there was remaining uncertainty. Evidence from comparisons between dressings of the same class can be found in the individual Cochrane reviews of particular types of dressings. Trials of this type are also identified as such in the list of excluded studies.

We anticipated that the great majority of participants would be treated with concurrent compression therapy and noted the type of compression therapy used. We also included any RCT in which other concurrent therapies were given (e.g. antibiotics, debridement), provided that these treatments were delivered in a standardised way across the trial arms of the individual trial (such that the treatment of interest is the only systematic difference). We did not treat separately comparisons with and without concurrent therapies, that is, we considered intervention $1+$ concurrent therapy versus intervention $2+$ concurrent therapy to be the same as intervention 1 versus intervention 2 .

We assumed that the interventions are exchangeable, that is, participants in the network could, in principle, be randomised to any of the treatments being compared. For example, that a person with a venous leg ulcer could be equally likely to be randomised to a silver dressing, a polyurethane foam dressing, honey or saline gauze. Depending on the wound requirements for the dressing (e.g. highly absorbent), this may not always be a good assumption for individual wounds, but may be reasonable across the population in the trials.

\section{Types of outcome measures}

We reported outcome measures at the last time point available (assumed to be at the end of follow-up if not specified) and the time point specified in the methods as being of primary interest (if this was different from latest time point available). Initially, we noted when studies reported results at other time points, or whether they included Kaplan-Meier plots, or both.

\section{Primary outcomes}

The primary outcome for this review is complete wound healing.

We regarded the following as providing the most relevant measures of outcome for the analyses:

- the proportion of wounds healed (frequency of complete healing: arm-level data);

- time to complete healing (survival data: study-level data reported as a hazard ratio (HR) with standard error (SE)).

We accepted the authors' definitions of what constitutes a healed wound.

\section{Secondary outcomes}

We did not consider any secondary outcomes here, however they are considered in other relevant reviews (Briggs 2012; O'Meara 2013; O'Meara 2014; O'Meara 2015; Westby 2016) and ongoing reviews (Ribeiro 2013; Ribeiro 2014).

\section{Search methods for identification of studies}

\section{Electronic searches}

We searched the following electronic databases to identify reports of relevant randomised clinical trials:

- Cochrane Wounds Specialised Register (searched 29 March 2017);

- Cochrane Central Register of Controlled Trials (CENTRAL; 2017, Issue 2) (searched 29 March 2017);

- Ovid MEDLINE (1946 to 29 March 2017);

- Ovid MEDLINE (In-Process \& Other Non-Indexed Citations, to 29 March 2017);

- Ovid Embase (1974 to 29 March 2017);

- EBSCO CINAHL Plus (1937 to 29 March 2017).

The search strategies for the Cochrane Wounds Specialised Register, CENTRAL, Ovid MEDLINE, Ovid Embase and EBSCO CINAHL Plus can be found in Appendix 2. We combined the Ovid MEDLINE search with the Cochrane Highly Sensitive Search Strategy for identifying randomised trials in MEDLINE: sensitivityand precision-maximising version (2008 revision) (Lefebvre 2011). We combined the Embase search with the Ovid Embase filter developed by the UK Cochrane Centre (Lefebvre 2011). We combined the CINAHL searches with the trial filters developed by the Scottish Intercollegiate Guidelines Network (SIGN 2018). There were no restrictions with respect to language, date of publication or study setting.

An updated search was conducted on 16 March 2018; these results have been added to Studies awaiting classification and Ongoing studies, and will be incorporated into the review at the next update.

\section{Searching other resources}

We tried to identify other potentially eligible trials or ancillary publications by searching the reference lists of retrieved included studies as well as relevant systematic reviews, meta-analyses, guidelines and health technology assessment reports. We used 
any additional unpublished data for included studies obtained by previous reviews, contacting review authors where appropriate, and undertook cross-checking to ensure that all relevant studies with evaluable outcome data were included.

\section{Data collection and analysis}

Data collection and analysis were carried out according to methods stated in the published protocol (Norman 2017), which were based on the Cochrane Handbook for Systematic Reviews of Interventions (Higgins 2011a).

\section{Selection of studies}

Two review authors independently assessed the titles and abstracts of the citations retrieved by the searches for relevance. After this initial assessment, we obtained full-text copies of all studies considered to be potentially relevant. Two review authors independently checked the full papers for eligibility; disagreements were resolved by discussion and, where required, the input of a third review author. Where required and possible, we attempted to contact study authors where the eligibility of a study was unclear. We recorded all reasons for exclusion of studies for which we had obtained full-text copies. We completed a PRISMA flowchart to summarise this process (Liberati 2009).

Where studies were reported in multiple publications/reports we sought to obtain all publications. Whilst the study was included only once in the review, we extracted data from all reports to ensure maximal relevant data were obtained.

\section{Data extraction and management}

We extracted the following information from each included study:

- interventions being compared, including any ineligible interventions randomised to additional trial groups;

- duration of the intervention;

- details of any co-interventions;

- unit of randomisation (e.g. participant or ulcer);

- number of ulcers per person;

- unit of analysis (including any selection methods for people with multiple ulcers);

- number of participants in each arm;

- hazard ratio (HR) and its $95 \%$ confidence interval (CI) (or any data that will allow its calculation (Parmar 1998; Tierney 2007)) for comparisons between arms);

- number of participants who healed in each arm, both at the latest time point and (if different) at another time specified as of primary interest in the study's methods section;

- all other follow-up times reported;

- if a Kaplan Meier plot is displayed;

- missing data rates per arm, and reasons for 'missingness', including the number of people dying.

\section{Data on potential effect modifiers}

We are not aware of any population-specific effect modifiers for this research question: there is no existing evidence to suggest that one type of dressing works better than another for certain subgroups, such as different baseline ulcer characteristics (e.g. size and duration of ulcer), although it may be the case that some dressings are evaluated only in particular groups (e.g. those classed as having 'hard-to-heal' ulcers).

However, we extracted from each included study data that may act as effect modifiers (in this context):

- type of funding (e.g. industry, academic, government); this was grouped into not-for-profit and other where reported;

- risk of bias; this was classed as low or unclear, high or very high.

We did not give more weight to any individual domains of the 'Risk of bias' assessment.

\section{Other data}

We also extracted the following baseline and study data, reporting separately for each intervention arm if possible:

- care setting;

- age of participants;

- duration of leg ulcer(s);

- size of venous leg ulcer(s) (area/volume);

- wound status (e.g. sloughy, necrotic, infected, 'hard-to-heal').

\section{Assessment of risk of bias in included studies}

We assessed risk of bias for each included study, and calculated separately the overall risk of bias for each direct pairwise metaanalysis for the complete healing data. Two review authors independently assessed included studies using the Cochrane tool for assessing risk of bias (Higgins 2011b); a third review author was consulted where consensus could not be reached. The Cochrane risk of bias tool addresses six specific domains: sequence generation, allocation concealment, blinding of outcome assessors, incomplete outcome data, selective outcome reporting and other issues (Appendix 3). We then summarised data for the key biases reflected by these domains: selection bias, detection bias, attrition bias, reporting bias and other bias. We also noted the comparability of participant characteristics at baseline across the two groups, including whether an adjusted analysis was conducted. We used these data to help inform decisions on the risk of selection bias. For the category of "other bias" we paid particular attention to unit of analysis errors since they are highly prevalent in wounds research. We recorded all problems of unit of analysis, for example, where participants with multiple wounds were randomised and each of their wounds contributed outcome data.

We interpreted the overall risk of bias for each contrast of the network meta-analysis, drawing on both indirect and direct data (see the section on Quality Assessment of Evidence (GRADE 2013), below).

\section{Overall risk of bias and linking to GRADE assessment}

In order to link these Cochrane risk of bias ratings to the GRADE assessment for study limitations (downgrading 0,1 or 2 times), we used a two-stage process. Firstly, we obtained an all-domain (overall) risk of bias classification for each study and then we used this to produce an overall risk of bias for each contrast.

\section{All-domain risk of bias for each study}

We summarised data for each of the key domains of selection bias, detection bias, attrition bias, reporting bias and other bias, assigning one of four ratings: low, unclear, high and very 
high. For example, selection bias was informed by sequence generation, allocation concealment and comparability of baseline characteristics.

In an adaption of the GRADE approach (Guyatt 2011), we produced an all-domain risk of bias, with four ratings defined as:

- 'very high' - two or more key domains with a high risk of bias or a single domain with very high levels of uncertainty (e.g. very high degree of differential missing data);

- ' 'high' - high risk of bias for any one domain or 'almost high' risk of bias across more than one domain;

- 'low' - low risk of bias for each of the key domains;

- 'unclear' - insufficient information for at least one key domain (with the other domains being at low risk of bias).

We included this all-domain risk of bias in the summary 'Risk of bias' figure, by adding additional columns to the 'Risk of bias' figure for each study. For the purposes of the GRADE assessment, we then grouped together studies with low and unclear all-domain risks of bias.

\section{Overall risk of bias for a direct comparison (the comparison of two} intervention in one or more trials)

Where a single study contributed to a comparison, the overall risk of bias was that of the all-domain risk of bias assigned to that study. Where more than one study contributed to a comparison, we assigned an overall comparison risk of bias by calculating a weighted average based on the inverse variance-derived weights from the meta-analysis, and using this in conjunction with the overall risk of bias (where numerical values were assigned to the all-domain ratings for each study: low/unclear (1), high (2) and very high (3)). We aligned comparison 'Risk of bias' assessment with the GRADE categories of no limitations (not downgraded for risk of bias), serious limitations (downgraded once), and very serious limitations (downgraded twice) (Guyatt 2011; Salanti 2014). We presented the overall risk of bias associated with each direct estimate in a network diagram using colours to represent different ratings.

\section{Overall risk of bias in the network}

Each direct contrast in the network contributed differently to the estimation of each NMA summary effect (each NMA comparison). The contribution of each piece of indirect evidence to a mixed treatment contrast depends on its point estimate, precision and relative location within the network, and on that of any direct evidence or other indirect evidence (Chaimani 2013; Salanti 2014). A recently published tool, Krahn 2013, allows the contribution of each direct estimate to be determined for each contrast in the network informed by mixed evidence (direct and indirect), or when multiple loops of indirect evidence inform the same link. We used the CINeMA web tool (CINeMA 2017) to calculate the percentage contribution of each direct contrast to each network estimate. The overall risk of bias for each NMA comparison estimate is a composite measure of the risks of bias for all the direct contrasts contributing to that NMA comparison and was determined by calculating a weighted average risk of bias using the percentage contributions and the all-domain risks of bias for all the direct contrasts. We acknowledge that this approach returns approximate weights.

\section{Measures of treatment effect}

\section{Relative treatment effects}

We were not able to calculate the hazard ratio (HR) for the majority of studies, and therefore presented the risk ratio (RR) $(95 \% \mathrm{Cl})$ for the proportion of people healed. In order to conduct these analyses (see Data synthesis), we used outcome data reported in individual studies, as raw data at the latest time point, unless otherwise stated. If there had been sufficient data, we had planned to calculate the $\mathrm{HR}$ with $95 \% \mathrm{Cl}$ and to model time-to-event data.

\section{Unit of analysis issues}

We expected the main unit of analysis issues to occur when participants had more than one wound per person. We treated the participant as the unit of analysis when the number of wounds assessed appeared equal to the number of participants (e.g. one wound per person). This included studies in which participants were randomised to treatments and there was more than one wound per person, but results were reported for one selected wound; we considered whether there was risk of bias in the selection process.

Where studies randomised at the participant level, we used the allocated treatment on multiple wounds per participant, and measured and analysed outcomes at the wound level, (e.g. wound healing), there were unit of analysis issues if the data were not correctly analysed. In these cases, we assessed whether it was possible and appropriate to approximate the correct analyses in accordance with Chapter 16 of the Cochrane Handbook for Systematic Reviews of Interventions, using information adapted from Higgins 2011c. Where this was not possible, we made a decision about inclusion of data in the analysis, and recorded these studies as being at high risk of bias if the number of participants and the mean number of wounds per person were judged to warrant this.

If cluster-randomised trials had been identified, we would have decided the analytical approach based on the type and volume of cluster data. We accounted for the correlation between the effect sizes from multi-arm studies in the analysis.

\section{Dealing with missing data}

It is common to have data missing from trial reports. Excluding participants post-randomisation, or ignoring those participants who withdraw from the trial or are lost to follow-up, compromises the randomisation and potentially introduces bias into the trial. Where there were missing data for the primary outcome of proportion of ulcers healed, we assumed participants did not have the outcome (i.e. they will be considered in the denominator but not the numerator). We considered examining this assumption in a sensitivity analysis but decided this was not necessary given the small numbers of trials with differences in attrition between treatment groups.

\section{Assessment of heterogeneity \\ Assessment of clinical and methodological heterogeneity within treatment comparisons}

We assessed the presence of clinical heterogeneity within each pairwise comparison (i.e. the degree to which studies vary in terms of participant, intervention and outcome characteristics) by comparing data extracted for included studies. We focused on 
key variables that are potential effect modifiers, such as whether studies were at high risk of bias in key domains and the source of funding for the study. We also considered the generalisability of our findings with reference to participant characteristics such as ulcer size and duration.

\section{Assessment of transitivity across treatment comparisons}

'Transitivity' refers to the situation in which an intervention effect measured using an indirect comparison is valid and equivalent to the intervention effect measured using a direct comparison. Thus, where there are differences in effect modifiers across comparisons, the transitivity assumption may not be met and there will be inconsistency in the network (Grant 2013; Jansen 2013). We did not identify any potential effect modifiers from the literature, and therefore had to assume that there is transitivity with respect to known effect modifiers across the pairwise comparisons. There are also limited underlying theoretical reasons to consider effect modification for these treatments - however, in preparing the network we explored the effect of differences in risk of bias as possible effect modifiers across the network. We investigated inconsistency in the network (see Data synthesis).

We had also planned to investigate the effect of funding source as a potential effect modifier. However although many studies reported funding by a manufacturer of one of the assessed interventions, a substantial number of studies did not report the funding source. Only a minority of trials clearly reported a third sector or public funding source; a much smaller number reported non-industry funding or a mixture of industry and non-industry sources. In view of this imbalance and the high level of uncertainty around trials which did not report funding sources we did not attempt this analysis.

\section{Assessment of reporting biases}

We assessed the presence of reporting bias using a contourenhanced funnel plot, (Peters 2008; Salanti 2014).

\section{Data synthesis}

\section{General methods}

We performed pairwise meta-analyses in a frequentist framework using the statistical software STATA 13 (STATA 2011; Salanti 2014). Experience (Westby 2017) suggested that there were likely to be insufficient data for us to model the impact of follow-up duration on estimates of effect. We therefore conducted analyses based on binary data, analysed using risk ratios (RRs). We had planned to extract or calculate HRs where possible using established methods (Parmar 1998; Tierney 2007), and would have considered modelling the hazard function (Dias 2014; Soares 2014) using WINBUGS (WinBUGS 2016). However, there were insufficient HR data.

We used STATA 13 (STATA 2011) to calculate the contributions matrix for the network and used the results of this together with the evaluation of risk of bias (see Assessment of risk of bias in included studies) to inform a GRADE evaluation for the entire network (Salanti 2014). We summarised the findings according to GRADE principles (GRADE 2013; Schünemann 2011a; Schünemann 2011b). Where there were zero events in any trial arm, we followed the general approach taken by STATA and added 0.5 to the numerator and 1 to the denominator for each arm in the trial.

\section{Methods for standard meta-analysis}

We performed pairwise meta-analyses in a frequentist framework using Review Manager 5 (RevMan 2014) or STATA 13 (STATA 2011) as appropriate, using inverse variance weighting and a random-effects model, and only analysing trials reporting that pairwise comparison. We also presented the data for these direct comparisons from the network in forest plots (Schünemann 2011a); for reasons of space we did not present all possible comparisons. While we report treatment effects for all data (see appendices), we focus on discussing selected comparisons chosen for their clinical relevance.

\section{Methods for network meta-analysis}

We used STATA 13 to produce a network diagram based on all included studies in order to inform the analysis plan (Chaimani 2013). We excluded from the analysis two-arm studies in which one of the interventions could be described as 'standard care' or 'mixed care'. These are treatment arms where the 'intervention' involves the choice of more than one treatment: they are unlikely to be consistently applied. We had anticipated that such interventions might have been acceptable for a grouped sensitivity analysis (see section on Sensitivity analysis), but experience (Westby 2017) led us to conclude that this was unlikely to be informative; such studies are therefore summarised in Appendix 4, but not considered further. We also excluded from the main analysis studies that had one intervention of direct interest (e.g. hydrocolloid) compared with one ineligible intervention (e.g. ultrasound), unless we found, after examining the network diagram, that the ineligible intervention linked two or more interventions of direct interest; such interventions were included in a sensitivity analysis looking at an expanded base-case.

We performed multivariable network meta-analysis using STATA 13. We used the 'mvmeta' command and adopted a random-effects approach and a consistency model. We used per-arm data (see Data extraction and management) throughout. The STATA routine took into account correlations between the effect sizes from multi-arm studies. The NMA results were reported for all 'mixed treatment contrasts', which means the meta-analysis involved both direct evidence and indirect evidence from across the whole network. The output was reported as pooled RRs, with their $95 \% \mathrm{Cls}$. If there were sufficient data we had also planned to perform an analysis of timeto-event data using the log HR with its standard error (SE).

We carried out analyses for network comparisons (where indirect evidence alone, or both direct and indirect evidence contributes) in a frequentist framework as above. Where required, we accounted for correlations induced by multi-arm studies. We also presented the data in forest plots.

We obtained a treatment hierarchy using the surface under the cumulative ranking curve (SUCRA) and mean ranks (Salanti 2011) for each treatment. Both these measures are based on an assessment of the probability of each treatment being best, second best, etc. in terms of being the most likely to heal venous leg ulcers (when compared with all other evaluated treatments). We used the STATA methods described by Chaimani 2013.

We had planned to present two different networks: one for individual treatments and a sensitivity analysis in which interventions were grouped in broader clinically relevant categories. In practice, there were many different dressings and 
a wide range of topical agents too, and we decided, post-hoc, to restrict the main analysis to treatments that were considered most important and widely used. Selection of treatments for analysis was decided by two review authors working independently, with guidance from a clinical review author who had not seen the data.This set of interventions was termed the 'base-case network'.

Interventions which were considered in the base-case were: alginate, cadexomer iodine, film, foam, gentian violet, hyaluronic acid, hyaluronic-acid with povidone iodine, hydrocolloid, hydrofibre, hydrogel, ibuprofen-releasing foam, nonadherent, octenidine, paste bandage, saline gauze, phenytoin, povidone iodine, protease-modulating matrix (PMM), PMM silver, silver sulfadiazine (SSD), sucralfate, silver and zinc oxide. Only one of these - phenytoin - could not subsequently be joined into the network. Sensitivity analyses explored the impact of extending the number of treatments included or further restricting it (see Sensitivity analysis).

Comparisons of two eligible interventions not joined into the network remained in the review and we reported the direct evidence.These included comparisons between a specified intervention such as cadexomer iodine, silver or honey and "standard care" as well as comparisons between two individual interventions where one or both were only partly relevant to the network or could not be joined to the network.

There was a very large number of contrasts in the NMA and we decided to focus our reporting of the analysis firstly on results for the network as a whole, and then in the 'Summary of findings' table to report the treatment effect data for some specific treatment comparisons. This was done in order to maximise the clinical utility of the NMA and the accessibility of the review. We decided, post-hoc to focus on the two treatments with the highest probabilities for being one of the best treatments and to examine in detail the results of their comparisons with three of the most common and widely used treatments (foam, hydrocolloid and nonadherent dressings). The results for all contrasts are also shown in forest plots.

\section{Subgroup analysis and investigation of heterogeneity Assessment of statistical heterogeneity}

We assessed the presence of heterogeneity within each pairwise comparison using the $I^{2}$ statistic that measures the percentage of variability that cannot be attributed to random error (Higgins 2003). We also took into account the overlap of confidence intervals and the variability in the point estimates. We regarded effect estimates where an $\mathrm{I}^{2}$ was less than $50 \%$ as having low levels of heterogeneity, given the potential for wide confidence intervals in pairwise comparisons within a network, which we had anticipated may be sparse.

\section{Assessment of statistical inconsistency}

We assessed inconsistency in two main ways: determining local inconsistencies (around particular contrasts in the network) and assessing inconsistency for the network as a whole. These tests are often underpowered so we carried out the assessment using the $90 \%$ significance level.

\section{Local approaches to evaluating inconsistency}

To evaluate the presence of inconsistency locally we used two main approaches. Firstly, we considered a loop-specific approach.
This method evaluates the consistency assumption in each closed loop of the network separately as the difference between direct and indirect estimates for a specific comparison in the loop (inconsistency factor, IF). Then, the magnitude of the inconsistency factors and their $90 \% \mathrm{Cls}$ can be used to make inferences about the presence of inconsistency in each loop. We assumed a common heterogeneity estimate within each loop.

Secondly, we considered a 'node splitting' approach (Dias 2010; Salanti 2014). This method was applied, singly, to each direct contrast (called a 'node' by Dias 2010). A STATA routine was used to calculate an indirect estimate using the rest of the network, by running the NMA after excluding the direct evidence for that contrast. The indirect estimates were then compared with the respective direct estimates.

For both approaches a ratio of risk ratios (RoRR) with its $90 \% \mathrm{Cl}$ was calculated for each contrast. If the $\mathrm{Cl}$ excluded 1 , there is statistically significant inconsistency. We also considered whether the $\mathrm{Cl}$ included 2 or more (or 0.5 or less). This would mean that the direct estimate could be twice as large (or half as big) as the indirect estimate, which is an indication of potential inconsistency (Chaimani 2013).

Where we detected serious inconsistency, either in the direct evidence or between the direct and indirect evidence for a contrast, we downgraded the evidence for that contrast.

\section{Global approaches to evaluating inconsistency}

We evaluated consistency in the entire network simultaneously, by extending the analysis to include an inconsistency model that omits consistency equations (Dias 2013). This used a designby-treatment interaction model, which allows for different trial designs (Higgins 2012; White 2012). This approach produced a set of inconsistency parameters. After fitting the inconsistency model we tested the null hypothesis of consistency by globally testing the set of inconsistency parameters using a global Wald test. This test may lack power and we considered a significance level of $P<0.1$. Inconsistency in the entire network was considered a reason for downgrading the certainty of the evidence which the network, as a whole, represented.

\section{Investigation of heterogeneity and inconsistency}

Where sufficient studies were available, we planned to perform network meta-regression (data permitting) or subgroup analyses using funding source and risk of bias as possible sources of inconsistency or heterogeneity, or both. In the event we were able to perform an analysis using risk of bias as a possible source of heterogeneity.

\section{Sensitivity analysis}

We re-analysed the network with studies removed if they were considered to be at high risk of bias for any one or more of selection, attrition or detection bias (Appendix 3).

We considered a sensitivity analysis to assess the possible impact of missing outcome data on the network estimates, via assessment of risk of attrition bias (as defined in Appendix 3), testing the assumption of imputation of no event for missing data.

Where one or more studies were clearly outliers (i.e. in terms of direction or size of relative treatment effect, or both, or as flagged 
in inconsistency testing), we had planned to conduct a sensitivity analysis where the study was removed from the network, as long as the network was still analysable; in the event we did not need to do this.

We had planned to conduct a sensitivity analysis, in which dressings interventions were grouped in broader categories, with clinical guidance, but this was not conducted. Instead, we conducted two post-hoc sensitivity analyses for the base-case network: one restricted the dataset to a narrower set of clinically appropriate interventions; the other included additional treatments outside the base-case, which reinforced the network with more links. The reduced network excluded the following interventions which were included in the base-case: gentian violet, hyaluronic-acid with povidone iodine, ibuprofen-releasing foam, octenidine, phenytoin and sucralfate. The expanded base-case added nine trials and the following supplementary interventions to the base-case decision set: blood product (non-eligible intervention); emollient cream; and growth factor (non-eligible intervention). We conducted this sensitivity analysis to investigate the impact of strengthening the network through indirect evidence provided by comparisons of key decision set interventions such as saline gauze and hydrogel with these supplementary interventions.

\section{Quality assessment of evidence (GRADE) generated from the network meta-analysis (NMA)}

We summarised the findings according to GRADE principles (Schünemann 2011a; Schünemann 2011b). The quality and certainty of the data included in any synthesis model are key to determining the validity of the results and of inferences made. We explored the application of GRADE methodology to NMA, focusing on the approach of Salanti 2014. We assessed evidence quality in two main ways, for each contrast and separately, for the network as a whole, in order to assess the quality of the ranking order. We assessed individual GRADE factors as follows.

- Risk of bias: contributions for each particular contrast were considered, and used to assess the overall risk of bias for that contrast. We assessed overall risk of bias per contrast and also for the network as a whole (see Assessment of risk of bias in included studies).

- Indirectness: this was assessed as without limitations because we did not identify any effect modifiers.

- Inconsistency: at the level of the contrast, we considered both heterogeneity in the direct evidence for that comparison and inconsistency related to different routes of analysis for the comparison (e.g. direct versus indirect evidence). We noted that inconsistency can only be assessed where there is both direct and indirect evidence. GRADE inconsistency was assessed as a serious limitation if there was heterogeneity in the direct estimate or inconsistency in the network with respect to that comparison. Very serious limitations were attributed to the comparison if there was severe heterogeneity or severe inconsistency or limitations with both heterogeneity and inconsistency. At the level of the network, we considered the global Wald test for inconsistency (see Data synthesis; Assessment of heterogeneity). Tests of this nature are typically underpowered, so a $\mathrm{P}$ value less than 0.1 was considered significant. Additionally, if several contrasts showed direct and indirect results that would have led to different clinical decisions, we considered inconsistency to be present.

- Imprecision: at the level of the contrast, we assessed imprecision for each pairwise comparison using the GRADE default minimally important difference (MID) values of 1.25 and 0.75 for the RR. For contrasts that were not part of the 'core' of the network, we also took into account the number of events informing the direct evidence and considered it in relation to the optimal information size. At the level of the network, we assessed the overlap of the rankograms and the magnitude of the SUCRA estimates.

- Publication bias: was assessed for each pairwise comparison using standard GRADE (where there were 10 or more studies); we used contour-enhanced funnel plots where appropriate to examine publication bias in the network as a whole.

\section{'Summary of Findings' tables}

We presented the main results of the review in a 'Summary of findings' table, reporting the results for a representative set of contrasts, with one row for each contrast. We focused on interventions which the SUCRA suggested were likely to be high ranked and the comparisons between these and commonlyused types of intervention. This table presents key information concerning the certainty of the evidence, the magnitude of the effects for the contrasts examined, and the sum of the available data (Schünemann 2011a). The 'Summary of findings' table also includes an overall grading of the evidence using the GRADE approach.

For calculating absolute risk differences for the probability of healing we used a 'control group risk', calculated as the median of the risks for the comparator across all direct evidence studies with these comparators.

\section{RE S U L T S}

\section{Description of studies}

\section{Results of the search}

Electronic searches identified 1836 records after deduplication. Of these, we excluded 1024 after initial screening of title and abstract. Full-text screening of 812 records led to the identification of 127 relevant reports of 78 studies (see Figure 1 ). 
Figure 1. Study flow diagram.

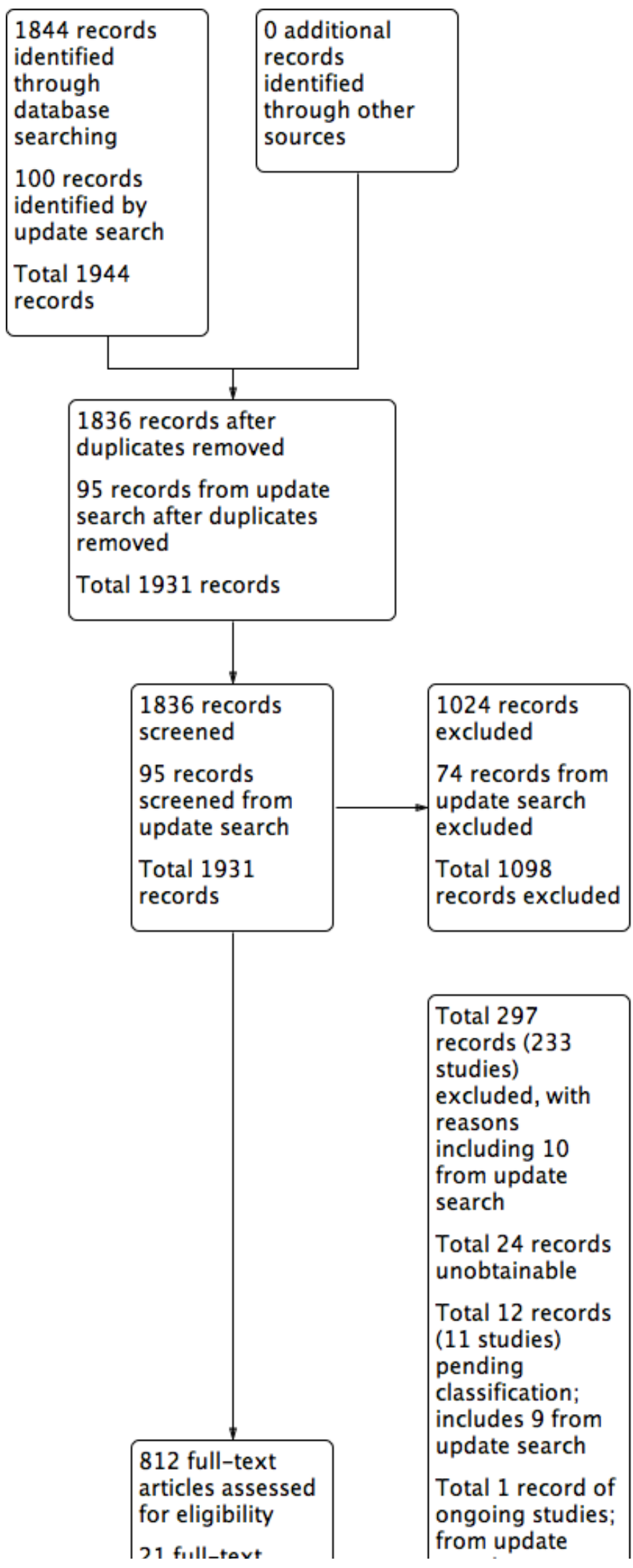


Figure 1. (Continued)

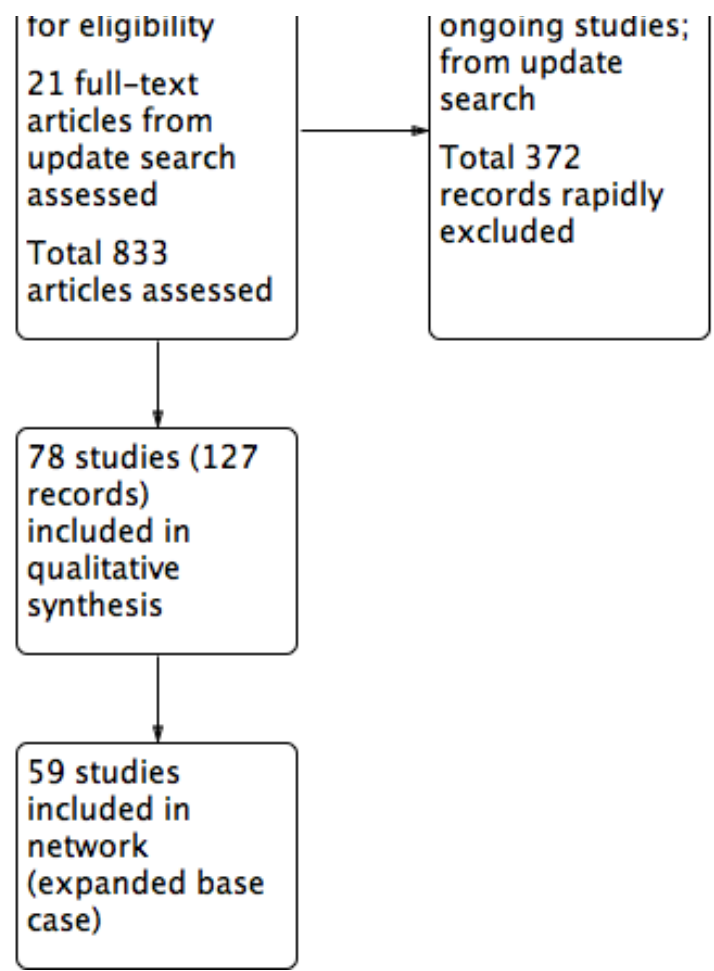

We included studies that compared two eligible interventions (see criteria for inclusion - interventions (Types of interventions). We also included studies that assessed only one eligible intervention, but which provided linking for the network of eligible studies. Therefore there were three types of included study:

- studies which compared two eligible interventions and which were included in the NMA;

- studies which compared two eligible interventions but which could not be joined into the NMA;

- studies which compared an eligible intervention with one or more ineligible interventions but which strengthened the network by linking other two or more eligible interventions.

A total of 78 studies with 7014 randomised participants was included in one or more of these categories.

An updated search in March 2018 retrieved 100 additional records. Of these 23 required consideration in detail. Two records were added as additional publications to studies already identified as excluded studies in the review. Ten studies (11 records) could be clearly excluded (see excluded studies) and nine studies were added to Studies awaiting classification. One study was added to ongoing studies (see Characteristics of ongoing studies).

\section{Included studies}

There were 47 studies that we joined into the network with two relevant interventions as outlined in Data synthesis: (Armstrong 1997; Backhouse 1987; Banerjee 1997; Blair 1988a; Blair 1988b; Bowszyc 1995; Brandrup 1990; Callam 1992; Casoni 2002; Charles 2002; Dimakakos 2009; Fogh 2012; Gottrup 2008; Hanft 2006; Hansson 1998; Harding 2001; Humbert 2013; Ivins 2006; Jørgensen 2005; Kelechi 2012; Kucharzewski 2013; Lanzara 2008; Leaper 1991;
Meaume 2012; Meredith 1988; Moffatt 1992a; Moffatt 1992b; Nelson 2007; Norkus 2005; Ohlsson 1994; Ormiston 1985; Petkov 1997; Romanelli 2015a; Rubin 1990; Schulze 2001; Scurr 1994; Senet 2014; Smith 1992; Smith 1994; Sopata 2016; Stacey 2000; Taddeucci 2004; Thomas 1997; Tumino 2008; Vanscheidt 2012; Vin 2002; Zuccarelli 1992).

A further 13 studies (Alvarez 2012; Beckert 2006; Bishop 1992; Caprio 1992; De Araujo 2016; Dereure 2012a; Greguric 1994; Luiza 2015; Kalis 1993; Moss 1987; Romero-Cerecero 2012; Solovastru 2015; Tarvainen 1988), all assessed comparisons between two eligible treatments, which could be linked to the network but where one or both interventions was considered to be only partly relevant and therefore only the direct evidence was considered, or the trial was included only in a sensitivity analysis. These interventions included dextranomer, A. Pinchinsensis extract, ozonated oil, shale oil, papain, magnesium sulphate and cellulose. Summaries of these comparisons are provided in Appendix 4.

There were a number of studies that evaluated relevant interventions but which could we could not connect into the network. This included the following studies that compared a particular treatment with 'standard care' (which was either not specified or included a range of different dressings or topical treatments): Arnold 1994; Brown 2014; Jull 2008; Harcup 1986; Lindsay 1986; Michaels 2009; Steele 1986. Other studies not joined into the network were Hokkam 2011, which compared two interventions which did not otherwise link to the network: phenytoin with no treatment and Salim 1992, which compared sulphadryl powders to inactive powder. Summaries of these comparisons are also provided in Appendix 4.

We included nine studies that had only one relevant intervention in an expanded base-case to strengthen the network (Arenbergerova 
2013; Biland 1985; Rasmussen 1991; Robson 1995; Robson 2001; Robson 2004; Senet 2003; Senet 2011; Stacey 1997). These were all two-arm trials with one relevant intervention from the basecase or partly relevant interventions such as emollient cream or an ineligible intervention.

Summary details of all trials in the review are shown in Table 1; a summary of the status of individual studies within the review and the networks is shown in Table 2, which clearly denotes which trials are included in the base-case and the sensitivity analyses and which are included only in the review and not in the network.

\section{Interventions}

Included studies evaluated a wide range of dressings and topical treatments. A total of 20 different types of dressings were evaluated; this included dressings which were impregnated with agents such as ibuprofen, silver, povidone iodine or zinc oxide. Sixteen different topical treatments were included. Although the majority of trials compared two dressings or two topical treatments (and most of these compared two dressings), some compared a dressing with a topical treatment (e.g. a hydrocolloid dressing compared with silver sulfadiazine (SSD)). A minority of trials compared arms which included more than one treatment option and these included both dressings and topical treatments.

The number and types of Interventions are fully detailed in the effects of interventions section (Effects of interventions) and in supplementary tables (Table 2; Table 3; Table 4), which also show the status of each trial in the review and network analyses.

\section{Characteristics of participants in included studies}

See Characteristics of included studies for full details

Most studies included only people with venous leg ulcers; six studies also included some participants with mixed aetiology or arterial ulcers (although we excluded those with more than $25 \%$ of such participants); in 10 studies it was not clear whether a minority of people with non-venous ulcers were included. The mean or median age range reported for participants ranged between 46 and 81 years. Almost all studies enrolled a majority of women; there were no single sex studies. The mean sizes of ulcers at baseline varied by up to a factor of 10 but were typically between $5 \mathrm{~cm}^{2}$ and $10 \mathrm{~cm}^{2}$. The mean duration of ulceration at enrolment ranged between one month and 75 months. Many studies excluded participants with either any type of infection or with a specified severity of infection (typically requiring systemic antibiotics); only one study specified that the participant must have an infected ulcer at baseline (Dimakakos 2009). Reporting of other types of ulcer characteristics such as level of slough or exudate was limited. All studies reported some use of compression although the methods and the specificity of the reporting of this varied.

\section{Characteristics of studies}

Where funding was reported, it was often industry funding by a manufacturer of one of the assessed interventions (30 studies). However, a substantial number of studies reported no funding or did not report the funding source. A minority of trials reported a third sector or public funding source. Most studies used participants as the unit of both randomisation and analysis, only two reported data at the ulcer or leg level Caprio 1992; Stacey 1997), while a small number appeared to randomise at the level of the person but analyse at the level of the ulcer; in each case these were dealt with in the "Risk of bias' assessment. Follow-up ranged between four weeks and 12 months but most trials had follow-up of three months or less.

For more details on study characteristics see Table 1.

\section{Excluded studies}

A large number of records were rapidly excluded after reading the full-text. A list of these studies is available on request from the authors (see Figure 1). Some studies were excluded after more detailed consideration. These studies are listed with reasons for their exclusion in Characteristics of excluded studies. An additional ten studies were excluded from records retrieved by an update search in March 2018.

Two studies are awaiting classification (Belcaro 2011; Polignano 2010) from the original search. A further nine studies are awaiting classification following an update search in March 2018 (Alvarez 2017; Cavalcanti 2017; Colenci 2016; Cullen 2017; Glukhov 2017; Moreno-Eutimio 2017; Oliveira 2017; Robinson 1988; Somani 2017). One ongoing study was identified in the update search (Jull 2018).

\section{Risk of bias in included studies}

\section{Allocation}

Risk of selection bias is assessed based on generation of randomisation sequence and allocation concealment. Many studies were at unclear risk of bias for one or both of these, most commonly for allocation concealment. High risk of bias for randomisation was documented for only one study where errors were noted to have compromised the process. However only a minority ( 20 studies) were considered to have a low risk of bias. The remainder did not report the processes used clearly enough for us to determine the risk of bias. The number of studies considered to be at low risk for allocation concealment was even lower, with only 12 considered to be clearly at low risk of bias.

\section{Blinding}

Many studies were at high or unclear risk of performance bias. Although only a minority (18 studies) were clearly at high risk, many more had an unclear risk. Only 10 studies were considered to be at low risk. For detection bias, we observed a similar pattern although more studies clearly had outcomes determined by blinded observers; 20 were considered to be at low risk of detection bias.

\section{Incomplete outcome data}

Twenty-six studies were considered to be at high risk of attrition bias. However, a larger number had a low risk of bias and only ten were considered to be at unclear risk.

\section{Selective reporting}

Only four studies were at high risk of selective reporting bias; a further 16 had an unclear risk in this domain; the remainder were considered to be at low risk of bias.

\section{Other potential sources of bias}

Thirteen studies were considered to be at high risk from other forms of bias, mostly due to issues with the analysis. A further 27 had an 
unclear risk of bias, again primarily related to the reporting of the analysis.

\section{All-domain risk of bias}

All-domain (overall) risk of bias was assessed for each study. In total 51 studies were considered to have a high or very high all- domain risk of bias (Figure 2) and 27 studies were considered to be at unclear or low overall risk of bias (these were grouped together for analysis purposes). No study was at low overall risk of bias since all studies had an unclear rating for one or more domains. 
Figure 2. 'Risk of bias' summary: review authors' judgements about each risk of bias item for each included study.

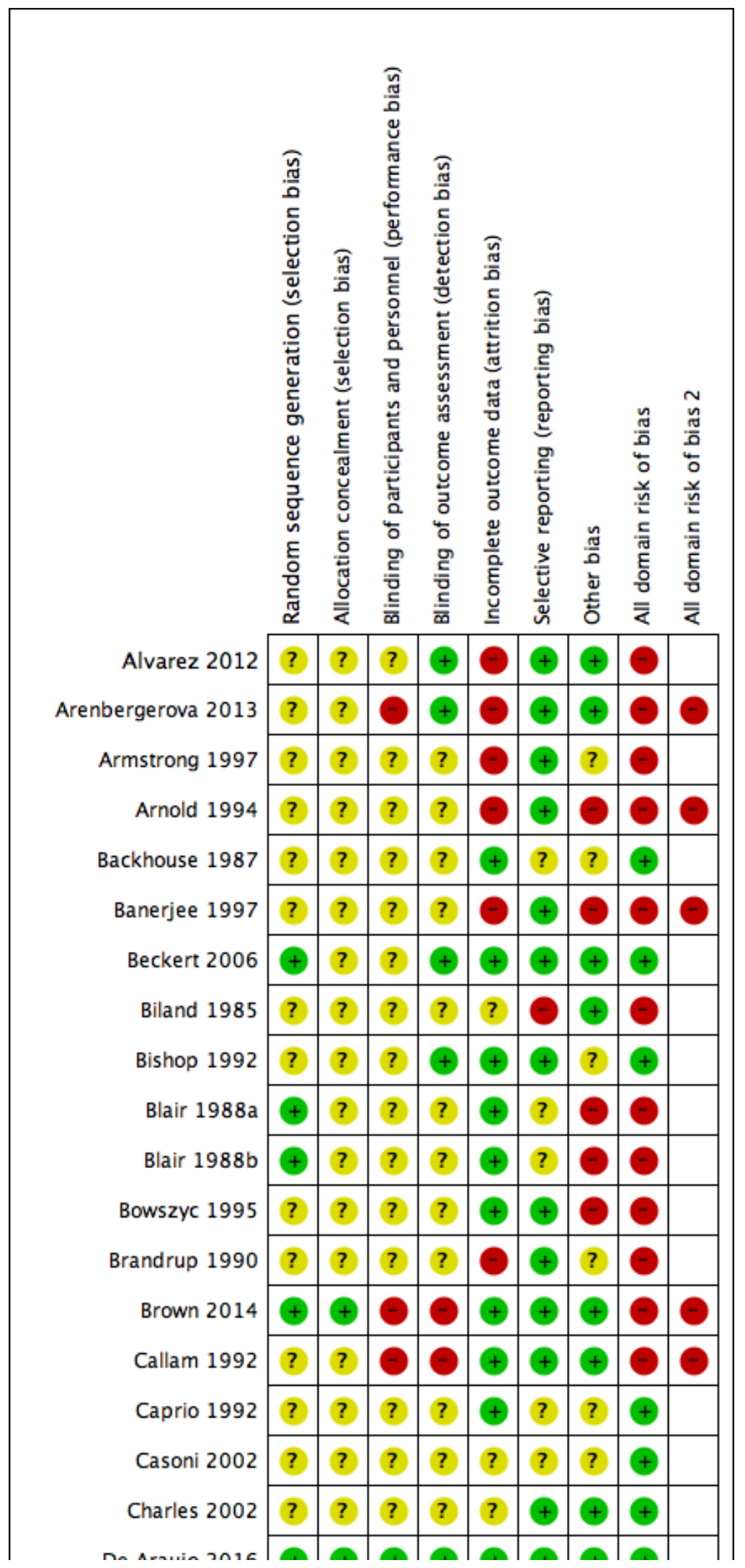


Figure 2. (Continued)

\begin{tabular}{|c|c|c|c|c|c|c|c|c|c|}
\hline Chaties cuve & : & 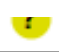 & 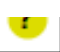 & 1 & 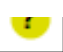 & 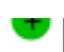 & $\top$ & $\top$ & \\
\hline De Araujo 2016 & $\odot$ & $\odot$ & $\odot$ & 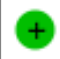 & $\odot$ & 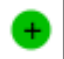 & 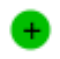 & $\odot$ & \\
\hline Dereure $2012 \mathrm{a}$ & 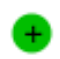 & $?$ & $\odot$ & $\odot$ & 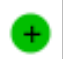 & 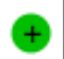 & $?$ & $\odot$ & \\
\hline Dimakakos 2009 & $?$ & $?$ & $?$ & $?$ & 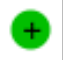 & 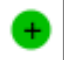 & $?$ & $\odot$ & \\
\hline Fogh 2012 & $\uparrow$ & 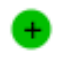 & $\odot$ & 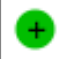 & $\odot$ & 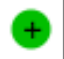 & $\uparrow$ & $\odot$ & \\
\hline Gottrup 2008 & $?$ & $?$ & $\odot$ & $\odot$ & $\odot$ & 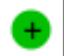 & 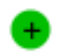 & - & \\
\hline Greguric 1994 & $?$ & $?$ & $?$ & $?$ & 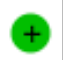 & 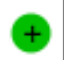 & $\odot$ & $\odot$ & \\
\hline Hanft 2006 & $?$ & $?$ & $?$ & $?$ & 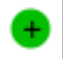 & - & $?$ & $\odot$ & \\
\hline Hansson 1998 & $?$ & $?$ & $?$ & $?$ & - & 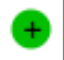 & $?$ & $\odot$ & \\
\hline Harcup 1986 & $?$ & $?$ & $?$ & $?$ & $?$ & $\odot$ & $?$ & $\odot$ & \\
\hline Harding 2001 & $?$ & $?$ & $\odot$ & O & 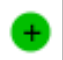 & 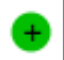 & $?$ & $\odot$ & 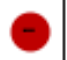 \\
\hline Hokkam 2011 & $\odot$ & $?$ & $?$ & $?$ & $\odot$ & 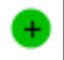 & $?$ & 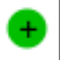 & \\
\hline Humbert 2013 & $?$ & $?$ & $?$ & $?$ & $\hookrightarrow$ & 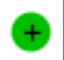 & $\odot$ & $\odot$ & \\
\hline Ivins 2006 & $?$ & $?$ & $?$ & $?$ & $?$ & $?$ & $?$ & 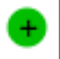 & \\
\hline Jull 2008 & 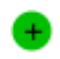 & $\odot$ & $\odot$ & $\odot$ & $\odot$ & $\odot$ & $\hookrightarrow$ & $\odot$ & $\Theta$ \\
\hline Jørgensen 2005 & 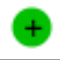 & $?$ & $?$ & $?$ & $\odot$ & 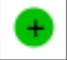 & $\oplus$ & 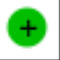 & \\
\hline Kalis 1993 & $?$ & $?$ & $\odot$ & $\Theta$ & - & $?$ & $\odot$ & $\odot$ & \\
\hline Kelechi 2012 & $\odot$ & $\odot$ & $\odot$ & $?$ & $\odot$ & $\odot$ & 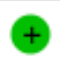 & $\odot$ & \\
\hline Kucharzewski 2013 & $?$ & $?$ & $?$ & $?$ & $\odot$ & $\odot$ & $?$ & $\odot$ & \\
\hline Lanzara 2008 & $?$ & $?$ & $?$ & $?$ & $?$ & 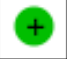 & - & $\odot$ & \\
\hline Leaper 1991 & $?$ & $?$ & $?$ & $?$ & + & $?$ & - & $\odot$ & \\
\hline Lind say 1986 & $?$ & $?$ & $?$ & $?$ & $?$ & $?$ & $?$ & $\odot$ & \\
\hline Luiza 2015 & 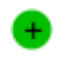 & $?$ & $\odot$ & 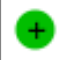 & $?$ & $\odot$ & $\odot$ & $\odot$ & \\
\hline Meaume 2012 & 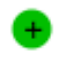 & $\uparrow$ & $\odot$ & 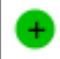 & $\odot$ & $?$ & $?$ & $\odot$ & \\
\hline Meredith 1988 & $\odot$ & $?$ & $?$ & $?$ & $\odot$ & $?$ & $?$ & $\odot$ & \\
\hline Michaels 2009 & $\odot$ & $\odot$ & $\odot$ & $\odot$ & $\odot$ & $\odot$ & $\odot$ & $\odot$ & \\
\hline Moffatt $1992 \mathrm{a}$ & $?$ & $?$ & $?$ & $?$ & $?$ & $\odot$ & $?$ & 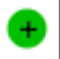 & \\
\hline Moffatt $1992 b$ & $?$ & $?$ & $?$ & $?$ & $\odot$ & $\odot$ & $?$ & $\odot$ & \\
\hline Moss 1987 & $?$ & $?$ & $\odot$ & O & $\odot$ & + & $\odot$ & $\odot$ & C \\
\hline Nelson 2007 & $\odot$ & $\odot$ & - & O & $\odot$ & 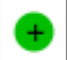 & 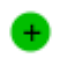 & $\odot$ & e \\
\hline Norkus 2005 & $\odot$ & 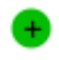 & $\odot$ & O & $\odot$ & + & 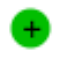 & $\odot$ & $\odot$ \\
\hline an & $=$ & $=$ & 0 & a & a & a & $=$ & $a$ & \\
\hline
\end{tabular}


Figure 2. (Continued)

\begin{tabular}{|c|c|c|c|c|c|c|c|c|c|}
\hline ivUi kus < UU & +1 & + & $\boldsymbol{\sigma}$ & $\nabla$ & + & + & + & $\nabla$ & $\boldsymbol{\sigma}$ \\
\hline Ohlsson 1994 & ? & $?$ & $?$ & 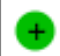 & $\odot$ & $\odot$ & $?$ & $\odot$ & \\
\hline Ormiston 1985 & $?$ & $\oplus$ & $?$ & $\odot$ & + & $?$ & $\odot$ & $\Theta$ & \\
\hline Petkov 1997 & $?$ & $?$ & $?$ & $?$ & $\oplus$ & $?$ & $?$ & 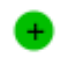 & \\
\hline Rasmussen 1991 & ? & $?$ & $?$ & $?$ & $\odot$ & $\odot$ & $\odot$ & $\odot$ & \\
\hline Robson 1995 & $?$ & $?$ & $?$ & + & + & + & + & + & \\
\hline Robson 2001 & $?$ & $?$ & $?$ & $?$ & $\odot$ & $\odot$ & 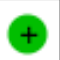 & - & \\
\hline Robson 2004 & $?$ & $?$ & $?$ & $?$ & $\uparrow$ & $\odot$ & $?$ & 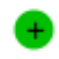 & \\
\hline Romanelli $2015 a$ & $?$ & $?$ & $?$ & $?$ & $\odot$ & $\odot$ & $\odot$ & $\odot$ & \\
\hline Romero-Cerecero 2012 & $?$ & $?$ & + & + & $\odot$ & + & + & 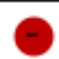 & \\
\hline Rubin 1990 & $?$ & $?$ & $?$ & $?$ & $\odot$ & $\odot$ & $?$ & - & \\
\hline Salim 1992 & $?$ & $?$ & $\uparrow$ & 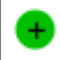 & $\odot$ & $\uparrow$ & 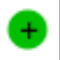 & $\odot$ & \\
\hline Schulze 2001 & + & $?$ & $\odot$ & - & $\odot$ & $\odot$ & $\odot$ & - & \\
\hline Scurr 1994 & $?$ & $?$ & $?$ & $?$ & + & + & + & + & \\
\hline Senet 2003 & $?$ & $?$ & $?$ & $?$ & $\odot$ & $?$ & $?$ & $\odot$ & \\
\hline Senet 2011 & $\odot$ & $\odot$ & $\odot$ & $\odot$ & $\odot$ & $\odot$ & $?$ & $\odot$ & \\
\hline Senet 2014 & $\odot$ & $\odot$ & $\odot$ & $\odot$ & $\odot$ & $\odot$ & $\odot$ & - & \\
\hline Smith 1992 & $\odot$ & $?$ & $\odot$ & $\Theta$ & $\odot$ & $\odot$ & 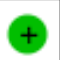 & $\Theta$ & P \\
\hline Smith 1994 & $?$ & $?$ & $\odot$ & O & $?$ & $\odot$ & $\odot$ & - & 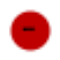 \\
\hline Solovastru 2015 & $?$ & $?$ & $?$ & $?$ & 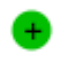 & $\odot$ & $\odot$ & 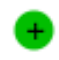 & \\
\hline Sopata 2016 & $?$ & $?$ & $?$ & $?$ & $\odot$ & $\odot$ & $\odot$ & - & \\
\hline Stacey 1997 & $?$ & $?$ & $?$ & $?$ & $\odot$ & + & $?$ & - & \\
\hline Stacey 2000 & $?$ & $?$ & $?$ & $?$ & $\odot$ & $\odot$ & $\odot$ & $\odot$ & \\
\hline Steele 1986 & $?$ & $?$ & $?$ & $?$ & $\odot$ & $?$ & $?$ & $\odot$ & \\
\hline Taddeucci 2004 & $?$ & $?$ & $\odot$ & O & $\odot$ & + & $\odot$ & $\Theta$ & 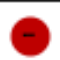 \\
\hline Tarvainen 1988 & $?$ & $?$ & $\odot$ & O & $\odot$ & $?$ & $?$ & - & $\odot$ \\
\hline Thomas 1997 & $?$ & $?$ & $\odot$ & O & 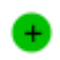 & $\odot$ & $?$ & - & 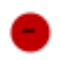 \\
\hline Tumino 2008 & $?$ & $?$ & + & + & - & + & + & O & \\
\hline Vanscheidt 2012 & $?$ & $?$ & $?$ & $?$ & $\odot$ & 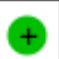 & 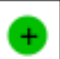 & 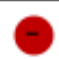 & \\
\hline Vin 2002 & $?$ & $?$ & $?$ & $\odot$ & $\odot$ & $\odot$ & $\odot$ & $\odot$ & \\
\hline Zuccarelli 1992 & $?$ & $?$ & $?$ & $?$ & $\odot$ & $?$ & $?$ & + & \\
\hline
\end{tabular}




\section{Effects of interventions}

See: Summary of findings for the main comparison NMA evidence: proportion with complete healing

\section{Interventions and comparisons: base-case network and sensitivity analyses}

The base-case network comprised 47 studies assessing 22 interventions: 12 eligible dressings (foam, hydrocolloid, hydrofibre, alginate, ibuprofen-releasing foam, nonadherent, paste bandage, protease-modulating (PMM), PMM-silver, silver-containing, film, saline gauze); and 10 topical agents (hydrogel, cadexomer iodine, gentian violet, hyaluronic acid, hyaluronic-acid with povidone iodine, octenidine, povidone iodine, silver sulfadiazine (SSD), sucralfate and zinc oxide). One study was a three-arm trial (Hansson 1998; hydrocolloid, nonadherent and cadexomer iodine). The total number of comparisons was 49, encompassing a total of 4026 participants, who experienced a total of 1479 events (complete healing).

The sensitivity analysis using an extended base case contained 59 studies assessing 25 interventions in 5156 participants with 1925 events; added interventions were blood product, emollient cream and growth factor. This explored the impact of strengthening the network with more links by including trials which contained an eligible intervention compared to one of three ineligible interventions.

An additional sensitivity analysis looked at a narrower set of 17 interventions assessed in 41 studies that included 3435 participants with 1331 events; removed interventions were ibuprofen-releasing foam, gentian violet, hyaluronic-acid with povidone iodine, octenidine and sucralfate. This explored the impact of restricting the network to a narrower set of interventions which excluded interventions that are not widely used in clinical practice.

In the base-case network, there were 31 different direct contrasts and 12 triangular loops; the extended base-case sensitivity analysis had 40 direct contrasts, 15 triangular loops and six quadratic loops; and the narrower network had 26 direct contrasts and 12 triangular loops.

We carried out network meta-analysis for the base-case and the two sensitivity analyses (Appendix 5). The extended base-case sensitivity analysis identified instability in the base-case results for contrasts of some treatments and in the rank order of treatments. Additionally, in the extended base-case, the point estimates and confidence intervals $(\mathrm{Cls})$ for contrasts with sucralfate were often considerably reduced compared with the base-case; and the direction of effect was reversed for most contrasts with hydrogel. This instability for some treatments is likely to occur because, in the base-case, the direct evidence (from single small studies) had an important contribution. As a consequence, we placed more reliance on the extended base-case sensitivity analysis and therefore report the results for this sensitivity analysis in the rest of the results section. Full details and results for the base-case and both sensitivity analyses are given in Appendix 5.

The network diagram for the extended base-case is shown in Figure 3. We weighted node (circle) size by the number of studies reporting each intervention and weighted the thickness of the edge lines according to the inverse variance of the treatment effect estimates for the direct evidence contrast (Chaimani 2013). 
Figure 3. Network diagram - extended network, by risk of bias (3 categories) Key: green = low/unclear; yellow = high; red = very high overall risk of bias for the contrast. The number of studies for each contrast is given in Table 3.

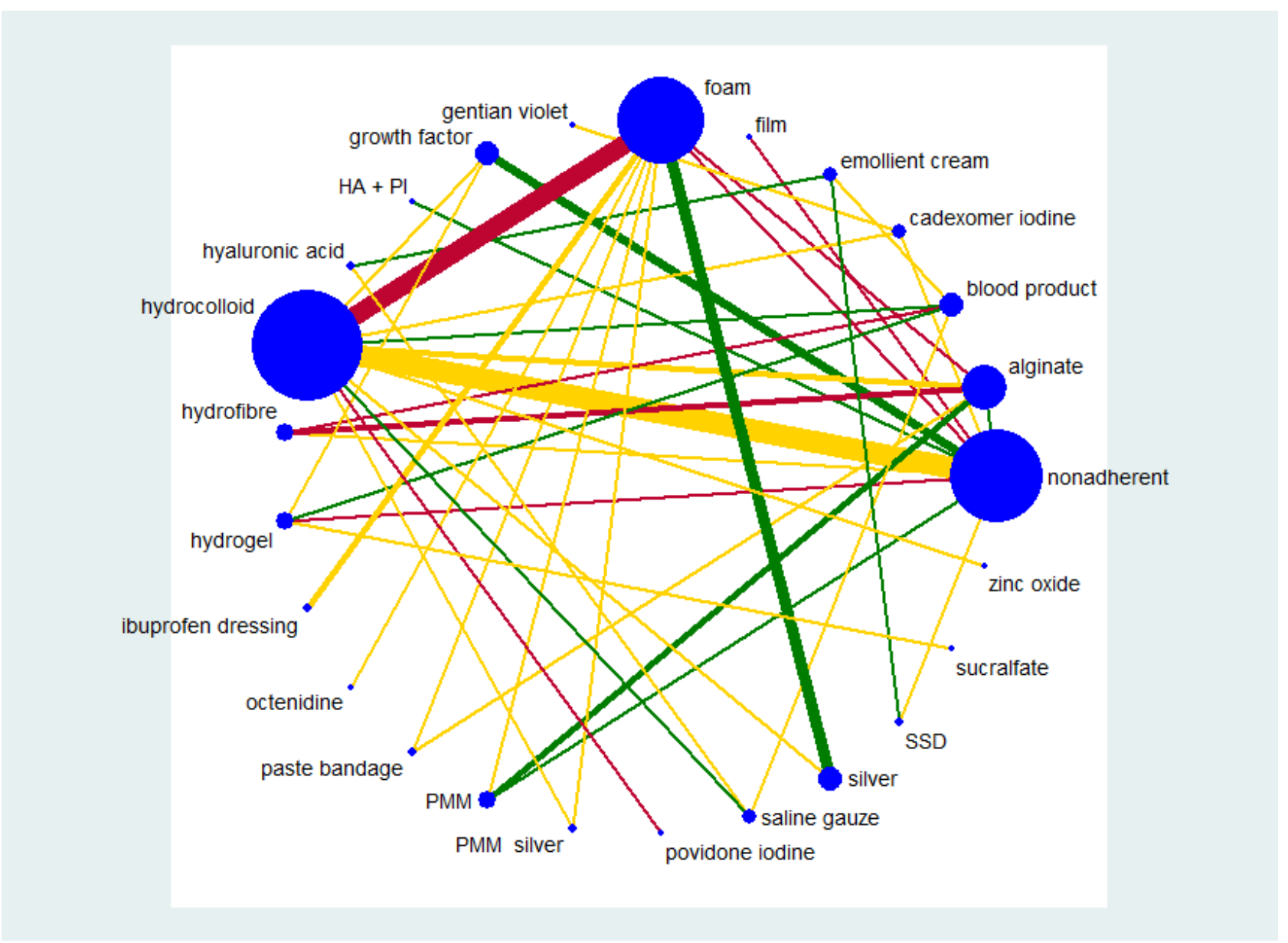

Most treatments in the extended base-case were part of at least one loop ('core interventions') and eight interventions were 'hanging' treatments (film, gentian violet, hyaluronic acid plus povidone iodine, ibuprofen dressing, octenidine, povidone iodine, sucralfate and zinc oxide).

\section{Risk of bias for the extended base-case network}

We report risk of bias in three ways (see Methods: Assessment of risk of bias in included studies):

- for each study, as the all-domain risk of bias - taking into account selection bias, detection bias, attrition bias, reporting bias and other bias;

- for each direct comparison of two interventions, as an overall risk of bias - taking into account the all-domain risk of bias for the studies ( 1 above) and the weighting in the meta-analysis for that comparison;

- for each contrast in the network (any pair of interventions in the network) as the overall risk of bias - taking into account the risk of bias for each direct comparison ( 2 above) and their percentage contributions to the network estimate. We also calculated the overall risk of bias in the network as a whole.

All-domain risk of bias for each study is shown in Figure 2. For the extended base-case network, we judged no included studies to be at low risk of bias and 21 at unclear risk of bias (Backhouse 1987; Bishop 1992; Casoni 2002; Charles 2002; De Araujo 2016; Dereure 2012a; Dimakakos 2009; Ivins 2006; Jørgensen 2005; Meredith 1988; Moffatt 1992a; Moffatt 1992b; Ohlsson 1994; Petkov 1997; Robson 1995; Robson 2004; Romanelli 2015a; Scurr 1994; Senet 2003; Vin 2002; Zuccarelli 1992). Twelve were at very high risk of bias (Arenbergerova 2013; Banerjee 1997; Callam 1992; Harding 2001; Nelson 2007; Norkus 2005; Schulze 2001; Smith 1992; Smith 1994; Sopata 2016; Taddeucci 2004; Thomas 1997), and the rest we assessed to be at high risk of bias. We grouped the low and unclear categories together.

We have indicated the overall risk of bias for each direct comparison in the network diagram in Figure 3, using colour for three risk of bias ratings: low/unclear (green), high (yellow), very high (red). There is a substantial amount of direct evidence at high or very high risk of bias. For selected contrasts in the network, we calculated the overall risk of bias as described in Appendix 6.

\section{Network meta-analysis results}

We examined the results in two ways: as risk ratios (RRs) with their $95 \% \mathrm{Cls}$ for each intervention compared with every other intervention in the network (NMA effect estimates); and for the network as a whole, giving the rank order for the interventions in 
the network and the probability that a particular intervention is the best, second best, etc treatment.

There are $\mathbf{3 0 0}$ mixed treatment contrasts in the extended network, so we report results for the rank order first, and then, for the NMA effect estimates, we focus on contrasts involving the top two treatments and three common and widely used treatments. In Appendix 5, we report results for all contrasts in the extended network, and give the full rank orders for the base-case and the two sensitivity analyses.

\section{Extended base-case network}

The NMA generated results for 300 mixed treatment contrasts (i.e. all possible pairwise combinations of the interventions). There were 40 direct contrasts, of which 32 were informed by only one study and the average number of events per mixed treatment contrast was around six (1925/300). The data were sparse and there was uncertainty around the estimates.

As a consequence of the sparseness in the network, only 55 of 300 contrasts had precise estimates. The majority of $\mathrm{Cls}$ were wide or very wide, crossing at least one default minimally important difference (MID); i.e. the value of 0.75 or 1.25 was included in the $\mathrm{Cl}$ (see Sensitivity analysis, GRADE assessment). Fifty-four contrasts with precise estimates had the whole of the $\mathrm{Cl}$ above the default
MID (i.e. the whole confidence interval lay above 1.25), but 21 of these involved treatments for which the direct evidence comprised one study and had small numbers of events in at least one arm ('fragility'): this applied to contrasts with sucralfate. Overall, $89 \%$ of the contrasts were considered to have imprecise results: the exceptions (ignoring contrasts with ineligible interventions) were silver versus each of the following: nonadherent, alginate, foam, hydrocolloid, hydrogel, povidone iodine, saline gauze, SSD; hydrocolloid versus foam; and saline gauze versus alginate,foam, hydrofibre, hyaluronic acid/povidone iodine, paste bandage, PMM and PMM silver.

\section{Ranking of treatments}

The NMA produced a large number of estimates. An alternative way of presenting and interpreting data from the whole NMA was to summarise using rankograms: data for each intervention were shown as the probability that each intervention is the best, second best, third best treatment, etc. These probabilities are based on uncertainty, reflecting the effectiveness from the network contrasts and the precision around the estimates. The closer the probability of a rank to $100 \%$ (or $0 \%$ ) and the narrower the distribution across different ranks, the greater the confidence in the ranking. Results are given in Figure 4, Figure 5 and Appendix 5 and summarised here, but must be interpreted in the light of the uncertainty and sparseness in the network.

Figure 4. Rankograms for the extended base-case showing the probability that each intervention is the best, second best, third best treatment, etc.

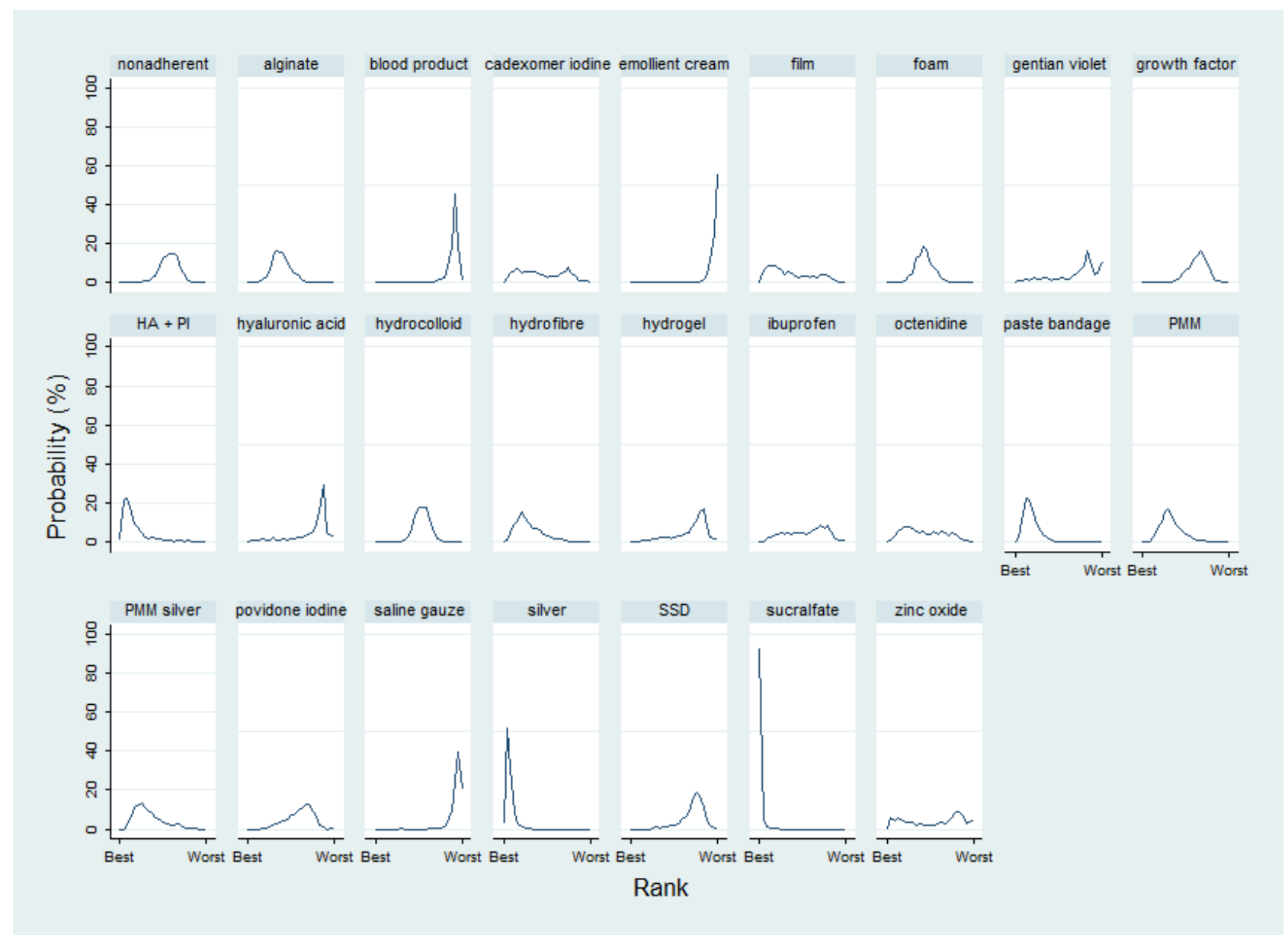

Dressings and topical agents for treating venous leg ulcers (Review) 
Figure 5. Rankograms for all treatments in the extended base-case network showing the probability that each intervention is the best, second best, third best treatment, etc.

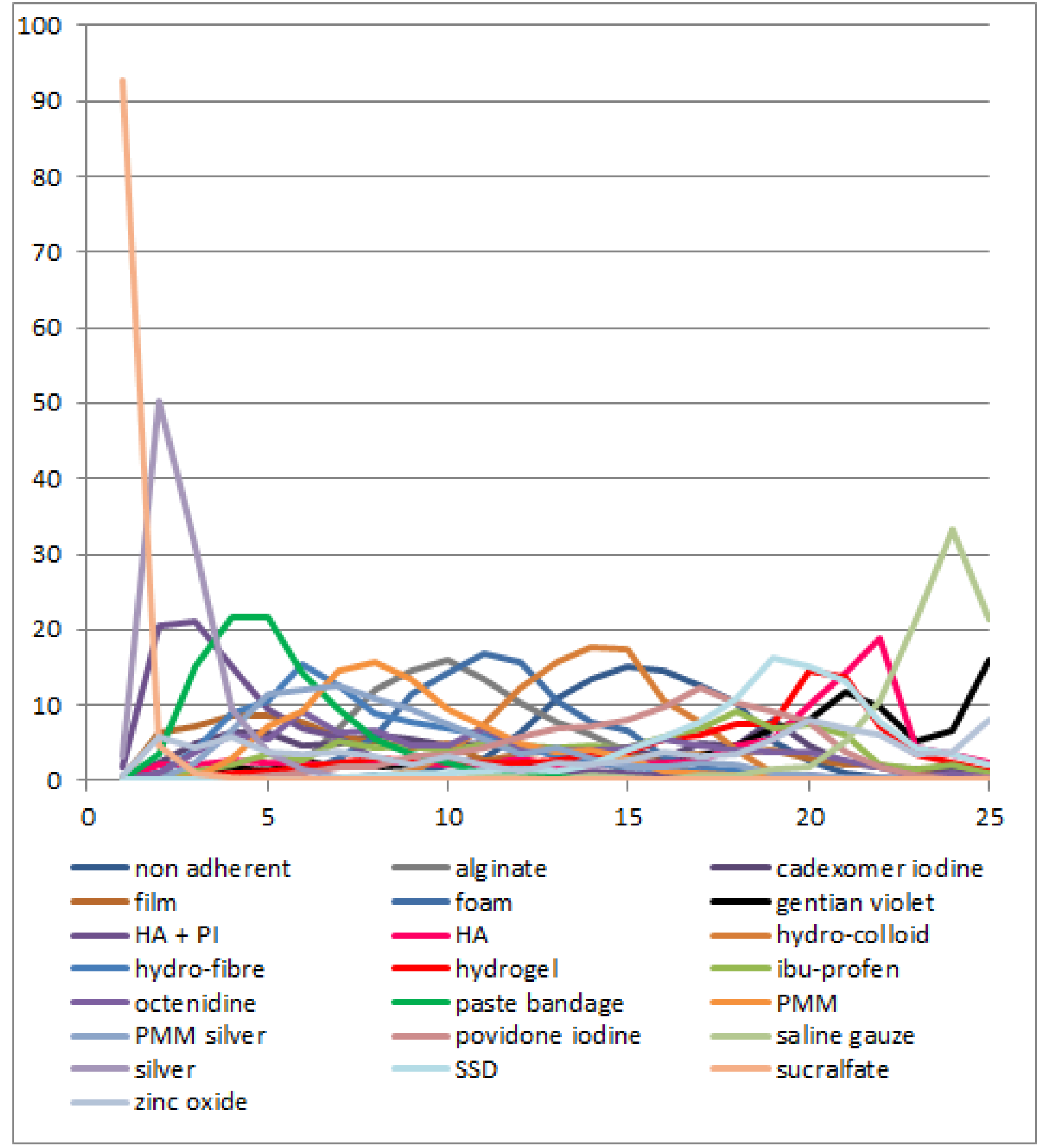

Numerically, sucralfate had by far the highest probability of being the best treatment (93\%), and saline gauze was most likely to be the worst treatment (33\%). However, the sucralfate ranking is likely to be artificially high: sucralfate is connected to the core of the network via hydrogel and the direct evidence for sucralfate versus hydrogel involves one study with 43 (of 50) healing events for sucralfate and five healing events for hydrogel. The NMA results for all comparisons with sucralfate have very wide $\mathrm{Cls}$ and large point estimates. Consequently, sucralfate (versus other interventions) has a high probability of having a very large effect estimate (at the upper confidence limit), in turn leading to an artificially high probability of being the best treatment. Silver also had a high 
probability of being among the most effective treatments (50\% at rank 2). Surface under the cumulative ranking curve (SUCRA) values were generally between 0.3 and 0.8 , but one treatment had a SUCRA value of 1 or 0 (sucralfate was 1 ), with another two treatments having values of 0.9 or 0.1 (silver 0.9 and saline gauze 0.1 ).

The rankograms for many treatments are broad and uninformative (Figure 4, Figure 5). Of the eligible interventions in the extended network, only five had a maximum probability above $20 \%$. The mean ranks for these treatments were: sucralfate 1.1 , silver 2.7 , hyaluronic acid plus povidone iodine 5.3, paste bandage 5.4 and saline gauze 23.0.

\section{Certainty/quality assessment of the evidence across the whole network}

Further details of information used for GRADE assessment can be found in Appendix 5, Appendix 6 and Appendix 7.
The risk of bias across the extended base-case network was estimated to be high (Appendix 6). There appeared to be little inconsistency in the network (Appendix 7 ) and there were relatively few contrasts with conflicting results for direct and indirect or NMA estimates, so across the network we did not downgrade for inconsistency. We downgraded the evidence once for imprecision: in addition to the sparseness (and probably as a consequence of it), there is some overlap of the individual rankograms (see Appendix 5). A contour-enhanced funnel plot is shown in Figure 6. There does not appear to be a small-studies effect. Overall, we classed the evidence for the whole network as being of low certainty (downgraded once for risk of bias and once for imprecision).

Figure 6. Contour-enhanced funnel plot for the extended base-case network showing comparison-specific pooled effect sizes $1=$ =non-adherent, $2=$ alginate, $3=$ blood product, $4=$ =cadexomer iodine, $5=$ =emollient cream, $6=$ film, $7=$ foam, $8=$ gentian violet, $9=$ growth factor,

10=hyaluronic acid + povidone iodine, 11=hyaluronic acid, 12=hydrocolloid, 13=hydrofibre, 14=hydrogel, $15=$ =ibuprofen, $16=$ octenidine,

17=paste bandage, 18=PMM, 19=PMM silver, 20=povidone iodine, 21=saline gauze, 22=silver, 23=SSD, 24=sucralfate, 25=zinc oxide

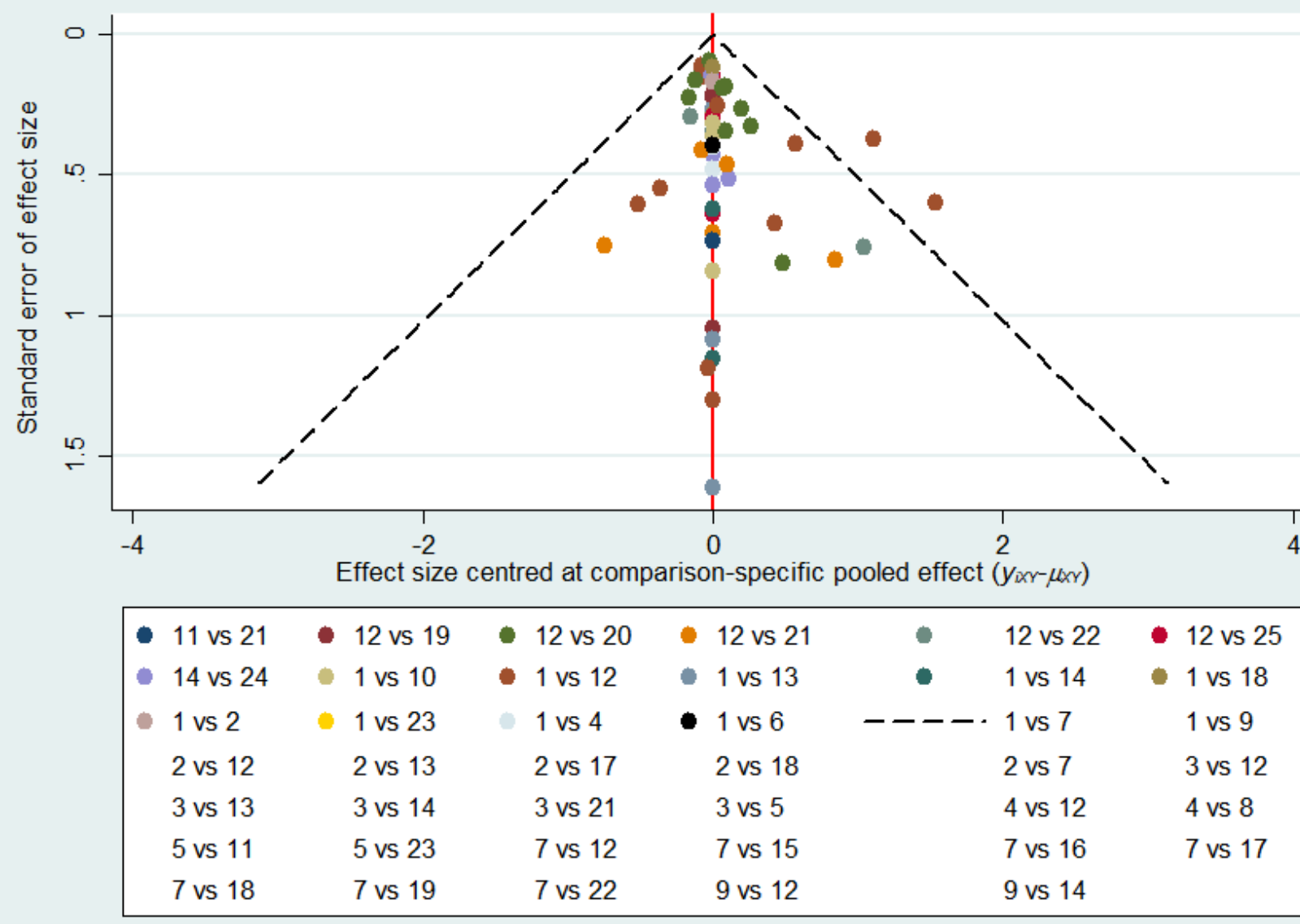




\section{Results and quality assessment for selected individual comparisons}

Here we focus on the treatment effect data for some specific treatment combinations to provide further insights into the results of the NMA. We considered comparisons of sucralfate, silver, foam, hydrocolloid and nonadherent dressings. These represent the two with the highest probabilities for ranks 1 to 3 in Figure 4. (sucralfate and silver) and three common and widely used treatments (foam, hydrocolloid and nonadherent dressings). These widely used treatments were selected by authors who did not have knowledge of the precise results of the network. The results for the extended base-case are shown in Table 5. We calculated absolute risk differences using the median risk for the comparator which was obtained from the risks for that comparator in all direct evidence studies. For all four comparators, the risk varied widely across studies. We report GRADE assessment of selected contrasts in Summary of findings for the main comparison. Most of the evidence for these individual contrasts was of low or very low certainty.

For the contrast of the two interventions with the highest mean ranks - sucralfate and silver dressing - it is unclear whether there is a difference in the probability of venous leg ulcer healing (RR 2.80, $95 \% \mathrm{Cl} 0.88$ to 8.97 ; very low-certainty evidence, downgraded once for risk of bias and twice for imprecision).

Silver dressings may increase the probability of venous leg ulcer healing, compared with nonadherent dressings (RR $2.43,95 \% \mathrm{Cl}$ 1.58 to 3.74; moderate-certainty evidence, downgraded for risk of bias). This corresponds to an absolute risk difference of 346 more people healed per 1000 ( $95 \% \mathrm{Cl} 140$ to 663 more), for a nonadherent median probability of healing of 242 per 1000 . Although this contrast was assessed as itself representing moderate-certainty evidence, it sits in the context of a network which was, overall, judged to represent low-certainty evidence, and should therefore be considered with appropriate caution. We also note that many of the trials which contributed to the contrast (and the direct comparison) were at an unclear risk of bias. Therefore, although there is no clear high risk of bias, there is also a lack of clarity about the true risk of bias.

For each of six contrasts the low certainty of the evidence means it is unclear whether the intervention increases the probability of healing; for two more the certainty of the evidence was very low:

- sucralfate versus foam dressing (RR 5.94, 95\% Cl 1.96 to 18.0 );

- sucralfate versus hydrocolloid dressing (RR $6.51 ; 95 \% \mathrm{Cl} 2.17$ to 19.6);

- sucralfate versus nonadherent dressing (RR $6.80,95 \% \mathrm{Cl} 2.24$ to 20.7);

- silver dressing versus foam dressing (RR 2.12; $95 \% \mathrm{Cl} 1.46$ to 3.07);

- silver dressing versus hydrocolloid dressing (RR 2.32; 95\% Cl 1.58 to 3.41);

- foam dressing versus nonadherent dressing (RR 1.15; $95 \% \mathrm{CI}$ 0.91 to 1.44 );

- foam dressing versus hydrocolloid dressing (RR 1.10; 95\% Cl 0.93 to 1.28 );

- hydrocolloid dressing versus nonadherent dressing (RR 1.04; $95 \% \mathrm{Cl} 0.85$ to 1.29$)$.
In each of these six contrasts, the evidence was graded as low certainty; downgraded either once for imprecision and once for risk of bias (sucralfate versus foam; sucralfate versus hydrocolloid; sucralfate versus nonadherent dressing; foam versus nonadherent) or twice for inconsistency (silver versus foam); or once for risk of bias and once for inconsistency (silver versus hydrocolloid).

It is unclear whether there is a difference in the probability of healing for the remaining two contrasts because the evidence is of very low certainty (downgraded for risk of bias (twice) and imprecision (once) or for risk of bias, imprecision and inconsistency): foam versus hydrocolloid; and hydrocolloid versus nonadherent dressing. The contrasts with sucralfate were informed by one study with 100 participants in the direct evidence, with 43/50 events for sucralfate and five events for hydrogel; we therefore downgraded further for imprecision to allow for the fragility this invoked.

\section{Comparison of results from the NMA with the direct evidence}

Of the eight contrasts with more than one study, five had an $\mathrm{I}^{2}$ of $0 \%$; the remaining three were downgraded for inconsistency; one was downgraded twice for inconsistency. Details are given in Table 3.

\section{DISCUSSION}

\section{Summary of main results}

We conducted a network meta-analysis (NMA) of dressings and topical agents for healing venous leg ulcers. The network included 59 studies with 5156 participants. The systematic review that underpins the NMA includes 78 RCTs involving a total of 7014 participants, comparing different dressings or topical agents or combinations of treatments for the healing of venous leg ulcers. This included a range of treatments from the most widely-used categories of dressings to experimental treatments assessed by a single research study.

We treated each topical agent as a separate intervention, but grouped dressings by class as described in the BNF 2016 (e.g. alginates, hydrocolloids). There were many interventions, often involving small single studies with atypical or experimental treatments. In order to simplify and rationalise the NMA, we produced a list of important and more widely-used treatments with clinical direction and input from review authors who had not seen the results. This led to the 'base-case' NMA, which we extended following sensitivity analysis, adding three linking 'ineligible' interventions to obtain greater robustness.

Alongside the analysis, we have applied a new method of GRADE assessment (Salanti 2014), which allows us to view the results in the light of the certainty of their findings. Using this approach, we found the evidence for the network as a whole was of low certainty (downgraded for risk of bias and imprecision). The network presents results derived from 59 studies of 25 interventions evaluating 40 direct comparisons: we highlight the results from contrasts involving the two treatments with the highest mean ranks (sucralfate and silver): the majority of the evidence for individual contrasts was of low or very low certainty, and was mainly downgraded for risk of bias and imprecision; there was a limited degree of inconsistency for some contrasts (see Quality of the evidence).

In summary: 
- overall findings reflect the uncertainty of the component evidence and the sparseness of the network. For the network as a whole, the evidence was of low certainty. With so many interventions that appeared to have similar efficacies, there was considerable uncertainty in the middle ranks, but numerically two treatments had more than $50 \%$ probability of being the best (sucralfate and silver dressings); - see also Quality of the evidence.

- for the head-to-head comparison of these two treatments with the highest mean ranks, it is very uncertain whether there is a difference between sucralfate and silver dressing in the probability of venous leg ulcer healing (very low-certainty evidence);

- silver dressings may increase the probability of venous leg ulcer healing, compared with nonadherent dressings: RR $2.43,95 \% \mathrm{CI}$ 1.58 to 3.74 (moderate-certainty evidence in the context of a lowcertainty network);

- in the other contrasts between these treatments with the highest probability of being best and the most widely-used dressing classes, it was unclear whether the intervention increased the probability of healing; in each case this was low- or very lowcertainty evidence characterised by wide confidence intervals;

- one of the sensitivity analyses highlighted some instability in key aspects of the network; this instability is likely to be due to sparseness. As a consequence, we reported the results of the extended sensitivity analysis.

\section{Overall completeness and applicability of evidence}

The studies included in the review do not represent all the studies which have been conducted on relevant interventions; substantial numbers of studies were excluded because they did not report the outcome of complete wound healing. However, this was an issue across treatments and did not appear to impact disproportionately on any particular treatment or comparison. As discussed below we believe that this approach was the appropriate one for the purpose of the review.

The populations represented in the included studies appear representative of the people who present with venous leg ulcers in clinical practice in terms of age, gender and ulcer characteristics at enrolment. However, although many studies specified characteristics such as ulcer dimensions, duration and infection in inclusion criteria or reported these in participant details, they were much less likely to specify or describe wound characteristics such as levels of slough, exudate or necrosis.

We identified a wide range of eligible interventions, and included both dressings and topical treatments; specific dressing types such as impregnated dressings and modern 'advanced' dressings were well represented. We conducted sensitivity analyses in order to assess the stability of the network and the impact of decreasing the number of included interventions to a smaller clinically-defined set, or expanding it in order to increase the amount of evidence available for key interventions which were particularly poorly linked into the network.

The review included a substantial number of studies not included in the network; in particular, studies which compared specific interventions such as honey with standard care or choices of multiple treatments. The inclusion of these studies in the review means that they are easily identifiable for researchers who may wish to conduct alternative analyses using this type of data. We believe that the choices we have made concerning data to include in the network meta-analysis are likely to maximise its relevance to clinical decision-making, but acknowledge that this is balanced against the availability of only direct evidence for some comparisons.

\section{Quality of the evidence}

A high proportion of the included studies were considered to be at high risk of bias for one or more domains and a substantial number were at very high risk of overall bias. The principal reasons for a study to be considered at high risk of bias were lack of blinding of one or more groups of participants, professionals and outcome assessors, and attrition bias. However, many studies which were not considered to be at high risk of bias had unclear risks of bias for several or even all domains. Therefore, even when a contrast has not been downgraded due to high risk of bias in the contributions matrix, this does not mean that we are confident that there is a low risk of bias pertaining to the contrast, but merely that there is no known high or very high risk of bias.

Many comparisons (the majority) were informed by a single trial, and most trials were small and underpowered. Only a few comparisons - between some of the most widely-used dressing types - were represented by multiple trials and substantial numbers of participants and events. This is reflected in the wide confidence intervals and therefore the imprecision of most contrasts in the NMA. Some contrasts were also judged to be affected by inconsistency. These factors, together with high risks of bias, meant that many key contrasts were judged to be low or very low certainty while the network as a whole was judged to represent low-certainty evidence.

The inclusion criteria and the nature of the evidence included meant that we did not downgrade for indirectness and we also found no evidence of publication bias.

\section{Potential biases in the review process}

Although all the included studies were reported in English, we ordered a number of full-texts in languages other than English; including Polish, German, Portuguese, Dutch, Norwegian, Chinese, Italian and Spanish. These were ultimately excluded as they did not meet the inclusion criteria, but would clearly have been included if they had proved eligible.

We searched a number of databases and checked the references of reviews and included studies; time constraints meant that the planned searches of trials registers were not conducted. We found no evidence of publication bias, and our focus on the single outcome of healing means that trials identified from registers were unlikely to have data which would have led to their inclusion in the network. We found a relatively small number of unobtainable records; close examination of the records for these led us to conclude that the studies they represented were unlikely to have been included in the review.

This NMA and review focused on the outcome of complete healing. The impact of including only studies reporting healing in this way was considerable; lack of these data was the single most common substantive reason for excluding a study. Complete healing is the outcome which is most important to people living with venous leg ulcers and therefore we believe that the decision to focus the 
network on this outcome was the right one. Other reviews include studies that focused on other outcomes considered important to people with lived experience of the condition; this review stands alongside those syntheses and does not seek to replicate them.

There is potential for bias in our choice of base-case and sensitivity analysis and also our choice of studies with only one eligible intervention for the expanded base-case sensitivity analysis. We made a post-hoc decision to focus on a base-case of interventions which were likely to be used in clinical practice. Clearly post-hoc decisions of this nature could be a source of bias in their impact on which interventions were included. However, no interventions were excluded from the review on the basis of this decision: comparisons including interventions judged to be partly relevant are included in the review and the direct evidence is available to the reader. The decisions on which interventions should be included in the base-case and the narrow sensitivity analysis were made on clinical grounds rather than on the basis of known results; they were made independently by two authors, one of whom had no access to the extracted data at that point, and who were in almost complete agreement when the decisions were compared; where there was a disagreement a more inclusive approach was adopted. The effect of the approach adopted was to remove some of the noise in what was a sparsely-populated network and to increase our ability to examine the relative effectiveness of treatments relevant to clinical practice.

Our updated search in March 2018 identified nine studies, which may be eligible for inclusion but which have not yet been incorporated into the review. None of these was large in absolute terms but the results of these studies may nevertheless have some impact on our sparse network.

\section{Agreements and disagreements with other studies or reviews}

We have been unable to identify any other NMAs examining dressings and topical agents for healing venous leg ulcers. The high level of uncertainty around contrasts between most dressings reflects that in the most recent NICE guidance (NICE 2016a) and the most recent report by the AHRQ (AHRQ 2013); these reflect in part the findings of a number of Cochrane reviews of individual types of dressing (see Why it is important to do this review). The 2010 guidance by SIGN (SIGN 2010) recommended the use of nonadherent dressings with possible alternatives being hydrocolloids, alginates or hydrogels. The results of the NMA do not conflict with this advice, suggesting broadly comparable efficacy for complete healing in these dressing categories.

The finding that silver dressings may increase the number of ulcers healed does not take account of the largest trial available for silver (Michaels 2009). This is because both arms of this trial contained more than one treatment class (specifically, silvercontaining dressings and silver sulfadiazine (SSD)), and hence could not be integrated into the NMA. Michaels 2009 found no difference in overall healing between the silver and non-silver arms of this study (an RR of 1.00, 95\% Cl 0.95 to 1.06 at one year's followup), but we note that the 'silver' arm included $39 \%$ of participants receiving SSD, which may have substantially changed the effect in this study. Nevertheless, the data from this trial should be borne in mind when considering the results and when planning any further research on these treatments.

\section{AUTHORS' CONCLUSIONS}

\section{Implications for practice}

The results of this network meta-analysis (NMA) are mostly findings of low-certainty evidence for key comparisons. Although there was some evidence that silver dressings may increase the probability of venous leg ulcer healing, compared with nonadherent dressings, this needs to be seen in the context of the low certainty of the network as a whole. We do not therefore believe that this evidence is a sufficient basis for treatment decisions. It is possible that the results may be affected by the studies which are awaiting classification and have not yet been incorporated into the review. The results of this NMA focus exclusively on complete healing; whilst this is of key importance to people living with venous leg ulcers, clinicians may wish to take into account other patientimportant outcomes reported in other reviews on this subject, whilst cost considerations will also be a factor for decision makers.

\section{Implications for research}

There is a lack of high-quality research evidence relating to whether particular wound dressings or topical treatments have a beneficial impact on healing of venous leg ulcers. This is despite the existence of a large number of trials relating to a range of treatments. The poor or uncertain quality of the evidence is problematic given the impact on the lives of individuals of living with chronic wounds and the substantive healthcare implications of caring for them. The NMA's findings of low-certainty evidence make clear the generally poor quality of randomised controlled trials (RCTs) of venous leg ulcer treatments, suggesting a need for radical improvements in the planning, conduct and reporting of trials in this field.

There was uncertainty surrounding most of the interventions evaluated when we look at the rankings of their relative effectiveness. Therefore, any future evaluations of interventions should focus - as this NMA does - on those most widely used in clinical practice; they may wish to look in particular at silvercontaining dressings. Where trials are conducted, they should be adequately powered to assess differences in complete wound healing, which should ideally be reported as time-to-event data. Choice of secondary outcomes should be informed by consultation with people with lived experience of leg ulcers. Trials should adhere to international guidance on design, conduct and reporting of randomised trials. In particular, they should undertake and report adequate randomisation and allocation procedures and blinded outcome assessments, while losses to follow-up should be fully accounted for.

\section{ACK N O WLEDGEMENTS}

The authors are grateful to the following peer reviewers of the protocol: Joan Webster (Cochrane Wounds Editor), Duncan Chambers, Gill Worthy, Clifford Richardson and Malcolm Brewster; Duncan Chambers, Gill Worthy, Clifford Richardson and Malcolm Brewster also peer reviewed the full review along with Andrew Jull (Cochrane Wounds Editor). They also thank Denise Mitchell who copy-edited the protocol and Heather Maxwell who copyedited the full review. They are grateful to Ross Atkinson, Zipporah Iheozor-Ejiofor and Zhenmi Liu for assistance with screening of records. Further thanks go to Emma McFarlane, Steve Sharp and Yolanda Martinez for assistance with data extraction. The authors are also grateful to the following for translation assistance: Paulo 
Alves, Diebrecht Appelen, Malgorzata Bala, Dawid Stroman, Milosz Jankowski, Zhenmi Liu, Mateusz Swierz, Wiktoria Lesniak, Jesús
Lopez Alcalde, Ingrid Töws, Birgit Smith, Teslin Seale Ahlenius, Anette Blümle and Peter Gøtzsche. 


\section{R E F E R E N C E S}

\section{References to studies included in this review}

Alvarez 2012 \{published data only\}

Alvarez O, Patel M, Phillips T, Menzoian J, Brown Etris M, Andriessen A. Prospective, randomized, controlled, multi-center clinical trial of a biocellulose wound dressing for the treatment of venous ulcers. EWMA Journal 2010;10(2):23. [Abstract 5]

* Alvarez OM, Phillips TJ, Menzoian J O, Patel M, Andriessen A. An RCT to compare a bio-cellulose wound dressing with a non-adherent dressing in VLUs. Journal of Wound Care 2012;21(9):448-53.

\section{Arenbergerova 2013 \{published data only\}}

Arenberger P, Elg F, Petyt J, Cutting K. Expected outcomes from topical haemoglobin spray in non-healing and worsening venous leg ulcers. Journal of Wound Care 2015;24(5):228, 230-2, 236.

* Arenbergerova M, Engels P, Gkalpakiotis S, Dubská Z, Arenberger P. Effect of topical haemoglobin on venous leg ulcer healing. EWMA Journal 2013;13(2):25-30.

\section{Armstrong 1997 \{published data only\}}

* Armstrong SG, Ruckley CV. Use of a fibrous dressing in exuding leg ulcers. Journal of Wound Care 1997;6(7):322-4.

Armstrong SH, Brown DA, Hill E, Ruckley CV, Pucheault M, Hofman D. A randomized comparative clinical trial of a new hydrofibre dressing versus an alginate dressing in the treatment of exuding leg ulcers. Fifth European Conference on Advances in Wound Management; 1995 November 21-4; Harrogate (UK). 1996:197-8.

\section{Arnold 1994 \{published data only\}}

Arnold TE, Stanley JC, Fellows EP, Moncada GA, Allen R, Hutchinson JJ, et al. Prospective, multicenter study of managing lower extremity venous ulcers. Annals of Vascular Surgery 1994;8(4):356-62.

\section{Backhouse 1987 \{published data only\}}

Backhouse CM, Blair SD, Savage AP, Walton J, McCollum CN. Controlled trial of occlusive dressings in healing chronic venous ulcers. British Journal of Surgery 1987;74(7):626-7.

\section{Banerjee 1997 \{published data only\}}

Banerjee AK, Levy DW, Rawlinson D. Leg ulcers: a comparative study of Synthaderm and conventional dressings. Care of the Elderly 1997;3:123-5.

\section{Beckert 2006 \{published data only\}}

Beckert S, Warnecke J, Zelenkova H, Kovnerystyy O, Stege H, Cholcha W, et al. Efficacy of topical pale sulfonated shale oil in the treatment of venous leg ulcers: a randomized, controlled, multicenter study. Journal of Vascular Surgery 2006;43(1):94-100.

\section{Biland 1985 \{published data only\}}

Biland L, Hürlimann F, Goor W, Körner W F, Kündig A, Madar G, et al. Treatment of venous ulcers. A multi-center randomized double-blind study. VASA. Zeitschrift fur Gefasskrankheiten. Journal for Vascular Diseases 1985;14(4):383-9.

Bishop 1992 \{published data only\}

Bishop JB, Phillips LG, Mustoe TA, VanderZee AJ, Wiersema L, Roach $D E$, et al. A prospective randomized evaluatorblinded trial of two potential wound healing agents for the treatment of venous stasis ulcers. Journal of Vascular Surgery 1992;16(2):251-7.

Blair 1988a \{published data only\}

Blair SD, Backhouse CM, Wright DD, Riddle E, McCollum CN. Do dressings influence the healing of chronic venous ulcers? Phlebology / Venous Forum of the Royal Society of Medicine 1988;3:129-34.

Blair 1988b \{published data only\}

Blair SD, Backhouse CM, Wright DD, Riddle E, McCollum CN. Do dressings influence the healing of chronic venous ulcers? Phlebology / Venous Forum of the Royal Society of Medicine 1988;3:129-34.

\section{Bowszyc 1995 \{published data only\}}

Bowszyc J, Silny W, Bowszyc-Dmochowska M, Kazmierowski M, Ben-Amer HM, Garbowska T, et al. A randomised controlled comparative clinical trial of Lyofoam versus Granuflex in the treatment of venous leg ulcers. Third Conference on Advances on Wound Management; 1993 October 19-22; Harrogate (UK). 1994:34-7.

* Bowszyc J, Silny W, Bowszyc-Dmochowska M, Kazmierowski M, Ben-Amer HM, Garbowska T, et al. Comparison of two dressings in the treatment of venous leg ulcers. Journal of Wound Care 1995;4(3):106-10.

Brandrup 1990 \{published data only\}

Brandrup F, Menné T, Agren MS, Strömberg HE, Holst R, Frisén M. A randomized trial of two occlusive dressings in the treatment of leg ulcers. Acta Dermato-Venereologica 1990;70(3):231-5.

\section{Brown 2014 \{published data only\}}

Brown A, Augustin M, Junger M, Zutt M, Dissemond J, Rabe E, et al. Randomized standard-of-care-controlled trial of a silica gel fibre matrix in the treatment of chronic venous leg ulcers. European Journal of Dermatology 2014;24(2):210-6.

\section{Callam 1992 \{published data only\}}

Callam MJ, Harper DR, Dale JJ, Brown D, Gibson B, Prescott RJ, et al. Lothian and Forth Valley leg ulcer healing trial. Part 1: Elastic versus non-elastic bandaging in the treatment of chronic leg ulceration. Phlebology 1992;7(4):136-41.

* Callam MJ, Harper DR, Dale JJ, Brown D, Gibson B, Prescott RJ, et al. Lothian and Forth Valley leg ulcer healing trial. Part 2: Knitted viscose dressing versus a hydrocellular dressing in the treatment of chronic leg ulceration. Phlebology 1992;7(4):142-5. 
Smith, Nephew. CTR87/29. Final report of a study to compare elastic versus non-elastic bandaging and knitted viscose dressings (Tricotex) versus hydrophilic polyurethane dressings (Allevyn) in the treatment of chronic venous leg ulcers. Volume 1. 1991.

\section{Caprio 1992 \{published data only\}}

* Caprio B, Mugiano GA, Siciliano G, Zurleni F. The cost and effectiveness of modern dressings in leg ulcer care. Second European Conference on Advances in Wound Management; 1992 October 20-3; Harrogate (UK). 1992:148-9.

Caprio B, Murgiano GA, Ricci E, Siciliano G, Zurleni G. The cost effectiveness of modern dressings in leg ulcer care. Fourth European Conference on Advances in Wound Management; 1994 September 6-9; Copenhagen, Denmark. 1995:199.

\section{Casoni 2002 \{published data only\}}

Casoni P. Randomized trial of a new dressing in the treatment of chronic non-healing leg ulcers. 15th Annual Congress of the American College of Phlebology; 2001 November 8-11; La Quinta (CA). 2001:Abstract.

* Casoni P, Gioacchino J. Randomized trial of a new dressing in the treatment of chronic non-healing leg ulcers. 16th Annual Congress of the American College of Phlebology; 2002 November 7-10; Fort Lauderdale (FL). 2002:Abstract.

\section{Charles 2002 \{published data only\}}

Charles H. Venous Ulcer Repair and Quality of Life [PhD thesis]. Buckingham (UK): Brunel University, 2001.

* Charles H, Callicot C, Mathurin D, Ballard K, Hart J. Randomised, comparative study of three primary dressings for the treatment of venous ulcers. British Journal of Community Nursing 2002;7((Suppl 6)):48-54.

Charles H, Callicott C, Mathurin D, Ballard K, Hart J. A randomised, comparative study of a recently introduced hydroactive foam dressing versus two well established hydrocolloid dressings in the treatment of venous leg ulcers using short-stretch compression bandages. Fourth Australian Wound Management Association Conference; 2002 March 7-10; Adelaide, South Australia. 2002:31.

Hart J, Charles H, Callicot C, Mathurin D, Ballard C, Harding KG. A randomised comparative study of a new hydroactive foam dressing versus two hydrocolloid dressings in the treatment of venous ulcers. Eighth European Conference on Advances in Wound Management; 1998 April 26-28; Madrid, Spain. 1999:88.

Hart J, Charles H, Callicot C, Mathurin D, Ballard K, Bale S, et al. Randomised, comparative study of Cutinova foam versus Comfeel and Granuflex (improved formulation) in the treatment of venous leg ulcers - interim results. 7th Annual Meeting of the European Tissue Repair Society; 1997 August 23-26; Koln, Germany. 1997:5.

\section{De Araujo 2016 \{published data only\}}

De Araujo IC, Defune E, Abbade LP, Miot HA, Bertanha M, de Carvalho LR, et al. Fibrin gel versus papain gel in the healing of chronic venous ulcers: a double-blind randomized controlled trial. Phlebology 2016;4:4.
Dereure 2012a \{published data only\}

Dereure O, Czubek M, Combemale P. Efficacy and safety of hyaluronic acid in treatment of leg ulcers: a double-blind RCT. Journal of Wound Care 2012;21(3):131-9.

Dimakakos 2009 \{published data only\}

Dimakakos EP, Katsenis K, Kalemikerakis J, Arkadopoulos N, Mylonas S, Arapoglou V, et al. Infected venous leg ulcers: management with silver-releasing foam dressing. Wounds 2009;21(1):4-8.

\section{Fogh 2012 \{published data only\}}

* Fogh K, Andersen MB, Bischoff-Mikkelsen M, Bause R, Zutt M, Schilling S, et al. Clinically relevant pain relief with an ibuprofen-releasing foam dressing: results from a randomized, controlled, double-blind clinical trial in exuding, painful venous leg ulcers. Wound Repair and Regeneration 2012;20(6):815-21.

Fogh K, Bischoff-Mikkelsen M, Bause R, Zutt M, Andersen MB, Jørgensen B. Results from a double-blind RCT of an ibuprofenreleasing foam dressing for the treatment of exuding, painful venous leg ulcers. EWMA Journal 2012;12(2):335.

\section{Gottrup 2008 \{published data only\}}

Gottrup F, Jørgensen B, Karlsmark T, Sibbald RG, Rimdeika R, Harding $\mathrm{K}$, et al. Less pain with Biatain-lbu: initial findings from a randomised, controlled, double-blind clinical investigation on painful venous leg ulcers. International Wound Journal 2007;4(Suppl 1):24-34.

* Gottrup F, Jørgensen B, Karlsmark T, Sibbald RG, Rimdeika R, Harding K, et al. Reducing wound pain in venous leg ulcers with Biatain Ibu: a randomized, controlled double-blind clinical investigation on the performance and safety. Wound Repair and Regeneration 2008;16(5):615-25.

Gottrupp F, Jørgensen B, Karlsmark T, Sibbald G, Rimdeika R, Harding K, et al. Reducing persistent wound pain with an ibuprofen-foam: a randomised, controlled, double-blind clinical investigation on the treatment of painful venous leg ulcers. 17th Conference of the European Wound Management Association; 2007 May 2-4; Glasgow, Scotland. 2007:168. [Poster 154]

\section{Greguric 1994 \{published data only\}}

Greguric S, Budimcic D, Soldo-Belic A, Tudoric M, Baricevic B, Cajkovac V, et al. Hydrocolloid dressing versus a conventional dressing using magnesium sulphate paste in the management of venous leg ulcers. Acta Dermatovenerologica Croatica 1994;2(2):65-71.

Hanft 2006 \{published data only\}

* Hanft J, Serena T, Snyder R. Evaluation of the clinical effectiveness of a collagen-orc antimicrobial matrix in venous leg ulcers. 16th Conference of the European Wound Management Association; 2006 May 18-20; Prague, Czech Republic. 2006:151.

Hanft JR, Serena T, Snyder R. A study to evaluate the clinical effectiveness of a Collagen-ORC Antimicrobial Matrix in venous leg ulcers. Wound Repair and Regeneration 2006;14(2):A64. 
Westby MW. Trial details needed for Cochrane review. Email to G Norman 19 October 2016.

\section{Hansson 1998 \{published data only\}}

Hansson C, Persson L M, Stenquist B, Nordin P, Roed-Petersen J, Westerhof $W$, et al. The effects of cadexomer iodine paste in the treatment of venous leg ulcers compared with hydrocolloid dressing and paraffin gauze dressing. Cadexomer lodine Study Group. International Journal of Dermatology 1998;37(5):390-6.

\section{Harcup 1986 \{published data only\}}

Harcup JW, Saul PA. A study of the effect of cadexomer iodine in the treatment of venous leg ulcers. British Journal of Clinical Practice 1986;40(9):360-4.

\section{Harding 2001 \{published data only\}}

* Harding KG, Price P, Robinson B, Thomas S, Hofman D. Cost and dressing evaluation of hydrofiber and alginate dressings in the management of community-based patients with chronic leg ulceration. Wounds 2001;13(6):229-36.

Harding KG, Price P, Robinson B, Thomas S, Holman D. Cost and dressing evaluation of a hydrofiber and alginate dressing in the management of community-based patients with chronic leg ulceration. Ostomy/Wound Management 2001;47(12):52.

\section{Hokkam 2011 \{published data only\}}

Hokkam E, El-Labban G, Shams M, Rifaat S, El-Mezaien M. The use of topical phenytoin for healing of chronic venous ulcerations. International Journal of Surgery 2011;9(4):335-8.

\section{Humbert 2013 \{published data only\}}

Humbert P, Mikosinki J, Benchikhi H, Allaert F-A. Efficacy and safety of a gauze pad containing hyaluronic acid in treatment of leg ulcers of venous or mixed origin: a doubleblind, randomised, controlled trial. International Wound Journal 2013;10(2):159-66.

\section{Ivins 2006 \{published data only\}}

* Ivins N, Harding KG, Price P, Jørgensen B, Lohmann M, Gottrup F, et al. Safety and efficacy in long-term use of a sustained silver-releasing foam dressing: a randomized, controlled trial on venous leg ulcers. Symposium on Advanced Wound Care (SAWC) \& Medical Research Forum on Wound Repair; 2006 April 30-May 3; San Antonio (TX). 2006:Poster 12.

Ivins N, Jørgensen B, Lohmann M, Harding KG, Price P, Gottrup F, et al. Safety and efficacy in long term use of a sustained silver-releasing foam dressing: a randomised, controlled trial on venous leg ulcers. Joint Scientific Meeting of ETRS, EWMA and DGfW; 2005 September 15-16; Stuttgart, Germany. 2005:284. [Poster 180]

\section{Jull 2008 \{published data only\}}

Jull A. Honey and venous leg ulceration: a systematic review and randomised controlled trial [PhD thesis]. Auckland, New Zealand: University of Auckland, 2007.

Jull A, Walker N, Parag V, Molan P, Arroll B, Waters J, et al. Honey as adjuvant therapy for leg ulcers (HALT) trial: a randomized controlled trial. 16th Conference of the European Wound
Management Association; 2006 May 18-20; Prague, Czech Republic. 2006:Abstract 29.

* Jull A, Walker N, Parag V, Molan P, Rodgers A, on behalf of the Honey as Adjuvant Leg Ulcer Therapy trial collaborators. Randomized clinical trial of honey-impregnated dressings for venous leg ulcers. British Journal of Surgery 2008;95(2):175-82.

Jull A, Walker N, Rodgers A, Bennett D, Molan P, Arroll B, et al. Honey for leg ulcers - the HALT trial. Second World Union of Wound Healing Societies Meeting; 2004 July 8-13; Paris, France. 2004:88.

\section{Jørgensen 2005 \{published data only\}}

* Jørgensen B, Price P, Andersen KE, Gottrup F, BechThomsen N, Scanlon E, et al. The silver-releasing foam dressing, Contreet Foam, promotes faster healing of critically colonised venous leg ulcers: a randomised, controlled trial. International Wound Journal 2005;2(1):64-73.

Jørgensen B, Thomsen JK. Safety and efficacy of a new hydrocapillary dressing in the treatment of leg ulcers. 13th Conference of the European Wound Management Association; 2003 May 22-24; Pisa, Italy. 2003:221.

\section{Kalis 1993 \{published data only\}}

Kalis B. Clinical evaluation of Granuflex and dextranomer dressing in leg ulcers. Second European Conference on Advances in Wound Management; 1993 October 20-23; Harrogate, UK. 1993:212.

\section{Kelechi 2012 \{published data only\}}

Kelechi T, Mueller M, Hankin C, Bronstone A, Samies J, Bonham P. A randomized, investigator-blinded, controlled pilot study to evaluate the safety and efficacy of a poly-N-acetyl glucosamine-derived membrane material in patients with venous leg ulcers. Journal of Wound, Ostomy and Continence Nursing 2011;38:S91.

* Kelechi TJ, Mueller M, Hankin CS, Bronstone A, Samies J, Bonham PA. A randomized, investigator-blinded, controlled pilot study to evaluate the safety and efficacy of a poly- $\mathrm{N}$ acetyl glucosamine-derived membrane material in patients with venous leg ulcers. Journal of the American Academy of Dermatology 2012;66(6):e209-15.

\section{Kucharzewski 2013 \{published data only\}}

Kucharzewski M, Wilemska-Kucharzewska K, Kozka M, Splakowska M. Leg venous ulcer healing process after application of membranous dressing with silver ions. Phlebologie 2013;42(6):340-6.

\section{Lanzara 2008 \{published data only\}}

Lanzara S, Tacconi G, Gianesini S, Menegatti E, Federici F, Liboni A, et al. A pilot randomized trial to determine the effects of a new active dressing on wound healing of venous leg ulcers [Abstract no. 114]. EWMA Journal 2008;8(Suppl 2):76. [Abstract 114]

\section{Leaper 1991 \{published data only\}}

Leaper DJ, Cameron S, Hewitt H, Winter A, Lucarotti ME. A community- and hospital-based comparative evaluation 
of Comfeel ulcer dressing for chronic leg ulcers. Journal of Dermatological Treatment 1991;2(3):103-6.

\section{Lindsay 1986 \{published data only\}}

Lindsay G, Latta D, Lyons KG, Livingstone ED, Thomson W. A study in general practice of the efficacy of cadexomer iodine in venous leg ulcers treated on alternate days. Acta Therapeutica 1986;12:141-7.

\section{Luiza 2015 \{published data only\}}

Luiza Soares Rodrigues A, Guitton Renaud Baptista de Oliveira B, Omena Futuro D, Regina Secoli S. Effectiveness of papain gel in venous ulcer treatment: randomized clinical trial. Revista Latino-Americana de Enfermagem 2015;23(3):458-65.

\section{Meaume 2012 \{published data only\}}

Augustin M, Herberger K, Kroeger K, Muenter KC, Goepel L, Rychlik R. Cost-effectiveness of treating vascular leg ulcers with UrgoStart and UrgoCell Contact. International Wound Journal 2016;13(1):82-7.

* Meaume S, Truchetet F, Cambazard F, Lok C, Debure C, Dalac $S$, et al. A randomized, controlled, double-blind prospective trial with a Lipido-Colloid Technology: Nano-Oligo Saccharide Factor wound dressing in the local management of venous leg ulcers. Wound Repair and Regeneration 2012:20(4):500-11.

\section{Meredith 1988 \{published data only\}}

Meredith K, Gray E. Dressed to heal. Jounral of District Nursing 1988;7(3):8-10

\section{Michaels 2009 \{published data only\}}

Michaels JA, Campbell B, King B, Palfreyman SJ, Shackley P, Stevenson M. Randomized controlled trial and costeffectiveness analysis of silver-donating antimicrobial dressings for venous leg ulcers (VULCAN trial). British Journal of Surgery 2009;96(10):1147-56.

* Michaels JA, Campbell WB, King BM, Macintyre J, Palfreyman SJ, Shackley $P$, et al. A prospective randomised controlled trial and economic modelling of antimicrobial silver dressings versus non-adherent control dressings for venous leg ulcers: the VULCAN trial. Health Technology Assessment 2009;13(56):1-114.

\section{Moffatt 1992a \{published data only\}}

Moffatt CJ, Franks PJ, Oldroyd MI, Greenhalgh RM. A randomized trial of an occlusive dressing to treat chronic non-healing venous ulcers. Second European Conference on Advances in Wound Management; 1992 October 20-23; Harrogate, UK. 1993:210-1.

* Moffatt CJ, Franks PJ, Oldroyd MI, Greenhalgh RM. Randomized trial of an occlusive dressing in the treatment of chronic non-healing leg ulcers. Phlebology 1992;7(3):105-7.

Moffatt CJ, Oldroyd MI, Dickson D. A trial of hydrocolloid dressing in the management of indolent ulceration. Journal of Wound Care 1992;1(3):20-2.

\section{Moffatt 1992b \{published data only\}}

Moffatt CJ, Oldroyd MI, Franks PJ. Assessing a calcium alginate dressing for venous ulcers of the leg. Journal of Wound Care 1992;1(4):22-4.

\section{Moss 1987 \{published data only\}}

Moss C, Taylor A, Shuster S. Comparative study of cadexomer iodine and dextranomer in chronic leg ulcers. Scottish Medical Journal 1984;54:25.

* Moss C, Taylor AE, Shuster S. Comparison of cadexomer iodine and dextranomer for chronic venous ulcers. Clinical and Experimental Dermatology 1987;12(6):413-8.

\section{Nelson 2007 \{published data only\}}

Dale JJ, Ruckley CV, Harper DR, Gibson B, Nelson EA, Prescott RJ. A factorial clinical trial of drugs, dressings and bandages in the treatment of leg ulcers. Fifth European Conference on Advances in Wound Management; 1995 November 21-24; Harrogate, UK. 1996:193-4.

Franks PJ, Bosanquet N, Brown D, Straub J, Harper DR, Ruckley CV. Perceived health in a randomised trial of single and multilayer bandaging for chronic ulceration. Phlebology 1995;95(Suppl 1):17-9.

Franks PJ, Bosanquet N, Brown D, Straub J, Harper DR, Ruckley CV. Perceived health in a randomised trial of treatment for chronic venous ulceration. European Journal of Vascular and Endovascular Surgery 1999;17(2):155-9.

Franks PJ, Bosanquet N, Brown D, Straub J, Harper DR, Ruckley CV. Perceived health in a randomised trial of treatment for chronic venous ulceration [personal communication]. Letter to: CV Ruckley (Lothian \& Forth Valley Leg Ulcer Study) 11 June 1996.

* Nelson EA, Prescott RJ, Harper DR, Gibson B, Brown D, Ruckley CV. A factorial, randomized trial of pentoxifylline or placebo, four-layer or single-layer compression, and knitted viscose or hydrocolloid dressings for venous ulcers. Journal of Vascular Surgery 2007;45(1):134-41.

Nelson EA, Ruckley CV, Harper DR, Gibson B, Dale JJ. A randomised trial of knitted viscose dressing in the treatment of chronic venous ulceration. Phlebology 1995;95(Suppl 1):915-6.

Nelson EA, Ruckley CV, Harper DR, Gibson B, Dale JJ, Prescott RJ. A randomised trial of a knitted viscose dressing and a hydrocolloid dressings in the treatment of chronic venous ulceration. Phlebology 1995;95(Suppl 1):913-4.

Prescott RJ, Nelson EA, Dale JJ, Harper DR, Ruckley CV. Design of randomized controlled trials in the treatment of leg ulcers: More answers with fewer patients. Phlebology 1998;13(3):107-12.

\section{Norkus 2005 \{published data only\}}

Norkus A, Dargis V, Thomsen JK, Harding KG, Ivins N, Serra N, et al. Use of a hydrocapillary dressing in the management of highly exuding ulcers: a comparative study. Journal of Wound Care 2005;14(9):429-32. 
Ohlsson 1994 \{published data only\}

Lindholm C, Larsson K, Holmgren T, Möller M, Ohlsson P. Leg ulcer treatment in primary care - comparison of gauze and DuoDERM in a prospective randomised study. Second European Conference on Advances in Wound Management; 1992 October 20-23; Harrogate, UK. 1993:131.

* Ohlsson P, Larsson K, Lindholm C, Möller M. A costeffectiveness study of leg ulcer treatment in primary care. Comparison of saline-gauze and hydrocolloid treatment in a prospective, randomized study. Scandinavian Journal of Primary Health Care 1994;12(4):295-9.

\section{Ormiston 1985 \{published data only\}}

Ormiston MC, Seymour MT, Venn GE, Cohen RI, Fox JA. A randomised comparison of cadexomer iodine and a standard treatment in out-patients with chronic venous ulcers. Cadexomer lodine: a Roundtable Discussion; 1983 January 22; Munich, Germany. Berlin: Schattauer, 1983:63-9.

* Ormiston MC, Seymour MT, Venn GE, Cohen RI, Fox JA. Controlled trial of lodosorb in chronic venous ulcers. British Medical Journal 1985;291(6491):308-10.

\section{Petkov 1997 \{published data only\}}

Petkov L. A comparative study of the influence of two topical wound dressings used during healing on subsequent venous ulcer recurrence. Sixth European Conference on Advances in Wound Management; 1996 October 1-4; Amsterdam, The Netherlands. 1997:267.

\section{Rasmussen 1991 \{published data only\}}

Rasmussen LH, Karlsmark T, Avnstorp C, Peters K, Jorgensen M, Jensen LT. Topical human growth hormone treatment of chronic leg ulcers. Phlebology 1991;6(1):23-30.

\section{Robson 1995 \{published data only\}}

Robson MC, Phillip LG, Cooper DM, Lyle WG, Robson LE, Odom L, et al. Safety and effect of transforming growth factor-beta(2) for treatment of venous stasis ulcers. Wound Repair and Regeneration 1995;3(2):157-67.

\section{Robson 2001 \{published data only\}}

Robson MC, Phillips TJ, Falanga V, Odenheimer DJ, Parish LC, Jensen JL, et al. Randomized trial of topically applied repifermin (recombinant human keratinocyte growth factor-2) to accelerate wound healing in venous ulcers. Wound Repair and Regeneration 2001;9(5):347-52.

\section{Robson 2004 \{published data only\}}

Brennan M, Serena TE, Hanft J, Snyder R. Patients with venous leg ulcerations have diminished quality of life: analysis of a multi-center randomized clinical trial. Symposium on Advanced Wound Care and The Wound Healing Society; 2010 April 17-20; Orlando, Florida. 2010:S19. [Abstract CR-017]

* Robson MC, Hanfnt J, Garner W, Jenson J, Serena T, Payne WG, et al. Healing of chronic venous ulcers is not enhanced by the addition of topical repifermin (KGF-2) to standardized care. Journal of Applied Research 2004;4(2):302-11.

\section{Romanelli 2015a \{published data only\}}

Romanelli M, Mulder G, Paggi B, Macchia M, Panduri S, Dini V. The use of a collagen matrix in hard-to-heal venous leg ulcers. Journal of Wound Care 2015;24(11):543-4, 546.

\section{Romero-Cerecero 2012 \{published data only\}}

Romero-Cerecero O, Zamilpa-Álvarez A, Jiménez-Ferrer E, Tortoriello J. Exploratory study on the effectiveness of a standardized extract from Ageratina pichinchensis in patients with chronic venous leg ulcers. Planta Medica 2012;78(4):304-10.

\section{Rubin 1990 \{published data only\}}

Rubin JR, Alexander J, Plecha EJ, Marman C. Unna's boot vs polyurethane foam dressings for the treatment of venous ulceration. A randomized prospective study. Archives of Surgery 1990;125(4):489-90.

\section{Salim 1992 \{published data only\}}

Salim AS. Role of sulphydryl-containing agents in the management of venous (varicose) ulceration. A new approach. Clinical and Experimental Dermatology 1992;17(6):427-32.

* Salim AS. The role of oxygen-derived free radicals in the management of venous (varicose) ulceration: a new approach. World Journal of Surgery 1991;15(2):264-9.

\section{Schulze 2001 \{published data only\}}

Schulze HJ, Lane C, Charles H, Ballard K, Hampton S, Moll I. Evaluating a superabsorbent hydropolymer dressing for exuding venous leg ulcers. Journal of Wound Care 2001;10(1):511-8.

\section{Scurr 1994 \{published data only\}}

Scurr JH, Wilson L A, Coleridge-Smith PD. A comparison of calcium alginate and hydrocolloid dressings in the management of chronic venous ulcers. Wounds 1994;6(1):1-8.

\section{Senet 2003 \{published data only\}}

Senet P. Clinical and biological study of platelets used as adjuvant therapy for venous ulcers. 20th World Congress of Dermatology; 2002 July 1-5; Paris, France. 2002:IC1738.

* Senet P, Bon FX, Benbunan M, Bussel A, Traineau R, Calvo F, et al. Randomized trial and local biological effect of autologous platelets used as adjuvant therapy for chronic venous leg ulcers. Journal of Vascular Surgery 2003;38(6):1342-8.

Senet 2011 \{published data only\}

Senet P, Vicaut E, Beneton N, Debure C, Lok C, Chosidow O. Topical treatment of hypertensive leg ulcers with plateletderived growth factor-BB: a randomized controlled trial. Archives of Dermatology 2011;147(8):926-30.

\section{Senet 2014 \{published data only\}}

* Senet P, Bause R, Jørgensen B, Fogh K. Clinical efficacy of a silver-releasing foam dressing in venous leg ulcer healing: a randomised controlled trial. International Wound Journal 2014;11(6):649-55. 
Senet P, Petersen B. Hard-to-heal venous leg ulcers: results from a double-blind RCT of a silver foam dressing. EWMA Journal 2012;12(2):188.

\section{Smith 1992 \{published data only\}}

Smith JM, Dore CJ, Charlett A, Lewis JD. A randomized trial of biofilm dressing for venous leg ulcers. Phlebology 1992;7(3):108-13.

\section{Smith 1994 \{published data only\}}

* Smith BA. The dressing makes the difference. Trial of two modern dressings on venous ulcers. Professional Nurse 1994;9(5):348, 350-2.

Smith BA. Venous ulcers - a well-healed dresser. Second European Conference on Advances in Wound Management; 1992 October 23-23; Harrogate, UK. 1993:211.

\section{Solovastru 2015 \{published data only\}}

Solovastru LG, Stincanu A, De Ascentii A, Cappare G, Mattana P, Vata D. Randomized, controlled study of innovative spray formulation containing ozonated oil and alpha-bisabolol in the topical treatment of chronic venous leg ulcers. Advances in Skin \& Wound Care 2015;28(9):406-9.

\section{Sopata 2016 \{published data only\}}

* Sopata M, Kucharzewski M, Tomaszewska E. Antiseptic with modern wound dressings in the treatment of venous leg ulcers: clinical and microbiological aspects. Journal of Wound Care 2016;25(8):419-26.

Sopata M, Tomaszewska E, Muszynski Z, Ciupinska M. Can antiseptics with modern wound dressings have beneficial effect on venous leg ulcers treatment? Clinical and microbiological aspects. 24th Annual Meeting of the Wound Healing Society; 2014 April 23-27; Orlando (FL). 2014:A60.

\section{Stacey 1997 \{published data only\}}

Stacey MC, Jopp McKay AG, Rashid P, Hoskin SE, Thompson PM. The influence of dressings on venous ulcer healing. First European Conference on Advances in Wound Management; 1991 September 4-6; Cardiff, UK. 1992:145-6.

* Stacey MC, Jopp-Mckay AG, Rashid P, Hoskin SE, Thompson PJ. The influence of dressings on venous ulcer healing - a randomised trial. European Journal of Vascular and Endovascular Surgery 1997;13(2):174-9.

\section{Stacey 2000 \{published data only\}}

Stacey MC, Mata SD, Trengove NJ, Mather CA. Randomised double-blind placebo controlled trial of tropical autologous platelet lysate in venous ulcer healing. European Journal of Vascular and Endovascular Surgery 2000;20(3):296-301.

\section{Steele 1986 \{published data only\}}

Steele K, Irwin G, Dowds N. Cadexomer iodine in the management of venous leg ulcers in general practice. Practitioner 1986;230(1411):63-8.

\section{Taddeucci 2004 \{published data only\}}

Taddeucci P, Pianigiani E, Colletta V, Torasso F, Andreassi L, Andreassi A. An evaluation of Hyalofill-F plus compression bandaging in the treatment of chronic venous ulcers. Journal of Wound Care 2004;13(5):202-4.

Tarvainen 1988 \{published data only\}

Tarvainen K. Cadexomer iodine (lodosorb) compared with dextranomer (Debrisan) in the treatment of chronic leg ulcers. Acta Chirurgica Scandinavica. Supplementum 1988;544:57-9.

\section{Thomas 1997 \{published data only\}}

Banks V, Fear M, Orpin J, Hagelstein S, Colgate G, Humphreys J, et al. A comparative open multi-centre trial of Tielle hydropolymer dressing and Granuflex improved formulation. Fifth European Conference on Advances in Wound Management; 1995 November 21-24; Harrogate, UK. 1996:163-7.

* Thomas S, Banks V, Bale S, Fear-Price M, Hagelstein S, Harding KG, et al. Evaluation. A comparison of two dressings in the management of chronic wounds. Journal of Wound Care 1997;6(8):383-6.

\section{Tumino 2008 \{published data only\}}

Tumino G, Masuelli L, Bei R, Simonelli L, Santoro A, Francipane $S$. Topical treatment of chronic venous ulcers with sucralfate: a placebo controlled randomized study. International Journal of Molecular Medicine 2008;22(1):17-23.

Vanscheidt 2012 \{published data only\}

Vanscheidt W, Harding K, Téot L, Siebert J. Effectiveness and tissue compatibility of a 12 -week treatment of chronic venous leg ulcers with an octenidine based antiseptic - a randomized, double-blind controlled study. International Wound Journal 2012;9(3):316-23.

\section{Vin 2002 \{published data only\}}

Delchambre J. Venous leg ulcers trials. Journal of Wound Care 2002;12(3 (Suppl)):6-7.

* Vin F, Téot L, Meaume S. The healing properties of Promogran in venous leg ulcers. Journal of Wound Care 2002;11(9):335-41.

Vin F, Téot L, Meaume S. The healing properties of Promogran in venous leg ulcers. Phlébologie 2003;56(1):77-86.

\section{Zuccarelli 1992 \{published data only\}}

* Zuccarelli F. A comparative study of the hydrocellular dressing Allevyn and the hydrocolloid dressing Duoderm in the local treatment of leg ulcers [Étude comparative du pansement hydrocellulaire Allevyn et du pansement hydrocolloide Duoderm dans le traitement local des ulcères de jambe]. Phlébologie 1992;45(4):529-33.

Zuccarelli F. A study to evaluate and compare the performance of a hydrocellular dressing with a hydrocolloid dressing in the treatment of venous leg ulcers. Second European Conference on Advances in Wound Management; 1992 October 20-23; Harrogate, UK. 1993:98.

\section{References to studies excluded from this review}

Acosta 1992 \{published data only\}

Acosta FJ, Novoa Mogollon FJ, Cobo P, Bilbao Arechabaleta G, Alvarez Cantalapiedra I. Topical treatment of ulcers with growth

Dressings and topical agents for treating venous leg ulcers (Review) 
hormone: comparative study with hydrocolloid occlusive dressing [Tratamiento tópico de las úlceras con hormona de crecimiento: estudio comparativo con apósito oclusivo hidrocoloide]. Actas Dermo-Sifiliograficas 1992;83(11):603-4.

\section{Alvarez 2004 \{published data only\}}

Alvarez OM, Patel M, Booker J, Markowitz L. Effectiveness of a biocellulose wound dressing for the treatment of chronic venous leg ulcers: results of a single center randomized study involving 24 patients. Wounds 2004;16(7):224-33.

\section{Andersen 2002 \{published data only\}}

Andersen KE, Franken CP, Gad P, Larsen A, Larsen JR, van Neer PA, et al. A randomized, controlled study to compare the effectiveness of two foam dressings in the management of lower leg ulcers. Ostomy/Wound Management 2002;48(8):34-41.

\section{Andreev 2010 \{published data only\}}

Andreev D, Paramonov B, Sominina A, Smirnova D, Sedov M, Kiselev IO. Efficacy of the treatment of venous leg ulcers with fetal fibroblasts. EWMA Journal 2010;10(2):264. [Abstract P314]

\section{Andriessen 2009 \{published data only\}}

Andriessen A, Polignano R, Abel M. Monitoring the microcirculation to evaluate dressing performance in patients with venous leg ulcers. Journal of Wound Care 2009;18(4):145-6.

\section{Asselman 1995 \{published data only\}}

Asselman AH, Veraart J, Gronenschild E, Neumann HA. Wound healing with a new growth factor formula. 5th Annual Meeting of the European Tissue Repair Society; 1995 August 30September 2; Padua, Italy. 1995:362.

\section{Bale 2004 \{published data only\}}

Bale S, Tebbie N, Price P. A topical metronidazole gel used to treat malodorous wounds. British Journal of Nursing 2004;13(11):S4-11.

\section{Bartoletti 1997 \{published data only\}}

Bartoletti PL, D'Alterio R, Pepe R, Marchitelli E. A new therapeutic approach for the treatment of leg ulcers. European Wound Management Association Conference; 1997 April 27-29; Milan, Italy. 1997:115-6.

\section{Bartoszewicz 2013 \{published data only\}}

Bartoszewicz M, Smutnicka D, Secewicz A, Feliks Junka A, Maczynska B, Krasowski G, et al. Effectiveness of octenidinebased dressing in eradication of persistent bacteria colonizing venous ulcers. EWMA Journal 2013;13(Suppl 1):79.

\section{Bastami 2012 \{published data only\}}

Bastami S, Frödin T, Ahlner J, Uppugunduri S. Topical morphine gel in the treatment of painful leg ulcers, a double-blind, placebo-controlled clinical trial: a pilot study. International Wound Journal 2012;9(4):419-27.

\section{Beitner 1985 \{published data only\}}

Beitner H. Treatment of chronic leg ulcers with topical application of benzoyl peroxide lotion. Current Therapeutic Research, Clinical and Experimental 1985;38(4):657-60.

\section{Belcaro 2007 \{published data only\}}

Belcaro G, Cesarone MR, Errichi BM, Di Renzo A, Errichi S, Ricci A, et al. Improvement of microcirculation and healing of venous hypertension and ulcers with Crystacide: evaluation with a microcirculatory model, including free radicals, laser doppler flux, and PO2/PCO2 measurements. Angiology 2007;58(3):323-8.

\section{Bianchi 2018 \{published data only\}}

Bianchi C, Cazzell S, Vayser D, Reyzelman AM, Dosluoglu H, Tovmassian $\mathrm{G}$, et al. A multicentre randomised controlled trial evaluating the efficacy of dehydrated human amnion/chorion membrane (EpiFix) allograft for the treatment of venous leg ulcers. International Wound Journal 2018;15(1):114-22.

\section{Binic 2010 \{published data only\}}

Binic I, Jankovic A, Jankovic D, Jankovic I, Vrucinic Z. Evaluation of healing and antimicrobiological effects of herbal therapy on venous leg ulcer: pilot study. Phytotherapy Research 2010;24(2):277-82.

\section{Bruckner 2009 \{published data only\}}

Bruckner M, Wild T, Schwarz C, Payrich M, Eberlein T. Autolytic wound cleansing potential of different cellulose-based dressings. EWMA Journal 2009;9(2):170. [Abstract P46]

\section{Bull 1995a \{published data only\}}

* Bull RH, Andersen KE, Larsen AM, Leigh IM. A comparative study on two alginate dressings: Kaltostat and Comfeel: alginate dressing for exudating venous leg ulcers. Fifth European Conference on Advances in Wound Management; 1995 November 21-24; Harrogate, UK. 1996:273.

Bull RH, Leigh IM. Alginate dressings for exudating leg ulcers: a randomized study of Comfeel: alginate dressing vs Kaltostat. Fifth Annual Meeting of the European Tissue Repair Society; 1995 August 30-September 2; Padua, Italy. 1995:362.

\section{Burgess 1993 \{published data only\}}

Burgess B. An investigation of hydrocolloids: a comparative prospective randomised trial of the performance of three hydrocolloid dressings. Professional Nurse 1993;8(Suppl 7):3-6.

* Burgess B, Robinson B. Comparative benefits. Nursing Times 1993;89(13):90-2.

\section{Burgos 1989 \{published data only\}}

Burgos H, Herd A, Bennett JP. Placental angiogenic and growth factors in the treatment of chronic varicose ulcers: preliminary communication. Journal of the Royal Society of Medicine 1989;82(10):598-9.

\section{Cabete 2004 \{published data only\}}

Cabete D. Evaluation of the efficacy of a dressing composed of hydrocolloid, hydrofibre and polyurethane. Second World Union of Wound Healing Societies Meeting; 2004 July 8-13; Paris, France. 2004:38. 


\section{Caetano 2009 \{published data only\}}

Caetano KS, Frade MA, Minatel DG, Santana LA, Enwemeka CS. Phototherapy improves healing of chronic venous ulcers. Photomedicine and Laser Surgery 2009;27(1):111-8.

\section{Callam 1987a \{published data only\}}

Callam MJ, Harper DR, Dale JJ, Ruckley CV, Prescott RJ. A controlled trial of weekly ultrasound therapy in chronic leg ulceration. Lancet 1987;2(8552):204-6.

\section{Cardinal 2009a \{published data only\}}

Cardinal M, Eisenbud DE, Armstrong DG. Wound shape geometry measurements correlate to eventual wound healing. Wound Repair and Regeneration 2009;17(2):173-8.

Cardinal 2009b \{published data only\}

Cardinal M, Phillips T, Eisenbud DE, Harding K, Mansbridge J, Armstrong DG. Nonlinear modeling of venous leg ulcer healing rates. BMC Dermatology 2009;9:2.

\section{Carville 2008 \{published data only\}}

Carville K, Kapp S, Newall N, Saflekas S, Lewin G, Gliddon T, et al. Predicting covert and overt infection in leg ulcers: a randomised controlled trial. Third Congress of the World Union of Wound Healing Societies Meeting; 2008 June 4-8; Toronto, Canada. 2008:OR124.

\section{Casoni 2006 \{published data only\}}

* Casoni P. Laser treatment in chronic leg ulcers.

Phlebolymphology 2006;14(2):113.

Casoni P, Japichino G. Laser treatment in chronic nonhealing leg ulcers. UIP World Congress Chapter Meeting; 2003 August 27-31; San Diego (CA). 2003:33.

\section{Cervadoro 2003 \{published data only\}}

Cervadoro G, Bachini L, Andreoli S, Pedrinazzi C, Cervadoro E. Valuation of re-epithelisation of venous leg ulcers by measurement of transcutaneous oxygen tension during systemic and topical therapy [Valutazione della riepitelizzazione di lesioni ulcero-venose agli arti inferiori mediante rilevazione ossimetrica transcutanea in corso di terapia topica e sistemica]. Giornale Italiano di Dermatologia e Venereologia 2003;138(3):237-42

\section{Chaloner 1992 \{published data only\}}

Chaloner D, Fletcher M, Milward P. Clinical trials: comparing dressings. Nursing Standard 1992;Tissue Viability Supplement(7):9-11.

\section{Chaloner 2004a \{published data only\}}

* Chaloner D. A comparative study of two silver containing dressings, Acticoat 7 and Avance in the treatment of chronic venous ulcers. Second World Union of Wound Healing Societies Meeting; 2004 July 8-13; Paris, France. 2004:134.

Chaloner D. A prospective, multi-centre, randomised, comparative study to compare the effects of Acticoat 7 antimicrobial barrier dressing to Avance silver impregnated foam film dressing in the treatment of chronic venous leg ulcers. Unpublished report 2004.

\section{Charles 2002a \{published data only\}}

Charles $\mathrm{H}$. Venous leg ulcer pain and its characteristics. Journal of Tissue Viability 2002;12(4):154-8.

Cherry 1992 \{published data only\}

Cherry GW, Powell SM, Ryan T. The efficacy of mupirocin in the management of venous leg ulcers. Second European Conference on Advances in Wound Management; 1992 October 20-23; Harrogate, UK. 1993:214.

Cherry 1998 \{published data only\}

Cherry GW, Hofman D, Poore S. Tissue repair in patients with chronic venous leg ulcers treated with Prezatide copper acetate gel or standard compression therapy. Wound Repair and Regeneration 1998;6(3):A243.

\section{Chiummariello 2009 \{published data only\}}

Chiummariello S, De Gado F, Monarca C, Ruggiero M, Carlesimo B, Scuderi N, et al. Multicentric study on a topical compound with lymph-draining action in the treatment of the phlebostatic ulcer of the inferior limbs [Studio multicentrico su un preparato topico ad azione linfodrenante nel trattamento dell'ulcera flebostatica degli arti inferiori]. Il Giornale di Chirurgia 2009;30(11-12):497-501.

\section{Choucair 1998 \{published data only\}}

Choucair M, Faria D, Fivenson D. Use of human skin equivalent in the successful treatment of chronic venous leg ulcers. Wounds 1998;10(3):97-104.

\section{Collier 1992 \{published data only\}}

Collier J. A moist, odour-free environment. A multicentred trial of a foamed gel and a hydrocolloid dressing. Professional Nurse 1992; $7(12): 804-8$

\section{Cordts 1992 \{published data only\}}

Cordts PR, Hanrahan LM, Rodriguez AA, Woodson J, LaMorte WW, Menzoian JO. A prospective, randomized trial of Unna's boot versus Duoderm CGF hydroactive dressing plus compression in the management of venous leg ulcers [see comments]. Journal of Vascular Surgery 1992;15(3):480-6.

Cullen 2012 \{published data only\}

* Cullen B, Gibson M, Nisbet L. Early adoption of collagen/ ORC therapies improves clinical outcome. Wound Repair and Regeneration 2012;20(5):A92.

Cullen B, Gibson M, Nisbet L. Targeted use of collagen/ORC improves clinical outcomes. Wound Repair and Regeneration 2012;20(5):A93.

\section{D'Alicandro 2003 \{published data only\}}

D'Alicandro G, Infascelli RM, Iuliano P, Silvestro M, Aprea G. Treatment of severe wounds using a multilayer dressing releasing silver crystals plus oxygen hyperbaric therapy [Abstract]. 13th Conference of the European Wound Management Association 2003 May 22-24; Pisa, Italy. 2003:182.

Daltrey 1981 \{published data only\}

Daltrey DC, Cunliffe WJ. A double-blind study of the effects of benzoyl peroxide $20 \%$ and eusol and liquid paraffin on 
the microbial flora of leg ulcers. Acta Dermato-Venereologica 1981;61(6):575-7.

\section{Davis 1992 \{published data only\}}

Davis LB, McCulloch JM, Neal MB. The effectiveness of Unna Boot and semipermeable film vs. Unna Boot alone in the healing of venous ulcers: a pilot report. Ostomy/Wound Management 1992;38(1):19-21.

\section{De Caridi 2016 \{published data only\}}

De Caridi G, Massara M, Acri I, Zavettieri S, Grande R, Butrico L, et al. Trophic effects of polynucleotides and hyaluronic acid in the healing of venous ulcers of the lower limbs: a clinical study. International Wound Journal 2016;13(5):754-8.

\section{De la Brassinne 2006 \{published data only\}}

De la Brassinne M, Thirion L, Horvat LI. A novel method of comparing the healing properties of two hydrogels in chronic leg ulcers. Journal of the European Academy of Dermatology and Venereology 2006;20(2):131-5.

\section{Dereure 2012b \{published data only\}}

Dereure O, Mikosinki J, Zegota Z, Allaert FA. RCT to evaluate a hyaluronic acid containing gauze pad in leg ulcers of venous or mixed aetiology. Journal of Wound Care 2012;21(11):539-42, $544,546$.

\section{Dini 2010 \{published data only\}}

* Dini V, Bertone M, Miteva M, Romanelli P, De Lorenzo A, Pensabene $L$, et al. Immunoistochemical evaluation of venous leg ulcers before and after negative pressure therapy. EWMA Journal 2010;10(2):90. [Abstract 120]

Dini V, Bertone MS, Romanelli M. Biochemical markers in venous leg ulcers during treatment with topical negative pressure. EWMA Journal 2009;9(2):78. [Abstract 118]

\section{Dini 2013 \{published data only\}}

Andriessen A, Dini V, Barbanera S, Bertone MS, Brilli C, Abel M, et al. Improvement of peri-wound skin condition increases venous leg ulcer healing rates: RCT comparing a bio-cellulose dressing with a foam. EWMA Journal 2011;11(Suppl 2):69.

* Dini V, Romanelli M, Andriessen A, Barbanera S, Bertone MS, Brilli $C$, et al. Improvement of periulcer skin condition in venous leg ulcer patients: prospective, randomized, controlled, single-blinded clinical trial comparing a biosynthetic cellulose dressing with a foam dressing. Advances in Skin \& Wound Care 2013;26(8):352-9.

\section{Dmochowska 1999 \{published data only\}}

Dmochowska M, Prokop J, Bielecka S, Urasinska K, Krolicki A, Nagaj E, et al. A randomized, controlled, parallel group clinical trial of a polyurethane foam dressing versus a calcium alginate dressing in the treatment of moderately to heavily exuding venous leg ulcers. Wounds 1999;11(1):21-8.

\section{Duhra 1992 \{published data only\}}

Duhra P, Blight A, Mountford E, Cheshire I, Withers A, Ilchyshyn A. A randomized controlled trial of cultured keratinocyte allografts for chronic venous ulcers. Journal of Dermatological Treatment 1992;3(4):189-91.
Egan 1983 \{published data only\}

Egan TJ, O'Driscoll J, Thakar DR. Human amnion in the management of chronic ulceration of the lower limb: a clinicopathologic study. Angiology 1983;34(3):197-203.

\section{El Heneidy 2016 \{published data only\}}

El Heneidy H, Omran E, Halwagy A, Al-Inany H, Al-Ansary M Gad A. Amniotic membrane can be a valid source for wound healing. International Journal of Women's Health 2016;8:225-31.

\section{Eriksson 1984a \{published data only\}}

Eriksson G. Comparative study of hydrocolloid dressing and double layer bandage in the treatment of venous stasis ulceration. In: Ryan TJ editor(s). An Environment for Healing: The Role of Occlusion. Issue 88 of International Congress and Symposium Series. London: Royal Society of Medicine, 1984:111-3.

\section{Eriksson 1984b \{published data only\}}

Eriksson G, Eklund AE, Kallings LO. The clinical significance of bacterial growth in venous leg ulcers. Scandinavian Journal of Infectious Diseases 1984;16(2):175-80.

\section{Eriksson 1984c \{published data only\}}

Eriksson G, Eklund AE, Liden S, Zetterquist S. Comparison of different treatments of venous leg ulcers: a controlled study using stereophotogrammetry. Current Therapeutic Research, Clinical and Experimental 1984;35(4):678-84.

\section{Eriksson 1991 \{published data only\}}

Eriksson SV, Lundeberg T, Malm M. A placebo controlled trial of ultrasound therapy in chronic leg ulceration. Scandinavian Journal of Rehabilitation Medicine 1991;23(4):211-3.

\section{Falabella 1998 \{published data only\}}

Falabella AF, Carson P, Eaglstein WH, Falanga V. The safety and efficacy of a proteolytic ointment in the treatment of chronic ulcers of the lower extremity. Journal of the American Academy of Dermatology 1998;39(5 (Pt 1)):737-40.

\section{Falanga 1996 \{published data only\}}

Falanga V, Carson P, Greenberg A, Hasan A, Nichols E, McPherson J. Topically applied recombinant tissue plasminogen activator for the treatment of venous ulcers. Preliminary report. Dermatologic Surgery 1996;22(7):643-4.

\section{Falanga 1998 \{published data only\}}

Falanga V. Clinical trials: experience with Apligraf in chronic wounds. Wound Repair and Regeneration 1998;6(5):A466.

* Falanga V, Margolis D, Alvarez O, Auletta M, Maggiacomo F, Altman M, et al. Rapid healing of venous ulcers and lack of clinical rejection with an allogeneic cultured human skin equivalent. Human Skin Equivalent Investigators Group. Archives of Dermatology 1998;134(3):293-300.

Falanga V, Saap LJ, Ozonoff A. Wound bed score and its correlation with healing of chronic wounds. Dermatologic Therapy 2006;19(6):383-90. 
Falanga 1999 \{published data only\}

Falanga V, Sabolinski M. A bilayered living skin construct (APLIGRAF(TM)) accelerates complete closure of hard-to-heal venous ulcers. Wound Repair and Regeneration 1999;7(4):201-7.

\section{Falanga 2000 \{published data only\}}

Falanga VJ. Tissue engineering in wound repair. Advances in Skin \& Wound Care 2000;13(Suppl 2):15-9.

\section{Falanga 2001 \{published data only\}}

Falanga V, Odenheimer D, Bagchi P. Repifermin (KGF-2) is able to reverse delayed healing in patients with high bacterial burden at presentation. Wound Healing Society 11th Annual Meeting and Educational Symposium; 2001 May 16-18; Albuquerque (NM). 2001:149.

\section{Farina 1997 \{published data only\}}

Farina M, Bonifati C, Dallavalle E. TEAM system in the treatment of venous leg ulcers. A comparative study. European Wound Management Association Conference; 1997 April 27-29; Milan, Italy. 1997:50-1.

\section{Fernández-Gines 2017 \{published data only\}}

Fernández-Ginés FD, Cortiñas-Sáenz $\mathrm{M}$, Mateo-Carrasco $\mathrm{H}$, de Aranda, AN, Navarro-Muñoz, E, Rodríguez-Carmona R, et al. Efficacy and safety of topical sevoflurane in the treatment of chronic skin ulcers. American Journal of Health-System Pharmacy 2017;74(9):e176-e182.

\section{Fischer 1984 \{published data only\}}

Fischer H, Gilliet F, Hornemann M, Leyh F, Lindemayr H, Stegmann W, et al. Report of a multicenter clinical comparative study with various enzyme preparations. Fortschritte der Medizin 1984;102(10):281-3.

\section{Floden 1978 \{published data only\}}

Floden $\mathrm{CH}$, Wikstram K. Controlled clinical trial with dextranomer (debrisan) on venous leg ulcers. Current Therapeutic Research, Clinical and Experimental 1978;24(7):753-60.

\section{Frade 2012 \{published data only\}}

Frade MA, Assis RV, Coutinho Netto J, Andrade TA, Foss NT. The vegetal biomembrane in the healing of chronic venous ulcers. Anais Brasileiros de Dermatologia 2012;87(1):45-51.

\section{Franek 2002 \{published data only\}}

Franek A, Król P, Kucharzewski M. Does low output laser stimulation enhance the healing of crural ulceration? Some critical remarks. Medical Engineering \& Physics 2002;24(9):607-15

\section{Franks 2007 \{published data only\}}

Franks PJ, Moffatt C. A prospective randomised, factorial, multicentre open trial to compare the performance of a new foam dressing (Mepilex) with an existing foam dressing (Allevyn non adhesive) and to compare four layer bandaging and short stretch bandaging in the treatment of venous ulceration. Unpublished protocol for clinical trial MPX-201-UK. Centre for Research and Implementation of Clinical Practice. 2000.
Franks PJ, Moody M, Moffatt CJ. Randomised trial of a soft silicone dressing a foam dressing in patients with chronic venous ulceration. 13th Conference of the European Wound Management Association; 2003 May 22-24; Pisa, Italy. 2003:51.

* Franks PJ, Moody M, Moffatt CJ, Hiskett G, Gatto P, Davies C, et al. Randomized trial of two foam dressings in the management of chronic venous ulceration. Wound Repair and Regeneration 2007;15(2):197-202.

Franks PJ, Moody M, Moffatt CJ, Martin R, Blewett R, Seymour E, et al. Randomized trial of cohesive short-stretch versus fourlayer bandaging in the management of venous ulceration. Wound Repair and Regeneration 2004;12(2):157-62.

Moody M, Moffatt CJ, Franks PJ. Relative performance of a soft silicone dressing and a foam dressing in patients with chronic venous ulceration. 13th Conference of the European Wound Management Association; 2003 May 22-24; Pisa, Italy. 2003:52.

Freak 1992a \{published data only\}

Freak L, Simon D, Edwards AT, McCollum CN. Comparative study of three primary dressings in the healing of chronic venous ulcers. British Journal of Surgery 1992;79(11):1235.

\section{Freak 1994 \{published data only\}}

Freak L, Simon D, Edwards AT, Herrick SE, Ferguson M, McCollum CN. A study of topical human growth hormone on the healing of chronic venous ulcers. Second European Conference on Advances in Wound Management; 1992 October 20-23; Harrogate, UK. 1993:173-5.

* Freak L, Simon D, Edwards AT, Herrick SE, Ferguson M, McCollum CN. The use of topical human growth hormone on chronic venous ulcers. Journal of Wound Care 1994;3(2):68-70.

\section{Fumal 2002 \{published data only\}}

Fumal I, Braham C, Paquet P, Pierard-Franchimont C, Pierard GE. The beneficial toxicity paradox of antimicrobials in leg ulcer healing impaired by a polymicrobial flora: a proof-ofconcept study. Dermatology 2002;204(Suppl 1):70-4.

\section{Galiano 2017 \{published data only\}}

Galiano RD, Eming SA, Cargill DI, Dickerson JE, Slade HB, Andersen CA, et al. Baseline factors affecting closure of venous leg ulcers. Journal of Vascular Surgery: Venous and Lymphatic Disorders 2017;5(6):829-35.e821.

\section{Garcia 1984 \{published data only\}}

Garcia HG, Cobian RR, Martin JR, Konaizeh S, Rahola JG. The effect on the reparation process of dextranomer (Debrisan) in perimalleolar ulcers due to chronic venous insufficiency. Clinical Trials Journal 1984;21(3):121-34.

\section{Garkaz 2014 \{published data only\}}

Garkaz A. High frequency and noncontact low frequency ultrasound therapy for venous leg ulcer treatment: a randomized controlled study. Iranian Journal of Radiology 2014;11(30):S90-S91. 
Gatti 2011 \{published data only\}

Gatti MA, Vieira LM, Barraviera B, Barraviera S. Treatment of venous ulcers with fibrin sealant derived from snake venom. Journal of Venomous Animals and Toxins including Tropical Diseases 2011;17(2):226-9.

\section{Gethin 2008 \{published data only\}}

* Gethin G, Cowman S. Bacteriological changes in sloughy venous leg ulcers treated with manuka honey or hydrogel: an RCT. Journal of Wound Care 2008;17(6):241-6.

Gethin G, Cowman S. Manuka honey versus hydrogel to deslough venous leg ulcers - a randomised controlled trial. 3rd Congress of the World Union of Wound Healing Societies Meeting; 2008 June 4-8; Toronto, Canada. 2008:OR004.

Gethin G, Cowman S. Manuka honey versus hydrogel to deslough venous leg ulcers: a randomised controlled trial. 17th Conference of the European Wound Management Association; 2007 May 2-4; Glasgow, Scotland. 2007:29.

Gethin G, Cowman S. Retraction statement: Manuka honey vs. hydrogel - a prospective, open label, multicentre, randomised controlled trial to compare desloughing efficacy and healing outcomes in venous ulcers [Retraction of Gethin G, Cowman S. Manuka honey vs. hydrogel. Journal of Clinical Nursing. 2009 Feb;18(3):466-74; PMID: 18752540]. Journal of Clinical Nursing 2015;24(17/18):2686.

\section{Ghatnekar 2015 \{published data only\}}

Ghatnekar GS, Grek CL, Armstrong DG, Desai SC, Gourdie RG. The effect of a connexin43-based peptide on the healing of chronic venous leg ulcers: a multicenter, randomized trial. Journal of Investigative Dermatology 2015;135(1):289-98.

\section{Gibbons 2015 \{published data only\}}

Gibbons GW, Orgill DP, Serena TE, Novoung S, O'Connell JB, Li WW, et al. A prospective, randomized, controlled trial comparing the effects of noncontact, low-frequency ultrasound to standard care in healing venous leg ulcers. Ostomy/Wound Management 2015;61(1):16-29.

\section{Gibson 1995 \{published data only\}}

Gibson, B. A cost effectiveness comparison of two gels in the treatment of sloughy leg ulcers. Presented at the Symposium on Advanced Wound Care and Medical Research Forum on Wound Repair; 1995 April; San Diego, CA. www.umsinsihealth.com/ Files/PDF/Granugel\%20(Duoderm)\%20vs\%20Intrasite \%20Gel.pdf (accessed 1 December 2017).

\section{Gilligan 2014 \{published data only\}}

Gilligan AM, Waycaster C. Cost-effectiveness of small intestinal submucosa extracellular matrix on wound closure in patients with difficult-to-heal wound of mixed arterial/venous and venous etiology. ISPOR 19th Annual International Meeting; 2014 May 31-June 4; Montreal, Canada. 2014:A272-3.

\section{Gravante 2013 \{published data only\}}

Gravante G, Sorge R, Giordan N, Georgescu SR, Morariu SH, Stoicescu I, et al. Multicenter clinical trial on the performance and tolerability of the Hyaluronic acid-collagenase ointment for the treatment of chronic venous ulcers: A preliminary pilot study. European Review for Medical and Pharmacological Sciences 2013;17(20):2721-7.

\section{Groenewald 1980 \{published data only\}}

Groenewald JH. An evaluation of dextranomer as a cleansing agent in the treatment of the post-phlebitic stasis ulcer. South African Medical Journal 1980;57(20):809-15.

\section{Groenewald 1981 \{published data only\}}

Groenewald JH. The treatment of varicose stasis ulcers: a controlled trial. Schweizerische Rundschau fur Medizin Praxis 1981;70(28):1273-8.

\section{Gronberg 2014 \{published data only\}}

Gronberg A, Mahlapuu M, Stahle M, Whately-Smith C, Rollman O. Treatment with LL-37 is safe and effective in enhancing healing of hard-to-heal venous leg ulcers: a randomized, placebo-controlled clinical trial. Wound Repair and Regeneration 2014;22(5):613-21.

\section{Grotewohl 1994 \{published data only\}}

Grotewohl JH. The phase-orientated wound dressing of ulcus crusis venosum. Experience with the use of the new hydrogel Opragel. Zeitschrift fur Allgemeinmedizin 1994;70(9):351-4.

\section{Guarnera 2010 \{published data only\}}

* Guarnera G, DeRosa A, Camerini R. The effect of thymosin treatment of venous ulcers. Annals of the New York Academy of Sciences 2010;1194:207-12.

Guarnera G, DeRosa A, Camerini R. Thymosin beta- 4 and venous ulcers: clinical remarks on a European prospective, randomized study on safety, tolerability, and enhancement on healing. Annals of the New York Academy of Sciences 2007;1112:407-12.

\section{Handfield-Jones 1988 \{published data only\}}

Handfield-Jones SE, Grattan CE, Simpson RA, Kennedy CT. Comparison of a hydrocolloid dressing and paraffin gauze in the treatment of venous ulcers. British Journal of Dermatology 1988;118(3):425-7.

\section{Harding 2005 \{published data only\}}

Harding KG, Krieg T, Eming SA, Flour ML, Jawien A, Cencora A, et al. Efficacy and safety of the freeze-dried cultured human keratinocyte lysate, LyphoDermTM $0.9 \%$, in the treatment of hard-to-heal venous leg ulcers. Wound Repair and Regeneration 2005;13(2):138-47.

\section{Harding 2012 \{published data only\}}

Harding K, Gottrup F, Jawien A, Mikosinski J, TwardowskaSaucha K, Kaczmarek S, et al. A prospective, multi-centre, randomised, open label, parallel, comparative study to evaluate effects of AQUACEL Ag and Urgotul Silver dressing on healing of chronic venous leg ulcers. International Wound Journal 2012;9(3):285-94.

\section{Harding 2013 \{published data only\}}

Harding K. An open randomised comparative study to evaluate the clinical and economic performance of two absorbent dressings in venous leg ulcers (VLU's). EWMA Journal 2013;13(Suppl 1):190. 


\section{Harvey 1985 \{published data only\}}

Harvey SG, Gibson JR. The effects on wound healing of three amino acids - a comparison of two models. British Journal of Dermatology 1984;111(Suppl 27):171-3.

* Harvey SG, Gibson JR, Burke CA. L-cysteine, glycine and dl-threonine in the treatment of hypostatic leg ulceration: a placebo-controlled study. Pharmatherapeutica 1985;4(4):227-30.

\section{He 2008 \{published data only\}}

He Q, Wu G, Yu B, Zhang T, Wang W, Gu Q. A prospective study on wound-healing hydrogel in treating chronic venous ulcer of lower extremities. Zhongguo xiu fu chong jian wai ke za zhi [Chinese Journal of Reparative and Reconstructive Surgery] 2008;22(3):311-3.

\section{Hellgren 1983 \{published data only\}}

Hellgren L. Cleansing properties of stabilized trypsin and streptokinase-streptodornase in necrotic leg ulcers. European Journal of Clinical Pharmacology 1983;24(5):623-8.

\section{Hill 2004 \{published data only\}}

Hill DP, Poore S, Wilson J, Robson MC, Cherry GW. Initial healing rates of venous ulcers: are they useful as predictors of healing?. American Journal of Surgery 2004;188(Suppl 1A):22-5.

\section{Hillstrom 1988 \{published data only\}}

Hillstrom L. lodosorb compared to standard treatment in chronic venous leg ulcers - a multicenter study. Acta Chirurgica Scandinavica Supplementum 1988;544(Suppl 544):53-6.

\section{Holloway 1989 \{published data only\}}

Holloway G, Johansen KH, Barnes RW, Pierce GE. Multicenter trial of cadexomer iodine to treat venous stasis ulcer. Western Journal of Medicine 1989;151(1):35-8.

\section{Hornemann 1987 \{published data only\}}

Hornemann M, Raptis G. Therapy of varicose ulcer using crilanomer and dextranomer. Zeitschrift fur Hautkrankheiten 1987;62(1):41-51.

\section{Humbert 2014 \{published data only\}}

Humbert P, Faivre B, Veran Y, Debure C, Truchetet F, Becherel PA, et al. Protease-modulating polyacrylate-based hydrogel stimulates wound bed preparation in venous leg ulcers - a randomized controlled trial. Journal of the European Academy of Dermatology and Venereology 2014;28(12):1742-50.

\section{Hutchinson 1994 \{published data only\}}

Hutchinson JJ. A prospective clinical trial of wound dressings to investigate the rate of infection under occlusion. Third European Conference on Advances in Wound Management; 1993 October 19-22; Harrogate, UK. 1994:93-6.

\section{Jasiel 1997a \{published data only\}}

Jasiel E, Nowak A, Gwiezdzinksi Z, Bowszyc J, Szarmach H, Blaszsyc $M$, et al. A randomized, controlled, parallel-group clinical trial of a new polyurethane foam dressing (Lyofoam Extra) versus a calcium alginate dressing (Melonin) in the treatment of moderate to heavily exuding venous leg ulcers. Sixth European Conference on Advances in Wound Management; 1996 October 1-4; Amsterdam, The Netherlands. 1997:78.

\section{Jasiel 1997b \{published data only\}}

Jasiel E, Nowak A, Gwiezdzinksi Z, Bowszyc J, Szarmach H, Czabanowska J, et al. A randomized, controlled, parallel-group clinical trial of a new debriding agent (Sterigel) versus paraffin gauze in the treatment of necrotic venous leg ulcers. Sixth European Conference on Advances in Wound Management; 1996 October 1-4; Amsterdam, The Netherlands. 1997:81.

\section{Jones 2003 \{published data only\}}

* Jones V. Comparison of the new multilayer composite wound dressing Versiva with Allevyn hydrocellular for managing venous leg ulcers: results of an international multicentre randomised trial [Abstract].. 13th Conference of the European Wound Management Association; 2003 May 22-24; Pisa, Italy. 2003:217.

Jones V. Comparison of the new multilayer composite wound dressing Versiva with Tielle Plus for managing venous leg ulcers: results of an international multicentre randomised trial. 13th Conference of the European Wound Management Association; 2003 May 22-24; Pisa, Italy. 2003:218.

Judy 2010 \{published data only\}

Judy D, Burton C, Johnson J, Yates S. Silver impregnated dressings: Do they help chronic venous ulcers heal?. 68th Annual Meeting of the American Academy of Dermatology; 2010 March 5-9; Miami, FL. 2010:AB150. [Poster P3701]

\section{Jørgensen 2006 \{published data only\}}

Jørgensen B, Friis GJ, Gottrup F. Pain and quality of life for patients with venous leg ulcers: proof of concept of the efficacy of Biatain-lbu, a new pain reducing wound dressing. Wound Repair and Regeneration 2006;14(3):233-9.

\section{Jørgensen 2008 \{published data only\}}

Jørgensen B, Sulcaite R, Vilkevicius G, Bech-Thomsen N, Rimdeika R, Gottrup F. A randomised, controlled trial on safety and performance of a new foam dressing on venous leg ulcers. EWMA Journal 2008;8(2 (Suppl)):138.

\section{Jørgensen 2009 \{published data only\}}

Jørgensen B, Polignano R, Mantovani M, Orsted H. Effects of a foam dressing with ibuprofen on wound pain from arterial leg ulcers and vasculitic ulcers. EWMA Journal 2009;9(2):193. [Abstract P4]

\section{Kerihuel 2010 \{published data only\}}

Kerihuel JC. Effect of activated charcoal dressings on healing outcomes of chronic wounds. Journal of Wound Care 2010;19(5):208-14.

\section{Kikta 1988 \{published data only\}}

Kikta MJ, Schuler JJ, Meyer JP, Durham JR, Eldrup-Jorgensen J, Schwarcz TH, et al. A prospective, randomized trial of Unna's boots versus hydroactive dressing in the treatment of venous stasis ulcers. Journal of Vascular Surgery 1988;7(3):478-83. 
Kirsner 2012 \{published data only\}

* Kirsner RS, Marston WA, Snyder RJ, Lee TD, Cargill DI, Slade HB. Spray-applied cell therapy with human allogeneic fibroblasts and keratinocytes for the treatment of chronic venous leg ulcers: a phase 2, multicentre, double-blind, randomised, placebo-controlled trial. Lancet 2012;380(9846):977-85.

Kirsner RS, Marston WA, Snyder RJ, Lee TD, Cargill DI, Zhang Y, et al. Durability of healing from spray-applied cell therapy with human allogeneic fibroblasts and keratinocytes for the treatment of chronic venous leg ulcers: a 6-month follow-up. Wound Repair and Regeneration 2013;21(5):682-7.

Lantis JC 2nd, Marston WA, Farber A, Kirsner RS, Zhang Y, Lee TD, et al. The influence of patient and wound variables on healing of venous leg ulcers in a randomized controlled trial of growth-arrested allogeneic keratinocytes and fibroblasts. Journal of Vascular Surgery 2013;58(2):433-9.

Marston W, Kirsner R, Snyder R, Lee T, Cargill I, Slade H. Variables affecting healing of venous leg ulcers in a randomized, vehicle-controlled trial of topical cellular therapy. Journal of Vascular Surgery 2012;55(1):303.

\section{Kirsner 2016a \{published data only\}}

Kirsner RS, Vanscheidt W, Keast DH, Lantis JC, Dove CR, Cazzell SM, et al. Phase 3 evaluation of HP802-247 in the treatment of chronic venous leg ulcers [American trial report]. Wound Repair and Regeneration 2016;24(5):894-903.

\section{Kirsner 2016b \{published data only\}}

Kirsner RS, Vanscheidt W, Keast DH, Lantis JC, Dove CR, Cazzell SM, et al. Phase 3 evaluation of HP802-247 in the treatment of chronic venous leg ulcers [European trial report]. Wound Repair and Regeneration 2016;24(5):894-903.

\section{Klemp 1986 \{published data only\}}

Klemp P, Ravnborg L, Staberg B. Pain reaction in patients with venous leg ulcers during treatment with Trypure. Ugeskrift for Laeger 1986;148(13):762-3.

\section{Klostermann 1974 \{published data only\}}

Klostermann GF, Jakob H. Comparative testing of a new creambase against unguentum diachylon in ulcus cruris. Munchener Medizinische Wochenschrift 1974;116(23):1169-70.

\section{Koksal 2003 \{published data only\}}

Koksal C, Bozkurt AK. Combination of hydrocolloid dressing and medical compression stocking versus Unna's boot for the treatment of venous leg ulcers. Swiss Medical Weekly 2003;133(25-26):364-8.

\section{König 2005 \{published data only\}}

König M, Vanscheidt W, Augustin M, Kapp H. Enzymatic versus autolytic debridement of chronic leg ulcers: a prospective randomised trial. Journal of Wound Care 2005;14(7):320-3.

Kopera 2005 \{published data only\}

* Kopera D, Kokol R, Berger C, Haas J. Does the use of low-level laser influence wound healing in chronic venous leg ulcers?. Journal of Wound Care 2005;14(8):391-4.
Kopera D, Kokol R, Berger C, Haas J. Low level laser: does it influence wound healing in venous leg ulcers? A randomized, placebo-controlled, double-blind study. British Journal of Dermatology 2005;152(6):1368-70.

\section{Krasowski 2015 \{published data only\}}

Krasowski G, Jawien A, Tukiendorf A, Rybak Z, Junka A, Olejniczak-Nowakowska $\mathrm{M}$, et al. A comparison of an antibacterial sandwich dressing vs dressing containing silver. Wound Repair and Regeneration 2015;23(4):525-30.

\section{Kucharzewski 2012 \{published data only\}}

Kucharzewski M, Misztal-Knyra J, Wilemska-Kucharzewska K, Bartoszewicz M, Kózka M. The impact of various types of dressings on bacterial flora in patients with chronic venous leg ulcers. EWMA Journal 2012;12(2):108.

\section{La Marca 1999 \{published data only\}}

La Marca G, Pumilia G, Martino A. Effectiveness of mesoglycan topical treatment of leg ulcers in subjects with chronic venous insufficiency. Minerva Cardioangiologica 1999;47(9):315-9.

\section{Lammoglia-Ordiales 2012 \{published data only\}}

Lammoglia L, Contreras-Ruiz J, Vega-Memije ME. Effectiveness of MTC-2G (Mimosa tenuiflora cortex extract) in venous leg ulcers treatment. 20th Annual Meeting of the Wound Healing Society SAWC/WHS Joint Meeting; 2010 April 17-20; Orlando (FL). 2010:A25.

* Lammoglia-Ordiales L, Vega-Memije ME, Herrera-Arellano A, Rivera-Arce E, Agüero J, Vargas-Martinez $F$, et al. A randomised comparative trial on the use of a hydrogel with tepescohuite extract ( Mimosa tenuiflora cortex extract-2G) in the treatment of venous leg ulcers. International Wound Journal 2012;9(4):412-8.

\section{Larsen 1995 \{published data only\}}

Larsen AM, Ulrik D, Madsen SM. Randomised study on Comfeel: alginate dressing vs Kaltostat on exudating venous leg ulcers. Fifth Annual Meeting of the European Tissue Repair Society; 1995 August 30-September 2; Padua, Italy. 1995:Poster.

\section{Larsen 1997 \{published data only\}}

Larsen AM, Andersen KE, Berg BK. A comparative study on the effect and function of Comfeel Purilon versus IntraSite gel on leg ulcers. European Wound Management Association Conference; 1997 April 27-29; Milan, Italy. 1997:44-6.

\section{Larsen 2005 \{published data only\}}

Larsen AM, Vogensen H, Haase L. Evaluation of a foam dressing with a new soft adherent layer. European Wound Management Association Conference; 2005 September 15-17; Stuttgart, Germany. 2005:293.

\section{Laudanska 1988 \{published data only\}}

Laudanska H, Gustavson B. In-patient treatment of chronic varicose venous ulcers. A randomised controlled trial of Cadexomer lodine versus standard dressings. Journal of International Medical Research 1988;16(6):428-35. 
Lazareth 2008 \{published data only\}

* Lazareth I, Meaume S, Sigal Grinberg ML, Combemale P, Le Guyadec T, Zagnoli A, et al. The role of a silver releasing lipido-colloid contact layer in venous leg ulcers presenting inflammatory signs suggesting heavy bacterial colonization: results of a randomized controlled study. Wounds 2008;20(6):158-66.

Lazareth I, Meaume S, Sigal-Grinberg ML, Combemale P, Le Guyadec T, Zagnoli A, et al. Efficacy of a silver lipidocolloid dressing on heavily colonised wounds: a republished RCT. Journal of Wound Care 2012;21(2):96-102.

\section{Limová 1996 \{published data only\}}

Limová M. Evaluation of a new hydrocolloid dressing in the management of venous stasis ulcers. Fifth European Conference on Advances in Wound Management; 1995 November 21-24; Harrogate, UK. 1996:271.

\section{Limová 2002 \{published data only\}}

Limová M, Troyer-Caudle J. Controlled, randomized clinical trial of two hydrocolloid dressings in the management of venous insufficiency ulcers. Journal of Vascular Nursing 2002;20(1):22-32.

\section{Limová 2003 \{published data only\}}

Limová M. Evaluation of two calcium alginate dressings in the management of venous ulcers. Ostomy/Wound management 2003;49(9):26-30.

\section{Lindgren 1998 \{published data only\}}

Lindgren C, Marcusson JA, Toftgård R. Treatment of venous leg ulcers with cryopreserved cultured allogeneic keratinocytes: a prospective open controlled study. British Journal of Dermatology 1998;139(2):271-5.

\section{Lindholm 1995 \{published data only\}}

Lindholm C. Leg ulcer treatment in hospital and primary care in Sweden: cost-effective care and quality of life. Advances in Wound Care 1995;8(5):48-50.

\section{Ljungberg 1998 \{published data only\}}

Ljungberg S. Dextranomer for treatment of venous leg ulcers: paste versus bead formulation. Current Therapeutic Research, Clinical and Experimental 1998;59(7):498-502.

Lofferer 1982 \{published data only\} Lofferer $\mathrm{O}$. Use of polymeric dextrans in cases of therapyresistant leg ulcers: a controlled study. Phlebologie und Proktologie 1982;11(3):303-6.

\section{Lopez 1998 \{published data only\}}

Lopez AP, Bello Y, Phillips TJ. A pilot study to test the effects of a radiant heat bandage on chronic venous ulcers. Wound Repair and Regeneration 1998;6(3):A245.

\section{Lundeberg 1990 \{published data only\}}

Lundeberg T, Nordström F, Brodda Jansen G, Eriksson SV, Kjartansson J, Samuelson UE. Pulsed ultrasound does not improve healing of venous ulcers. Scandinavian Journal of Rehabilitation Medicine 1990;22(4):195-7.

\section{Lundeberg 1991 \{published data only\}}

Lundeberg T, Malm M. Low-power HeNe laser treatment of venous leg ulcers. Annals of Plastic Surgery 1991;27(6):537-9.

\section{Maggio 2007 \{published data only\}}

Maggio G, Scalise A, Durante C. Improved health related activities of daily living for patients with wound pain treated with ibuprofen foam dressing. 17th Conference of the European Wound Management Association; 2007 May 2-4; Glasgow, Scotland. 2007:173. [Poster 163]

\section{Maggio 2012 \{published data only\}}

Maggio G, Armenio A, Ruccia F, Giglietto D, Pascone M, Ribatti D. A new protocol for the treatment of the chronic venous ulcers of the lower limb. Clinical and Experimental Medicine 2012;12(1):55-60.

\section{Mansson 1997 \{published data only\}}

Mansson T. Effect of lodosorb dressing, Duoderm E and Jelonet on symptomatic parameters in exudative venous leg ulcers. Fifth European Conference on Advances in Wound Management; 1995 November 21-24; Harrogate, UK. 1996:160-2.

* Mansson T, Tenvall GR, Sundberg J. A cost analysis as part of a clinical comparative leg ulcer study of lodosorb dressing, Duoderm E and Jelonet. New Approaches to the Management of Chronic Wounds 1997:142-3.

\section{Meaume 2005a \{published data only\}}

* Meaume S, Ourabah Z, Cartier H, Granel-Brocard F, Combemale P, Bressieux JM, et al. Evaluation of a lipidocolloid wound dressing in the local management of leg ulcers. Journal of Wound Care 2005;14(7):329-34.

Meaume S, Senet P, Bressieux JM, Bohbot S, Bressieux JM. Efficacy and tolerance of wound dressings Urgotul and Duoderm $E$ in the treatment of venous and mixed leg ulcers: results of randomised clinical study. European Wound Management Association Conference; 2005 September 15-17; Stuttgart, Germany. 2005:293. 2005:271.

Meaume S, Senet P, Bressieux JM, Bohbot, Coll S. Urgotul and Duoderm $E$ in the treatment of venous or mixed leg ulcers: results of a randomised clinical study. Second World Union of Wound Healing Societies Meeting; 2004 July 8-13; Paris, France. 2004:42-3.

\section{Meaume 2005c \{published data only\}}

* Meaume S, Vallet D, Morere MN, Téot L. Evaluation of a silverreleasing hydroalginate dressing in chronic wounds with signs of local infection. Journal of Wound Care 2005;14(9):411-9.

Meaume S, Vallet D, Morere MN, Téot L. Evaluation of a silverreleasing hydroalginate dressing in chronic wounds with signs of local infection. Zeitschrift fur Wundheilung 2006;11(5):236-45.

Meaume 2008 \{published data only\}

* Meaume S, Ourabah Z, Romanelli M, Manopulo R, De Vathaire F, Salomon D, et al. Efficacy and tolerance of a hydrocolloid dressing containing hyaluronic acid for the treatment of leg ulcers of venous or mixed origin. Current Medical Research and Opinion 2008;24(10):2729-39. 
Meaume S, Senet P, Pannier M, Bohbot S. Efficacy and tolerance of a contact layer and hydrocolloid dressing in the treatment of venous and mixed leg ulcers: results of randomized clinical study. Journal of Wound, Ostomy, and Continence Nursing 2008;35(Suppl 3):S8.

\section{Meaume 2014 \{published data only\}}

Meaume S, Dissemond J, Addala A, Vanscheidt W, Stücker M, Goerge T, et al. Evaluation of two fibrous wound dressings for the management of leg ulcers: results of a European randomised controlled trial (EARTH RCT). Journal of Wound Care 2014;23(3):105-6.

\section{Mehtar 1988 \{published data only\}}

Mehtar S, Fox D. A double-blind comparative study with Mupirocin vs placebo base in the treatment of chronic leg ulcers. British Journal of Clinical Practice 1988;42(8):324-8.

\section{Miller 2010 \{published data only\}}

Karimi L, Miller C, Kapp S, Newall N, Lewin G, Carville K, et al. Client perceptions of two types of antimicrobial dressings and compressions bandaging. Wound Practice and Research 2010;18(3):124-132.

Miller C, Kapp S, Newall N, Lewin G, Karimi L, Carville K, et al. Predicting concordance with multilayer compression bandaging. Journal of Wound Care 2011;20(3):101-6.

Miller CN, Carville K, Newall N, Kapp S, Lewin G, Karimi L, et al. Assessing bacterial burden in wounds: comparing clinical observation and wound swabs. International Wound Journal 2011;8(1):45-55.

* Miller CN, Newall N, Kapp SE, Lewin G, Karimi L, Carville K, et al. A randomized-controlled trial comparing cadexomer iodine and nanocrystalline silver on the healing of leg ulcers. Wound Repair and Regeneration 2010;18(4):359-67.

\section{Milward 1991 \{published data only\}}

Milward P. Comparing treatments for leg ulcers. Nursing Times 1991;87(13):70.

\section{Moffatt 2014 \{published data only\}}

Moffatt CJ, Stanton J, Murray S, Doody V, Davis P J, Franks P J. A randomised trial to compare the performance of Oxyzyme and lodozyme with standard care in the treatment of patients with venous and mixed venous/arterial ulceration. Wound Medicine 2014;6:1-10.

\section{Morimoto 2015 \{published data only\}}

Morimoto N, Kakudo N, Matsui M, Ogura T, Hara T, Suzuki K, et al. Exploratory clinical trial of combination wound therapy with a gelatin sheet and platelet-rich plasma in patients with chronic skin ulcers: study protocol. BMJ 2015;5(5):e007733.

\section{Mosti 2010 \{published data only\}}

Mosti G, Mattaliano V, Conte R, Abel M. Promotion of healing, pain relief, tolerability and quality of life: results of a prospective, controlled, randomized comparison study with two wound dressings in out-patients with non-infected leg ulcers. EWMA Journal 2010;10(2):59. [Abstract 77]

\section{Mosti 2015 \{published data only\}}

Mosti G, Magliaro A, Mattaliano V, Picerni P, Angelotti N. Comparative study of two antimicrobial dressings in infected leg ulcers: a pilot study. Journal of Wound Care 2015;24(3):121-7.

\section{Mostow 2005 \{published data only\}}

Demling RH, Niezgoda JA, Haraway GD, Mostow EN. Small intestinal submucosa wound matrix and full-thickness venous ulcers: preliminary results. Wounds 2004;16(1):18-22.

Hodde JP, Hiles MC, Sillings N, Metzger DW. Characterization of the local wound environment following treatment of chronic leg ulcers with SIS wound matrix: small intestinal submucosa. 19th Annual Symposium on Advanced Wound Care; 2006 April 30-May 3; San Antonio (TX). 2006; Vol. 4:105-6.

* Mostow EN, Haraway GD, Dalsing M, Hodde JP, King D, Oasis Venus Ulcer Study Group. Effectiveness of an extracellular matrix graft (OASIS Wound Matrix) in the treatment of chronic leg ulcers: a randomized clinical trial. Journal of Vascular Surgery 2005;41(5):837-43.

\section{Mudge 2014 \{published data only\}}

Mudge E, Price P, Harding K. A randomised controlled trial of larval therapy for the debridement of leg ulcers. EWMA Journal 2013;13(Suppl 1):79.

* Mudge E, Price P, Neal W, Harding KG. A randomized controlled trial of larval therapy for the debridement of leg ulcers: results of a multicenter, randomized, controlled, open, observer blind, parallel group study. Wound Repair and Regeneration 2014;22(1):43-51.

\section{Mulder 1995 \{published data only\}}

* Mulder G, Como A, Seeley J, Peak-Andrews KA. A randomised clinical study to evaluate and compare the performance of Allevyn hydrocellular dressing and Kaltostat alginate dressing in the treatment of venous ulcers. European Wound Management Association Conference; 1994 September 6-9; Copenhagen, Denmark. 1995:199.

Mulder G, Jensen J, Seeley J. Use of hydrocellular dressing versus a calcium alginate in the treatment of venous leg ulcers. Fifth Annual Meeting of the European Tissue Repair Society; 1995 August 30-September 2; Padua, Italy. 1995:368.

Mulligan 1988 \{published data only\}

Mulligan CM, Bragg AJ, O'Toole OB. A controlled comparative trial of Actisorb activated charcoal cloth dressing in the community. British Journal of Clinical Practice 1988;40:145-8.

\section{Nagl 2003 \{published data only\}}

Nagl M, Nguyen VA, Gottardi W, Ulmer H, Höpfl R. Tolerability and efficacy of $\mathrm{N}$-chlorotaurine in comparison with chloramine $T$ for the treatment of chronic leg ulcers with a purulent coating: a randomized phase II study. British Journal of Dermatology 2003;149(3):590-7.

\section{Navratilova 2004 \{published data only\}}

Navratilova Z, Slonkova V, Semradova V, Adler J. Cryopreserved and lyophilized cultured epidermal allografts in the treatment 
of leg ulcers: a pilot study. Journal of the European Academy of Dermatology and Venereology 2004;18(2):173-9.

\section{Neander 2003 \{published data only\}}

Neander K, Hesse F. Wound care. The protective effects on wound edges of a new preparation. Nursing Times 2004;100(4):61-3.

* Neander KD, Hesse F. The protective effects of a new preparation on wound edges. Journal of Wound Care 2003;12(10):369-71.

\section{Nelson 2011 \{published data only\}}

Chuang LH, Soares MO, Watson JM, Bland JM, Cullum N, Iglesias $\mathrm{C}$, et al. Economic evaluation of a randomized controlled trial of ultrasound therapy for hard-to-heal venous leg ulcers. British Journal of Surgery 2011;98(8):1099-106.

Nelson A, Watson JM, Kang'ombe AR, Soares M, Chuang LH, Worthy G, et al. Venus III: a randomised controlled trial of ultrasound for "hard to heal" venous leg ulcers. EWMA Journal 2011;11(Suppl 2):83.

* Watson JM, Kang'ombe AR, Soares M O, Chuang LH, Worthy G, Bland JM, et al. Use of weekly, low dose, high frequency ultrasound for hard to heal venous leg ulcers: the VenUS III randomised controlled trial. BMJ 2011;342(7797):d1092.

Watson JM, Kang'ombe AR, Soares M, Chuang LH, Worthy G, Bland JM, et al. VenUS III: a randomized controlled trial of ultrasound for 'hard to heal' venous leg ulcers. Phlebology 2011;26(6):260.

\section{Nieves 2015 \{published data only\}}

Nieves E, Ramirez M, Fajardo E, Camacho E, Giraldo O. Venous ulcer treatment with sclerofoam versus a conventional treatment: randomized prospective clinical trial. Angiologia 2015;67(1):32-7.

\section{Nowak 1996 \{published data only\}}

Nowak A, Gwiezdzinski Z, Bowszyc J, Szarmach H, Czabanowska J, Harding EF. A randomized controlled parallelgroup clinical trial of a new debriding agent in the treatment of necrotic venous ulcers. Fifth European Conference on Advances in Wound Management; 1995 November 21-24; Harrogate, UK. 1996:190-3.

\section{Nyfors 1982 \{published data only\}}

Nyfors A, Helland S, Solberg V. Synthaderm in the treatment of leg ulcers. A prospective controlled study. Tidsskrift for den Norske Laegeforening 1982;102(7):424-5.

\section{Olyaie 2013 \{published data only\}}

Olyaie M, Rad FS, Elahifar MA, Garkaz A, Mahsa G. Highfrequency and noncontact low-frequency ultrasound therapy for venous leg ulcer treatment: a randomized, controlled study. Ostomy/Wound management 2013;59(8):14-20.

\section{Omar 2004 \{published data only\}}

Omar AA, Mavor AI, Jones AM, Homer-Vanniasinkam S. Treatment of venous leg ulcers with Dermagraft. European Journal of Vascular and Endovascular Surgery 2004;27(6):666-72.
Ortonne 1996 \{published data only\}

Ortonne JP. A controlled study of the activity of hyaluronic acid in the treatment of venous leg ulcers. Journal of Dermatological Treatment 1996;7(2):75-81.

\section{Osman 2014 \{published data only\}}

Osman AO, El Ansary MM, Metwally HG, Gad AA, Al-Inany HG, Elbadawy $\mathrm{AH}$. A hope for healing using amniotic membrane and stem cells. Clinical Chemistry 2014;60(10 (Suppl 1)):S31.

\section{Pardes 1993 \{published data only\}}

Pardes JB, Carson PA, Eaglstein WH, Falanga V. Mupirocin treatment of exudative venous ulcers. Journal of the American Academy of Dermatology 1993;29(3):497-8.

\section{Passarini 1982 \{published data only\}}

Passarini B, Tosti A, Fanti PA, Varotti C. Effect of hyaluronic acid on the reparative process of non-healing ulcers. Comparative study. Giornale Italiano di Dermatologia e Venereologia 1982;117(3):XXVII-XXX.

\section{Peschen 1997 \{published data only\}}

Peschen M, Vanscheidt W. Low frequency ultrasound of chronic venous leg ulcers as part of an out-patient treatment. Fifth European Conference on Advances in Wound Management; 1995 November 21-24; Harrogate, UK. 1996:271.

* Peschen M, Weichenthal M, Schöpf E, Vanscheidt W. Lowfrequency ultrasound treatment of chronic venous leg ulcers in an outpatient therapy. Acta Dermato-Venereologica 1997;77(4):311-4.

\section{Pessenhofer 1989 \{published data only\}}

Pessenhofer $\mathrm{H}$, Stangl $\mathrm{M}$. The effect on wound healing of venous leg ulcers of a two-layered polyurethane foam wound dressing. Arzneimittel-Forschung 1989;39(9):1173-7.

\section{Pessenhofer 1992 \{published data only\}}

Pessenhofer H, Stangl M. The effect of a two-layered polyurethane foam wound dressing on the healing of venous leg ulcers. Journal of Tissue Viability 1992;2(57):57-61.

\section{Petres 1994 \{published data only\}}

Petres J, Rompel R, Nölting S, Payne J. Alginates versus hydrocolloids in the treatment of venous leg ulcers. Third European Conference on Advances in Wound Management; 1993 October 1921-22; Harrogate, UK. 1994:165.

\section{Planinsek 2007a \{published data only\}}

Planinsek TR. Effectiveness of non-alcohol film forming skin protector on the skins isles inside the ulcers and the healing rate of venous leg ulcers: randomized clinical study. EWMA Journal 2007;7(1):23-5.

\section{Planinsek 2007b \{published data only\}}

Planinsek TR. Comparative effects of honey based and silver/ charcoal based dressings on the healing of venous leg ulcers: a randomized clinical study. 17th Conference of the European Wound Management Association; 2007 May 2-4; Glasgow, Scotland. 2007:54. 


\section{Polignano 2001 \{published data only\}}

Polignano R, Turrini P, Andriessen A. The effect on microcirculation in leg ulcers comparing traditional vs $\mathrm{MWH}$ dressings: a pilot study. 11th Conference of the European Wound Management Association; 2001 May 17-19; Dublin, Ireland. 2001:79.

* Polignano R, Turrini P, Andriessen A. The effect on microcirculation in leg ulcers comparing traditional vs MWH dressings: a pilot study. Wound Repair and Regeneration 2001;9(5):402.

\section{Poskitt 1987 \{published data only\}}

Poskitt KR, James AH, Lloyd-Davies ER, Walton J, McCollum C, Lloyd Davies ER. Pinch skin grafting or porcine dermis in venous ulcers: a randomised clinical trial. British Medical Journal 1987;294(6573):674-6.

\section{Price 2004 \{published data only\}}

Price P, Contreet Study Group. Health-related quality of life aspects after treatment with a foam dressing and a silver containing foam dressing in chronic leg ulcers. Second World Union of Wound Healing Societies Meeting; 2004 July 8-13; Paris, France. 2004:161.

\section{Prins $\mathbf{2 0 0 0}$ \{published data only\}}

Prins C. Autohemotherapy for the treatment of leg ulcers: a randomized, prospective study. Dermatology 2000;201:91.

\section{Purcell 2017 \{published data only\}}

* Purcell A, Buckley T, Fethney J, King J, Moyle W, Marshall AP. The effectiveness of EMLA as a primary dressing on painful chronic leg ulcers: effects on wound healing and health-related quality of life. International Journal of Lower Extremity Wounds 2017;16(3):163-72

Purcell A, Buckley T, Fethney J, King J, Moyle W, Marshall AP. TheeEffectiveness of EMLA as a primary dressing on painful chronic leg ulcers: a pilot randomized controlled trial. Advances in Skin \& Wound Care 2017;30(8):354-63.

\section{Rainey 1993 \{published data only\}}

Rainey J. A comparison of two dressings in the treatment of heavily exuding leg ulcers. Journal of Wound Care 1993;2(4):199-200.

\section{Rainey 1996 \{published data only\}}

Rainey J. Comparing dressings. Journal of Community Nursing 1996;10(1):16-7.

\section{Raposio 2018 \{published data only\}}

Raposio E, Bertozzi N, Simonacci F, Grieco MP. Therapeutic effects of a pulsed electromagnetic device in chronic cutaneous ulcers of the lower limbs. Wound Medicine 2018;20:18-20.

\section{Rivera-Arce 2007 \{published data only\}}

Rivera-Arce E, Chávez-Soto MA, Herrera-Arellano A, Arzate S, Agüero J, Feria-Romero IA, et al. Therapeutic effectiveness of a Mimosa tenuiflora cortex extract in venous leg ulceration treatment. Journal of Ethnopharmacology 2007;109(3):523-8.

\section{Robinson 1993 \{published data only\}}

Robinson BJ. Prospective study of cost benefit and other criteria when using hydrocolloid dressings in the community management oc chronic venous leg ulcers. Second European Conference on Advances in Wound Management; 1992 October 20-23; Harrogate, UK. 1993:211.

Robinson 1998 \{published data only\}

* Robinson C, Santilli SM. Warm-up active wound therapy: a novel approach to the management of chronic venous stasis ulcers. Journal of Vascular Nursing 1998;16(2):38-42.

Santilli SM, Robinson C, Vosskuhler RJ. Warm-up active wound therapy: a novel approach to the outpatient treatment of chronic venous stasis ulcers. Wound Repair and Regeneration 1998;6(5):A479.

Roldan 2009 \{published data only\}

Roldan A, Cuervo F. Efficiacy of a polyhexanide/betaine wound gel in the treatment of hard to heal wounds. EWMA Journal 2009;9(2):129. [Abstract P62]

Romanelli 2006 \{published data only\}

* Romanelli M, Dini V, Bertone M. Histological evaluation of venous leg ulcers treated with amelogenin. EWMA Journal 2011;11(Suppl 2):224

Romanelli M, Ellervee T, Jarve H, Kaha E. Amelogenins (Xelma) in hard-to-heal venous leg ulcers, an open regime investigation. 16th Conference of the European Wound Management Association; 2006 May 18-20; Prague, Czech Republic. 2006:143.

Romanelli M, Vowden P, Price P. An open, randomised, comparative, parallel group, multi-centre clinical trial of amelogenin extracellular matrix therapy in the treatment of hard-to-heal venous leg ulcers: follow-up data. 3rd Congress of the World Union of Wound Healing Societies Meeting; 2008 June 4-8; Toronto, Canada. 2008:OR100.

\section{Romanelli 2008 \{published data only\}}

Romanelli M, Dini V, Barbanerera S, Bertone MS, Brilli A, De Lorenzo A. Improvement of treatment in patients with venous leg ulcers by a new pain-reducing wound dressing with hydrobalance. EWMA Journal 2008;8(Suppl 2):286.

\section{Romanelli 2009 \{published data only\}}

* Romanelli M, Dini V, Polignano R, Bonadeo P, Maggio G. Ibuprofen slow-release foam dressing reduces wound pain in painful exuding wounds: preliminary findings from an international real-life study. Journal of Dermatological Treatment 2009;20(1):19-26.

Romanelli M, Fogh C, Kusch I. Effects of a foam dressing with ibuprofen on wound pain from venous leg ulcers and mixed venous arterial leg ulcers. EWMA Journal 2009;9(2):194. [Abstract P5]

Romanelli 2011 \{published data only\}

Romanelli M, Dini V, Barbanera S, Tonfoni V. Exudate management of hard to heal venous leg ulcer with a fiber dressing. EWMA Journal 2011;11(Suppl 2):190. 
Romanelli 2015 \{published data only\}

Romanelli M, Macchia M, Panduri S, Paggi B, Saponati G, Dini V. Clinical evaluation of the efficacy and safety of a medical device in various forms containing Triticum vulgare for the treatment of venous leg ulcers: a randomized pilot study. Drug Design, Development and Therapy 2015;9:2787-92.

\section{Rucigaj 2007 \{published data only\}}

Rucigaj TP. Effectiveness of non-alcohol film forming skin protector on the skins isles inside the ulcers and the healing rate of venous leg ulcers: randomized clinical study. EWMA Journal 2007;7(1):23-53.

\section{Rundle 1981 \{published data only\}}

Rundle JS, Elton RA, Cameron SH, Watson N, Gunn AA, Ruckley CV. Porcine dermis in varicose ulcers - a clinical trial. VASA. Zeitschrift fur Gefasskrankheiten. Journal for Vascular Diseases 1981;10(3):246-8.

\section{Sabolinski 1996 \{published data only\}}

Sabolinski ML, Alvarez O, Auletta M, Mulder G, Parenteau NL. Cultured skin as a 'smart material' for healing wounds: experience in venous ulcers. Biomaterials 1996;17(3):311-20.

\section{Sánchez-Vázquez 2008 \{published data only\}}

Sánchez-Vázquez R, Briseño-Rodríguez G, Cardona-Muñoz EG, Gálvez-Gastélum FJ, Totsuka-Sutto SE, Garcia-Benavides L. Isosorbide dinitrate spray as therapeutic strategy for treatment of chronic venous ulcers. Angiology 2008;59(1):64-71.

\section{Santamato 2012 \{published data only\}}

Santamato A, Panza F, Fortunato F, Portincasa A, Frisardi V, Cassatella $\mathrm{G}$, et al. Effectiveness of the frequency rhythmic electrical modulation system for the treatment of chronic and painful venous leg ulcers in older adults. Rejuvenation Research 2012;15(3):281-7.

\section{Scalise 2017 \{published data only\}}

Scalise A, Campitiello F, Della Corte A, Longobardi P, Di Salvo M. Tartaglione $\mathrm{C}$, et al. Enzymatic debridement: is HA-collagenase the right synergy? Randomized double-blind controlled clinical trial in venous leg ulcers. European Review for Medical \& Pharmacological Sciences 2017;21(6):1421-31.

\section{Schmutz 1997 \{published data only\}}

Schmutz JL. Comparison of the new hydrofibre dressing Aquacel and a conventional dressing for the treatment of leg ulcers. Sixth European Conference on Advances in Wound Management; 1996 October 1-4; Amsterdam, The Netherlands. 1997:88.

\section{Schmutz 2008 \{published data only\}}

Dompmartin A, Schmutz JL, Collier M, Smith J, Bohbot S. Management of venous leg ulcers with two active wound dressings. Protocol of a randomized clinical trial. 17th Conference of the European Wound Management Association; 2007 May 2-4; Glasgow, Scotland. 2007:55.

Meaume S, Dompmartin A, Lok C, Lazareth I, Sigal M, Truchetet F, et al. CHALLENGE Study Group. Quality of life in patients with leg ulcers: results from CHALLENGE, a double- blind randomised controlled trial. Journal of Wound Care 2017;26(7):368-79.

Meaume S, Dompmartin A, Schmutz JL, Ourabah Z, Thirion V, Thirion V, et al. Management of venous leg ulcers with two active wound dressings. Results of a randomized clinical trial. 18th Conference of the European Wound Management Association; 2008 May 14-16; Lisbon, Portugal. 2008, issue Suppl 2:38. [Abstract 38]

Meaume S, Schmutz JL, Dompmartin A, Fays S, Ourabah Z, Thirion V, et al. Management of venous leg ulcers with two active wound dressings. Results of a randomized clinical trial. Third Congress of the World Union of Wound Healing Societies Meeting; 2008 June 4-8; Toronto, Canada.. 2008:OR047.

* Schmutz JL, Meaume S, Fays S, Ourabah Z, Guillot B, Thirion V, et al. Evaluation of the nano-oligosaccharide factor lipido-colloid matrix in the local management of venous leg ulcers: results of a randomised, controlled trial. International Wound Journal 2008;5(2):172-182.

\section{Serena 2011 \{published data only\}}

Serena T, Bannan S, Data J, Singh M, Phillips A, Johns T, et al. Acceleration of venous ulcer healing using a topical connexin43 antisense compound: Phase 2 results. Wound Repair and Regeneration 2011;19(2):A50.

* Serena T, Bannan S, Singh M, Phillips A, Johns T, Schmidt E, et al. Acceleration of venous ulcer healing using a topical connexin43 antisense compound: phase 2 results. EWMA Journal 2011;11(2):84.

\section{Serena 2014 \{published data only\}}

* Serena TE, Carter MJ, Le LT, Sabo MJ, Dimarco DT, Lullove E, et al. A multicenter, randomized, controlled clinical trial evaluating the use of dehydrated human amnion/chorion membrane allografts and multilayer compression therapy vs. multilayer compression therapy alone in the treatment of venous leg ulcers. Wound Repair and Regeneration 2014;22 (6):668-93.

Serena TE, Yaakov R, DiMarco D, Le L, Taffe E, Donaldson M, et al. Dehydrated human amnion/chorion membrane treatment of venous leg ulcers: correlation between 4-week and 24-week outcomes. Wound Medicine 2015;24(11):530-4.

\section{Serra 2010 \{published data only\}}

Serra N, Palomar F, Fornes B, Capillas R, Berenguer M, Aranda J, et al. Effectiveness of the association of multilayer compression therapy and periwound protection with Cavilon (no sting barrier film) in the treatment of venous leg ulcers. Gerokomos 2010;21(3):124-30.

\section{Sibbald 2005 \{published data only\}}

Sibbald G, Brassard A, Kay D, Gulliver W, Hull P, Giard F, et al. Evaluation of a new fibronectin based dressing in the treatment of venous leg ulcers. European Wound Management Association Conference; 2005 September 15-17; Stuttgart, Germany. 2005:293. 2005:91. 
Sibbald 2007 \{published data only\}

Sibbald RG, Coutts P, Fierheller M, Woo K. A pilot (real-life) randomised clinical evaluation of a pain-relieving foam dressing: (Ibuprofen-foam versus local best practice). International Wound Journal 2007;4(Suppl 1):16-23.

Sibbald 2011 \{published data only\} Sibbald RG, Coutts P, Woo KY. Reduction of bacterial burden and pain in chronic wounds using a new polyhexamethylene biguanide antimicrobial foam dressing-clinical trial results. Advances in Skin \& Wound Care 2011;24(2):78-84.

\section{Siqueira 2014 \{published data only\}}

Siqueira CP, de Paula Ramos S, Gobbi CA, Shigaki L, Kashimoto RK, Venancio EJ, et al. Effects of weekly LED therapy at $625 \mathrm{~nm}$ on the treatment of chronic lower ulcers. Lasers in Medical Science 2014;30(1):367-73.

\section{Skog 1983 \{published data only\}}

Skog E, Arnesjö B, Troëng T, Gjöres JE, Bergljung L, Gundersen J, et al. A randomized trial comparing cadexomer iodine and standard treatment in the out-patient management of chronic venous ulcers. British Journal of Dermatology 1983;109(1):77-83.

\section{Smeets 2008 \{published data only\}}

Smeets R, Ulrich D, Unglaub F, Wöltje M, Pallua N. Effect of oxidised regenerated cellulose/collagen matrix on proteases in wound exudate of patients with chronic venous ulceration. International Wound Journal 2008;5(2):195-203.

\section{Smith-Strom 2006 \{published data only\}}

Smith-Strom H. Comparison of healing and costs with two different treatments. A randomized controlled study of patient with leg ulcers, treated in the primary health care. Vard $i$ Norden 2006;26(2):4-9.

\section{Soares 2009 \{published data only\}}

Soares MO, Iglesias CP, Bland JM, Cullum N, Dumville JC, Nelson EA, et al. Cost effectiveness analysis of larval therapy for leg ulcers. BMJ 2009;338(7702):b825.

\section{Sparholt 2002 \{published data only\}}

Sparholt SH, Wilhelmsen F. Outcome evaluation of two hydrogels. Ostomy/Wound management 2002;48(4):74.

\section{Sridhar 2017 \{published data only\}}

Sridhar S, Nanjappa N. Microbiological and clinical response of superoxidized solution versus povidone iodine in the management of lower limb ulcers. National Journal of Physiology, Pharmacy and pharmacology 2017;7(10):1074-80.

\section{Sriram 2014 \{published data only\}}

Sriram S, Kavitha MM, Tamilselvam TN, Euphrasia Latha J, Rajeswari S. Role and efficacy of platelet rich plasma (PRP) in chronic non healing resistant vasculitic ulcers. Indian Journal of Rheumatology 2014;9((5 Supplement)):S1-2.

\section{Sriram 2015 \{published data only\}}

Sriram S. Role and efficacy of autologous platelet rich plasma in chronic resistant non healing vasculitic ulcers. Annals of the Rheumatic Diseases 2015;74:1120.
Stiller 1992 \{published data only\}

Stiller MJ, Pak GH, Shupack JL, Thaler S, Kenny C, Jondreau L. A portable pulsed electromagnetic field (PEMF) device to enhance healing of recalcitrant venous ulcers: a double-blind, placebo-controlled clinical trial. British Journal of Dermatology 1992;127(2):147-54.

\section{Stone 2016a \{published data only\}}

Stone RC, Stojadinovic O, Rosa AM, Sawaya A, Ramirez H, Badiavas EV, et al. In vivo mechanisms by which a bioengineered living cell construct stimulates healing of chronic ulcers: Activation, inflammation and remodeling. Journal of Investigative Dermatology 2016;136(5 (Suppl 1)):S133.

\section{Stone 2016b \{published data only\}}

Stone RC, Stojadinovic O, Sawaya AP, Rosa AM, Badiavas E, Blumenberg M. Treatment of chronic venous leg ulcers with a bioengineered living cell construct induces metallothioneins and MMP8 to resolve matrix fibrosis and reactivates a healthy remodeling response. Wound Repair and Regeneration. 2016; Vol. 24 (2):A25.

\section{Taradaj 2008 \{published data only\}}

Taradaj J, Franek A, Brzezinska Wcislo L, Cierpka L, Dolibog P, Chmielewska $D$, et al. The use of therapeutic ultrasound in venous leg ulcers: a randomized, controlled clinical trial. Phlebology 2008;23(4):178-183.

\section{Teepe 1993 \{published data only\}}

Teepe RG, Roseeuw DI, Hermans J, Koebrugge EJ, Altena T, De Coninck A, et al. Randomized trial comparing cryopreserved cultured epidermal allografts with hydrocolloid dressings in healing chronic venous ulcers. Journal of the American Academy of Dermatology 1993;29(6):982-8.

\section{Texier 1980 \{published data only\}}

Texier L, Geniaux M, Meraud JP, Delaunay MM. Clinical trial of Debrisan in venous ulcer of the leg. Bordeaux Medical 1980;13(17):859-60.

\section{Thomas 1997a \{published data only\}}

Thomas S, Banks V, Fear M, Hagelstein S, Bale S, Harding K. A study to compare two film dressings used as secondary dressings. Journal of Wound Care 1997;6(7):333-6.

\section{Vanscheidt 2004 \{published data only\}}

Vanscheidt W, Sibbald RG, Eager CA. Comparing a foam composite to a hydrocellular foam dressing in the management of venous leg ulcers: a controlled clinical study. Ostomy/Wound Management 2004;50(11):42-48 5 .

\section{Vanscheidt 2007 \{published data only\}}

Vanscheidt W, Ukat A, Horak V, Brüning H, Hunyadi J, Pavlicek R, et al. Treatment of recalcitrant venous leg ulcers with autologous keratinocytes in fibrin sealant: A multinational randomized controlled clinical trial. Wound Repair and Regeneration 2007;15(3):308-15.

\section{Vas 2008 \{published data only\}}

Vas J, Modesto M, Mendez C, Perea-Milla E, Aguilar I, CarrascoLozano JM, et al. Effectiveness of acupuncture, special 
dressings and simple, low-adherence dressings for healing venous leg ulcers in primary healthcare: Study protocol for a cluster-randomized open-labeled trial. BMC Complementary and Alternative Medicine 2008;8:29.

\section{Veraart 1994a \{published data only\}}

* Veraart J, Neumann HA, Hulsmans RF, van den Broek MJ. Interim results of a comparative study on the characteristics of comfeel leg ulcer dressing in terms of healing, effects on periulcer skin and patient comfort. Wound Repair and Regeneration 1994;2(3):203.

Veraart J, Neumann MH, Hulsmans R, van den Broek MJ. Interim results of a comparative study on the characteristics of comfeel leg ulcer dressing in terms of healing, effects on periulcer skin and patient comfort. First Joint Meeting of the Wound Healing Society and the European Tissue Repair Society; 1993 August; Amsterdam, The Netherlands. 1993:92.

Veraart JC, Neumann HA, Hulsmans RF, van den Broek MB. A comparative study on the characteristics of Comfeel Extra Absorbing Dressing in terms of healing, effects on periulcer skin, and patient comfort in care of leg ulcers. Fourth European Tissue Repair Society Meeting; 1994 August 25-28; Oxford, UK. Oxford: ETRS, 1994:279. 1994:279.

\section{Vitse 2017 \{published data only\}}

Vitse J, Bekara F, Byun S, Herlin C, Teot, L. A double-blind, placebo-controlled randomized evaluation of the effect of lowlevel laser therapy on venous leg ulcers. International Journal of Lower Extremity Wounds 2017;16(1):29-35.

\section{Vowden 2007 \{published data only\}}

Romanelli M, Kaha E, Stege H, Wnorowski JW, Vowden P, Majamaa $\mathrm{H}$, et al. Effect of amelogenin extracellular matrix protein and compression on hard-to-heal venous leg ulcers: follow-up data. Journal of Wound Care 2008;17(1):17-8.

Vowden P, Romanelli M. Effect of amelogenin matrix protein solution as add-on treatment to compression in hard-toheal venous leg ulcers: A randomised controlled trial. 17th Conference of the European Wound Management Association; 2007 May 2-4; Glasgow, Scotland. 2007:54.

Vowden P, Romanelli M, Peter R, Bostrom A, Josefsson A, Stege $H$. The effect of amelogenins (XelmaTM) on hard-toheal venous leg ulcers. Wound Repair and Regeneration 2006;14(3):240-6.

* Vowden P, Romanelli M, Price P. Effect of amelogenin extracellular matrix protein and compression on hard-to-heal venous leg ulcers. Journal of Wound Care 2007;16(5):189-95.

\section{Vuerstaek 2006 \{published data only\}}

Vuerstaek JD, Vainas T, Wuite J, Nelemans P, Neumann MHA, Veraart J. State-of-the-art treatment of chronic leg ulcers: a randomized controlled trial comparing vacuum-assisted closure (VAC) with modern wound dressings. Journal of Vascular Surgery 2006;44(5):1029-38.

\section{Wayman 2000 \{published data only\}}

Wayman J, Nirojogi Walker A, Sowinski A, Walker MA. The cost effectiveness of larval therapy in venous ulcers. Journal of Tissue Viability 2000;10(3):91-4.

* Wayman J, Walker A, Sowinski A, Walker MA. Larval debridement therapy: a cost-effective alternative to hydrogel in necrotic venous ulcers: a randomized trial. British Journal of Surgery 2000;87:507.

\section{Weiss 1996 \{published data only\}}

Weiss RA, Weiss MA, Ford RW. Randomized comparative study of cutinova foam and allevyn with Jobst UlcerCare stockings for the treatment of venous stasis ulcers. Phlebology 1996;11(Suppl 1):S14-16.

\section{Werner-Schlenzka 1994 \{published data only\}}

Werner-Schlenzka H, Lehnert W. Topical treatment of venous leg ulcers with a prostacyclin hydrogel: a double blind trial. Prostaglandins Leukotrienes and Essential Fatty Acids 1994;51(3):203-6.

\section{Westh 1998 \{published data only\}}

Westh H, Warburg FE, Madsen SM, Larsen SO, Danielsen L. Cellulitis in venous leg ulcers treated with a hydrocolloid dressing. Phlebology 1998;13(2):68-72.

Wieman 2003 \{published data only\}

Wieman TJ. Efficacy and safety of recombinant human plateletderived growth factor-BB (becaplermin) in patients with chronic venous ulcers: a pilot study. Wounds 2003;15(8):257-64.

\section{Wild 2010 \{published data only\}}

Wild T, Eberlein T, Andriessen A. Wound cleansing efficacy of two cellulose-based dressings. Wounds UK 2010;6(3):14-21.

\section{Wong 2006 \{published data only\}}

Wong IK, Lee DT, Thompson DR. Modern wound care and compression: a randomized controlled study for the comparison of modern wound management only or in combination either with short or long stretch compression bandages in the treatment of venous ulcers. Vasomed 2006;18(4):149-50.

\section{Woo 2009 \{published data only\}}

Woo KY, Coutts PM, Price P, Harding K, Sibbald RG. A randomized crossover investigation of pain at dressing change comparing 2 foam dressings. Advances in Skin \& Wound Care 2009;22(7):304-10.

Woo 2010 \{published data only\}

Woo K, Sibbald G, Coutts P. Reduction of infection and pain in chronic wounds using a new antimicrobial foam dressing. EWMA Journal 2010;10(2):59. [Abstract 78]

\section{Wunderlich 1991 \{published data only\}}

Wunderlich U, Orfanos CE. Treatment of venous ulcer cruris with dry wound dressings. Phase overlapping use of silver impregnated activated charcoal xero-dressing. Der Hautarzt; Zeitschrift fur Dermatologie, Venerologie, und Verwandte Gebiete 1991;42(7):446-50. 


\section{References to studies awaiting assessment}

\section{Alvarez 2017 \{published data only\}}

Alvarez OM, Makowitz L, Patel M. Venous ulcers treated with a hyaluronic acid extracellular matrix and compression therapy: interim analysis of a randomized controlled trial. Wounds- $A$ Compendium of Clinical Research \& Practice 2017;29(7):E51-4.

\section{Belcaro 2011 \{published data only\}}

Belcaro G, Cesarone MR, Errichi BM, Ricci A, Antelman P, Dugall $M$, et al. Silver oxide ointment wound dressing in venous ulcerations: home, self-management. Panminerva Medica 2011;53(3 (Suppl 1)):29-33.

Belcaro G, Cesarone MR, Errichi BM, Ricci A, Dugall M, Pellegrini $L$, et al. Venous and diabetic ulcerations: management with topical multivalent silver oxide ointment. Panminerva Medica 2010;52(2 (Suppl 1)):37-42.

\section{Cavalcanti 2017 \{published data only\}}

Cavalcanti LM. Pinto FC, de Oliveira GM, Lima SV, Aguiar JL, Lins EM. Efficacy of bacterial cellulose membrane for the treatment of lower limbs chronic varicose ulcers: a randomized and controlled trial. [Eficácia da membrana de celulose bacteriana no tratamento de úlceras venosas de membros inferiores: estudo randomizado e controlado]. Revista do Colegio Brasileiro de Cirurgioes 2017;44(1):72-80.

\section{Colenci 2016 \{published data only\}}

Colenci R, Jacinto, JS, Miot HA, Marques ME, Schmitt JV, Abbade LP. Biomembrane of hemicellulose dressing versus collagenase in the treatment of chronic venous ulcers: randomized clinical trial, open and controlled study. Wound Repair and Regeneration. Conference: 28th Annual Meeting of the Wound Healing Society, sawc-spring/whs joint meeting.. 2016; Vol. 24 (2):A5.

\section{Cullen 2017 \{published data only\}}

Cullen BM, Serena TE, Gibson MC, Snyder RJ, Hanft JR, Yaakov RA. Randomized controlled trial comparing collagen/ oxidized regenerated cellulose/silver to standard of care in the management of venous leg ulcers. Advances in Skin \& Wound Care 2017;30(10):464-8.

\section{Glukhov 2017 \{published data only\}}

Glukhov AA, Aralova MV. The study of the effectiveness of the drug combination of collagen and platelet-rich plasma for the regional treatment of venous ulcers. Research Journal of Pharmaceutical, Biological and Chemical Sciences 2017;8(2):2258-63.

\section{Moreno-Eutimio 2017 \{published data only\}}

Moreno-Eutimio MA, Moreno J, Cueto-Garcia J. Effect of a polymer polysaccharide with zinc oxide in the reduction of the ulcer size in chronic venous ulcers. Revista Mexicana de Angiologia 2016;44(2):67-71.

\section{Oliveira 2017 \{published data only\}}

Oliveira MG, Abbade LP, Miot HA, Ferreira RR, Deffune E. Pilot study of homologous platelet gel in venous ulcers. Anais Brasileiros de Dermatologia 2017;92(4):499-504.
Polignano 2010 \{published data only\}

Polignano R, Terriaca P, Pavanelli A, Forma O, De Ponti I, Sparavigna A. Evaluation of the efficacy of a cream with purified omental lipids (P.O.L.) in the management of peri-lesional skin in chronic vascular ulcers. Journal of Plastic Dermatology 2010;6(3):235-44.

\section{Robinson 1988 \{published data only\}}

Robinson BJ. Randomized comparative trial of Duoderm vs Viscopaste PB7 bandage in the management of venous leg ulceration and cost to the community.. Beyond Occlusion: wound care proceedings. International Congress and Symposium Series, Royal Society of Medicine, London. (1988); Vol. 136:101-4.

\section{Somani 2017 \{published data only\}}

Somani A, Rai R. Comparison of efficacy of autologous plateletrich fibrin versus saline dressing in chronic venous leg ulcers: a randomised controlled trial. Journal of Cutaneous and Aaesthetic Surgery 2017;10(1):8-12.

\section{References to ongoing studies}

Jull 2018 \{published data only\}

Jull A, Wadham A, Bullen C, Parag V, Waters J. Wool-derived keratin dressings versus usual care dressings for treatment of slow-healing venous leg ulceration: study protocol for a randomised controlled trial (Keratin4VLU). BMJ Open 2018;8(2):e020319..

\section{Additional references}

\section{AHRQ 2013}

Agency for Healthcare Research and Quality (AHRQ), US Department of Health. Chronic venous ulcers: a comparative effectiveness review of treatment modalities. December 2013. www.ncbi.nlm.nih.gov/books/NBK179151/ (accessed 9 November 2016).

\section{Ashby 2014}

Ashby RL, Gabe R, Ali S, Adderly U. Clinical and costeffectiveness of compression hosiery versus compression bandages in treatment of venous leg ulcers (Venous leg Ulcer Study IV, VenUS IV): a randomised controlled trial. Lancet 2014;383:871-9.

\section{Augustin 2012}

Augustin M, Brocatti LK, Rustenbach SJ, Schafer I, Herberger K. Cost-of-illness of leg ulcers in the community. International Wound Journal 2012;11(3):283-92.

\section{BNF 2016}

British Medical Association, British Royal Pharmaceutical Society of Great Britain. British National Formulary (BNF): wound management products and elasticated garments. www.medicinescomplete.com/mc/bnf/current/PHP101071wound-management-products-and-elasticated-garments.htm. London: British Medical Association, (accessed 9 November 2016). 


\section{Bouza 2005}

Bouza C, Munoz A, Amate JM. Efficacy of modern dressings in the treatment of leg ulcers: a systematic review. Wound Repair and Regeneration 2005;13(3):218-29.

\section{Bradley 1999}

Bradley M, Cullum N, Nelson EA, Petticrew M, Sheldon T, Torgerson D. Systematic reviews of wound care management: (2) dressings and topical agents used in the healing of chronic wounds. Health Technology Assessment 1999;3(17 (part 2)):1-35.

\section{Briggs 2012}

Briggs M, Nelson EA, Martyn-St James M. Topical agents or dressings for pain in venous leg ulcers. Cochrane Database of Systematic Reviews 2012, Issue 11. [DOI: 10.1002/14651858.CD001177.pub3]

\section{Caldwell 2005}

Caldwell DM, Ades A, Higgins J. Simultaneous comparison of multiple treatments: combining direct and indirect evidence as well. BMJ 2005;331(7521):897-900.

\section{Caldwell 2014}

Caldwell DM. An overview of conducting systematic reviews with network meta-analysis. Systematic Reviews 2014;3:109.

\section{Callam 1987b}

Callam MJ, Harper DR, Dale JJ, Ruckley CV. Chronic ulcer of the leg: clinical history. BMJ 1987;294(6584):1389-91.

\section{Cardinal 2009}

Cardinal M, Eisenbud DE, Armstrong DG, Zelen C, Driver V, Attinger $\mathrm{C}$, et al. Serial surgical debridement: a retrospective study on clinical outcomes in chronic lower extremity wounds. Wound Repair and Regeneration 2009;17(3):306-11.

\section{Chaimani 2013}

Chaimani A, Higgins JP, Mavridis D, Spyridonos P, Salanti G. Graphical tools for network meta-analysis in STATA. PLOS One 2013;8(10):e76654. [DOI: 10.1371/journal.pone.0076654]

\section{CINeMA 2017 [Computer program]}

Institute of Social and Preventive Medicine. Confidence in Network Meta-Analysis (CINeMA). University of Bern: Institute of Social and Preventive Medicine, 2017.

\section{Cipriani 2013}

Cipriani A, Higgins JP, Geddes JR, Salanti G. Conceptual and technical challenges in network meta-analysis. Annals of Internal Medicine 2013;159:130-7.

\section{Coleridge Smith 1988}

Coleridge Smith PD, Thomas P, Scurr JH, Dormandy JA. Causes of venous ulceration: a new hypothesis. BMJ 1988;296(6638):1726-7.

\section{Cullum 2016}

Cullum N, Buckley H, Dumville J, Hall J, Lamb K, Madden M, et al. Wounds research for patient benefit: a 5-year programme of research. Programme Grants for Applied Research 2016;4(13):1-149. [DOI: 10.3310/pgfar04130]

\section{Cutting 2002}

Cutting K, White RJ. Maceration of the skin and wound bed 1: its nature and causes. Journal of Wound Care 2002;11(7):275-8.

\section{Dat 2012}

Dat AD, Poon F, Pham KB, Doust J. Aloe vera for treating acute and chronic wounds. Cochrane Database of Systematic Reviews 2012, Issue 2. [DOI: 10.1002/14651858.CD008762.pub2]

\section{Dias 2010}

Dias S, Welton NJ, Caldwell DM, Ades AE. Checking consistency in mixed treatment comparison meta-analysis. Statistics in Medicine 2010;29(7-8):932-44.

\section{Dias 2013}

Dias S, Welton NJ, Sutton AJ, Caldwell DM, Lu G, Ades AE. Evidence synthesis for decision making 4: inconsistency in networks of evidence based on randomized controlled trials. Medical Decision Making 2013;33:641-56.

\section{Dias 2014}

Dias S, Welton NJ, Sutton AJ, Ades AE. NICE DSU technical support document 2: a generalised linear modelling framework for pairwise and network meta-analysis of randomised controlled trials. April 2014. www.nicedsu.org.uk/ TSD2\%20General\%20meta\%20analysis\%20corrected \%2015April2014.pdf (accessed 5 February 2015).

\section{Dumville 2009}

Dumville JC, Worthy G, Soares MO, Bland JM. VenUS II: a randomised controlled trial of larval therapy in the management of leg ulcers. Health Technology Assessment 2009;13(55):1-206.

\section{Dyson 1992}

Dyson M, Young SR, Hart J, Lynch JA, Lang S. Comparison of the effects of moist and dry conditions on the process of angiogenesis during dermal repair. Journal of Investigative Dermatology 1992;99(6):729-33.

\section{Ghauri 2010}

Ghauri AS, Nyamekye IK. Leg ulceration: the importance of treating the underlying pathophysiology. Phlebology/Venous Forum of the Royal Society of Medicine 2010;25(S1):42-51.

\section{Gohel 2005}

Gohel MS, Taylor M, Earnshaw JJ, Heather BP, Poskitt KR, Whyman MR. Risk factors for delayed healing and recurrence of chronic venous leg ulcers - an analysis of 1324 legs. European Journal of Vascular and Endovascular Surgery 2005;29(1):74-7.

\section{GRADE 2013}

Schünemann H, Brożek J, Guyatt G, Oxman A, editor(s), GRADE working group. Handbook for grading the quality of evidence and the strength of recommendations using the GRADE approach. October 2013. gdt.guidelinedevelopment.org/ central_prod/_design/client/handbook/handbook.html (accessed 5 February 2016). 


\section{Graham 2003}

Graham ID, Harrison MB, Nelson EA, Lorimer K, Fisher A. Prevalence of lower-limb ulceration: a systematic review of prevalence studies. Advances in Skin and Wound Care 2003;16(6):305-16.

\section{Grant 2013}

Grant ES, Calderbank-Batista T. Network meta-analysis for complex social interventions: problems and potential. Journal of the Society for Social Work and Research 2013;4(4):406-20.

\section{Greer 2013}

Greer N, Foman NA, MacDonald R, Dorrian J, Fitzgerald P, Rutks I, et al. Advanced wound care therapies for nonhealing diabetic, venous, and arterial ulcers: a systematic review. Annals of Internal Medicine 2013;159(8):532-42.

\section{Guyatt 2011}

Guyatt GH, Oxman AD, Kunz R, Brozek J, Alonso-Coello P, Rind $D$, et al. GRADE guidelines 6: rating the quality of evidence - imprecision. Journal of Clinical Epidemiology 2011;64(12):1283-93.

\section{Hall 2014}

Hall J, Buckley HL, Lamb KA, Stubbs N, Saramago P, Dumville JC, et al. Point prevalence of complex wounds in a defined United Kingdom population. Wound Repair and Regeneration 2014;22(6):694-700. [DOI: 10.1111/wrr.12230]

\section{Herber 2007}

Herber OR, Schnepp W, Rieger MA. A systematic review on the impact of leg ulceration on patients' quality of life. Health and Quality of Life Outcomes 2007;5:44. [DOI: 10.1186/1477-7525-5-44]

\section{Higgins 1996}

Higgins JP, Whitehead A. Borrowing strength from external trials in a meta-analysis. Statistics in Medicine 1996;15:2733-49.

\section{Higgins 2003}

Higgins JP, Thompson SG, Deeks JJ, Altman DG. Measuring inconsistency in meta-analyses. BMJ 2003;327:557-60.

\section{Higgins 2011a}

Higgins JP, Green S, editor(s). Cochrane Handbook for Systematic Reviews of Interventions Version 5.1.0 (updated March 2011). The Cochrane Collaboration, 2011. Available from handbook.cochrane.org.

\section{Higgins 2011b}

Higgins JP, Altman DG, Sterne JA, editor(s). Chapter 8: Assessing risk of bias in included studies. In: Higgins JP, Green S, editor(s). Cochrane Handbook for Systematic Reviews of Interventions Version 5.1.0 (updated March 2011). The Cochrane Collaboration, 2011. Available from handbook.cochrane.org.

\section{Higgins 2011c}

Higgins JP, Deeks JJ, Altman DG, editor(s). Chapter 16: Special topics in statistics. In: Higgins JP, Green S, editor(s). Cochrane Handbook for Systematic Reviews of Interventions Version
5.1.0 (updated March 2011). The Cochrane Collaboration, 2011. Available from handbook.cochrane.org.

\section{Higgins 2012}

Higgins JP, Jackson D, Barrett JK, Lu G, Ades AE, White IR. Consistency and inconsistency in network meta-analysis: concepts and models for multi-arm studies. Research Synthesis Methods 2012;3:98-110.

\section{Hutchinson 1991}

Hutchinson JJ, Lawrence JC. Wound infections under occlusive dressings. Journal of Hospital Infection 1991;17(2):83-94.

\section{Jansen 2013}

Jansen JP, Naci H. Is network meta-analysis as valid as standard pairwise meta-analysis? It all depends on the distribution of effect modifiers. BMC Medicine 2013;11:159-66.

\section{Johnson 1995}

Johnson M. The prevalence of leg ulcers in older people: implications for community nursing. Public Health Nursing 1995;12(4):269-75.

\section{Jull 2015}

Jull AB, Cullum N, Dumville JC, Westby MJ, Deshpande S, Walker N. Honey as a topical treatment for wounds. Cochrane Database of Systematic Reviews 2015, Issue 3. [DOI: 10.1002/14651858.CD005083.pub4]

\section{Krahn 2013}

Krahn U, Binder H, König J. A graphical tool for locating inconsistency in network meta-analyses. BMC Medical Research Methodology 2013;13:35-52.

\section{Lefebvre 2011}

Lefebvre C, Manheimer E, Glanville J. Chapter 6: Searching for studies. In: Higgins JP, Green S, editor(s). Cochrane Handbook for Systematic Reviews of Interventions Version 5.1.0 (updated March 2011). The Cochrane Collaboration, 2011. Available from handbook.cochrane.org.

\section{Liberati 2009}

Liberati A, Altman DG, Tetzlaff J, Mulrow C, Gotzsche PC, Ioannidis JP, et al. The PRISMA statement for reporting systematic reviews and meta-analyses of studies that evaluate health care interventions: explanation and elaboration. PLOS Medicine 2009;6:e1000100.

\section{Lu 2004}

Lu G, Ades AE. Combination of direct and indirect evidence in mixed treatment comparisons. Statistics in Medicine 2004;23(20):3105-24.

\section{Madden 2014}

Madden M. Is research in chronic wound care focusing on the outcomes that matter most to patients?. British Sociological Association Annual Conference: Changing Society. 2014:232.

\section{Maddox 2012}

Maddox D. Effects of venous leg ulceration on patients' quality of life. Nursing Standard 2012;26(38):42-49. 


\section{Moffatt 2004}

Moffatt CJ, Franks PJ, Doherty DC, Martin R, Blewett R, Ross F. Prevalence of leg ulceration in a London population. QJM: Monthly Journal of the Association of Physicians 2004;97(7):431-7.

\section{Nelson 2014}

Nelson EA, Hillman A, Thomas K. Intermittent pneumatic compression for treating venous leg ulcers. Cochrane Database of Systematic Reviews 2014, Issue 5. [DOI: 10.1002/14651858.CD001899.pub4]

\section{Nelzen 1994}

Nelzen O, Berqvist D, Lindhagen A. Venous and non-venous leg ulcers: clinical history and appearance in a population study. British Journal of Surgery 1994;81:182-7.

\section{Nelzen 1997}

Nelzen O, Bergqvist D, Lindhagen A. Long-term prognosis for patients with chronic leg ulcers: a prospective cohort study. European Journal of Vascular and Endovascular Surgery 1997;15:500-8.

\section{Nelzen 2008}

Nelzen O. Prevalence of venous leg ulcer: the importance of the data collection method. Phlebolymphology 2008;15(4):143-50.

\section{NICE 2016a}

National Institute for Health and Care Excellence (NICE). Clinical knowledge summaries. Leg ulcer - venous. February 2016. cks.nice.org.uk/leg-ulcer-venous\#!topic summary (accessed 9 November 2016).

\section{NICE 2016b}

National Institute for Health and Care Excellence (NICE). Chronic wounds: advanced wound dressings and antimicrobial dressings. Evidence summary [ESMPB2]. March 2016. www.nice.org.uk/advice/esmpb2/chapter/key-points-from-theevidence (accessed 9 November 2016).

\section{O'Donnell 2006}

O'Donnell JR, Lau J. A systematic review of randomized controlled trials of wound dressings for chronic venous ulcer. Journal of Vascular Surgery 2006;44(5):1118-25.

\section{O'Meara 2012}

O'Meara S, Cullum N, Nelson EA, Dumville JC. Compression for venous leg ulcers. Cochrane Database of Systematic Reviews 2012, Issue 11. [DOI: 10.1002/14651858.CD000265.pub3]

\section{O'Meara 2013}

O'Meara S, Martyn-St James M. Foam dressings for venous leg ulcers. Cochrane Database of Systematic Reviews 2013, Issue 6. [DOI: 10.1002/14651858.CD009907.pub2]

\section{O'Meara 2014}

O'Meara S, Al-Kurdi D, Ologun Y, Ovington LG, Martyn-St James M, Richardson R. Antibiotics and antiseptics for venous leg ulcers. Cochrane Database of Systematic Reviews 2014, Issue 1. [DOI: 10.1002/14651858.CD003557.pub5]

\section{O'Meara 2015}

O'Meara S, Martyn-St James M, Adderley UJ. Alginate dressings for venous leg ulcers. Cochrane Database of Systematic Reviews 2015, Issue 8. [DOI: 10.1002/14651858.CD010182.pub3]

\section{Parmar 1998}

Parmar MK, Torri V, Stewart L. Extracting summary statistics to perform meta-analyses of the published literature for survival endpoints. Statistics in Medicine 1998;17:2815-34.

\section{Persoon 2004}

Persoon A, Heinen MM, Van der Vleuten CJ, De Rooji MJ, Van de Kerkhof PC, Van Achterberg T. Leg ulcers: a review of their impact on daily life. Journal of Clinical Nursing 2004;13(3):341-54.

\section{Peters 2008}

Peters J, Sutton A, Jones D, Abrams K, Rushton L. Contourenhanced meta-analysis funnel plots help distinguish publication bias from other causes of asymmetry. Journal of Clinical Epidemiology 2008;61(10):991-6.

\section{Ragnarson 2005}

Ragnarson TG, Hjelmgren J. Annual costs of treatment for venous leg ulcers in Sweden and the United Kingdom. Wound Repair and Regeneration 2005;13(1):13-8.

\section{RCN 2013}

Royal College of Nursing (RCN). The nursing management of patients with venous leg ulcers: recommendations. www.rcn.org.uk/professional-development/publications/ pub-000989 (accessed 9 November 2016).

\section{RevMan 2014 [Computer program]}

The Nordic Cochrane Centre, The Cochrane Collaboration. Review Manager 5 (RevMan 5). Version 5.3. Copenhagen: The Nordic Cochrane Centre, The Cochrane Collaboration, 2014.

\section{Ribeiro 2013}

Ribeiro CT, Dias FA, Fregonezi GA. Hydrogel dressings for venous leg ulcers. Cochrane Database of Systematic Reviews 2013, Issue 9. [DOI: 10.1002/14651858.CD010738]

\section{Ribeiro 2014}

Ribeiro CT, Fregonezi GA, Resqueti VR, Dornelas de Andrade A, Dias FA. Hydrocolloid dressings for healing venous leg ulcers. Cochrane Database of Systematic Reviews 2014, Issue 1. [DOI: 10.1002/14651858.CD010918]

\section{Robson 2006}

Robson MC, Cooper DM, Aslam R, Gould LJ, Harding KG, Margolis DJ, et al. Guidelines for the treatment of venous ulcers. Wound Repair and Regeneration 2006;14(6):649-62.

\section{Salanti 2008}

Salanti G, Higgins JP, Ades AE, loannidis JP. Evaluation of networks of randomized trials. Statistical Methods in Medical Research 2008;17:279-301. 


\section{Salanti 2011}

Salanti G, Ades A, loannidis J. Graphical methods and numerical summaries for presenting results from multiple-treatment meta-analysis: an overview and tutorial. Journal of Clinical Epidemiology 2011;64:163-71.

\section{Salanti 2014}

Salanti G, Del Giovane C, Chaimani A, Caldwell DM, Higgins JP. Evaluating the quality of evidence from a network metaanalysis. PLOS One 2014;9:e99682.

\section{Schünemann 2011a}

Schünemann HJ, Oxman AD, Higgins JP, Vist GE, Glasziou P, Guyatt GH. Chapter 11: Presenting results and 'Summary of findings' tables. In: Higgins JP, Green S, editor(s). Cochrane Handbook for Systematic Reviews of Interventions Version 5.1.0 (updated March 2011). The Cochrane Collaboration, 2011. Available from handbook.cochrane.org.

\section{Schünemann 2011b}

Schünemann HJ, Oxman AD, Higgins JP, Deeks JJ, Glasziou P, Guyatt GH. Chapter 12: Interpreting results and drawing conclusions. In: Higgins JP, Green S, editor(s). Cochrane Handbook for Systematic Reviews of Interventions Version 5.1.0 (updated March 2011). The Cochrane Collaboration, 2011. Available from handbook.cochrane.org.

\section{Shaw 2007}

Shaw J, Hughes CM, Lagan KM, Bell PM. The clinical effect of topical phenytoin on wound healing: a systematic review. British Journal of Dermatology 2007;157(5):997-1004.

\section{SIGN 2010}

Scottish Intercollegiate Guidelines Network (SIGN). Management of chronic venous leg ulcers. SIGN guideline 120. 2010. www.sign.ac.uk/pdf/sign120.pdf. Edinburgh: Scottish Intercollegiate Guidelines Network, Healthcare Improvement Scotland, (accessed 9 November 2016).

\section{SIGN 2018}

Scottish Intercollegiate Guidelines Network (SIGN). Search filters. www.sign.ac.uk/search-filters.html (accessed 18 January 2018).

\section{Soares 2014}

Soares MO, Dumville JC, Ades AE, Welton NJ. Treatment comparisons for decision making: facing the problems of sparse and few data. Journal of the Royal Statistical Society Series A 2014;177(1):259-79.

\section{Spiegelhalter 2003}

Spiegelhalter D, Abrams K, Myles J. Bayesian Approaches to Clinical Trials and Health-care Evaluation. Chichester: Wiley, 2003.

\section{Srinivasaiah 2007}

Srinivasaiah N, Dugdall H, Barrett S, Drew PJ. A point prevalence survey of wounds in north-east England. Journal of Wound Care 2007;16(10):413-9.

\section{STATA 2011 [Computer program]}

StataCorp. Stata Statistical Software. Version 13. College Station, TX: StataCorp, 2011.

\section{Svensjö 2000}

Svensjö T, Pomahac B, Yao F, Slama J, Eriksson E. Accelerated healing of full-thickness skin wounds in a wet environment. Plastic and Reconstructive Surgery 2000;106(3):602-12.

\section{Thorlund 2012}

Thorlund K, Mills EJ. Sample size and power considerations in network meta-analysis. Systematic Reviews 2012;1:41-54.

\section{Tierney 2007}

Tierney JF, Stewart LA, Ghersi D, Burdett S, Sydes MR. Practical methods for incorporating summary time-to-event data into meta-analysis. Trials 2007;7(8):16.

\section{Tu 2012}

Tu Y-K, Faggion CM. A primer on network meta-analysis for dental research. International Scholarly Research Notices: Dentistry 2012 June 21 [Epub]:Article ID: 276520. [DOI: 10.5402/2012/276520]

\section{Turner 2012}

Turner RM, Davey J, Clarke MJ, Thompson SG, Higgins JP. Predicting the extent of heterogeneity in meta-analysis, using empirical data from the Cochrane Database of Systematic Reviews. International Journal of Epidemiology 2012;41(3):818-27.

\section{Valencia 2001}

Valencia IC, Falabella A, Kirsner RS, Eaglestein WH. Chronic venous insufficiency and venous leg ulceration. Journal of the American Academy of Dermatology 2001;44:401-21.

\section{Vermeulen 2007}

Vermeulen H, Van Hattem JM, Storm-Versloot MN, Ubbink DT, Westerbos SJ. Topical silver for treating infected wounds. Cochrane Database of Systematic Reviews 2007, Issue 1. [DOI: 10.1002/14651858.CD005486.pub2]

\section{Vowden 2009a}

Vowden K, Vowden P. The resource costs of wound care in Bradford and Airedale primary care trust in the UK. Journal of Wound Care 2009;18(3):93-102.

\section{Vowden 2009b}

Vowden KR, Vowden P. The prevalence, management and outcome for patients with lower limb ulceration identified in a wound care survey within one English health care district. Journal of Tissue Viability 2009;18(1):13-9.

\section{Walker 2002}

Walker N, Rodgers A, Birchall N, Norton R, MacMahon S. The occurrence of leg ulcers in Auckland: results of a population-based survey. New Zealand Medical Journal 2002;115(1151):159-62. 


\section{Westby 2016}

Westby MJ, Dumville JC, Stubbs N, Norman G, Cullum N. Protease-modulating matrix treatments for healing venous leg ulcers. Cochrane Database of Systematic Reviews 2016, Issue 12. [DOI: 10.1002/14651858.CD011918]

\section{Westby 2017}

Westby MJ, Dumville JC, Soares MO, Stubbs N, Norman G. Dressings and topical agents for treating pressure ulcers. Cochrane Database of Systematic Reviews 2017, Issue 6. [DOI: 10.1002/14651858.CD011947]

\section{White 2012}

White IR, Barrett JK, Jackson D, Higgins JP. Consistency and inconsistency in network meta-analysis: model estimation using multivariate meta-regression. Research Synthesis Methods 2012;3:111-25.

\section{WinBUGS 2016 [Computer program]}

MRC Biostatistics Unit, Cambridge Biomedical Campus, Cambridge Institute of Public Health. WinBUGS. Version 1.4.3. Cambridge: MRC Biostatistics Unit, 2016.

\section{Winter 1962}

Winter GD. Formation of the scab and the rate of epithelization of superficial wounds in the skin of the young domestic pig. Nature 1962;193:293-4.

\section{CHARACTERISTICS OF STUDIES}

Characteristics of included studies [ordered by study ID]

\section{Winter 1963a}

Winter GD. Effect of air exposure and occlusion on experimental human skin wounds. Nature 1963;200:378-9.

\section{Winter 1963b}

Winter GD, Scales JT. Effect of air drying and dressings on the surface of a wound. Nature 1963;197:91-2.

\section{Woo 2013}

Woo KY, Alavi A, Evans R, Despatis M, Allen J. New advances in compression therapy for venous leg ulcers. Surgical Technology International 2013;23:61-8.

\section{References to other published versions of this review}

\section{Norman 2017}

Norman G, Dumville JC, Westby MJ, Stubbs N, Soares MO. Dressings and topical agents for treating venous leg ulcers. Cochrane Database of Systematic Reviews 2017, Issue 3. [DOI: 10.1002/14651858.CD012583]

* Indicates the major publication for the study

Alvarez 2012

$\begin{array}{ll}\text { Methods } & \text { RCT } \\ \text { Arms: } 2 \\ \text { Unit of randomisation: participant } \\ \text { Unit of analysis: participant } \\ \text { Follow-up: } 12 \text { weeks }\end{array}$

Participants

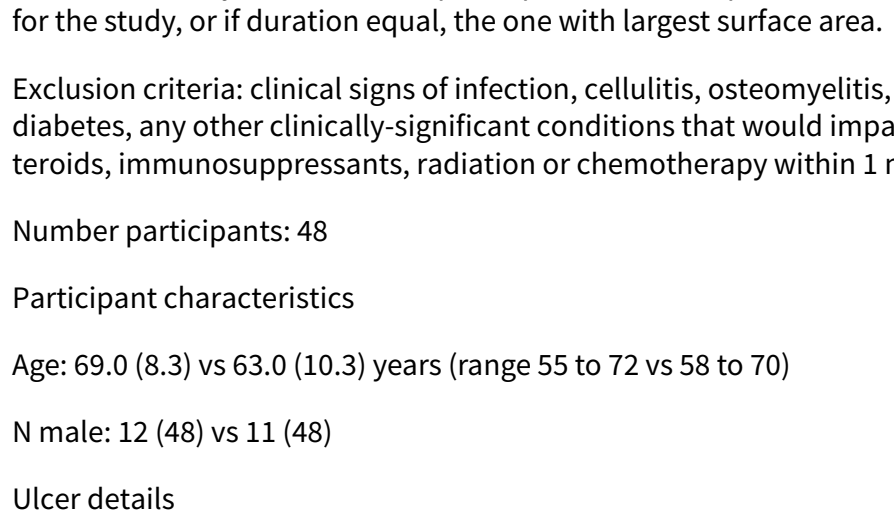
for the study, or if duration equal, the one with largest surface area.

Number participants: 48

Participant characteristics

Age: 69.0 (8.3) vs 63.0 (10.3) years (range 55 to 72 vs 58 to 70 )

N male: 12 (48) vs $11(48)$

Ulcer details VLU of minimum 2 months duration and requiring autolytic debridement ( $>50 \%$ ulcer bed covered with non-viable yellow tissue). If participants had multiple VLU, the ulcer of longest duration was used

Exclusion criteria: clinical signs of infection, cellulitis, osteomyelitis, inadequate nutrition, uncontrolled diabetes, any other clinically-significant conditions that would impair wound healing. Use of corticosteroids, immunosuppressants, radiation or chemotherapy within 1 month prior to study entry. 
Alvarez 2012 (Continued)

Size: 743.9 (103.8) vs $629.0(106.9) \mathrm{mm}^{2}$ (median 785 vs $627 \mathrm{~mm}^{2}$ )

Duration: 10.9 (2.2) vs 8.9 (1.2) months (range 8 to 14 vs 4 to 12 )

\begin{tabular}{ll} 
Interventions & Intervention 1 class: biosynthetic (bio-cellulose) \\
Intervention 1 details (name and details of application): Suprasorb X (Lohmann \& Rauscher) changed \\
weekly \\
Intervention 2 class: nonadherent \\
Intervention 2 details (name and details of application): Adaptic (Systagenix) changed weekly \\
Compression: modified Unna's boot or a 4-layer bandage system (Viscopaste, Profore; Smith \& Nephew \\
Inc, Coban LF; 3M Inc) \\
Other co-interventions: wound cleansing with saline, without forceful irrigation \\
\hline Intervention $1: 7 / 25$ \\
Intervention 2: $7 / 23$ \\
Futcomes \\
Funding type: industry \\
\hline Notes
\end{tabular}

\section{Risk of bias}

\begin{tabular}{|c|c|c|}
\hline Bias & Authors' judgement & Support for judgement \\
\hline \multirow[t]{2}{*}{$\begin{array}{l}\text { Random sequence genera- } \\
\text { tion (selection bias) }\end{array}$} & Unclear risk & $\begin{array}{l}\text { Quote: "eligible patients were allocated ... according to a block randomisation } \\
\text { schedule" }\end{array}$ \\
\hline & & Comment: method of generating the sequence was not stated \\
\hline \multirow[t]{2}{*}{$\begin{array}{l}\text { Allocation concealment } \\
\text { (selection bias) }\end{array}$} & Unclear risk & $\begin{array}{l}\text { Quote: "randomisation was done using sealed envelopes, which were opened } \\
\text { after pre-test measurements were taken" }\end{array}$ \\
\hline & & Comment: unclear if the envelopes were sequentially numbered and opaque \\
\hline $\begin{array}{l}\text { Blinding of participants } \\
\text { and personnel (perfor- } \\
\text { mance bias) } \\
\text { All outcomes }\end{array}$ & Unclear risk & Comment: not reported \\
\hline \multirow{2}{*}{$\begin{array}{l}\text { Blinding of outcome as- } \\
\text { sessment (detection bias) } \\
\text { All outcomes }\end{array}$} & Low risk & $\begin{array}{l}\text { Quote: "digital photographs were assessed by a clinician who was blinded as } \\
\text { to the treatment allocation" }\end{array}$ \\
\hline & & Comment: blinded outcome assessment \\
\hline $\begin{array}{l}\text { Incomplete outcome data } \\
\text { (attrition bias) }\end{array}$ & High risk & $\begin{array}{l}\text { Comment: } 28 \% \text { and } 35 \% \text { of participants were excluded from the analysis - vari- } \\
\text { ety of reasons and it is not clear if these were reasonable }\end{array}$ \\
\hline \multicolumn{3}{|l|}{ All outcomes } \\
\hline $\begin{array}{l}\text { Selective reporting (re- } \\
\text { porting bias) }\end{array}$ & Low risk & Comment: all outcomes appear to have been reported \\
\hline Other bias & Low risk & No evidence of other bias \\
\hline All domain risk of bias & High risk & \\
\hline
\end{tabular}




$\begin{array}{ll}\text { Methods } & \text { RCT } \\ \text { Arms: } 2 \\ \text { Unit of randomisation: participant } \\ \text { Unit of analysis: participant } \\ \text { Follow-up: } 13 \text { weeks }\end{array}$

Inclusion criteria: VLU minimum $1.6 \mathrm{~cm}$ in all directions, maximum area $50 \mathrm{~cm}^{2},>8$ weeks duration, $\mathrm{ABI}$
$>0.8$
Exclusion criteria: vasculitis, non-venous leg ulcer, treatment with systemic antibiotics, corticosteroids
or oral immunosuppressants, pregnancy
Participant characteristics
Number participants: 72
Age: 65 vs 59 years
N (\%) male: 11 (30.6) vs $15(41.7)$
Ulcer details
Size: mean (SD) 18.7 (9.9) $\mathrm{cm}^{2}$ vs 17.5 (9.3) $\mathrm{cm}^{2}$
Duration: mean (range) 2 years (3 months to 6 years) vs 2 years ( 3 months to 6 years)

Interventions Intervention 1 class: blood product

Intervention 1 details (name and details of application): haemoglobin spray (10\% purified porcine haemoglobin in aqueous solution) + Nanotextile (Elmarco), fixed with gauze. Daily dressing change. Treated in hospital for 2 weeks, then at home

Intervention 2 class: placebo

Intervention 2 details (name and details of application): placebo spray ( $0.9 \%$ saline) + Nanotextile (Elmarco) fixed with gauze

Compression: compression therapy used in all according to current guidelines in Czech Republic based on clinical experience, initiated 2 weeks prior to study inclusion. All used Ideal/Hartmann bandages

Other co-interventions: meticulous wound cleaning and disinfection prior to dressing.

\begin{tabular}{ll}
\hline Outcomes & Intervention $1: 1 / 36$ \\
& Intervention 2: $0 / 36$ \\
\hline Notes & Funding type and details: non-industry \\
& Funding details: Czech Ministry of Health
\end{tabular}

\section{Risk of bias}

\section{Bias}

Authors' judgement Support for judgement

Random sequence genera- Unclear risk tion (selection bias)
Comment: study described as randomised but no methods reported 
Arenbergerova 2013 (Continued)

Allocation concealment $\quad$ Unclear risk $\quad$ Comment: no information reported
(selection bias)

Blinding of participants High risk Quote: "the nurses involved in treatment and wound care were not blinded"
and personnel (perfor-
mance bias)
All outcomes

\begin{tabular}{|c|c|c|}
\hline $\begin{array}{l}\text { Blinding of outcome as- } \\
\text { sessment (detection bias) }\end{array}$ & Low risk & $\begin{array}{l}\text { Quote: "the attending doctor whom evaluated the wound surface area and as- } \\
\text { sessed the condition of the wound were blinded" }\end{array}$ \\
\hline
\end{tabular}

All outcomes

\begin{tabular}{lll}
\hline $\begin{array}{l}\text { Incomplete outcome data } \\
\text { (attrition bias) } \\
\text { All outcomes }\end{array}$ & High risk & $\begin{array}{l}\text { Comment: 2/36 vs 5/36 dropped out of study, reasons reported but disparity } \\
\text { and higher than healing rate }\end{array}$ \\
\hline $\begin{array}{l}\text { Selective reporting (re- } \\
\text { porting bias) }\end{array}$ & Low risk & Comment: all outcomes appear to be reported \\
\hline Other bias & Low risk & Comment: no evidence of other bias \\
\hline All domain risk of bias & High risk & \\
\hline All domain risk of bias 2 & High risk \\
\hline
\end{tabular}

\section{Armstrong 1997}

\begin{tabular}{|c|c|}
\hline \multirow[t]{5}{*}{ Methods } & $\mathrm{RCT}$ \\
\hline & Arms: 2 \\
\hline & Unit of randomisation: participant \\
\hline & Unit of analysis: participant \\
\hline & Follow-up: 6 weeks \\
\hline \multirow[t]{10}{*}{ Participants } & Inclusion criteria: ulcer $7.5 \mathrm{~cm}$ or larger in diameter producing moderate to heavy amounts of exudate \\
\hline & Exclusion criteria: not reported \\
\hline & Participant characteristics \\
\hline & Number participants: 44 \\
\hline & Age: $71(10)$ vs $65(11)$ years \\
\hline & $\mathrm{N}(\%)$ male: $10(48)$ vs $13(57)$ \\
\hline & Ulcer details \\
\hline & Non VLU: $<25 \%$ mixed/arterial); 3 (14\%) vs $3(13 \%)$ mixed aetiology, $1(5 \%)$ vs $1(4 \%)$ other \\
\hline & Size: median (range) 491 (64 to 2081 ) $\mathrm{mm}^{2}$ vs 611 (60 to 1830$) \mathrm{mm}^{2}$ \\
\hline & Duration: median (range) 9 ( 1 to 47 ) months vs 12 ( 1 to 120 ) months \\
\hline
\end{tabular}

Interventions

Intervention 1 class: hydrofibre 
Armstrong 1997 (Continued)

Intervention 1 details (name and details of application): Aquacel; dressing changed every 7 days (or sooner if leakage, infection suspected or pain)

Intervention 2 class: alginate

Intervention 2 details (name and details of application): Kaltostat; dressing changed every 7 days (or sooner if leakage, infection suspected or pain)

Compression: class 3c compression bandage (Tensopress)

Other co-interventions: secondary dressing, occlusive hydrocolloid (DuoDerm Extra Thin) and, if indicated, orthopaedic padding

\begin{tabular}{ll}
\hline Outcomes & Intervention $1: 6 / 21$ \\
& Intervention 2: $2 / 23$ \\
\hline Notes & Funding type: industry \\
& Funding details: ConvTec Ltd \\
\hline
\end{tabular}

\section{Risk of bias}

Bias Authors' judgement Support for judgement

Random sequence genera- Unclear risk tion (selection bias)
Quote: "subjects were then randomised to the primary dressings under investigation by the use of sealed envelopes opened in numerical order"

Comment: unclear how the randomisation sequence was generated

Quote: "subjects were then randomised to the primary dressings under investigation by the use of sealed envelopes opened in numerical order"

Comment: not clear whether the envelopes used were opaque

Allocation concealment $\quad$ Unclear risk
(selection bias)
(selection bias)

\section{Not reported}

Blinding of participants Unclear risk Not reported
and personnel (perfor-
mance bias)

\begin{tabular}{lll}
\hline $\begin{array}{l}\text { Blinding of outcome as- } \\
\text { sessment (detection bias) } \\
\text { All outcomes }\end{array}$ & Unclear risk & Not reported \\
\hline $\begin{array}{l}\text { Incomplete outcome data } \\
\text { (attrition bias) } \\
\text { All outcomes }\end{array}$ & High risk & $\begin{array}{l}\text { Comment: high levels of withdrawals (24\% vs 30\%) all but one due to adverse } \\
\text { events }\end{array}$ \\
\hline $\begin{array}{l}\text { Selective reporting (re- } \\
\text { porting bias) }\end{array}$ & Low risk & Comment: no evidence of selective reporting \\
\hline $\begin{array}{l}\text { Other bias } \\
\text { All domain risk of bias }\end{array}$ & High risk & $\begin{array}{l}\text { Comment: no evidence of other bias but secondary dressing appears to have } \\
\text { been a problem; cause of the high adverse events }\end{array}$ \\
\hline
\end{tabular}


Arnold 1994

\begin{tabular}{ll}
\hline Methods & RCT \\
& Arms: 2 \\
& Unit of randomisation: participant \\
& Unit of analysis: participant \\
& Follow-up: 10 weeks
\end{tabular}

Participants

Inclusion criteria: non-infected lower leg ulceration secondary to venous stasis

Exclusion criteria: ulcers resulting from arterial insufficiency, vasculitis, rheumatoid arthritis, sickle cell anaemia, tumours, other dermatological conditions. Evidence of periwound erythema, cellulitis, oedema. Deep dermal involvement and exposure of muscle, tendon or bone

Participant characteristics

Number participants: 70

Age: 65 (SE 3.3) vs 60 (SE 2.9) years

$\%$ male 36 or 37 (calculating from \%) (52)

Ulcer details

Size: $2100 \mathrm{~mm}^{2}$ (SE 685) vs $1983 \mathrm{~mm}^{2}$ (SE 659)

Duration: 47.8 weeks vs 46.2 weeks

Intervention 1 details (name and details of application): DuoDERM CGF (ConvaTec); dressing changed every 7 days

Intervention 2 class: nonadherent

Intervention 2 details (name and details of application): gauze (paraffin-impregnated in US study centres, saline/betadine-impregnated in UK); US centres: Telfa (Kendall Healthcare Products); dressing changed every 7 days

Compression: zinc oxide paste bandage (Unna's boot) and gradient compression bandage (worn during working hours)

Other co-interventions: not reported

\section{Outcomes}

Intervention 1: 11/35

Intervention 2: 14/35

Notes Funding type: not reported

Funding details: 2 of the authors are from Bristol-Myers Squibb Pharmaceuticals

\section{Risk of bias}

Bias Authors' judgement Support for judgement

Random sequence genera- Unclear risk tion (selection bias)
Quote: "following the initial assessment, patients were randomly assigned to the study or control treatment"

Comment: unclear how the randomisation sequence was generated 
Arnold 1994 (Continued)

$\begin{aligned} & \text { Allocation concealment } \\ & \text { (selection bias) }\end{aligned} \quad \begin{aligned} & \text { Quote: "following the initial assessment, patients were randomly assigned to } \\ & \text { the study or control treatment" }\end{aligned}$
(selection bias)

Comment: unclear whether allocation was adequately concealed

Blinding of participants Unclear risk
and personnel (perfor-

\begin{tabular}{lll}
\hline $\begin{array}{l}\text { Blinding of outcome as- } \\
\text { sessment (detection bias) } \\
\text { All outcomes }\end{array}$ & Unclear risk & Not reported \\
\hline $\begin{array}{l}\text { Incomplete outcome data } \\
\text { (attrition bias) } \\
\text { All outcomes }\end{array}$ & High risk & Comment: 20\% vs 26\% withdrawal for various reasons but ITT analysis \\
\hline $\begin{array}{l}\text { Selective reporting (re- } \\
\text { porting bias) }\end{array}$ & Low risk & Comment: no evidence of selective reporting \\
\hline $\begin{array}{l}\text { Other bias } \\
\text { All domain risk of bias }\end{array}$ & High risk risk & $\begin{array}{l}\text { Comment: authors highlight differences between outcomes in different study } \\
\text { centres }\end{array}$ \\
\hline All domain risk of bias 2 & High risk & \\
\hline
\end{tabular}

Backhouse 1987

$\begin{array}{ll}\text { Methods } & \text { RCT } \\ \text { Arms: } 2 \\ \text { Unit of randomisation: participant } \\ \text { Unit of analysis: participant } \\ \text { Follow-up: } 12 \text { weeks }\end{array}$

Participants Inclusion criteria: Doppler-assessed venous or gravitational ulcers

Exclusion criteria: ulcers $>10 \mathrm{~cm}^{2}$ in area

Participant characteristics

Number participants: 56

Age: 69.9 vs 67.5 years

$\%$ male: $23(41)$

Ulcer details

Non VLU: comment: ulcers were "gravitational or venous"

Size: $3.4(0.4) \mathrm{cm}^{2}$ vs $3.1(0.4) \mathrm{cm}^{2}$

Duration: 22 vs 21 months (median) 
Backhouse 1987 (Continued)

Interventions

Intervention 1 class: hydrocolloid

Intervention 1 details (name and details of application) Granuflex (Squibb Surgicare), no further details Intervention 2 class: nonadherent

Intervention 2 details (name and details of application): NR (Johnson \& Johnson), no further details

Compression: below-knee graduated compression bandage; layer crepe bandage, layer Elset bandage (Seton Products Ltd); layer Coban cohesive bandage (3M Health Care Ltd)

Other co-interventions: saline wash, removal of slough, absorbent velband (Johnson \& Johnson) over dressing

\begin{tabular}{ll}
\hline Outcomes & Intervention $1: 21 / 28$ \\
& Intervention 2: $22 / 28$ \\
\hline Notes & Funding type: industry \\
& $\begin{array}{l}\text { Funding details: Johnson \& Johnson Ltd, 3M Health Care, Sigvaris (Camp Ltd), Zyma UK Ltd, Squibb } \\
\text { Surgicare }\end{array}$
\end{tabular}

\section{Risk of bias}

\begin{tabular}{lll}
\hline Bias & Authors' judgement & Support for judgement \\
\hline $\begin{array}{l}\text { Random sequence genera- } \\
\text { tion (selection bias) }\end{array}$ & Unclear risk & Quote: "fifty-six patients referred to a venous ulcer clinic were randomized". \\
& & Comment: no detail on how randomisation sequence generated \\
\hline $\begin{array}{l}\text { Allocation concealment } \\
\text { (selection bias) }\end{array}$ & Unclear risk & Quote: "fifty-six patients referred to a venous ulcer clinic were randomized". \\
\hline $\begin{array}{l}\text { Blinding of participants } \\
\text { and personnel (perfor- } \\
\text { mance bias) } \\
\begin{array}{l}\text { All outcomes } \\
\text { Comment: no information on whether allocation was adequately concealed. }\end{array}\end{array}$ & Unclear risk & Comment: no information was reported on blinding participants or personnel \\
\end{tabular}

Blinding of outcome as- Unclear risk Comment: no information on who performed the assessment

sessment (detection bias)

All outcomes

\begin{tabular}{lll}
\hline $\begin{array}{l}\text { Incomplete outcome data } \\
\text { (attrition bias) } \\
\text { All outcomes }\end{array}$ & Low risk & Comment: all randomised participants were included in the analysis \\
\hline $\begin{array}{l}\text { Selective reporting (re- } \\
\text { porting bias) }\end{array}$ & Unclear risk & $\begin{array}{l}\text { Comment: planned outcomes were not clearly reported so difficult to be sure } \\
\text { whether they were fully reported }\end{array}$ \\
\hline Other bias & Unclear risk & Comment: no evidence of other bias but reporting insufficient to be certain \\
\hline All domain risk of bias & Low risk & unclear/low \\
\hline
\end{tabular}

\section{Banerjee 1997}

Methods RCT


Banerjee 1997 (Continued)
Arms: 2
Unit of randomisation: participant
Unit of analysis: participant
Follow-up: 17 weeks

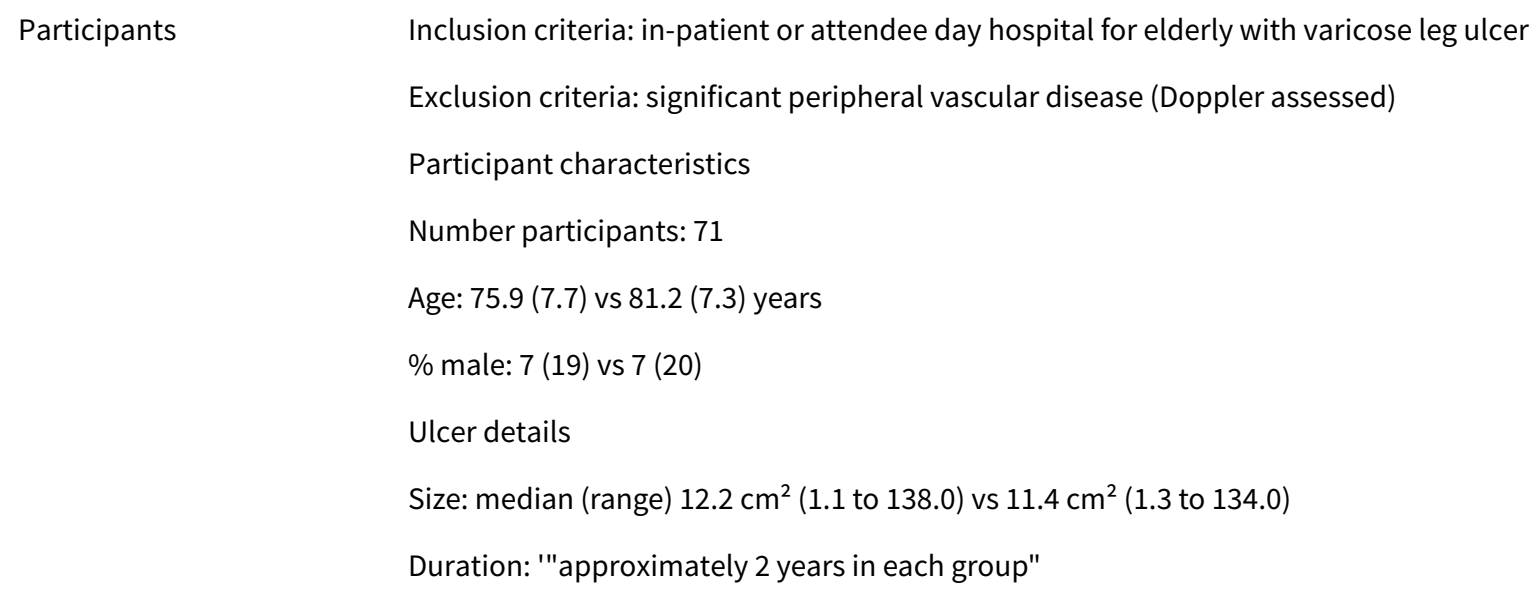

Intervention 1 details (name and details of application): polyurethane 'synthetic skin'; Synthaderm (Arrow Pharmaceuticals)

Intervention 2 class: nonadherent

Intervention 2 details (name and details of application): paratulle (no further details)

Other co-interventions: warm saline poured over ulcer to clean. Primary dressing was backed by a pad and a support bandage applied using a K-bnd Parema conforming bandage from toes to just below the knee.

$\begin{array}{ll}\text { Outcomes } & \text { Intervention 1: 11/36 } \\ & \text { Intervention 2: 8/35 }\end{array}$

Notes Funding type and details: not reported

Notes: a high proportion of ulcers were infected $29(81 \%)$ vs $21(60 \%)$

\section{Risk of bias}

\begin{tabular}{lll}
\hline Bias & Authors' judgement & Support for judgement \\
\hline $\begin{array}{l}\text { Random sequence genera- } \\
\text { tion (selection bias) }\end{array}$ & Unclear risk & Quote: "treatment allocation was random" \\
& & Comment: unclear how randomisation sequence was generated \\
\hline $\begin{array}{l}\text { Allocation concealment } \\
\text { (selection bias) }\end{array}$ & Unclear risk & Quote: "treatment allocation was random" \\
\hline $\begin{array}{l}\text { Blinding of participants } \\
\text { and personnel (perfor- } \\
\text { mance bias) }\end{array}$ & Unclear risk & Comment: unclear whether allocation was adequately concealed \\
All outcomes & & \\
\hline
\end{tabular}


Banerjee 1997 (Continued)

Blinding of outcome as- Unclear risk Not reported sessment (detection bias)

All outcomes

Incomplete outcome data High risk $\quad$ Withdrawal was 3\% vs 23\% giving a large imbalance between the arms
(attrition bias)

(attrition bias)

All outcomes

Selective reporting (re- Low risk Comment: no evidence of selective reporting
porting bias)

\begin{tabular}{lll}
\hline Other bias & High risk & Comment: differences in nursing time/visits noted by authors \\
\hline All domain risk of bias & High risk & \\
\hline All domain risk of bias 2 & High risk \\
\hline
\end{tabular}

\section{Beckert 2006}

$\begin{array}{ll}\text { Methods } & \text { RCT } \\ \text { Arms: } 2 \\ \text { Unit of randomisation: participant } \\ \text { Unit of analysis: participant } \\ \text { Follow-up: } 20 \text { weeks }\end{array}$

Participants

Inclusion criteria: leg ulcer due to $\mathrm{CVI}>$ or $=3 \mathrm{~cm}^{2}, \mathrm{ABI}>0.8$

Exclusion criteria: ulceration not due to CVI, severe cardiac, respiratory, gastrointestinal, live or renal disease, malignancy, signs of wound infection. Pregnant or nursing mothers

Participant characteristics

Number participants: 119

Age: 66.8 (13.7) vs $70.6(11.1)$ years

$\%$ male: 20 (32.3) vs 19 (33.3)

Ulcer details

Size: mean (SD) $26.2(49.0) \mathrm{cm}^{2}$ vs $17.2(21.0) \mathrm{cm}^{2}$

Duration: mean (SD) 24.9 (51.2) months vs 17.8 (18.4) months

Intervention 1 details (name and details of application) 10\% Leukichtan (Ichthyol-Gesellschaft); gel applied to wound daily as $2 \mathrm{~mm}$ to $2.5 \mathrm{~mm}$ thick layer

Intervention 2 class: vehicle (gel)

Intervention 2 details (name and details of application): gel applied to wound daily as $2 \mathrm{~mm}$ to $2.5 \mathrm{~mm}$ thick layer.

Compression: short stretch elastic bandages (Putter-Bandages, Hartmann) 
Beckert 2006 (Continued)

Other co-interventions: Jelonet (Smith \& Nephew) nonadherent gauze dressing applied over the gel

\begin{tabular}{ll} 
Outcomes & Intervention 1: $21 / 62$ \\
& Intervention 2: $13 / 57$ \\
\hline Notes & Funding type and details: industry \\
& Funding details: Ichthyol-Gesellschaft Cordes, Hermanni \& Co (GmbH \& Co)
\end{tabular}

\section{Risk of bias}

\begin{tabular}{lll}
\hline Bias & Authors' judgement & Support for judgement \\
\hline $\begin{array}{ll}\text { Random sequence genera- } \\
\text { tion (selection bias) }\end{array}$ & Low risk & $\begin{array}{l}\text { Quote: "patients were randomized to one of the treatment groups by using a } \\
\text { centralized computer system with block randomization (1:1) (Randcode, IDV, } \\
\text { Gauting, Germany)" } \\
\text { Comment: appropriate method of sequence generation }\end{array}$ \\
& &
\end{tabular}

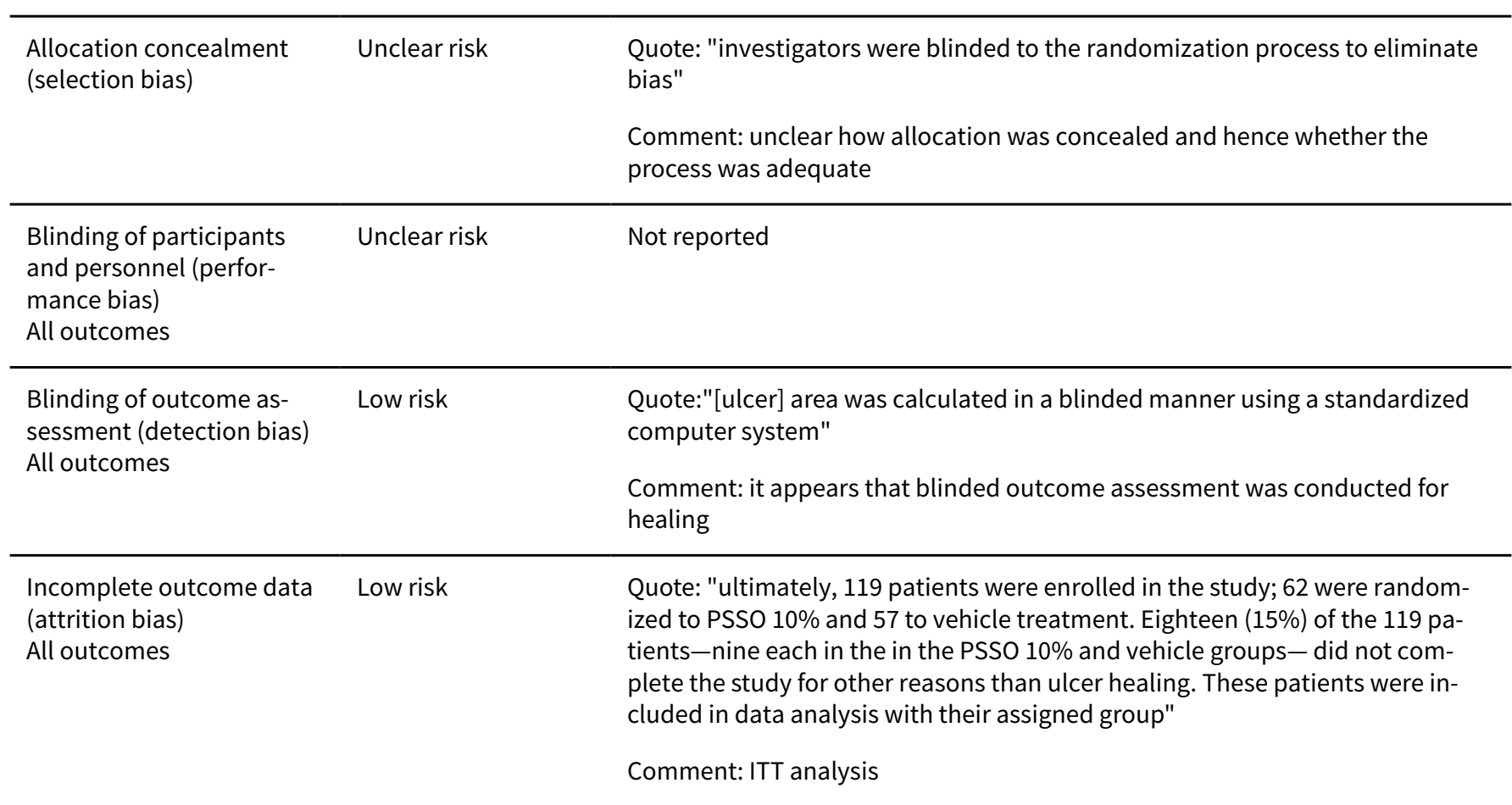

\begin{tabular}{lll}
\hline $\begin{array}{l}\text { Selective reporting (re- } \\
\text { porting bias) }\end{array}$ & Low risk & All specified outcomes were fully reported \\
\hline Other bias & Low risk & No evidence of other bias and reporting sufficient \\
\hline All domain risk of bias & Low risk & low/unclear \\
\hline
\end{tabular}

Biland 1985

Methods RCT

Arms: 4 
Biland 1985 (Continued)

Unit of randomisation: participant

Unit of analysis: participant

Follow-up: 6 weeks

\section{Participants}

Inclusion criteria: venous or mixed arteriovenous ulcers, minimum diameter $1.5 \mathrm{~cm}$, without claudication

Exclusion criteria: purely arterial ulcers, neuropathy, treatment with vaso-active drugs, antibiotics or steroids

Participant characteristics

Number participants: 197

Age: 61 (15) vs 60 (12) vs 60 (12) vs 61 (12) years

N (\%) male: 15 (34) vs $13(23)$ vs 17 (33) vs 10 (22)

Ulcer details

Non VLU: $<25 \%$ mixed/arterial

Size: range $2 \mathrm{~cm}^{2}$ to $321 \mathrm{~cm}^{2}$, median $32 \mathrm{~cm}^{2}$

Duration: < 12 weeks 26 (59\%) vs $30(54 \%)$ vs $31(60 \%)$ vs $27(60 \%), 12-24$ weeks $6(14 \%)$ vs $11(20 \%)$ vs 6 $(12 \%)$ vs $3(7 \%)$, > 24 weeks $12(27 \%)$ vs $15(27 \%)$ vs $15(29 \%)$ vs $15(33 \%)$

Intervention 1 details (name and details of application): haemodialysate ointment (dialysate of calf blood: Solcoseryl (Solco Basle Ltd)) plus placebo IV

Intervention 2 class: placebo

Intervention 2 details (name and details of application): placebo ointment plus placebo IV

Intervention 3 class: blood product

Intervention 3 details (name and details of application): haemodialysate ointment + haemodialysate IV

Intervention 4 class: placebo

Intervention 4 details (name and details of application): placebo ointment + haemodialysate IV

Compression: all received continuous compression with foam-rubber padded bandage

Other co-interventions: twice daily application of compress with isotonic saline. $3 \times$ weekly painting of skin around ulcer with $4 \%$ methylrosaniline chloride

$\begin{array}{ll}\text { Outcomes } & \text { Intervention } 1: 21 / 44 \\ & \text { Intervention 2: } 18 / 56 \\ & \text { Intervention 3: } 25 / 52 \\ & \text { Intervetnion 4: } 19 / 45\end{array}$

$\begin{array}{ll}\text { Notes } & \text { Funding type: not reported } \\ & \text { Funding details: not reported }\end{array}$

\section{Risk of bias}

Dressings and topical agents for treating venous leg ulcers (Review) 
Biland 1985 (Continued)

\section{Bias Authors' judgement Support for judgement}

Random sequence genera- Unclear risk Comment: described as randomised and mention of stratification but no tion (selection bias) method details

\begin{tabular}{lll}
\hline $\begin{array}{l}\text { Allocation concealment } \\
\text { (selection bias) }\end{array}$ & Unclear risk & Not reported \\
\hline $\begin{array}{l}\text { Blinding of participants } \\
\text { and personnel (perfor- } \\
\text { mance bias) } \\
\text { All outcomes }\end{array}$ & Unclear risk & Comment: described as "double blind" but no method detail \\
\hline $\begin{array}{l}\text { Blinding of outcome as- } \\
\text { sessment (detection bias) } \\
\text { All outcomes }\end{array}$ & Unclear risk & Comment: described as "double blind" but no method detail \\
\hline $\begin{array}{l}\text { Incomplete outcome data } \\
\text { (attrition bias) } \\
\text { All outcomes }\end{array}$ & Unclear risk & $\begin{array}{l}\text { Comment: 13/210 dropped out of study, reasons given; unclear which arms } \\
\text { these were from }\end{array}$ \\
\hline $\begin{array}{l}\text { Selective reporting (re- } \\
\text { porting bias) }\end{array}$ & High risk & $\begin{array}{l}\text { Comment: no evidence of selective reporting but withdrawals not clearly re- } \\
\text { ported }\end{array}$ \\
\hline $\begin{array}{l}\text { Other bias } \\
\text { All domain risk of bias }\end{array}$ & High risk & Comment: no evidence of other bias \\
\hline
\end{tabular}

\section{Bishop 1992}

\begin{tabular}{ll}
\hline Methods & RCT \\
Arms: 3 \\
Unit of randomisation: participant \\
Unit of analysis: participant \\
Follow-up: 4 weeks
\end{tabular}

\section{Participants}

Inclusion criteria: age 21-90, venous stasis ulcer of at least 3 months duration, surface area $3 \mathrm{~cm}^{2}$ to 50 $\mathrm{cm}^{2}$, for relevant participants negative pregnancy test and use of adequate contraception

Exclusion criteria: hypersensitivity to test medication, $>10^{5}$ bacteria/g of tissue in ulcer, systemic sepsis or bone infection arm/ankle arterial perfusion index $<0.5$, hypercupraemia, systemic immunosuppressive or cytotoxic therapy, insulin-dependent diabetes

Participant characteristics

Number participants: 93 randomised (86 analysed)

Age: 58.2 (14.5) vs $58.2(17.3)$ vs $51.6(14.6)$ years

$\%$ male: 14 (48) vs 9 (32) vs 20 (69)

Ulcer details

Size: mean (SD) $9.9(8.5) \mathrm{cm}^{2}$ vs $11.9(11.2)$ vs $9.6(8.1) \mathrm{cm}^{2}$ median 6.5 vs $6.9 \mathrm{~cm}^{2}$ vs $6.2 \mathrm{~cm}^{2}$ 
Intervention 1 details (name and details of application): copper tripeptide complex cream; GHK: $\mathrm{Cu}$; participant applied cream and covered with nonadherent dressing

Intervention 2 class: SSD

Intervention 2 details (name and details of application): 1\% silver sulfadiazine cream; Silvadene (Marion Laboratories); participant applied cream and covered with nonadherent dressing

Intervention 3 class: vehicle (cream)

Intervention 3 details (name and details of application): Unibase (Parke-Davis); participant applied cream and covered with non adherent dressing

Compression: "elastic wrap"

Other co-interventions: saline used to clean wound at dressing change

\begin{tabular}{ll}
\hline Outcomes & Intervention $1: 0 / 29$ \\
& Intervention 2: $6 / 28$ \\
& Intervention $3: 1 / 29$ \\
\hline Notes & Funding type: industry \\
& Funding details: Schering-Plough Research \\
& Notes: 1 -year follow-up found $5 / 6$ healed participants in silver sulfadiazine group still healed, as well as \\
& the healed placebo-treated participant
\end{tabular}

\section{Risk of bias}

\begin{tabular}{|c|c|c|}
\hline Bias & Authors' judgement & Support for judgement \\
\hline \multirow[t]{2}{*}{$\begin{array}{l}\text { Random sequence genera- } \\
\text { tion (selection bias) }\end{array}$} & Unclear risk & $\begin{array}{l}\text { Quote: "this study reports a prospective randomized evaluator-blinded trial } \\
\text { comparing ..." }\end{array}$ \\
\hline & & Comment: no information on how the randomisation sequence was generated \\
\hline \multirow[t]{2}{*}{$\begin{array}{l}\text { Allocation concealment } \\
\text { (selection bias) }\end{array}$} & Unclear risk & $\begin{array}{l}\text { Quote: "this study reports a prospective randomized evaluator-blinded trial } \\
\text { comparing ..." }\end{array}$ \\
\hline & & Comment: no information on whether allocation was adequately concealed \\
\hline
\end{tabular}

\begin{tabular}{|c|c|c|}
\hline $\begin{array}{l}\text { Blinding of participants } \\
\text { and personnel (perfor- } \\
\text { mance bias) }\end{array}$ & Unclear risk & $\begin{array}{l}\text { There is no information on this but the fact that study medication was re- } \\
\text { moved before a blinded assessor saw the wound means that there may be an } \\
\text { inherent lack of blinding }\end{array}$ \\
\hline
\end{tabular}

All outcomes

$\begin{aligned} & \text { Blinding of outcome as- } \\ & \text { sessment (detection bias) }\end{aligned}$
$\begin{aligned} & \text { All outcomes } \\ & \text { cleansed to keep the evaluator blinded" }\end{aligned}$

All outcomes

Comment: assessors were blinded to treatment allocation.

Incomplete outcome data Low risk Comment: all the participants were included in the analysis
(attrition bias)

All outcomes 
Bishop 1992 (Continued)

Selective reporting (re- Low risk $\quad$ Comment: all planned outcomes were reported
porting bias)

\begin{tabular}{lll}
\hline Other bias & Unclear risk & Comment: no evidence of other bias but reporting insufficient to be certain \\
\hline All domain risk of bias & Low risk & low/unclear \\
\hline
\end{tabular}

Blair 1988a

\begin{tabular}{ll}
\hline Methods & RCT \\
Arms: 2 [see notes] \\
Unit of randomisation: participant \\
Unit of analysis: participant \\
Follow-up: 12 weeks
\end{tabular}

Inclusion criteria: venous ulcers $<10 \mathrm{~cm}^{2}$
Exclusion criteria: ABPI $<0.8$ on Doppler (arterial insufficiency)
Participant characteristics
Number participants: 120
Age: 69.9 (range 34 to 92 ) vs 67.5 (30 to 90) years
\% male: not reported
Ulcer details
Size: 3.4 (SEM 0.4) vs 3.1 (SEM 0.4) $\mathrm{cm}^{2}$
Duration: 22 (SEM 1.9) vs $21(\mathrm{SEM} 2.7)$ months

Intervention 1 details (name and details of application): Granuflex (Squibb Surgicare); no further details

Intervention 2 class: nonadherent

Intervention 2 details (name and details of application): manufactured by Johnson \& Johnson; no further details

Compression: standard high-pressure graduated compression bandage 4 layers: Velband (Johnson \& Johnson) + crepe bandage + Elset (Seton Products) + Coban (3M Health Care)

Other co-interventions: ulcers cleaned with saline prior to dressing

\begin{tabular}{ll}
\hline Outcomes & Intervention $1: 22 / 30$ \\
& Intervention 2: $23 / 30$ \\
\hline Notes & Funding type and details: not reported \\
& Notes: study was in 2 parts which actually form 2 different randomised trials
\end{tabular}


Blair 1988a (Continued)

Risk of bias

\begin{tabular}{lll}
\hline Bias & Authors' judgement & Support for judgement \\
\hline $\begin{array}{l}\text { Random sequence genera- } \\
\text { tion (selection bias) }\end{array}$ & Low risk & $\begin{array}{l}\text { Quote: "the ulcers were cleaned with saline and the dressing applied accord- } \\
\text { ing to randomisation using a sequential system of sealed envelopes with treat- } \\
\text { ment allocation by random number table" }\end{array}$ \\
& $\begin{array}{l}\text { Comment: an appropriate method for deriving the randomisation sequence } \\
\text { was reported }\end{array}$
\end{tabular}

$\begin{array}{ll}\begin{array}{l}\text { Allocation concealment } \\ \text { (selection bias) }\end{array} & \begin{array}{l}\text { Unclear risk } \\ \text { Quote: "the ulcers were cleaned with saline and the dressing applied accord- } \\ \text { ing to randomisation using a sequential system of sealed envelopes with treat- } \\ \text { ment allocation by random number table" }\end{array} \\ \text { Comment: unclear if the envelopes used were opaque }\end{array}$

Blinding of participants $\quad$ Unclear risk
and personnel (perfor-
mance bias)
All outcomes

\begin{tabular}{|c|c|c|}
\hline $\begin{array}{l}\text { Blinding of outcome as- } \\
\text { sessment (detection bias) } \\
\text { All outcomes }\end{array}$ & Unclear risk & Not reported \\
\hline
\end{tabular}

Incomplete outcome data Low risk Comment: all participants were included in the analysis
(attrition bias)

All outcomes

\begin{tabular}{lll}
\hline $\begin{array}{l}\text { Selective reporting (re- } \\
\text { porting bias) }\end{array}$ & Unclear risk & Comment: there was no evidence of selective reporting \\
\hline Other bias & High risk & $\begin{array}{l}\text { Comment: it is unclear how the randomisation was managed across the two } \\
\text { trials reported together }\end{array}$
\end{tabular}

\begin{tabular}{ll}
\hline All domain risk of bias $\quad$ High risk \\
\hline
\end{tabular}

\section{Blair 1988b}

\begin{tabular}{ll}
\hline Methods & RCT \\
Arms: 2 (see notes) \\
Unit of randomisation: participant \\
Unit of analysis: participant \\
Follow-up: 12 weeks \\
\hline Inclusion criteria: venous ulcers $<10 \mathrm{~cm}^{2}$ \\
Exclusion criteria: ABPI <0.8 on Doppler (arterial insufficiency) \\
Participant characteristics \\
Number participants: 120 \\
Age: 70.1 (42 to 90 ) vs 67.3 (36 to 86$)$ years
\end{tabular}


Blair 1988b (Continued)

\author{
$\%$ male: not reported
}

Ulcer details

Size: 3.8 (SEM 0.6) $\mathrm{cm}^{2}$ vs 3.4 (SEM 0.5) $\mathrm{cm}^{2}$

Duration 27.8 (SEM 3.4) months vs 33.4 (SEM 4.1)

Interventions
Intervention 1 details (name and details of application): manufactured by Johnson \& Johnson; no fur-
ther details
Intervention 2 class: SSD
Intervention 2 details (name and details of application): Flamazine (Smith \& Nephew); no further de-
tails
Compression: standard high-pressure graduated compression bandage 4 layers: Velband (Johnson \&
Johnson) + crepe bandage + Elset (Seton Products) + Coban (3M Health Care)
Other co-interventions: ulcers cleaned with saline prior to dressing

Outcomes Intervention 1:24/30

Intervention 3: 19/30

Notes

Funding type and details: not reported

Notes: Study was in 2 parts which actually form 2 different randomised trials

\title{
Risk of bias
}

\begin{tabular}{lll}
\hline Bias & Authors' judgement & Support for judgement \\
\hline $\begin{array}{l}\text { Random sequence genera- } \\
\text { tion (selection bias) }\end{array}$ & Low risk & $\begin{array}{l}\text { Quote: "the ulcers were cleaned with saline and the dressing applied accord- } \\
\text { ing to randomisation using a sequential system of sealed envelopes with treat- } \\
\text { ment allocation by random number table" }\end{array}$ \\
& $\begin{array}{l}\text { Comment: an appropriate method for deriving the randomisation sequence } \\
\text { was reported }\end{array}$ \\
\end{tabular}

\begin{tabular}{|c|c|c|}
\hline $\begin{array}{l}\text { Allocation concealment } \\
\text { (selection bias) }\end{array}$ & Unclear risk & $\begin{array}{l}\text { Quote: "the ulcers were cleaned with saline and the dressing applied accord- } \\
\text { ing to randomisation using a sequential system of sealed envelopes with treat- } \\
\text { ment allocation by random number table" } \\
\text { Comment: unclear if the envelopes used were opaque }\end{array}$ \\
\hline $\begin{array}{l}\text { Blinding of participants } \\
\text { and personnel (perfor- } \\
\text { mance bias) } \\
\text { All outcomes }\end{array}$ & Unclear risk & Not reported \\
\hline
\end{tabular}

\begin{tabular}{ll}
\hline Blinding of outcome as- & Unclear risk \\
sessment (detection bias) & \\
All outcomes & \\
\hline
\end{tabular}

Incomplete outcome data Low risk Comment: all participants were included in the analysis
(attrition bias)

(attrition bias)
All outcomes 
Blair 1988b (Continued)

Selective reporting (re- Unclear risk Comment: there was no evidence of selective reporting
porting bias)

\begin{tabular}{ll}
\hline Other bias $\quad$ High risk & $\begin{array}{l}\text { Comment: it is unclear how the randomisation was managed across the two } \\
\text { trials reported together }\end{array}$
\end{tabular}

All domain risk of bias High risk

\section{Bowszyc 1995}

\begin{tabular}{ll}
\hline Methods & RCT \\
& Arms: 2 \\
& Unit of randomisation: participant \\
& Unit of analysis: leg \\
& Follow-up: 16 weeks
\end{tabular}

\begin{tabular}{|c|c|}
\hline \multirow[t]{9}{*}{ Participants } & Inclusion criteria: chronic venous ulcer \\
\hline & $\begin{array}{l}\text { Exclusion criteria: } \mathrm{API}<0.8 \text { (arterial insufficiency), diabetes, heavily exuding wounds, necrotic tissue in } \\
\text { ulcer, clinically infected wound, general poor state of health, immunosuppressed, receiving corticos- } \\
\text { teroid treatment }\end{array}$ \\
\hline & Participant characteristics \\
\hline & Number participants: 80 \\
\hline & Age: $64.2(14.4)$ vs $55.5(14.7)$ years \\
\hline & \% male: 12 (29) vs 15 (37) \\
\hline & Ulcer details \\
\hline & Size: $3.95(6.89) \mathrm{cm}^{2}$ vs $3.47(7.76) \mathrm{cm}^{2}$ (total ulcer area) \\
\hline & Duration: 26.2 (37.6) vs 36.1 (70.9) weeks \\
\hline
\end{tabular}

Intervention 1 details (name and details of application): Lyofoam; changed weekly or when exudate leaked visibly through bandage

Intervention 2 class: hydrocolloid

Intervention 2 details (name and details of application): Granuflex; changed weekly or when exudate leaked visibly through bandage

Compression: high compression bandage (Setopress)

Other co-interventions: sloughy wounds treated with sodium chloride solution (Chlorasol) before entry to the study

Outcomes
Intervention 1: $24 / 41$
Intervention 2: $24 / 41$

Notes

Funding type: industry 
Notes: 2 participants had ulcers on both legs and analysis was by leg giving $n=82$

\section{Risk of bias}

Bias Authors' judgement Support for judgement

Random sequence genera- Unclear risk tion (selection bias)

Quote: "patients were allocated to treatment groups according to a pre-prepared randomisation listing"

Comment: unclear how the randomisation sequence was generated

\begin{tabular}{|c|c|c|}
\hline $\begin{array}{l}\text { Allocation concealment } \\
\text { (selection bias) }\end{array}$ & Unclear risk & $\begin{array}{l}\text { Quote: "patients were allocated to treatment groups according to a pre-pre- } \\
\text { pared randomisation listing" }\end{array}$ \\
\hline
\end{tabular}

Comment: unclear how allocation concealment was undertaken

\begin{tabular}{lll}
\hline $\begin{array}{l}\text { Blinding of participants } \\
\text { and personnel (perfor- }\end{array}$ & Unclear risk & Not reported \\
mance bias) & \\
All outcomes & \\
\hline $\begin{array}{l}\text { Blinding of outcome as- } \\
\text { sessment (detection bias) }\end{array}$ & Unclear risk & Not reported \\
All outcomes & &
\end{tabular}

\begin{tabular}{l}
\hline Incomplete outcome data Low risk 4 withdrew in each group for various reasons \\
(attrition bias) \\
All outcomes
\end{tabular}

Selective reporting (re- Low risk No evidence of selective reporting
porting bias)

\begin{tabular}{lll}
\hline Other bias & High risk & $\begin{array}{l}\text { There is uncertainty over the unit of analysis as participants/legs/ulcers re- } \\
\text { ferred to in different places, see notes }\end{array}$ \\
\hline All domain risk of bias & High risk & \\
\hline
\end{tabular}

Brandrup 1990

\begin{tabular}{ll}
\hline Methods & RCT \\
Arms: 2 & Unit of randomisation: participant \\
& Unit of analysis: participant \\
& Follow-up: 8 weeks \\
\hline Participants & Inclusion criteria: ulcers with area between $1 \mathrm{~cm}^{2}$ to $100 \mathrm{~cm}^{2}$, with lowest edge in lower two-thirds of \\
the lower leg and upper edge above the malleoli. Negative patch tests to the dressings \\
Exclusion criteria: not reported \\
Participant characteristics \\
Number participants: 43
\end{tabular}


Brandrup 1990 (Continued)

\author{
Age: 73 (14) vs $77(9)$ years \\ $\%$ male: 5 (31)vs 2 (13) \\ Ulcer details \\ Non VLU: $<25 \%$ mixed/arterial - 7 (16\%) arterial \\ Size: $13.7 \mathrm{~cm}^{2}(15.9)$ vs $11.1 \mathrm{~cm}^{2}(9.1)$ \\ Duration: median (range) 8 months ( 2 to 24 ) vs 5 months ( 1 to 68 )
}

\begin{tabular}{l} 
Interventions \\
Intervention 1 class: nonadherent \\
Intervention 1 details (name and details of application): occlusive zinc-oxide medicated dressing; Mez- \\
inc (Mölnlycke); applied to ulcer and $0.5 \mathrm{~cm}$ surrounding skin. Changed daily for first 14 days, then \\
every third day \\
Intervention 2 class: hydrocolloid \\
Intervention 2 details (name and details of application): Duoderm; applied to ulcer and $0.5 \mathrm{~cm}$ sur- \\
rounding skin. Changed daily for first 14 days, then every third day \\
Compression: compression bandage Dauerbinde (Lohmann) used on venous ulcers \\
Other co-interventions: loosely attached necrotic material removed and ulcers cleaned with $0.9 \%$ NaCl \\
at each dressing change. Absorbent material used on top of dressings for heavily discharging ulcers \\
Intervention 1: $4 / 22$ \\
Intervention 2: $4 / 21$ \\
\hline Outcomes \\
Funding type and details: not reported \\
Notes: baseline stats were given for completers ( $\mathrm{n}=16 \mathrm{vs} \mathrm{n}=15$ ). For participants with multiple ulcers, \\
all were treated but only largest was monitored.
\end{tabular}

\title{
Risk of bias
}

\section{Bias}

Authors' judgement Support for judgement

Random sequence genera- Unclear risk tion (selection bias)

Quote: "patients were consecutively matched in pairs within these two groups [venous and arterial]" "from sealed envelopes, each member of the pair was randomly allocated."

Comment: no information on how the randomisation sequence was generated

Allocation concealment Unclear risk
(selection bias)

Quote: "Patients were consecutively matched in pairs within these two groups (selection bias) [venous and arterial]" "from sealed envelopes, each member of the pair was randomly allocated."

Comment: no information on how allocation was concealed.

\begin{tabular}{lll}
\hline $\begin{array}{l}\text { Blinding of participants } \\
\text { and personnel (perfor- }\end{array}$ & Unclear risk & \\
mance bias) & \\
All outcomes & \\
\hline $\begin{array}{l}\text { Blinding of outcome as- } \\
\text { sessment (detection bias) }\end{array}$ & Unclear risk & Not reported \\
All outcomes & \\
\hline
\end{tabular}


Brandrup 1990 (Continued)

Incomplete outcome data High risk Data are only presented for completers (withdrawal $27 \%$ vs $29 \%$ for various (attrition bias) reasons)

All outcomes

Selective reporting (re- Low risk There was no evidence of selective reporting
porting bias)

\begin{tabular}{|c|c|c|}
\hline Other bias & Unclear risk & $\begin{array}{l}\text { Protocol was incorrectly followed in one participant. No other evidence of oth- } \\
\text { er sources of bias but reporting insufficient to be certain }\end{array}$ \\
\hline
\end{tabular}

All domain risk of bias High risk

Brown 2014

$\begin{array}{ll}\text { Methods } & \text { RCT } \\ \text { Arms: } 2 & \text { Unit of randomisation: participant } \\ & \text { Unit of analysis: participant } \\ & \text { Follow-up: } 12 \text { weeks (24 weeks but optional cross-over at 12) }\end{array}$

Participants

Inclusion criteria: chronic venous ulcer (confirmed with duplex or Doppler sonography and an$\mathrm{kle} /$ brachial arterial Doppler pressure index between 0.8 and 1.3), duration between 3 months and 5 years, size $5 \mathrm{~cm}^{2}$ to $40 \mathrm{~cm}^{2}$, viable wound bed with granulation tissue and no exposed muscle, tendon or bone

Exclusion criteria: ulcers of non-venous aetiology, signs of ulcer infection, medications and therapies inhibiting wound healing, uncontrolled diabetes, uncontrolled organ failure, active malignancies, pregnant or nursing women

Participant characteristics

Number participants: 121

Age: 65.5 (13.3) vs 70.1 (13.8) years

$\%$ male: 28 (46.7) vs $30(50.0)$

Ulcer details

Size: mean (SD) $13.7(8.2) \mathrm{cm}^{2}$ vs $13.4(9.0) \mathrm{cm}^{2}$

Duration: mean (SD) 18.9 months (16.0) vs 18.1 (15.3) months

Intervention 1 details (name and details of application): dressing $0.2 \mathrm{~cm}$ thick, cut to exact size and applied at baseline visit. Re-application only took place if it was completely absorbed

Intervention 2 class: mixed standard comparators

Intervention 2 details (name and details of application): Mepilex for exudative wounds or Mepitel for non-exudative (Molnlycke Healthcare); dressing changed at least twice weekly, debridement or cleansing with isotonic sodium chloride solution was performed as necessary

Compression: 4-layer bandaging system (Profore, Smith \& Nephew) from toe to knee 
Brown 2014 (Continued)

Other co-interventions: complete sharp or ultrasonic debridement of all non-viable tissue prior to initial dressing

\begin{tabular}{ll}
\hline Outcomes & Intervention 1: $10 / 60$ \\
& Intervention 2: $16 / 60$ \\
\hline Notes & Funding type: industry \\
& Funding details: Bayer Innovation GmbH \\
& Note: authors were contacted to confirm that compression treatment was applied equally to both \\
& groups
\end{tabular}

\section{Risk of bias}

\section{Bias}

Random sequence genera- Low risk tion (selection bias)

\section{Authors' judgement Support for judgement}

Quote: "the randomization list was generated by the Biometrical Department of Winicker Norimed GmbH"

Comment: appears to be appropriate computer-generated randomisation sequence

\begin{tabular}{ll}
\hline $\begin{array}{l}\text { Allocation concealment } \\
\text { (selection bias) }\end{array}$ & Low risk \\
& $\begin{array}{l}\text { Quote: "randomization numbers were assigned to eligible subjects in ascend- } \\
\text { ing order at each centre. Enrolment of subjects was competitive across all par- } \\
\text { ticipating centres" }\end{array}$ \\
$\begin{array}{l}\text { Comment: appears that central allocation will have ensured adequate con- } \\
\text { cealment. }\end{array}$
\end{tabular}

\begin{tabular}{|c|c|c|}
\hline $\begin{array}{l}\text { Blinding of participants } \\
\text { and personnel (perfor- } \\
\text { mance bias) } \\
\text { All outcomes }\end{array}$ & High risk & Trial was described as "open" \\
\hline $\begin{array}{l}\text { Blinding of outcome as- } \\
\text { sessment (detection bias) } \\
\text { All outcomes }\end{array}$ & High risk & Trial was described as "open" \\
\hline $\begin{array}{l}\text { Incomplete outcome data } \\
\text { (attrition bias) } \\
\text { All outcomes }\end{array}$ & Low risk & $\begin{array}{l}127 \text { entered study; } 121 \text { participants "randomised and treated at least once"; } \\
120 \text { analysed }\end{array}$ \\
\hline
\end{tabular}

\begin{tabular}{lll}
\hline $\begin{array}{l}\text { Selective reporting (re- } \\
\text { porting bias) }\end{array}$ & Low risk & No evidence of this \\
\hline Other bias & Low risk & No evidence of other bias \\
\hline All domain risk of bias & High risk & \\
\hline All domain risk of bias 2 & High risk & \\
\hline
\end{tabular}

Callam 1992

$\begin{array}{ll}\text { Methods } & \text { RCT } \\ \text { Arms: } 4 \text { (factorial design; participants also randomised to different types of bandaging) }\end{array}$


Callam 1992 (Continued)

Unit of randomisation: participant

Unit of analysis: participant

Follow-up: 12 weeks

Participants

Inclusion criteria: patients attending leg ulcer clinics with a VLU of at least 4 weeks duration

Exclusion criteria: Doppler ultrasound $\mathrm{ABPI}<0.8$; unable to walk; on waiting list for inpatient treatment; rheumatoid arthritis or diabetes; taking medication for venous disorders, e.g. Paroven, Trental, stanozolol

Participant characteristics

Number participants: 132

Age: 63 vs 64 years

$\%$ male: 30 (45) vs 29 (44)

Ulcer details

Size: $8.35 \mathrm{~cm}^{2}$ vs $10.87 \mathrm{~cm}^{2}$

Duration: 11.2 vs 11.7 months

Interventions
Intervention 1 class: foam
Intervention 2 class: nonadherent
Intervention 2 details (name and details of application): knitted viscose dressing (Tricotex)
Compression: factorial design - half participants randomised to elastic bandaging and half to non-elas-
tic bandaging
Other co-interventions: cleansed with water and if necessary loose debris and slough removed physi-
cally. If appropriate surrounding skin treated for dry eczema (Betnovate RD cream) or weeping eczema
(2\% aqueous eosin).

\begin{tabular}{ll}
\hline Outcomes & Intervention 1:31/66 \\
& Intervention 2: $23 / 66$ \\
\hline Notes & Funding type: industry \\
& Funding details: Smith and Nephew \\
\hline
\end{tabular}

\section{Risk of bias}

\begin{tabular}{lll}
\hline Bias & Authors' judgement & Support for judgement \\
\hline $\begin{array}{l}\text { Random sequence genera- } \\
\text { tion (selection bias) }\end{array}$ & Unclear risk & Study described as randomised - currently no additional information \\
\hline $\begin{array}{l}\text { Allocation concealment } \\
\text { (selection bias) }\end{array}$ & Unclear risk & Study described as randomised - currently no additional information \\
\hline $\begin{array}{l}\text { Blinding of participants } \\
\begin{array}{l}\text { and personnel (perfor- } \\
\text { mance bias) }\end{array}\end{array}$ & High risk & Study described as "open" \\
\end{tabular}


Callam 1992 (Continued)

All outcomes

\begin{tabular}{|c|c|c|}
\hline $\begin{array}{l}\text { Blinding of outcome as- } \\
\text { sessment (detection bias) } \\
\text { All outcomes }\end{array}$ & High risk & Study described as "open" \\
\hline $\begin{array}{l}\text { Incomplete outcome data } \\
\text { (attrition bias) } \\
\text { All outcomes }\end{array}$ & Low risk & All participants included in analysis \\
\hline $\begin{array}{l}\text { Selective reporting (re- } \\
\text { porting bias) }\end{array}$ & Low risk & No evidence of this \\
\hline Other bias & Low risk & No evidence of other bias \\
\hline All domain risk of bias & High risk & \\
\hline All domain risk of bias 2 & High risk & \\
\hline
\end{tabular}

\section{Caprio 1992}

$\begin{array}{ll}\text { Methods } & \text { RCT } \\ \text { Arms: } 2 \\ \text { Unit of randomisation: ulcer } \\ \text { Unit of analysis: ulcer } \\ \text { Follow-up: } 8 \text { weeks }\end{array}$

\section{Participants}

Inclusion criteria: clean leg ulcers of venous origin

Exclusion criteria: not reported

Participant characteristics

Number participants: 93 with 98 ulcers

Age: not reported

$\%$ male: not reported

Ulcer details

Size: not reported

Duration: not reported

Intervention 1 details (name and details of application): Duoderm E covered by gauze and cotton bandage

Intervention 2 class: collagen

Intervention 2 details (name and details of application): lyophilised collagen tablets covered by gauze and cotton bandage

Compression: not reported 
Caprio 1992 (Continued)

Other co-interventions: not reported

\begin{tabular}{|c|c|c|}
\hline Outcomes & \multicolumn{2}{|l|}{$\begin{array}{l}\text { Intervention 1: 25/47 } \\
\text { Intervention 2: 20/49 }\end{array}$} \\
\hline Notes & \multicolumn{2}{|c|}{$\begin{array}{l}\text { Funding type and details: not reported } \\
\text { Abstract only so information incomplete and numbers unclear }\end{array}$} \\
\hline \multicolumn{3}{|l|}{ Risk of bias } \\
\hline Bias & Authors' judgement & Support for judgement \\
\hline $\begin{array}{l}\text { Random sequence genera- } \\
\text { tion (selection bias) }\end{array}$ & Unclear risk & $\begin{array}{l}\text { Quote "ulcers were randomised" } \\
\text { Comment: no information on how the randomisation sequence was generated }\end{array}$ \\
\hline $\begin{array}{l}\text { Allocation concealment } \\
\text { (selection bias) }\end{array}$ & Unclear risk & $\begin{array}{l}\text { Quote "ulcers were randomised" } \\
\text { Comment: no information on how allocation was concealed }\end{array}$ \\
\hline $\begin{array}{l}\text { Blinding of participants } \\
\text { and personnel (perfor- } \\
\text { mance bias) } \\
\text { All outcomes }\end{array}$ & Unclear risk & Not reported \\
\hline
\end{tabular}

\begin{tabular}{|c|c|c|}
\hline $\begin{array}{l}\text { Blinding of outcome as- } \\
\text { sessment (detection bias) } \\
\text { All outcomes }\end{array}$ & Unclear risk & $\begin{array}{l}\text { Quote: "a clinical examination was made" } \\
\text { Comment: no information on who made the assessment and whether they } \\
\text { were blinded to treatment allocation }\end{array}$ \\
\hline $\begin{array}{l}\text { Incomplete outcome data } \\
\text { (attrition bias) } \\
\text { All outcomes }\end{array}$ & Low risk & All ulcers were included in the analysis \\
\hline $\begin{array}{l}\text { Selective reporting (re- } \\
\text { porting bias) }\end{array}$ & Unclear risk & Insufficient reporting to be certain whether this was an issue \\
\hline Other bias & Unclear risk & Insufficient reporting to be certain whether this was an issue \\
\hline All domain risk of bias & Low risk & low/unclear \\
\hline
\end{tabular}

Casoni 2002

\begin{tabular}{ll}
\hline Methods & RCT \\
& Arms: 2 \\
& Unit of randomisation: participant \\
& Unit of analysis: participant \\
& Follow-up: 3 months \\
\hline Participants & Inclusion criteria: non-healing vascular leg ulcers (failed to reduce by $10 \%$ after 4 weeks conventional \\
& treatment)
\end{tabular}


Casoni 2002 (Continued)

Exclusion criteria: diabetes, severe peripheral atherosclerotic disease with $\mathrm{ABP}<0.6$, severe chronic cardiac or hepatic failure, nephrotic syndrome

Participant characteristics

Number participants: 65

Age: not reported

$\%$ male: not reported

Ulcer details

Size: not reported

Duration: not reported

Intervention 1 class: hyaluronic acid plus povidone iodine
Intervention 1 details (name and details of application): occlusive dressing with hyaluronic acid and
povidone iodine
Intervention 2 class: nonadherent
Intervention 2 details (name and details of application): no details
Compression: Unna bandage changed weekly
Other co-interventions: not reported

Outcomes

Intervention 1: 15/32

Intervention 2: 8/33

Notes

Funding type and details: not reported

Abstract only so information incomplete

\section{Risk of bias}

\begin{tabular}{|c|c|c|}
\hline Bias & Authors' judgement & Support for judgement \\
\hline \multirow[t]{2}{*}{$\begin{array}{l}\text { Random sequence genera- } \\
\text { tion (selection bias) }\end{array}$} & Unclear risk & $\begin{array}{l}\text { Quote: "65 homogeneous [sic] cases with non-healing vascular leg ulcers were } \\
\text { randomized } 4 \text { weeks after conventional treatment" }\end{array}$ \\
\hline & & Comment: no information on how the randomisation sequence was generated \\
\hline \multirow[t]{2}{*}{$\begin{array}{l}\text { Allocation concealment } \\
\text { (selection bias) }\end{array}$} & Unclear risk & $\begin{array}{l}\text { Quote: "65 homogeneous [sic] cases with non-healing vascular leg ulcers were } \\
\text { randomized } 4 \text { weeks after conventional treatment" }\end{array}$ \\
\hline & & Comment: no information on how allocation was concealed \\
\hline
\end{tabular}

Blinding of participants Unclear risk No information was reported on blinding
and personnel (perfor-
mance bias)

Blinding of outcome as- Unclear risk sessment (detection bias)

All outcomes
Quote: "The main end point for this trial was the time to complete healing, anyway a comparison of images and of life tables up to 3 months of treatment was done."

Comment: no information on who performed the outcome assessment or whether they were blinded to treatment allocation 
Casoni 2002 (Continued)

Incomplete outcome data Unclear risk Quote: "Results: At the end of the study 48\% of patients treated with occlusive (attrition bias) dressing and $24 \%$ to an NA pancement [sic] had completely healed.

All outcomes

Comment: Reporting was insufficient to be sure whether all participants were included in the analysis

\section{Selective reporting (re- Unclear risk $\quad$ Reporting was insufficient to know whether this was an issue} porting bias)

$\begin{array}{ll}\text { Other bias } \quad \text { Unclear risk } & \begin{array}{l}\text { Reporting was insufficient to know whether there were additional sources of } \\ \text { potential bias }\end{array}\end{array}$
potential bias

All domain risk of bias Low risk Low/unclear

Charles 2002

$\begin{array}{ll}\text { Methods } & \text { RCT } \\ \text { Arms: } 3 \\ \text { Unit of randomisation: participant } \\ \text { Unit of analysis: participant } \\ \text { Follow-up: } 12 \text { weeks }\end{array}$

Participants Inclusion criteria: ambulatory participants with venous leg ulcer $2 \mathrm{~cm}$ to $12 \mathrm{~cm}$ at widest perpendicular diameter, $\mathrm{ABPI}>$ or $=0.8$

Exclusion criteria: corticosteroid treatment within last 2 months, insulin-dependent diabetics, allergy to test product, history of radiation or cytotoxic treatment near ulcer site, primary arterial occlusive disease, HIV+, registered alcoholic, unlikely to comply with treatment/follow-up

Participant characteristics

Number participants: 91

Age: mean (range) $71(53-84)$ vs $72(53-91)$ vs $72(56-85)$ years

$\mathrm{N}(\%)$ male: 15 (48) vs $12(39)$ vs $13(45)$

Ulcer details

Size: mean (range) 881 (271 to 3182 ) $\mathrm{mm}^{2}$ vs 930 (234 to 3642) mm² vs 1035 (205 to 3795 ) mm²

Duration: mean (range) 137 (4 to 1560) vs 95 ( 1 to 1560 ) vs 104 ( 3 to 1040) weeks

Intervention 1 class: foam
Intervention 1 details (name and details of application): Cutinova; applied according to manufacturer's
instructions and changed as frequently as necessary
Intervention 2 class: hydrocolloid
Intervention 2 details (name and details of application): Granuflex new formulation; applied according
to manufacturer's instructions and changed as frequently as necessary
Intervention 3 class: hydrocolloid
Intervention 3 details (name and details of application): Comfeel; applied according to manufacturer's
instructions and changed as frequently as necessary


Other co-interventions: secondary dressing of padding on bony prominences

\begin{tabular}{|c|c|c|}
\hline Outcomes & \multicolumn{2}{|l|}{$\begin{array}{l}\text { Intervention 1: 18/31 } \\
\text { Intervention 2: } 17 / 31 \\
\text { Intervention 3: } 17 / 29\end{array}$} \\
\hline Notes & \multicolumn{2}{|c|}{$\begin{array}{l}\text { Funding type: industry } \\
\text { Funding details: Biersdorf UK (BSN Medical) }\end{array}$} \\
\hline \multicolumn{3}{|l|}{ Risk of bias } \\
\hline Bias & Authors' judgement & Support for judgement \\
\hline $\begin{array}{l}\text { Random sequence genera- } \\
\text { tion (selection bias) }\end{array}$ & Unclear risk & $\begin{array}{l}\text { Quote: "patients were randomly allocated ... using a minimisation method de- } \\
\text { rived from that of Pocock and Simon (1976)" } \\
\text { Comment: insufficient information on how the randomisation sequence was } \\
\text { generated. }\end{array}$ \\
\hline $\begin{array}{l}\text { Allocation concealment } \\
\text { (selection bias) }\end{array}$ & Unclear risk & $\begin{array}{l}\text { Quote: "patients were randomly allocate ... using a minimisation method de- } \\
\text { rived from that of Pocock and Simon (1976)" } \\
\text { Comment: insufficient information on how allocation concealment was } \\
\text { achieved }\end{array}$ \\
\hline $\begin{array}{l}\text { Blinding of participants } \\
\text { and personnel (perfor- } \\
\text { mance bias) } \\
\text { All outcomes }\end{array}$ & Unclear risk & No information was reported on blinding \\
\hline $\begin{array}{l}\text { Blinding of outcome as- } \\
\text { sessment (detection bias) } \\
\text { All outcomes }\end{array}$ & Unclear risk & No information was reported on blinding \\
\hline $\begin{array}{l}\text { Incomplete outcome data } \\
\text { (attrition bias) } \\
\text { All outcomes }\end{array}$ & Unclear risk & $\begin{array}{l}\text { Comment: } 7 \% \text { withdrawal but all included in analysis; some slight imbalance } \\
\text { between groups but unclear whether this was sufficient to impact analysis }\end{array}$ \\
\hline $\begin{array}{l}\text { Selective reporting (re- } \\
\text { porting bias) }\end{array}$ & Low risk & Comment: no evidence of selective reporting \\
\hline Other bias & Low risk & Comment: no evidence of other sources of bias; extensive reporting \\
\hline All domain risk of bias & Low risk & Low/unclear \\
\hline
\end{tabular}

De Araujo 2016

\begin{tabular}{ll}
\hline Methods & RCT \\
Arms: 3 \\
Unit of randomisation: participant \\
Unit of analysis: ulcer \\
\hline
\end{tabular}


De Araujo 2016 (Continued)

Follow-up: 60 days

Participants

Inclusion criteria: chronic venous ulcer $>5 \mathrm{~cm}^{2}$, wound bed with devitalised tissues, no use of venonic drugs or active topical agents for prior 2 weeks

Exclusion criteria: severely infected ulcer (criteria given) arterial or mixed aetiology, $A B I<0.9$ or chronic ulcer of other aetiology, pregnancy or breastfeeding

Participant characteristics

Number participants: 55 with 63 ulcers

Age: median (range) 62 (28 to 85$)$ for all participants years

$\%$ male: 12 (57) vs 8 (42) vs $11(48)$

Ulcer details

Size: data presented on a graph only

Duration: mean (SD) 62.9 (2.9) vs 57.9 (3.4) vs 63.9 (3.5) months

Interventions

Intervention 1 class: blood product

Intervention 1 details (name and details of application): fibrin gel; gel prepared from pool of 5 cryoprecipitate units, $100 \mathrm{I} / \mathrm{mL}$ purified human thrombin cryoprecipitate, $6 \%$ vitamin $\mathrm{A}$ and $\mathrm{E}, 5 \%$ calcium gluconate in carbopol gel; participants received pack and instructions and followed up every 15 days

Intervention 2 class: papain

Intervention 2 details (name and details of application): papain gel; $8 \%$ papain in carbopol gel; participants received pack and instructions and followed up every 15 days

Intervention 3 class: placebo

Intervention 3 details (name and details of application): carbopol gel (carrier vehicle used for the other interventions); participants received pack and instructions and followed up every 15 days

Compression: Compressive elastic bandage (Surepress)

Other co-interventions: wound bed flushed with warm $0.9 \%$ saline at dressing changes

$\begin{array}{ll}\text { Outcomes } & \text { Intervention } 1: 3 / 21 \\ & \text { Intervention } 2: 4 / 19 \\ & \text { Intervention } 3: 7 / 23\end{array}$

Notes

Funding type: non-industry

Funding details: funded by Botucatu Medical School, and Boston Medical Device donated high compression bandages.

\section{Risk of bias}

\begin{tabular}{lll}
\hline Bias & Authors' judgement & Support for judgement \\
\hline $\begin{array}{l}\text { Random sequence genera- } \\
\text { tion (selection bias) }\end{array}$ & Low risk & $\begin{array}{l}\text { Quote "randomization protocol was based on numbers randomly generated } \\
\text { by software" } \\
\text { Comment: appropriate method of randomisation sequence generation }\end{array}$ \\
\hline $\begin{array}{l}\text { Allocation concealment } \\
\text { (selection bias) }\end{array}$ & Low risk & $\begin{array}{l}\text { Quote: "the pharmacist ... prepared all the products which were numbered } \\
\text { and similar in appearance and presentation. The pharmacist kept the en- }\end{array}$ \\
\hline
\end{tabular}


De Araujo 2016 (Continued)

velopes and the randomization list. The investigators were unblinded only by the end of the study"

Comment: appears that allocation concealment was adequate

$\begin{array}{ll}\begin{array}{l}\text { Blinding of participants } \\ \text { and personnel (perfor- }\end{array} & \begin{array}{l}\text { Quote: "the pharmacist ... prepared all the products which were numbered } \\ \text { and similar in appearance and presentation. The pharmacist kept the en- } \\ \text { mance bias) }\end{array} \\ \begin{array}{ll}\text { All outcomes } & \text { velopes and the randomization list. The investigators were unblinded only by } \\ \text { the end of the study" }\end{array}\end{array}$

Comment: appears that both personnel and participants were blinded to treatment allocation

\begin{tabular}{|c|c|c|}
\hline $\begin{array}{l}\text { Blinding of outcome as- } \\
\text { sessment (detection bias) } \\
\text { All outcomes }\end{array}$ & Low risk & $\begin{array}{l}\text { Quote: "the investigators were unblinded only by the end of the study" } \\
\text { Comment: presume this means they were blinded for duration of study includ- } \\
\text { ing for outcome assessment }\end{array}$ \\
\hline $\begin{array}{l}\text { Incomplete outcome data } \\
\text { (attrition bias) } \\
\text { All outcomes }\end{array}$ & Low risk & Quote: "no dropouts, data presented for all" \\
\hline $\begin{array}{l}\text { Selective reporting (re- } \\
\text { porting bias) }\end{array}$ & Low risk & Comment: no evidence of selective reporting \\
\hline Other bias & Low risk & Comment: no evidence of other bias; adequate reporting \\
\hline All domain risk of bias & Low risk & \\
\hline
\end{tabular}

Dereure 2012a

$\begin{array}{ll}\text { Methods } & \text { RCT } \\ \text { Arms: } 2 \\ \text { Unit of randomisation: participant } \\ \text { Unit of analysis: participant } \\ \text { Follow-up: } 60 \text { days }\end{array}$

Participants

Inclusion criteria: in- or outpatient with at least one leg ulcer of venous or mixed aetiology of 2 months to 4 years duration, surface area $5 \mathrm{~cm}^{2}$ to $40 \mathrm{~cm}^{2}$ with no necrotic tissue, suitability to and use of compression therapy, $\mathrm{ABPI}>0.8$, albuminaemia $>25 \mathrm{~g} / \mathrm{L}$, history of DVT or clinical evidence of post-thrombotic syndrome or Doppler evidence of residual thrombosis or a reflux on the venous system. If more than one ulcer, target ulcer selected as best meeting inclusion criteria

Exclusion criteria: ulcer of non-vascular origin or due to general cause, significant arterial insufficiency (ABPI < 0.8), clinical suspicion of infection, hepatic or renal failure, venous thrombosis within previous 3 months, diabetes, allergy to local anaesthetic or study treatment, treatment that delays healing process

Participant characteristics

Number participants: 101 (multiple ulcers, one selected per participant)

Age: 68.6 (12.4) vs $69.7(14.7)$ years

$\mathrm{N}(\%)$ male: 23 (46) vs $22(43)$ 
Dereure 2012a (Continued)

Ulcer details

Non VLU: not clearly reported how many had mixed aetiology

Size: median (range) 11.1 (2.8 to 39.3$) \mathrm{cm}^{2}$ vs 11.7 (3.67 to 41.1 ) $\mathrm{cm}^{2}$

Duration: median (range) 7.5 ( 1 to 48 ) months vs 9.0 (2 to 42 ) months

Interventions

Intervention 1 class: hyaluronic acid

Intervention 1 details (name and details of application): Ialuset cream (Laboratoires Genevrier); applied daily, in a $2 \mathrm{~mm}$ to $3 \mathrm{~mm}$-thick layer, then covered with a bandage (grade 2 or 3 ) in accordance with standard care

Intervention 2 class: placebo

Intervention 2 details (name and details of application): same formulation as laluset cream without hyaluronic acid (Laboratoires Genevrier); applied daily, in a $2 \mathrm{~mm}$ to $3 \mathrm{~mm}$-thick layer, then covered with a bandage (grade 2 or 3 ) in accordance with standard care

Compression: type 2 long-stretch elastic (90\% participants) or multilayer bandages

Other co-interventions: systemic antibiotics could be used if clinically relevant infection

\begin{tabular}{ll}
\hline Outcomes & Intervention $1: 3 / 50$ \\
& Intervention 2: $4 / 51$ \\
\hline Notes & Funding type: industry \\
& Funding details: Laboratoires Genevrier \\
\hline
\end{tabular}

\section{Risk of bias}

\begin{tabular}{lll}
\hline Bias & Authors' judgement & Support for judgement \\
\hline $\begin{array}{l}\text { Random sequence genera- } \\
\text { tion (selection bias) }\end{array}$ & Low risk & $\begin{array}{l}\text { Quote: "the randomisation list was generated by a computer and prepared by } \\
\text { the data management and statistics unit of IBSA using validated software" }\end{array}$ \\
& $\begin{array}{l}\text { Comment: an appropriate method was used to generate the randomisation se- } \\
\text { quence }\end{array}$ \\
\hline
\end{tabular}

Allocation concealment Unclear risk Quote: "the randomisation list was generated by a computer and prepared by (selection bias) the data management and statistics unit of IBSA using validated software"

Comment: not clear how allocation concealment was ensured although remote management of randomisation suggests it may have been adequate

$\begin{array}{ll}\begin{array}{l}\text { Blinding of participants } \\ \text { and personnel (perfor- } \\ \text { mance bias) }\end{array} & \begin{array}{l}\text { Quote: "both treatments were supplied in the same form, external packaging, } \\ \text { shape, odour and texture, in order to maintain the double blinding" }\end{array} \\ \text { All outcomes } & \text { Comment: effective double-blinding }\end{array}$

\begin{tabular}{|c|c|c|}
\hline $\begin{array}{l}\text { Blinding of outcome as- } \\
\text { sessment (detection bias) } \\
\text { All outcomes }\end{array}$ & Low risk & $\begin{array}{l}\text { Quote: "treatment allocation and evaluation were assessed by a blinded physi- } \\
\text { cian" }\end{array}$ \\
\hline
\end{tabular}

$\begin{array}{ll}\begin{array}{l}\text { Incomplete outcome data } \\ \text { (attrition bias) }\end{array} & \text { Low risk } \\ \begin{array}{ll}\text { All outcomes } & \text { Quote: "The primary analysis was conducted on an intention-to-treat (ITT) ba- } \\ \text { sis on all randomised patients who received, at least once, the allocated treat- } \\ \text { ments. }\end{array}\end{array}$

All outcomes ments.

Comment: ITT analysis - 0 patients received no treatments 
Dereure 2012a (Continued)

Selective reporting (re- Low risk No evidence of selective reporting
porting bias)

\begin{tabular}{|c|c|c|}
\hline Other bias & Unclear risk & $\begin{array}{l}\text { Quote: "in patients with multiple ulcers, only one ulcer was selected by the in- } \\
\text { vestigator (on the basis that it complied best with the inclusion criteria)" }\end{array}$ \\
\hline & & $\begin{array}{l}\text { Comment: if allocation concealment/blinding was effective this would not } \\
\text { present a risk, allocation concealment has an unclear risk of bias, however }\end{array}$ \\
\hline All domain risk of bias & Low risk & Low/unclear \\
\hline
\end{tabular}

Dimakakos 2009

$\begin{array}{ll}\text { Methods } & \text { RCT } \\ \text { Arms: } 2 \\ \text { Unit of randomisation: participant } \\ \text { Unit of analysis: participant } \\ \text { Follow-up: } 9 \text { weeks }\end{array}$

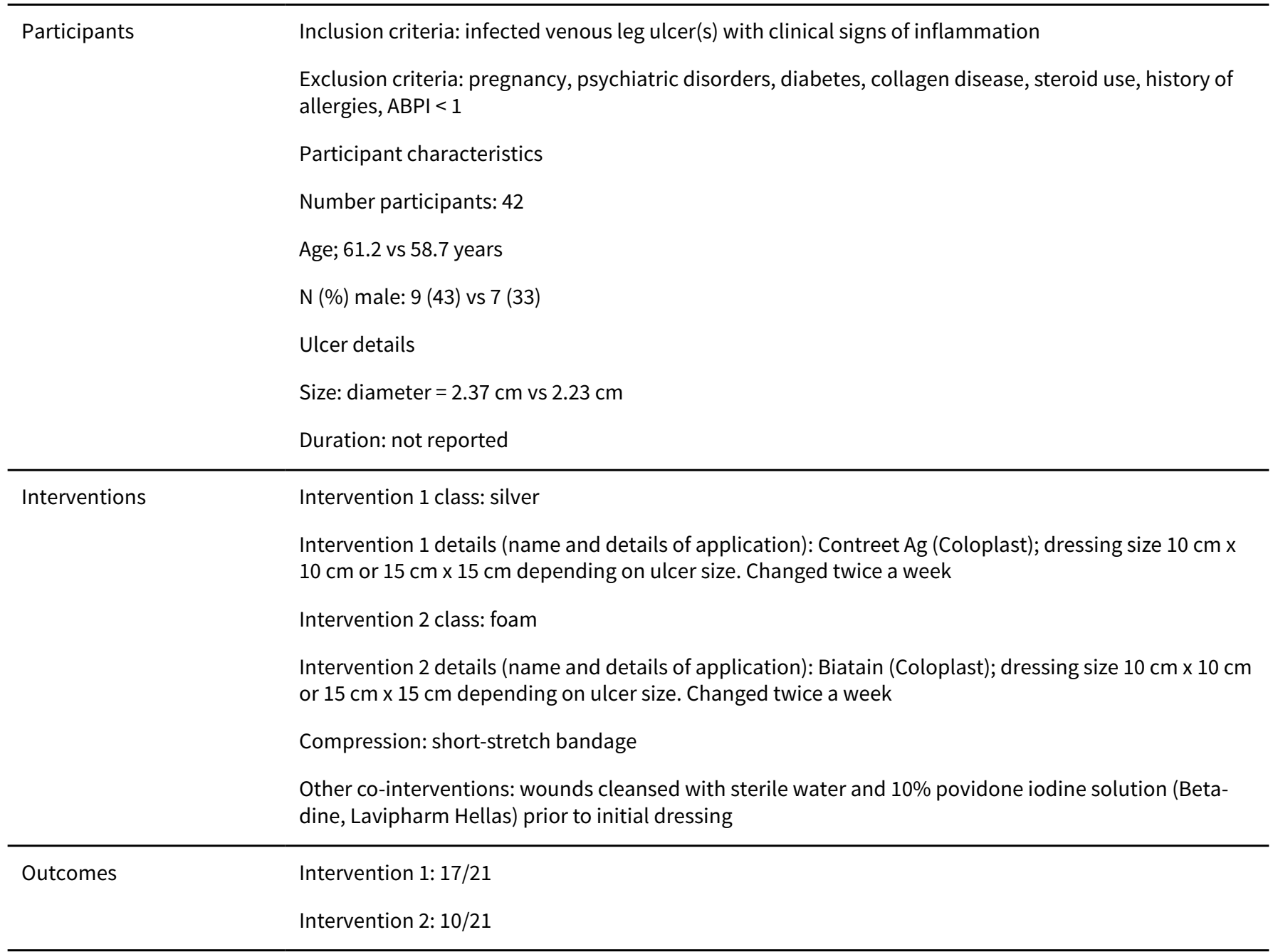


Dimakakos 2009 (Continued)

Notes Funding type and details: not reported

\section{Risk of bias}

Bias Authors' judgement Support for judgement

Random sequence genera- Unclear risk
tion (selection bias)

Quote: "forty-two patients were included in the study and were randomized into two groups."

Comment: unclear whether an appropriate method was used to generate the randomisation sequence

\begin{tabular}{|c|c|c|}
\hline $\begin{array}{l}\text { Allocation concealment } \\
\text { (selection bias) }\end{array}$ & Unclear risk & $\begin{array}{l}\text { Quote: "forty-two patients were included in the study and were randomized in- } \\
\text { to two groups." } \\
\text { Comment: unclear whether an appropriate method was used to ensure alloca- } \\
\text { tion concealment }\end{array}$ \\
\hline $\begin{array}{l}\text { Blinding of participants } \\
\text { and personnel (perfor- } \\
\text { mance bias) } \\
\text { All outcomes }\end{array}$ & Unclear risk & Not reported \\
\hline $\begin{array}{l}\text { Blinding of outcome as- } \\
\text { sessment (detection bias) } \\
\text { All outcomes }\end{array}$ & Unclear risk & Not reported \\
\hline $\begin{array}{l}\text { Incomplete outcome data } \\
\text { (attrition bias) } \\
\text { All outcomes }\end{array}$ & Low risk & All participants were included in the analysis \\
\hline $\begin{array}{l}\text { Selective reporting (re- } \\
\text { porting bias) }\end{array}$ & Low risk & There was no evidence of selective outcome reporting \\
\hline Other bias & Unclear risk & $\begin{array}{l}\text { There was no evidence of other sources of bias but reporting was not sufficient } \\
\text { to be certain. }\end{array}$ \\
\hline All domain risk of bias & Low risk & Low/unclear \\
\hline
\end{tabular}

Fogh 2012

\begin{tabular}{ll}
\hline Methods & RCT \\
Arms: 2 \\
Unit of randomisation: participant \\
Unit of analysis: participant \\
Follow-up: 6 weeks
\end{tabular}

Participants

Inclusion criteria: moderately to highly exuding, painful (at least 4 on 11 point scale) VLU on lower limb. Duration $>8$ weeks, $A B I>0.8$, size $1.6 \mathrm{~cm}$ to $11 \mathrm{~cm}$ in any direction. Treated with moist wound-healing dressings and compression for 2 weeks prior

Exclusion criteria: use of per need medication in 3 days prior, painful ulcer resistant to analgesics for 6 months, hypersensitivity to study products, infection, vasculitis, erysipelas, cellulitis, contraindica- 
Fogh 2012 (Continued)

tion to analgesics, diabetes, use of systemic antibiotics corticosteroids, immunosuppressants cancer chemotherapy, pregnancy or lactation

Participant characteristics

Number participants: 120

Age: $71.6(12.8)$ vs $69.5(12.5)$ years

$\%$ male: 18 (30) vs $20(33)$

Ulcer details

Size: mean (SD) $9.1(10.9) \mathrm{cm}^{2}$ vs $12.2(9.4) \mathrm{cm}^{2}$, median (range) 4.82 (1.09 to 57.6$) \mathrm{cm}^{2}$ vs 8.18 (0.93 to $40.1) \mathrm{cm}^{2}$

Duration: mean (SD) 1.5 (3.0) vs 11.5 (2.5) years

Intervention 1 details (name and details of application): Biatain Ibu Non-Adhesive (Coloplast) [foam] Intervention 2 class: foam

Intervention 2 details (name and details of application); Biatain Non-Adhesive (Coloplast)

Compression: use of compression mandatory, appropriate compression selected by investigator.

No change in compression type during first 5 days of study. Actual compression used included short stretch ( $48 \%$ vs $50 \%)$, long stretch ( $32 \%$ vs $42 \%)$, 4 layer ( $5 \%$ vs $0 \%$ ), other mainly compression stockings ( $15 \%$ vs $8 \%)$

Other co-interventions: not reported

\begin{tabular}{ll}
\hline Outcomes & Intervention 1: $9 / 60$ \\
& Intervention 2: 11/60 \\
\hline Notes & Funding type: industry \\
& Funding details: Coloplast
\end{tabular}

\section{Risk of bias}

Bias Authors' judgement Support for judgement

Random sequence genera- Low risk tion (selection bias)
Quote: "by using the IVRS, the subjects were centrally randomized and allocated to one of the two treatment groups."

Comment: external company randomised participants centrally using interactive voice response system. Stratification by pain intensity

Allocation concealment Low risk
(selection bias)

Quote: "by using the IVRS, the subjects were centrally randomized and allocated to one of the two treatment groups."

Comment: appropriate methods to ensure allocation concealment

\begin{tabular}{|c|c|c|}
\hline $\begin{array}{l}\text { Blinding of participants } \\
\text { and personnel (perfor- } \\
\text { mance bias) } \\
\text { All outcomes }\end{array}$ & Low risk & $\begin{array}{l}\text { Quote: "therefore, allocation of treatment to each patient was blinded to the } \\
\text { clinicians, the patient, and the sponsor." } \\
\text { Comment: blinding of relevant groups }\end{array}$ \\
\hline $\begin{array}{l}\text { Blinding of outcome as- } \\
\text { sessment (detection bias) }\end{array}$ & Low risk & $\begin{array}{l}\text { Quote: "the ulcer margins were traced on wound tracing sheets and ulcer area } \\
\text { and perimeter were calculated at Coloplast A/S" }\end{array}$ \\
\hline
\end{tabular}


Fogh 2012 (Continued)

All outcomes

Incomplete outcome data High risk Comment: $12 / 60$ vs $15 / 60$ withdrawals, reasons given but a high number
(attrition bias)

All outcomes

\begin{tabular}{lll}
\hline $\begin{array}{l}\text { Selective reporting (re- } \\
\text { porting bias) }\end{array}$ & Low risk & Comment: no evidence of selective reporting \\
\hline Other bias & Low risk & $\begin{array}{l}\text { Comment: no evidence of other sources of bias and reporting sufficient to be } \\
\text { reasonably confident }\end{array}$ \\
\hline
\end{tabular}

All domain risk of bias High risk

\section{Gottrup 2008}

$\begin{array}{ll}\text { Methods } & \text { RCT } \\ & \text { Arms: } 2 \\ & \text { Unit of randomisation: participant } \\ & \text { Unit of analysis: participant } \\ \text { Follow-up: } 42 \text { days }\end{array}$

Participants

Inclusion criteria: painful chronic venous leg ulcer $>8$ weeks duration, diagnosis based on $A B P I>0.8$, duplex scan/phlebography, clinical diagnosis, toe pressure and palpable foot pulse. Minimum length $1.6 \mathrm{~cm}$, maximum area $50 \mathrm{~cm}^{2}$. Minimum moderate pain score on 5-point verbal rating scale

Exclusion criteria: painful ulcers resistant to analgesic treatment for $6+$ months, pregnant or lactating women, clinical infection, local infection or bacterial imbalance, vasculitis, allergy to ibuprofen or related analgesics, history of asthma, rhinitis or urticaria, diabetes, use of various medications

Participant characteristics

Number participants:122

Age: 66.0 (14.8) vs 70.0 (11.7) years

$\%$ male: 19 (31) vs 23 (38)

Ulcer details

Size: mean (SD) $11.0(9.6) \mathrm{cm}^{2}$ vs $7.3(5.7) \mathrm{cm}^{2}$

Duration: mean (SD) 23.1 (42.9) months vs 19.8 (41.8) months

Intervention 1 details (name and details of application): Biatain-Ibu Non-Adhesive foam dressing (Coloplast A/S); dressing changed every 48 hours

Intervention 2 class: foam

Intervention 2 details (name and details of application): Biatain Non-Adhesive (Coloplast A/S); dressing changed every 48 hours

Compression: compression use required for 2 weeks prior to inclusion and throughout study period. Same compression to be used throughout and to keep a constant circumference at the ankle 
Gottrup 2008 (Continued)

Other co-interventions: not reported

\begin{tabular}{ll}
\hline Outcomes & Intervention $1: 8 / 62$ \\
& Intervention 2: $8 / 60$ \\
\hline Notes & Funding type: industry \\
& Funding details: Coloplast A/S \\
\hline
\end{tabular}

\section{Risk of bias}

Bias Authors' judgement Support for judgement

Random sequence genera- Unclear risk tion (selection bias)

Quote: "randomization in closed envelopes took place after inclusion and before study initiation. The patients were randomized 1:1 either to the ibuprofen-foam group or to the comparator group. Block randomization was applied in blocks of 4."

Comment: unclear how the blocked randomisation sequence was generated

\begin{tabular}{ll}
\hline $\begin{array}{l}\text { Allocation concealment } \\
\text { (selection bias) }\end{array}$ & $\begin{array}{l}\text { Quote: "randomization in closed envelopes took place after inclusion and be- } \\
\text { fore study initiation ... The randomization was carried out before packaging of } \\
\text { the products, which were packed and labelled specifically for each patient due } \\
\text { to the blinding." }\end{array}$ \\
& Comment: not completely clear how allocation concealment was achieved
\end{tabular}

\begin{tabular}{|c|c|c|}
\hline $\begin{array}{l}\text { Blinding of participants } \\
\text { and personnel (perfor- } \\
\text { mance bias) } \\
\text { All outcomes }\end{array}$ & Low risk & $\begin{array}{l}\text { Quote: "study personnel and patients were blind to treatment" "both dress- } \\
\text { ings were specially designed for this double-blind study to be anonymous with } \\
\text { the use of top-films without any print" } \\
\text { Comment: blinding of these groups recorded. }\end{array}$ \\
\hline $\begin{array}{l}\text { Blinding of outcome as- } \\
\text { sessment (detection bias) } \\
\text { All outcomes }\end{array}$ & Low risk & $\begin{array}{l}\text { Quote: "the ulcer area was assessed with wound tracings of the ulcer margins } \\
\text { at baseline, at days } 15,29 \text {, and at day } 42 \text {. Wound healing was also tested using } \\
\text { a linear healing parameter" } \\
\text { Comment: it was not clear who performed the outcome assessment but since } \\
\text { personnel were blinded it was likely to have been a blinded assessment }\end{array}$ \\
\hline
\end{tabular}

Incomplete outcome data High risk
(attrition bias)

Quote: "there were 29 dropouts: 16 in the ibuprofen-foam group and 13 in the comparator group"; at 42 day crossover point these numbers were 15 vs 11

All outcomes

Comment: there were a substantial number of dropouts who were not included in the analysis

\begin{tabular}{lll}
\hline $\begin{array}{l}\text { Selective reporting (re- } \\
\text { porting bias) }\end{array}$ & Low risk & Comment: there was no evidence of selective reporting of outcomes \\
\hline Other bias & Low risk & $\begin{array}{l}\text { Comment: there was no evidence of other bias and reporting was sufficient to } \\
\text { be reasonably confident }\end{array}$ \\
\hline
\end{tabular}

All domain risk of bias High risk

\section{Greguric 1994}

Methods RCT


Greguric 1994 (Continued)

Arms: 2

Unit of randomisation: participant

Unit of analysis: participant

Follow-up: until healing or 10 dressings used but dressing changes were at different frequencies in the two groups ( 2.10 days vs 1.01 days)

Participants

Inclusion criteria: venous ulcer $2.5 \mathrm{~cm}$ to $5 \mathrm{~cm}$ diameter. Diagnosis based on medical history and ABPI > or $=0.9$

Exclusion criteria: ulcer due to arterial insufficiency, rheumatoid arthritis, sickle cell disease, known sensitivity to treatment materials, malignant ulcers, malignant disease including use of antineoplastic agents, corticosteroid treatment $>5 \mathrm{mg}$ prednisolone daily, immune deficiency, use of immune suppressive drugs, pregnancy, conditions causing abnormal wound healing, those better treated by alternative regimen

Participant characteristics

Number participants: 110

Age: 61 (15) vs 61 (13) years

$\%$ male: 21 (38) vs 24 (44)

Ulcer details

Size: not reported

Duration: median (95\% central range) 1737 (15902) days vs 1987 (12218) days

Intervention 1 details (name and details of application): Varihesive $\mathrm{E} ; 10 \mathrm{~cm} \times 10 \mathrm{~cm}$ dressing. Held in place with tubular gauze over lower leg. Changed before the softened area reached the edge of the dressing or when leakage occurred

Intervention 2 class: magnesium sulphate paste

Intervention 2 details (name and details of application): approximately $15 \mathrm{~g}$ magnesium sulphate paste spread into ulcer, Vaseline type ointment rubbed gently onto surrounding skin, then ulcer covered with approximately 6 pieces of sterile gauze

Compression: two tubular bandages used to create toe-to-knee compression

Other co-interventions: ulcer cleansed with mixture of normal saline and hydrogen peroxide solution and dried with sterile gauze.

Outcomes Intervention 1:3/55

Intervention 2: 0/55

Notes Funding type and details: not reported

\section{Risk of bias}

\section{Bias}

Authors' judgement Support for judgement

Random sequence genera- Unclear risk tion (selection bias)
Comment: study described as randomised but no details given on how sequence was generated 
Greguric 1994 (Continued)

Allocation concealment (selection bias)
Unclear risk

Quote: "a sealed envelope with the next consecutive patient number was then opened to determine which dressing the patient had been randomized to receive"

Comment: unclear whether envelopes were opaque

\begin{tabular}{lll}
$\begin{array}{l}\text { Blinding of participants } \\
\text { and personnel (perfor- }\end{array}$ & Unclear risk & Not reported \\
mance bias) & \\
All outcomes & \\
\hline $\begin{array}{l}\text { Blinding of outcome as- } \\
\text { sessment (detection bias) }\end{array}$ & Unclear risk & Not reported \\
All outcomes & &
\end{tabular}

Incomplete outcome data Low risk Comment: it appears that all participants were included in the analysis
(attrition bias)

(attrition bias)

All outcomes

Selective reporting (re- Low risk Comment: there was no evidence of selective reporting
porting bias)

\begin{tabular}{ll}
\hline Other bias $\quad$ High risk & $\begin{array}{l}\text { Comment: duration of study was } 10 \text { dressing changes and frequency of dress- } \\
\text { ing change was different in the two groups }\end{array}$
\end{tabular}

All domain risk of bias

High risk

Hanft 2006

\begin{tabular}{|c|c|}
\hline \multirow[t]{5}{*}{ Methods } & $\mathrm{RCT}$ \\
\hline & Arms: 2 \\
\hline & Unit of randomisation: unclear \\
\hline & Unit of analysis: unclear \\
\hline & Follow-up: 12 weeks \\
\hline \multirow[t]{9}{*}{ Participants } & $\begin{array}{l}\text { Inclusion criteria: } \geq 18 \text { years; VLU ulcer area }>3 \mathrm{~cm}^{2} \text { but }<25 \mathrm{~cm}^{2} ; \text { ulcer open for }>1 \text { month but }<18 \\
\text { months; } \mathrm{ABI}>0.8, \mathrm{HbA} 1 \mathrm{c}<10 \text {; free of clinical signs of infection }\end{array}$ \\
\hline & $\begin{array}{l}\text { Exclusion criteria: prior treatment with becaplermin or other topical recombinant therapy within } 30 \\
\text { days; prior treatment with skin substitute or growth factor; significant acute or chronic disease; enzy- } \\
\text { matic debridement in previous } 7 \text { days }\end{array}$ \\
\hline & Participant characteristics \\
\hline & Number participants: 49 \\
\hline & Age: not reported \\
\hline & $\%$ male: not reported \\
\hline & Ulcer details \\
\hline & Size: mean $6.9 \mathrm{~cm}^{2}$ vs $5.6 \mathrm{~cm}^{2}$ \\
\hline & Duration: mean 4.3 months vs 5.1 months \\
\hline
\end{tabular}


Hanft 2006 (Continued)

Interventions

Intervention 1 class: PMM silver

Intervention 1 details (name and details of application): protease-modulating matrix + silver dressing + hydrocolloid dressing: collagen, silver \& oxidised regenerated cellulose matrix dressing + hydrocolloid (Collagen/ORC + silver + Adaptic $\left.^{\circledR}\right)$

Intervention 2 class: hydrocolloid

Intervention 2 details (name and details of application); hydrocolloid dressing: nonadherent petrolatum impregnated dressing (Adaptic ${ }^{\circledast}$ (Johnson \& Johnson)); ( $\mathrm{n}=27$; duration 12 weeks)

Compression: standardised compression therapy

Other co-interventions: prior treatment: 1 week run in with standardised leg compression; debridement

Outcomes Intervention $1: 14 / 22$

Intervention 2: 16/27

Notes Funding type and details: not reported

\section{Risk of bias}

\begin{tabular}{|c|c|c|}
\hline Bias & Authors' judgement & Support for judgement \\
\hline $\begin{array}{l}\text { Random sequence genera- } \\
\text { tion (selection bias) }\end{array}$ & Unclear risk & Not stated \\
\hline $\begin{array}{l}\text { Allocation concealment } \\
\text { (selection bias) }\end{array}$ & Unclear risk & Not stated \\
\hline $\begin{array}{l}\text { Blinding of participants } \\
\text { and personnel (perfor- } \\
\text { mance bias) } \\
\text { All outcomes }\end{array}$ & Unclear risk & Quote: "randomized, prospective, open-label, multicenter, comparative trial" \\
\hline $\begin{array}{l}\text { Blinding of outcome as- } \\
\text { sessment (detection bias) } \\
\text { All outcomes }\end{array}$ & Unclear risk & $\begin{array}{l}\text { Quote: "randomized, prospective, open-label, multicenter, comparative trial" } \\
\text { Comment: outcome assessors likely to be unblinded }\end{array}$ \\
\hline $\begin{array}{l}\text { Incomplete outcome data } \\
\text { (attrition bias) } \\
\text { All outcomes }\end{array}$ & Low risk & $\begin{array}{l}\text { Quote from author communication: "intervention group } 9 \%(2 / 22) \text { did not } \\
\text { complete the study, } 1 \text { was lost to follow up and } 1 \text { chose to withdraw. In the } \\
\text { control group } 11 \% \text { ( } 3 / 27 \text { ) did not complete, } 2 \text { subjects died from severe AEs } \\
\text { (unrelated to the study interventions) and one chose to withdraw." Healing } \\
\text { risks were } 64 \% \text { and } 59 \%\end{array}$ \\
\hline $\begin{array}{l}\text { Selective reporting (re- } \\
\text { porting bias) }\end{array}$ & High risk & $\begin{array}{l}\text { Limited reporting of results - some obtained from the author, but some proto- } \\
\text { col outcomes not reported }\end{array}$ \\
\hline Other bias & Unclear risk & Insufficient information to assess whether an important risk of bias exists \\
\hline All domain risk of bias & High risk & \\
\hline
\end{tabular}

Hansson 1998

Methods RCT


Hansson 1998 (Continued)

\author{
Arms: 3 \\ Unit of randomisation: participant \\ Unit of analysis: participant \\ Follow-up: 12 weeks
}

\begin{abstract}
Participants
Inclusion criteria: exudating or sloughy venous leg ulcer $1 \mathrm{~cm}^{2}$ to $100 \mathrm{~cm}^{2}$ on lower leg

Exclusion criteria: systolic ankle pressure $<80 \mathrm{mmHg}$ or systolic ankle/arm index $<0.8$, clinical infection in or around ulcer with redness and pain, diabetes, known sensitivity to study products, treatment with systemic antimicrobials or study product in week before trial, systemic corticosteroids or cytostatic drugs in 4 weeks before trial, disease that could affect ulcer healing, undergoing investigation of thyroid gland
\end{abstract}

Participant characteristics

Number participants: 153

Age: 74 vs 74 vs 72 years

$\mathrm{N}(\%)$ male: $48(31)$

Ulcer details

Size: $8.8(11.9) \mathrm{cm}^{2}$ vs $10.7(20.6) \mathrm{cm}^{2}$ vs $7.1(7.1) \mathrm{cm}^{2}$

Duration: not reported

Interventions

Intervention 1 class: cadexomer iodine

Intervention 1 details (name and details of application): cadexomer iodine paste lodosorb (Perstorp $A B$ ); changed when moisture saturated

Intervention 2 class: hydrocolloid

Intervention 2 details (name and details of application): Duoderm E (ConvaTec); changed when leaking or saturated with fluid

Intervention 3 class: nonadherent

Intervention 3 details (name and details of application) paraffin gauze; Jelonet (Smith \& Nephew); changed when leaking or saturated with fluid

Compression: short stretch bandage; Comprilan (Beiersdorf AG)

Other co-interventions: not reported

\begin{tabular}{ll}
\hline Outcomes & Intervention 1: 8/56 \\
& Intervention 2: 5/48 \\
& Intervention 3: 7/49
\end{tabular}

\begin{tabular}{ll}
\hline Notes & Funding type: industry \\
& Funding details: Perstorp Pharma
\end{tabular}

\title{
Risk of bias
}

\section{Bias}

Authors' judgement Support for judgement 
Hansson 1998 (Continued)

Random sequence genera- Unclear risk Quote: "patients were randomized to receive one of three treatments" tion (selection bias)

Comment: no detail of method of sequence generation

\begin{tabular}{ll}
\hline $\begin{array}{l}\text { Allocation concealment } \\
\text { (selection bias) }\end{array}$ & Unclear risk \\
\end{tabular}

\begin{tabular}{|c|c|c|}
\hline $\begin{array}{l}\text { Blinding of participants } \\
\text { and personnel (perfor- } \\
\text { mance bias) } \\
\text { All outcomes }\end{array}$ & Unclear risk & Not reported \\
\hline $\begin{array}{l}\text { Blinding of outcome as- } \\
\text { sessment (detection bias) } \\
\text { All outcomes }\end{array}$ & Unclear risk & Not reported \\
\hline $\begin{array}{l}\text { Incomplete outcome data } \\
\text { (attrition bias) } \\
\text { All outcomes }\end{array}$ & High risk & $\begin{array}{l}\text { Participants withdrawn due to reasons unrelated to efficacy were excluded } \\
\text { from analysis (18\%) but those who withdrew for reasons related to efficacy } \\
(11 \%) \text { were included. }\end{array}$ \\
\hline $\begin{array}{l}\text { Selective reporting (re- } \\
\text { porting bias) }\end{array}$ & Low risk & There was no evidence of selective reporting \\
\hline Other bias & Unclear risk & There was no evidence of other sources but reporting was limited \\
\hline All domain risk of bias & High risk & \\
\hline
\end{tabular}

\section{Harcup 1986}

$\begin{array}{ll}\text { Methods } & \text { RCT } \\ \text { Arms: } 2 \\ \text { Unit of randomisation: participant } \\ \text { Unit of analysis: participant } \\ \text { Follow-up: } 4 \text { weeks (8 weeks, cross-over at } 4 \text { weeks) }\end{array}$

Participants

Inclusion criteria: aged over 30, exuding chronic venous ulcers of lower limbs, not responding favourably to existing treatments

Exclusion criteria: concomitant serious or life-threatening disease, suspected malignant change in ulcer, insulin-dependent diabetes, pregnancy, iodine-sensitivity, psychiatric disease, very low intelligence, dementia or other condition affecting patient compliance

Participant characteristics

Number participants: 72

Age: mean (range) 67.8 (40 to 85 ) years

$\mathrm{N}(\%)$ male: $22(31)$

Ulcer details

Size: $7.74(1.04) \mathrm{cm}^{2}$ vs $9.08(1.37) \mathrm{cm}^{2}$ 
Harcup 1986 (Continued)

Duration: mean (range) 16.9 (1 to 256 ) months

Interventions Intervention 1 class: cadexomer iodine $(\mathrm{Cl})$

Intervention 1 details (name and details of application): cadexomer iodine microbeads; lodosorb (Stuart Pharmaceuticals and Perstorp AB) applied to the whole ulcer area - at least $3 \mathrm{~mm}$ depth and covered with dry sterile dressing. $\mathrm{Cl}$ replaced daily, ulcer cleaned using sterile wet swab, stream of water or saline and/or soaking.

Intervention 2 class: standard dressing (various)

Intervention 2 details (name and details of application): "Dry dressing" or elastocrepe bandaging, Sofra-Tulle, Melolin, Polyfax ointment, Betadine ointment, Dermicel tape, Aserbine cream, Gamgee tissue, Flamazine cream, Tubigrip, bactigras. Generally a dry dressing plus support bandaging. Use of a topical antibacterial cleanser (e.g. Eusol) permitted.

Compression: support bandaging or stocking

Other co-interventions: not reported

Outcomes Intervention $1: 13 / 41$

Intervention 2: 1/31

Notes Funding type and details: not reported

\section{Risk of bias}

\begin{tabular}{|c|c|c|}
\hline Bias & Authors' judgement & Support for judgement \\
\hline $\begin{array}{l}\text { Random sequence genera- } \\
\text { tion (selection bias) }\end{array}$ & Unclear risk & $\begin{array}{l}\text { Quote: "patients were randomised to receive either standard dressing or } \mathrm{Cl} \\
\text { Comment: sequence generation methods were not reported. }\end{array}$ \\
\hline $\begin{array}{l}\text { Allocation concealment } \\
\text { (selection bias) }\end{array}$ & Unclear risk & $\begin{array}{l}\text { Quote: "patients were randomised to receive either standard dressing or CI" } \\
\text { Comment: allocation concealment was not reported }\end{array}$ \\
\hline $\begin{array}{l}\text { Blinding of participants } \\
\text { and personnel (perfor- } \\
\text { mance bias) } \\
\text { All outcomes }\end{array}$ & Unclear risk & Not reported \\
\hline $\begin{array}{l}\text { Blinding of outcome as- } \\
\text { sessment (detection bias) } \\
\text { All outcomes }\end{array}$ & Unclear risk & Not reported \\
\hline $\begin{array}{l}\text { Incomplete outcome data } \\
\text { (attrition bias) } \\
\text { All outcomes }\end{array}$ & Unclear risk & $\begin{array}{l}\text { Comment: it appears that all participants were included in the } 4 \text { week analysis } \\
\text { although two participants assigned to standard treatment received } \mathrm{Cl} \text { so were } \\
\text { included in that group instead. }\end{array}$ \\
\hline $\begin{array}{l}\text { Selective reporting (re- } \\
\text { porting bias) }\end{array}$ & Low risk & There was no evidence of selective reporting of outcomes \\
\hline Other bias & Unclear risk & $\begin{array}{l}\text { There was no evidence of other sources of bias but reporting insufficient to be } \\
\text { sure }\end{array}$ \\
\hline All domain risk of bias & Low risk & Low/unclear \\
\hline
\end{tabular}


Harding 2001

\begin{tabular}{ll}
\hline Methods & RCT \\
Arms: 2 \\
Unit of randomisation: participant \\
Unit of analysis: participant \\
Follow-up: 12 weeks \\
\hline Inclusion criteria: not reported in available copy \\
Exclusion criteria: not reported in available copy \\
Participant characteristics \\
Number participants: 131 \\
Age: not reported \\
\% male: not reported \\
Ulcer details \\
Size: not reported \\
Duration: not reported
\end{tabular}

Interventions

Intervention 1 class: hydrofibre

Intervention 1 details (name and details of application): Aquacel (ConvaTec) frequency of dressing change according to clinical need, could be left up to 7 days

Intervention 2 class: alginate

Intervention 2 details (name and details of application): Sorbsan (Maersk) frequency of dressing change according to clinical need, could be left up to 7 days

Compression: Class 3c bandage (SurePress, ConvaTec Ltd) over orthopaedic padding

Other co-interventions: if wound became infected, systemic antibiotic prescribed and, if in alginate group, dressing changed daily

\begin{tabular}{ll}
\hline Outcomes & Intervention 1: 17/66 \\
& Intervention 2: 17/65 \\
\hline Notes & Funding type and details: industry \\
& Funding details: Convatec Inc
\end{tabular}

\section{Risk of bias}

\begin{tabular}{lll}
\hline Bias & Authors' judgement & Support for judgement \\
\hline $\begin{array}{l}\text { Random sequence genera- } \\
\text { tion (selection bias) }\end{array}$ & Unclear risk & $\begin{array}{l}\text { Quote: "an open, prospective, randomized, controlled, multicenter evalua- } \\
\text { tion" }\end{array}$ \\
& & Comment: no information on how the randomisation sequence was generated \\
\hline $\begin{array}{l}\text { Allocation concealment } \\
\text { (selection bias) }\end{array}$ & Unclear risk & $\begin{array}{l}\text { Quote: "an open, prospective, randomized, controlled, multicenter evalua- } \\
\text { tion" }\end{array}$
\end{tabular}


Harding 2001 (Continued)

\begin{tabular}{|c|c|c|}
\hline $\begin{array}{l}\text { Blinding of participants } \\
\text { and personnel (perfor- } \\
\text { mance bias) } \\
\text { All outcomes }\end{array}$ & High risk & $\begin{array}{l}\text { Quote: "an open, prospective, randomized, controlled, multicenter evalua- } \\
\text { tion" } \\
\text { Comment: The trial had an open design }\end{array}$ \\
\hline $\begin{array}{l}\text { Blinding of outcome as- } \\
\text { sessment (detection bias) } \\
\text { All outcomes }\end{array}$ & High risk & $\begin{array}{l}\text { Quote: "an open, prospective, randomized, controlled, multicenter evalua- } \\
\text { tion" } \\
\text { Comment: the trial had an open design }\end{array}$ \\
\hline $\begin{array}{l}\text { Incomplete outcome data } \\
\text { (attrition bias) } \\
\text { All outcomes }\end{array}$ & Low risk & It appeared that all participants were included in the ITT analysis. \\
\hline $\begin{array}{l}\text { Selective reporting (re- } \\
\text { porting bias) }\end{array}$ & Low risk & Comment: there was no evidence of selective outcome reporting \\
\hline Other bias & Unclear risk & $\begin{array}{l}\text { Comment: there was no evidence of other sources of bias but the reporting } \\
\text { was insufficient to be sure. }\end{array}$ \\
\hline All domain risk of bias & High risk & \\
\hline All domain risk of bias 2 & High risk & \\
\hline
\end{tabular}

Hokkam 2011

\begin{tabular}{ll}
\hline Methods & RCT \\
Arms: 2 \\
Unit of randomisation: participant \\
Unit of analysis: participant \\
Follow-up: 8 weeks \\
\hline
\end{tabular}

\section{Participants}

Inclusion criteria: single chronic venous leg ulcer (clean and with healthy granulation tissue)

Exclusion criteria: allergy to phenytoin, Marjolin's ulcers, ulcers with infected gangrene, multiple ulcers, surgery within previous 6 months

Participant characteristics

Number participants: 104

Age: 47.3 (6.4) vs 45.9 (3.8) years

$\mathrm{N}(\%)$ male: $21(38.9)$ vs $21(42)$

Ulcer details

Size: $5.7(2.8) \mathrm{cm}^{2}$ vs $6.1(3.1) \mathrm{cm}^{2}$

Duration: 3.1 (1.3) weeks vs 3.9 (1.0) weeks
Intervention 1 class: phenytoin 
Hokkam 2011 (Continued)

Intervention 1 details (name and details of application): phenytoin lotion; thin layer of phenytoin applied then covered with gauze. Daily dressing

Intervention 2 class: placebo

Intervention 2 details (name and details of application) placebo unclear, saline stated, possibly covered with gauze

Compression: compression bandage

Other co-interventions: oral phlebotrophic drug (Diosmin). Washed with normal saline

\begin{tabular}{ll}
\hline Outcomes & Intervention $1: 35 / 54$ \\
& Intervention 2: $26 / 50$ \\
\hline Notes & Funding type and details: Not reported
\end{tabular}

\section{Risk of bias}

Bias Authors' judgement Support for judgement

Random sequence genera- Low risk tion (selection bias)

Quote: "the study was carried out as randomized controlled trial." "they were divided into study group and control group using coin flipping technique"

Comment: Coin toss represents an adequate method of sequence generation.

\begin{tabular}{ll}
\hline $\begin{array}{l}\text { Allocation concealment } \\
\text { (selection bias) }\end{array}$ & Unclear risk \\
& Comment: no information on how allocation was concealed \\
\hline
\end{tabular}

Blinding of participants Unclear risk There was no information on this

and personnel (perfor-

mance bias)

All outcomes

Blinding of outcome as-
sessment (detection bias) $\quad$ Unclear risk

bias)

All outcomes

Quote: "the ulcer status was assessed every week and at the end of the eight weeks the ulcer's condition was evaluated as complete healing, partial healing, no improvement and worsening"

Comment: no information on who performed the evaluation

\begin{tabular}{lll}
\hline $\begin{array}{l}\text { Incomplete outcome data } \\
\text { (attrition bias) } \\
\text { All outcomes }\end{array}$ & Low risk & All randomised participants were evaluated \\
\hline $\begin{array}{l}\text { Selective reporting (re- } \\
\text { porting bias) }\end{array}$ & Low risk & There was no evidence of selective outcome reporting. \\
\hline Other bias & Unclear risk & $\begin{array}{l}\text { There was no evidence of other sources of bias but reporting insufficient to be } \\
\text { certain }\end{array}$ \\
\hline All domain risk of bias & Low risk & Low/unclear \\
\hline
\end{tabular}

Humbert 2013

\begin{tabular}{ll}
\hline Methods & RCT \\
& Arms: 2 \\
\hline
\end{tabular}


Humbert 2013 (Continued)

Unit of randomisation: participant

Unit of analysis: participant

Follow-up: 60 days

\section{Participants}

Inclusion criteria: venous or mixed leg ulcers, present for 2 months to 4 years, $5 \mathrm{~cm}^{2}$ to $40 \mathrm{~cm}^{2}$, no necrotic tissue, history/evidence of DVT or post-thrombotic syndrome, post-phlebitic sequels, reflux on venous system, ABPI $0.8+$. No use of HA in previous 3 months. Use of compression device. If several, target ulcer selected

Exclusion criteria: ulcer of non-vascular or general cause, diabetes, arterial insufficiency $(A B P I<0.8)$, hepatic or renal failure, recent history of venous thrombosis ( $<3$ months), pregnancy or breastfeeding, allergy to local anaesthetic or study materials, treatment delaying healing process.

Participant characteristics

Number participants: 89

Age: mean (SEM) 59.4 (2.5) vs 64.1 (2.7) years

N (\%) male: 25 (55.6) vs $20(45.5)$

Ulcer details

Non VLU - not clear

Size: Mean (SEM) $13.8(1.3) \mathrm{cm}^{2}$ vs $12.9(1.3) \mathrm{cm}^{2}$

Duration: Mean (SD) 12.4 (12.3) vs 12.8 (12.2) months

Intervention 1 details (name and details of application): $0.05 \%$ hyaluronic acid impregnated cotton gauze pad, Ialuset (Laboratoires Genevrier), pad applied then covered with sterile gauze and appropriate bandage. Changed daily

Intervention 2 class: placebo

Intervention 2 details (name and details of application): neutral vehicle pad; laluset without HA (Laboratoires Genevrier); pad applied then covered with sterile gauze and appropriate bandage. Changed daily

Compression: type 2 compression with long stretching elastic bandage (>96\% participants)

Other co-interventions: surgical wound excision procedures, systemic analgesia, systemic antibiotics used if necessary

\section{Outcomes}

Intervention 1: 17/45

Intervention 2: 7/43

\section{Notes}

Funding type and details: industry

Funding details: Laboratoires Genevrier

\section{Risk of bias}

\begin{tabular}{lll}
\hline Bias & Authors' judgement & Support for judgement \\
\hline $\begin{array}{ll}\text { Random sequence genera- } \\
\text { tion (selection bias) }\end{array}$ & Unclear risk & $\begin{array}{l}\text { Quote: "for each patient included in the study, a target ulcer was selected by } \\
\text { the investigator and randomly assigned to be locally treated" }\end{array}$
\end{tabular}




\begin{tabular}{|c|c|c|}
\hline $\begin{array}{l}\text { Allocation concealment } \\
\text { (selection bias) }\end{array}$ & Unclear risk & $\begin{array}{l}\text { Quote: "for each patient included in the study, a target ulcer was selected by } \\
\text { the investigator and randomly assigned to be locally treated }\end{array}$ \\
\hline
\end{tabular}

Comment: unclear how the allocation was concealed

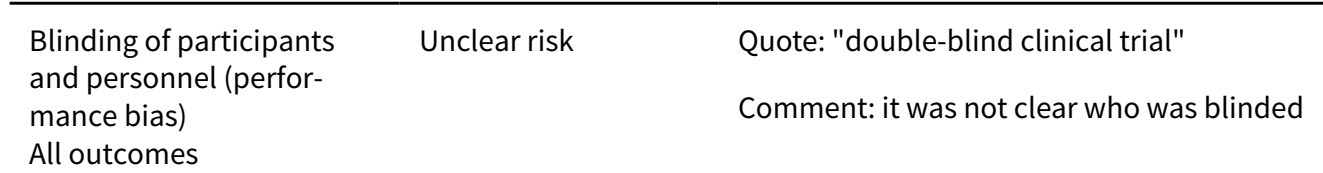

\begin{tabular}{lll}
\hline $\begin{array}{l}\text { Blinding of outcome as- } \\
\text { sessment (detection bias) } \\
\text { All outcomes }\end{array}$ & Unclear risk & $\begin{array}{l}\text { Quote: "double-blind clinical trial" } \\
\text { Comment: it was not clear who was blinded }\end{array}$ \\
\hline $\begin{array}{l}\text { Incomplete outcome data } \\
\text { (attrition bias) } \\
\text { All outcomes }\end{array}$ & Low risk & All except one participant, who died, were included in the analysis \\
\hline $\begin{array}{l}\text { Selective reporting (re- } \\
\text { porting bias) }\end{array}$ & Low risk & There was no evidence of selective reporting \\
\hline $\begin{array}{l}\text { Other bias } \\
\text { All domain risk of bias }\end{array}$ & High risk & $\begin{array}{l}\text { Unclear how the investigator selected the target ulcer; potential for bias here } \\
\text { given the lack of clarity over risk of selection bias }\end{array}$ \\
\hline
\end{tabular}

Ivins 2006

\begin{tabular}{ll} 
Methods & RCT \\
Arms: 2 & Unit of randomisation: participant \\
& Unit of analysis: participant \\
& Follow-up: 4 weeks \\
\hline Inclusion criteria: chronic venous or mixed venous/arterial e.g. ulcers with delayed healing \\
Exclusion criteria: not reported \\
Participant characteristics \\
Number participants: 45 \\
Age: not reported \\
\% male: not reported \\
Ulcer details \\
Non VLU - unclear how many mixed venous/arterial ulcers \\
Size: not reported \\
Duration: not reported \\
\end{tabular}


Ivins 2006 (Continued)

Intervention 1 class: silver
Intervention 1 details (name and details of application): not reported
Intervention 2 class: foam
Intervention 2 details (name and details of application): not reported
Compression: not reported
Other co-interventions: not reported

\section{Outcomes}

Intervention 1: 2/25

Intervention 2: 1/20

Notes Funding type and details: not reported

\section{Risk of bias}

\begin{tabular}{|c|c|c|}
\hline Bias & Authors' judgement & Support for judgement \\
\hline $\begin{array}{l}\text { Random sequence genera- } \\
\text { tion (selection bias) }\end{array}$ & Unclear risk & $\begin{array}{l}\text { Quote: "[the patients] were re-randomised to receive treatment with either the } \\
\text { silver foam or the non-silver foam" }\end{array}$ \\
\hline $\begin{array}{l}\text { Allocation concealment } \\
\text { (selection bias) }\end{array}$ & Unclear risk & Not reported \\
\hline $\begin{array}{l}\text { Blinding of participants } \\
\text { and personnel (perfor- } \\
\text { mance bias) } \\
\text { All outcomes }\end{array}$ & Unclear risk & Not reported \\
\hline $\begin{array}{l}\text { Blinding of outcome as- } \\
\text { sessment (detection bias) } \\
\text { All outcomes }\end{array}$ & Unclear risk & Not reported \\
\hline $\begin{array}{l}\text { Incomplete outcome data } \\
\text { (attrition bias) } \\
\text { All outcomes }\end{array}$ & Unclear risk & No details \\
\hline $\begin{array}{l}\text { Selective reporting (re- } \\
\text { porting bias) }\end{array}$ & Unclear risk & Abstract only so limited reporting \\
\hline Other bias & Unclear risk & Not enough information to judge \\
\hline All domain risk of bias & Low risk & Unclear \\
\hline
\end{tabular}

Jull 2008

$\begin{array}{ll}\text { Methods } & \text { RCT } \\ \text { Arms: } 2 \\ \text { Unit of randomisation: participant } \\ \text { Unit of analysis: participant }\end{array}$


Jull 2008 (Continued)

Follow-up: 12 weeks

Participants Inclusion criteria: venous ulcer (ankle brachial pressure index $>0.8$ ) or mixed venous/arterial ulcer (ankle brachial pressure index $>0.7$ ), can tolerate compression

Exclusion criteria: history of diabetes, rheumatoid arthritis or peripheral arterial disease, allergy to calcium alginate or Manuka honey, already using honey treatment

Participant characteristics

Number participants: 368

Age: 66.9 (17.5) vs $68.3(17.1)$ years

$\mathrm{N}(\%)$ male: 91 (48) vs 89 (49)

Ulcer details

Non VLU: $2(1 \%)$ vs $5(3 \%)$ mixed

Size: median (range) 2.7 (0.1 to 193) $\mathrm{cm}^{2}$ vs 2.6 (0.2 to 81$) \mathrm{cm}^{2}$

Duration: median (range) 20 ( 3 to 688) weeks vs 16 ( 2 to 999) weeks

\begin{tabular}{|c|c|}
\hline Interventions & Intervention 1 class: honey \\
\hline & $\begin{array}{l}\text { Intervention } 1 \text { details (name and details of application): Manuka-honey-impregnated calcium algina } \\
\text { Apinate UMF } 12+\text { (Comvita New Zealand); changed at frequency determined by clinical need }\end{array}$ \\
\hline & Intervention 2 class: standard care \\
\hline & $\begin{array}{l}\text { Intervention } 2 \text { details (name and details of application): usual care; various dressings (alginate, hydr } \\
\text { bre, hydrocolloid, foam, hydrogel, nonadherent, iodine, silver); dressing dependent on local availabi } \\
\text { and as deemed appropriate by district nurse }\end{array}$ \\
\hline & $\begin{array}{l}\text { Compression: all received compression bandaging varying according to range available at study cen } \\
\text { tres and nurse/patient choice }\end{array}$ \\
\hline & Other co-interventions: not reported \\
\hline Outcomes & Intervention 1: 104/187 \\
\hline & Intervention 2: 90/181 \\
\hline Notes & Funding type: Mixed \\
\hline & $\begin{array}{l}\text { Funding details: Funding both non-industry (Health Research Council of New Zealand) and industry } \\
\text { (Comvita New Zealand, USL Medical) }\end{array}$ \\
\hline
\end{tabular}

Risk of bias

Bias Authors' judgement Support for judgement

Random sequence genera- Low risk tion (selection bias)

Quote: "participants were randomly assigned to one of two groups by an independent central telephone service; The allocation sequence was stratified by study centre and the Margolis index using minimization."

Comment: appears that an appropriate method was used to generate the randomisation sequence

\begin{tabular}{ll}
\hline $\begin{array}{l}\text { Allocation concealment } \\
\text { (selection bias) }\end{array}$ & Low risk
\end{tabular}




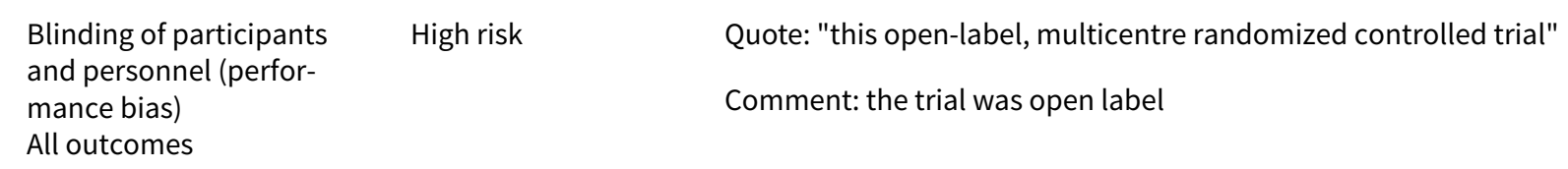

\begin{tabular}{|c|c|c|}
\hline $\begin{array}{l}\text { Blinding of outcome as- } \\
\text { sessment (detection bias) } \\
\text { All outcomes }\end{array}$ & High risk & $\begin{array}{l}\text { Quote: "the primary outcome measure was....Determined by the research } \\
\text { nurse. The research nurse was not blind to allocation" } \\
\text { Comment: unblinded outcome assessment }\end{array}$ \\
\hline $\begin{array}{l}\text { Incomplete outcome data } \\
\text { (attrition bias) } \\
\text { All outcomes }\end{array}$ & Low risk & All participants were included in the ITT analysis \\
\hline $\begin{array}{l}\text { Selective reporting (re- } \\
\text { porting bias) }\end{array}$ & Low risk & There was no evidence of selective outcome reporting \\
\hline Other bias & Low risk & There was no evidence of other potential sources of bias \\
\hline All domain risk of bias & High risk & \\
\hline All domain risk of bias 2 & High risk & \\
\hline
\end{tabular}

Jørgensen 2005

$\begin{array}{ll}\text { Methods } & \text { RCT } \\ \text { Arms: } 2 \\ \text { Unit of randomisation: participant } \\ \text { Unit of analysis: participant } \\ \text { Follow-up: } 4 \text { weeks }\end{array}$

Participants

Inclusion criteria: moderately or highly exuding, chronic venous or mixed venous/arterial leg ulcer with delayed healing $\left(0.5 \mathrm{~cm}^{2}\right.$ or less area reduction) and at least one sign of critical colonisation (increased exudate, increased pain, discolouration of granulation tissue, foul odour) in past 4 weeks, $A B I>0.65$, compression therapy for past 4 weeks, ulcer dimension $>2 \mathrm{~cm}^{2}$ and fitting within $10 \times 10 \mathrm{~cm}$ dressing with $1.5 \mathrm{~cm}$ edge

Exclusion criteria: clinical infection including erysipelas and cellulitis of peri-ulcer skin, treatment with antiseptics or antibiotics from 1 week prior to inclusion, uncontrolled diabetes, treatment with systemic corticosteroids $>10 \mathrm{mg} /$ day, immunosuppressants from 4 weeks prior to inclusion, diseases that may interfere with ulcer healing

Participant characteristics

Number participants: 129

Age: median (range) 72.0 (40 to 99) vs 75.5 (42 to 90 ) years

$\mathrm{N}(\%)$ male: $21(32)$ vs $26(41)$

Ulcer details

Non VLU - not clear 
Duration: median (range) 1.1 (0.1 to 32.0 ) years vs 1.0 (0.1 to 10.0 ) years

\begin{tabular}{ll}
\hline Interventions & Intervention 1 class: silver \\
Intervention 1 details (name and details of application): silver foam; Contreet (Coloplast); dressing \\
changes left as long as clinically possible - max 7 days \\
Intervention 2 class: foam \\
Intervention 2 details (name and details of application): Allevyn (Smith \& Nephew) \\
Compression: mandatory compression (according to clinical practice of treatment centre) \\
Other co-interventions: wound cleansed with sterile saline or tap water at dressing changes. When nec- \\
essary, peri-ulcer area treated with mild zinc cream (Conveen) or topical steroid ointment \\
\hline Outcomes \\
Intervention 1: $5 / 65$ \\
Intervention 2: $5 / 64$ \\
\hline Fotes \\
Funding type and details: industry \\
\hline
\end{tabular}

\section{Risk of bias}

\begin{tabular}{|c|c|c|}
\hline Bias & Authors' judgement & Support for judgement \\
\hline $\begin{array}{l}\text { Random sequence genera- } \\
\text { tion (selection bias) }\end{array}$ & Low risk & $\begin{array}{l}\text { Quote: "patients were randomised ... by computer-generated randomisation" } \\
\text { Comment: appropriate method of randomisation }\end{array}$ \\
\hline $\begin{array}{l}\text { Allocation concealment } \\
\text { (selection bias) }\end{array}$ & Unclear risk & $\begin{array}{l}\text { Quote: "patients were randomised ... by computer-generated randomisation" } \\
\text { Comment: no information on how allocation was concealed }\end{array}$ \\
\hline $\begin{array}{l}\text { Blinding of participants } \\
\text { and personnel (perfor- } \\
\text { mance bias) } \\
\text { All outcomes }\end{array}$ & Unclear risk & Not reported \\
\hline $\begin{array}{l}\text { Blinding of outcome as- } \\
\text { sessment (detection bias) } \\
\text { All outcomes }\end{array}$ & Unclear risk & Not reported \\
\hline $\begin{array}{l}\text { Incomplete outcome data } \\
\text { (attrition bias) } \\
\text { All outcomes }\end{array}$ & Low risk & $\begin{array}{l}\text { Comment: all participants included in ITT analysis, PP analysis also performed } \\
\text { excluding participants withdrawn for protocol violation }\end{array}$ \\
\hline $\begin{array}{l}\text { Selective reporting (re- } \\
\text { porting bias) }\end{array}$ & Low risk & There was no evidence of selective reporting \\
\hline Other bias & Low risk & There was no evidence of other forms of bias \\
\hline All domain risk of bias & Low risk & Low/unclear \\
\hline
\end{tabular}


Kalis 1993

\begin{tabular}{ll}
\hline Methods & RCT \\
Arms: 2 \\
Unit of randomisation: unclear \\
Unit of analysis: ulcer \\
Follow-up: 56 days
\end{tabular}

Participants
Exclusion criteria: leg ulcer of venous or mixed origin
Participant characteristics
Number participants: 89 participants with 109 ulcers
Age: not reported
\% male: not reported
Ulcer details
Non VLU - some unknown
Size: not reported
Duration: not reported

Intervention 1 details (name and details of application): Granuflex

Intervention 2 class: dextranomer

Intervention 2 details (name and details of application): paste covered by dressing and cotton band

Compression: not reported

Other co-interventions: not reported

\begin{tabular}{|c|c|c|}
\hline \multirow[t]{2}{*}{ Outcomes } & \multicolumn{2}{|l|}{ Intervention $1: 13 / 54$} \\
\hline & \multicolumn{2}{|l|}{ Intervention 2: 10/54 } \\
\hline Notes & \multicolumn{2}{|c|}{ Funding type and details: not reported } \\
\hline \multicolumn{3}{|l|}{ Risk of bias } \\
\hline Bias & Authors' judgement & Support for judgement \\
\hline \multirow[t]{2}{*}{$\begin{array}{l}\text { Random sequence genera- } \\
\text { tion (selection bias) }\end{array}$} & Unclear risk & $\begin{array}{l}\text { Quote: "we carried out an open, comparative and randomised good clinical } \\
\text { practice (GCP) trial" }\end{array}$ \\
\hline & & Comment: no information on how randomisation sequence was generated. \\
\hline \multirow[t]{2}{*}{$\begin{array}{l}\text { Allocation concealment } \\
\text { (selection bias) }\end{array}$} & Unclear risk & $\begin{array}{l}\text { Quote: "we carried out an open, comparative and randomised good clinical } \\
\text { practice (GCP) trial" }\end{array}$ \\
\hline & & Comment: no information on how allocation was concealed \\
\hline
\end{tabular}


Kalis 1993 (Continued)

\begin{tabular}{|c|}
\hline $\begin{array}{l}\text { Blinding of participants } \\
\text { and personnel (perfor- }\end{array}$ \\
\hline
\end{tabular}

Comment: open trial

mance bias

All outcomes

Quote: "we carried out an open, comparative and randomised good clinical practice (GCP) trial"

Blinding of outcome as- High risk sessment (detection bias)

Comment: open trial

All outcomes

Incomplete outcome data High risk

(attrition bias)

Quote: "drop-outs were more frequent in the dextranomer group (10 cases), All outcomes due to deterioration (2 patients), clinical infection (3), cutaneous reaction (4),

\begin{tabular}{lll}
$\begin{array}{l}\text { Selective reporting (re- } \\
\text { porting bias) }\end{array}$ & Unclear risk & Insufficient information to determine \\
\hline Other bias & High risk & $\begin{array}{l}\text { Unclear if there is a difference between the unit of randomisation and the unit } \\
\text { of analysis; potential for unit of analysis issues very unclear }\end{array}$
\end{tabular}

All domain risk of bias High risk

All domain risk of bias $2 \quad$ High risk

Kelechi 2012

\begin{tabular}{ll}
\hline Methods & RCT \\
Arms: 2 \\
Unit of randomisation: participant \\
Unit of analysis: participant \\
Follow-up: 20 weeks
\end{tabular}

Participants

Inclusion criteria: people aged 21+ with partial-thickness venous ulcer, diagnosed in previous 4 weeks, size $2 \mathrm{~cm}^{2}$ to $20 \mathrm{~cm}^{2}$, no recent skin grafts or use of growth factors, viable clean wound bed $90 \%$ free of necrotic debris.

Exclusion criteria: full thickness ulcers extending beyond dermis, infection, $\mathrm{ABI}<0.8$ or $>1.3$, duration $>6$ months, history of collagen vascular disease, severe arterial disease, organ transplant, Charcot disease, sickle cell disease, radiation therapy, haemodialysis, pregnant

Participant characteristics

Number participants: 82

Age: 59 (13.5) vs $63.2(14.8)$ vs 60.8 (12.2) vs 63.0 (15.3) years

$\mathrm{N}(\%)$ male: 5 (25) vs 13 (59.1) vs 13 (65) vs 10 (50)

Ulcer details

Size: mean (SD) $12.1(11.3) \mathrm{cm}^{2}$ vs $9.8(7.3) \mathrm{cm}^{2}$ vs $10.5(10.3) \mathrm{cm}^{2}$ vs $12.8(12.0) \mathrm{cm}^{2}$

Duration: mean (SD) 3.4 (1.5) months vs 3.6 (1.8) months vs 2.7 (2.1) months vs 2.7 (1.6) months 
Kelechi 2012 (Continued)

Intervention 1 details (name and details of application): pG1cNAc nanofibre matrix (Talymed, Marine Polymer Technologies) applied once + nonadherent dressing (Mepilex, Molnlycke HealthCare)

Intervention 2 class: nanofibre matrix

Intervention 2 details (name and details of application): pG1cNAc nanofibre matrix (Talymed, Marine Polymer Technologies) applied every other week + nonadherent dressing (Mepilex, Molnlycke HealthCare).

Intervention 3 class: nanofibre matrix

Intervention 3 details (name and details of application): pG1cNAc nanofibre matrix (Talymed, Marine Polymer Technologies) applied every third week + nonadherent dressing (Mepilex, Molnlycke HealthCare).

Intervention 4 class: nonadherent

Intervention 4 details (name and details of application): Mepilex (Molnlycke Health Care)

Compression: zinc oxide impregnated bandage (Viscopaste PB7, Smith \& Nephew), cotton padding wrap, self-adherent elastic wrap (Coban, 3M)

Other co-interventions: wound cleaned with saline, patted dry with gauze, moisture barrier applied

\begin{tabular}{ll}
\hline Outcomes & Intervention 1: $9 / 20$ \\
& Intervention 2: $19 / 22$ \\
& Intervention 3: $13 / 20$ \\
& Intervention 4: $9 / 20$ \\
\hline Notes & Funding type: industry \\
& Funding details: supported by Marine Polymer Technologies Inc
\end{tabular}

\section{Risk of bias}

\section{Bias}

Authors' judgement Support for judgement

Random sequence genera- Low risk tion (selection bias)
Quote: "randomization to treatment groups after informed consent, eligible patients were randomly assigned to 1 of 4 study arms using computer-generated, stratified, permuted block randomization"

Comment: appropriate generation of randomisation sequence
Quote: "randomization was stratified by site to ensure equal subject allocation across the 4 treatment arms. Block size was randomly varied to minimize the likelihood that study nurses could guess the next allocation on the basis of previous allocations"

Comment: appears that central allocation took appropriate steps to ensure concealment

Blinding of participants High risk
and personnel (perfor-
mance bias)
All outcomes

Blinding of outcome as-

Unclear risk sessment (detection bias) All outcomes
Quote: "patients and certified wound care nurses, who provided wound treatment and applied the wound-healing product, were not blinded to subject group assignment"

Comment: neither participants nor personnel were blinded

Quotes: "randomized, investigator-blinded, parallel group, controlled trial" "study nurses measured wound length and width at each visit" 
Kelechi 2012 (Continued)

Comment: it is not clear whether the unblinded study nurses or the blinded investigators determined outcomes

\begin{tabular}{ll}
\hline $\begin{array}{l}\text { Incomplete outcome data } \\
\text { (attrition bias) }\end{array}$ & $\begin{array}{l}\text { Quote: "82 subjects were randomly assigned to one of the } 4 \text { study groups, and } \\
71 \text { completed the study. Seven subjects were lost to follow-up and } 4 \text { subjects } \\
\text { All outcomes }\end{array}$ \\
who developed systemic infections were withdrawn" \\
Comment: an ITT analysis was performed with clear procedures for dealing \\
with data from participants lost to follow-up
\end{tabular}

Selective reporting (re- Low risk No evidence of selective reporting
porting bias)

Other bias Low risk No evidence of other sources of bias

All domain risk of bias High risk

\section{Kucharzewski 2013}

\begin{tabular}{ll}
\hline Methods & RCT \\
& Unit of randomisation: participant \\
& Unit of analysis: participant \\
& Follow-up: 16 weeks (data extracted at 7 weeks) \\
\hline
\end{tabular}

\section{Participants}

Inclusion criteria: chronic venous ulcer due to primary varicosis

Exclusion criteria: not reported

Participant characteristics

Number participants: 58

Age: 65.3 (9.1) vs $66.9(6.4)$ years

$\mathrm{N}(\%)$ male: $11(37)$ vs $10(36)$

Ulcer details

Size: mean (range) $8.52(7.02-9.89) \mathrm{cm}^{2}$ vs $8.29(7.02-10.1) \mathrm{cm}^{2}$

Duration: mean (range) $2.5(1.2-3.4)$ years vs 2.4 (1.1- 3.6) years

Interventions

Intervention 1 class: silver

Intervention 1 details (name and details of application): silver membrane plus gauze; Texts Bioactiv (Biocell); ulcer washed with Ringer's solution before application of silver membrane, then gauze pads and elastic bandage. Dressing rinsed several times daily with Ringers. External dressing changed daily, membrane every 7 days

Intervention 2 class: hydrocolloid

Intervention 2 details (name and details of application): hydrocolloid with Unna's boot, applied after saline rinse, changed every 7 days

Compression: all received compression therapy 
Kucharzewski 2013 (Continued)

Other co-interventions: wounds were bathed in detergent ( $\mathrm{pH}$ 5.5), washed with saline and rinsed with Octenisept, surgically cleaned, washed with saline and covered with an Octenisept compress

\begin{tabular}{ll}
\hline Outcomes & Intervention $1: 30 / 30$ \\
& Intervention $2: 6 / 28$ \\
\hline Notes & Funding type and details: not reported \\
& Notes: Data reported for healing curve; time point selected
\end{tabular}

\section{Risk of bias}

\begin{tabular}{|c|c|c|}
\hline Bias & Authors' judgement & Support for judgement \\
\hline $\begin{array}{l}\text { Random sequence genera- } \\
\text { tion (selection bias) }\end{array}$ & Unclear risk & $\begin{array}{l}\text { Quote: "patients were divided randomly ..." } \\
\text { Comment: no information on sequence generation }\end{array}$ \\
\hline $\begin{array}{l}\text { Allocation concealment } \\
\text { (selection bias) }\end{array}$ & Unclear risk & $\begin{array}{l}\text { Quote: "patients were divided randomly ..." } \\
\text { Comment: no information on how allocation was concealed }\end{array}$ \\
\hline $\begin{array}{l}\text { Blinding of participants } \\
\text { and personnel (perfor- } \\
\text { mance bias) } \\
\text { All outcomes }\end{array}$ & Unclear risk & Not reported \\
\hline $\begin{array}{l}\text { Blinding of outcome as- } \\
\text { sessment (detection bias) } \\
\text { All outcomes }\end{array}$ & Unclear risk & Not reported \\
\hline $\begin{array}{l}\text { Incomplete outcome data } \\
\text { (attrition bias) } \\
\text { All outcomes }\end{array}$ & Low risk & All patients were followed until healing \\
\hline $\begin{array}{l}\text { Selective reporting (re- } \\
\text { porting bias) }\end{array}$ & High risk & There was no defined endpoint \\
\hline Other bias & Unclear risk & $\begin{array}{l}\text { There was no evidence of other sources of bias but reporting was insufficient } \\
\text { to be confident }\end{array}$ \\
\hline
\end{tabular}

All domain risk of bias

High risk

\section{Lanzara 2008}

\begin{tabular}{ll}
\hline Methods & RCT \\
Arms: 2 \\
Unit of randomisation: participant \\
Unit of analysis: participant \\
Follow-up: 12 weeks
\end{tabular}


Lanzara 2008 (Continued)

Exclusion criteria: not reported

Participant characteristics

Number participants: 30

Age: not reported

$\%$ male: not reported

Ulcer details

Size: not reported

Duration: not reported

\begin{tabular}{|c|c|}
\hline \multirow[t]{6}{*}{ Interventions } & Intervention 1 class: PMM silver \\
\hline & $\begin{array}{l}\text { Intervention } 1 \text { details (name and details of application): PMM + silver dressing + foam dressing - col- } \\
\text { lagen, silver \& oxidised regenerated cellulose matrix dressing + hydropolymer foam (Collagen/ORC + } \\
\text { silver (Systagenix) + Tielle Family }{ }^{\circledast} \text { (Systagenix) + Tielle Family }{ }^{\circledast} \text { (Systagenix)): dressing changes every } \\
\text { week; }(n=15 ; \text { duration } 12 \text { weeks) }\end{array}$ \\
\hline & Intervention 2 class: foam \\
\hline & $\begin{array}{l}\text { Intervention } 2 \text { details (name and details of application): foam dressing (Tielle Family }{ }^{\circledast} \text { (Systagenix)); (n } \\
=15 ; \text { duration } 12 \text { weeks) }\end{array}$ \\
\hline & Compression: short stretch multilayer compression for all \\
\hline & Other co-interventions: not reported \\
\hline \multirow[t]{2}{*}{ Outcomes } & Intervention 1: 11/15 \\
\hline & Intervention $2: 7 / 15$ \\
\hline \multirow[t]{3}{*}{ Notes } & Funding type: industry \\
\hline & Funding details: appears to be Systagenix \\
\hline & Notes: poster presentation \\
\hline
\end{tabular}

\section{Risk of bias}

Bias Authors' judgement Support for judgement

$\begin{array}{ll}\begin{array}{l}\text { Random sequence genera- } \\ \text { tion (selection bias) }\end{array} & \text { Unclear risk } \\ \end{array}$

\begin{tabular}{lll}
\hline $\begin{array}{l}\text { Allocation concealment } \\
\text { (selection bias) }\end{array}$ & Unclear risk & $\begin{array}{l}\text { Quote: "patients... were randomized" } \\
\text { Comment: no information on how allocation was concealed }\end{array}$ \\
\hline $\begin{array}{l}\text { Blinding of participants } \\
\begin{array}{l}\text { and personnel (perfor- } \\
\text { mance bias) }\end{array}\end{array}$ & Unclear risk & $\begin{array}{l}\text { Comment: dressings were sufficiently different for participants and personnel } \\
\text { to be unblinded - two dressings versus one dressing }\end{array}$ \\
All outcomes &
\end{tabular}

\begin{tabular}{|c|c|c|}
\hline $\begin{array}{l}\text { Blinding of outcome as- } \\
\text { sessment (detection bias) }\end{array}$ & Unclear risk & $\begin{array}{l}\text { Quote: "study duration was } 12 \text { weeks, with dressing changes every week as } \\
\text { well as measurements on wound size and assessment of wound appearance" }\end{array}$ \\
\hline
\end{tabular}


Comment: implication that outcome assessors were also responsible for dressing changes, who were not blinded as above

\begin{tabular}{lll}
\hline $\begin{array}{l}\text { Incomplete outcome data } \\
\text { (attrition bias) } \\
\text { All outcomes }\end{array}$ & Unclear risk & Apparently no missing data, but no details \\
\hline $\begin{array}{l}\text { Selective reporting (re- } \\
\text { porting bias) }\end{array}$ & Low risk & $\begin{array}{l}\text { Unclear reporting. Some results (healing) only reported on the Systagenix } \\
\text { website }\end{array}$ \\
\hline Other bias & High risk & Baseline differences in ulcer size: $6 \mathrm{~cm}^{2}$ versus $9 \mathrm{~cm}^{2}$ \\
\hline All domain risk of bias & High risk & \\
\hline
\end{tabular}

Leaper 1991

Methods

RCT

Arms: 2

Unit of randomisation: unclear

Unit of analysis: ulcer

Follow-up: 12 weeks; cross-over of some participants at 6 weeks

Participants Inclusion criteria: leg ulcers, community or hospital based

Exclusion criteria: critically Ischaemic vascular disease (Doppler index $<0.5$ ), insulin-dependent diabetes, terminal illness

Participant characteristics

Number participants: 76 participants with 94 ulcers

Age: 75.0 (10.4) vs $73.8(9.8)$ years

$\%$ male: 17 (45) vs $11(29)$

Ulcer details

Non VLU: unclear - "the majority of leg ulcers were of venous origin"

Size: $15.9(38.3) \mathrm{cm}^{2}$ vs $19.4(31.4) \mathrm{cm}^{2}$

Duration: range 2 weeks to 43 years "the durations of the ulcer existence were similar in the two dressing groups"

Intervention 1 class: hydrocolloid

Intervention 1 details (name and details of application): Comfeel Ulcer Dressing (Coloplast); dressing covered minimum $2 \mathrm{~cm}$ rim of skin around ulcer. Changed every 2-3 days during debridement stage, 3 to 4 days during healthy granulation, 5 to 7 days during epithelialisation and contraction

Intervention 2 class: nonadherent

Intervention 2 details (name and details of application): gauze (paraffin-impregnated); Jelonet (Smith $\&$ Nephew); dressing covered minimum $2 \mathrm{~cm}$ rim of skin around ulcer. Changed every 2 to 3 days during debridement stage, 3 to 4 days during healthy granulation, 5 to 7 days during epithelialisation and contraction 
Other co-interventions: irrigation and wash with sterile saline solution and cotton wool soaks before dressing. Some ulcers required surgical debridement

\begin{tabular}{ll}
\hline Outcomes & Intervention 1: 14/46 \\
& Intervention 2: 3/48 \\
\hline Notes & Funding type: industry \\
& Funding details: Coloplast
\end{tabular}

\section{Risk of bias}

\begin{tabular}{|c|c|c|}
\hline Bias & Authors' judgement & Support for judgement \\
\hline \multirow[t]{2}{*}{$\begin{array}{l}\text { Random sequence genera- } \\
\text { tion (selection bias) }\end{array}$} & Unclear risk & $\begin{array}{l}\text { Quote: "a clinical assessment was made for each patient ... prior to randomiza- } \\
\text { tion to a treatment group, with stratification" }\end{array}$ \\
\hline & & Comment: no details of sequence generation method \\
\hline \multirow[t]{2}{*}{$\begin{array}{l}\text { Allocation concealment } \\
\text { (selection bias) }\end{array}$} & Unclear risk & $\begin{array}{l}\text { Quote: "a clinical assessment was made for each patient ... prior to randomiza- } \\
\text { tion to a treatment group, with stratification" }\end{array}$ \\
\hline & & Comment: no details of allocation concealment given \\
\hline $\begin{array}{l}\text { Blinding of participants } \\
\text { and personnel (perfor- } \\
\text { mance bias) } \\
\text { All outcomes }\end{array}$ & Unclear risk & Not reported \\
\hline
\end{tabular}

\begin{tabular}{|c|c|c|}
\hline $\begin{array}{l}\text { Blinding of outcome as- } \\
\text { sessment (detection bias) } \\
\text { All outcomes }\end{array}$ & Unclear risk & Not reported \\
\hline $\begin{array}{l}\text { Incomplete outcome data } \\
\text { (attrition bias) } \\
\text { All outcomes }\end{array}$ & Low risk & Information reported for all participants/ulcers \\
\hline $\begin{array}{l}\text { Selective reporting (re- } \\
\text { porting bias) }\end{array}$ & Unclear risk & $\begin{array}{l}\text { There is no evidence of selective reporting but it is not clearly reported enough } \\
\text { to be sure }\end{array}$ \\
\hline \multirow[t]{2}{*}{ Other bias } & High risk & $\begin{array}{l}\text { There is strong potential for a unit of analysis issue as it appears that randomi- } \\
\text { sation was at the participant level but that analysis was at the level of the ul- } \\
\text { cer. }\end{array}$ \\
\hline & & $\begin{array}{l}\text { There was cross-over at } 6 \text { weeks for some but not all participants; they were } \\
\text { analysed in the groups to which they were randomised however. }\end{array}$ \\
\hline
\end{tabular}

All domain risk of bias High risk

\section{Lindsay 1986}

Methods RCT

Arms: 2 
Lindsay 1986 (Continued)

Unit of randomisation: participant

Unit of analysis: participant

Follow-up: 4 weeks - but see notes

Participants

Inclusion criteria: female, over 30, chronic exuding venous ulcer(s) of lower limbs, not responding favourable to existing treatments

Exclusion criteria: concomitant serious or life-threatening disease, suspected malignant change in ulcer, insulin-dependent diabetes, pregnancy, iodine sensitivity, psychiatric disease, very low intelligence, dementia or other condition affecting patient compliance

Participant characteristics

Number participants: 28

Age: mean (range) 66.7 (52 to 90 ) years

$\%$ male: 0

Ulcer details

Size: not reported

Duration: mean 20.1 months

Interventions Intervention 1 class: cadexomer iodine (Cl)

Intervention 1 details (name and details of application): lodosorb (Stuart Pharmaceuticals and Perstorp $A B$ ); cadexomer iodine applied to whole ulcer surface to depth of at least $3 \mathrm{~mm}$ and wound covered with dry sterile dressing. Changed on alternate days. $\mathrm{Cl}$ removed using sterile wet swab or stream of water or saline or soaking

Intervention 2 class: standard care

Intervention 2 details (name and details of application): various, generally sterile nonadherent dressing including Terra-Sortril, povidone iodine, Savlon, Bactigras, Melolin, Sofra Tulle, crepe bandage, elastocrepe bandage; changed on alternate days

Compression: see other co-interventions

Other co-interventions: "dressing secured with support bandaging or stocking as required" (cadexomer iodine and most of the standard treatment)

\section{Outcomes}

Intervention 1: 4/14

Intervention 2: 1/14

Notes Funding type and details: industry

Funding details: Stuart Pharmaceutical

Notes: 10 week trial but optional cross-over at 4 weeks so main analysis applied at this point (with numbers $\mathrm{N}=12$ vs $\mathrm{N}=13$ ). 1 participant was removed from demographic data - her ulcer duration was "60+". It is not clear whether the healing data refer to the 4 weeks time point

\section{Risk of bias}

\begin{tabular}{lll}
\hline Bias & Authors' judgement & Support for judgement \\
\hline $\begin{array}{l}\text { Random sequence genera- } \\
\text { tion (selection bias) }\end{array}$ & Unclear risk & Quote: "patients were randomised to receive either standard dressing or Cl"
\end{tabular}


Lindsay 1986 (Continued)

Comment: no details of sequence generation

\begin{tabular}{|c|c|c|}
\hline $\begin{array}{l}\text { Allocation concealment } \\
\text { (selection bias) }\end{array}$ & Unclear risk & $\begin{array}{l}\text { Quote: "patients were randomised to receive either standard dressing or } \mathrm{Cl} " \\
\text { Comment: no details of allocation sequence }\end{array}$ \\
\hline
\end{tabular}

Blinding of participants $\quad$ Unclear risk
and personnel (perfor-

\begin{tabular}{lll}
\hline $\begin{array}{l}\text { Blinding of outcome as- } \\
\text { sessment (detection bias) } \\
\text { All outcomes }\end{array}$ & Unclear risk & Not reported \\
\hline $\begin{array}{l}\text { Incomplete outcome data } \\
\text { (attrition bias) } \\
\text { All outcomes }\end{array}$ & Unclear risk & $\begin{array}{l}\text { Unclear how many participants had dropped out and for what reason - } 4 \\
\text { weeks analysis appears to include 25/28 participants }\end{array}$ \\
\hline $\begin{array}{l}\text { Selective reporting (re- } \\
\text { porting bias) }\end{array}$ & Unclear risk & Unclear whether outcomes were pre-specified \\
\hline Other bias & Unclear risk & No evidence of other bias but reporting insufficient to be confident \\
\hline All domain risk of bias & Low risk & Low/unclear \\
\hline
\end{tabular}

Luiza 2015

\begin{tabular}{ll}
\hline Methods & RCT \\
Arms: 2 \\
Unit of randomisation: participant \\
Unit of analysis: ulcer \\
Follow-up: 12 weeks \\
\hline
\end{tabular}

Exclusion criteria: infected ulcer, erysipelas, cellulitis, lymphangitis, devitalized tissue covering wound bed, circular limb lesions, non-palpable distal pulse, alcoholism or psychiatric disease, liver or kidney problems, allergy to study materials or latex

Participant characteristics

Number participants: 21 participants (data reported for 18 completers and 28 ulcers)

Age: all: 61.94 (12.5) range 45 to 85 ; grouped: < 60 years $40 \%$ vs $50 \%,>60$ years $60 \%$ vs $50 \%$

$\%$ male: 4 (40) vs $5(62.5)$

Ulcer details

Non VLU: unclear

Size: not reported

Duration: not reported by group $>10$ years $53.6 \%, 7$ to 10 years $3.6 \%, 4$ to 6 years $32.1 \%,<3$ years $10.7 \%$ 
Luiza 2015 (Continued)

Interventions

Intervention 1 class: papain

Intervention 1 details (name and details of application): 2\% papain gel developed at university pharmacy

Intervention 2 class: placebo

Intervention 2 details (name and details of application): $2 \%$ carboxymethyl cellulose gel developed at university pharmacy

Compression: not reported

Other co-interventions: dressing kit contained gauze, bandage, $0.9 \%$ saline solution, soothing solution for the skin surrounding the lesion

Outcomes Intervention $1: 2 / 16$

Intervention 2: 0/12

Notes Funding type and details: not reported

\section{Risk of bias}

\begin{tabular}{|c|c|c|}
\hline Bias & Authors' judgement & Support for judgement \\
\hline \multirow[t]{2}{*}{$\begin{array}{l}\text { Random sequence genera- } \\
\text { tion (selection bias) }\end{array}$} & Low risk & $\begin{array}{l}\text { Quote: "for the sake of randomization a research collaborator used a table } \\
\text { with random numbers" }\end{array}$ \\
\hline & & Comment: appropriate method of allocation concealment \\
\hline \multirow[t]{2}{*}{$\begin{array}{l}\text { Allocation concealment } \\
\text { (selection bias) }\end{array}$} & Unclear risk & $\begin{array}{l}\text { Quote: "the study participants were only informed about which group the pa- } \\
\text { tient would be allocated to at the moment of each volunteer's first consulta- } \\
\text { tion" }\end{array}$ \\
\hline & & $\begin{array}{l}\text { Comment: it was unclear whether allocation was also concealed from person- } \\
\text { nel }\end{array}$ \\
\hline
\end{tabular}

\begin{tabular}{|c|c|c|}
\hline $\begin{array}{l}\text { Blinding of participants } \\
\text { and personnel (perfor- } \\
\text { mance bias) } \\
\text { All outcomes }\end{array}$ & High risk & $\begin{array}{l}\text { Quote: "the blinding of the participants and researchers was compromised } \\
\text { due to the product characteristics" } \\
\text { Comment: appears that unblinding occurred }\end{array}$ \\
\hline $\begin{array}{l}\text { Blinding of outcome as- } \\
\text { sessment (detection bias) } \\
\text { All outcomes }\end{array}$ & Low risk & $\begin{array}{l}\text { Quote: "the evaluators of the result, who carried out the statistical analysis of } \\
\text { the data, were blinded" } \\
\text { Comment: appears that outcome assessment was blinded }\end{array}$ \\
\hline $\begin{array}{l}\text { Incomplete outcome data } \\
\text { (attrition bias) } \\
\text { All outcomes }\end{array}$ & Unclear risk & $\begin{array}{l}\text { Three participants (unknown number of ulcers) did not complete; } 1 \text { in the in- } \\
\text { tervention group and } 2 \text { in the control group. Because the number of ulcers is } \\
\text { unknown the impact on the estimate is unclear }\end{array}$ \\
\hline $\begin{array}{l}\text { Selective reporting (re- } \\
\text { porting bias) }\end{array}$ & Low risk & There was no evidence of selective outcome reporting \\
\hline Other bias & High risk & $\begin{array}{l}\text { There is a probable unit of analysis issue because randomisation took place at } \\
\text { the level of the participant while analysis took place at the level of the ulcer }\end{array}$ \\
\hline All domain risk of bias & High risk & \\
\hline
\end{tabular}


Meaume 2012

\begin{tabular}{ll}
\hline Methods & RCT \\
Arms: 2 \\
Unit of randomisation: participant \\
Unit of analysis: participant \\
Follow-up: 8 weeks
\end{tabular}

Participants

Inclusion criteria: venous leg ulcer, $5 \mathrm{~cm}^{2}$ to $-50 \mathrm{~cm}^{2}, 6$ to 36 month duration, ABPI 0.8-1.3, at least $50 \%$ wound bed covered with granulation tissue without any black necrotic tissue. If multiple ulcers, the one best meeting selection criteria was selected (had to be at least $3 \mathrm{~cm}$ from other wounds)

Exclusion criteria: infection requiring systemic antibiotics, known sensitivity to carboxymethylcellulose, venous surgery in previous 2 months, DVT in previous 3 months, concomitant severe comorbid disease or poor health status, malignant wound degeneration, treatment with immunosuppressive agents or high-dose corticosteroids

Participant characteristics

Number participants: 187

Age: 72.6 (13.0) vs $74.4(12.1)$ years

$\%$ male: 31 (33.3) vs $34(36.2)$

Ulcer details

Size: mean (SD) $17.0(15.6) \mathrm{cm}^{2}$ vs $16.6(15.8) \mathrm{cm}^{2}$, median (range) 12.9 (2.3 to 86.9) $\mathrm{cm}^{2}$ vs 10.5 (2.7 to 85.3) $\mathrm{cm}^{2}$

Duration: mean (SD) 15.6 (9.1) vs 15.1 (8.7) months, median (range) 12 (3 to 35) vs 12 (6 to 36) months

Intervention 1 class: PMM
Intervention 1 details (name and details of application): Urgostart (Laboratoires Urgo)
Intervention 2 class: foam
Intervention 2 details (name and details of application): Urgotul Absorb (Laboratoires Urgo)
Compression: "an appropriate compression therapy system, according to patient and ulcer status, was
selected and applied by the investigating physician"
Other co-interventions: not reported

Outcomes Intervention 1: 6/93

Intervention 2: 7/94

Notes Funding type: industry

Funding details: Laboratoires URGO

\section{Risk of bias}

\begin{tabular}{lll}
\hline Bias & Authors' judgement & Support for judgement \\
\hline $\begin{array}{ll}\text { Random sequence genera- } \\
\text { tion (selection bias) }\end{array}$ & Low risk & $\begin{array}{l}\text { Quote: "the randomization code was generated in blocks of two using a com- } \\
\text { puter program and was stratified by center" }\end{array}$
\end{tabular}




Allocation concealment Low risk

Quote: "Individual sterile dressings were packed in boxes of 35 dressings per participant. Each box and dressing was identified by a center identification number and participant number corresponding to the chronological participant inclusion number... the procedure to break the randomization code was not provided to the participating centers"

Comment: probably sufficient for low risk of bias

$\begin{array}{ll}\text { Blinding of participants } & \text { Low risk } \\ \begin{array}{l}\text { and personnel (perfor- } \\ \text { mance bias) }\end{array} & \begin{array}{l}\text { Quote: "both dressings were identical in appearance, shape, color and packag- } \\ \text { ing ... they could be used in a double-blind trial" "the procedure to break the } \\ \text { randomization code was not provided to the participating centers" }\end{array}\end{array}$

All outcomes

Comment: appears personnel and participants were blinded

\begin{tabular}{|c|c|c|}
\hline $\begin{array}{l}\text { Blinding of outcome as- } \\
\text { sessment (detection bias) } \\
\text { All outcomes }\end{array}$ & Low risk & $\begin{array}{l}\text { Quote: "the VLU was evaluated by the investigating physician ... at each visit, } \\
\text { the wound evaluations were repeated (clinical assessment, acetate tracing, } \\
\text { and wound photo)" }\end{array}$ \\
\hline
\end{tabular}

Comment: double-blind trial and outcome assessors were the investigators

\begin{tabular}{lll}
\hline $\begin{array}{l}\text { Incomplete outcome data } \\
\text { (attrition bias) }\end{array}$ & High risk & $4 / 93(4 \%)$ and $6 / 94(6 \%)$ withdrew and were lost to follow-up. An addition- \\
All outcomes & al $11 / 93(12 \%)$ and $11 / 94(12 \%)$ switched to "another" dressing, but were fol- \\
& lowed up in the groups to which they were randomised. Number missing com- \\
& parable with number of events for healing (6 and 7$)$
\end{tabular}

\begin{tabular}{lll}
\hline $\begin{array}{l}\text { Selective reporting (re- } \\
\text { porting bias) }\end{array}$ & Unclear risk & $\begin{array}{l}\text { High risk for outcomes other than healing; unclear whether there may be is- } \\
\text { sues with the healing reporting }\end{array}$ \\
\hline Other bias & Unclear risk & $\begin{array}{l}\text { Potential for baseline differences between groups but unclear what the impact } \\
\text { of these would be }\end{array}$ \\
\hline
\end{tabular}

All domain risk of bias High risk

Meredith 1988

$\begin{array}{ll}\text { Methods } & \text { RCT } \\ & \text { Arms: } 2 \\ & \text { Unit of randomisation: participant } \\ & \text { Unit of analysis: participant } \\ & \text { Follow-up: } 6 \text { weeks }\end{array}$

Participants Inclusion criteria: leg ulcer diagnosed clinically as due to venous insufficiency. All clinic attendees eligible, including diabetics

Exclusion criteria: treatment with Jelonet or Granuflex in previous 2 weeks, treatment with systemic corticosteroids exceeding $0.5 \mathrm{mg} /$ day, malignant ulcer, obvious peripheral arterial ischaemia

Participant characteristics

Number participants: 50 (49 reported on)

Age: mean (range) 70.4 (32 to 92 ) years

$\%$ male: 15 (30) 
Meredith 1988 (Continued)

Ulcer details

Size: not reported

Duration: not reported

Interventions

Intervention 1 class: hydrocolloid

Intervention 1 details (name and details of application): Granuflex; applied to extend at least $3 \mathrm{~cm}$ beyond ulcer margin. Changed weekly, or sooner if exudate leaked

Intervention 2 class: nonadherent

Intervention 2 details (name and details of application): paraffin gauze; Jelonet; applied to cover the ulcer then cotton dressing gauze pad placed over and secured with micropore tape. Changed when exudate penetrated to outer layers of dressings

Compression: support bandaging with elastocrepe or non-shaped Tubigrip

Other co-interventions: ulcers cleaned with saline and/or povidone iodine

Outcomes Intervention 1: 19/25

Intervention 2: 6/25

Notes $\quad$ Funding type: not reported

Funding details: not reported but Squibb Surgicare employees listed in acknowledgements

\section{Risk of bias}

Bias Authors' judgement Support for judgement

Random sequence genera- Low risk tion (selection bias)

Quote: "they were randomised to either of the two treatments according to a table of random numbers held by ourselves"

Comment: appropriate method of random sequence generation

\begin{tabular}{ll}
\hline $\begin{array}{l}\text { Allocation concealment } \\
\text { (selection bias) }\end{array}$ & $\begin{array}{l}\text { Unclear risk } \\
\text { Quote: "they were randomised to either of the two treatments according to a } \\
\text { table of random numbers held by ourselves" }\end{array}$ \\
& Comment: unclear how allocation was concealed \\
\hline
\end{tabular}

Blinding of participants Unclear risk Not reported

and personnel (perfor-

mance bias)

All outcomes

\begin{tabular}{ll}
\hline Blinding of outcome as- & Unclear risk
\end{tabular}

\begin{tabular}{ll}
\hline $\begin{array}{l}\text { Incomplete outcome data } \\
\text { (attrition bias) }\end{array}$ & Low risk \\
All outcomes & One participant withdrew and was excluded from results but this is unlikely to \\
\end{tabular}

\begin{tabular}{lll}
\hline $\begin{array}{l}\text { Selective reporting (re- } \\
\text { porting bias) }\end{array}$ & Unclear risk & Not clear which outcomes were pre-specified \\
\hline Other bias & Unclear risk & No evidence of other bias but reporting insufficient to be certain \\
\hline
\end{tabular}


Meredith 1988 (Continued)
All domain risk of bias
Low risk
Low/unclear

Michaels 2009

$\begin{array}{ll}\text { Methods } & \text { RCT } \\ \text { Arms: } 2 \\ \text { Unit of randomisation: participant } \\ \text { Unit of analysis: leg (1 limb/participant designated as index) } \\ \text { Follow-up: } 12 \text { weeks }\end{array}$

Participants Inclusion criteria: ulceration of lower leg present for $>6$ weeks. If ulceration on both legs, that with greater ulcer area was index limb

Exclusion criteria: insulin-controlled diabetes, pregnancy, sensitivity to silver, $A B P I<0.8$, ulcer with maximum diameter $<1 \mathrm{~cm}$, atypical ulcers, oral or parenteral antibiotics

Participant characteristics

Number participants: 213 (107 vs 106), 208 included in results

Age: 68.8 (16.7) vs $72.4(13.7)$ years

$\%$ male: 54 (50) vs 44 (42)

Ulcer details:

Size: > $3 \mathrm{~cm}: 30(28 \%)$ vs $30(28 \%),<3 \mathrm{~cm} 77(72 \%)$ vs $76(72 \%)$

Duration: not reported

\begin{tabular}{ll}
\hline Interventions & Intervention 1 class: silver \\
& Intervention 1 details (name and details of application): choice of Aquacel Ag (ConvaTec), Acticoat, \\
Acticoat 7, Acticoat Absorbent (all Smith \& Nephew), Contreet Foam (Coloplast), Urgotul SSD (Urgo); \\
dressings changed on weekly basis (or sooner if judged necessary) \\
Intervention 2 class: nonadherent \\
Intervention 2 details (name and details of application): Urgotul, Biatain (Coloplast), Atrauman (Paul \\
Hartmann Ltd), Allevyn (Smith \& Nephew); dressings changed on weekly basis (or sooner if judged nec- \\
essary) \\
Compression: multilayer compression bandaging \\
Other co-interventions: debridement if clinically appropriate \\
\hline Intervention 1: $62 / 104$ \\
Intervention 2: $59 / 104$ \\
\hline Futcomes \\
Funding type and details: non-industry
\end{tabular}

Risk of bias 
Michaels 2009 (Continued)

\section{Bias Authors' judgement Support for judgement}

Random sequence genera- Low risk tion (selection bias)

Quote: "treatment allocation ... was carried out using a computer program to generate stratified block randomisation with variable block size"

Comment: appropriate methods of sequence generation

Allocation concealment Low risk
(selection bias)

Quote: "trial numbers and randomisation were allocated through a telephone-based service"

Comment: appropriate method of allocation concealment

\begin{tabular}{|c|c|c|}
\hline $\begin{array}{l}\text { Blinding of participants } \\
\text { and personnel (perfor- } \\
\text { mance bias) }\end{array}$ & High risk & $\begin{array}{l}\text { Quote: "it was not possible to blind either the patients or the nurses applying } \\
\text { the dressings" }\end{array}$ \\
\hline All outcomes & & Comment: neither participants nor personnel were blinded \\
\hline
\end{tabular}

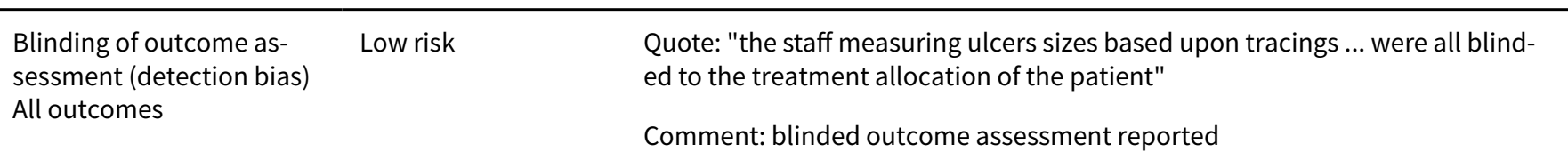

\begin{tabular}{lll}
$\begin{array}{l}\text { Incomplete outcome data } \\
\text { (attrition bias) } \\
\text { All outcomes }\end{array}$ & Low risk & $\begin{array}{l}\text { Only } 5 \text { participants were not included in the analysis. This is unlikely to have } \\
\text { affected the treatment effect. }\end{array}$ \\
\hline $\begin{array}{l}\text { Selective reporting (re- } \\
\text { porting bias) }\end{array}$ & Low risk & No evidence of selective reporting \\
\hline Other bias & Low risk & No evidence of other sources of bias \\
\hline All domain risk of bias & High risk & \\
\hline
\end{tabular}

\section{Moffatt 1992a}

\begin{tabular}{ll}
\hline Methods & RCT \\
Arms: 2 & Unit of randomisation: participant \\
& Unit of analysis: participant \\
& Follow-up: 12 weeks \\
\hline Inclusion criteria: venous ulcer that had failed to heal within 24 weeks of high compression therapy or \\
had failed to reduce in size by more than $20 \%$ within 12 weeks \\
Exclusion criteria: arterial disease (ABI < 0.8$)$, known allergy to study products \\
Participant characteristics \\
Number participants: 60 \\
Age: median (range) 74 (50 to 89$)$ vs 71 (26 to 87 ) years \\
\% male: 15 (50) vs 12 (40) \\
Ulcer details
\end{tabular}


Moffatt 1992a (Continued)

Size: median (range) 7.3 (1.3 to 66.3 ) $\mathrm{cm}^{2}$ vs 6.7 (2.6 to 14.9$) \mathrm{cm}^{2}$

Duration: not reported

Intervention 1 class: hydrocolloid
Intervention 1 details (name and details of application): Comfeel (Coloplast)
Intervention 2 class: nonadherent
Intervention 2 details (name and details of application): not reported
Compression: 4 layer bandage technique
Other co-interventions: not reported

Outcomes Intervention 1: 13/30

Intervention 2: $7 / 30$

\begin{tabular}{ll}
\hline Notes & Funding type and details: industry \\
& Funding details: Comfeel Ltd \\
\hline
\end{tabular}

\section{Risk of bias}

Bias Authors' judgement Support for judgement

Random sequence genera- Unclear risk Quote: "randomization took place by assigning sequential numbers to each tion (selection bias) patient as they entered the trial, and relating this number to a randomization group"

Comment: unclear how the randomisation sequence was generated

\begin{tabular}{|c|c|c|}
\hline \multirow[t]{2}{*}{$\begin{array}{l}\text { Allocation concealment } \\
\text { (selection bias) }\end{array}$} & Unclear risk & $\begin{array}{l}\text { Quote: "randomization took place by assigning sequential numbers to each } \\
\text { patient as they entered the trial, and relating this number to a randomization } \\
\text { group" }\end{array}$ \\
\hline & & Comment: unclear how allocation concealment was carried out \\
\hline
\end{tabular}

Blinding of participants Unclear risk Not reported
and personnel (perfor-
mance bias)
All outcomes

\begin{tabular}{lll}
\hline Blinding of outcome as- & Unclear risk & Not reported \\
sessment (detection bias) & \\
All outcomes &
\end{tabular}

All outcomes

Incomplete outcome data Unclear risk (attrition bias)

Quote: "patients were followed up to 12 weeks with the exception of four pa-

All outcomes tients, two of whom refused to continue with the treatment, and two patients who died within the 12-week period"

Comment: it was not clear to which group participants who were not followed up were assigned.

\begin{tabular}{lll}
\hline $\begin{array}{l}\text { Selective reporting (re- } \\
\text { porting bias) }\end{array}$ & Low risk & The main endpoint was specified and reported \\
\hline Other bias & Unclear risk & $\begin{array}{l}\text { There was no evidence of other sources of bias but reporting was insufficient } \\
\text { to be confident of this }\end{array}$ \\
\hline
\end{tabular}


Moffatt 1992a (Continued)
All domain risk of bias
Low risk
Low/unclear

Moffatt 1992b

$\begin{array}{ll}\text { Methods } & \text { RCT } \\ \text { Arms: } 2 \\ \text { Unit of randomisation: participant } \\ \text { Unit of analysis: participant } \\ \text { Follow-up: } 12 \text { weeks }\end{array}$

Inclusion criteria: Venous leg ulcer with surface area $<10 \mathrm{~cm}^{2}$
Exclusion criteria: $\mathrm{ABPI}<0.8$ (arterial component to ulcer)
Participant characteristics
Number participants: 60
Age: median (range) 78 (44 to 88$)$ vs 70 (38 to 88 ) years
\% male: 10 (33) vs $13(44)$
Ulcer details
Size: median (range) $3.6(0.9$ to 9.8$) \mathrm{cm}^{2}$ vs $6.4(1.1$ to 9.9$) \mathrm{cm}^{2}$
Duration: median (range) $2.0(1$ to 192 ) vs $3(1$ to 20$)$ (units not reported - months?)

\begin{tabular}{ll}
\hline Interventions & Intervention 1 class: alginate \\
Intervention 1 details (name and details of application) Tegagel (3M); Dressing changed weekly unless \\
excessive exudate or infection \\
Intervention 2 class: nonadherent \\
Intervention 2 details (name and details of application): NA (Johnson \& Johnson); Dressing changed \\
weekly unless excessive exudate or infection \\
Compression: Graduated compression bandage system- 40 mmHg2 at ankle \\
Other co-interventions: not reported \\
\hline Intervention 1: $26 / 30$ \\
Intervention 2: $24 / 30$ \\
\hline Futcomes \\
Funding type: industry
\end{tabular}

\section{Risk of bias}

Bias Authors' judgement Support for judgement

\begin{tabular}{|c|c|c|}
\hline $\begin{array}{l}\text { Random sequence genera- } \\
\text { tion (selection bias) }\end{array}$ & Unclear risk & $\begin{array}{l}\text { Quote: "patients were entered into the trial and randomised to either of the } \\
\text { two dressing types" }\end{array}$ \\
\hline
\end{tabular}




\begin{tabular}{|c|c|c|}
\hline $\begin{array}{l}\text { Allocation concealment } \\
\text { (selection bias) }\end{array}$ & Unclear risk & $\begin{array}{l}\text { Quote: "patients were entered into the trial and randomised to either of the } \\
\text { two dressing types" } \\
\text { Comment: unclear how the allocation was concealed }\end{array}$ \\
\hline $\begin{array}{l}\text { Blinding of participants } \\
\text { and personnel (perfor- } \\
\text { mance bias) } \\
\text { All outcomes }\end{array}$ & Unclear risk & This was not reported on \\
\hline $\begin{array}{l}\text { Blinding of outcome as- } \\
\text { sessment (detection bias) } \\
\text { All outcomes }\end{array}$ & Unclear risk & This was not reported on \\
\hline $\begin{array}{l}\text { Incomplete outcome data } \\
\text { (attrition bias) } \\
\text { All outcomes }\end{array}$ & Low risk & All participants appeared to be included in the analysis. \\
\hline $\begin{array}{l}\text { Selective reporting (re- } \\
\text { porting bias) }\end{array}$ & Low risk & $\begin{array}{l}\text { There was no evidence of selective reporting; reporting was limited but the tri- } \\
\text { al appeared designed to measure the outcome reported }\end{array}$ \\
\hline Other bias & Unclear risk & $\begin{array}{l}\text { There was no evidence of other sources of bias but reporting was insufficient } \\
\text { to be certain }\end{array}$ \\
\hline All domain risk of bias & Low risk & Low/unclear \\
\hline
\end{tabular}

Moss 1987

$\begin{array}{ll}\text { Methods } & \text { RCT } \\ \text { Arms: } 2 \\ \text { Unit of randomisation: participant } \\ \text { Unit of analysis: participant } \\ \text { Follow-up: } 6 \text { weeks (26 week trial with optional cross-over at } 6 \text { weeks) }\end{array}$

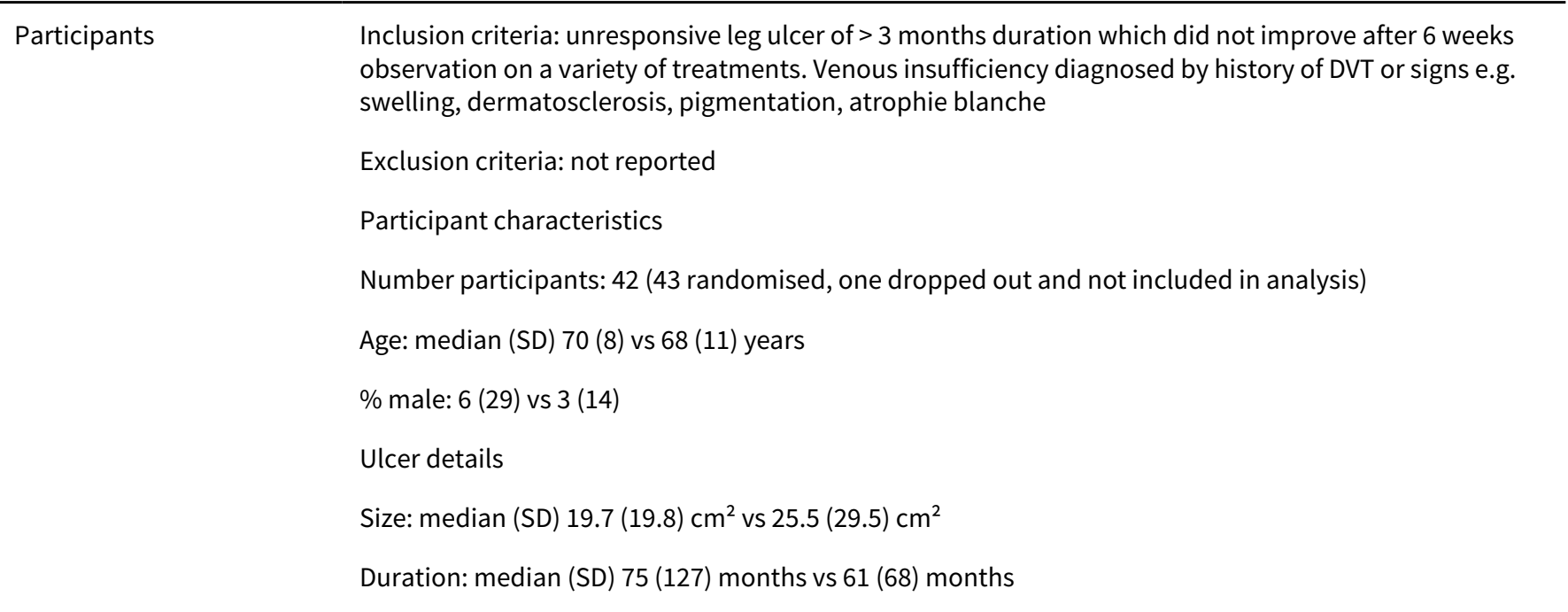


Moss 1987 (Continued)

Interventions

Intervention 1 class: cadexomer iodine $(\mathrm{Cl})$

Intervention 1 details (name and details of application): lodosorb; ulcer cleaned with saline, then filled with powder and covered with non-adhesive pad. Changed daily

Intervention 2 class: dextranomer

Intervention 2 details (name and details of application): Debrisan; ulcer cleaned with saline, then filled with powder and covered with non-adhesive pad. Changed daily

Compression: see other co-interventions

Other co-interventions: saline wash; treatment powder dressing covered with non adhesive pad, cotton-wool wadding, stockingnette and firm elastic bandage

\begin{tabular}{ll}
\hline Outcomes & Intervention 1: 0/21 at 6-week cross-over \\
& Intervention 2: 0/21 at 6-week cross-over \\
\hline Notes & Funding type: industry \\
& Funding details: TIL (Medical) Ltd \\
\hline
\end{tabular}

\section{Risk of bias}

\begin{tabular}{lll}
\hline Bias & Authors' judgement & Support for judgement \\
\hline $\begin{array}{ll}\text { Random sequence genera- } \\
\text { tion (selection bias) }\end{array}$ & Unclear risk & $\begin{array}{l}\text { Quote: "those still not improving }(\mathrm{n}=42) \text { were randomly allocated to treat- } \\
\text { ment with either dextranomer or } \mathrm{Cl}\end{array}$ \\
& & Comment: unclear how the randomisation sequence was generated \\
\hline
\end{tabular}

\begin{tabular}{|c|c|c|}
\hline $\begin{array}{l}\text { Allocation concealment } \\
\text { (selection bias) }\end{array}$ & Unclear risk & $\begin{array}{l}\text { Quote: "those still not improving }(n=42) \text { were randomly allocated to treat- } \\
\text { ment with either dextranomer or } \mathrm{Cl} \text { " }\end{array}$ \\
\hline
\end{tabular}

Comment: unclear how allocation was concealed

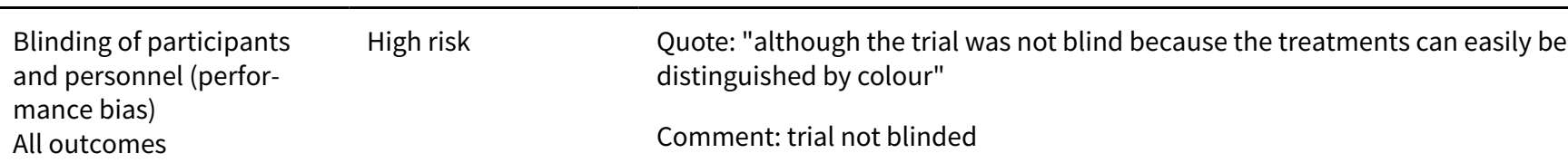

\begin{tabular}{|c|c|c|}
\hline $\begin{array}{l}\text { Blinding of outcome as- } \\
\text { sessment (detection bias) }\end{array}$ & High risk & $\begin{array}{l}\text { Quote: "assessments [...] could not be blind because, even after the dressings } \\
\text { were removed, difference in colour were still apparent" }\end{array}$ \\
\hline
\end{tabular}

\begin{tabular}{|c|c|c|}
\hline $\begin{array}{l}\text { Incomplete outcome data } \\
\text { (attrition bias) } \\
\text { All outcomes }\end{array}$ & Low risk & Only one participant was not included in the analysis \\
\hline $\begin{array}{l}\text { Selective reporting (re- } \\
\text { porting bias) }\end{array}$ & Low risk & There was no evidence of selective reporting of outcomes \\
\hline Other bias & Low risk & $\begin{array}{l}\text { There was no evidence of other sources of bias; it was not clear whether the } \\
\text { cross-over was planned but this does not impact on the data before the cross- } \\
\text { over point. }\end{array}$ \\
\hline
\end{tabular}

\begin{tabular}{ll}
\hline All domain risk of bias & High risk \\
\hline All domain risk of bias 2 & High risk \\
\hline
\end{tabular}




$\begin{array}{ll}\text { Methods } & \text { RCT } \\ \text { Arms: } 2 \text { relevant groups (a } 2 \times 2 \times 2 \text { factorial design for compression and pentoxifylline also) } \\ \text { Unit of randomisation: participant } \\ \text { Unit of analysis: participant } \\ \text { Follow-up: } 24 \text { weeks }\end{array}$

Participants Inclusion criteria: clinically diagnosed (clinical signs and Doppler confirmation of venous pathology) venous leg ulcer at least $1 \mathrm{~cm}$ length and 8 weeks duration

Exclusion criteria: significant arterial disease $(\mathrm{ABPI}<0.8)$, diabetes mellitus, pregnant or lactating women, known concurrent severe illness, sensitivity to methylxanthines or caffeine, using warfarin, steroids, oxpentifylline, oxerutins, Naftidrofuryl, life expectancy $<6$ months, grossly infected or gangrenous ulcer, immobile, immunosuppression

Participant characteristics

Number participants: 245

Age: 70.3 (12.0) vs $69.7(10.6)$ years

$\%$ male: 43 (34) vs 37 (31)

Ulcer details

Size: mean (SD) 794 (1210) mm² vs 910 (2600) mm², median (range) 404 (50 to 10118) mm² vs 359 (63 to 26311) $\mathrm{mm}^{2}$

Duration: mean (SD) 11.3 (25.0) months vs 14.8 (29.8) months, median (range) 4.0 (2 to 204) months vs 6.5 (2 to 240 ) months

Intervention 1 details (name and details of application): Granuflex E (ConvaTec), also known as Duoderm CGF; dressing changed weekly or more frequently if required

Intervention 2 class: nonadherent

Intervention 2 details (name and details of application): NA (Johnson \& Johnson); dressing changed weekly or more frequently if required

Compression: participants were randomised to either 4-layer bandage applied using Charing Cross technique or single layer hydrocolloid-lined, woven, elastomeric, adhesive bandage applied in figure-8 technique

Other co-interventions: ulcers cleansed with tap water and skin moisturised with arachis or olive oil. Within factorial design participants were also randomised to receive pentoxifylline or placebo

\begin{tabular}{ll}
\hline Outcomes & Intervention 1: $72 / 127$ \\
& Intervention 2: $69 / 118$
\end{tabular}

Notes

Funding type and details: industry/mixed

Funding details: "supported by Hoechst Roussel Ltd, ConvaTec UK Ltd and Chief Scientist Office, Scotland"

\section{Risk of bias}


Nelson 2007 (Continued)

\section{Bias Authors' judgement Support for judgement}

Random sequence genera- Low risk tion (selection bias)

Quote: "randomization was stratified by clinical center and simple/non simple venous disease using permuted blocks of length 8 "

Comment: likely that appropriate method used to generate sequence

\begin{tabular}{ll}
\hline $\begin{array}{l}\text { Allocation concealment } \\
\text { (selection bias) }\end{array}$ & Low risk \\
& $\begin{array}{l}\text { Quote: "sealed, sequentially numbered opaque envelopes were use to allocate } \\
\text { participants" }\end{array}$ \\
& $\begin{array}{l}\text { Comment: appropriate method used to ensure adequate allocation conceal- } \\
\text { ment }\end{array}$
\end{tabular}

\begin{tabular}{|c|c|c|}
\hline $\begin{array}{l}\text { Blinding of participants } \\
\text { and personnel (perfor- }\end{array}$ & High risk & $\begin{array}{l}\text { Quote: "both patients and nurses were aware of the allocated bandage and } \\
\text { dressing after assignment" }\end{array}$ \\
\hline
\end{tabular}

mance bias)

Comment: neither participants nor personnel were blinded

\begin{tabular}{lll}
\hline $\begin{array}{l}\text { Blinding of outcome as- } \\
\text { sessment (detection bias) }\end{array}$ & High risk & $\begin{array}{l}\text { Quote: "nurses completed a dressing log at each leg ulcer dressing visit, which } \\
\text { recorded whether or not an ulcer was healed" }\end{array}$
\end{tabular}

All outcomes

Comment: outcome assessed by unblinded nurses

\begin{tabular}{lll}
\hline $\begin{array}{l}\text { Incomplete outcome data } \\
\text { (attrition bias) } \\
\text { All outcomes }\end{array}$ & Low risk & ITT analysis \\
\hline $\begin{array}{l}\text { Selective reporting (re- } \\
\text { porting bias) }\end{array}$ & Low risk & There was no evidence of selective outcome reporting and reporting was clear \\
\hline Other bias & Low risk & There was no evidence of other sources of bias \\
\hline All domain risk of bias & High risk & \\
\hline All domain risk of bias 2 & High risk
\end{tabular}

Norkus 2005

\begin{tabular}{ll}
\hline Methods & RCT \\
Arms: 2 & Unit of randomisation: participant \\
& Unit of analysis: participant \\
& Follow-up: up to 12 months \\
\hline Participants & ABclusion criteria: highly exuding leg ulcer present for at least 4 weeks, maximum ulcer size $8 \mathrm{~cm} \times 8 \mathrm{~cm}$, \\
& Exclusion criteria: clinical signs of wound infection, severe eczema, lymphatic or malignant ulcers, sys- \\
& temic treatment with corticosteroids other immunosuppressants during study or in 3 months prior \\
& Participant characteristics \\
& Number participants: 97 \\
& Age: median (range) 70 ( 33 to 89 ) vs 70 (29 to 97 ) years
\end{tabular}


Norkus 2005 (Continued)
$\%$ male: 21 (43) vs $23(48)$
Ulcer details
Non VLU: $89.6 \%$ vs $93.5 \%$ venous, protocol violation meant some mixed $(10.4 \%$ vs $4.4 \%)$ and arterial (0\% vs $2.1 \%$ ) were included
Size: median (range) $9.3 \mathrm{~cm}^{2}$ (0.9 to 38.1 ) $\mathrm{cm}^{2}$ vs $6.4 \mathrm{~cm}^{2}$ (0.5 to 51.4$) \mathrm{cm}^{2}$
Duration: median (range) 1.0 (0.1 to 19.0$)$ years vs 0.7 (0.1 to 27.0) years

\begin{tabular}{ll}
\hline Interventions & Intervention 1 class: foam \\
Intervention 1 details (name and details of application): Alione (Coloplast A/S); Dressing changed when \\
necessary (maximum 7 days) \\
Intervention 2 class: hydrocolloid \\
Intervention 2 details (name and details of application): Tielle and Tielle plus (Johnson \& Johnson); \\
Tielle Plus used at start of study, changing to Tielle when dressing changes required less than once per \\
day. Dressing changed when necessary (maximum 7 days) \\
Compression: those treated with compression at the start continued using it throughout study (36 \\
(75\%) vs 32 (68\%) participants used it) \\
Other co-interventions: ulcers cleaned and debrided if necessary according to normal practice at cen- \\
tre \\
\hline Intervention 1: $25 / 49$ \\
Intervention 2: $19 / 48$ \\
\hline Futcomes \\
Funding type and details: industry \\
\hline Notes
\end{tabular}

\section{Risk of bias}

Bias Authors' judgement Support for judgement

\begin{tabular}{ll}
\hline $\begin{array}{l}\text { Random sequence genera- } \\
\text { tion (selection bias) }\end{array}$ & Low risk \\
& $\begin{array}{l}\text { Quote: "the study used an open comparative block randomised multicentre } \\
\text { design" }\end{array}$ \\
& $\begin{array}{l}\text { Comment: appears very likely that appropriate sequence generation methods } \\
\text { were used }\end{array}$
\end{tabular}

\begin{tabular}{ll}
\hline $\begin{array}{l}\text { Allocation concealment } \\
\text { (selection bias) }\end{array}$ & Low risk \\
& $\begin{array}{l}\text { Quote: "the study used an open comparative block randomised multicentre } \\
\text { design". }\end{array}$ \\
& $\begin{array}{l}\text { Comment: appears that centralised allocation will have ensured concealed al- } \\
\text { location }\end{array}$ \\
\hline
\end{tabular}

\begin{tabular}{|c|c|c|}
\hline $\begin{array}{l}\text { Blinding of participants } \\
\text { and personnel (perfor- } \\
\text { mance bias) }\end{array}$ & High risk & $\begin{array}{l}\text { Quote: "the study used an open comparative block randomised multicentre } \\
\text { design" }\end{array}$ \\
\hline All outcomes & & Comment: an open design was used \\
\hline
\end{tabular}

Blinding of outcome as- High risk sessment (detection bias) All outcomes
Quote: "after cleansing with water or isotonic saline, the ulcer was traced using planimetry, photographed and redressed"

Comment: it was not clear who assessed healing but the open design means there is a high risk of bias 
Norkus 2005 (Continued)

Incomplete outcome data Low risk Quote: "the statistical analysis was carried out as intention to treat (ITT) with (attrition bias) last observation carried forward (LOCF)"

All outcomes

Comment: ITT analysis

\begin{tabular}{lll}
\hline $\begin{array}{l}\text { Selective reporting (re- } \\
\text { porting bias) }\end{array}$ & Low risk & All the specified outcomes were fully reported \\
\hline Other bias & Low risk & $\begin{array}{l}\text { There was no apparent risk of other bias and reporting was sufficient to be rea- } \\
\text { sonably confident of this }\end{array}$ \\
\hline All domain risk of bias & High risk & \\
\hline All domain risk of bias 2 & High risk \\
\hline
\end{tabular}

Ohlsson 1994

$\begin{array}{ll}\text { Methods } & \text { RCT } \\ \text { Arms: } 2 \\ \text { Unit of randomisation: participant } \\ \text { Unit of analysis: participant } \\ \text { Follow-up: } 6 \text { weeks }\end{array}$

Participants Inclusion criteria: leg ulcer of venous or mixed aetiology

Exclusion criteria: not reported

Participant characteristics

Number participants: 30 (28 analysed)

Age: median (range) 76 (49 to 89 ) years

$\%$ male: 4 (13)

Ulcer details

Non VLU: 4/14 (29\%) vs 2/14 (14\%) mixed venous/arterial (21\% overall)

Size: mean $1387 \mathrm{~mm}^{2}$ vs $857 \mathrm{~mm}^{2}$

Duration: not reported
Interventions
Intervention 1 class: hydrocolloid
Intervention 1 details (name and details of application): changed once a week or more frequently if needed
Intervention 2 class: saline gauze
Intervention 2 details (name and details of application): changed once a week or more frequently if needed
Compression: low-stretch compression bandage
Other co-interventions: ulcers cleaned with soap and water 
Ohlsson 1994 (Continued)

Outcomes Intervention $1: 7 / 14$

Intervention 2: 2/14

\begin{tabular}{|c|c|c|}
\hline Notes & \multicolumn{2}{|c|}{ Funding type and details: not reported } \\
\hline \multicolumn{3}{|l|}{ Risk of bias } \\
\hline Bias & Authors' judgement & Support for judgement \\
\hline $\begin{array}{l}\text { Random sequence genera- } \\
\text { tion (selection bias) }\end{array}$ & Unclear risk & $\begin{array}{l}\text { Quote: "the patients were randomly allocated ..." } \\
\text { Comment: no information on how the randomisation sequence was generated }\end{array}$ \\
\hline $\begin{array}{l}\text { Allocation concealment } \\
\text { (selection bias) }\end{array}$ & Unclear risk & $\begin{array}{l}\text { Quote: "the patients were randomly allocated ..." } \\
\text { Comment: no information on how allocation was concealed }\end{array}$ \\
\hline $\begin{array}{l}\text { Blinding of participants } \\
\text { and personnel (perfor- } \\
\text { mance bias) } \\
\text { All outcomes }\end{array}$ & Unclear risk & Not reported \\
\hline $\begin{array}{l}\text { Blinding of outcome as- } \\
\text { sessment (detection bias) } \\
\text { All outcomes }\end{array}$ & Low risk & $\begin{array}{l}\text { Quote: "changes in ulcer area/healing were blindly measured by two indepen- } \\
\text { dent investigators" } \\
\text { Comment: blinded outcome evaluation }\end{array}$ \\
\hline $\begin{array}{l}\text { Incomplete outcome data } \\
\text { (attrition bias) } \\
\text { All outcomes }\end{array}$ & Low risk & 2 participants dropped out of the study one in each group, reasons were given \\
\hline $\begin{array}{l}\text { Selective reporting (re- } \\
\text { porting bias) }\end{array}$ & Low risk & There was no evidence of selective reporting of outcomes \\
\hline Other bias & Unclear risk & $\begin{array}{l}\text { There was no evidence of other sources of bias but reporting was insufficient } \\
\text { to be certain }\end{array}$ \\
\hline All domain risk of bias & Low risk & Low/unclear \\
\hline
\end{tabular}

\section{Ormiston 1985}

\begin{tabular}{ll}
\hline Methods & RCT \\
Arms: 2 \\
Unit of randomisation: participant \\
Unit of analysis: participant \\
Follow-up: 24 weeks (optional cross-over at 12 weeks) \\
\hline Inclusion criteria: chronic venous ulcer $>3$ months \\
Exclusion criteria: clinical or laboratory evidence ulcer was of non-venous aetiology, ABPI <0.7, expect- \\
ed poor compliance \\
Participant characteristics
\end{tabular}


Ormiston 1985 (Continued)

Number participants: 61 (60 analysed)

Age: 67.3 (9.7) vs 70.3 (13.3) years

\% male: 13 (43\%) vs $8(27 \%)$

Ulcer details

Size: mean (SD) $12.1(13.9) \mathrm{cm}^{2}$ vs $10.2(8.7) \mathrm{cm}^{2}$

Duration: mean (SD) 45.9 (105.9 months) vs 15.9 (19.5) months, median (range) 8.5 (3 to 517) vs 6 (3 to 96) months

\begin{tabular}{|c|c|c|}
\hline \multirow[t]{6}{*}{ Interventions } & \multicolumn{2}{|c|}{ Intervention 1 class: cadexomer iodine } \\
\hline & \multicolumn{2}{|c|}{$\begin{array}{l}\text { Intervention } 1 \text { details (name and details of application): ulcer cleaned with saline; sprinkled in layer } 0.3 \\
\mathrm{~cm} \text { to } 0.5 \mathrm{~cm} \text { deep, covered with gauze pad }\end{array}$} \\
\hline & \multicolumn{2}{|c|}{ Intervention 2 class: gentian violet } \\
\hline & \multicolumn{2}{|c|}{$\begin{array}{l}\text { Intervention } 2 \text { details (name and details of application): gentian violet and polyfax (polymyxin and bac- } \\
\text { itracin) ointment; gentian violet painted on, polyfax applied over in generous layer, covered with non- } \\
\text { adherent (Melolin) pad }\end{array}$} \\
\hline & \multicolumn{2}{|c|}{ Compression: crepe bandage followed by cotton crepe compression bandage } \\
\hline & \multicolumn{2}{|c|}{ Other co-interventions: ulcer cleaned with saline } \\
\hline \multirow[t]{2}{*}{ Outcomes } & \multicolumn{2}{|l|}{ Intervention $1: 12 / 30$} \\
\hline & \multicolumn{2}{|l|}{ Intervention 2: $7 / 30$} \\
\hline Notes & \multicolumn{2}{|c|}{ Funding type and details: not reported; Perstorp AB provided cadexomer iodine } \\
\hline \multicolumn{3}{|l|}{ Risk of bias } \\
\hline Bias & Authors' judgement & Support for judgement \\
\hline \multirow[t]{2}{*}{$\begin{array}{l}\text { Random sequence genera- } \\
\text { tion (selection bias) }\end{array}$} & Unclear risk & $\begin{array}{l}\text { Quote: "for each number there was a double sealed envelope that contained } \\
\text { a paper stating which treatment the patient should receive. The sequence [...] } \\
\text { Was randomised and the code of randomisation was not available to the inves- } \\
\text { tigators" }\end{array}$ \\
\hline & & Comment: generation of randomisation sequence was unclear \\
\hline \multirow[t]{2}{*}{$\begin{array}{l}\text { Allocation concealment } \\
\text { (selection bias) }\end{array}$} & Low risk & $\begin{array}{l}\text { Quote: "for each number there was a double sealed envelope that contained a } \\
\text { paper stating which treatment the patient should receive. The sequence... Was } \\
\text { randomised and the code of randomisation was not available to the investiga- } \\
\text { tors" }\end{array}$ \\
\hline & & Comment: appropriate concealment of allocation \\
\hline
\end{tabular}

\begin{tabular}{lll}
$\begin{array}{l}\text { Blinding of participants } \\
\text { and personnel (perfor- }\end{array}$ & Unclear risk & \\
mance bias) & & \\
All outcomes & & \\
\hline $\begin{array}{l}\text { Blinding of outcome as- } \\
\text { sessment (detection bias) } \\
\text { All outcomes }\end{array}$ & Low risk & Not reported \\
\hline
\end{tabular}


Ormiston 1985 (Continued)
Incomplete outcome data
Low risk
Almost all participants were included in the analysis
(attrition bias)

All outcomes

\begin{tabular}{|c|c|c|}
\hline $\begin{array}{l}\text { Selective reporting (re- } \\
\text { porting bias) }\end{array}$ & Unclear risk & There is no obvious selective reporting but outcomes are not clearly specified \\
\hline Other bias & High risk & $\begin{array}{l}\text { Quote: "ulcers in the group receiving cadexomer iodine had not healed for a } \\
\text { mean of } 46 \text { months, compared with } 16 \text { months for the standard group" }\end{array}$ \\
\hline & & $\begin{array}{l}\text { Comment: impact of this baseline imbalance was unclear but it is substantial } \\
\text { enough to constitute a risk of bias }\end{array}$ \\
\hline
\end{tabular}

All domain risk of bias High risk

\section{Petkov 1997}

\begin{tabular}{|c|c|}
\hline \multirow[t]{5}{*}{ Methods } & $\mathrm{RCT}$ \\
\hline & Arms: 2 \\
\hline & Unit of randomisation: participant \\
\hline & Unit of analysis: participant \\
\hline & Follow-up: 6 months \\
\hline \multirow[t]{9}{*}{ Participants } & Inclusion criteria: exuding venous ulcers, $<100 \mathrm{~cm}^{2}$, not infected, ABPI $>0.7$ \\
\hline & $\begin{array}{l}\text { Exclusion criteria: current treatment with topical medications, ulcer covered with dry necrotic tissue, } \\
\text { undergoing therapy which may retard wound healing, pregnant or lactating, silver sulphadiazine used } \\
\text { in previous } 7 \text { days, in another research study in previous } 3 \text { months }\end{array}$ \\
\hline & Participant characteristics \\
\hline & Number participants: 100 \\
\hline & Age: not reported \\
\hline & $\%$ male: not reported \\
\hline & Ulcer details \\
\hline & Size: not reported \\
\hline & Duration: not reported \\
\hline \multirow[t]{6}{*}{ Interventions } & Intervention 1 class: PMM \\
\hline & Intervention 1 details (name and details of application): Fibracol (Johnson \& Johnson) \\
\hline & Intervention 2 class: alginate \\
\hline & Intervention 2 details (name and details of application): Kaltostat (ConvaTec) \\
\hline & Compression: "standardized compression bandaging" \\
\hline & Other co-interventions: not reported \\
\hline
\end{tabular}

Outcomes

Intervention 1: 34/50 
Petkov 1997 (Continued)

Intervention 2: 32/50 (author information - public data says 31/50)

Notes Funding type and details: not reported

\section{Risk of bias}

Bias Authors' judgement Support for judgement

Random sequence genera- Unclear risk Q Quote: "100 patients ... were randomised"
tion (selection bias)

Comment: no details on method

\begin{tabular}{lll}
\hline $\begin{array}{l}\text { Allocation concealment } \\
\text { (selection bias) }\end{array}$ & Unclear risk & $\begin{array}{l}\text { Quote: "100 patients ... were randomised" } \\
\text { Comment: no details on method }\end{array}$ \\
\hline $\begin{array}{l}\text { Blinding of participants } \\
\text { and personnel (perfor- } \\
\text { mance bias) } \\
\text { All outcomes }\end{array}$ & Unclear risk & Not reported \\
\hline $\begin{array}{l}\text { Blinding of outcome as- } \\
\text { sessment (detection bias) } \\
\text { All outcomes }\end{array}$ & Unclear risk & Not reported \\
\hline $\begin{array}{l}\text { Incomplete outcome data } \\
\begin{array}{l}\text { (attrition bias) } \\
\text { All outcomes }\end{array}\end{array}$ & Low risk & No missing data \\
\hline $\begin{array}{l}\text { Selective reporting (re- } \\
\text { porting bias) }\end{array}$ & Unclear risk & Insufficient information to determine if reporting bias \\
\hline $\begin{array}{l}\text { Other bias } \\
\text { All domain risk of bias }\end{array}$ & Low risk & Low/unclear \\
\hline
\end{tabular}

\section{Rasmussen 1991}

\begin{tabular}{ll}
\hline Methods & RCT \\
Arms: 2 \\
Unit of randomisation: participant \\
Unit of analysis: participant \\
Follow-up: 12 weeks \\
\hline
\end{tabular}

Participants Inclusion criteria: chronic leg ulceration

Exclusion criteria: diabetes mellitus, malignant or rheumatic disease, allergy to dressings, peripheral arterial disease, cellulitis, anaemia, sever maceration of surrounding skin

Participant characteristics

Number participants: 37 randomised, 29 included in analysis (18 vs 11)

Age: 80.7 (6.7) vs $78.1(11.8)$ years 
Rasmussen 1991 (Continued)

\author{
$\%$ male: 5 (28) vs 4 (36) \\ Ulcer details \\ Non VLU: 2 (11\%) vs $1(9 \%)$ mixed \\ Size: mean (SD) $10.7(2.0) \mathrm{cm}^{2}$ vs $8.15(2.5) \mathrm{cm}^{2}$ \\ Duration: not reported (minimum 3 weeks)
}

\begin{tabular}{ll}
\hline Interventions & Intervention 1 class: human growth hormone \\
Intervention 1 details (name and details of application): Norditropin (Novo-Nordisk) + Comfeel (Colo- \\
plast); biosynthetic human growth hormone + hydrocolloid; Norditropin dissolved in water adminis- \\
tered 5 days per week through connecting piece in the dressing. Treatment for at least 2 weeks \\
Intervention 2 class: placebo + hydrocolloid \\
Intervention 2 details (name and details of application): Comfeel (Coloplast); placebo administered 5 \\
days per week through connecting piece in the dressing. Treatment for at least 2 weeks \\
Compression: Compression bandages worn by all (Comprilan, Beirsdorf) \\
Other co-interventions: not reported \\
$\begin{array}{ll}\text { Intervention } 1: 3 / 18 \\
\text { Intervention } 2: 1 / 11\end{array}$ \\
$\begin{array}{l}\text { Funding type and details: Coloplast and Beiresdorf provided study materials, but study funding not re- } \\
\text { ported }\end{array}$
\end{tabular}

\title{
Risk of bias
}

\begin{tabular}{|c|c|c|}
\hline Bias & Authors' judgement & Support for judgement \\
\hline $\begin{array}{l}\text { Random sequence genera- } \\
\text { tion (selection bias) }\end{array}$ & Unclear risk & $\begin{array}{l}\text { Comment: stratification before randomisation explained but randomisation } \\
\text { method not described }\end{array}$ \\
\hline $\begin{array}{l}\text { Allocation concealment } \\
\text { (selection bias) }\end{array}$ & Unclear risk & Comment: not reported how allocation was concealed \\
\hline $\begin{array}{l}\text { Blinding of participants } \\
\text { and personnel (perfor- } \\
\text { mance bias) } \\
\text { All outcomes }\end{array}$ & Unclear risk & Not reported \\
\hline $\begin{array}{l}\text { Blinding of outcome as- } \\
\text { sessment (detection bias) } \\
\text { All outcomes }\end{array}$ & Unclear risk & Not reported \\
\hline $\begin{array}{l}\text { Incomplete outcome data } \\
\text { (attrition bias) } \\
\text { All outcomes }\end{array}$ & High risk & $18 / 37$ withdrawals which were not included in analysis. Reasons provided \\
\hline $\begin{array}{l}\text { Selective reporting (re- } \\
\text { porting bias) }\end{array}$ & Low risk & There was no evidence of selective reporting \\
\hline Other bias & Low risk & There was no evidence of other sources of bias \\
\hline All domain risk of bias & High risk & \\
\hline
\end{tabular}




Methods
Arms: 3
Unit of randomisation: participant
Unit of analysis: participant
Follow-up: 6 weeks

Participants

Inclusion criteria: chronic venous ulcers $1 \mathrm{~cm}^{2}$ to $25 \mathrm{~cm}^{2},>3$ months duration, or proximal to malleolus and distal to tibial tuberosity, no clinical signs of infection, aged 18 to $90,>45 \mathrm{~kg}, \mathrm{ABI}>0.5$, if female, postmenopausal or surgically sterile

Exclusion criteria: bleeding disorder, severe dermatosclerosis, organised oedema, local or systemic infection, disease or medication interfering with healing, hypersensitivity to bovine collagen

Participant characteristics

Number participants: 36

Age: 48.4 (17.6) vs $56.3(8.0)$ vs $54.2(11.4)$ years

$\%$ male: 4 (33) vs 7 (58) vs 5 (42)

Ulcer details

Size: mean (SD) $3.9(3.20) \mathrm{cm}^{2}$ vs $5.9(5.6) \mathrm{cm}^{2}$ vs $7.1(5.6) \mathrm{cm}^{2}$

Duration: mean (SD) 22 (40 vs 14 (13) vs 20 (16) months

Intervention 1 details (name and details of application): bTGF-B2 in collagen matrix (Celtrix Pharmaceutical); matrix cut to fit ulcer, hydrated with sterile saline if necessary, covered with non-absorbant dressing and layer of gauze sponge

Intervention 2 class: placebo + collagen

Intervention 2 details (name and details of application): placebo collagen matrix (Celtrix Pharmaceutical); matrix cut to fit ulcer, hydrated with sterile saline if necessary, covered with non-absorbant dressing and layer of gauze sponge

Intervention 3 class: nonadherent

Intervention 3 details: gauze dressing; Xeroform (Sparta Surgical Corp), 3 x per week

Compression: ace elastic compression bandage (Becton-Dickenson) consisting of 2 layers in opposing figure of eight configuration

Other co-interventions: sterile saline used to cleanse ulcer at weekly clinic visits

\begin{tabular}{ll}
\hline Outcomes & Intervention $1: 3 / 12$ \\
& Intervention $2: 3 / 12$ \\
& Intervention $3: 2 / 12$ \\
\hline Notes & $\begin{array}{l}\text { Funding type and details: Celtrix Pharmaceuticals produced clinical study material, some authors work } \\
\text { for them }\end{array}$
\end{tabular}


Robson 1995 (Continued)

Risk of bias

\begin{tabular}{|c|c|c|}
\hline Bias & Authors' judgement & Support for judgement \\
\hline $\begin{array}{l}\text { Random sequence genera- } \\
\text { tion (selection bias) }\end{array}$ & Unclear risk & $\begin{array}{l}\text { Quote: "patients }[. . .] \text { were randomized to one of the treatment groups. Ran- } \\
\text { domization was balanced for gender and age and for ulcer area and duration" } \\
\text { Comment: no method detail for sequence generation }\end{array}$ \\
\hline $\begin{array}{l}\text { Allocation concealment } \\
\text { (selection bias) }\end{array}$ & Unclear risk & $\begin{array}{l}\text { Quote: "patients [...] were randomized to one of the treatment groups. Ran- } \\
\text { domization was balanced for gender and age and for ulcer area and duration" } \\
\text { Comment: no information on how allocation was concealed }\end{array}$ \\
\hline $\begin{array}{l}\text { Blinding of participants } \\
\text { and personnel (perfor- } \\
\text { mance bias) } \\
\text { All outcomes }\end{array}$ & Unclear risk & Not reported \\
\hline $\begin{array}{l}\text { Blinding of outcome as- } \\
\text { sessment (detection bias) } \\
\text { All outcomes }\end{array}$ & Low risk & $\begin{array}{l}\text { Quote: "all assessments were performed by an observer blinded to the ulcer } \\
\text { treatment" } \\
\text { Comment: blinded outcome assessment }\end{array}$ \\
\hline $\begin{array}{l}\text { Incomplete outcome data } \\
\text { (attrition bias) } \\
\text { All outcomes }\end{array}$ & Low risk & $\begin{array}{l}4 \text { participants withdrew ( } 3 \text { from bTGF-B2 group, } 1 \text { from standard dressing), de- } \\
\text { cision to exclude from analysis made before unblinding. (randomised numbers } \\
\text { extracted here, however) }\end{array}$ \\
\hline $\begin{array}{l}\text { Selective reporting (re- } \\
\text { porting bias) }\end{array}$ & Low risk & There was no evidence of selective reporting \\
\hline Other bias & Low risk & There was no evidence of other sources of bias \\
\hline
\end{tabular}

Robson 2001

$\begin{array}{ll}\text { Methods } & \text { RCT } \\ \text { Arms: } 3 & \\ \text { Unit of randomisation: participant } \\ \text { Unit of analysis: participant } \\ \text { Follow-up: } 12 \text { weeks } \\ \text { Inclusion criteria: venous insufficiency with ulcer } 3 \mathrm{~cm}^{2} \text { to } 30 \mathrm{~cm}^{2} \text { and } 3 \text { to } 36 \text { months duration } \\ \text { Exclusion criteria: significant arterial insufficiency, increased bacterial burden, active vasculitis, celluli- } \\ \text { tis or collagen vascular disease, active skin disease, malignant neoplasm, significant acute or chron- } \\ \text { ic systemic disease, significant clinical laboratory abnormalities, known allergies to study materials, } \\ \text { treatment with investigational agents, pentoxifylline, immunosuppressive or cytotoxic agent, pregnan- } \\ \text { cy, use of topical antibiotics in } 7 \text { days prior or during treatment } \\ \text { Participant characteristics } \\ \text { Number participants: } 94\end{array}$


Robson 2001 (Continued)

Age: 61 (13) vs 59 (14) vs 59 (13) years

$\%$ male: $71(22)$ vs 66 (21) vs 58 (18)

Ulcer details

Size: mean (SD) $8.7(6.2) \mathrm{cm}^{2}$ vs $8.4(.5)$ vs $8.1(6.7) \mathrm{cm}^{2}$

Duration: mean (SD) 11 (8) vs 14 (10) vs 11 (7) months

Interventions
Intervention 1 class: human growth hormone 1 details (name and details of application): Repifermin spray $\left(20 \mu \mathrm{g} / \mathrm{cm}^{2}\right)+$ nonadherent
dressing
Intervention 2 class: human growth hormone
Intervention 2 details (name and details of application): Repifermin spray $\left(60 \mu \mathrm{g} / \mathrm{cm}^{2}\right)+$ nonadherent
dressing
Intervention 3 class: nonadherent (placebo spray)
Intervention 3 (name and details of application): placebo + nonadherent dressing
Compression: self-adherent elastic wrap
Other co-interventions: not reported

\begin{tabular}{ll}
\hline Outcomes & Intervention 1: 10/31 \\
& Intervention 2: $12 / 32$ \\
& Intervention 3: $9 / 31$ \\
\hline Notes & Funding type and details: industry \\
& Funding details: Human Genome Sciences Inc
\end{tabular}

\section{Risk of bias}

Bias Authors' judgement Support for judgement

Random sequence genera- Unclear risk tion (selection bias)

Quote: "patients with venous insufficiency (aged 18 years or older) were randomized as follows"

Comment: described as randomised but no methods given

\begin{tabular}{|c|c|c|}
\hline $\begin{array}{l}\text { Allocation concealment } \\
\text { (selection bias) }\end{array}$ & Unclear risk & $\begin{array}{l}\text { Quote: "Patients with venous insufficiency (aged } 18 \text { years or older) were ran- } \\
\text { domized as follows" }\end{array}$ \\
\hline & & Comment: described as randomised but no methods given \\
\hline
\end{tabular}

\begin{tabular}{|c|c|c|}
\hline $\begin{array}{l}\text { Blinding of participants } \\
\text { and personnel (perfor- }\end{array}$ & Unclear risk & $\begin{array}{l}\text { Described as double-blind, placebo-controlled but no details given so not } \\
\text { clear who was blinded }\end{array}$ \\
\hline
\end{tabular}

mance bias)

All outcomes

\begin{tabular}{|c|c|c|}
\hline $\begin{array}{l}\text { Blinding of outcome as- } \\
\text { sessment (detection bias) }\end{array}$ & Unclear risk & $\begin{array}{l}\text { Described as double-blind, placebo-controlled but no details given so not } \\
\text { clear who was blinded }\end{array}$ \\
\hline
\end{tabular}

All outcomes

Incomplete outcome data High risk $\quad 5$ withdrawals (9.7\% vs 3.1\% vs 3.2\%), ITT
(attrition bias)


Robson 2001 (Continued)

All outcomes

Selective reporting (re- Low risk No evidence of selective outcome reporting
porting bias)

Other bias Low risk No evidence of other sources of bias

All domain risk of bias High risk

\section{Robson 2004}

$\begin{array}{ll}\text { Methods } & \text { RCT } \\ \text { Arms: } 2 \\ \text { Unit of randomisation: participant } \\ \text { Unit of analysis: participant } \\ \text { Follow-up: } 20 \text { weeks }\end{array}$

Participants

Inclusion criteria: venous ulcer $3 \mathrm{~cm}^{2}$ to $25 \mathrm{~cm}^{2}$ and 3 to 36 months duration, venous insufficiency (venous duplex scanning or impedance plethysmography), prescribed compression for 7 to 28 days prior to trial

Exclusion criteria: participated in a clinical trial of an investigational agent within the last 30 days, been treated with repifermin (KGF-2) have the designated ulcer below the malleolus, on the foot, or above the base of the knee, have had the study ulcer treated with Regranex (PDGF-BB) within the last 30 days or treated at any time with a skin substitute or an autologous growth factor, had a surgical procedure to treat venous or arterial disease within the last 90 days, evidence of significant arterial insufficiency (an ankle brachial index of 1.2 must have a toe brachial index of $>0.6$ or a supine transcutaneous oxygen measurement (TcPO2) $>30 \mathrm{mmHg}$, clinical evidence of active infection at the ulcer site, a granulation tissue colony count $\geq 106 / \mathrm{g}$ of tissue or beta-haemolytic streptococci at any level, evidence of active vasculitis, cellulitis, or collagen vascular disease, a history of malignant neoplasm within the last 5 years, except for adequately treated cancers of the skin or uterine cervix, significant acute or chronic diseases (i.e. cardiovascular, pulmonary, gastrointestinal, hepatic, renal, neurological, or infectious diseases), which are not adequately controlled by medical treatment as determined by the investigator's judgment, diabetes mellitus with a haemoglobin $A 1 c \geq 8 \%$, active skin disease, such as psoriasis, which could impair the ability to assess the wound, an allergy to the dressings used in the study,require treatment to the study ulcer with any topical agent other than normal saline within 7 days of the first repifermin/placebo treatment or with topical lidocaine for anaesthesia prior to study ulcer debridement after the first repifermin/placebo treatment, or concomitant use of pentoxifylline or clopidogrel bisulphate during the study, undergone enzymatic debridement at any time during the screening period, known history of allergies to Escherichia coli-derived or paraben-containing products, any requirement for the use of systemic steroids or immunosuppressive or cytotoxic compounds during the period of the study, expected to undergo hyperbaric oxygen therapy at any time during treatment or through the 4-week follow-up visit, pregnant female or nursing mother (all females with an intact uterus, regardless of age must have a negative serum pregnancy test result at screening and use contraception during the study), during the first 20 weeks of the study be expected to miss 3 or more consecutive visits or be expected to miss 2 consecutive visits more than once.

Participant characteristics

Number participants: 352

Age: 61.8 (15.6) vs 60.9 (13.7) vs 61.0 (15.4) years

\% male: 59 (52.7) vs 76 (61.8) vs 81 (69.2)

Ulcer details 
Robson 2004 (Continued)

Size: mean (SD) $8.7(5.3) \mathrm{cm}^{2}$ vs $9.4(5.4) \mathrm{cm}^{2}$ vs $9.9(6.2) \mathrm{cm}^{2}$, median (range) 7.1 (2.4 to 22.9) $\mathrm{cm}^{2}$ vs 8.4 (3.0 to 25.0$) \mathrm{cm}^{2}$ vs 7.4 (3.0 to 24.3$) \mathrm{cm}^{2}$

Duration: mean (SD) 8.7 (5.3) months vs 12.3 (9.2) vs 11.8 (9.3) months, median (range) 6.0 (3.0 to 36.0 ) months vs 9.0 (3.0 to 36.0 ) months vs 7.0 (3.0 to 35.0 ) months

Interventions

Intervention 1 class: human growth hormone

Intervention 1 details (name and details of application): growth factor-repifermin (KGF-2) higher dose $\left(120 \mu \mathrm{g} / \mathrm{cm}^{2}\right)+$ petrolatum gauze; Gauze dressing = ADAPTIC (Johnson \& Johnson); 2 x per week spray application of drug, then covered with dressing

Intervention 2 class: human growth hormone

Intervention 2 details (name and details of application): growth factor-repifermin (KGF-2) lower dose $\left(60 \mathrm{\mu g} / \mathrm{cm}^{2}\right)+$ petrolatum gauze; Gauze dressing = ADAPTIC (Johnson \& Johnson); 2 x per week spray application of drug, then covered with dressing

Intervention 3 class: nonadherent (placebo spray) placebo + petrolatum gauze: gauze dressing= ADAPTIC (Johnson \& Johnson)

Intervention 3 details (name and details of application): not reported

Compression: multi-layer sustained graduated compression bandage system (DYNAFLEX, Johnson \& Johnson)

Other co-interventions: pre-study screening period involved debridement and biopsy to check infection

\begin{tabular}{ll}
\hline Outcomes & Intervention 1: $58 / 112$ \\
& Intervention 2: $72 / 123$ \\
Intervention 3: $72 / 117$
\end{tabular}

Notes Funding type and details: not reported

\section{Risk of bias}

Bias Authors' judgement Support for judgement

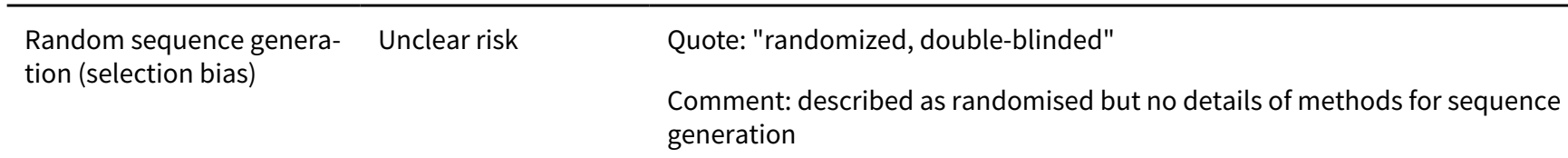

\begin{tabular}{ll}
\hline $\begin{array}{l}\text { Allocation concealment } \\
\text { (selection bias) }\end{array}$ & Unclear risk \\
& $\begin{array}{l}\text { Quote: "randomized, double-blinded" } \\
\text { Comment: described as randomised but no details of methods for allocation } \\
\text { concealment }\end{array}$ \\
\hline
\end{tabular}

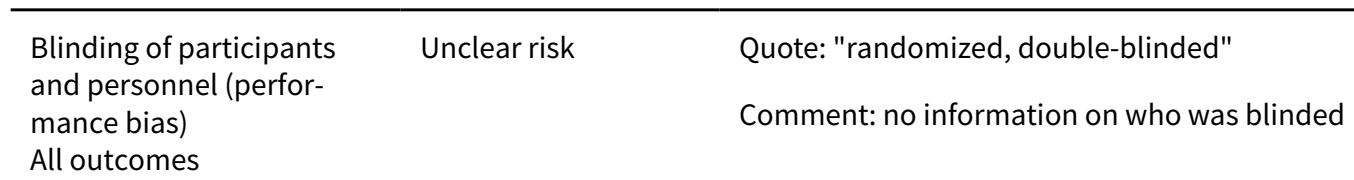

\begin{tabular}{lll}
\hline $\begin{array}{l}\text { Blinding of outcome as- } \\
\text { sessment (detection bias) } \\
\text { All outcomes }\end{array}$ & Unclear risk & Quote: "randomized, double-blinded" \\
\hline $\begin{array}{l}\text { Incomplete outcome data } \\
\text { (attrition bias) }\end{array}$ & Low risk & Comment: no information on who was blinded \\
\hline
\end{tabular}


Robson 2004 (Continued)

All outcomes

Selective reporting (re- Low risk No evidence of selective reporting.
porting bias)

\begin{tabular}{lll}
\hline Other bias & Unclear risk & No evidence of other sources of bias \\
\hline All domain risk of bias & Low risk & Low/unclear \\
\hline
\end{tabular}

\section{Romanelli 2015a}

\begin{tabular}{ll}
\hline Methods & RCT \\
Arms: 2 \\
Unit of randomisation: participant \\
Unit of analysis: participant \\
Follow-up: 12 weeks
\end{tabular}

\section{Participants}

Inclusion criteria: venous leg ulcer, venous insufficiency established by colour Doppler test, no measurable improvement over 6 weeks standard treatment

Exclusion criteria: diabetes, autoimmune disease, peripheral arterial disease $\mathrm{ABPI}<0.8$, smokers, ulcer with signs of infection

Participant characteristics

Number participants: 40

Age: 68 (5) vs 65 (2) years

$\%$ male: $7(35)$ vs $5(25)$

Ulcer details

Size: mean (SD) 26 (4) vs 24 (5) $\mathrm{cm}^{2}$

Duration: mean (SD) 24 (6) vs 20 (4) weeks

Intervention 1 details (name and details of application): collagen membrane + non adherent + alginate; ProHeal (MedSkin Solutions) + Adaptic (Systa Genix) + Curasorb (Kendal); dressing changed twice a week

Intervention 2 class: alginate

Intervention 2 details (name and details of application): Curasorb (Kendal); dressing changed twice a week

Compression: short stretch bandaging (Rosidal K, Lohmann and Rauscher)

Other co-interventions: saline used to cleanse wounds

$\begin{array}{ll}\text { Outcomes } & \text { Intervention 1: 6/20 } \\ \text { Intervention 2: 5/20 }\end{array}$


Romanelli 2015a (Continued)

Funding details: MedSkin Solutions

\section{Risk of bias}

\section{Bias Authors' judgement Support for judgement}

Random sequence genera- Unclear risk Quote: "randomisation was established by a random permuted block of five tion (selection bias) patients, prepared in advance"

Comment: not specified how the sequence was generated

\begin{tabular}{|c|c|c|}
\hline $\begin{array}{l}\text { Allocation concealment } \\
\text { (selection bias) }\end{array}$ & Unclear risk & $\begin{array}{l}\text { Quote: "randomisation was established by a random permuted block of five } \\
\text { patients, prepared in advance" }\end{array}$ \\
\hline & & Comment: allocation concealment method was not reported \\
\hline
\end{tabular}

\begin{tabular}{|c|c|c|}
\hline $\begin{array}{l}\text { Blinding of participants } \\
\text { and personnel (perfor- } \\
\text { mance bias) } \\
\text { All outcomes }\end{array}$ & Unclear risk & Not reported \\
\hline $\begin{array}{l}\text { Blinding of outcome as- } \\
\text { sessment (detection bias) } \\
\text { All outcomes }\end{array}$ & Unclear risk & Not reported \\
\hline $\begin{array}{l}\text { Incomplete outcome data } \\
\text { (attrition bias) } \\
\text { All outcomes }\end{array}$ & Low risk & All participants were included in the analysis \\
\hline $\begin{array}{l}\text { Selective reporting (re- } \\
\text { porting bias) }\end{array}$ & Low risk & No evidence of selective reporting \\
\hline Other bias & Low risk & No evidence of additional sources of bias \\
\hline All domain risk of bias & Low risk & Low/unclear \\
\hline
\end{tabular}

Romero-Cerecero 2012

\begin{tabular}{|c|c|}
\hline \multirow[t]{5}{*}{ Methods } & $\mathrm{RCT}$ \\
\hline & Arms: 2 \\
\hline & Unit of randomisation: participant \\
\hline & Unit of analysis: participant \\
\hline & Follow-up: 10 months \\
\hline \multirow[t]{4}{*}{ Participants } & $\begin{array}{l}\text { Inclusion criteria: people aged } 18 \text { to } 70 \text { with clinical diagnosis of chronic venous leg ulcer } 2 \mathrm{~cm} \text { to } 15 \mathrm{~cm} \\
\text { in diameter, <10 years duration, no infection or severe oedema, no previous topical treatment in previ- } \\
\text { ous month }\end{array}$ \\
\hline & $\begin{array}{l}\text { Exclusion criteria: pregnancy or breastfeeding, sensitivity to topical treatments, oedema in legs, dia- } \\
\text { betes }\end{array}$ \\
\hline & Participant characteristics \\
\hline & Number participants: 34 \\
\hline
\end{tabular}


Romero-Cerecero 2012 (Continued)

\author{
Age: $60.5(17)$ vs $61.5(20)$ years \\ $\%$ male: $7 / 17(41)$ vs $3 / 17(18)$ \\ Ulcer details
}

Size: mean (SD) 1894.8 (51.3) vs 2068.6 (52.9) (unit of size unclear)

Duration: $<1$ year $32.2 \%$ vs $47.0 \%, 1$ to 5 years $41.4 \%$ vs $32.2 \%, 6$ to 10 years $23.4 \%$ vs $17.6 \%$

Intervention 1 class: A.pichinchensis extract
Intervention 1 details (name and details of application): administered weekly
Intervention 2 class: alginate
Intervention 2 details (name and details of application): $7 \%$ propylene glycol alginate (control) admin-
istered weekly
Compression: not reported
Other co-interventions: "strict wound hygiene, plus debridement and the placement of dressings"

\begin{tabular}{ll}
\hline Outcomes & Intervention 1: $15 / 17$ \\
& Intervention 2: $9 / 17$ \\
\hline Notes & Funding type and details: mixed \\
& Funding details: CONACYT and Mexican Institute of Social Security \\
\hline
\end{tabular}

\title{
Risk of bias
}

\begin{tabular}{|c|c|c|}
\hline Bias & Authors' judgement & Support for judgement \\
\hline \multirow[t]{2}{*}{$\begin{array}{l}\text { Random sequence genera- } \\
\text { tion (selection bias) }\end{array}$} & Unclear risk & $\begin{array}{l}\text { Quotes: "two treatment groups were randomly organized" "treatments were } \\
\text { randomly assigned" }\end{array}$ \\
\hline & & Comment: no information on how the randomisation sequence was generated \\
\hline \multirow[t]{2}{*}{$\begin{array}{l}\text { Allocation concealment } \\
\text { (selection bias) }\end{array}$} & Unclear risk & $\begin{array}{l}\text { Quotes: "two treatment groups were randomly organized" "treatments were } \\
\text { randomly assigned" }\end{array}$ \\
\hline & & Comment: no information on how allocation was concealed \\
\hline \multirow{2}{*}{$\begin{array}{l}\text { Blinding of participants } \\
\text { and personnel (perfor- } \\
\text { mance bias) } \\
\text { All outcomes }\end{array}$} & Low risk & $\begin{array}{l}\text { Quotes: "in order to blind the experimental procedure, both treatments were } \\
\text { formulated and packed in identical collapsible tubes" "neither the patient nor } \\
\text { the physician knew the identity of the treatments" }\end{array}$ \\
\hline & & Comment: both participants and personnel were blinded \\
\hline \multirow[t]{2}{*}{$\begin{array}{l}\text { Blinding of outcome as- } \\
\text { sessment (detection bias) } \\
\text { All outcomes }\end{array}$} & Low risk & $\begin{array}{l}\text { Quotes: "in order to blind the experimental procedure, both treatments were } \\
\text { formulated and packed in identical collapsible tubes" "neither the patient nor } \\
\text { the physician knew the identity of the treatments" }\end{array}$ \\
\hline & & $\begin{array}{l}\text { Comment: it appears that outcome assessment was performed by personnel } \\
\text { who were blinded }\end{array}$ \\
\hline $\begin{array}{l}\text { Incomplete outcome data } \\
\text { (attrition bias) } \\
\text { All outcomes }\end{array}$ & High risk & $\begin{array}{l}6 / 17 \text { vs } 2 / 17 \text { withdrawals; however there was an ITT analysis, the impact of the } \\
\text { withdrawals is unclear but unbalanced }\end{array}$ \\
\hline
\end{tabular}


Romero-Cerecero 2012 (Continued)
Selective reporting (re-
Low risk
There was no evidence of selective outcome reporting porting bias)

\begin{tabular}{lll}
\hline Other bias & Low risk & There was no evidence of any other source of bias \\
\hline All domain risk of bias & High risk & \\
\hline
\end{tabular}

Rubin 1990

\begin{tabular}{|c|c|}
\hline \multirow[t]{5}{*}{ Methods } & $\mathrm{RCT}$ \\
\hline & Arms: 2 \\
\hline & Unit of randomisation: participant \\
\hline & Unit of analysis: participant \\
\hline & Follow-up: 12 months \\
\hline \multirow[t]{9}{*}{ Participants } & Inclusion criteria: ambulatory with lower-extremity chronic venous stasis ulceration \\
\hline & $\begin{array}{l}\text { Exclusion criteria: history of non-compliance, significant arterial insufficiency (Doppler ankle brachial } \\
\text { pressure index }<0.8 \text { ), history of significant associated medical risk factors e.g. collagen vascular dis- } \\
\text { ease, uncontrolled diabetes, ongoing dermatologic disease, chronic corticosteroid therapy }\end{array}$ \\
\hline & Participant characteristics \\
\hline & Number participants: 36 \\
\hline & Age: not reported \\
\hline & $\%$ male: not reported \\
\hline & Ulcer details \\
\hline & Size: mean (range) $32.2 \mathrm{~cm}^{2}$ (6.0 to 270 ) vs $76.0 \mathrm{~cm}^{2}$ (0.02 to 600 ) \\
\hline & Duration: not reported \\
\hline
\end{tabular}

\begin{tabular}{ll}
\hline Interventions & Intervention 1 class: foam \\
Intervention 1 details (name and details of application): PFD (Synthaderm Armour Pharmaceutical); \\
dressing changed on weekly and/or biweekly schedule \\
Intervention 2 class: paste bandage \\
Intervention 2 details (name and details of application): gauze bandage impregnated with glycerin, zinc \\
oxide and calamine lotion; dressing changed on weekly and/or biweekly schedule \\
Compression: all participants had elastic bandages applied from toes to knees. \\
Other co-interventions: wounds were cleansed routinely with 20\% Poloxamer cleansing solution Shur- \\
Cleans (Merck \& Co) \\
\hline Intervention 1: 7/17 \\
Intervention 2: $18 / 19$ \\
\hline Futcomes
\end{tabular}


Rubin 1990 (Continued)

Risk of bias

\begin{tabular}{|c|c|c|}
\hline Bias & Authors' judgement & Support for judgement \\
\hline $\begin{array}{l}\text { Random sequence genera- } \\
\text { tion (selection bias) }\end{array}$ & Unclear risk & $\begin{array}{l}\text { Quote: "each patient was randomized by the study co-ordinator" } \\
\text { Comment: unclear how randomisation sequence was generated }\end{array}$ \\
\hline $\begin{array}{l}\text { Allocation concealment } \\
\text { (selection bias) }\end{array}$ & Unclear risk & $\begin{array}{l}\text { Quote: "the study co-ordinator did not see the randomization card and was } \\
\text { therefore blinded as to the treatment cohort" } \\
\text { Comment: blinding but unclear allocation concealment. }\end{array}$ \\
\hline $\begin{array}{l}\text { Blinding of participants } \\
\text { and personnel (perfor- } \\
\text { mance bias) } \\
\text { All outcomes }\end{array}$ & Unclear risk & $\begin{array}{l}\text { Quote: "the study co-ordinator did not see the randomization card and was } \\
\text { therefore blinded as to the treatment cohort" } \\
\text { Comment: not clear whether other personnel and participants were blinded }\end{array}$ \\
\hline $\begin{array}{l}\text { Blinding of outcome as- } \\
\text { sessment (detection bias) } \\
\text { All outcomes }\end{array}$ & Unclear risk & $\begin{array}{l}\text { Quote: "the study co-ordinator did not see the randomization card and was } \\
\text { therefore blinded as to the treatment cohort" } \\
\text { Comment: not clear whether outcome assessors were blinded }\end{array}$ \\
\hline $\begin{array}{l}\text { Incomplete outcome data } \\
\text { (attrition bias) } \\
\text { All outcomes }\end{array}$ & High risk & $\begin{array}{l}9(52.9 \%) \text { of Group } 1 \text { withdrew due to wound odour whereas } 100 \% \text { of group } 2 \\
\text { completed the study }\end{array}$ \\
\hline $\begin{array}{l}\text { Selective reporting (re- } \\
\text { porting bias) }\end{array}$ & Low risk & There was no evidence of selective reporting \\
\hline Other bias & Unclear risk & No evidence of other sources of bias but insufficient evidence to be certain \\
\hline All domain risk of bias & High risk & \\
\hline
\end{tabular}

\section{Salim 1992}

\begin{tabular}{ll}
\hline Methods & RCT \\
Arms: 3 \\
Unit of randomisation: participant \\
Unit of analysis: participant \\
Follow-up: 12 weeks
\end{tabular}

Participants

Inclusion criteria: venous ulceration (diagnosed from history, examination and Doppler assessment of arterial pressure at ankles) of one leg, on medial side, $<10 \mathrm{~cm}^{2}$, occurring for the first time, not yet treated in any way, not infected or associated with gross leg oedema

Exclusion criteria: surgery or injection sclerotherapy for varicose veins, alcoholism, pregnancy, diabetes, hypertension, steroid or NSAIDSs in previous year, on regular medication, hepatic or renal disorder, serious underlying disease, rheumatoid arthritis, collagen disease

Participant characteristics

Number participants: 168 randomised; 137 analysed

Age: mean (range) 56 (31 to 68) vs 57 (29 to 71 ) vs 58 (28 to 71 ) years 
Salim 1992 (Continued)

\author{
$\%$ male: 23 (50) vs 21 (47) vs 21 (46) \\ Ulcer details \\ Size: mean (SD) $5.3(0.3) \mathrm{cm}^{2}$ vs $5.5(0.1)$ vs $4.6(0.2) \mathrm{cm}^{2}$ \\ Duration: mean 20 months vs 24 vs 22 months
}

Interventions

Intervention 1 class: sulphadryl

Intervention 1 details (name and details of application): DL-cysteine powder + Terylene and cotton gauze; powder manufactured by Sigma, Terylene dressing NADD (Johnson \& Johnson); powder liberally sprayed on ulcer, covered with dressings. Repeated every day for 7 days, then weekly

Intervention 2 class: sulphadryl

Intervention 2 details (name and details of application): DL-methionine-methyl sulphonium chloride powder + Terylene and cotton gauze; powder manufactured by Sigma, Terylene dressing NADD (Johnson \& Johnson); powder liberally sprayed on ulcer, covered with dressings. Repeated every day for 7 days, then weekly

Intervention 3 class: inactive powder (placebo)

Intervention 3 details (name and details of application): placebo powder + Terylene and cotton gauze; powder manufactured by Sigma, Terylene dressing NADD (Johnson \& Johnson); powder liberally sprayed on ulcer, covered with dressings. Repeated every day for 7 days, then weekly

Compression: below knee graduated compression bandage (layer of crepe bandage, layer of Elset (Seton Ltd) and layer of Coban cohesive bandage (3M Health Care Ltd))

Other co-interventions: ulcer cleaned with olive oil and washed with saline. Skin surrounding ulcer and of leg oiled with propylene glycol monostearate (BP)

\begin{tabular}{ll}
\hline Outcomes & Intervention $1: 43 / 46$ \\
& Intervention 2: $42 / 45$ \\
& Intervention 3: $32 / 46$ \\
\hline Notes & Funding type and details: not reported
\end{tabular}

\title{
Risk of bias
}

\begin{tabular}{lll}
\hline Bias & Authors' judgement & Support for judgement \\
\hline $\begin{array}{l}\text { Random sequence genera- } \\
\text { tion (selection bias) }\end{array}$ & Unclear risk & $\begin{array}{l}\text { Quote: "randomization was carried out by drawing sealed envelopes" } \\
\text { Comment: unclear how the sequence was generated }\end{array}$ \\
\hline $\begin{array}{l}\text { Allocation concealment } \\
\text { (selection bias) }\end{array}$ & Unclear risk & Quote: "randomization was carried out by drawing sealed envelopes" \\
\hline $\begin{array}{l}\text { Blinding of participants } \\
\text { and personnel (perfor- } \\
\text { mance bias) }\end{array}$ & Low risk & Comment: unclear how allocation was concealed \\
All outcomes & & $\begin{array}{l}\text { Quote: "the treatment code was only broken } 3 \text { months after treatment had } \\
\text { started (end point of the study)" }\end{array}$ \\
\hline
\end{tabular}

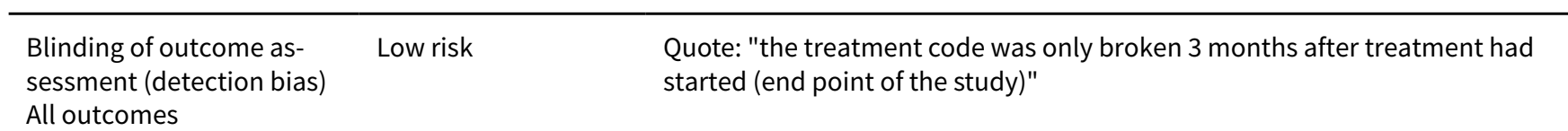


Salim 1992 (Continued)

Comment: described as double-blind; appears that blinded outcome assessment was used

\begin{tabular}{lll}
\hline $\begin{array}{l}\text { Incomplete outcome data } \\
\text { (attrition bias) } \\
\text { All outcomes }\end{array}$ & High risk & $9 / 55$ vs $11 / 57$ vs $11 / 56$ excluded from analysis- reasons given \\
\hline $\begin{array}{l}\text { Selective reporting (re- } \\
\text { porting bias) }\end{array}$ & Low risk & No evidence of selective reporting \\
\hline Other bias & Low risk & No evidence of other sources of bias \\
\hline All domain risk of bias & High risk & \\
\hline
\end{tabular}

Schulze 2001

$\begin{array}{ll}\text { Methods } & \text { RCT } \\ \text { Arms: } 3 \\ \text { Unit of randomisation: participant } \\ \text { Unit of analysis: participant } \\ \text { Follow-up: } 4 \text { weeks }\end{array}$

Participants

Inclusion criteria: moderate to heavily exuding leg ulcers of venous origin (ABPI $>$ or $=0.8$ measured by Doppler ultrasound or colour Duplex sonography), $<1 \mathrm{~cm}$ deep, $<11 \mathrm{~cm}$ wide

Exclusion criteria: wounds with hard black necrotic tissue, wounds with clinical signs of infection, known hypersensitivity to study dressings, treatment in another research study within previous 30 days

Participant characteristics

Number participants: 113

Age: $73.6(13.9)$ vs $72.4(13.5)$ vs 72.7 (14.5) years

$\%$ male: 16 (30) vs $10(45)$ vs $12(32)$

Ulcer details

Size: mean (SD) $13.7(12.2) \mathrm{cm}^{2}$ vs $18.5(18.5) \mathrm{cm}^{2}$ vs $11.2(13.2) \mathrm{cm}^{2}$, median (range) $8.8(0.7$ to 48.8$) \mathrm{cm}^{2}$ vs $12.9(0.3$ to 75.2$) \mathrm{cm}^{2}$ vs $7.5(0.6$ to 68.3$) \mathrm{cm}^{2}$

Duration: mean (SD) 49.5 (131.5) months vs 45.6 (97.2) months vs 35.0 (74.1) months, range 0.5 to 744 vs 0.5 to 396 vs 0.2 to 360 months

Intervention 1 details (name and details of application): Tielle plus hydropolymer adhesive dressing (Johnson \& Johnson Medical); changed when clinically required, maximum 7 days; secondary dressing of film (Opsite flexigrid, Smith \& Nephew). Changed when clinically required, maximum 7 days Intervention 2 class: alginate Intervention 2 details (name and details of application): Kaltostat wound dressing (ConvaTec) Intervention 3 class: alginate 
Schulze 2001 (Continued)

Intervention 3 details (name and details of application): Kaltostat wound dressing (ConvaTec); secondary dressing switched later in the study to sterile swabs (Topper-8, Johnson \& Johnson) due to side effects. Changed when clinically required, maximum 7 days

Compression: all participants had short-stretch compression bandaging

Other co-interventions: not reported

\begin{tabular}{ll}
\hline Outcomes & Intervention $1: 2 / 54$ \\
& Intervention $2: 3 / 22$ \\
& Intervention $3: 1 / 37$ \\
\hline Notes & Funding type and details: industry \\
& Funding details: Johnson \& Johnson Medical
\end{tabular}

\section{Risk of bias}

Bias Authors' judgement Support for judgement

Random sequence genera- Low risk tion (selection bias)

Quote: "assignment to treatment group was by random allocation according to a predetermined, computer-generated, randomisation schedule"

Comment: appropriate sequence generation

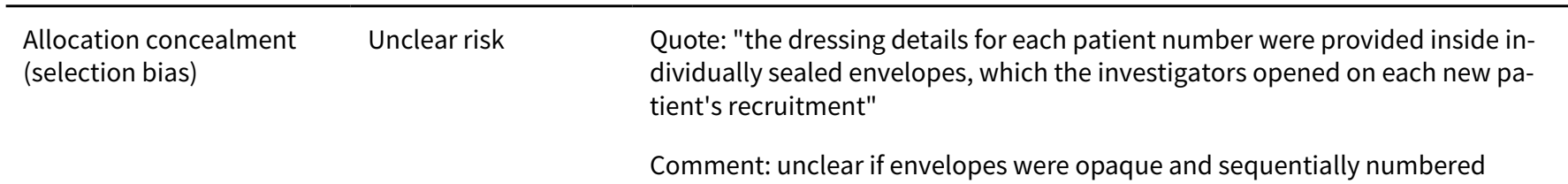

Blinding of participants $\quad$ High risk Comment: trial described as "open"
and personnel (perfor-
mance bias)

\begin{tabular}{lll}
\hline $\begin{array}{l}\text { Blinding of outcome as- } \\
\text { sessment (detection bias) } \\
\text { All outcomes }\end{array}$ & High risk & Comment: trial described as "open" \\
\hline $\begin{array}{l}\text { Incomplete outcome data } \\
\text { (attrition bias) } \\
\text { All outcomes }\end{array}$ & High risk & $\begin{array}{l}\text { All participants accounted for, but high number of withdrawals for adverse } \\
\text { events especially in alginate + film group 10/22 }\end{array}$ \\
\hline $\begin{array}{l}\text { Selective reporting (re- } \\
\text { porting bias) }\end{array}$ & Low risk & No evidence of selective reporting \\
\hline $\begin{array}{l}\text { Other bias } \\
\text { All domain risk of bias }\end{array}$ & High risk & No evidence of other sources of bias \\
\hline All domain risk of bias 2 & High risk & \\
\hline
\end{tabular}

\section{Scurr 1994}

\section{Methods}

RCT 
Scurr 1994 (Continued)
Arms: 2
Unit of randomisation: participant
Unit of analysis: participant
Follow-up: 6 weeks

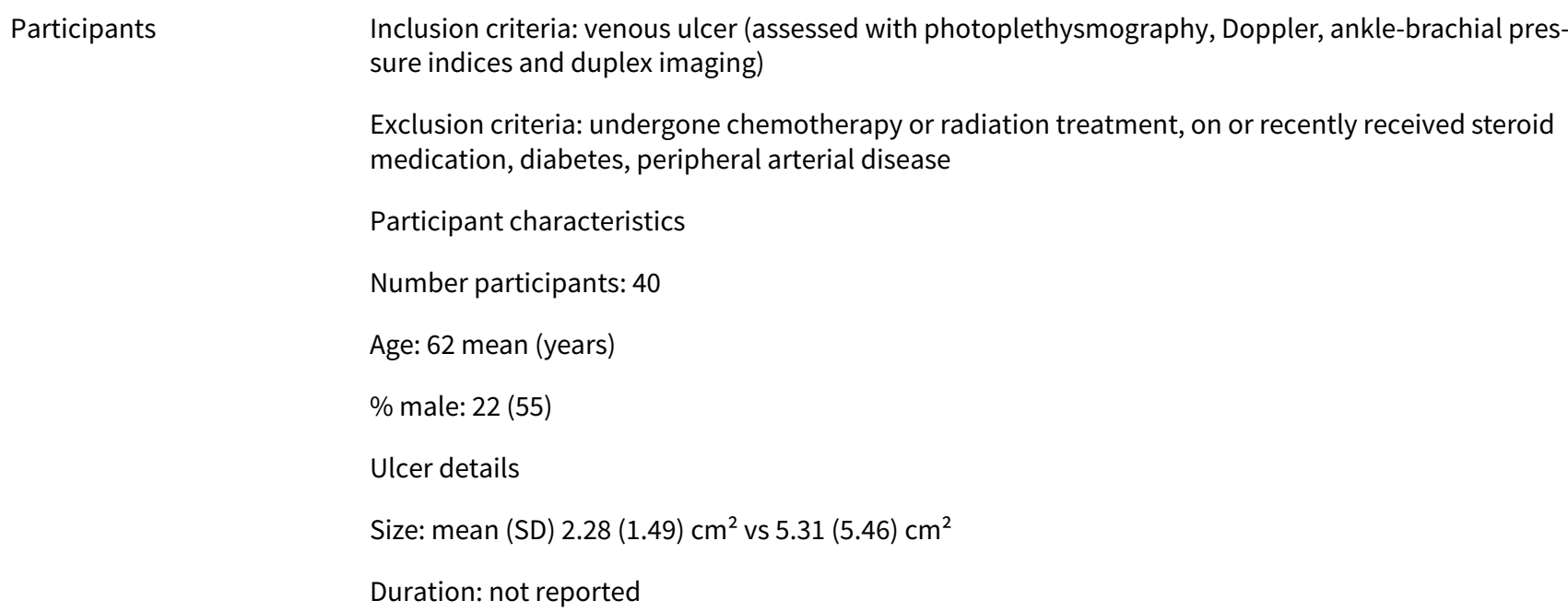

Exclusion criteria: undergone chemotherapy or radiation treatment, on or recently received steroid medication, diabetes, peripheral arterial disease

Participant characteristics

Number participants: 40

Age: 62 mean (years)

\% male: 22 (55)

Ulcer details

Size: mean (SD) $2.28(1.49) \mathrm{cm}^{2}$ vs $5.31(5.46) \mathrm{cm}^{2}$

Duration: not reported

Interventions
Intervention 1 class: alginate
Intervention 1 details (name and details of application): Sorbsan (Steriseal); dressing applied and cov-
ered with 2 layers of gauze and 1 layer surgical pad dressing. held in place with tape. Dressing change
frequency determined by wound discharge (range daily to weekly)
Intervention 2 class: hydrocolloid
Intervention 2 details (name and details of application): DuoDerm (Convatec, US) also known as Granu-
flex (UK); dressing applied and secured with tape. Changed every 2-7 days
Compression: class III graduated elastic compression stocking
Other co-interventions: before applying dressings, wounds were adequately debrided and slough re-
moved. Saline irrigation used to clean wounds at dressing changes
Intervention $1: 6 / 20$
Intervention $2: 2 / 20$
Outcomes
Funding type and details: industry
Funding details: Grants from Steriseal Ltd and Dow B Hickam

\section{Risk of bias}

Bias Authors' judgement Support for judgement

\begin{tabular}{|c|c|c|}
\hline \multirow[t]{2}{*}{$\begin{array}{l}\text { Random sequence genera- } \\
\text { tion (selection bias) }\end{array}$} & Unclear risk & $\begin{array}{l}\text { Quote: "patients ... were randomly allocated either to the calcium alginate or } \\
\text { the hydrocolloid group" }\end{array}$ \\
\hline & & Comment: method of sequence generation unclear \\
\hline
\end{tabular}

\begin{tabular}{|c|c|c|}
\hline $\begin{array}{l}\text { Allocation concealment } \\
\text { (selection bias) }\end{array}$ & Unclear risk & $\begin{array}{l}\text { Quote: "patients ... were randomly allocated either to the calcium alginate or } \\
\text { the hydrocolloid group" }\end{array}$ \\
\hline
\end{tabular}




Blinding of participants Unclear risk
and personnel (perfor-

\begin{tabular}{lll}
\hline Blinding of outcome as- & Unclear risk & Not reported \\
sessment (detection bias) & \\
All outcomes &
\end{tabular}

\begin{tabular}{lll}
\hline $\begin{array}{l}\text { Incomplete outcome data } \\
\text { (attrition bias) } \\
\text { All outcomes }\end{array}$ & Low risk & All participants included in analysis \\
\hline $\begin{array}{l}\text { Selective reporting (re- } \\
\text { porting bias) }\end{array}$ & Low risk & No evidence of selective reporting \\
\hline $\begin{array}{ll}\text { Other bias } \\
\text { All domain risk of bias }\end{array}$ & Low risk & $\begin{array}{l}\text { Authors noted difference in size between groups due to one participant and } \\
\text { performed analyses both with and without them }\end{array}$ \\
\hline
\end{tabular}

Senet 2003

$\begin{array}{ll}\text { Methods } & \text { RCT } \\ \text { Arms: } 2 \\ \text { Unit of randomisation: participant } \\ \text { Unit of analysis: participant } \\ \text { Follow-up: } 12 \text { weeks }\end{array}$

Participants Inclusion criteria: at least one venous ulcer, duration at least 2 months, $3 \mathrm{~cm}^{2}$ to $50 \mathrm{~cm}^{2}$, no tendency for healing in past 2 months, venous disease confirmed by venous duplex ultrasound scan and clinical symptoms, absence of arterial insufficiency $A B I>0.8$

Exlcusion criteria: pregnancy, allergy to hydrocolloid dressings, uncontrolled or evolving systemic disease, serum creatinine > 180 umol/L, systemic corticosteroids or cytotoxic drugs, limited physical capacity or immobility, ulcer with exposed tendon/bone, infected ulcer requiring systemic antibiotics, uncontrolled diabetes, various serological findings (details in paper)

Participant characteristics

Number participants: 15 randomised (data analysed for 13)

Age:mean (range) 72.3 ( 45 to 88 ) vs 72.3 (50 to 83 ) years

$\%$ male: 4 (57) vs 3 (50)

Ulcer details

Size: mean (range) 13.7 (4.8 to 27.25$) \mathrm{cm}^{2}$ vs 10.85 (3.7 to 26.5$) \mathrm{cm}^{2}$

Duration: mean (range) 50.6 (4 to 240 ) vs 70 (24 to 120 ) months 
Senet 2003 (Continued)

Intervention 1 details (name and details of application): frozen autologous platelets (FAP) (suspension in saline) + hydrocolloid; Comfeel Plus Opaque (Coloplast); FAP suspension applied to wound surface with syringe. Dressings changed $3 \times$ per week

Intervention 2 class: saline/hydrocolloid (placebo)

Intervention 2 details (name and details of application): placebo (saline) + hydrocolloid; placebo applied to wound surface with syringe. Dressings changed $3 \times$ per week.

Compression: standard graded compression with cotton bandages (Nylex, Laboratoires URGO) and elastic bandages (Biflex Plus Forte, Laboratoires Thuasne)

Other co-interventions: not reported

\begin{tabular}{ll}
\hline Outcomes & Intervention $1: 1 / 7$ \\
& Intervention $2: 1 / 6$ \\
\hline Notes & Funding type and details: mixed \\
& Funding details: grants from Institut national de la santé et de la recherche médicale and Coloplast \\
& Note: participants randomised immediately after collection of platelets.
\end{tabular}

\section{Risk of bias}

Bias Authors' judgement Support for judgement

Random sequence genera- Unclear risk Quote: "patients who complied with entry and exclusion criteria were rantion (selection bias) domised to one of two treatment groups"

Comment: method of sequence generation unclear

\begin{tabular}{|c|c|c|}
\hline $\begin{array}{l}\text { Allocation concealment } \\
\text { (selection bias) }\end{array}$ & Unclear risk & $\begin{array}{l}\text { Quote: "patients who complied with entry and exclusion criteria were ran- } \\
\text { domised to one of two treatment groups" }\end{array}$ \\
\hline
\end{tabular}

Comment: method of allocation concealment unclear

Blinding of participants Unclear risk Comment: described as double-blind but no details

and personnel (perfor-

mance bias)

All outcomes

\begin{tabular}{lll}
\hline $\begin{array}{l}\text { Blinding of outcome as- } \\
\text { sessment (detection bias) } \\
\text { All outcomes }\end{array}$ & Unclear risk & Comment: described as double-blind but no details \\
\hline $\begin{array}{l}\text { Incomplete outcome data } \\
\text { (attrition bias) } \\
\text { All outcomes }\end{array}$ & Low risk & $1 / 8 \mathrm{vs} 1 / 7$ withdrawals, included in analysis as failure to heal \\
\hline $\begin{array}{l}\text { Selective reporting (re- } \\
\text { porting bias) }\end{array}$ & Unclear risk & No evidence of selective reporting but reporting insufficient \\
\hline $\begin{array}{l}\text { Other bias } \\
\text { All domain risk of bias }\end{array}$ & Low risk & No evidence of other sources of bias but reporting insufficient \\
\hline
\end{tabular}


Senet 2011

\begin{tabular}{ll}
\hline Methods & RCT \\
Arms: 2 \\
Unit of randomisation: participant \\
Unit of analysis: participant \\
Follow-up: 12 weeks
\end{tabular}

Participants

Inclusion criteria: people with one or more hypertensive leg ulcers (defined by clinical criteria) $1 \mathrm{~cm}^{2}$ to $30 \mathrm{~cm}^{2}$, with hypertension and/or diabetes without clinical signs of severe CVI and without significant peripheral arterial occlusive disease (presence of peripheral pulses or $A B I>0.8$ ); if several ulcers, most recent chosen

Exclusion criteria: cutaneous vasculitis, systemic disease associated with pyoderma gangrenosum or necrotising vasculitis (e.g. rheumatoid arthritis), autoimmune disease, cryobulinemia, allergy to study materials, cancer, evolving systemic disease, creatinemia, uncontrolled diabetes, exposed bone or joint, corticosteroids, immunosuppressive or cytotoxic drugs, iloprost in prior 3 months

Participant characteristics

Number participants: 64 randomised, data from 59

Age: 73.7 (8.3) vs 75.3 (9.7) years

$\%$ male: 12 (43) vs 11 (35)

Ulcer details

Size: mean (SD) $19.6(20.1) \mathrm{cm}^{2}$ vs $24.4(24.6) \mathrm{cm}^{2}$

Duration: mean (SD) 11.8 (8.6) vs 10.5 (9.7)

Intervention 1 details (name and details of application): Becaplermin (human platelet derived growth factor) $0.1 \%$ in hydrogel + gauze; Regranex gel (Ethicon division of Johnson \& Johnson Wound Management); continuous thin layer of gel applied, covered with moist saline gauze and bandage. Treatment for 8 weeks

Intervention 2 class: hydrogel (placebo gel)

Intervention 2 details (name and details of application): DuoDerm Hydrogel (ConvaTec) + gauze; continuous thin layer of gel applied, covered with moist saline gauze and bandage. Treatment for 8 weeks

Compression: not reported; unclear if bandage applied compression

Other co-interventions: wound irrigation with saline. Moist saline gauze and bandage

\begin{tabular}{ll}
\hline Outcomes & Intervention 1: 10/28 \\
& Intervention 2: $8 / 31$ \\
\hline Notes & Funding type and details: mixed \\
& $\begin{array}{l}\text { Funding details: study supported by AP-HP (Assistance publique - Hôpitaux de Paris), the French Soci- } \\
\text { ety of Dermatology, and the AFSSAPS (Agence nationale de sécurité du médicament et des produits de } \\
\text { santé); Johnson \& Johnson provided study materials (Regranex) }\end{array}$
\end{tabular}

\section{Risk of bias}


Senet 2011 (Continued)

Random sequence genera- Low risk Quote: "eligible participants were randomly assigned by facsimile through a tion (selection bias)

central automated system designed by the Clinical Research Regional Department (AP-HP)" "a computer engineer not responsible for data acquisition prepared the assignments"

Comment: appropriate sequence generation method appears to have been used

Allocation concealment Low risk
(selection bias)

Quote: "a central automated system ... a computer engineer not responsible for data acquisition prepared the assignments"

Comment: appears to be appropriate allocation concealment

\begin{tabular}{|c|c|c|}
\hline $\begin{array}{l}\text { Blinding of participants } \\
\text { and personnel (perfor- } \\
\text { mance bias) } \\
\text { All outcomes }\end{array}$ & Low risk & $\begin{array}{l}\text { Quote: "all participants and investigators were blinded to assigned treatment" } \\
\text { "masked } 15 \mathrm{~g} \text { tubes ... identical in color, shape and size, were provided in blis- } \\
\text { ter packs by the AP-HP central pharmacy" } \\
\text { Comment: blinding of both groups }\end{array}$ \\
\hline $\begin{array}{l}\text { Blinding of outcome as- } \\
\text { sessment (detection bias) } \\
\text { All outcomes }\end{array}$ & Low risk & $\begin{array}{l}\text { Quote: "all participants and investigators were blinded to assigned treatment" } \\
\text { "masked } 15 \mathrm{~g} \text { tubes ... identical in color, shape and size, were provided in blis- } \\
\text { ter packs by the AP-HP central pharmacy" }\end{array}$ \\
\hline & & Comment: appears that assessors were blinded \\
\hline
\end{tabular}

$\begin{array}{lll}\begin{array}{l}\text { Incomplete outcome data } \\ \text { (attrition bias) }\end{array} & \text { High risk } & \begin{array}{l}7 / 28 \mathrm{vs} 13 / 31 \text { did not receive treatment or complete follow-up - ITTanalysis } \\ \text { performed but this is a very high rate of loss with disparity between arms. }\end{array}\end{array}$

All outcomes performed but this is a very high rate of loss with disparity between arms.

\begin{tabular}{lll}
\hline $\begin{array}{l}\text { Selective reporting (re- } \\
\text { porting bias) }\end{array}$ & Low risk & No evidence of selective reporting \\
\hline Other bias & Unclear risk & No evidence of other source of bias \\
\hline All domain risk of bias & High risk &
\end{tabular}

Senet 2014

$\begin{array}{ll}\text { Methods } & \text { RCT } \\ \text { Arms: } 2 \\ \text { Unit of randomisation: participant } \\ \text { Unit of analysis: participant } \\ \text { Follow-up: } 6 \text { weeks }\end{array}$

Participants Inclusion criteria: venous or predominantly venous leg ulcer $(A B I>0.8)$ between $2 \mathrm{~cm}$ and $13 \mathrm{~cm}$ in all directions, moderately or severely exudating in the phase of debridement or formation of granulation tissue, size reduction $<20 \%$ in 4 -week pre-study treatment phase

Exclusion criteria: clinically infected ulcer requiring systemic antibiotics, surgery on saphenous trunk within 2 months prior, systemic antibiotics 2 weeks prior, systemic corticoids or cytostatics within 3 months prior, unbalanced diabetes, known allergy to study dressings, pregnant or breastfeeding, taking part in another study

Participant characteristics 
Senet 2014 (Continued)

Number participants: 182 (1 erroneously enrolled and subsequently excluded)

Age: 72.1 (12.4) vs 75.1 (11.8) years

$\%$ male: 50 (53) vs 34 (39)

Ulcer details

Size: mean (SD) $15.4(14.1) \mathrm{cm}^{2}$ vs $14.5(13.4) \mathrm{cm}^{2}$

Duration: mean (SD) 2.8 (4.2) years vs 2.9 (5.1) years

\begin{tabular}{ll}
\hline Interventions & Intervention 1 class: foam \\
Intervention 1 details (name and details of application): Biatain (Coloplast A/S) \\
Intervention 2 class: silver (foam) \\
Intervention 2 details (name and details of application): Biatain-Ag (Coloplast A/S) \\
Compression: compression therapy was mandatory for all according to clinical practice of the centre \\
Other co-interventions: not reported \\
\hline Intervention 1: $3 / 94$ \\
Intervention 2: $7 / 87$ \\
\hline Notes & Funding type: industry \\
\hline
\end{tabular}

\section{Risk of bias}

\begin{tabular}{|c|c|c|}
\hline Bias & Authors' judgement & Support for judgement \\
\hline $\begin{array}{l}\text { Random sequence genera- } \\
\text { tion (selection bias) }\end{array}$ & Low risk & $\begin{array}{l}\text { Quote: "centrally randomised (by computer system)" } \\
\text { Comment: appropriate method of sequence generation }\end{array}$ \\
\hline $\begin{array}{l}\text { Allocation concealment } \\
\text { (selection bias) }\end{array}$ & Low risk & $\begin{array}{l}\text { Quote: "allocated ... using Interactive Voice Response Service (IVRS)" } \\
\text { Comment: appropriate allocation concealment }\end{array}$ \\
\hline $\begin{array}{l}\text { Blinding of participants } \\
\text { and personnel (perfor- } \\
\text { mance bias) } \\
\text { All outcomes }\end{array}$ & Low risk & $\begin{array}{l}\text { Quote: "the study was designed as double-blinded. All products were ... } \\
\text { packed in identical packing and blinded by an external company ... No dress- } \\
\text { ings could be compared by the subject or investigator in the knowledge that } \\
\text { they were different products" } \\
\text { Comment: effective blinding described }\end{array}$ \\
\hline $\begin{array}{l}\text { Blinding of outcome as- } \\
\text { sessment (detection bias) } \\
\text { All outcomes }\end{array}$ & Low risk & $\begin{array}{l}\text { Quote: "the planimetry records were read blind by a person who was not } \\
\text { aware of the nature of the treatment" } \\
\text { Comment: blinded outcome assessment }\end{array}$ \\
\hline $\begin{array}{l}\text { Incomplete outcome data } \\
\text { (attrition bias) } \\
\text { All outcomes }\end{array}$ & High risk & $\begin{array}{l}11 \text { vs } 18 \text { withdrawals - reasons given and ITT analysis performed but still a high } \\
\text { level of withdrawal and an imbalance between the groups }\end{array}$ \\
\hline $\begin{array}{l}\text { Selective reporting (re- } \\
\text { porting bias) }\end{array}$ & Low risk & No evidence of selective reporting \\
\hline
\end{tabular}


Senet 2014 (Continued)

Other bias Low risk No evidence of other sources of bias

All domain risk of bias High risk

Smith 1992

\begin{tabular}{ll}
\hline Methods & RCT \\
Arms: 2 \\
Unit of randomisation: participant \\
Unit of analysis: participant \\
Follow-up: 4 months
\end{tabular}

Participants

Inclusion criteria: venous leg ulceration assessed by continuous wave ultrasound and photoplethysmography

Exclusion criteria: brachial ankle systolic pressure $<0.75$, diabetes, rheumatoid arthritis, infected ulcers requiring treatment, known intolerance to iodine, neurological disease causing trophic impairment

Participant characteristics

Number participants: 200

Age: 74 (12) vs 72 (13) vs 76 (8) vs 73 (11) years

$\%$ male: not reported

Ulcer details

Size: median (IQR) 3.1 (2 to 5) $\mathrm{cm}^{2}$ vs 2.6 (2 to 4 ) $\mathrm{cm}^{2}$ vs 13.3 (9 to 27 ) $\mathrm{cm}^{2}$ vs 17.6 (9 to 38 ) $\mathrm{cm}^{2}$

Duration: median (IQR) 5 ( 3 to 9) vs 3 ( 2 to 10 ) vs 14 ( 2 to 45 ) vs 17 (6 to 58 ) months

\begin{tabular}{ll} 
Interventions & Intervention 1 class: hydrocolloid \\
Intervention 1 details (name and details of application): Biofilm (Clinimed); ulcer filled with biofilm \\
powder until level with margins, then biofilm dressing applied with $2 \mathrm{~cm}$ overlap \\
Intervention 2 class: povidone iodine \\
Intervention 2 details (name and details of application): standard Jelonet/Betadine dressing; Betadine \\
+ Jelonet (Smith \& Nephew); Dressing cut to exactly fit ulcer and absorbant pad placed over \\
Compression: 2 layers of shaped Tubigrip or a Venosan 2002 stocking for all participants \\
Other co-interventions: ulcers cleansed with sterile isotonic saline \\
\hline Outcomes \\
Intervention $1: 38+12 / 64+35$ \\
Intervention 2: $43+4 / 62+39$ \\
Funding type: industry \\
Funding details: Clinimed Ltd provided financial support to one study nurse co-ordinator
\end{tabular}

\section{Risk of bias}


Smith 1992 (Continued)

\section{Bias Authors' judgement Support for judgement}

\section{Random sequence genera- High risk} tion (selection bias)
Quote: "patients ... were randomly allocated to each treatment group"

Comment: stratification and block size mentioned but not method of sequence generation; 'Clerical errors' with treatment allocation - randomisation compromised

\begin{tabular}{|c|c|c|}
\hline $\begin{array}{l}\text { Allocation concealment } \\
\text { (selection bias) }\end{array}$ & Unclear risk & Comment: no information on how allocation was concealed \\
\hline $\begin{array}{l}\text { Blinding of participants } \\
\text { and personnel (perfor- } \\
\text { mance bias) } \\
\text { All outcomes }\end{array}$ & High risk & Described as "not a blind study" \\
\hline $\begin{array}{l}\text { Blinding of outcome as- } \\
\text { sessment (detection bias) } \\
\text { All outcomes }\end{array}$ & High risk & Described as "not a blind study" \\
\hline $\begin{array}{l}\text { Incomplete outcome data } \\
\text { (attrition bias) } \\
\text { All outcomes }\end{array}$ & High risk & $\begin{array}{l}60(30 \%) \text { dropped out, reasons given. } 5 \text { received incorrect treatment due to } \\
\text { 'clerical error', included as PP }\end{array}$ \\
\hline $\begin{array}{l}\text { Selective reporting (re- } \\
\text { porting bias) }\end{array}$ & Low risk & No evidence of this \\
\hline Other bias & Low risk & No additional risks - see random sequence generation \\
\hline All domain risk of bias & High risk & \\
\hline All domain risk of bias 2 & High risk & \\
\hline
\end{tabular}

\section{Smith 1994}

\begin{tabular}{ll}
\hline Methods & RCT \\
& Arms: 2 \\
& Unit of randomisation: participant \\
& Unit of analysis: participant \\
& Follow-up: 6 weeks
\end{tabular}

\section{Participants}

Inclusion criteria: venous leg ulcer $>2.5 \mathrm{~cm}$ diameter

Exclusion criteria: condition which might affect wound healing (infection, immune deficiency, steroid treatment, malignant disease), if ulcer not clearly venous, fibrinolytic or anticoagulant therapy

Participant characteristics

Number participants: 40

Age: not reported

$\%$ male: not reported

Ulcer details 
Smith 1994 (Continued)

Size: mean $12.74 \mathrm{~cm}^{2}$ vs $22.17 \mathrm{~cm}^{2}$

Duration: not reported

Intervention 1 class: alginate
Intervention 1 details (name and details of application): gauze used as secondary dressing
Intervention 2 class: hydrocolloid
Intervention 2 details (name and details of application): improved formulation Granuflex
Compression: compression bandaging used for all participants

Other co-interventions: wounds cleaned with saline

\begin{tabular}{ll} 
Outcomes & Intervention $1: 2 / 18$ \\
& Intervention 2: 4/22 \\
\hline Notes & Funding type: industry \\
& Funding details: Convatec
\end{tabular}

\section{Risk of bias}

\begin{tabular}{|c|c|c|}
\hline Bias & Authors' judgement & Support for judgement \\
\hline $\begin{array}{l}\text { Random sequence genera- } \\
\text { tion (selection bias) }\end{array}$ & Unclear risk & $\begin{array}{l}\text { Quote: "eligible patients were allocated randomly" } \\
\text { Comment: no information on how randomisation sequence generated }\end{array}$ \\
\hline $\begin{array}{l}\text { Allocation concealment } \\
\text { (selection bias) }\end{array}$ & Unclear risk & $\begin{array}{l}\text { Quote: "eligible patients were allocated randomly" } \\
\text { Comment: no information on how allocation was concealed }\end{array}$ \\
\hline $\begin{array}{l}\text { Blinding of participants } \\
\text { and personnel (perfor- } \\
\text { mance bias) } \\
\text { All outcomes }\end{array}$ & High risk & Trial described as open \\
\hline $\begin{array}{l}\text { Blinding of outcome as- } \\
\text { sessment (detection bias) } \\
\text { All outcomes }\end{array}$ & High risk & Trial described as open \\
\hline $\begin{array}{l}\text { Incomplete outcome data } \\
\text { (attrition bias) } \\
\text { All outcomes }\end{array}$ & Unclear risk & $6 / 18$ vs $6 / 22$ withdrawals, reasons given \\
\hline $\begin{array}{l}\text { Selective reporting (re- } \\
\text { porting bias) }\end{array}$ & Low risk & No evidence of this \\
\hline Other bias & Low risk & No evidence of this \\
\hline All domain risk of bias & High risk & \\
\hline All domain risk of bias 2 & High risk & \\
\hline
\end{tabular}


Solovastru 2015

\begin{tabular}{ll}
\hline Methods & RCT \\
Arms: 2 \\
Unit of randomisation: participant \\
Unit of analysis: participant \\
Follow-up: 30 days \\
\hline
\end{tabular}

Participants

Inclusion criteria: chronic VLUs $<2$ years duration

Exclusion criteria: confined to bed 24 hours, ulcers covered by necrosis or fibrin, infected ulcers, multiresistant germs in wound, poorly controlled diabetes, those on dialysis, advanced peripheral arterial occlusive disease (ABPI $<0.80$ and presence of distal pulse), immunodeficiency, lymphopenia, hepatic insufficiency, renal insufficiency, anaemia, autoimmune disease, BMI > 30, hypersensitivity to study materials, low white blood cells or thrombocytes.

Participant characteristics

Number participants: 29

Age: 58.0 vs 59.0 years

$\%$ male: 9 (60) vs 10 (71)

Ulcer details

Size: mean (SD) $4.36(5.61) \mathrm{cm}^{2}$ vs $4.59(3.46) \mathrm{cm}^{2}$

Duration: mean 13 months vs 16 months

Interventions

Intervention 1 class: ozonated oil

Intervention 1 details (name and details of application): ozonated oil and alpha-bisabolol spray + gauze; sunflower oil with $\mathrm{O}^{3}$ (Neozone, Neovalis) and Azexin (Alfa Wassermann); administered daily for 30 days

Intervention 2 class: emollient cream

Intervention 2 details (name and details of application): epithelialization cream (vitamins A \& E, talc, zinc oxide, Vaseline) + gauze; administered daily for 30 days

Compression: none

Other co-interventions: mechanical debridement at days $0,7,14$

Outcomes

Intervention 1:5/15

Intervention 2: 0/14

Notes

Funding type and details: not reported but authors employed by pharmaceutical company

\section{Risk of bias}

\begin{tabular}{lll}
\hline Bias & Authors' judgement & Support for judgement \\
\hline $\begin{array}{l}\text { Random sequence genera- } \\
\text { tion (selection bias) }\end{array}$ & Unclear risk & Quote: "patients were randomly divided into 2 groups" \\
& & Comment: no information on how sequence was generated \\
\hline $\begin{array}{l}\text { Allocation concealment } \\
\text { (selection bias) }\end{array}$ & Unclear risk & Quote: "patients were randomly divided into 2 groups" \\
\hline
\end{tabular}




Blinding of participants $\quad$ Unclear risk Not reported
and personnel (perfor-
mance bias)
All outcomes

Blinding of outcome as- Unclear risk Not reported
sessment (detection bias)

All outcomes

\begin{tabular}{lll}
\hline $\begin{array}{l}\text { Incomplete outcome data } \\
\text { (attrition bias) } \\
\text { All outcomes }\end{array}$ & Low risk & All participants included in analysis \\
\hline $\begin{array}{l}\text { Selective reporting (re- } \\
\text { porting bias) }\end{array}$ & Low risk & No evidence of this \\
\hline Other bias & Low risk & No evidence of this \\
\hline All domain risk of bias & Low risk & Low/unclear \\
\hline
\end{tabular}

\section{Sopata 2016}

\begin{tabular}{ll}
\hline Methods & RCT \\
Arms: 2 \\
Unit of randomisation: participant \\
Unit of analysis: participant \\
Follow-up: until participants healed (maximum 40 weeks) or died
\end{tabular}

\section{Participants}

Inclusion criteria: people with VLU confirmed by ultrasound Doppler and ABPI, no clinical signs of infection, no intolerance or allergy to octenidine dihydrochloride

Exclusion criteria: not reported

Participant characteristics

Number participants: 50

Age (years): female 39 to $91,68.9 \pm 12.2$, mean $=70.5$; male 24 to $93,65.7 \pm 20.2$, mean $=70$

$\%$ male: $15(30)$

Ulcer details

Size: female: 3.0 to $156.5 \mathrm{~cm}^{2}, 28.8 \pm 28.5$, mean $=24.2$; male $2.8-75.2 \mathrm{~cm}^{2}, 20.4 \pm 27.1$, mean $=12.2$

Duration: not reported

Intervention 1 class: hydrocolloid
Intervention 1 details (name and details of application): Granuflex (ConvaTec); dressing changed every
2-4 days
Intervention 2 class: foam


Intervention 2 details (name and details of application): Biatain (Coloplast); dressing changed every 2-4 days

Compression: short stretch bandages used for all participants, with a spiral two layer bandaging technique

Other co-interventions: for 4 weeks prior to randomisation all participants were treated with nonadherent silicone N-A dressing (Systagenix) and Sterilux EX (Hartmann) gauze bandages soaked in octenidine dihydrochloride antiseptic (Octenisept) and covered with absorbent Zetuvit (Hartmann) dressing

\begin{tabular}{ll}
\hline Outcomes & Intervention $1: 17 / 25$ \\
& Intervention $2: 21 / 25$ \\
\hline Notes & Funding type: non-industry \\
& Funding details: Grant from University of Medical Science, Poznan \\
& Notes: Demographic data not presented by treatment group \\
\hline
\end{tabular}

\section{Risk of bias}

\begin{tabular}{|c|c|c|}
\hline Bias & Authors' judgement & Support for judgement \\
\hline \multirow[t]{2}{*}{$\begin{array}{l}\text { Random sequence genera- } \\
\text { tion (selection bias) }\end{array}$} & Unclear risk & $\begin{array}{l}\text { Quote: "in the second period the patients were randomly allocated to two } \\
\text { groups" }\end{array}$ \\
\hline & & Comment: no information on how the randomisation sequence was generated \\
\hline \multirow[t]{2}{*}{$\begin{array}{l}\text { Allocation concealment } \\
\text { (selection bias) }\end{array}$} & Unclear risk & $\begin{array}{l}\text { Quote: "in the second period the patients were randomly allocated to two } \\
\text { groups" }\end{array}$ \\
\hline & & Comment: no information on how the allocation was concealed \\
\hline $\begin{array}{l}\text { Blinding of participants } \\
\text { and personnel (perfor- } \\
\text { mance bias) } \\
\text { All outcomes }\end{array}$ & Unclear risk & Not reported \\
\hline $\begin{array}{l}\text { Blinding of outcome as- } \\
\text { sessment (detection bias) } \\
\text { All outcomes }\end{array}$ & Unclear risk & Not reported \\
\hline $\begin{array}{l}\text { Incomplete outcome data } \\
\text { (attrition bias) } \\
\text { All outcomes }\end{array}$ & Low risk & $\begin{array}{l}\text { All participants included in analysis (those that did not have final assessment } \\
\text { explained in text) }\end{array}$ \\
\hline $\begin{array}{l}\text { Selective reporting (re- } \\
\text { porting bias) }\end{array}$ & High risk & Study design does not have defined time end point \\
\hline Other bias & High risk & No baseline information for study groups, just split male vs female \\
\hline All domain risk of bias & High risk & \\
\hline All domain risk of bias 2 & High risk & \\
\hline
\end{tabular}


Stacey 1997

\begin{tabular}{ll}
\hline Methods & RCT \\
Arms: 3 \\
Unit of randomisation: leg \\
Unit of analysis: leg \\
Follow-up: 9 months
\end{tabular}

Participants

Inclusion criteria: proven venous ulcers $0.5 \mathrm{~cm}$ to $10 \mathrm{~cm}$ diameter

Exclusion criteria: diabetes, rheumatoid arthritis, arterial diease, cellulitis

Participant characteristics

Number participants: 133 legs (113 participants)

Age: median (range) 73 (33 to 89 ) vs 76 ( 31 to 89 ) vs 70.5 (36 to 92) years

$\%$ male: 17 (41) vs $16(39)$ vs 22 (48)

Ulcer details

Size: mean $10.11 \mathrm{~cm}^{2}$ vs 9.14 vs $11.02 \mathrm{~cm}^{2}$, median (range) $3.60(0.15$ to 57.46$) \mathrm{cm}^{2}$ vs $2.94 \mathrm{~cm}^{2}(0.24$ to $75.37) \mathrm{cm}^{2}$ vs $4.57 \mathrm{~cm}^{2}$ (0.36 to 61.32$) \mathrm{cm}^{2}$

Duration: median (range) 6.00 (0.25 to 192 ) vs 6.00 ( 0.25 to 5.04 ) vs 4.00 (0.25 to 2.64 ) months

Intervention 1 class: paste bandage

Intervention 1 details (name and details of application): zinc oxide paste bandage; Viscopaste (Smith \& Nephew); applied in spiral fashion from base of toes to just below the knee. Changed weekly or sooner if excessive exudate

Intervention 2 class: paste bandage

Intervention 2 details (name and details of application): zinc oxide stockingette; Acoband (Auspharm); applied from base of toes to just below knee. Changed weekly or sooner if excessive exudate

Intervention 3 class: alginate

Intervention 3 details (name and details of application): Kaltostat (Faulding Pharmaceuticals); moistened with saline and applied over ulcer. Changed weekly or sooner if excessive exudate

Compression: over dressings 2 elastocrepe bandages (Smith \& Nephew) applied from toe to knee and Tubigrip stockingette (Seton) over them

Other co-interventions: leg and foot washed in soap-water bath and ulcer debrided

\begin{tabular}{ll}
\hline Outcomes & Intervention 1: $34 / 43$ \\
& Intervention 2: $26 / 44$ \\
& Intervention 3: $26 / 46$ \\
\hline Notes & Funding type and details: not reported \\
\hline Risk of bias & \\
\hline Bias & Authors' judgement Support for judgement \\
\hline
\end{tabular}


Stacey 1997 (Continued)

Random sequence genera- Unclear risk Described as randomised but no methods given tion (selection bias)

\begin{tabular}{lll}
\hline $\begin{array}{l}\text { Allocation concealment } \\
\text { (selection bias) }\end{array}$ & Unclear risk & No information provided \\
\hline $\begin{array}{l}\text { Blinding of participants } \\
\text { and personnel (perfor- } \\
\text { mance bias) }\end{array}$ & Unclear risk & Not reported \\
All outcomes & \\
\hline
\end{tabular}

\begin{tabular}{lll}
\hline $\begin{array}{l}\text { Blinding of outcome as- } \\
\text { sessment (detection bias) } \\
\text { All outcomes }\end{array}$ & Unclear risk & Not reported \\
\hline $\begin{array}{l}\text { Incomplete outcome data } \\
\begin{array}{l}\text { (attrition bias) } \\
\text { All outcomes }\end{array}\end{array}$ & High risk & $5 / 43$ vs $6 / 44$ vs $10 / 46$ withdrawals, reasons given. Imbalance between groups. \\
\hline $\begin{array}{l}\text { Selective reporting (re- } \\
\text { porting bias) }\end{array}$ & Low risk & No evidence of this \\
\hline Other bias & Unclear risk & Unclear if the analysis adjusted for some clustering of data \\
\hline All domain risk of bias & High risk & \\
\hline
\end{tabular}

Stacey 2000

\begin{tabular}{|c|c|}
\hline \multirow[t]{5}{*}{ Methods } & $\mathrm{RCT}$ \\
\hline & Arms: 2 \\
\hline & Unit of randomisation: participant \\
\hline & Unit of analysis: participant \\
\hline & Follow-up: 9 months \\
\hline \multirow[t]{9}{*}{ Participants } & Inclusion criteria: venous ulcer (established with photoplethysmography - venous refilling time < 25s) \\
\hline & Exclusion criteria: arterial disease $(\mathrm{ABPI}<0.9)$ \\
\hline & Participant characteristics \\
\hline & Number participants: 66 \\
\hline & Age: Median (range) 72 (35 to 90 ) vs 70 ( 26 to 92 ) years \\
\hline & $\%$ male: 15 (36) vs $21(48)$ \\
\hline & Ulcer details \\
\hline & $\begin{array}{l}\text { Size: mean (SD) } 5.06(8.70) \mathrm{cm}^{2} \text { vs } 4.79(8.24) \mathrm{cm}^{2} \text {, median (range) } 1.79(0.23 \text { to } 50.76) \mathrm{cm}^{2} \text { vs } 2.09(0.15 \\
\text { to } 47.8) \mathrm{cm}^{2}\end{array}$ \\
\hline & Duration: median (range) 3.0 ( 1 to 244 ) months vs 3.0 (0.75 to 360 ) months \\
\hline Interventions & Intervention 1 class: blood product \\
\hline
\end{tabular}


Stacey 2000 (Continued)

Intervention 1 details (name and details of application): platelet lysate-soaked gauze; dressing changed twice weekly

Intervention 2 class: saline gauze (placebo/vehicle liquid)

Intervention 2 details (name and details of application): placebo (buffer solution) soaked gauze; dressing changed twice weekly

Compression: dressings covered with Viscopaste bandage (Smith \& Nephew) followed by 2 Comprilan bandages (Beiersdorf) and Tubigrip stockingette (Seton)

Other co-interventions: see above

\begin{tabular}{ll}
\hline Outcomes & Intervention 1: $34 / 42$ \\
& Intervention 2: $33 / 44$ \\
\hline Notes & Funding type: mixed \\
& Funding details: Medical Research Fund of Western Australia and Beiersdorf AG \\
\hline
\end{tabular}

\section{Risk of bias}

\begin{tabular}{|c|c|c|}
\hline Bias & Authors' judgement & Support for judgement \\
\hline $\begin{array}{l}\text { Random sequence genera- } \\
\text { tion (selection bias) }\end{array}$ & Unclear risk & $\begin{array}{l}\text { Quote: "randomisation was by a sealed envelope system" } \\
\text { Comment: no information on sequence generation }\end{array}$ \\
\hline $\begin{array}{l}\text { Allocation concealment } \\
\text { (selection bias) }\end{array}$ & Unclear risk & $\begin{array}{l}\text { Quote: "randomisation was by a sealed envelope system" } \\
\text { Comment: no information on allocation concealment }\end{array}$ \\
\hline $\begin{array}{l}\text { Blinding of participants } \\
\text { and personnel (perfor- } \\
\text { mance bias) } \\
\text { All outcomes }\end{array}$ & Unclear risk & Comment: described as "double blind" but no further details given \\
\hline $\begin{array}{l}\text { Blinding of outcome as- } \\
\text { sessment (detection bias) } \\
\text { All outcomes }\end{array}$ & Unclear risk & Comment: described as "double blind" but no further details given \\
\hline $\begin{array}{l}\text { Incomplete outcome data } \\
\text { (attrition bias) } \\
\text { All outcomes }\end{array}$ & High risk & $5 / 42$ vs $6 / 44$ withdrawals, reasons given, over $10 \%$ lost \\
\hline $\begin{array}{l}\text { Selective reporting (re- } \\
\text { porting bias) }\end{array}$ & Low risk & No evidence of this \\
\hline Other bias & Low risk & No evidence of this \\
\hline All domain risk of bias & High risk & \\
\hline
\end{tabular}

\section{Steele 1986}

Methods RCT

Arms: 2 
Steele 1986 (Continued)

Unit of randomisation: participant

Unit of analysis: participant

Follow-up: 6 weeks

Participants

Inclusion criteria: venous leg ulcers present for 3 months and $>2 \mathrm{~cm}^{2}$

Exclusion criteria: arterial disease (palpable dorsalis pedis and posterior tibial pulses and absence of ischaemic skin signs), diabetes, rheumatoid arthritis, neurological disease, connective tissue disease

Participant characteristics

Number participants: 60

Age: mean (SE) 69.5 (2.4) vs 73.4 (1.6) years

$\%$ male: 8 (29) vs 8 (28)

Ulcer details

Size: mean (SE) 1264 (291) $\mathrm{mm}^{2}$ vs 1759 (397) $\mathrm{mm}^{2}$

Duration: mean (SE) 16.6 (2.7) months vs 16.3 (2.5) months

Interventions

Intervention 1 class: cadexomer iodine

Intervention 1 details (name and details of application) powder sprinkled onto ulcer and covered with gauze. Changed 3 times per week

Intervention 2 class: standard treatment

Intervention 2 details (name and details of application): various including topical antibiotics, antiseptics, hydrophilic agents, bland agents, steroids, dry dressings; dressing applied and covered with gauze. Changed 3 times per week

Compression: all participants wore crepe compression bandages

Other co-interventions: ulcers cleansed with saline

Outcomes Intervention $1: 3 / 28$

Intervention 2: 1/29

Notes Funding type and details: not reported

\section{Risk of bias}

\begin{tabular}{|c|c|c|}
\hline Bias & Authors' judgement & Support for judgement \\
\hline $\begin{array}{l}\text { Random sequence genera- } \\
\text { tion (selection bias) }\end{array}$ & Unclear risk & $\begin{array}{l}\text { Quote "the patients were divided into two groups using random numbers" } \\
\text { Comment: unclear how the random number sequence was obtained }\end{array}$ \\
\hline $\begin{array}{l}\text { Allocation concealment } \\
\text { (selection bias) }\end{array}$ & Unclear risk & $\begin{array}{l}\text { Quote "the patients were divided into two groups using random numbers" } \\
\text { Comment: unclear how allocation was concealed }\end{array}$ \\
\hline $\begin{array}{l}\text { Blinding of participants } \\
\text { and personnel (perfor- } \\
\text { mance bias) } \\
\text { All outcomes }\end{array}$ & Unclear risk & Not reported \\
\hline
\end{tabular}


Steele 1986 (Continued)

Blinding of outcome as-
sessment (detection bias)

All outcomes

Incomplete outcome data Low risk $\quad 57 / 60$ completed and reasons for withdrawal given
(attrition bias)

\begin{tabular}{lll}
\hline $\begin{array}{l}\text { Selective reporting (re- } \\
\text { porting bias) }\end{array}$ & Unclear risk & No evidence of this \\
\hline Other bias & Unclear risk & No evidence of this \\
\hline All domain risk of bias & Low risk & Low/unclear \\
\hline
\end{tabular}

\section{Taddeucci 2004}

\begin{tabular}{ll}
\hline Methods & RCT \\
Arms: 2 \\
Unit of randomisation: participant \\
Unit of analysis:ulcer \\
Follow-up: 8 weeks \\
\hline
\end{tabular}

\section{Participants}

Inclusion criteria: venous ulceration present for $>3$ months

Exclusion criteria: arterial, metabolic or traumatic ulcers, infected ulcers with cellulitis, immunosuppressive, corticosteroid or cytostatic therapy in previous 4 weeks, insulin-dependent diabetes, concomitant diseases, pregnancy

Participant characteristics

Number participants: 17 participants (24 ulcers)

Age: not reported

$\%$ male: not reported

Ulcer details

Size: not reported

Duration: not reported

Intervention 1 details (name and details of application): Hyalofill-F (Fidia Advanced Biopolymers); dressing applied and covered with sterile gauze. Changed every 2-3 days initially then less frequently depending on wound condition

Intervention 2 class: nonadherent

Intervention 2 details (name and details of application): paraffin gauze; dressing applied and covered with sterile gauze. Changed every 2-3 days initially then less frequently depending on wound condition

Compression: compression bandage Pehacrepp E (Paul Hartmann) 
Taddeucci 2004 (Continued)

Other co-interventions: initial debridement if necessary, then cleansing with saline at every dressing change

\begin{tabular}{ll}
\hline Outcomes & Intervention $1: 2 / 12$ \\
& Intervention $2: 1 / 12$ \\
\hline Notes & Funding type and details: funding not reported but some authors work for Fidia Advanced Biopolymers
\end{tabular}

\section{Risk of bias}

\begin{tabular}{lll}
\hline Bias & Authors' judgement & Support for judgement \\
\hline $\begin{array}{l}\text { Random sequence genera- } \\
\text { tion (selection bias) }\end{array}$ & Unclear risk & $\begin{array}{l}\text { Described as randomised study "subjects ... were ... assigned sequentially to } \\
\text { one of two treatments" }\end{array}$ \\
& & Comment: unclear how randomisation sequence was generated
\end{tabular}

\begin{tabular}{ll}
\hline $\begin{array}{l}\text { Allocation concealment } \\
\text { (selection bias) }\end{array}$ & $\begin{array}{l}\text { Unclear risk } \\
\text { Described as randomised study "subjects ... were ... assigned sequentially to } \\
\text { one of two treatments" }\end{array}$ \\
& Comment: unclear how allocation was concealed
\end{tabular}

\begin{tabular}{|c|c|c|}
\hline $\begin{array}{l}\text { Blinding of participants } \\
\text { and personnel (perfor- } \\
\text { mance bias) } \\
\text { All outcomes }\end{array}$ & High risk & Trial described as "open" \\
\hline $\begin{array}{l}\text { Blinding of outcome as- } \\
\text { sessment (detection bias) } \\
\text { All outcomes }\end{array}$ & High risk & Trial described as "open" \\
\hline $\begin{array}{l}\text { Incomplete outcome data } \\
\text { (attrition bias) } \\
\text { All outcomes }\end{array}$ & High risk & $\begin{array}{l}1 / 12 \text { vs } 5 / 12 \text { ulcers withdrawn, reasons given; imbalance and larger numbers } \\
\text { than those healed }\end{array}$ \\
\hline $\begin{array}{l}\text { Selective reporting (re- } \\
\text { porting bias) }\end{array}$ & Low risk & No evidence of this \\
\hline Other bias & High risk & Unit of analysis issue. Unclear if clustering of some data adjusted for \\
\hline All domain risk of bias & High risk & \\
\hline All domain risk of bias 2 & High risk & \\
\hline
\end{tabular}

\section{Tarvainen 1988}

\begin{tabular}{ll}
\hline Methods & RCT \\
Arms: 2 \\
Unit of randomisation: participant \\
Unit of analysis: participant \\
Follow-up: 8 weeks \\
\hline Participants & Inclusion criteria: chronic exuding leg ulcer
\end{tabular}


Tarvainen 1988 (Continued)

Exclusion criteria: insulin-dependent diabetes, rheumatoid arthritis, connective tissue disease, goitre, known allergy to iodine

Participant characteristics

Number participants: 27 randomised; 21 analysed

Age: 67.7 (13.3) vs 68.8 (14.6), range 39 to 86 vs 38 to 87 years

$\%$ male: 4 (29) vs 3 (23)

Ulcer details

Non VLU: "[ulcers] were clinically judged to be mainly of venous origin"

Size: not reported

Duration: mean (SD) 54.8 (108.7) months vs 12.2 (23.0) months, range 1 to 360 months vs 1 to 72 months

Interventions Intervention 1 class: cadexomer iodine

Intervention 1 details (name and details of application): cadexomer iodine powder; applied in 3mm layer, then "covered with protective clean compress". Changed daily

Intervention 2 class: dextranomer

Intervention 2 details (name and details of application): dextranomer powder; applied in 3mm layer, then "covered with protective clean compress". Changed daily

Compression: "a normal compression bandage was applied"

Other co-interventions: ulcers washed with water or saline solution

\begin{tabular}{ll}
\hline Outcomes & Intervention $1: 7 / 11$ \\
& Intervention 2: 5/10 \\
\hline Notes & Funding type and details: not reported
\end{tabular}

\section{Risk of bias}

\begin{tabular}{lll}
\hline Bias & Authors' judgement & Support for judgement \\
\hline $\begin{array}{l}\text { Random sequence genera- } \\
\text { tion (selection bias) }\end{array}$ & Unclear risk & $\begin{array}{l}\text { Quote: "random allocation to treatment" } \\
\text { Comment: no details of sequence generation }\end{array}$ \\
\hline $\begin{array}{l}\text { Allocation concealment } \\
\text { (selection bias) }\end{array}$ & Unclear risk & $\begin{array}{l}\text { Quote: "each patient was allocated to the treatment by using a sealed enclo- } \\
\text { sure envelope containing the treatment code of the individual patient" }\end{array}$ \\
\hline $\begin{array}{l}\text { Blinding of participants } \\
\text { and personnel (perfor- } \\
\text { mance bias) } \\
\text { All outcomes }\end{array}$ & High risk & Described as "open" \\
\hline
\end{tabular}

\begin{tabular}{lll}
\hline $\begin{array}{l}\text { Blinding of outcome as- } \\
\text { sessment (detection bias) } \\
\text { All outcomes }\end{array}$ & High risk & Described as "open" \\
\hline $\begin{array}{l}\text { Incomplete outcome data } \\
\text { (attrition bias) }\end{array}$ & High risk & $\begin{array}{l}3 / 14 \text { vs } 5 / 13 \text { appear to have dropped out for reasons other than healing - rea- } \\
\text { sons given but numbers do not tally with text }\end{array}$ \\
\hline
\end{tabular}


Tarvainen 1988 (Continued)

All outcomes

Selective reporting (re- $\quad$ Unclear risk $\quad$ Results section confusing - data don't match
porting bias)

\begin{tabular}{lll}
\hline Other bias & Unclear risk & Reporting somewhat unclear; risks of bias uncertain \\
\hline All domain risk of bias & High risk & High risk \\
\hline All domain risk of bias 2 & Hign \\
\hline
\end{tabular}

Thomas 1997

$\begin{array}{ll}\text { Methods } & \text { RCT } \\ \text { Arms: } 2 \\ \text { Unit of randomisation: participant } \\ \text { Unit of analysis: participant } \\ \text { Follow-up: } 13 \text { weeks }\end{array}$

Participants Inclusion criteria: over 16 years. Venous leg ulcer maximum dimension $8 \mathrm{~cm}$ confirmed by medical history, clinical examination and $\mathrm{ABPI}>0.8$

Exclusion criteria: history of poor compliance, insulin-dependent diabetes, unlikely to survive study period, previous adverse reaction to study materials, clinically infected wounds

Participant characteristics

Number participants: 100

Age: 75.3 (14.4) vs $73.4(13.2)$ years

$\%$ male: 16 (32) vs $13(26)$

Ulcer details

Non VLU: (pressure ulcers included in separate stratified analysis)

Size: mean (range) 335 (10 to 2758$) \mathrm{mm}^{2}$ vs 431 (16 to 1876$) \mathrm{mm}^{2}$

Duration: no summary statistic, grouped data < 1 month ( 3 vs 2 ) 1 to 3 months ( 13 vs 9 ) > 3 months (34 vs 39)

Intervention 1 details (name and details of application): Granuflex

Intervention 2 class: foam

Intervention 2 details (name and details of application): Tielle

Compression: type 3c compression bandage (Tensopress) applied over layer of orthopaedic wadding (Velband)

Other co-interventions: Wounds cleansed with $0.9 \% \mathrm{NaCl}$ (saline) solution as necessary

Outcomes Intervention 1: 19/50


Thomas 1997 (Continued)

Intervention 2: 17/50

Notes Funding type and details: not reported

\section{Risk of bias}

Bias Authors' judgement Support for judgement

Random sequence genera- Unclear risk tion (selection bias)

Quote: "patients ... were allocated to the two treatment groups on a randomised basis, using a system of sealed envelopes"

Comment: unclear how the randomisation sequence was generated

\begin{tabular}{|c|c|c|}
\hline $\begin{array}{l}\text { Allocation concealment } \\
\text { (selection bias) }\end{array}$ & Unclear risk & $\begin{array}{l}\text { Quote: "patients ... were allocated to the two treatment groups on a ran- } \\
\text { domised basis, using a system of sealed envelopes" }\end{array}$ \\
\hline $\begin{array}{l}\text { Blinding of participants } \\
\text { and personnel (perfor- } \\
\text { mance bias) } \\
\text { All outcomes }\end{array}$ & High risk & Described as "open" \\
\hline $\begin{array}{l}\text { Blinding of outcome as- } \\
\text { sessment (detection bias) } \\
\text { All outcomes }\end{array}$ & High risk & Described as "open" \\
\hline $\begin{array}{l}\text { Incomplete outcome data } \\
\text { (attrition bias) } \\
\text { All outcomes }\end{array}$ & Low risk & All participants accounted for \\
\hline $\begin{array}{l}\text { Selective reporting (re- } \\
\text { porting bias) }\end{array}$ & Low risk & No evidence of this \\
\hline Other bias & Unclear risk & No evidence of this but reporting insufficient \\
\hline All domain risk of bias & High risk & \\
\hline All domain risk of bias 2 & High risk & \\
\hline
\end{tabular}

Tumino 2008

\begin{tabular}{ll}
\hline Methods & RCT \\
Arms: 2 \\
Unit of randomisation: participant \\
Unit of analysis: participant \\
Follow-up: 90 days \\
\hline
\end{tabular}

Participants
$\begin{aligned} & \text { Exclusion criteria: non-infected venous stasis or post-phlebitis ulcers } \\ & \text { previous use of local treatment for ulcer }\end{aligned}$
Participant characteristics
Number participants: 100


Tumino 2008 (Continued)

Age: 64.9 (12.1) vs $67.7(6.5)$ years

$\%$ male: 23 (46) vs 26 (52)

Ulcer details

Size: 6.6 (8.9) vs 4.7 (9.1) (unit of size unclear)

Duration: not reported

Intervention 1 details (name and details of application): SUC-LIS 95 (Lisapharma); sucralfate hydrophilic gel; applied once daily for 30 to 90 days, covered with dry gauze

Intervention 2 class: hydrogel (placebo gel)

Intervention 2 details (name and details of application): manufactured by Lisapharma; applied once daily for 30 to 90 days, covered with dry gauze

Compression: a few cases were covered with elastic bandage (no further details)

Other co-interventions: cleaning with saline and iodine solution following surgical removal of debris

Outcomes Intervention 1: 43/50

Intervention 2: 5/50

Notes $\quad$ Funding type and details: not reported

\section{Risk of bias}

\begin{tabular}{|c|c|c|}
\hline Bias & Authors' judgement & Support for judgement \\
\hline $\begin{array}{l}\text { Random sequence genera- } \\
\text { tion (selection bias) }\end{array}$ & Unclear risk & Described as randomised but no information on how sequence was generated \\
\hline $\begin{array}{l}\text { Allocation concealment } \\
\text { (selection bias) }\end{array}$ & Unclear risk & No information on how allocation was concealed \\
\hline $\begin{array}{l}\text { Blinding of participants } \\
\text { and personnel (perfor- } \\
\text { mance bias) } \\
\text { All outcomes }\end{array}$ & Low risk & Described as double-blind and uses placebo manufactured externally \\
\hline $\begin{array}{l}\text { Blinding of outcome as- } \\
\text { sessment (detection bias) } \\
\text { All outcomes }\end{array}$ & Low risk & Described as double-blind and uses placebo manufactured externally \\
\hline $\begin{array}{l}\text { Incomplete outcome data } \\
\text { (attrition bias) } \\
\text { All outcomes }\end{array}$ & High risk & $\begin{array}{l}5 / 50 \text { vs } 4 / 50 \text { dropouts or deviations from protocol; not a high rate but close to } \\
\text { the event rate in the placebo arm }\end{array}$ \\
\hline $\begin{array}{l}\text { Selective reporting (re- } \\
\text { porting bias) }\end{array}$ & Low risk & No evidence of this \\
\hline Other bias & Low risk & No evidence of this \\
\hline All domain risk of bias & High risk & \\
\hline
\end{tabular}


Vanscheidt 2012

$\begin{array}{ll}\text { Methods } & \text { RCT } \\ \text { Arms: } 2 \\ \text { Unit of randomisation: participant } \\ \text { Unit of analysis: participant } \\ \text { Follow-up: } 12 \text { weeks }\end{array}$
Participants Inclusion criteria: locally infected chronic venous leg ulcer below knee joint (CVI grade C6 according to CEAP classification), confirmed diagnosis of CVI, ulcer duration 4 weeks to 2 years, $2 \mathrm{~cm}^{2}$ to $20 \mathrm{~cm}^{2}$, presence of at least 2/9 infection criteria
Exclusion criteria: contraindication with local wound therapy and compression therapy with bandages, hypersensitivity to study materials, previous or concomitant therapy with non permitted local or sys- temic drug therapy
Participant characteristics
Number participants: 126 (demographics for 124)
Age: 66.9 (10.6) vs $68.7(13.0)$ years
$\%$ male: 30 (51) vs $23(35)$
Ulcer details
Size: mean (SD) $6.68(4.76) \mathrm{cm}^{2}$ vs $6.98(5.51) \mathrm{cm}^{2}$
Duration: not reported

Intervention 1 details (name and details of application): octenidine solution spray (+ non adhesive foam dressing); Ulcer completely moistened with spray at each dressing change (at least once a week, maximum $3 \times$ per week)

Intervention 2 class: foam (placebo (Ringer solution) spray)

Intervention 2 details (name and details of application): Ringer solution spray (+ non adhesive foam dressing); ulcer completely moistened with spray at each dressing change (at least once a week, maximum $3 \times$ per week)

Compression: elastic bandages

Other co-interventions: non-adhesive foam dressing used for all

\begin{tabular}{|c|c|c|}
\hline Outcomes & $\begin{array}{l}\text { Intervention 1: 15/60 } \\
\text { Intervention 2: 16/66 }\end{array}$ & \\
\hline Notes & \multicolumn{2}{|c|}{ Funding type and details: not reported } \\
\hline \multicolumn{3}{|l|}{ Risk of bias } \\
\hline Bias & Authors' judgement & Support for judgement \\
\hline $\begin{array}{l}\text { Random sequence genera- } \\
\text { tion (selection bias) }\end{array}$ & Unclear risk & Described as randomised but no methods given \\
\hline
\end{tabular}


Vanscheidt 2012 (Continued)

Allocation concealment Unclear risk $\quad$ Described as randomised but no methods given
(selection bias)

Blinding of participants Unclear risk Described as double-blind. Methods not clear about who was blinded
and personnel (performance bias)

All outcomes

\begin{tabular}{ll}
\hline Blinding of outcome as- & Unclear risk
\end{tabular}

\section{All outcomes}

\begin{tabular}{|c|c|c|}
\hline $\begin{array}{l}\text { Incomplete outcome data } \\
\text { (attrition bias) } \\
\text { All outcomes }\end{array}$ & High risk & $\begin{array}{l}\text { Reasons for dropouts explained - some were lost from analysis due to wound } \\
\text { healing which is our outcome of interest. }\end{array}$ \\
\hline
\end{tabular}

\begin{tabular}{lll}
\hline $\begin{array}{l}\text { Selective reporting (re- } \\
\text { porting bias) }\end{array}$ & Low risk & No evidence of this \\
\hline Other bias & Low risk & No evidence of this \\
\hline All domain risk of bias & High risk & \\
\hline
\end{tabular}

Vin 2002

\begin{tabular}{ll}
\hline Methods & RCT \\
Arms: 2 \\
Unit of randomisation: participant \\
Unit of analysis: participant \\
Follow-up: 12 weeks \\
\hline
\end{tabular}

\begin{tabular}{|c|c|}
\hline \multirow[t]{9}{*}{ Participants } & $\begin{array}{l}\text { Inclusion criteria: venous leg ulcer }>30 \text { days duration, not infected, venous aetiology confirmed by } \\
\text { Doppler ultrasound and } \mathrm{ABPI}>\text { or }=0.8 \text {, between } 2 \mathrm{~cm} \text { and } 10 \mathrm{~cm} \text { in any dimension. If multiple ulcers, } \\
\text { largest selected (had to be } 3 \mathrm{~cm} \text { away from other ulcers) }\end{array}$ \\
\hline & $\begin{array}{l}\text { Exclusion criteria: unwilling to wear compression bandages, immobile, concomitant wound healing } \\
\text { condition e.g. carcinoma, vasculitis, connective tissue disease, immune system disorder, used corticos- } \\
\text { teroids, immunosuppressive agents, radiation therapy or chemotherapy within } 30 \text { days prior }\end{array}$ \\
\hline & Participant characteristics \\
\hline & Number participants: 73 \\
\hline & Age: 74.1 (12.1) vs 71.7 (11.4), range 33 to 87 vs 37 to 88 years \\
\hline & $\%$ male: 15 (40.5) vs $11(30.6)$ \\
\hline & Ulcer details \\
\hline & Size: mean (SD) $7.0(6.8) \mathrm{cm}^{2}$ vs $9.5(9.5) \mathrm{cm}^{2}$, range 1.6 to 35.5 vs 1.2 to $34.5 \mathrm{~cm}^{2}$ \\
\hline & Duration: mean (SD) 8.5 (11) vs 9.9 (20.2) months \\
\hline
\end{tabular}


Vin 2002 (Continued)

Intervention 1 details (name and details of application): Promogran (Johnson \& Johnson) (+ Adaptic);

Promogran cut to fit ulcer, Adaptic placed over the top. Dressing changed at least twice weekly

Intervention 2 class: nonadherent

Intervention 2 details (name and details of application): Adaptic (Johnson and Johnson Medical)

Compression: compression bandages Biflex $16+$ graduated version with tension indicator (Thuasne) worn continuously by all between dressing changes

Other co-interventions: wound cleaned with warm sterile saline before dressing. Gauze pad (Topper, Johnson \& Johnson) applied as secondary dressing to all

\begin{tabular}{ll}
\hline Outcomes & Intervention 1: $18 / 37$ \\
& Intervention 2: $12 / 63$ \\
\hline Notes & Funding type and details: industry \\
& Funding details: Johnson \& Johnson Wound Management, France \\
\hline
\end{tabular}

\section{Risk of bias}

\begin{tabular}{lll}
\hline Bias & Authors' judgement & Support for judgement \\
\hline $\begin{array}{l}\text { Random sequence genera- } \\
\text { tion (selection bias) }\end{array}$ & Unclear risk & Described as randomised study. No details reported \\
\hline $\begin{array}{l}\text { Allocation concealment } \\
\text { (selection bias) }\end{array}$ & Unclear risk & Described as randomised study. No details reported \\
\hline $\begin{array}{l}\text { Blinding of participants } \\
\text { and personnel (perfor- } \\
\text { mance bias) }\end{array}$ & Unclear risk & Not reported \\
All outcomes & \\
\hline
\end{tabular}

\begin{tabular}{lll}
$\begin{array}{l}\text { Blinding of outcome as- } \\
\text { sessment (detection bias) } \\
\text { All outcomes }\end{array}$ & Low risk & $\begin{array}{l}\text { Quote: "all measures were performed by an investigator blinded to treatment } \\
\text { allocation" }\end{array}$ \\
\hline $\begin{array}{l}\text { Incomplete outcome data } \\
\text { (attrition bias) } \\
\text { All outcomes }\end{array}$ & Low risk & Data reported for all participants, ITT and PP analyses \\
\hline $\begin{array}{l}\text { Selective reporting (re- } \\
\text { porting bias) }\end{array}$ & Low risk & No evidence \\
\hline Other bias & Low risk & No evidence \\
\hline All domain risk of bias & Low risk & low/unclear \\
\hline
\end{tabular}

Zuccarelli 1992

$\begin{array}{ll}\text { Methods } & \text { RCT } \\ & \text { Arms: } 2 \\ & \text { Unit of randomisation: participant }\end{array}$


Zuccarelli 1992 (Continued)

Unit of analysis: participant

Follow-up: 12 weeks

\begin{tabular}{|c|c|}
\hline \multirow[t]{10}{*}{ Participants } & Inclusion criteria: leg ulcer clinic outpatients \\
\hline & Exclusion criteria: not reported \\
\hline & Participant characteristics \\
\hline & Number participants: 38 \\
\hline & Age: not reported \\
\hline & $\%$ male: not reported \\
\hline & Ulcer details \\
\hline & Non VLU: not reported \\
\hline & Size: not reported \\
\hline & Duration: not reported \\
\hline \multirow[t]{6}{*}{ Interventions } & Intervention 1 class: foam \\
\hline & Intervention 1 details (name and details of application): Allevyn \\
\hline & Intervention 2 class: hydrocolloid \\
\hline & Intervention 2 details (name and details of application): not reported \\
\hline & Compression: "elastic compression bandaging was standardised" \\
\hline & Other co-interventions: not reported \\
\hline
\end{tabular}

Outcomes Intervention 1: 9/19

Intervention 2: 9/19

Notes

Funding type: industry (unclear)

Funding details: Smith and Nephew (unclear)

\section{Risk of bias}

\begin{tabular}{lll}
\hline Bias & Authors' judgement & Support for judgement \\
\hline $\begin{array}{l}\text { Random sequence genera- } \\
\text { tion (selection bias) }\end{array}$ & Unclear risk & Quote: "patients were recruited and randomised.." \\
& & Comment: no information on sequence generation \\
\hline $\begin{array}{l}\text { Allocation concealment } \\
\text { (selection bias) }\end{array}$ & Unclear risk & Quote: "patients were recruited and randomised.." \\
\hline $\begin{array}{l}\text { Blinding of participants } \\
\text { and personnel (perfor- } \\
\text { mance bias) }\end{array}$ & Unclear risk & Comment: No information \\
$\begin{array}{l}\text { All outcomes } \\
\end{array}$ & \\
\hline
\end{tabular}

\begin{tabular}{|c|c|}
\hline $\begin{array}{l}\text { Blinding of outcome as- } \\
\text { sessment (detection bias) }\end{array}$ & Unclear risk \\
\hline
\end{tabular}


Zuccarelli 1992 (Continued)

All outcomes

\begin{tabular}{lll}
\hline $\begin{array}{l}\text { Incomplete outcome data } \\
\text { (attrition bias) } \\
\text { All outcomes }\end{array}$ & Low risk & All participants included \\
\hline $\begin{array}{l}\text { Selective reporting (re- } \\
\text { porting bias) }\end{array}$ & Unclear risk & Limited information reported \\
\hline Other bias & Unclear risk & Too little information to be confident \\
\hline All domain risk of bias & Low risk & Low/unclear \\
\hline
\end{tabular}

Abbreviations::ABI: ankle brachial index; ABPI: ankle brachial pressure index; BMI: body mass index; CEAP: Comprehensive Classification System for Chronic Venous Disorders; CVI : chronic venous insufficiency; DVT: deep vein thrombosis; HbA1c: glycated; haemoglobin (average plasma glucose concentration (blood sugar levels)); HTA: health technology assessment; IQR: interquartile range; ITT: intentionto-treat (an ITT analysis is a comparison of the treatment groups that includes all patients as originally allocated after randomisation); IV: intravascular; LOCF: LAST IBSERVATION CARRIED FORWARD; NaCL: sodium chloride; NIHR: National Institute for Health Research; PMM: protease-modulating-matrix; PP: per-protocol (a PP analysis is a comparison of treatment groups that includes only those patients who completed treatment); RCT: randomised controlled trial; SD: standard deviation; SE: standard error; SEM: standard error of the mean; SSD: silver sulfadiazine; VLU: venous leg ulcer; vs versus

Characteristics of excluded studies [ordered by study ID]

\begin{tabular}{|c|c|}
\hline Study & Reason for exclusion \\
\hline Acosta 1992 & Did not report wound healing \\
\hline Alvarez 2004 & Did not report analysable healing data \\
\hline Andersen 2002 & Compares dressings of the same type \\
\hline Andreev 2010 & Did not report analysable healing data \\
\hline Andriessen 2009 & Did not report wound healing \\
\hline Asselman 1995 & Did not report analysable healing data \\
\hline Bale 2004 & Did not report wound healing \\
\hline Bartoletti 1997 & Dressing is not the only difference between groups \\
\hline Bartoszewicz 2013 & Did not report wound healing \\
\hline Bastami 2012 & Did not report wound healing \\
\hline Beitner 1985 & Did not report analysable healing data \\
\hline Belcaro 2007 & Did not report analysable healing data \\
\hline Bianchi 2018 & Only one eligible intervention, does not link network \\
\hline Binic 2010 & Did not report analysable healing data \\
\hline Bruckner 2009 & Did not report analysable healing data \\
\hline
\end{tabular}




\begin{tabular}{|c|c|}
\hline Study & Reason for exclusion \\
\hline Bull 1995a & Compares dressings of the same type \\
\hline Burgess 1993 & Compares dressings of the same type \\
\hline Burgos 1989 & Did not report wound healing \\
\hline Cabete 2004 & Did not report wound healing \\
\hline Caetano 2009 & Only one eligible intervention, does not link network \\
\hline Callam 1987a & Only one eligible intervention, does not link network \\
\hline Cardinal 2009a & Did not report analysable healing data \\
\hline Cardinal 2009b & Did not report analysable healing data \\
\hline Carville 2008 & Did not report wound healing \\
\hline Casoni 2006 & Only one eligible intervention, does not link network \\
\hline Cervadoro 2003 & Dressing is not the only difference between groups \\
\hline Chaloner 1992 & Did not report analysable healing data \\
\hline Chaloner 2004a & Compares dressings of the same type \\
\hline Charles 2002a & Did not report wound healing \\
\hline Cherry 1992 & Did not report wound healing \\
\hline Cherry 1998 & Did not report analysable healing data \\
\hline Chiummariello 2009 & Did not report analysable healing data \\
\hline Choucair 1998 & Dressing is not the only difference between groups \\
\hline Collier 1992 & Did not report analysable healing data \\
\hline Cordts 1992 & Dressing is not the only difference between groups \\
\hline Cullen 2012 & Did not report analysable healing data \\
\hline D'Alicandro 2003 & Did not report wound healing \\
\hline Daltrey 1981 & Did not report wound healing \\
\hline Davis 1992 & Did not report analysable healing data \\
\hline De Caridi 2016 & Did not report analysable healing data \\
\hline De la Brassinne 2006 & Compares dressings of the same type \\
\hline Dereure 2012b & More than $25 \%$ non-venous ulcers \\
\hline Dini 2010 & Did not report wound healing \\
\hline
\end{tabular}




\begin{tabular}{|c|c|}
\hline Study & Reason for exclusion \\
\hline Dini 2013 & Did not report analysable healing data \\
\hline Dmochowska 1999 & Did not report analysable healing data \\
\hline Duhra 1992 & Only one eligible intervention, does not link network \\
\hline Egan 1983 & Did not report wound healing \\
\hline El Heneidy 2016 & Only one eligible intervention, does not link network \\
\hline Eriksson 1984a & Dressing is not the only difference between groups \\
\hline Eriksson 1984b & Did not report analysable healing data \\
\hline Eriksson $1984 \mathrm{C}$ & Did not report analysable healing data \\
\hline Eriksson 1991 & Only one eligible intervention, does not link network \\
\hline Falabella 1998 & Did not report analysable healing data \\
\hline Falanga 1996 & Did not report wound healing \\
\hline Falanga 1998 & Only one eligible intervention, does not link network \\
\hline Falanga 1999 & Only one eligible intervention, does not link network \\
\hline Falanga 2000 & Only one eligible intervention, does not link network \\
\hline Falanga 2001 & Only one eligible intervention, does not link network \\
\hline Farina 1997 & Did not report analysable healing data \\
\hline Fernández-Gines 2017 & Ineligible population (includes participants with pressure ulcers) \\
\hline Fischer 1984 & Did not report wound healing \\
\hline Floden 1978 & Did not report analysable healing data \\
\hline Frade 2012 & Did not report analysable healing data \\
\hline Franek 2002 & Did not report analysable healing data \\
\hline Franks 2007 & Compares dressings of the same type \\
\hline Freak 1992a & Did not report analysable healing data \\
\hline Freak 1994 & Did not report analysable healing data \\
\hline Fumal 2002 & Did not report analysable healing data \\
\hline Galiano 2017 & Only one eligible intervention, does not link network \\
\hline Garcia 1984 & Did not report analysable healing data \\
\hline Garkaz 2014 & Did not report analysable healing data \\
\hline
\end{tabular}




\begin{tabular}{|c|c|}
\hline Study & Reason for exclusion \\
\hline Gatti 2011 & Did not report wound healing \\
\hline Gethin 2008 & Retracted study \\
\hline Ghatnekar 2015 & Compares dressings of the same type \\
\hline Gibbons 2015 & Only one eligible intervention, does not link network \\
\hline Gibson 1995 & Compares dressings of the same type \\
\hline Gilligan 2014 & More than $25 \%$ non-venous ulcers \\
\hline Gravante 2013 & Did not report analysable healing data \\
\hline Groenewald 1980 & Did not report analysable healing data \\
\hline Groenewald 1981 & Did not report analysable healing data \\
\hline Gronberg 2014 & Ineligible interventions \\
\hline Grotewohl 1994 & Did not report analysable healing data \\
\hline Guarnera 2010 & Only one eligible intervention, does not link network \\
\hline Handfield-Jones 1988 & Did not report analysable healing data \\
\hline Harding 2005 & Only one eligible intervention, does not link network \\
\hline Harding 2012 & Compares dressings of the same type \\
\hline Harding 2013 & Did not report wound healing \\
\hline Harvey 1985 & Did not report analysable healing data \\
\hline He 2008 & Did not report analysable healing data \\
\hline Hellgren 1983 & Did not report analysable healing data \\
\hline Hill 2004 & Did not report analysable healing data \\
\hline Hillstrom 1988 & Did not report analysable healing data \\
\hline Holloway 1989 & Did not report analysable healing data \\
\hline Hornemann 1987 & Did not report analysable healing data \\
\hline Humbert 2014 & Did not report analysable healing data \\
\hline Hutchinson 1994 & Did not report wound healing \\
\hline Jasiel 1997a & Did not report wound healing \\
\hline Jasiel 1997b & Did not report wound healing \\
\hline Jones 2003 & Compares dressings of the same type \\
\hline
\end{tabular}




\begin{tabular}{|c|c|}
\hline Study & Reason for exclusion \\
\hline Judy 2010 & Did not report analysable healing data \\
\hline Jørgensen 2006 & Not an RCT \\
\hline Jørgensen 2008 & Did not report wound healing \\
\hline Jørgensen 2009 & Did not report analysable healing data \\
\hline Kerihuel 2010 & Did not report analysable healing data \\
\hline Kikta 1988 & Dressing is not the only difference between groups \\
\hline Kirsner 2012 & Only one eligible intervention, does not link network \\
\hline Kirsner 2016a & Only one eligible intervention, does not link network \\
\hline Kirsner 2016b & Only one eligible intervention, does not link network \\
\hline Klemp 1986 & Did not report wound healing \\
\hline Klostermann 1974 & Did not report analysable healing data \\
\hline Koksal 2003 & Dressing is not the only difference between groups \\
\hline Kopera 2005 & Did not report analysable healing data \\
\hline Krasowski 2015 & Did not report analysable healing data \\
\hline Kucharzewski 2012 & Did not report wound healing \\
\hline König 2005 & Did not report analysable healing data \\
\hline La Marca 1999 & Compares dressings of the same type \\
\hline Lammoglia-Ordiales 2012 & Compares dressings of the same type \\
\hline Larsen 1995 & Did not report analysable healing data \\
\hline Larsen 1997 & Did not report analysable healing data \\
\hline Larsen 2005 & Compares dressings of the same type \\
\hline Laudanska 1988 & Did not report analysable healing data \\
\hline Lazareth 2008 & Did not report analysable healing data \\
\hline Limová 1996 & Compares dressings of the same type \\
\hline Limová 2002 & Compares dressings of the same type \\
\hline Limová 2003 & Compares dressings of the same type \\
\hline Lindgren 1998 & Only one eligible intervention, does not link network \\
\hline Lindholm 1995 & Did not report wound healing \\
\hline
\end{tabular}




\begin{tabular}{|c|c|}
\hline Study & Reason for exclusion \\
\hline Ljungberg 1998 & Compares dressings of the same type \\
\hline Lofferer 1982 & Did not report analysable healing data \\
\hline Lopez 1998 & Did not report analysable healing data \\
\hline Lundeberg 1990 & Only one eligible intervention, does not link network \\
\hline Lundeberg 1991 & Only one eligible intervention, does not link network \\
\hline Maggio 2007 & Did not report wound healing \\
\hline Maggio 2012 & Only one eligible intervention, does not link network \\
\hline Mansson 1997 & Did not report analysable healing data \\
\hline Meaume 2005a & Did not report analysable healing data \\
\hline Meaume $2005 c$ & Did not report analysable healing data \\
\hline Meaume 2008 & Did not report analysable healing data \\
\hline Meaume 2014 & Did not report analysable healing data \\
\hline Mehtar 1988 & Did not report analysable healing data \\
\hline Miller 2010 & More than $25 \%$ non-venous ulcers \\
\hline Milward 1991 & Did not report analysable healing data \\
\hline Moffatt 2014 & More than $25 \%$ non-venous ulcers \\
\hline Morimoto 2015 & Not an RCT \\
\hline Mosti 2010 & Did not report analysable healing data \\
\hline Mosti 2015 & Did not report wound healing \\
\hline Mostow 2005 & Only one eligible intervention, does not link network \\
\hline Mudge 2014 & Did not report wound healing \\
\hline Mulder 1995 & Did not report analysable healing data \\
\hline Mulligan 1988 & Did not report analysable healing data \\
\hline Nagl 2003 & Did not report wound healing \\
\hline Navratilova 2004 & Only one eligible intervention, does not link network \\
\hline Neander 2003 & Did not report wound healing \\
\hline Nelson 2011 & Only one eligible intervention, does not link network \\
\hline Nieves 2015 & Only one eligible intervention, does not link network \\
\hline
\end{tabular}




\begin{tabular}{|c|c|}
\hline Study & Reason for exclusion \\
\hline Nowak 1996 & Did not report analysable healing data \\
\hline Nyfors 1982 & Did not report analysable healing data \\
\hline Olyaie 2013 & Only one eligible intervention, does not link network \\
\hline Omar 2004 & Only one eligible intervention, does not link network \\
\hline Ortonne 1996 & Did not report analysable healing data \\
\hline Osman 2014 & Only one eligible intervention, does not link network \\
\hline Pardes 1993 & Did not report wound healing \\
\hline Passarini 1982 & Did not report analysable healing data \\
\hline Peschen 1997 & Only one eligible intervention, does not link network \\
\hline Pessenhofer 1989 & Did not report analysable healing data \\
\hline Pessenhofer 1992 & Did not report analysable healing data \\
\hline Petres 1994 & Did not report analysable healing data \\
\hline Planinsek 2007a & Did not report analysable healing data \\
\hline Planinsek 2007b & Did not report analysable healing data \\
\hline Polignano 2001 & Did not report wound healing \\
\hline Poskitt 1987 & Only one eligible intervention, does not link network \\
\hline Price 2004 & Did not report wound healing \\
\hline Prins 2000 & Did not report analysable healing data \\
\hline Purcell 2017 & Ineligible population $<75 \%$ with venous aetiology \\
\hline Rainey 1993 & Did not report wound healing \\
\hline Rainey 1996 & Compares dressings of the same type \\
\hline Raposio 2018 & Quasi-RCT \\
\hline Rivera-Arce 2007 & Did not report analysable healing data \\
\hline Robinson 1993 & Compares dressings of the same type \\
\hline Robinson 1998 & Did not report analysable healing data \\
\hline Roldan 2009 & Did not report analysable healing data \\
\hline Romanelli 2006 & Did not report analysable healing data \\
\hline Romanelli 2008 & Did not report analysable healing data \\
\hline
\end{tabular}




\begin{tabular}{|c|c|}
\hline Study & Reason for exclusion \\
\hline Romanelli 2009 & Did not report wound healing \\
\hline Romanelli 2011 & Did not report analysable healing data \\
\hline Romanelli 2015 & Compares dressings of the same type \\
\hline Rucigaj 2007 & Did not report analysable healing data \\
\hline Rundle 1981 & Only one eligible intervention, does not link network \\
\hline Sabolinski 1996 & Dressing is not the only difference between groups \\
\hline Santamato 2012 & Did not report analysable healing data \\
\hline Scalise 2017 & Did not report wound healing \\
\hline Schmutz 1997 & Did not report wound healing \\
\hline Schmutz 2008 & Did not report analysable healing data \\
\hline Serena 2011 & Only one eligible intervention, does not link network \\
\hline Serena 2014 & Only one eligible intervention, does not link network \\
\hline Serra 2010 & Did not report analysable healing data \\
\hline Sibbald 2005 & Did not report analysable healing data \\
\hline Sibbald 2007 & Did not report analysable healing data \\
\hline Sibbald 2011 & Did not report analysable healing data \\
\hline Siqueira 2014 & Only one eligible intervention, does not link network \\
\hline Skog 1983 & Did not report analysable healing data \\
\hline Smeets 2008 & Did not report analysable healing data \\
\hline Smith-Strom 2006 & Did not report analysable healing data \\
\hline Soares 2009 & Only one eligible intervention, does not link network \\
\hline Sparholt 2002 & Compares dressings of the same type \\
\hline Sridhar 2017 & Ineligible population \\
\hline Sriram 2014 & Ineligible population \\
\hline Sriram 2015 & Did not report analysable healing data \\
\hline Stiller 1992 & Only one eligible intervention, does not link network \\
\hline Stone 2016a & Did not report wound healing \\
\hline Stone $2016 b$ & Only one eligible intervention, does not link network \\
\hline
\end{tabular}




\begin{tabular}{|c|c|}
\hline Study & Reason for exclusion \\
\hline Sánchez-Vázquez 2008 & Did not report analysable healing data \\
\hline Taradaj 2008 & Only one eligible intervention, does not link network \\
\hline Teepe 1993 & Only one eligible intervention, does not link network \\
\hline Texier 1980 & Did not report analysable healing data \\
\hline Thomas 1997a & Compares dressings of the same type \\
\hline Vanscheidt 2004 & Compares dressings of the same type \\
\hline Vanscheidt 2007 & Only one eligible intervention, does not link network \\
\hline Vas 2008 & Only one eligible intervention, does not link network \\
\hline Veraart 1994a & Did not report wound healing \\
\hline Vitse 2017 & Only one eligible intervention, does not link network \\
\hline Vowden 2007 & Only one eligible intervention, does not link network \\
\hline Vuerstaek 2006 & Compares dressings of the same type \\
\hline Wayman 2000 & Only one eligible intervention, does not link network \\
\hline Weiss 1996 & Compares dressings of the same type \\
\hline Werner-Schlenzka 1994 & Compares dressings of the same type \\
\hline Westh 1998 & Did not report wound healing \\
\hline Wieman 2003 & Compares dressings of the same type \\
\hline Wild 2010 & Did not report analysable healing data \\
\hline Wong 2006 & Did not assess eligible interventions \\
\hline Woo 2009 & Compares dressings of the same type \\
\hline Woo 2010 & Did not report analysable healing data \\
\hline Wunderlich 1991 & Did not report analysable healing data \\
\hline
\end{tabular}

Abbreviations:RCT: randomised controlled trial

Characteristics of studies awaiting assessment [ordered by study ID]

\begin{tabular}{ll} 
Alvarez 2017 & \\
\hline Methods & RCT; 2 arms \\
\hline Participants & 16 participants with venous leg ulcers with at least 6 months duration \\
\hline Interventions & Hyaluronic extracellular matrix \\
\hline
\end{tabular}


Alvarez 2017 (Continued)

$$
\text { Nonadherent silicone foam dressing }
$$

\begin{tabular}{ll} 
Outcomes & Complete wound healing at 16 weeks \\
\hline Notes & Identified in updated search March 2018 \\
& Interim analysis
\end{tabular}

Belcaro 2011

\begin{tabular}{ll}
\hline Methods & RCT; 2 arms \\
\hline Participants & People with "difficult" venous leg ulceration \\
\hline Interventions & Four weeks treatment with silver oxide ointment or "best management" \\
\hline Outcomes & Healing rate \\
\hline Notes & Abstracts only, unable to obtain full paper despite ILL \\
\hline
\end{tabular}

Cavalcanti 2017

\begin{tabular}{ll}
\hline Methods & RCT; 2 arms \\
\hline Participants & 25 participants with chronic venous leg ulcers \\
\hline Interventions & Bacterial cellulose membrane \\
& Triglyceride oil \\
\hline Outcomes & Complete wound healing at 120 days \\
\hline Notes & Identified in updated search March 2018 \\
\hline
\end{tabular}

\section{Colenci 2016}

\begin{tabular}{ll}
\hline Methods & RCT; 2 arms \\
\hline Participants & 29 participants with venous ulcers \\
\hline Interventions & Hemicellulose biomembrane \\
& Collagenase \\
\hline Outcomes & Complete wound healing at 90 days \\
\hline Notes & Identified in updated search March 2018 \\
& Conference abstract only \\
\hline
\end{tabular}


Cullen 2017

\begin{tabular}{ll}
\hline Methods & RCT; 2 arms \\
\hline Participants & 49 participants with venous leg ulcers \\
\hline Interventions & Collagen, oxidised regenerated cellulose and silver dressing \\
& Nonadherent dressing \\
\hline Outcomes & Wound healing at 12 weeks \\
\hline Notes & Identified in updated search March 2018 \\
\hline
\end{tabular}

Glukhov 2017

\begin{tabular}{ll}
\hline Methods & RCT; 4 arms \\
\hline Participants & 85 participants with venous leg ulcers (stage II) \\
\hline Interventions & Collagen and platelet-rich plasma \\
& Foam, hydrogel, alginate or hydrocolloid dressings \\
& Collagen only \\
& Platelet rich plasma only \\
\hline Outcomes & Complete wound healing \\
\hline Notes & Identified in update search March 2018 \\
\hline
\end{tabular}

\section{Moreno-Eutimio 2017}

\begin{tabular}{ll}
\hline Methods & RCT; 2 arms \\
\hline Participants & 40 participants with venous leg ulcers \\
\hline Interventions & Polysacharide with zinc oxide \\
& "Simple dressings" \\
\hline Outcomes & Complete wound healing may be reported \\
\hline Notes & Identified in update search March 2018 \\
& Spanish language - will require translation to confirm eligibility \\
\hline
\end{tabular}

Oliveira 2017

\begin{tabular}{ll}
\hline Methods & RCT; 2 arms \\
\hline Participants & 16 participants with 21 venous leg ulcers
\end{tabular}


Oliveira 2017 (Continued)

\begin{tabular}{ll} 
Interventions & Hydrocolloid dressing \\
& Homologous platelet gel \\
\hline Outcomes & Complete wound healing \\
\hline Notes & Identified in updated search March 2018
\end{tabular}

\section{Polignano 2010}

\begin{tabular}{ll}
\hline Methods & RCT; 2 arms \\
\hline Participants & 29 participants with venous leg ulcers present for at least 6 months \\
\hline Interventions & Purified omental lipids (POL) cream \\
& zinc oxide \\
& Three months treatment/follow-up \\
& $\begin{array}{l}\text { Unclear if there is an additional difference between arms and ulcer aetiologies also unclear from } \\
\text { Italian text }\end{array}$ \\
\hline Outcomes & Healing \\
\hline Notes & $\begin{array}{l}\text { Paper in Italian, eligibility unclear without author contact and further translator assistance if eligi- } \\
\text { ble }\end{array}$ \\
\hline
\end{tabular}

Robinson 1988

\begin{tabular}{ll}
\hline Methods & Unclear, potential RCT \\
\hline Participants & Potentially people with venous leg ulcers \\
\hline Interventions & Duoderm \\
& Viscopaste PB7 bandage \\
\hline Outcomes & Not known \\
\hline Notes & Identified in updated search March 2018 \\
& Title record only \\
\hline
\end{tabular}

Somani 2017

\begin{tabular}{ll}
\hline Methods & RCT; 2 arms \\
\hline Participants & 15 participants with venous leg ulcers of at least 6 months duration \\
\hline Interventions & Saline dressing
\end{tabular}


Somani 2017 (Continued)

Blood-based topical treatment

\begin{tabular}{ll}
\hline Outcomes & Complete closure reported for 5 participants in blood group versus 0 in saline group \\
\hline Notes & Identified in updated search March 2018 \\
& Would potentially contribute to extended base-case network \\
\hline
\end{tabular}

Abbreviations: ILL: inter-library loan; RCT: randomised controlled trial

Characteristics of ongoing studies [ordered by study ID]

Jull 2018

\begin{tabular}{ll}
\hline Trial name or title & Keratin4VLU \\
\hline Methods & 2-arm RCT \\
\hline
\end{tabular}

Participants People with a venous leg ulcer present for more than 26 weeks or an ulcer $>5 \mathrm{~cm}^{2}$.

Interventions Keramatrix - keratin-based dressing

Usual care non-medicated dressing selected from the formulary of dressings available at each study centre. These dressings will include hydrogel, alginate, hydrofibre, polyurethane foam and silicon-impregnated dressings.

Compression therapy in both arms; secondary dressings as appropriate

\begin{tabular}{ll}
\hline Outcomes & Primary outcome - complete healing at 24 weeks \\
\hline Starting date & Recruitment began March 2017 \\
\hline Contact information & a.jull@auckland.ac.nz \\
\hline Notes & NCT02896725 \\
\hline
\end{tabular}

Abbreviation: $\mathbf{R C T}$ : randomised controlled trial

\section{DATA AND ANALYSES}

\section{Comparison 1. Direct evidence - included in base-case network}

\begin{tabular}{lllll}
\hline Outcome or subgroup title & No. of studies & $\begin{array}{l}\text { No. of partici- } \\
\text { pants }\end{array}$ & Statistical method & Effect size \\
\hline 1 Alginate vs nonadherent & 1 & 60 & Risk Ratio (IV, Random, 95\% Cl) & $1.08[0.86,1.36]$ \\
\hline $\begin{array}{l}\text { 2 Cadexomer iodine vs non- } \\
\text { adherent }\end{array}$ & 1 & 105 & Risk Ratio (IV, Random, 95\% Cl) & $1.0[0.39,2.56]$ \\
\hline 3 Film vs nonadherent & 1 & 71 & Risk Ratio (IV, Random, 95\% Cl) & $1.34[0.61,2.92]$ \\
\hline 4 Foam vs nonadherent & 1 & 132 & Risk Ratio (IV, Random, 95\% Cl) & $1.35[0.89,2.05]$ \\
\hline
\end{tabular}




\begin{tabular}{|c|c|c|c|c|}
\hline Outcome or subgroup title & No. of studies & $\begin{array}{l}\text { No. of partici- } \\
\text { pants }\end{array}$ & Statistical method & Effect size \\
\hline $\begin{array}{l}5 \text { Hyaluronic plus povidone } \\
\text { vs nonadherent }\end{array}$ & 1 & 65 & Risk Ratio (IV, Random, 95\% CI) & $1.93[0.95,3.92]$ \\
\hline $\begin{array}{l}6 \text { Hydrocolloid vs non-adher- } \\
\text { ent }\end{array}$ & 7 & 662 & Risk Ratio (IV, Random, 95\% CI) & $1.26[0.92,1.72]$ \\
\hline 7 Hydrofibre vs nonadherent & 1 & 82 & Risk Ratio (M-H, Random, 95\% Cl) & $1.47[0.88,2.46]$ \\
\hline 8 Hydrogel vs nonadherent & 1 & 24 & Risk Ratio (IV, Random, 95\% CI) & $2.0[0.21,19.23]$ \\
\hline 9 PMM vs nonadherent & 1 & 74 & Risk Ratio (IV, Random, 95\% CI) & $1.42[0.80,2.51]$ \\
\hline 10 SSD vs nonadherent & 1 & 60 & Risk Ratio (IV, Random, 95\% CI) & $0.79[0.57,1.10]$ \\
\hline 11 Foam vs alginate & 1 & 113 & Risk Ratio (IV, Random, 95\% CI) & $0.55[0.10,2.86]$ \\
\hline 12 Hydrocolloid vs alginate & 2 & 80 & Risk Ratio (IV, Random, 95\% CI) & $0.72[0.15,3.42]$ \\
\hline 13 Hydrofibre vs alginate & 2 & 175 & Risk Ratio (IV, Random, 95\% CI) & $1.47[0.48,4.47]$ \\
\hline 14 Paste bandage vs alginate & 1 & 133 & Risk Ratio (IV, Fixed, 95\% CI) & $1.22[0.91,1.63]$ \\
\hline 15 PMM vs alginate & 2 & 140 & Risk Ratio (IV, Random, 95\% CI) & $1.10[0.84,1.46]$ \\
\hline $\begin{array}{l}16 \text { Gentian violet vs cadex- } \\
\text { omer iodine }\end{array}$ & 1 & 60 & Risk Ratio (IV, Random, 95\% CI) & $0.58[0.27,1.28]$ \\
\hline $\begin{array}{l}17 \text { Hydrocolloid vs cadex- } \\
\text { omer iodine }\end{array}$ & 1 & 104 & Risk Ratio (IV, Random, 95\% CI) & $0.73[0.26,2.08]$ \\
\hline 18 Hydrocolloid vs foam & 6 & 458 & Risk Ratio (IV, Random, 95\% CI) & $0.92[0.77,1.08]$ \\
\hline 19 Ibuprofen foam vs foam & 2 & 242 & Risk Ratio (IV, Random, 95\% CI) & $0.88[0.48,1.61]$ \\
\hline 20 Octenidine vs foam & 1 & 126 & Risk Ratio (IV, Random, 95\% CI) & $1.03[0.56,1.90]$ \\
\hline 21 Paste bandage vs foam & 1 & 36 & Risk Ratio (IV, Random, 95\% CI) & $2.30[1.29,4.10]$ \\
\hline 22 PMM vs foam & 1 & 187 & Risk Ratio (IV, Random, 95\% CI) & $0.87[0.30,2.48]$ \\
\hline 23 PMM silver vs foam & 1 & 30 & Risk Ratio (IV, Random, 95\% CI) & $1.57[0.84,2.92]$ \\
\hline 24 Silver vs foam & 4 & 397 & Risk Ratio (M-H, Random, 95\% Cl) & $1.65[1.08,2.52]$ \\
\hline $\begin{array}{l}25 \text { Saline gauze vs hyaluronic } \\
\text { acid }\end{array}$ & 1 & 88 & Risk Ratio (IV, Random, 95\% CI) & $0.52[0.23,1.17]$ \\
\hline 26 PMM silver vs hydrocolloid & 1 & 49 & Risk Ratio (M-H, Random, 95\% Cl) & $1.07[0.69,1.67]$ \\
\hline $\begin{array}{l}27 \text { Povidone iodine vs hydro- } \\
\text { colloid }\end{array}$ & 1 & 200 & Risk Ratio (M-H, Random, 95\% Cl) & $0.92[0.69,1.23]$ \\
\hline $\begin{array}{l}28 \text { Saline gauze vs hydrocol- } \\
\text { loid }\end{array}$ & 1 & 28 & Risk Ratio (IV, Fixed, 95\% CI) & $0.29[0.07,1.14]$ \\
\hline
\end{tabular}




\begin{tabular}{llllll}
\hline Outcome or subgroup title & No. of studies & $\begin{array}{l}\text { No. of partici- } \\
\text { pants }\end{array}$ & Statistical method & Effect size \\
\hline 29 Silver vs hydrocolloid & 1 & 58 & Risk Ratio (M-H, Random, 95\% Cl) & $4.39[2.23,8.65]$ \\
\hline 30 Zinc oxide vs hydrocolloid & 1 & 43 & Risk Ratio (M-H, Random, 95\% Cl) & $0.95[0.27,3.33]$ \\
\hline 31 Sucralfate vs hydrogel & 1 & 100 & Risk Ratio (IV, Random, 95\% Cl) & $8.60[3.72,19.90]$ \\
\hline
\end{tabular}

Analysis 1.1. Comparison 1 Direct evidence - included in base-case network, Outcome 1 Alginate vs nonadherent.

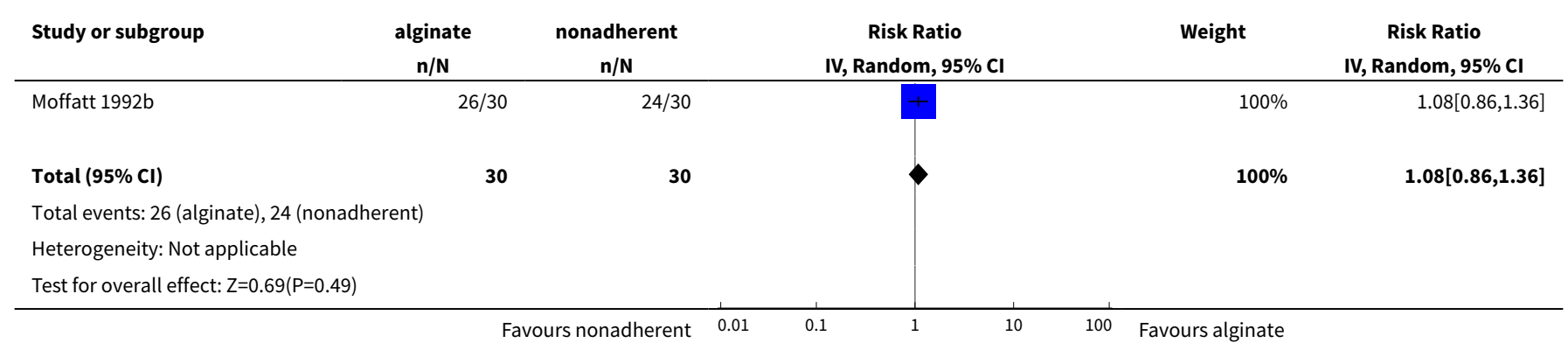

Analysis 1.2. Comparison 1 Direct evidence - included in basecase network, Outcome 2 Cadexomer iodine vs nonadherent.

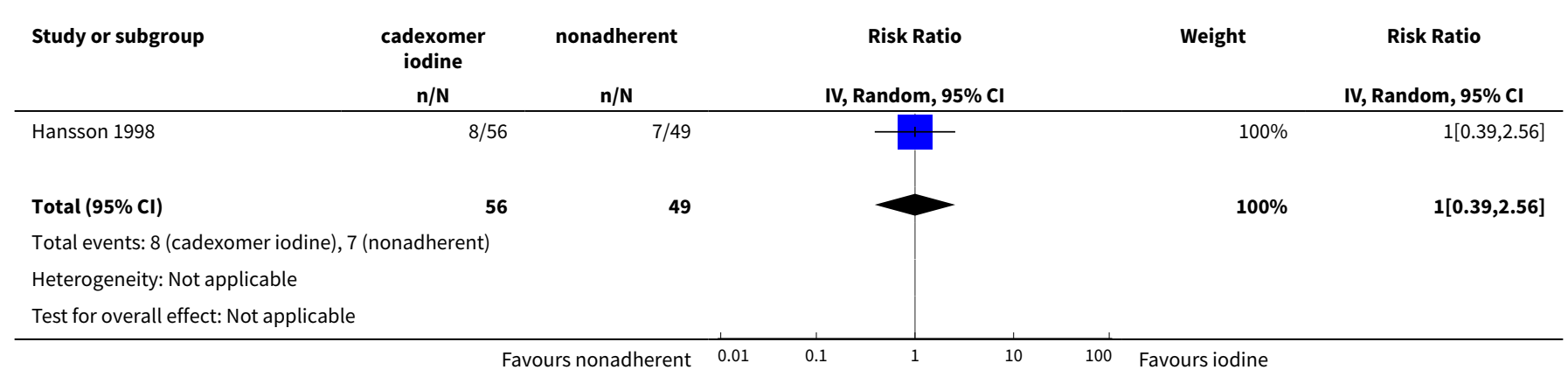

\section{Analysis 1.3. Comparison 1 Direct evidence - included in base-case network, Outcome 3 Film vs nonadherent.}

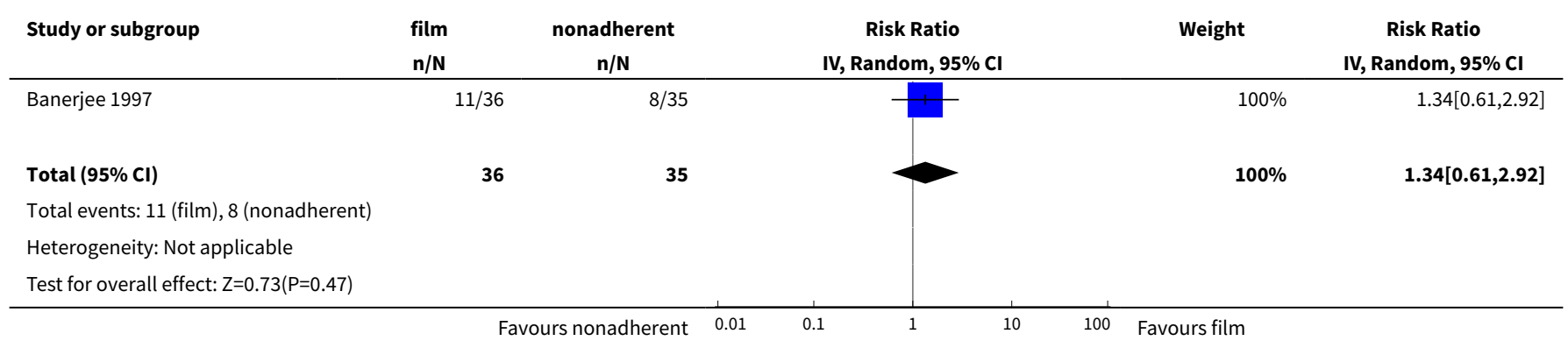


Analysis 1.4. Comparison 1 Direct evidence - included in base-case network, Outcome 4 Foam vs nonadherent.

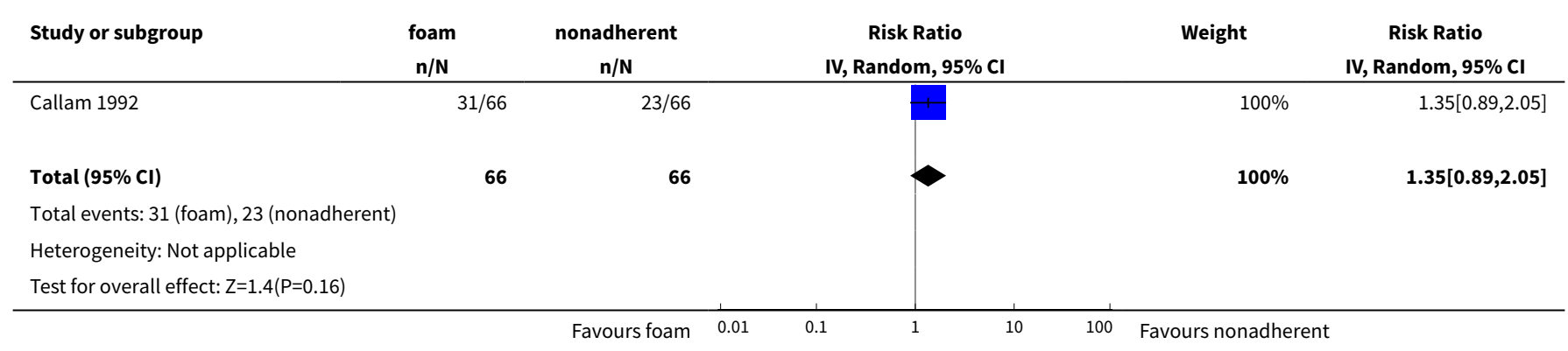

Analysis 1.5. Comparison 1 Direct evidence - included in basecase network, Outcome 5 Hyaluronic plus povidone vs nonadherent.

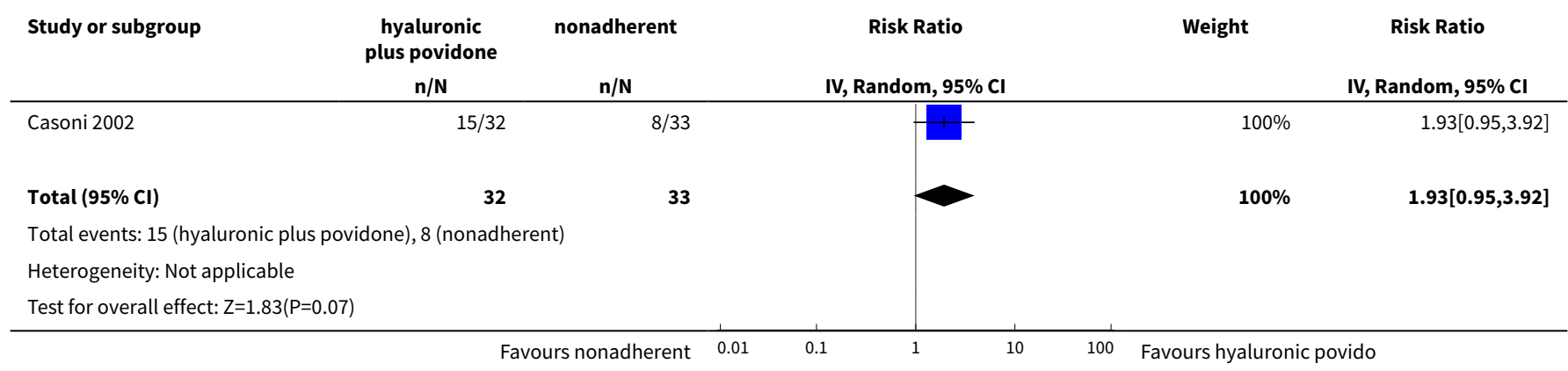

Analysis 1.6. Comparison 1 Direct evidence - included in basecase network, Outcome 6 Hydrocolloid vs non-adherent.

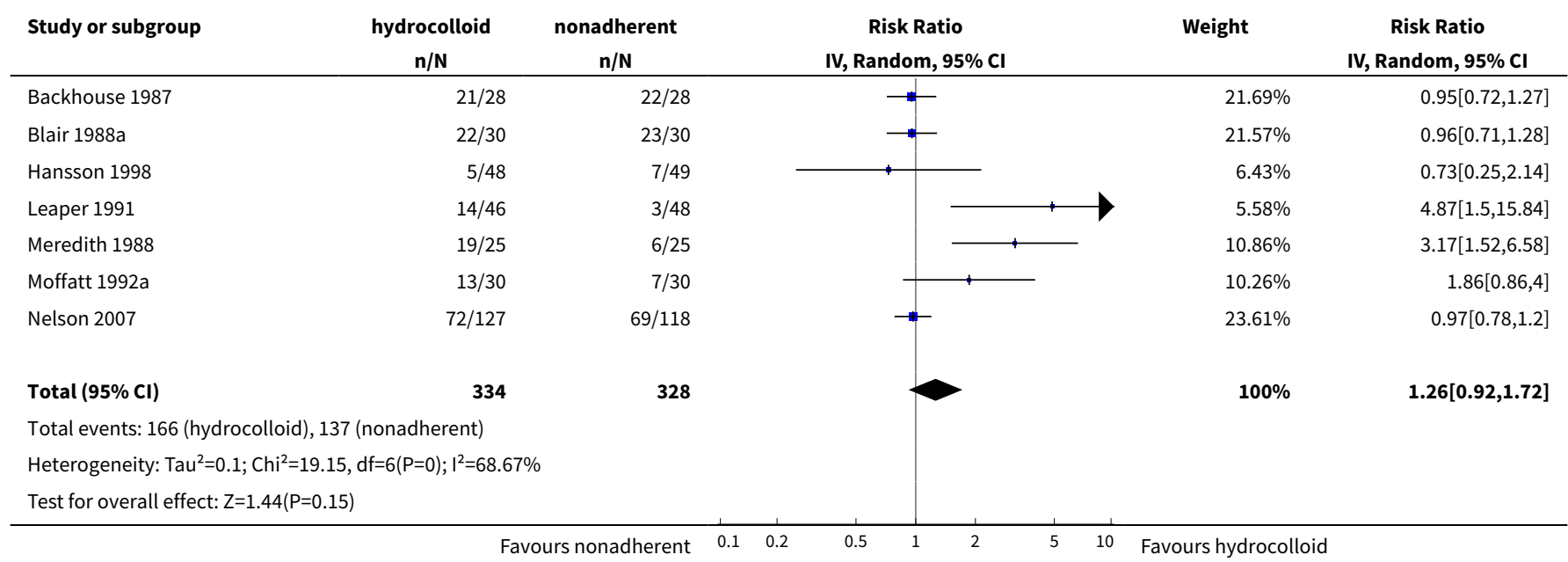


Analysis 1.7. Comparison 1 Direct evidence - included in base-case network, Outcome 7 Hydrofibre vs nonadherent.

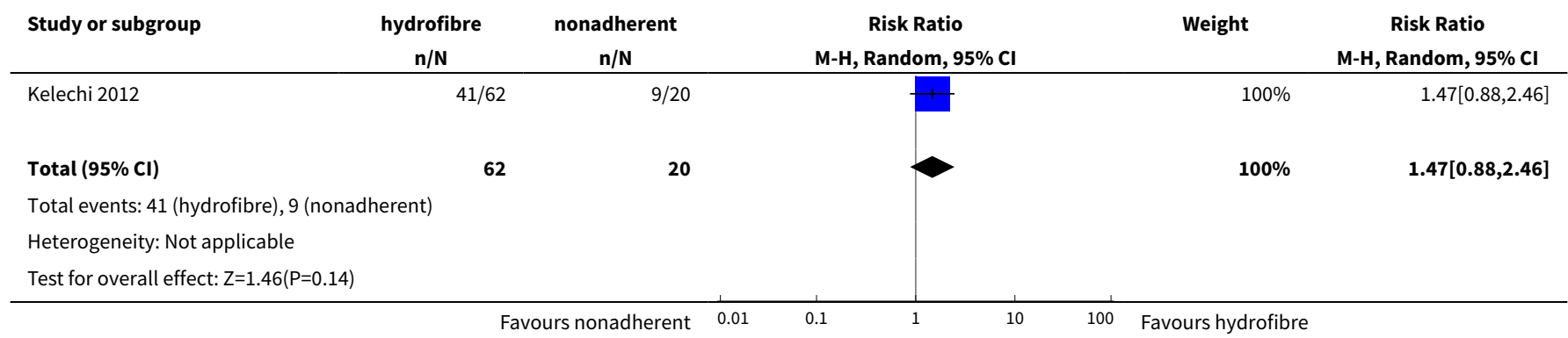

Analysis 1.8. Comparison 1 Direct evidence - included in base-case network, Outcome 8 Hydrogel vs nonadherent.

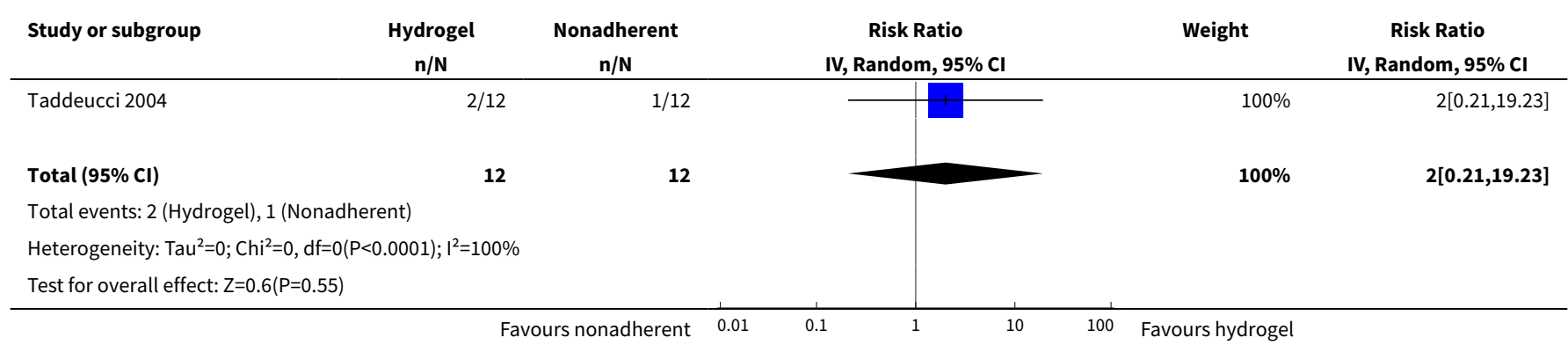

Analysis 1.9. Comparison 1 Direct evidence - included in base-case network, Outcome 9 PMM vs nonadherent.

\begin{tabular}{|c|c|c|c|c|c|}
\hline Study or subgroup & $\begin{array}{l}\text { PMM } \\
\text { n/N }\end{array}$ & $\begin{array}{c}\text { nonadherent } \\
n / N\end{array}$ & $\begin{array}{c}\text { Risk Ratio } \\
\text { IV, Random, } 95 \% \text { CI }\end{array}$ & Weight & $\begin{array}{c}\text { Risk Ratio } \\
\text { IV, Random, } 95 \% \mathrm{CI}\end{array}$ \\
\hline Vin 2002 & $18 / 38$ & $12 / 36$ & + & $100 \%$ & $1.42[0.8,2.51]$ \\
\hline Total $(95 \% \mathrm{Cl})$ & 38 & 36 & & $100 \%$ & $1.42[0.8,2.51]$ \\
\hline \multicolumn{6}{|c|}{ Total events: 18 (PMM), 12 (nonadherent) } \\
\hline \multicolumn{6}{|c|}{ Heterogeneity: Not applicable } \\
\hline
\end{tabular}

\section{Analysis 1.10. Comparison 1 Direct evidence - included in base-case network, Outcome 10 SSD vs nonadherent.}

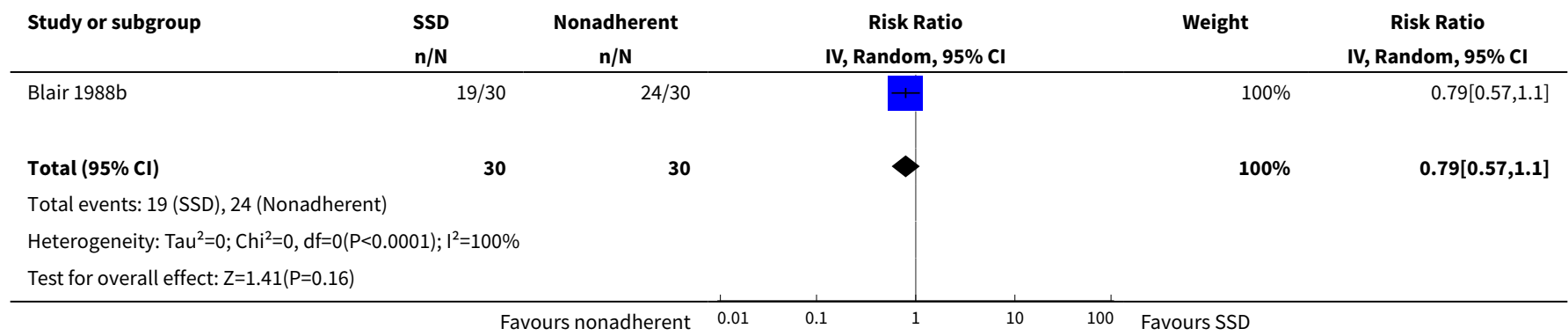


Analysis 1.11. Comparison 1 Direct evidence - included in base-case network, Outcome 11 Foam vs alginate.

\begin{tabular}{|c|c|c|c|c|c|}
\hline Study or subgroup & $\begin{array}{c}\text { Foam } \\
\mathrm{n} / \mathrm{N}\end{array}$ & $\begin{array}{c}\text { Alginate } \\
\mathrm{n} / \mathrm{N}\end{array}$ & $\begin{array}{c}\text { Risk Ratio } \\
\text { IV, Random, } 95 \% \mathrm{CI}\end{array}$ & Weight & $\begin{array}{c}\text { Risk Ratio } \\
\text { IV, Random, } 95 \% \mathrm{CI}\end{array}$ \\
\hline Schulze 2001 & $2 / 54$ & $4 / 59$ & 1 & $100 \%$ & $0.55[0.1,2.86]$ \\
\hline Total $(95 \% \mathrm{Cl})$ & 54 & 59 & & $100 \%$ & $0.55[0.1,2.86]$ \\
\hline \multicolumn{6}{|c|}{ Total events: 2 (Foam), 4 (Alginate) } \\
\hline \multicolumn{6}{|c|}{ Heterogeneity: Not applicable } \\
\hline Test for overall effect & & & & & \\
\hline
\end{tabular}

Analysis 1.12. Comparison 1 Direct evidence - included in base-case network, Outcome 12 Hydrocolloid vs alginate.

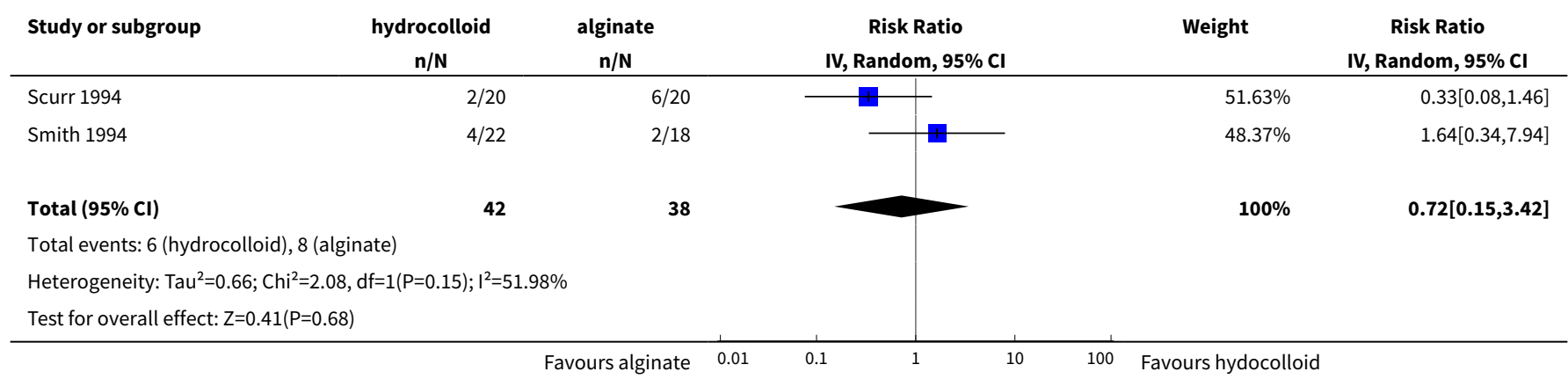

Analysis 1.13. Comparison 1 Direct evidence - included in base-case network, Outcome 13 Hydrofibre vs alginate.

\begin{tabular}{|c|c|c|c|c|c|}
\hline Study or subgroup & $\begin{array}{c}\text { Hydrofibre } \\
\mathrm{n} / \mathrm{N} \\
\end{array}$ & $\begin{array}{c}\text { alginate } \\
n / N\end{array}$ & $\begin{array}{c}\text { Risk Ratio } \\
\text { IV, Random, } 95 \% \mathrm{Cl}\end{array}$ & Weight & $\begin{array}{c}\text { Risk Ratio } \\
\text { IV, Random, } 95 \% \text { CI }\end{array}$ \\
\hline Armstrong 1997 & $6 / 21$ & $2 / 23$ & 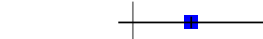 & $33.18 \%$ & $3.29[0.74,14.53]$ \\
\hline Harding 2001 & $17 / 66$ & $17 / 65$ & 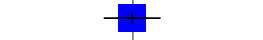 & $66.82 \%$ & $0.98[0.55,1.76]$ \\
\hline Total $(95 \% \mathrm{Cl})$ & 87 & 88 & & $100 \%$ & $1.47[0.48,4.47]$ \\
\hline \multicolumn{6}{|c|}{ Total events: 23 (Hydrofibre), 19 (alginate) } \\
\hline Test for overall effec & & & & & \\
\hline
\end{tabular}

Analysis 1.14. Comparison 1 Direct evidence - included in base-case network, Outcome 14 Paste bandage vs alginate.

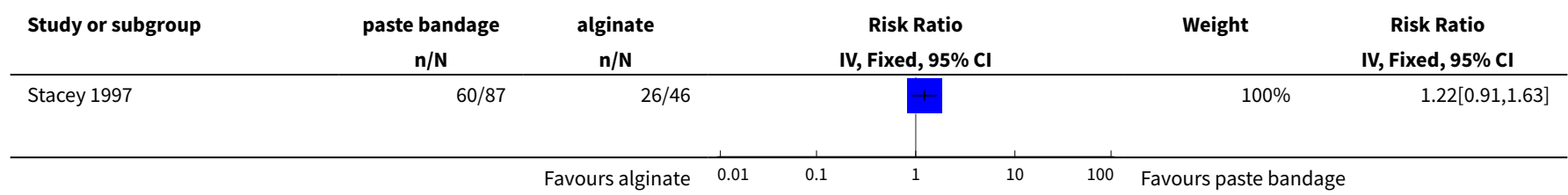




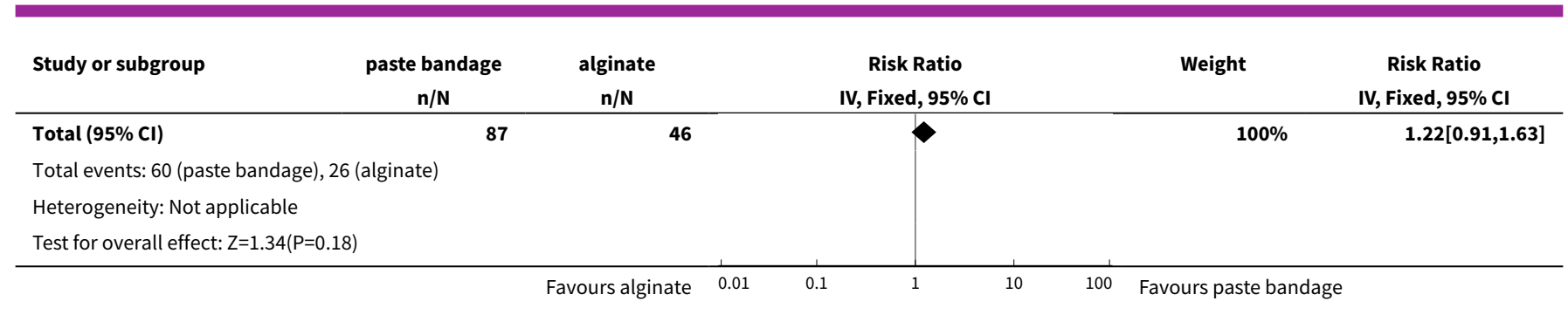

\section{Analysis 1.15. Comparison 1 Direct evidence - included in base-case network, Outcome 15 PMM vs alginate.}

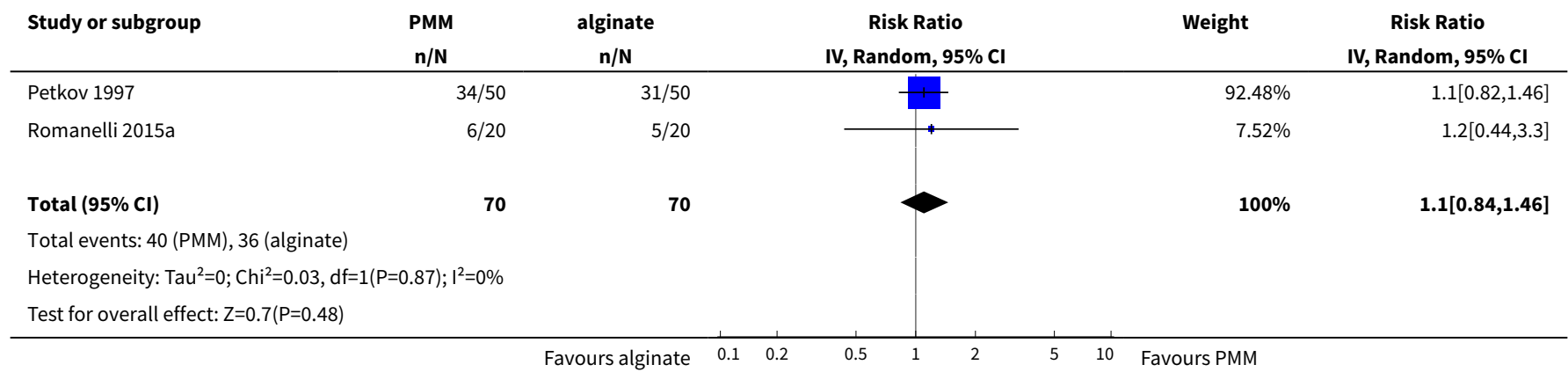

Analysis 1.16. Comparison 1 Direct evidence - included in basecase network, Outcome 16 Gentian violet vs cadexomer iodine.

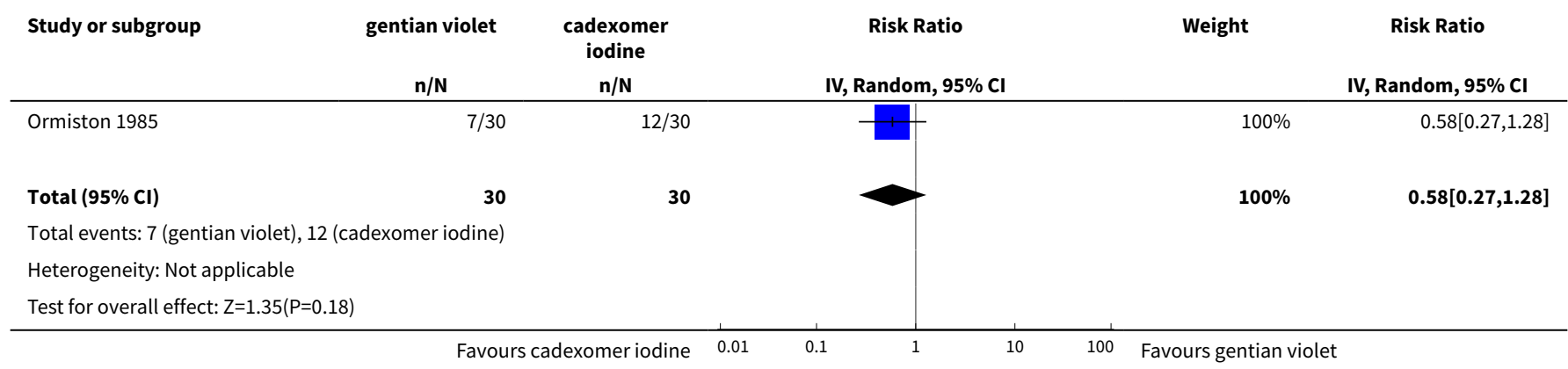

Analysis 1.17. Comparison 1 Direct evidence - included in basecase network, Outcome 17 Hydrocolloid vs cadexomer iodine.

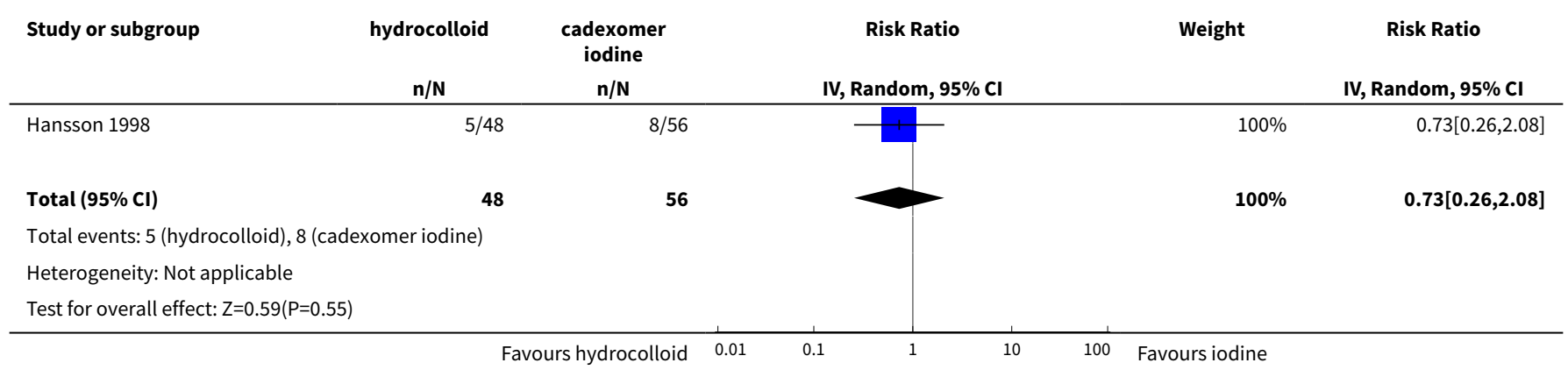


Analysis 1.18. Comparison 1 Direct evidence - included in base-case network, Outcome 18 Hydrocolloid vs foam.

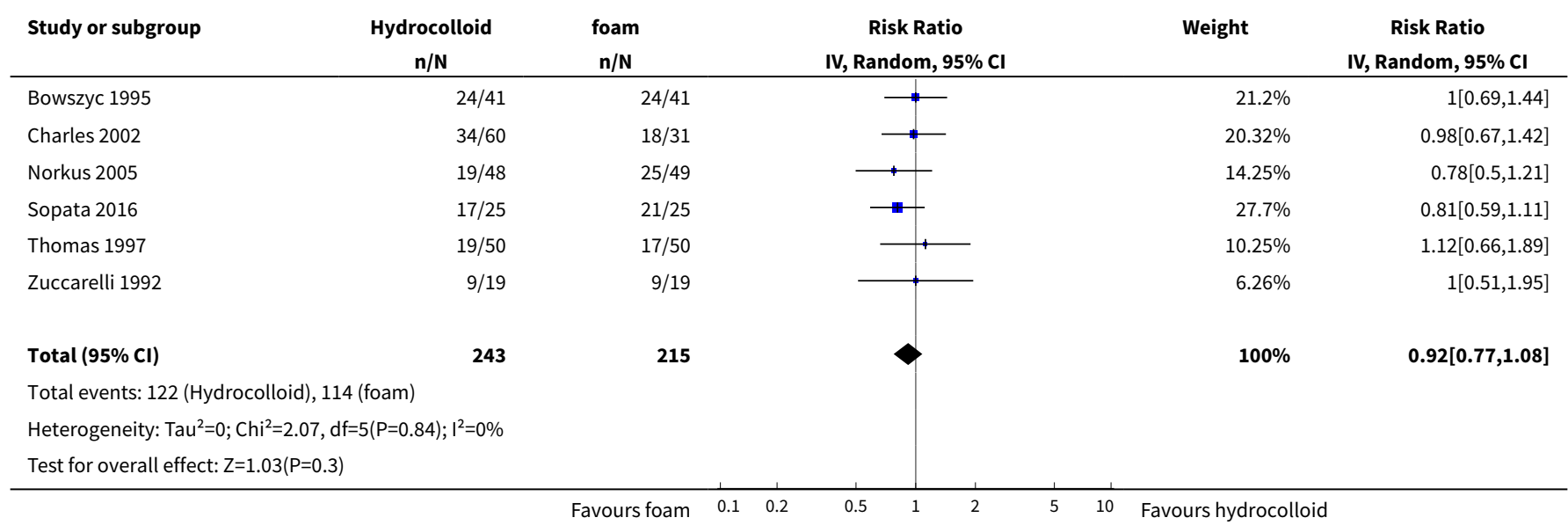

Analysis 1.19. Comparison 1 Direct evidence - included in base-case network, Outcome 19 lbuprofen foam vs foam.

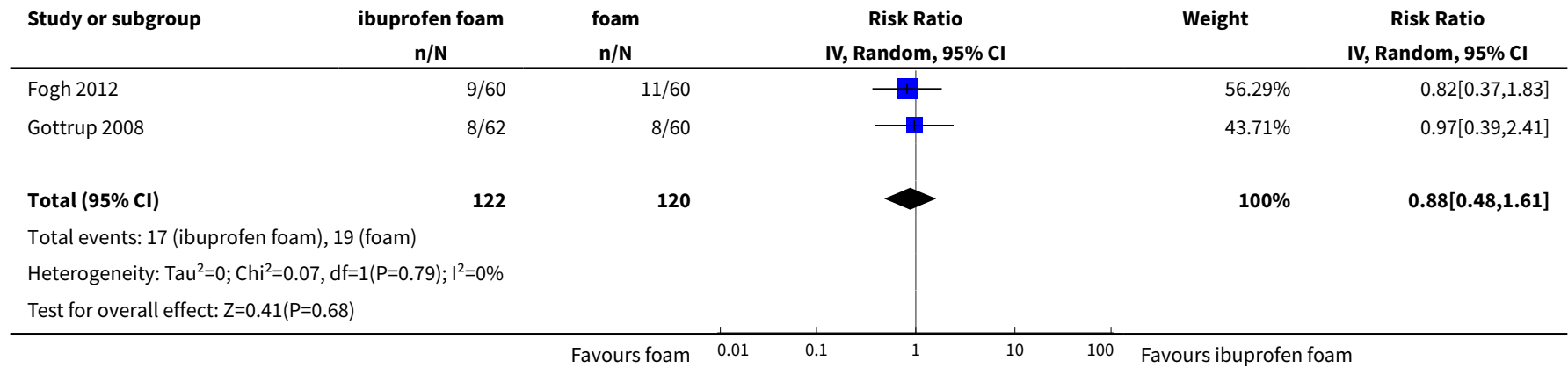

Analysis 1.20. Comparison 1 Direct evidence - included in base-case network, Outcome 20 Octenidine vs foam.

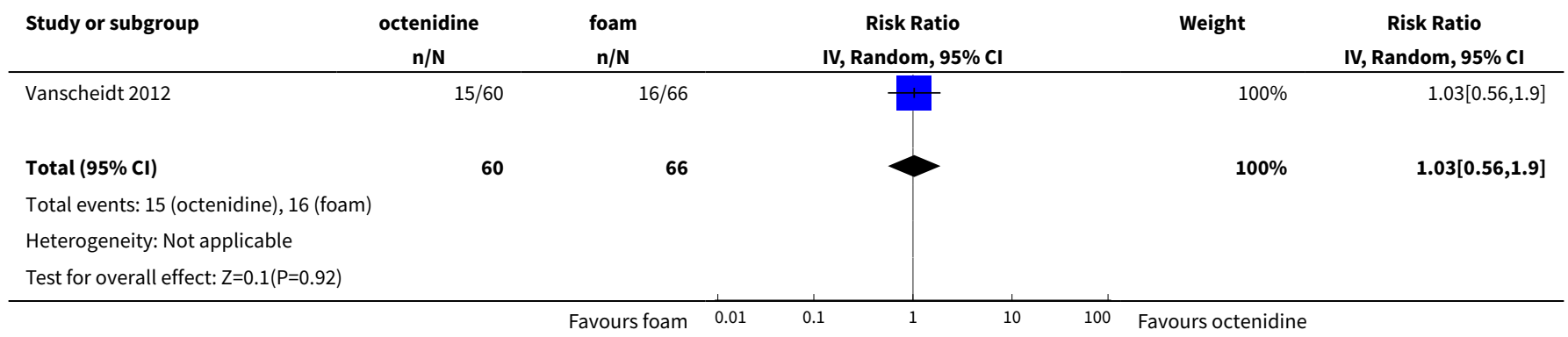


Analysis 1.21. Comparison 1 Direct evidence - included in base-case network, Outcome 21 Paste bandage vs foam.

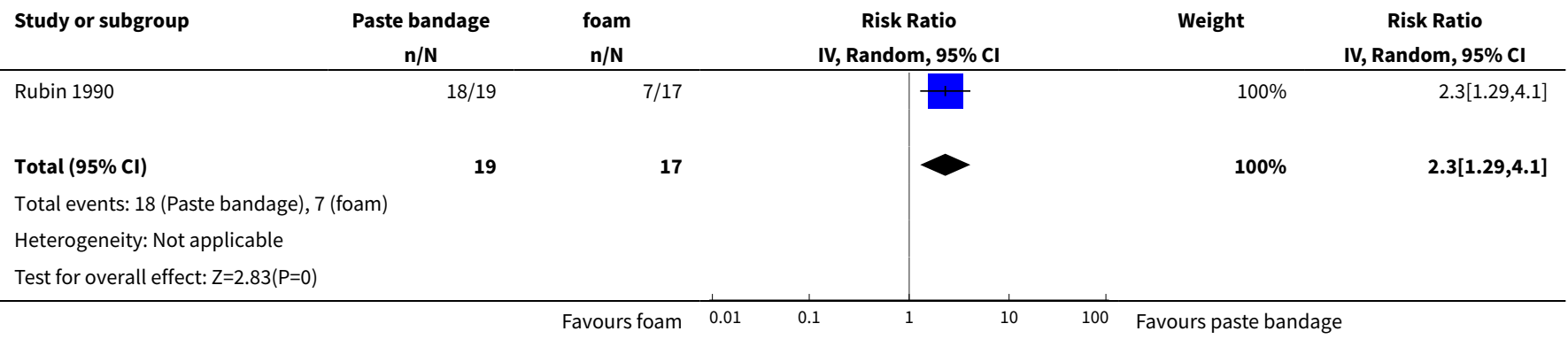

Analysis 1.22. Comparison 1 Direct evidence - included in base-case network, Outcome 22 PMM vs foam.

\begin{tabular}{|c|c|c|c|c|c|}
\hline Study or subgroup & $\begin{array}{l}\text { PMM } \\
\text { n/N }\end{array}$ & $\begin{array}{c}\text { foam } \\
n / N\end{array}$ & $\begin{array}{c}\text { Risk Ratio } \\
\text { IV, Random, } 95 \% \mathrm{Cl}\end{array}$ & Weight & $\begin{array}{c}\text { Risk Ratio } \\
\text { IV, } \text { Random, } 95 \% \mathrm{CI}\end{array}$ \\
\hline Meaume 2012 & $6 / 93$ & $7 / 94$ & - & $100 \%$ & $0.87[0.3,2.48]$ \\
\hline Total $(95 \% \mathrm{Cl})$ & 93 & 94 & & $100 \%$ & $0.87[0.3,2.48]$ \\
\hline \multicolumn{6}{|c|}{ Total events: 6 (PMM), 7 (foam) } \\
\hline \multicolumn{6}{|c|}{ Heterogeneity: Not applicable } \\
\hline \multicolumn{6}{|c|}{ Test for overall effect: $\mathrm{Z}=0.27(\mathrm{P}=0.79)$} \\
\hline
\end{tabular}

Analysis 1.23. Comparison 1 Direct evidence - included in base-case network, Outcome 23 PMM silver vs foam.

\begin{tabular}{|c|c|c|c|c|c|}
\hline Study or subgroup & $\begin{array}{l}\text { PMM silver } \\
n / \mathbf{N}\end{array}$ & $\begin{array}{c}\text { foam } \\
n / N\end{array}$ & $\begin{array}{c}\text { Risk Ratio } \\
\text { IV, Random, } 95 \% \text { CI }\end{array}$ & Weight & $\begin{array}{c}\text { Risk Ratio } \\
\text { IV, Random, } 95 \% \mathrm{CI}\end{array}$ \\
\hline Lanzara 2008 & $11 / 15$ & $7 / 15$ & +1 & $100 \%$ & $1.57[0.84,2.92]$ \\
\hline Total $(95 \% \mathrm{Cl})$ & 15 & 15 & & $100 \%$ & $1.57[0.84,2.92]$ \\
\hline \multicolumn{6}{|c|}{ Total events: 11 (PMM silver), 7 (foam) } \\
\hline \multicolumn{6}{|c|}{ Heterogeneity: Not applicable } \\
\hline
\end{tabular}

Analysis 1.24. Comparison 1 Direct evidence - included in base-case network, Outcome 24 Silver vs foam.

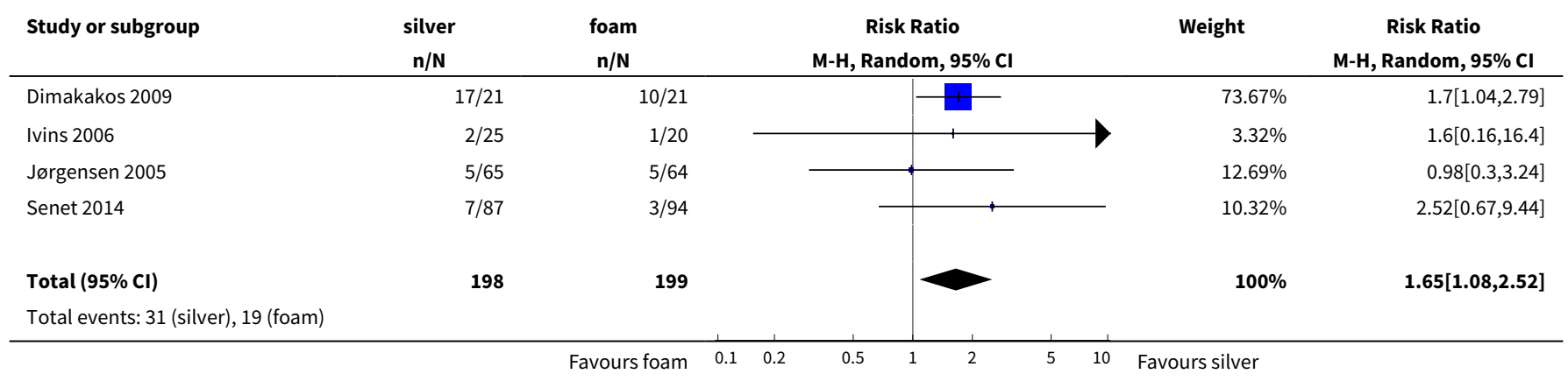




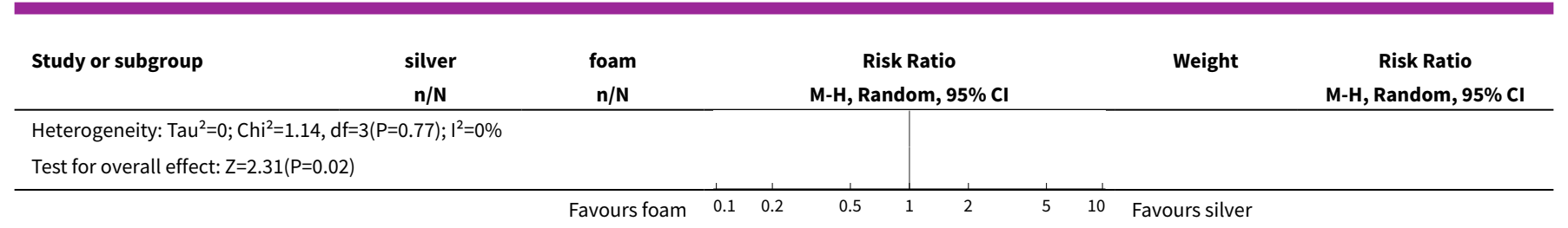

Analysis 1.25. Comparison 1 Direct evidence - included in basecase network, Outcome 25 Saline gauze vs hyaluronic acid.

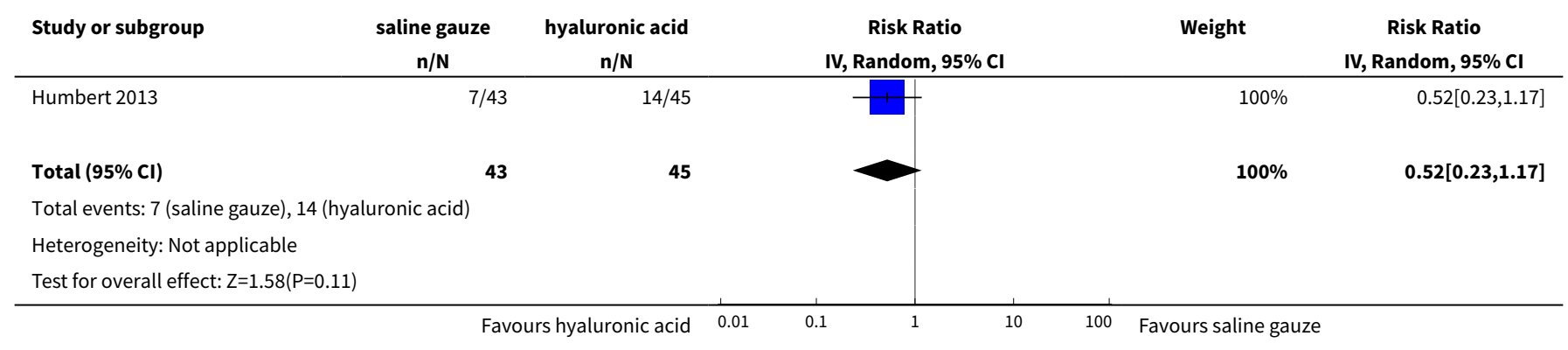

Analysis 1.26. Comparison 1 Direct evidence - included in base-case network, Outcome 26 PMM silver vs hydrocolloid.

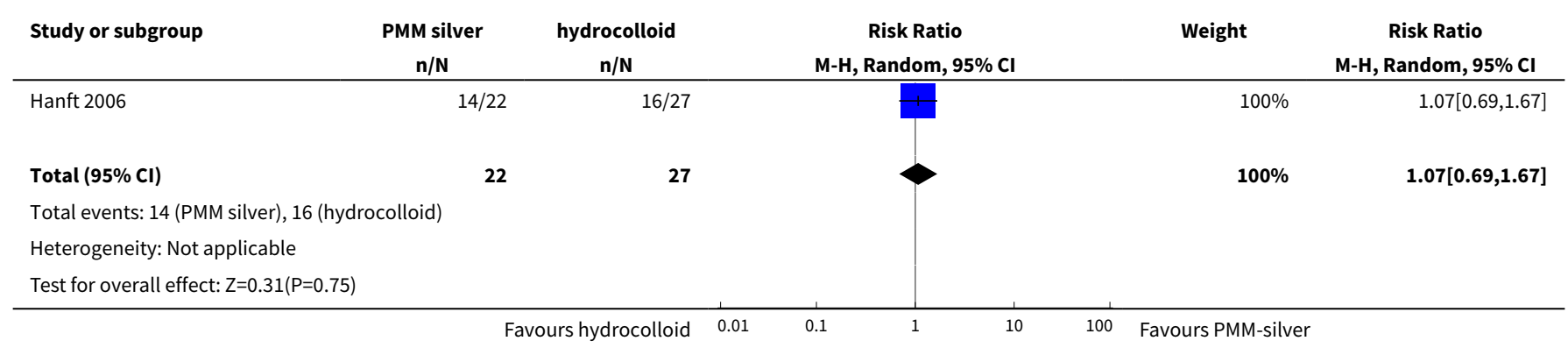

Analysis 1.27. Comparison 1 Direct evidence - included in basecase network, Outcome 27 Povidone iodine vs hydrocolloid.

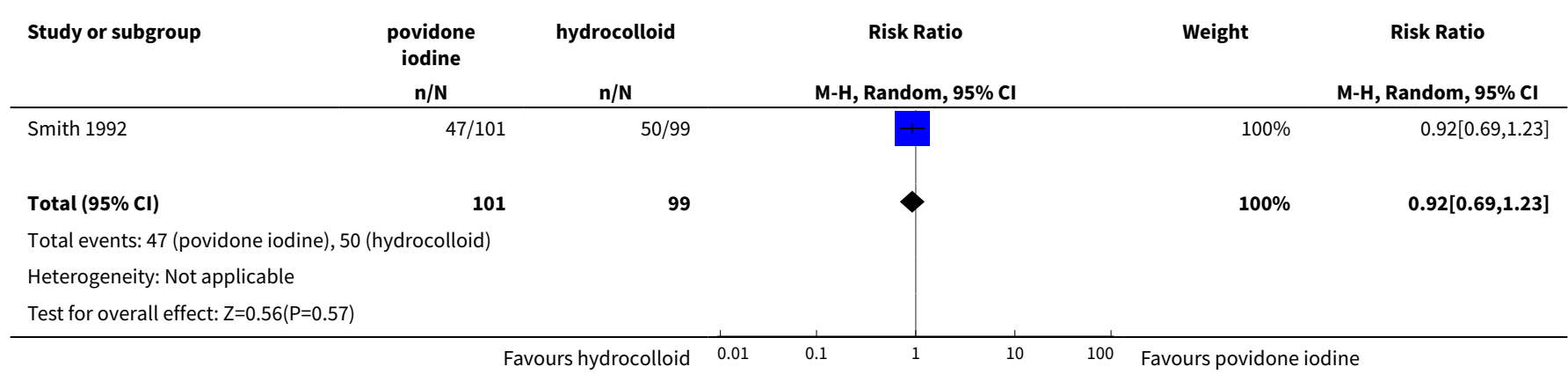


Analysis 1.28. Comparison 1 Direct evidence - included in basecase network, Outcome 28 Saline gauze vs hydrocolloid.

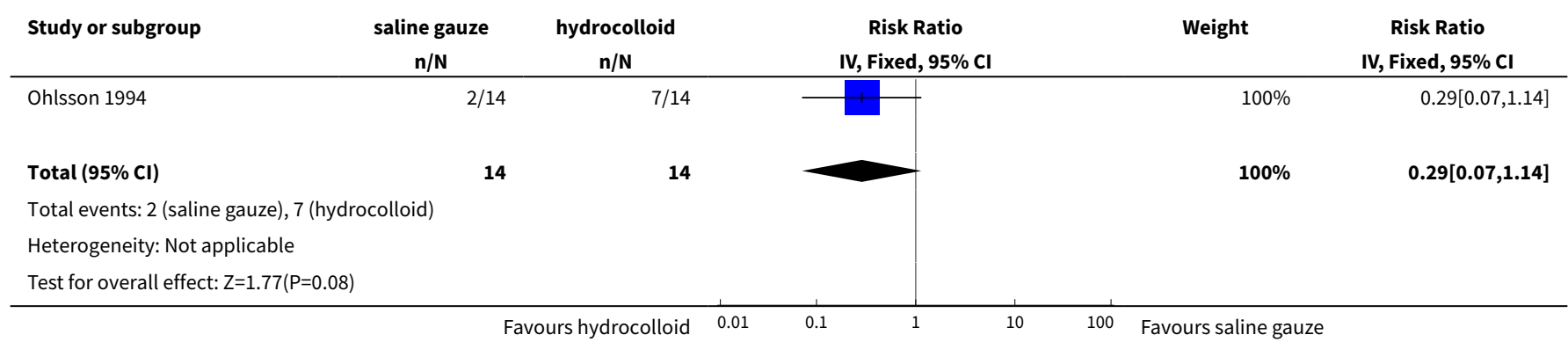

Analysis 1.29. Comparison 1 Direct evidence - included in base-case network, Outcome 29 Silver vs hydrocolloid.

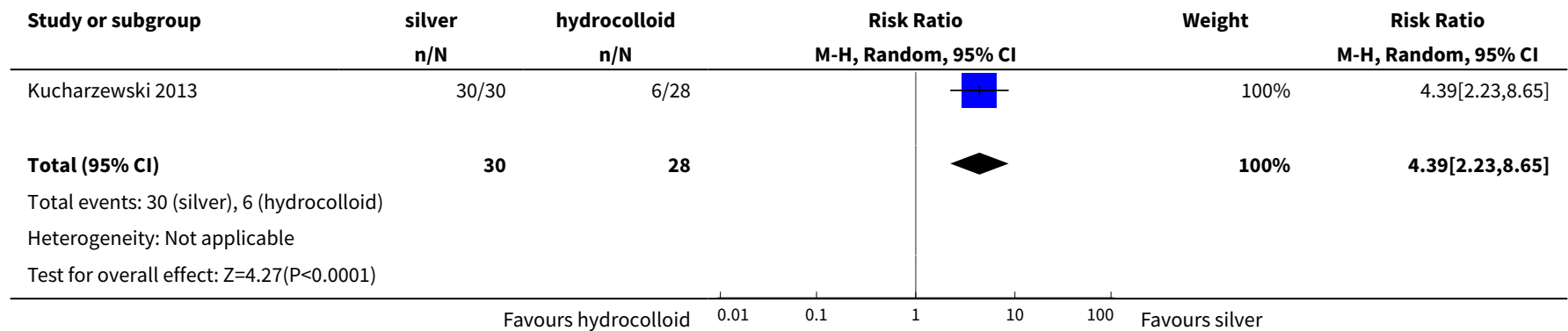

Analysis 1.30. Comparison 1 Direct evidence - included in base-case network, Outcome 30 Zinc oxide vs hydrocolloid.

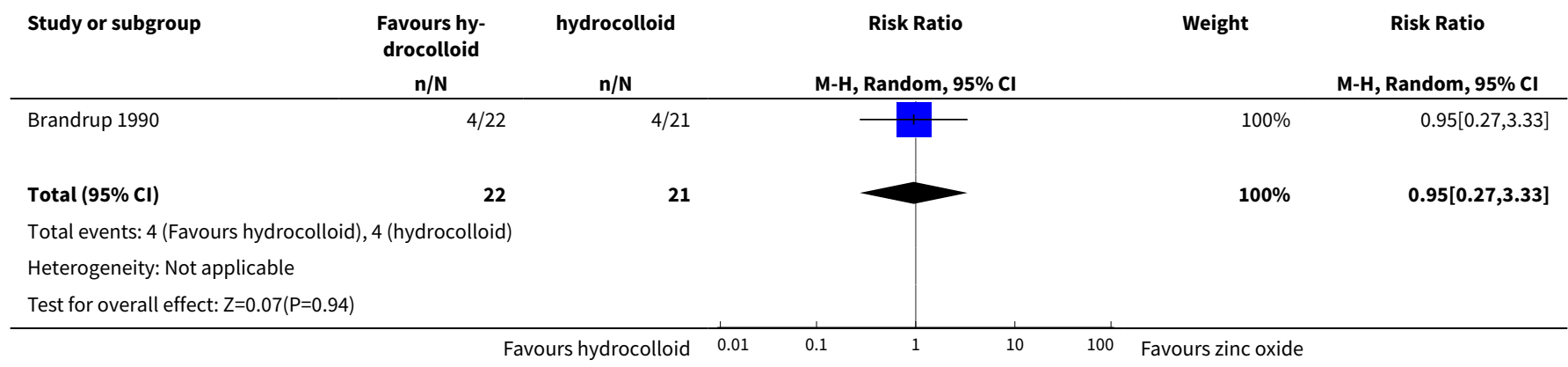

Analysis 1.31. Comparison 1 Direct evidence - included in base-case network, Outcome 31 Sucralfate vs hydrogel.

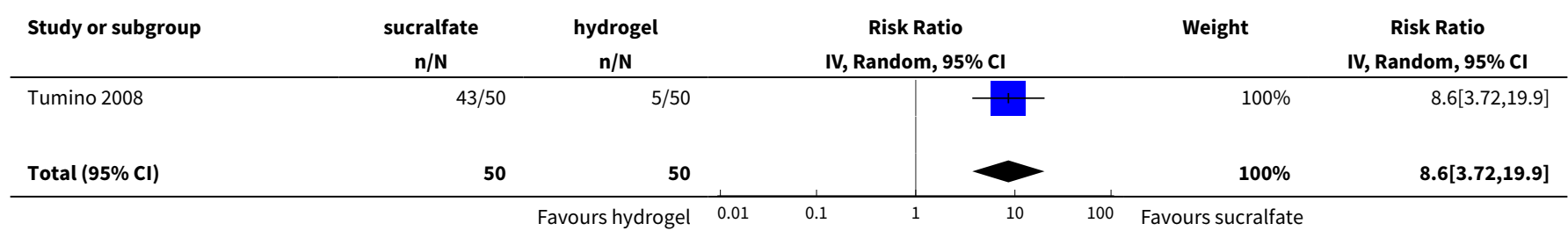




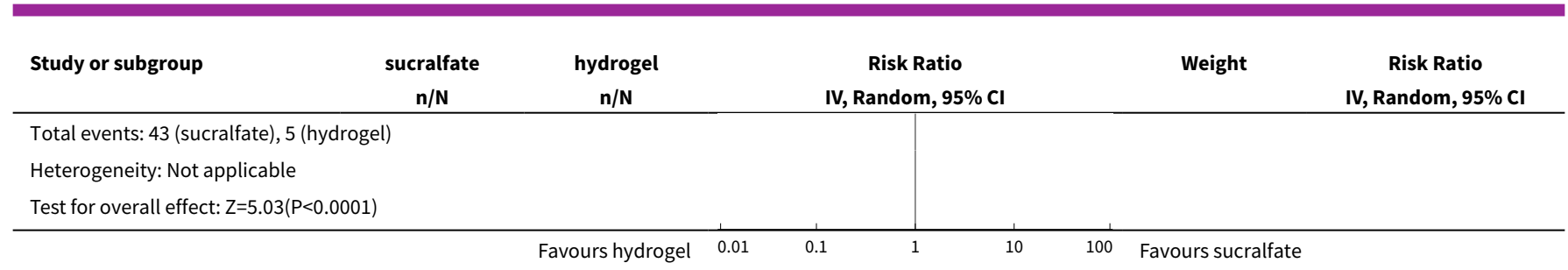

\section{Comparison 2. Direct evidence - not in base case network, in expanded base case}

\begin{tabular}{|c|c|c|c|c|}
\hline Outcome or subgroup title & No. of studies & $\begin{array}{l}\text { No. of partici- } \\
\text { pants }\end{array}$ & Statistical method & Effect size \\
\hline 1 Blood product vs emollient & 1 & 197 & Risk Ratio (M-H, Random, 95\% Cl) & $1.31[0.94,1.82]$ \\
\hline $\begin{array}{l}2 \text { Blood product vs hydrocol- } \\
\text { loid }\end{array}$ & 1 & 13 & Risk Ratio (M-H, Random, 95\% Cl) & $0.86[0.07,10.96]$ \\
\hline 3 Blood product vs hydrogel & 1 & 44 & Risk Ratio (M-H, Random, 95\% Cl) & $0.47[0.14,1.58]$ \\
\hline $\begin{array}{l}4 \text { Blood product vs saline } \\
\text { gauze }\end{array}$ & 1 & 86 & Risk Ratio (M-H, Random, 95\% Cl) & $1.08[0.86,1.35]$ \\
\hline $\begin{array}{l}5 \text { Hyaluronic vs emollient } \\
\text { cream }\end{array}$ & 1 & 101 & Risk Ratio (M-H, Random, 95\% Cl) & $0.77[0.18,3.25]$ \\
\hline $\begin{array}{l}6 \text { Growth factor vs hydrocol- } \\
\text { loid }\end{array}$ & 1 & 29 & Risk Ratio (M-H, Random, 95\% Cl) & $1.83[0.22,15.51]$ \\
\hline 7 Growth factor vs hydrogel & 1 & 59 & Risk Ratio (M-H, Random, 95\% Cl) & $1.38[0.64,3.01]$ \\
\hline $\begin{array}{l}8 \text { Growth factor vs nonadher- } \\
\text { ent }\end{array}$ & 3 & 460 & Risk Ratio (M-H, Random, 95\% Cl) & $0.96[0.81,1.14]$ \\
\hline 9 SSD vs emollient & 1 & 57 & Risk Ratio (M-H, Random, 95\% Cl) & $6.21[0.80,48.38]$ \\
\hline
\end{tabular}

Analysis 2.1. Comparison 2 Direct evidence - not in base case network, in expanded base case, Outcome 1 Blood product vs emollient.

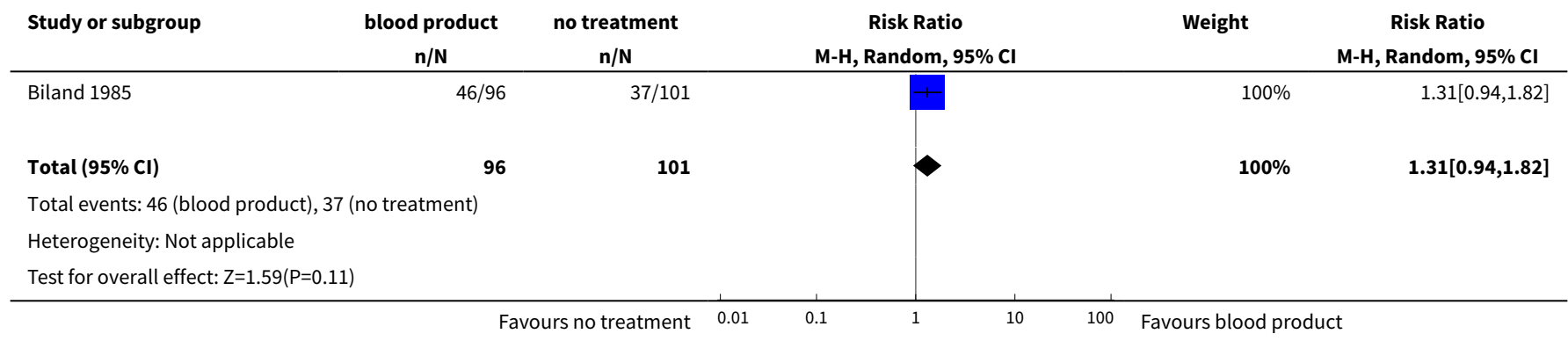


Analysis 2.2. Comparison 2 Direct evidence - not in base case network, in expanded base case, Outcome 2 Blood product vs hydrocolloid.

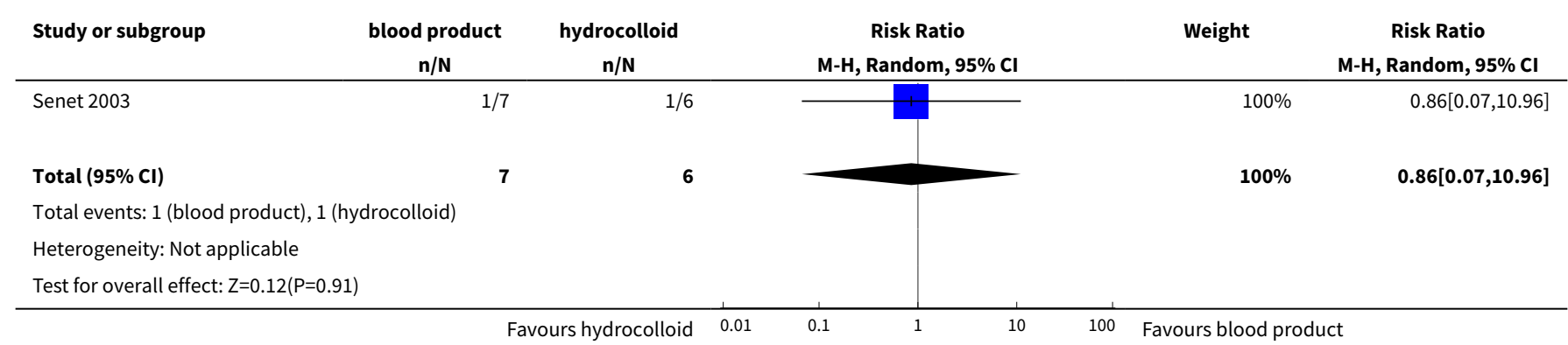

Analysis 2.3. Comparison 2 Direct evidence - not in base case network, in expanded base case, Outcome 3 Blood product vs hydrogel.

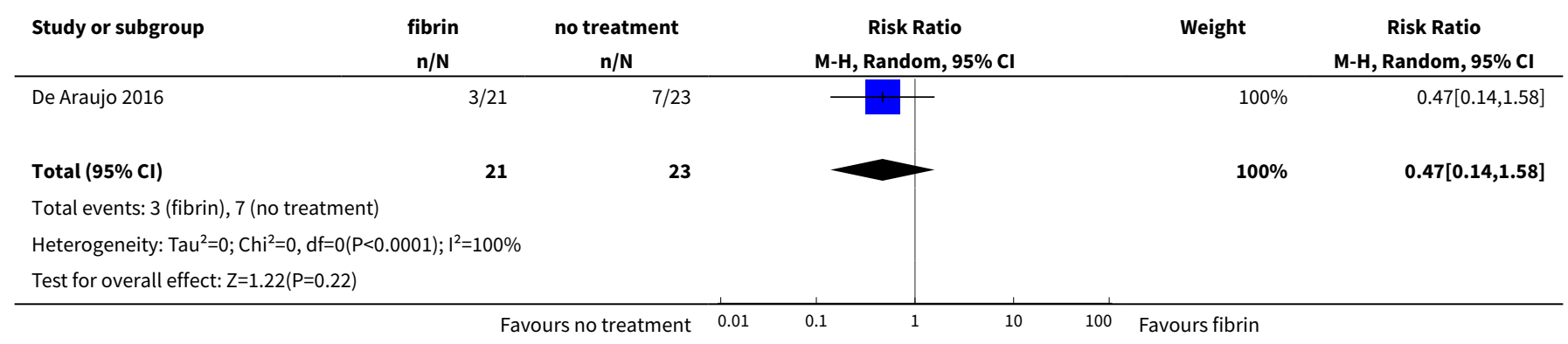

Analysis 2.4. Comparison 2 Direct evidence - not in base case network, in expanded base case, Outcome 4 Blood product vs saline gauze.

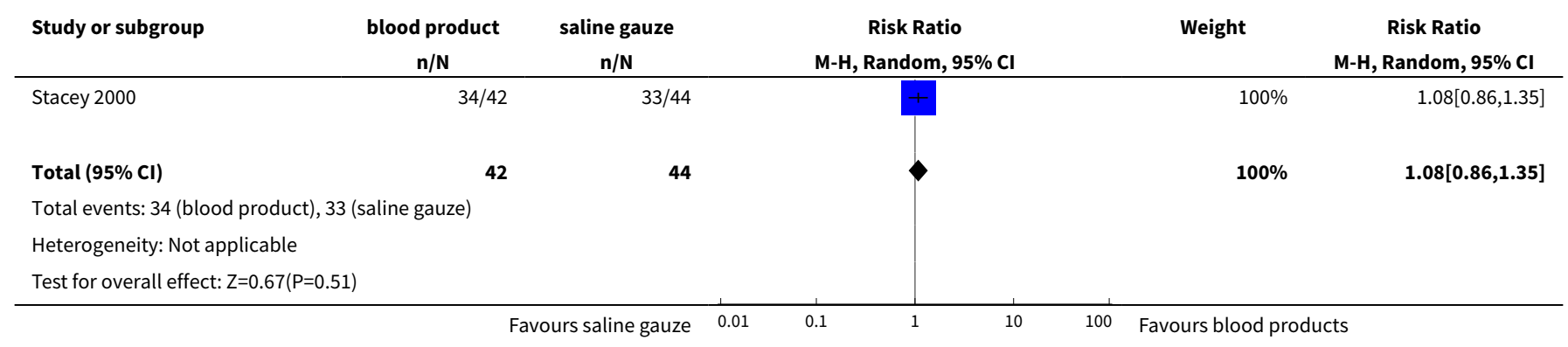

Analysis 2.5. Comparison 2 Direct evidence - not in base case network, in expanded base case, Outcome 5 Hyaluronic vs emollient cream.

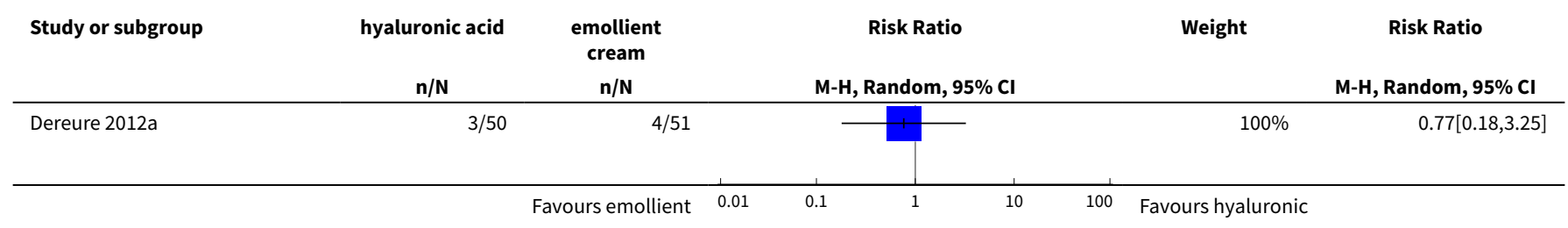




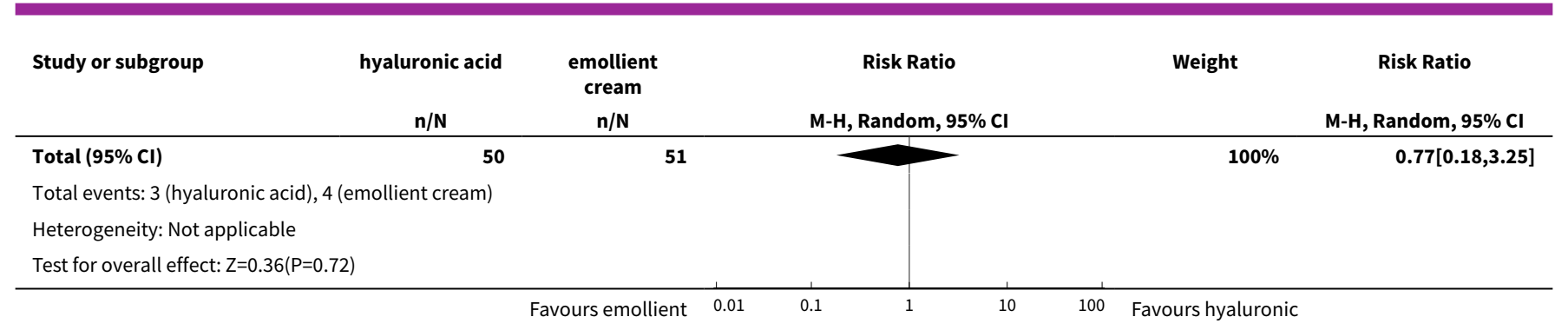

Analysis 2.6. Comparison 2 Direct evidence - not in base case network, in expanded base case, Outcome 6 Growth factor vs hydrocolloid.

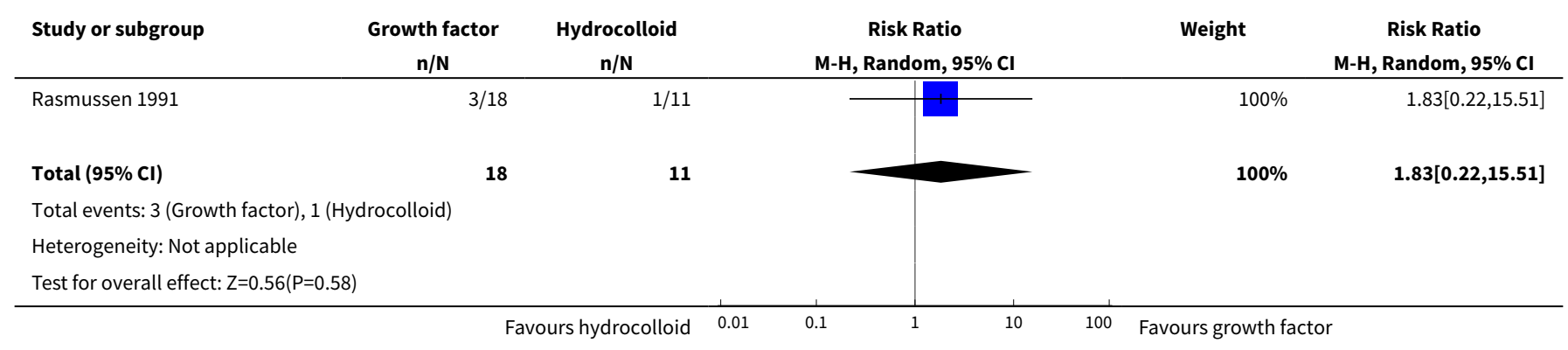

Analysis 2.7. Comparison 2 Direct evidence - not in base case network, in expanded base case, Outcome 7 Growth factor vs hydrogel.

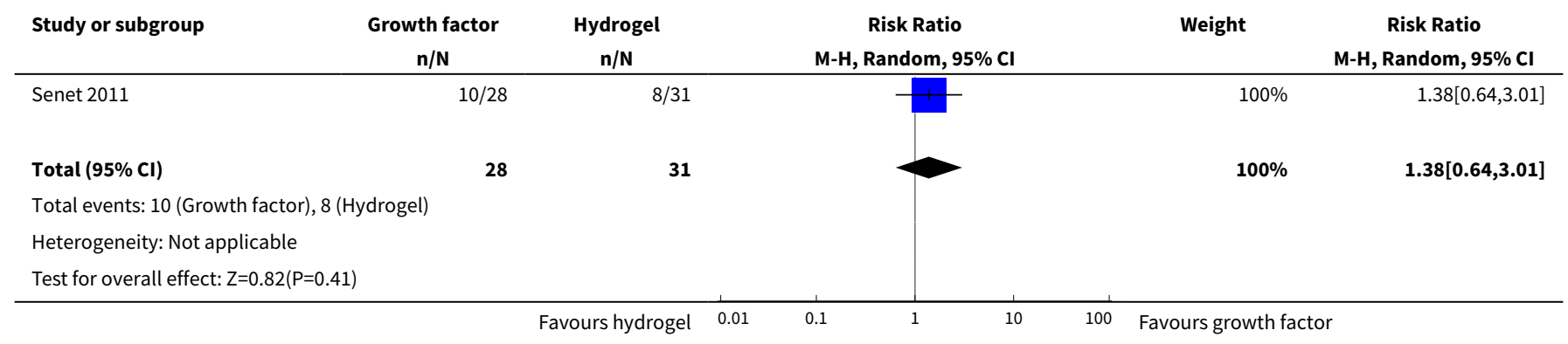

Analysis 2.8. Comparison 2 Direct evidence - not in base case network, in expanded base case, Outcome 8 Growth factor vs nonadherent.

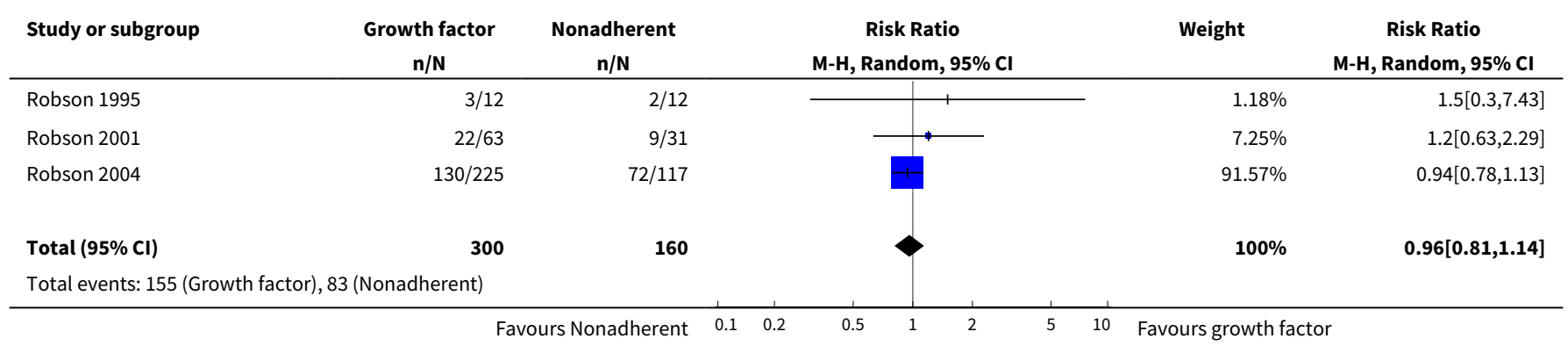




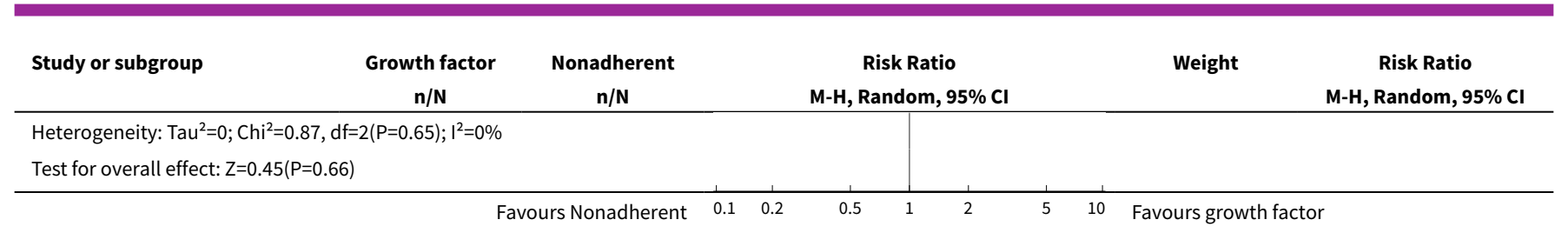

Analysis 2.9. Comparison 2 Direct evidence - not in base case network, in expanded base case, Outcome 9 SSD vs emollient.

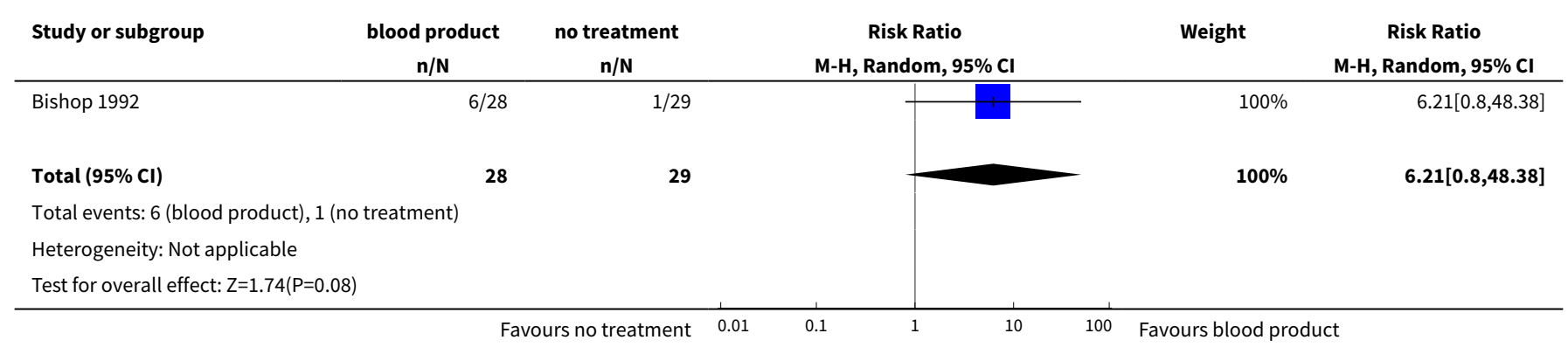

\section{Comparison 3. Direct evidence - not in network}

\begin{tabular}{|c|c|c|c|c|}
\hline Outcome or subgroup title & No. of studies & $\begin{array}{l}\text { No. of partici- } \\
\text { pants }\end{array}$ & Statistical method & Effect size \\
\hline 1 A. Pichinchensis vs alginate & 1 & 34 & Risk Ratio (M-H, Random, 95\% Cl) & $1.67[1.03,2.70]$ \\
\hline 2 Non-adherent vs cellulose & 1 & 48 & Risk Ratio (M-H, Random, 95\% Cl) & $0.92[0.38,2.22]$ \\
\hline 3 Phenytoin vs no treatment & 1 & 104 & Risk Ratio (M-H, Random, 95\% Cl) & $1.25[0.90,1.74]$ \\
\hline $\begin{array}{l}4 \text { Cadexomer iodine vs stan- } \\
\text { dard treatment }\end{array}$ & 3 & 157 & Risk Ratio (M-H, Random, 95\% Cl) & $5.16[1.56,17.10]$ \\
\hline 5 Honey vs standard treatment & 1 & 368 & Risk Ratio (M-H, Random, 95\% Cl) & $1.12[0.92,1.36]$ \\
\hline 6 Papain vs hydrogel & 2 & 70 & Risk Ratio (M-H, Random, 95\% Cl) & $0.94[0.25,3.49]$ \\
\hline 7 Shale oil vs hydrogel & 1 & 119 & Risk Ratio (M-H, Random, 95\% Cl) & $1.49[0.82,2.68]$ \\
\hline $\begin{array}{l}8 \text { Tripeptide copper vs hydro- } \\
\text { gel }\end{array}$ & 1 & 57 & Risk Ratio (M-H, Random, 95\% Cl) & $0.07[0.00,1.26]$ \\
\hline 9 Hydrocolloid vs collagen & 1 & 96 & Risk Ratio (M-H, Random, 95\% Cl) & $0.77[0.50,1.18]$ \\
\hline $\begin{array}{l}10 \text { Hydrocolloid vs dextra- } \\
\text { nomer }\end{array}$ & 1 & 108 & Risk Ratio (M-H, Random, 95\% Cl) & $0.77[0.37,1.60]$ \\
\hline $\begin{array}{l}11 \text { Hydrocolloid vs magnesium } \\
\text { sulphate }\end{array}$ & 1 & 110 & Risk Ratio (M-H, Random, 95\% Cl) & $7.0[0.37,132.40]$ \\
\hline
\end{tabular}




\begin{tabular}{|c|c|c|c|c|}
\hline Outcome or subgroup title & No. of studies & $\begin{array}{l}\text { No. of partici- } \\
\text { pants }\end{array}$ & Statistical method & Effect size \\
\hline $\begin{array}{l}12 \text { Hydrocolloid vs nonadher- } \\
\text { ent or iodine }\end{array}$ & 1 & 70 & Risk Ratio (M-H, Random, 95\% Cl) & $0.79[0.42,1.48]$ \\
\hline 13 Ozonated oil vs zinc oxide & 1 & 29 & Risk Ratio (M-H, Random, 95\% Cl) & $10.31[0.62,170.96]$ \\
\hline $\begin{array}{l}14 \text { Cadexomer iodine vs dex- } \\
\text { tranomer }\end{array}$ & 2 & 63 & Risk Ratio (M-H, Random, 95\% Cl) & $1.33[0.64,2.75]$ \\
\hline $\begin{array}{l}15 \text { Silica gel fibre vs standard } \\
\text { care }\end{array}$ & 1 & 120 & Risk Ratio (M-H, Random, 95\% Cl) & $0.63[0.31,1.26]$ \\
\hline 16 Silver vs non-silver & 1 & 213 & Risk Ratio (M-H, Random, 95\% Cl) & $1.05[0.94,1.16]$ \\
\hline $\begin{array}{l}17 \text { Sulphadryl vs inactive pow- } \\
\text { der }\end{array}$ & 1 & 168 & Risk Ratio (M-H, Random, 95\% Cl) & $1.31[1.10,1.56]$ \\
\hline $\begin{array}{l}18 \text { Tripeptide copper vs emol- } \\
\text { lient cream }\end{array}$ & 1 & 58 & Risk Ratio (M-H, Random, 95\% Cl) & $0.33[0.01,7.86]$ \\
\hline 19 Tripeptide copper vs SSD & 1 & 57 & Risk Ratio (M-H, Random, 95\% Cl) & $0.07[0.00,1.26]$ \\
\hline
\end{tabular}

Analysis 3.1. Comparison 3 Direct evidence - not in network, Outcome 1 A. Pichinchensis vs alginate.

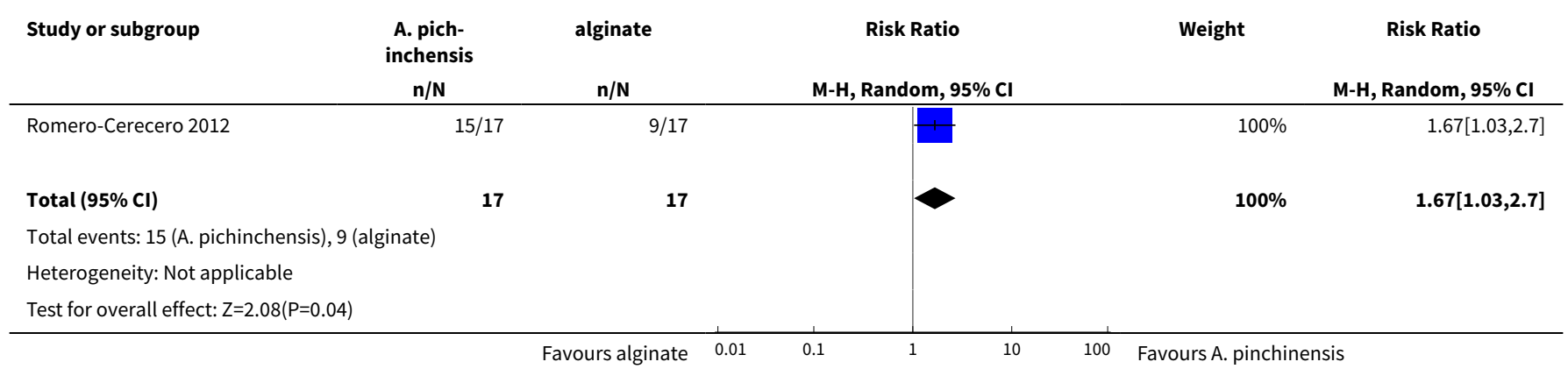

Analysis 3.2. Comparison 3 Direct evidence - not in network, Outcome 2 Non-adherent vs cellulose.

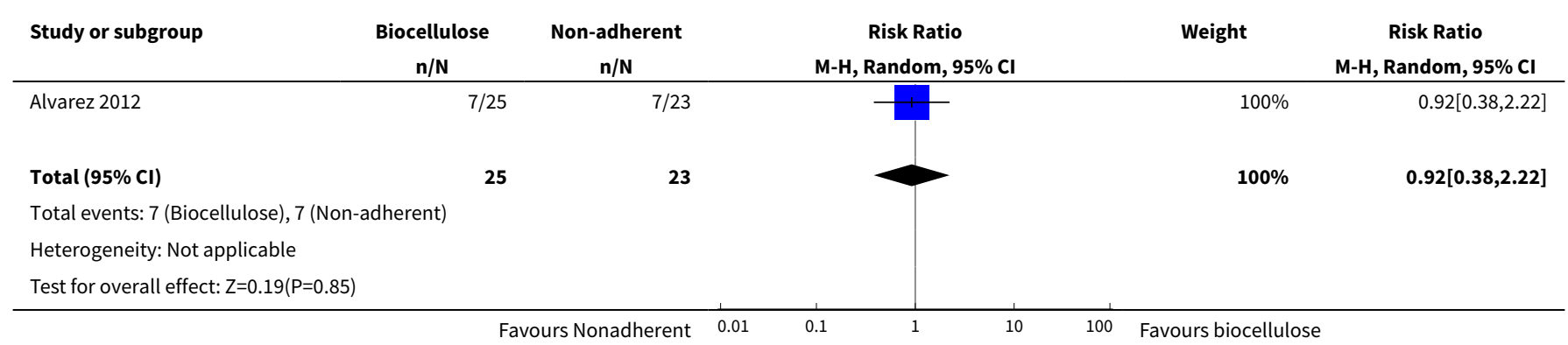


Analysis 3.3. Comparison 3 Direct evidence - not in network, Outcome 3 Phenytoin vs no treatment.

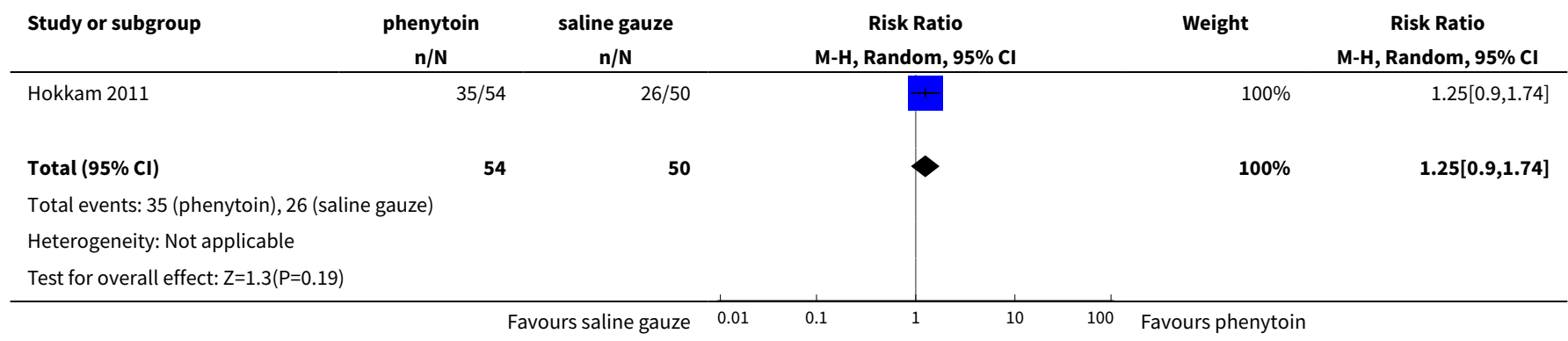

Analysis 3.4. Comparison 3 Direct evidence - not in network, Outcome 4 Cadexomer iodine vs standard treatment.

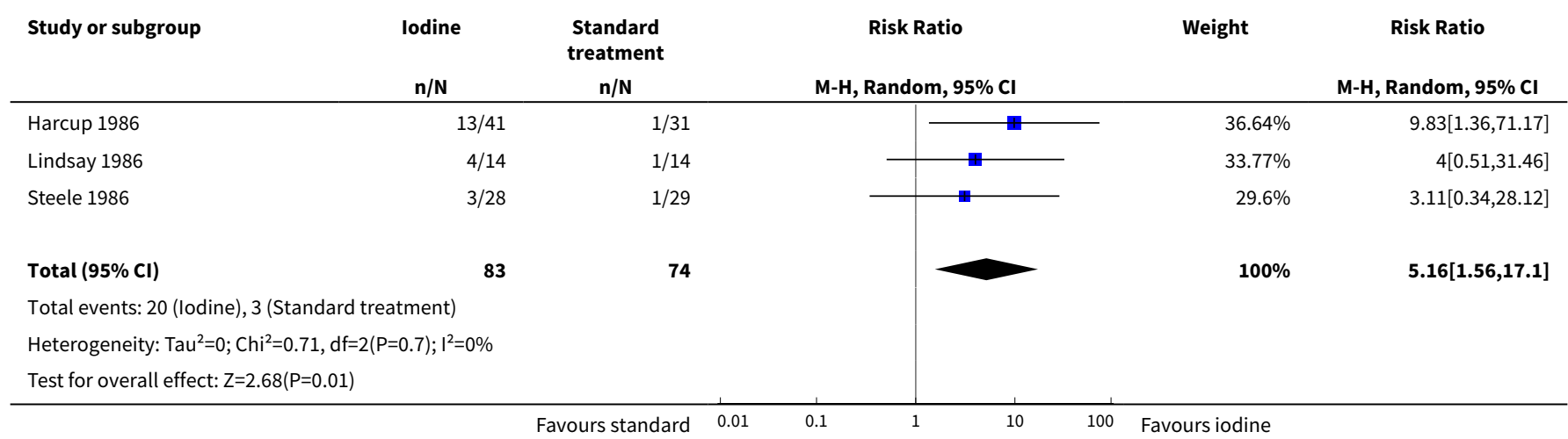

Analysis 3.5. Comparison 3 Direct evidence - not in network, Outcome 5 Honey vs standard treatment.

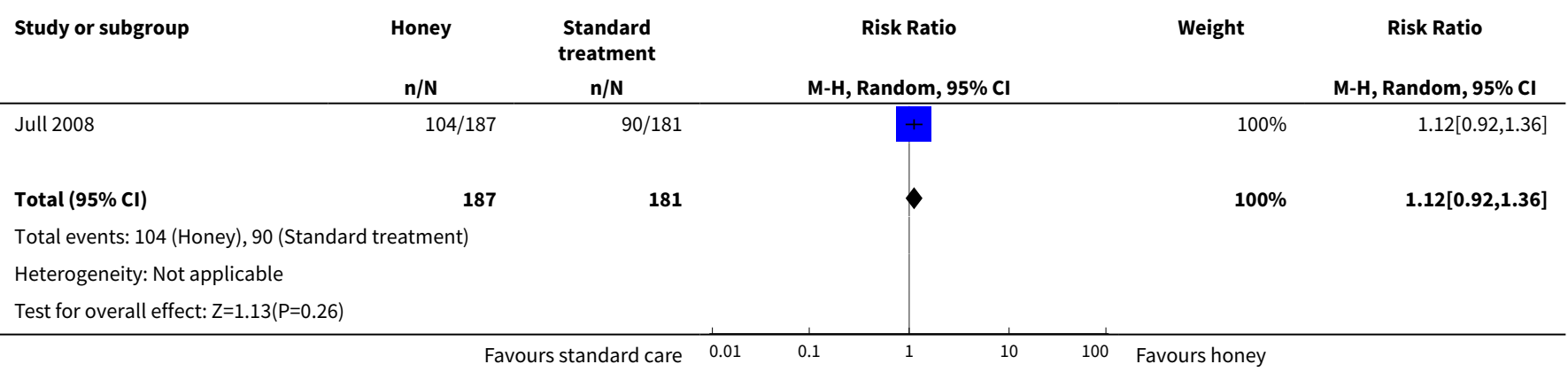

Analysis 3.6. Comparison 3 Direct evidence - not in network, Outcome 6 Papain vs hydrogel.

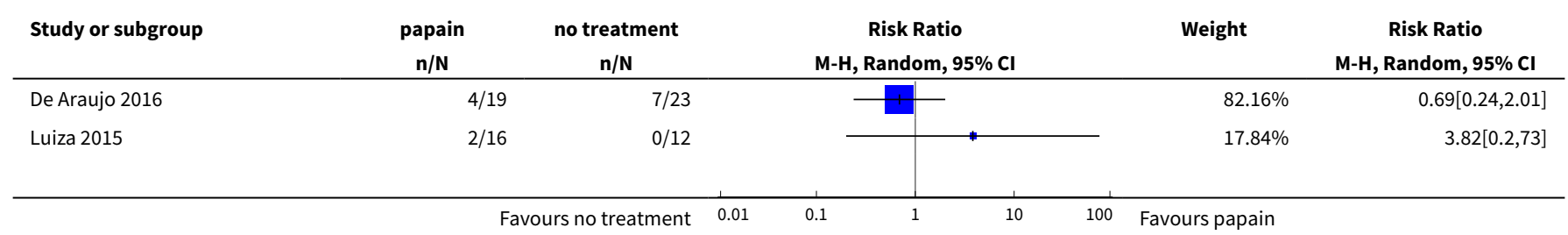




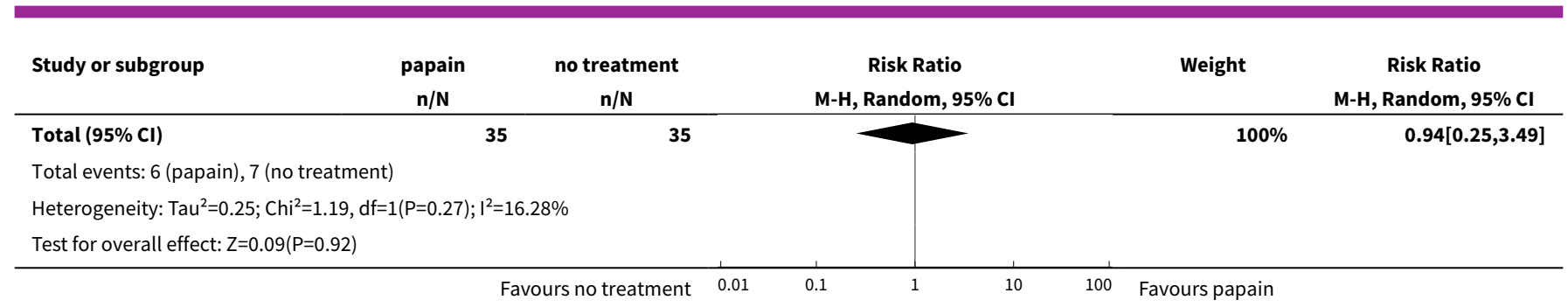

Analysis 3.7. Comparison 3 Direct evidence - not in network, Outcome 7 Shale oil vs hydrogel.

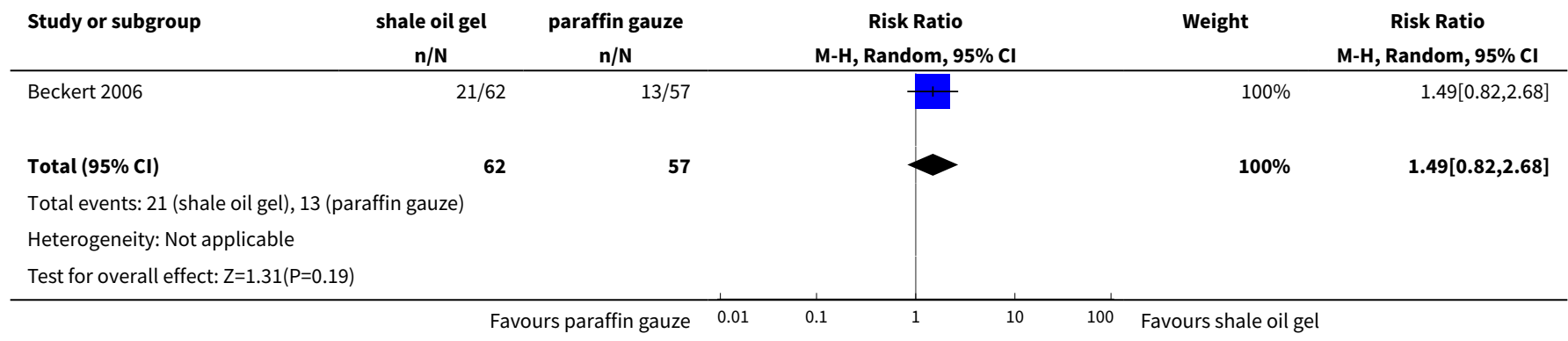

Analysis 3.8. Comparison 3 Direct evidence - not in network, Outcome 8 Tripeptide copper vs hydrogel.

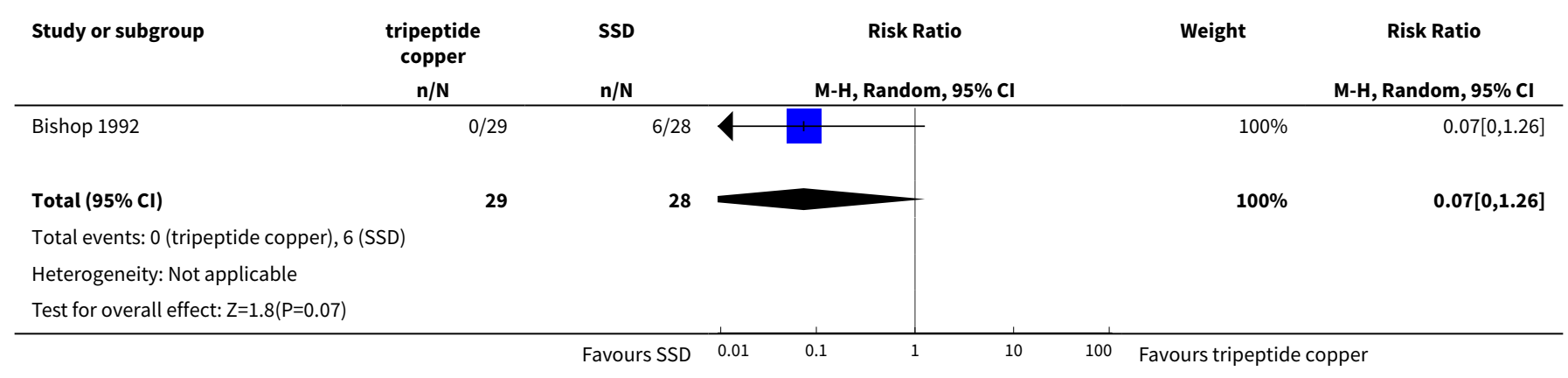

Analysis 3.9. Comparison 3 Direct evidence - not in network, Outcome 9 Hydrocolloid vs collagen.

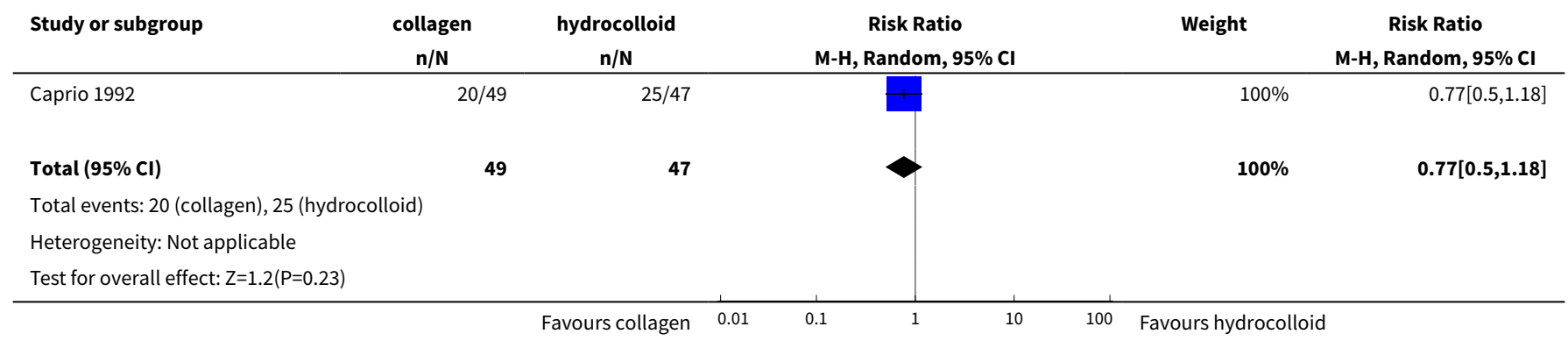


Analysis 3.10. Comparison 3 Direct evidence - not in network, Outcome 10 Hydrocolloid vs dextranomer.

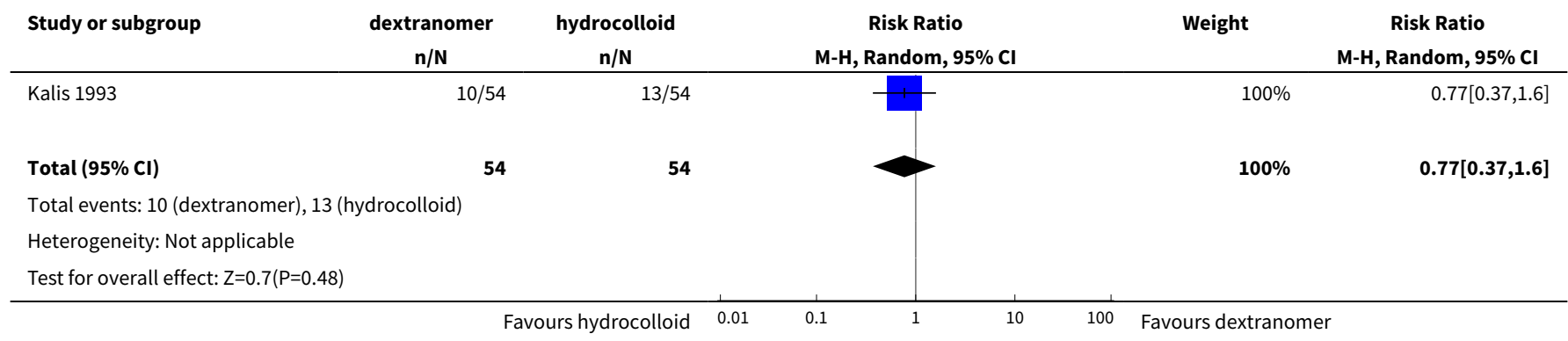

Analysis 3.11. Comparison 3 Direct evidence - not in network, Outcome 11 Hydrocolloid vs magnesium sulphate.

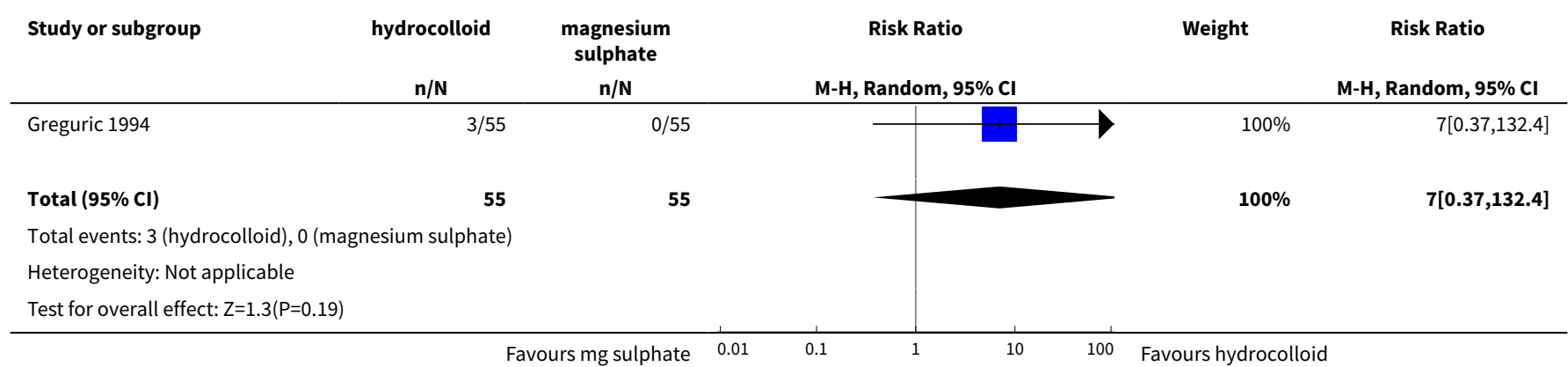

Analysis 3.12. Comparison 3 Direct evidence - not in network, Outcome 12 Hydrocolloid vs nonadherent or iodine.

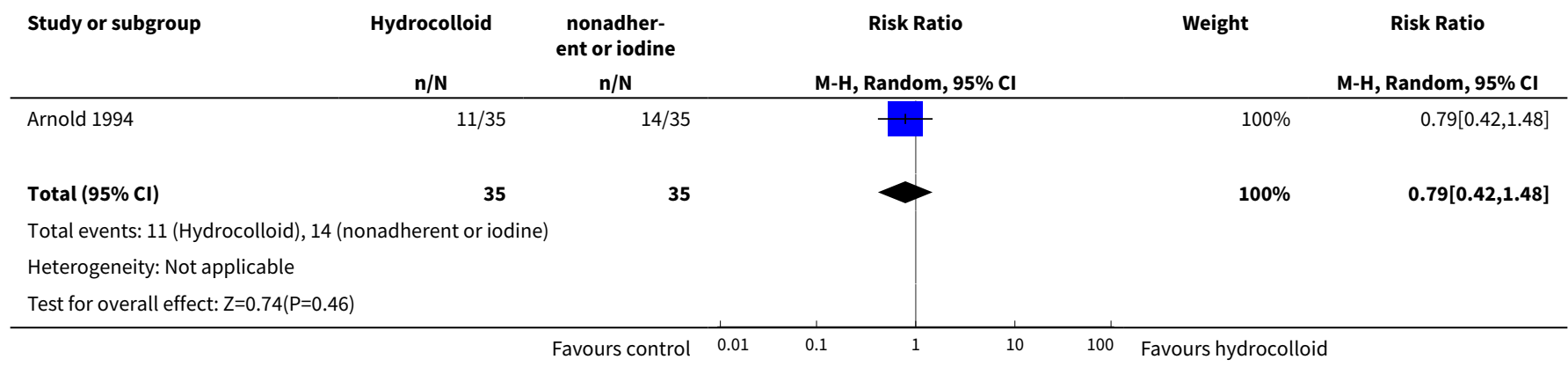

Analysis 3.13. Comparison 3 Direct evidence - not in network, Outcome 13 Ozonated oil vs zinc oxide.

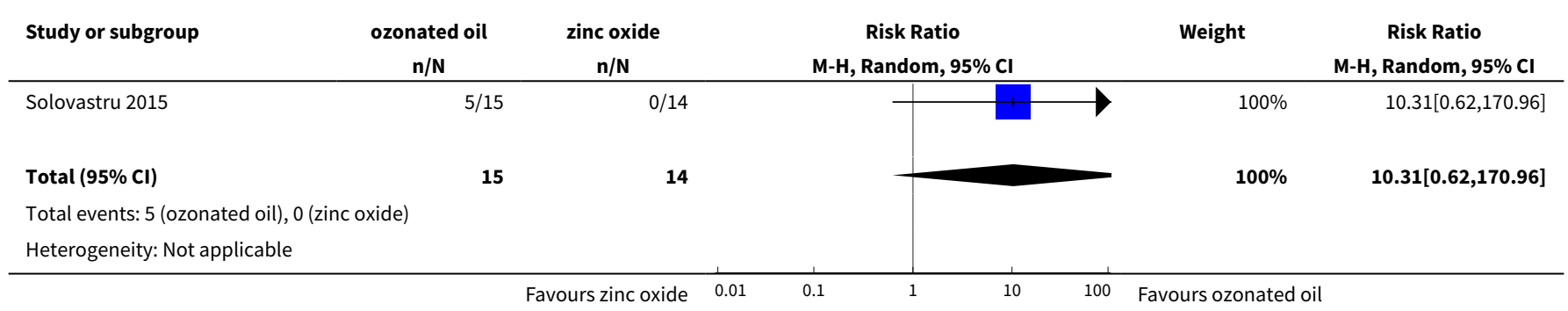




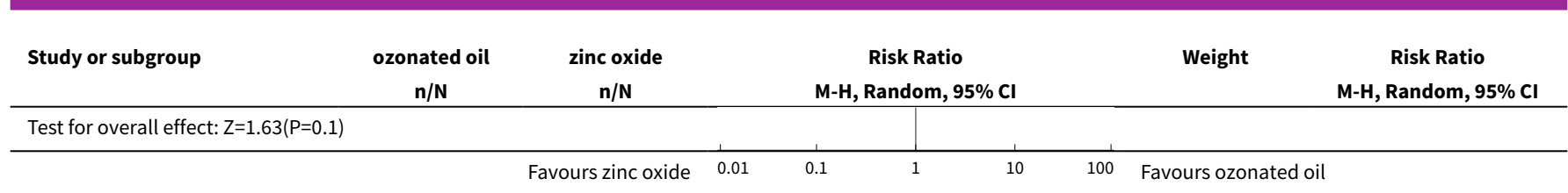

\section{Analysis 3.14. Comparison 3 Direct evidence - not in network, Outcome 14 Cadexomer iodine vs dextranomer.}

\begin{tabular}{|c|c|c|c|c|c|}
\hline Study or subgroup & $\begin{array}{c}\text { iodine } \\
\mathrm{n} / \mathrm{N}\end{array}$ & $\begin{array}{c}\text { dextranomer } \\
\mathrm{n} / \mathrm{N} \\
\end{array}$ & $\begin{array}{c}\text { Risk Ratio } \\
\text { M-H, Random, 95\% Cl }\end{array}$ & Weight & $\begin{array}{c}\text { Risk Ratio } \\
\text { M-H, Random, } 95 \% \text { Cl }\end{array}$ \\
\hline Moss 1987 & $2 / 21$ & $1 / 21$ & $\longrightarrow$ & $9.76 \%$ & $2[0.2,20.41]$ \\
\hline Tarvainen 1988 & $7 / 11$ & $5 / 10$ & & $90.24 \%$ & $1.27[0.59,2.73]$ \\
\hline Total $(95 \% \mathrm{Cl})$ & 32 & 31 & & $100 \%$ & $1.33[0.64,2.75]$ \\
\hline \multicolumn{6}{|c|}{ Total events: 9 (iodine), 6 (dextranomer) } \\
\hline Test for overall effect & & & & & \\
\hline
\end{tabular}

\section{Analysis 3.15. Comparison 3 Direct evidence - not in network, Outcome 15 Silica gel fibre vs standard care.}

\begin{tabular}{|c|c|c|c|c|c|}
\hline Study or subgroup & $\begin{array}{c}\text { Silica gel fibre } \\
\mathrm{n} / \mathrm{N} \\
\end{array}$ & $\begin{array}{c}\text { Standard care } \\
\mathrm{n} / \mathrm{N} \\
\end{array}$ & $\begin{array}{c}\text { Risk Ratio } \\
\text { M-H, Random, 95\% Cl }\end{array}$ & Weight & $\begin{array}{c}\text { Risk Ratio } \\
\text { M-H, Random, } 95 \% \mathrm{Cl}\end{array}$ \\
\hline Brown 2014 & $10 / 60$ & $16 / 60$ & t & $100 \%$ & $0.63[0.31,1.26]$ \\
\hline Total $(95 \% \mathrm{Cl})$ & 60 & 60 & & $100 \%$ & $0.63[0.31,1.26]$ \\
\hline \multicolumn{6}{|c|}{ Total events: 10 (Silica gel fibre), 16 (Standard care) } \\
\hline \multicolumn{6}{|c|}{ Heterogeneity: Not applicable } \\
\hline
\end{tabular}

Analysis 3.16. Comparison 3 Direct evidence - not in network, Outcome 16 Silver vs non-silver.

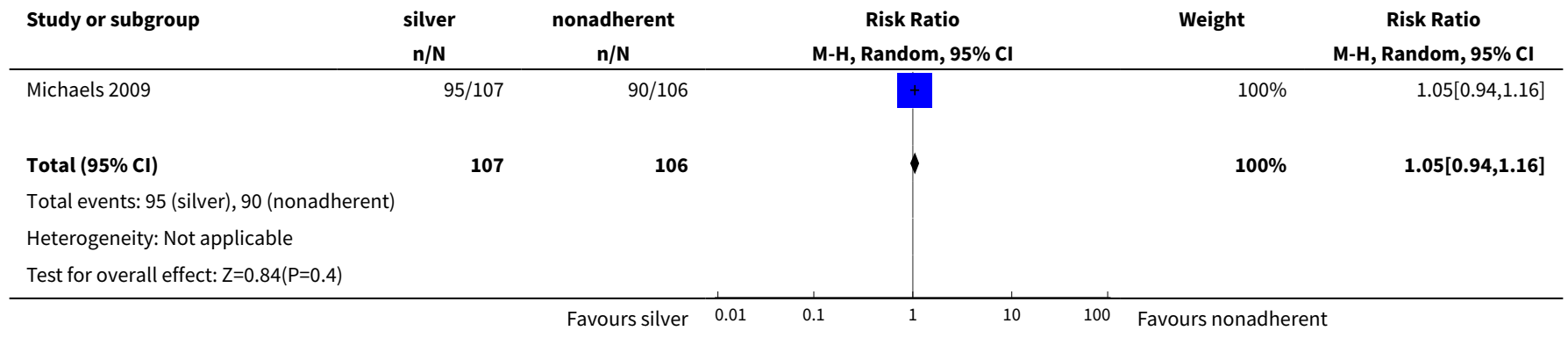


Analysis 3.17. Comparison 3 Direct evidence - not in network, Outcome 17 Sulphadryl vs inactive powder.

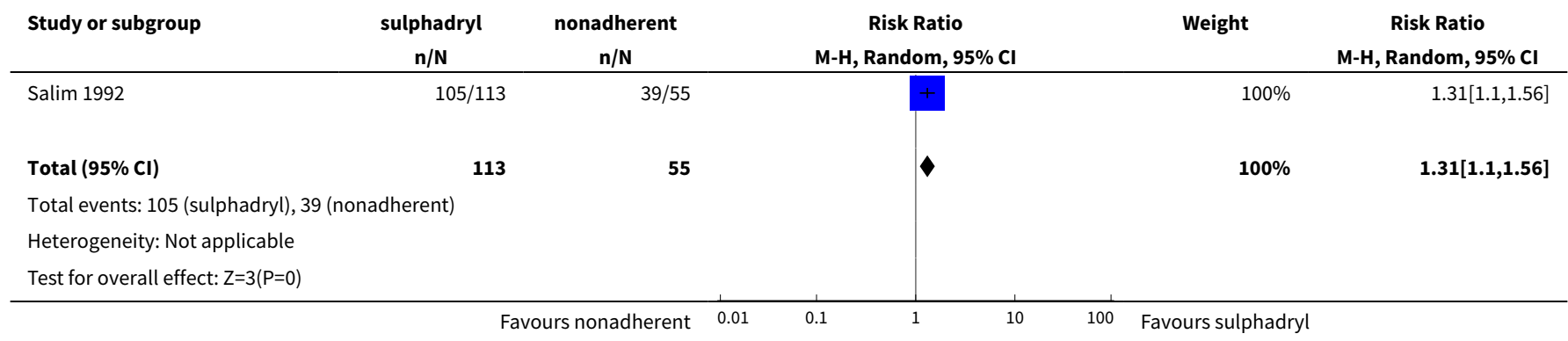

Analysis 3.18. Comparison 3 Direct evidence - not in network, Outcome 18 Tripeptide copper vs emollient cream.

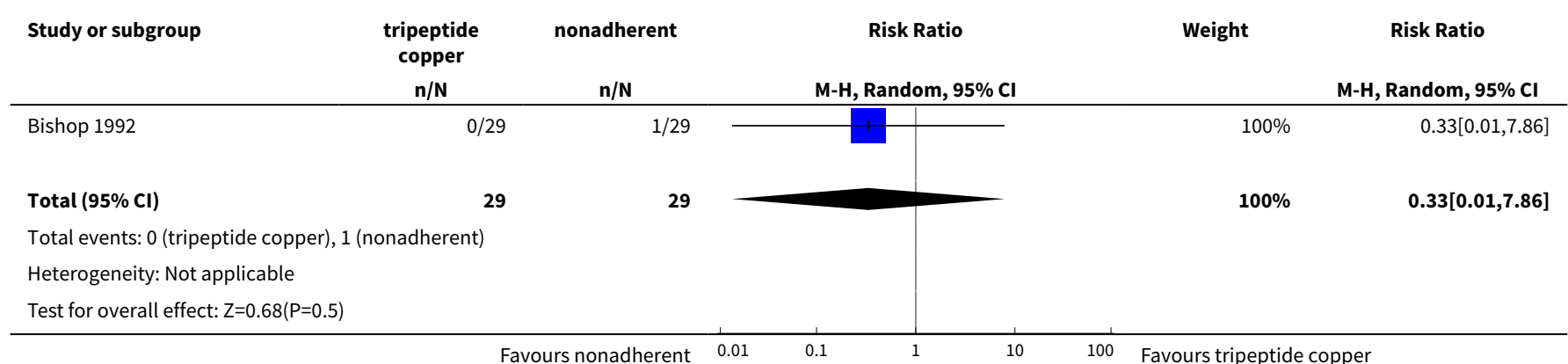

Analysis 3.19. Comparison 3 Direct evidence - not in network, Outcome 19 Tripeptide copper vs SSD.

\begin{tabular}{|c|c|c|c|c|c|}
\hline \multirow[t]{2}{*}{ Study or subgroup } & $\begin{array}{l}\text { tripeptide } \\
\text { copper }\end{array}$ & \multirow[t]{2}{*}{ SSD } & Risk Ratio & \multirow[t]{2}{*}{ Weight } & \multirow{2}{*}{$\begin{array}{c}\text { Risk Ratio } \\
\text { M-H, Random, } 95 \% \mathrm{CI}\end{array}$} \\
\hline & $n / N$ & & M-H, Random, $95 \% \mathrm{Cl}$ & & \\
\hline Bishop 1992 & $0 / 29$ & $6 / 28$ & + & $100 \%$ & $0.07[0,1.26]$ \\
\hline Total $(95 \% \mathrm{Cl})$ & 29 & 28 & & $100 \%$ & $0.07[0,1.26]$ \\
\hline \multicolumn{6}{|c|}{ Total events: 0 (tripeptide copper), 6 (SSD) } \\
\hline \multicolumn{6}{|c|}{ Test for overall effect: $Z=1.8(P=0.07)$} \\
\hline & & Favours SSD & 0.01 & 100 Favours tripeptide & opper \\
\hline
\end{tabular}

\section{ADDITIONAL TABLES}

Table 1. Summary characteristics of individual studies

\begin{tabular}{ll}
\hline Study characteristic & Details of studies \\
\hline Publication & Abstract or poster only: Caprio 1992; Casoni 2002; Hanft 2006; Ivins 2006; Kalis 1993; Lanzara 2008; \\
& Petkov 1997; Zuccarelli 1992. \\
& All other studies had a full publication \\
\hline
\end{tabular}


Table 1. Summary characteristics of individual studies (Continued)

Multiple interventions

Three arms: Bishop 1992; De Araujo 2016; Hansson 1998; Robson 1995.

All other studies had two arms

\begin{tabular}{ll}
\hline Unit of randomisation & Ulcer: Caprio 1992 \\
& Leg: Stacey 1997 \\
& Unclear: Hanft 2006; Kalis 1993; Leaper 1991 \\
& All other studies used participants as the unit of randomisation
\end{tabular}

Funding

Industry: Armstrong 1997; Backhouse 1987; Beckert 2006; Bishop 1992; Bowszyc 1995; Charles 2002; Dereure 2012a; Fogh 2012; Gottrup 2008; Hansson 1998; Humbert 2013; Jørgensen 2005; Kelechi 2012; Lanzara 2008; Leaper 1991; Meaume 2012; Moffatt 1992a; Moffatt 1992b; Moss 1987; Nelson 2007; Norkus 2005; Robson 1995; Scurr 1994; Senet 2003; Senet 2014; Smith 1992; Smith 1994; Stacey 2000; Vin 2002; Zuccarelli 1992.

Others did not report funding source or reported no funding or a non-industry source

Follow-up time

4 weeks: Bishop 1992; Ivins 2006; Jørgensen 2005; Schulze 2001; 30 days: Solovastru 2015; 6 weeks: Armstrong 1997; Biland 1985;Fogh 2012; Gottrup 2008; Leaper 1991; Meredith 1988; Ohlsson 1994; Robson 1995; Scurr 1994; Senet 2014; Smith 1994;Steele 1986; 8 weeks: Brandrup 1990; Caprio 1992; Meaume 2012; Taddeucci 2004; Tarvainen 1988; 60 days: De Araujo 2016; Dereure 2012a; Humbert 2013; 9 weeks: Dimakakos 2009; Kalis 1993

10 weeks: Arnold 1994;12 weeks: Backhouse 1987; Blair 1988a; Blair 1988b; Callam 1992; Charles 2002; Hanft 2006; Hansson 1998; Harding 2001; Lanzara 2008; Luiza 2015; Moffatt 1992a; Moffatt 1992b; Ormiston 1985; Rasmussen 1991; Robson 2001; Romanelli 2015a; Salim 1992; Senet 2003; Senet 2011; Vanscheidt 2012; Vin 2002; Zuccarelli 1992; 3 months: Casoni 2002; 90 days: Tumino 2008; 13 weeks:Arenbergerova 2013; Thomas 1997; 4 months: Smith 1992; 20 weeks: Beckert 2006; Kelechi 2012; Robson 2004; 24 weeks: Nelson 2007;26 weeks: Moss 1987; Petkov 1997; 9 months: Stacey 1997; Stacey 2000; 10 months: Romero-Cerecero 2012; 12 months; Norkus 2005; Rubin 1990; Unclear/till healing: Greguric 1994; Sopata 2016 (max 40 weeks) Kucharzewski 2013 (max 16 weeks)

Included $<25 \%$ non venous leg ulcers
Included non-venous leg ulcers: Armstrong 1997; Biland 1985; Brandrup 1990; Norkus 2005; Ohlsson 1994; Rasmussen 1991

Unclear: Backhouse 1987; Humbert 2013; Ivins 2006; Jørgensen 2005; Leaper 1991; Luiza 2015; Romero-Cerecero 2012; Senet 2011; Tarvainen 1988; Zuccarelli 1992.

All others enrolled only participants with VLU

VLU: venous leg ulcers

Table 2. Studies: status in network/review

\begin{tabular}{|c|c|c|c|c|c|c|}
\hline Study & Interventions & $\begin{array}{l}\text { No eligible } \\
\text { interven- } \\
\text { tions }\end{array}$ & $\begin{array}{l}\text { Expanded } \\
\text { base-case }\end{array}$ & Base-case & $\begin{array}{l}\text { Sensitivity } \\
\text { analysis }\end{array}$ & Risk of bias \\
\hline \multirow[t]{2}{*}{ Alvarez $2012^{c}$} & Cellulose & 2 & $x$ & $x$ & $x$ & High \\
\hline & Nonadherent & & & & & \\
\hline \multirow{2}{*}{$\begin{array}{l}\text { Arenbergerova } \\
2013 b\end{array}$} & Hydrofibre & 1 & $\sqrt{ }$ & $x$ & $x$ & Very high \\
\hline & Blood product & & & & & \\
\hline Armstrong $1997^{a}$ & Alginate & 2 & $\sqrt{ }$ & $\sqrt{ }$ & $\sqrt{ }$ & High \\
\hline
\end{tabular}

Dressings and topical agents for treating venous leg ulcers (Review) 
Table 2. Studies: status in network/review (Continued)

Hydrofibre

\begin{tabular}{|c|c|c|c|c|c|c|}
\hline Arnold $1994 c$ & $\begin{array}{l}\text { Hydrocolloid } \\
\text { lodine OR nonadherent }\end{array}$ & 2 & $x$ & $x$ & $x$ & Very high \\
\hline Backhouse $1987^{a}$ & $\begin{array}{l}\text { Nonadherent } \\
\text { Hydrocolloid }\end{array}$ & 2 & $\sqrt{ }$ & $\sqrt{ }$ & $\sqrt{ }$ & Low/Unclear \\
\hline Banerjee $1997 a$ & $\begin{array}{l}\text { Nonadherent } \\
\text { Film }\end{array}$ & 2 & $\sqrt{ }$ & $\sqrt{ }$ & $\sqrt{ }$ & Very high \\
\hline Beckert 2006c & $\begin{array}{l}\text { Shale oil } \\
\text { Hydrogel }\end{array}$ & 2 & $x$ & $x$ & $x$ & Low/unclear \\
\hline Biland $1985^{b}$ & $\begin{array}{l}\text { Blood product } \\
\text { Emollient cream }\end{array}$ & 1 & $\sqrt{ }$ & $x$ & $x$ & High \\
\hline Bishop $1992^{b}$ & $\begin{array}{l}\text { Tripeptide copper } \\
\text { Emollient cream } \\
\text { SSD }\end{array}$ & 3 & $\sqrt{ }$ & $x$ & $x$ & Low/unclear \\
\hline Blair 1988aa & $\begin{array}{l}\text { Nonadherent } \\
\text { Hydrocolloid }\end{array}$ & 2 & $\sqrt{ }$ & $\sqrt{ }$ & $\sqrt{ }$ & High \\
\hline
\end{tabular}

\begin{tabular}{lllllll}
\hline Blair 1988ba & Nonadherent & 2 & $\sqrt{ }$ & $\sqrt{ }$ & & High \\
& SSD & & & & \\
\hline Bowszyc 1995a & Foam & 2 & $\sqrt{ }$ & $\sqrt{ }$ & $\sqrt{ }$ & High
\end{tabular}

Hydrocolloid

\begin{tabular}{|c|c|c|c|c|c|c|}
\hline Brandrup $1990 a$ & $\begin{array}{l}\text { Hydrocolloid } \\
\text { Zinc oxide }\end{array}$ & 2 & $\sqrt{ }$ & $\sqrt{ }$ & $\sqrt{ }$ & High \\
\hline Brown $2014 c$ & $\begin{array}{l}\text { Silica gel } \\
\text { Alternative traditional dressings }\end{array}$ & 2 & $x$ & $x$ & $x$ & Very high \\
\hline Callam 1992a & $\begin{array}{l}\text { Nonadherent } \\
\text { Foam }\end{array}$ & & $\sqrt{ }$ & $\sqrt{ }$ & $\sqrt{ }$ & Very high \\
\hline Caprio 1992 C & $\begin{array}{l}\text { Hydrocolloid } \\
\text { Collagen }\end{array}$ & 2 & $x$ & $x$ & $x$ & Low/unclear \\
\hline Casoni $2002^{a}$ & $\begin{array}{l}\text { Nonadherent } \\
\text { Hyaluronic+Povidone }\end{array}$ & 2 & $\sqrt{ }$ & $\sqrt{ }$ & $x$ & Low/unclear \\
\hline
\end{tabular}

Charles 2002a

Foam

2

$\sqrt{ }$

Low/unclear 
Table 2. Studies: status in network/review (Continued)

Hydrocolloid

\begin{tabular}{|c|c|c|c|c|c|c|}
\hline De Araujo 2016b & $\begin{array}{l}\text { Blood product } \\
\text { Hydrogel } \\
\text { Papain }\end{array}$ & $\begin{array}{l}3 \text { ( } 2 \text { in net- } \\
\text { work) }\end{array}$ & $\sqrt{ }$ & $x$ & $x$ & Low/unclear \\
\hline Dereure $2012 a b$ & $\begin{array}{l}\text { Hyaluronic acid } \\
\text { Emollient cream }\end{array}$ & 2 & $\sqrt{ }$ & $x$ & $x$ & Low/unclear \\
\hline Dimakakos 2009a & $\begin{array}{l}\text { Foam } \\
\text { Silver }\end{array}$ & 2 & $\sqrt{ }$ & $\sqrt{ }$ & $\sqrt{ }$ & Low/unclear \\
\hline Fogh $2012^{a}$ & $\begin{array}{l}\text { Foam } \\
\text { Silver }\end{array}$ & 2 & $\sqrt{ }$ & $\sqrt{ }$ & $\sqrt{ }$ & High \\
\hline Gottrup $2008^{a}$ & $\begin{array}{l}\text { Foam } \\
\text { Silver }\end{array}$ & 2 & $\sqrt{ }$ & $\sqrt{ }$ & $\sqrt{ }$ & High \\
\hline Greguric $1994 c$ & $\begin{array}{l}\text { Magnesium sulphate } \\
\text { Hydrocolloid }\end{array}$ & 2 & $x$ & $x$ & $x$ & High \\
\hline Hanft $2006 a$ & $\begin{array}{l}\text { PMM silver } \\
\text { Hydrocolloid }\end{array}$ & 2 & $\sqrt{ }$ & $\sqrt{ }$ & $\sqrt{ }$ & High \\
\hline Hansson $1998^{a}$ & $\begin{array}{l}\text { Nonadherent } \\
\text { Cadexomer iodine } \\
\text { Hydrocolloid }\end{array}$ & 3 & $\sqrt{ }$ & $\sqrt{ }$ & $\sqrt{ }$ & High \\
\hline Harcup $1986 c$ & $\begin{array}{l}\text { Standard care } \\
\text { Cadexomer iodine }\end{array}$ & 2 & $x$ & $x$ & $x$ & Low/unclear \\
\hline Harding $2001^{a}$ & $\begin{array}{l}\text { Alginate } \\
\text { Hydrofibre }\end{array}$ & 2 & $\sqrt{ }$ & $\sqrt{ }$ & $\sqrt{ }$ & Very high \\
\hline Hokkam 2011 c & $\begin{array}{l}\text { Phenytoin } \\
\text { No treatment }\end{array}$ & 2 & $x$ & $x$ & $x$ & Low/unclear \\
\hline Humbert $2013^{a}$ & $\begin{array}{l}\text { Hyaluronic acid } \\
\text { Saline gauze }\end{array}$ & 2 & $\sqrt{ }$ & $\sqrt{ }$ & $\sqrt{ }$ & High \\
\hline Ivins $2006^{a}$ & $\begin{array}{l}\text { Foam } \\
\text { Silver }\end{array}$ & 2 & $\sqrt{ }$ & $\sqrt{ }$ & $\sqrt{ }$ & Low/unclear \\
\hline Jørgensen 2005a & $\begin{array}{l}\text { Foam } \\
\text { Silver }\end{array}$ & 2 & $\sqrt{ }$ & $\sqrt{ }$ & $\sqrt{ }$ & Low/unclear \\
\hline
\end{tabular}


Table 2. Studies: status in network/review (Continued)

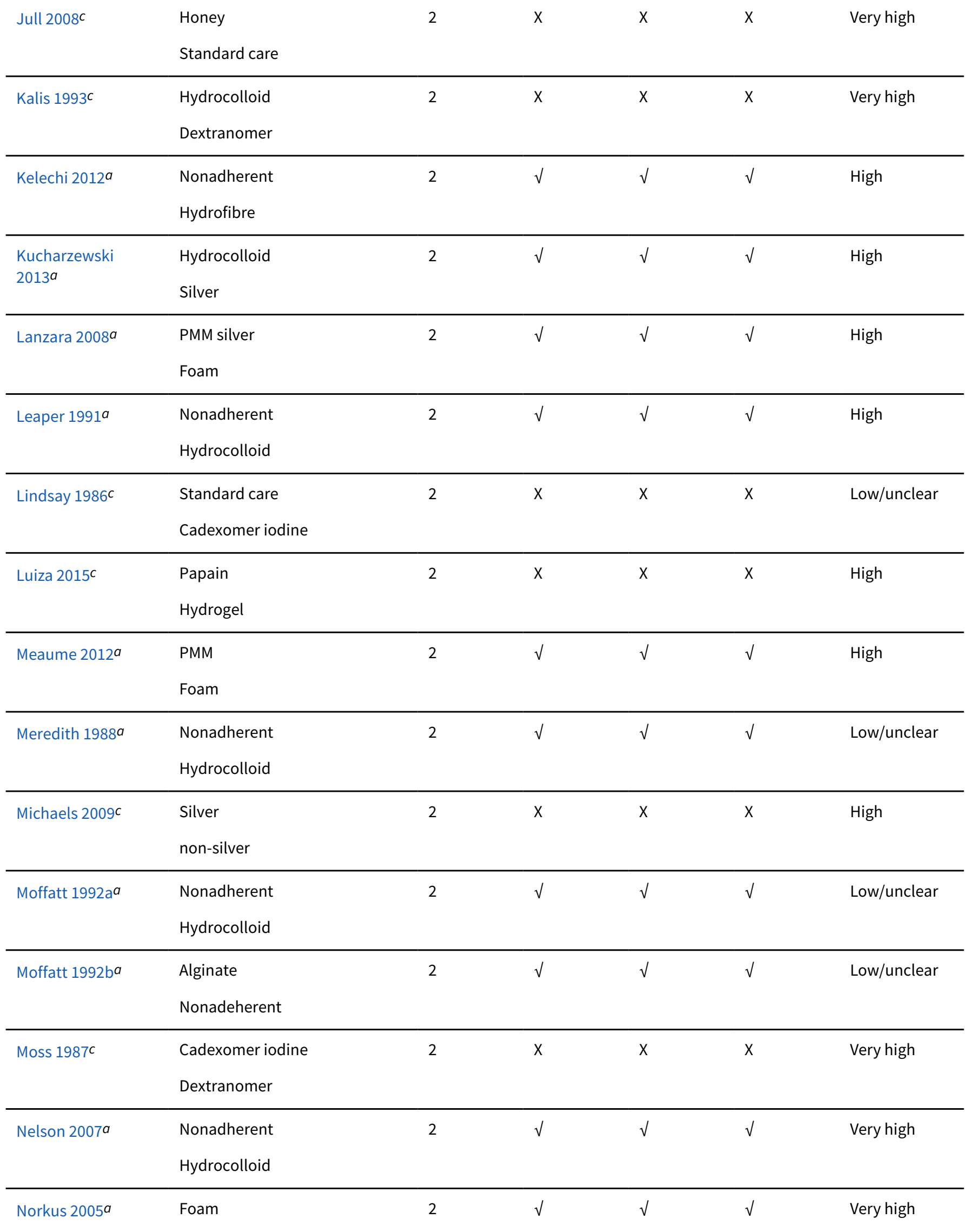


Table 2. Studies: status in network/review (Continued)

Hydrocolloid

\begin{tabular}{|c|c|c|c|c|c|c|}
\hline Ohlsson $1994 a$ & $\begin{array}{l}\text { Hydrocolloid } \\
\text { Saline gauze }\end{array}$ & 2 & $\sqrt{ }$ & $\sqrt{ }$ & $\sqrt{ }$ & Low/unclear \\
\hline Ormiston $1985 b$ & $\begin{array}{l}\text { Cadexomer iodine } \\
\text { gentian violet }\end{array}$ & 2 & $\sqrt{ }$ & $\sqrt{ }$ & $x$ & High \\
\hline Petkov $1997 a$ & $\begin{array}{l}\text { PMM } \\
\text { Alginate }\end{array}$ & 2 & $\sqrt{ }$ & $\sqrt{ }$ & $\sqrt{ }$ & Low/unclear \\
\hline Rasmussen $1991 b$ & $\begin{array}{l}\text { Growth factor } \\
\text { Hydrocolloid }\end{array}$ & 1 & $x$ & $x$ & $\sqrt{ }$ & High \\
\hline Robson $1995 b$ & $\begin{array}{l}\text { Growth factor } \\
\text { Nonadherent }\end{array}$ & 1 & $x$ & $x$ & $\sqrt{ }$ & Low/unclear \\
\hline Robson $2001^{b}$ & $\begin{array}{l}\text { Growth factor } \\
\text { Nonadherent }\end{array}$ & 1 & $x$ & $x$ & $\sqrt{ }$ & High \\
\hline Robson $2004 b$ & $\begin{array}{l}\text { Growth factor } \\
\text { Nonadherent }\end{array}$ & 1 & $x$ & $x$ & $\sqrt{ }$ & Low/unclear \\
\hline Romanelli 2015aa & $\begin{array}{l}\text { PMM } \\
\text { Alginate }\end{array}$ & 2 & $\sqrt{ }$ & $\sqrt{ }$ & $\sqrt{ }$ & Low/unclear \\
\hline $\begin{array}{l}\text { Romero-Cerecero } \\
2012 c\end{array}$ & $\begin{array}{l}\text { A. Pichinchensis } \\
\text { Alginate }\end{array}$ & 2 & $x$ & $x$ & $x$ & High \\
\hline Rubin $1990 a$ & $\begin{array}{l}\text { Foam } \\
\text { paste bandage }\end{array}$ & 2 & $\sqrt{ }$ & $\sqrt{ }$ & $\sqrt{ }$ & High \\
\hline Salim $1992 c$ & $\begin{array}{l}\text { Sulphadryl } \\
\text { Inactive powder }\end{array}$ & 2 & $x$ & $x$ & $x$ & High \\
\hline Schulze $2001^{a}$ & $\begin{array}{l}\text { Foam } \\
\text { alginate }\end{array}$ & 2 & $\sqrt{ }$ & $\sqrt{ }$ & $\sqrt{ }$ & Very high \\
\hline Scurr $1994 a$ & $\begin{array}{l}\text { Hydrocolloid } \\
\text { Alginate }\end{array}$ & 2 & $\sqrt{ }$ & $\sqrt{ }$ & $\sqrt{ }$ & Low/unclear \\
\hline Senet $2003 b$ & $\begin{array}{l}\text { Blood product } \\
\text { Hydrocolloid }\end{array}$ & 1 & $x$ & $x$ & $\sqrt{ }$ & Low/unclear \\
\hline Senet $2011^{b}$ & $\begin{array}{l}\text { Growth factor } \\
\text { Hydrogel }\end{array}$ & 1 & $x$ & $x$ & $\sqrt{ }$ & High \\
\hline
\end{tabular}


Table 2. Studies: status in network/review (Continued)

\begin{tabular}{|c|c|c|c|c|c|c|}
\hline Senet $2014^{a}$ & $\begin{array}{l}\text { silver } \\
\text { foam }\end{array}$ & 2 & $\sqrt{ }$ & $\sqrt{ }$ & $\sqrt{ }$ & High \\
\hline Smith $1992^{a}$ & $\begin{array}{l}\text { Hydrocolloid } \\
\text { Povidone iodine }\end{array}$ & 2 & $\sqrt{ }$ & $\sqrt{ }$ & $\sqrt{ }$ & Very high \\
\hline Smith $1994 a$ & $\begin{array}{l}\text { Hydrocolloid } \\
\text { alginate }\end{array}$ & 2 & $\sqrt{ }$ & $\sqrt{ }$ & $\sqrt{ }$ & Very high \\
\hline Solovastru $2015 \mathrm{C}$ & $\begin{array}{l}\text { Ozonated oil } \\
\text { Emollient cream }\end{array}$ & 2 & $x$ & $x$ & $x$ & Low/unclear \\
\hline Sopata $2016 a$ & $\begin{array}{l}\text { hydrocolloid } \\
\text { foam }\end{array}$ & 2 & $\sqrt{ }$ & $\sqrt{ }$ & $\sqrt{ }$ & Very high \\
\hline Stacey $1997^{a}$ & $\begin{array}{l}\text { Paste bandage } \\
\text { alginate }\end{array}$ & 2 & $\sqrt{ }$ & $\sqrt{ }$ & $\sqrt{ }$ & High \\
\hline Stacey $2000^{b}$ & $\begin{array}{l}\text { Blood product } \\
\text { Saline gauze }\end{array}$ & 1 & $x$ & $x$ & $\sqrt{ }$ & High \\
\hline Steele $1986 \mathrm{C}$ & $\begin{array}{l}\text { Standard care } \\
\text { Cadexomer iodine }\end{array}$ & 2 & $x$ & $x$ & $x$ & Low/unclear \\
\hline Taddeucci $2004 a$ & $\begin{array}{l}\text { Nonadherent } \\
\text { Hydrogel }\end{array}$ & 2 & $\sqrt{ }$ & $\sqrt{ }$ & $\sqrt{ }$ & Very high \\
\hline Tarvainen $1988^{c}$ & $\begin{array}{l}\text { Cadexomer iodine } \\
\text { Dextranomer }\end{array}$ & 2 & $x$ & $x$ & $x$ & Very high \\
\hline Thomas $1997 a$ & $\begin{array}{l}\text { Foam } \\
\text { Hydrocolloid }\end{array}$ & 2 & $\sqrt{ }$ & $\sqrt{ }$ & $\sqrt{ }$ & Very high \\
\hline Tumino $2008 a$ & $\begin{array}{l}\text { Sucralfate } \\
\text { Hydrogel }\end{array}$ & 2 & $\sqrt{ }$ & $\sqrt{ }$ & $\sqrt{ }$ & High \\
\hline Vanscheidt 2012a & $\begin{array}{l}\text { Octenidine } \\
\text { Foam }\end{array}$ & 2 & $\sqrt{ }$ & $\sqrt{ }$ & $x$ & High \\
\hline $\operatorname{Vin} 2002^{a}$ & $\begin{array}{l}\text { PMM } \\
\text { nonadherent }\end{array}$ & 2 & $\sqrt{ }$ & $\sqrt{ }$ & $\sqrt{ }$ & Low/unclear \\
\hline Zuccarelli 1992a & $\begin{array}{l}\text { Foam } \\
\text { Hydrocolloid }\end{array}$ & 2 & $\sqrt{ }$ & $\sqrt{ }$ & $\sqrt{ }$ & Low/unclear \\
\hline
\end{tabular}

Abbreviations: PMM: protease modulating matrix; SSD: silver sulphadiazine 
aStudy in original base-case

bStudy only included in sensitivity analysis

cStudy included in review but not in network

\section{Table 3. Direct comparisons for individual interventions compared with NMA results}

\begin{tabular}{lllll}
\hline $\begin{array}{l}\text { Contrast/com- } \\
\text { parison }\end{array}$ & $\begin{array}{l}\text { Number of stud- } \\
\text { ies (participants) }\end{array}$ & Studies & RR $(95 \% \mathrm{Cl})$ direct evidence. Ran- & NMA results (extended \\
& & dom effects (inverse variance) & base-case; consistency as- \\
& & Heterogeneity statistics & sumption): RR (95\% Cl)
\end{tabular}

Comparisons with nonadherent: $R R>1$ indicates greater proportion healing with specified alternative treatment

\begin{tabular}{|c|c|c|c|c|}
\hline Alginate & $1(113)$ & Moffatt 1992b & $1.08(0.86$ to 1.36$)$ & 1.21 (0.92 to 1.60$)$ \\
\hline $\begin{array}{l}\text { Cadexomerio- } \\
\text { dine }\end{array}$ & $1(105)$ & Hansson 1998 & 1.00 (0.39 to 2.56$)$ & 1.16 (0.50 to 2.69 ) \\
\hline Film & $1(71)$ & Banerjee 1997 & 1.34 (0.61 to 2.92$)$ & 1.34 (0.61 to 2.95$)$ \\
\hline Foam & $1(124)$ & Callam 1992 & 1.35 (0.89 to 2.05 ) & 1.15 (0.91 to 1.44$)$ \\
\hline $\begin{array}{l}\text { Hyaluronic acid } \\
\text { plus povidone io- } \\
\text { dine }\end{array}$ & $1(55)$ & Casoni 2002 & 1.93 (0.95 to 3.92 ) & 1.93 (0.94 to 3.96 ) \\
\hline Hydrocolloid & $7(662)$ & $\begin{array}{l}\text { Backhouse 1987; Blair } \\
\text { 1988a; Hansson 1998; } \\
\text { Leaper 1991; Meredith } \\
\text { 1988; Moffatt 1992a; Nel- } \\
\text { son } 2007\end{array}$ & $\begin{array}{l}1.26(0.92 \text { to } 1.72) \\
I^{2}=69 \% ; P=0.004\end{array}$ & 1.04 (0.85 to 1.29 ) \\
\hline Hydrofibre & $1(82)$ & Kelechi 2012 & 1.47 (0.88 to 2.46$)$ & 1.39 (0.93 to 2.08 ) \\
\hline Hydrogel & $1(24)$ & Taddeucci 2004 & $2.00(0.21$ to 19.23$)$ & 0.79 (0.39 to 1.62$)$ \\
\hline PMM & $1(74)$ & Vin 2002 & 1.42 (0.80 to 2.51$)$ & 1.31 (0.93 to 1.84$)$ \\
\hline SSD & $1(60)$ & Blair 1988b & $0.79(0.57$ to 1.10$)$ & $0.81(0.57$ to 1.15$)$ \\
\hline Growth factor $a$ & $3(460)$ & $\begin{array}{l}\text { Robson 1995; Robson } \\
\text { 2001; Robson } 2004\end{array}$ & $\begin{array}{l}0.96(0.81 \text { to } 1.14) \\
I^{2}=0 \% ; P=0.65\end{array}$ & 0.95 (0.72 to 1.25$)$ \\
\hline
\end{tabular}

Comparisons with alginate: $R R>1$ indicates greater proportion healing with specified alternative treatment

\begin{tabular}{lllll}
\hline Foam & $1(113)$ & Schulze 2001 & $0.55(0.10$ to 2.86) & 0.94 (0.72 to 1.23) \\
\hline Hydrocolloid & $2(80)$ & Scurr 1994; Smith 1994 & $0.72(0.15$ to 3.42) \\
& & & $I^{2}=52 \% ; P=0.15$ & $0.86(0.68$ to 1.11$)$ \\
\hline Hydrofibre & $2(175)$ & Armstrong 1997; Harding & $1.47(0.48$ to 4.47) & $1.15(0.77$ to 1.72$)$ \\
\hline Paste bandage & $1(133)$ & Stacey 1997 & $I^{2}=54 \% ; P=0.14$ & $1.39(1.01$ to 1.90$)$ \\
\hline PMM & $2(140)$ & Petkov 1997; Romanelli & $1.10(0.84$ to 1.46$)$ & $1.08(0.83$ to 1.40$)$ \\
\hline
\end{tabular}


Table 3. Direct comparisons for individual interventions compared with NMA results (Continued)

$\mathrm{I}^{2}=0 \% ; \mathrm{P}=0.87$

\begin{tabular}{|c|c|c|c|c|}
\hline Hydrocolloid & $1(104)$ & Hansson 19980 & $0.73(0.26$ to 2.08$)$ & 0.90 (0.39 to 2.10$)$ \\
\hline Gentian violet & $1(60)$ & Ormiston 1985 & $0.58(0.271 .28)$ & $0.58(0.26$ to 1.29$)$ \\
\hline \multicolumn{5}{|c|}{ Comparisons with foam: $R R>1$ indicates greater proportion healing with specified alternative treatment } \\
\hline Hydrocolloid & $6(458)$ & $\begin{array}{l}\text { Bowszyc 1995; Charles } \\
\text { 2002; Norkus 2005; Sopa- } \\
\text { ta 2016; Thomas 1997; } \\
\text { Zuccarelli } 1992\end{array}$ & $\begin{array}{l}0.92(0.77 \text { to } 1.08) \\
\mathrm{I}^{2}=0 \% ; \mathrm{P}=0.84\end{array}$ & 0.91 (0.78 to 1.07$)$ \\
\hline Ibuprofen & $2(242)$ & Fogh 2012; Gottrup 2008 & $\begin{array}{l}0.88(0.48 \text { to } 1.61) \\
\mathrm{I}^{2}=0 \% ; \mathrm{P}=0.79\end{array}$ & $0.88(0.48$ to 1.62$)$ \\
\hline Octenidine & $1(126)$ & Vanscheidt 2012 & 1.03 (0.56 to 1.90$)$ & 1.03 (0.55 to 1.92$)$ \\
\hline Paste bandage & $1(36)$ & Rubin 1990 & $2.30(1.29$ to 4.10$)$ & 1.47 (0.99 to 2.17$)$ \\
\hline PMM & $1(187)$ & Meaume 2012 & 0.87 (0.30 to 2.48$)$ & $1.14(0.82$ to 1.60$)$ \\
\hline PMM silver & $1(30)$ & Lanzara 2008 & 1.57 (0.84 to 2.92 ) & 1.15 (0.78 to 1.71$)$ \\
\hline Silver & $4(397)$ & $\begin{array}{l}\text { Dimakakos 2009; Ivins } \\
\text { 2006; Jørgensen 2005; } \\
\text { Senet } 2014\end{array}$ & $\begin{array}{l}1.65(1.08 \text { to } 2.52) \\
\mathrm{I}^{2}=0 \% ; \mathrm{P}=0.77\end{array}$ & 2.12 (1.46 to 3.07 ) \\
\hline
\end{tabular}

Comparisons with hyaluronic acid: $R R>1$ indicates greater proportion healing with specified alternative treatment

\begin{tabular}{|c|c|c|c|c|}
\hline Saline gauze & $1(88)$ & Humbert 2013 & 0.52 (0.23 to 1.17$)$ & $0.57(95 \% \mathrm{Cl} 0.28$ to 1.14$)$ \\
\hline Emollient cream & $1(101)$ & Dereure $2012 a$ & $1.31(0.31$ to 5.55$)$ & 1.75 (0.87 to 3.52$)$ \\
\hline
\end{tabular}

Comparisons with hydrocolloid: $R R>1$ indicates greater proportion healing with specified alternative treatment

\begin{tabular}{|c|c|c|c|c|}
\hline PMM silver & $1(49)$ & Hanft 2006 & 1.07 (0.69 to 1.67 ) & 1.27 (0.87 to 1.85$)$ \\
\hline Povidone iodine & $1(200)$ & Smith 1992 & $0.92(0.69$ to 1.23$)$ & 0.92 (0.68 to 1.26$)$ \\
\hline Saline gauze & $1(28)$ & Ohlsson 1994 & $0.29(0.07$ to 1.14$)$ & $0.34(95 \% \mathrm{Cl} 0.15$ to 0.8$)$ \\
\hline \multirow[t]{2}{*}{ Silver } & $1(58)$ & Kucharzewski 2013 & 4.39 (2.23 to 8.65$)$ & 2.32 (1.58 to 3.41$)$ \\
\hline & & & Note $100 \%$ events i & \\
\hline Zinc oxide & $1(43)$ & Brandrup 1990 & $0.95(0.27$ to 3.33$)$ & 0.95 (0.27 to 3.35$)$ \\
\hline Blood product $a$ & $1(13)$ & Senet 2003 & $0.86(0.07$ to 10.96$)$ & $0.38(95 \% \mathrm{Cl} 0.17$ to 0.88$)$ \\
\hline Growth factor ${ }^{a}$ & $1(29)$ & Rasmussen 1991 & $1.83(0.22$ to 15.51$)$ & 0.91 (0.71 to 1.17$)$ \\
\hline
\end{tabular}

Comparisons withhydrogel: $R R>1$ indicates greater proportion healing with specified alternative treatment 
Table 3. Direct comparisons for individual interventions compared with NMA results (Continued)

\begin{tabular}{lllll} 
Sucralfate & $1(100)$ & Tumino 2008 & 8.60 (3.72 to 19.90) & 8.60 (3.68 to 20.07) \\
\hline Blood product $a$ & $1(44)$ & De Araujo 2016 & $0.47(0.14$ to 1.58$)$ & 0.51 (Cl 0.21 to 1.23$)$ \\
\hline Growth factor $a$ & $1(59)$ & Senet 2011 & $1.38(0.64$ to 3.01) & 1.20 (0.61 to 2.35)
\end{tabular}

Comparisons with blood product: $R R>1$ indicates greater proportion healing with specified alternative treatment

\begin{tabular}{lllll}
\hline Saline gauze & $1(67)$ & Stacey 2000 & $0.93(0.74$ to 1.16$)$ & $0.89(0.68$ to 1.17$)$ \\
\hline Emollient cream & $1(147)$ & Biland 1985 & $0.76[0.55,1.06]$ & $0.79(0.56$ to 1.11$)$
\end{tabular}

Comparisons with emollient cream: $R R>1$ indicates greater proportion healing with specified alternative treatment

\begin{tabular}{llll}
\hline SSD & $1(57)$ & Bishop 1992 & 6.21 (0.80 to 48.38)
\end{tabular}

Abbreviations: PMM: protease modulating matrix; RR: relative risk; SSD: silver sulphadiazine

${ }^{a}$ Non-eligible linking intervention

\section{Table 4. Interventions in the included studies}

\begin{tabular}{|c|c|c|c|}
\hline Intervention & $\begin{array}{l}\text { Number of included } \\
\text { studies }\end{array}$ & Included studies & $\begin{array}{l}\text { Number of partic- } \\
\text { ipants in included } \\
\text { studies }\end{array}$ \\
\hline A. Pichinchensis & 1 & Romero-Cerecero 2012 & 34 \\
\hline Alginate & 10 & $\begin{array}{l}\text { Armstrong 1997; Harding 2001; Moffatt 1992b; Petkov 1997; } \\
\text { Romanelli 2015a; Romero-Cerecero 2012; Schulze 2001; Scurr } \\
\text { 1994; Smith 1994; Stacey } 1997\end{array}$ & 735 \\
\hline Blood product $a$ & 5 & $\begin{array}{l}\text { Arenbergerova 2013; Biland 1985; De Araujo 2016; Senet 2003; } \\
\text { Stacey } 2000\end{array}$ & 431 \\
\hline Cadexomer iodine & 7 & $\begin{array}{l}\text { Hansson 1998; Harcup 1986; Lindsay 1986; Moss 1987; Ormiston } \\
\text { 1985; Steele 1986; Tarvainen } 1988\end{array}$ & 433 \\
\hline Cellulose & 1 & Alvarez 2012 & 48 \\
\hline Collagen & 2 & Caprio 1992; Robson 1995 & 132 \\
\hline Dextranomer & 3 & Kalis 1993; Moss 1987; Tarvainen 1988 & 171 \\
\hline Emollient cream & 3 & Biland 1985; Bishop 1992; Dereure 2012a & 384 \\
\hline Film & 1 & Banerjee 1997 & 56 \\
\hline Foam & 18 & $\begin{array}{l}\text { Bowszyc 1995; Callam 1992; Charles 2002; Dimakakos 2009; } \\
\text { Fogh 2012; Gottrup 2008; Ivins 2006; Jørgensen 2005; Lanzara } \\
\text { 2008; Meaume 2012; Norkus 2005; Rubin 1990; Schulze 2001; } \\
\text { Senet 2014; Sopata 2016; Thomas 1997; Vanscheidt 2012; Zuc- } \\
\text { carelli 1992 }\end{array}$ & 1672 \\
\hline Gentian violet & 1 & Ormiston 1985 & 60 \\
\hline
\end{tabular}


Table 4. Interventions in the included studies (Continued)

\begin{tabular}{lll} 
Growth factora & 5 & $\begin{array}{l}\text { Rasmussen 1991; Robson 1995; Robson 2001; Robson 2004; } \\
\text { Senet 2011 }\end{array}$ \\
\hline Honey & 1 & Jull 2008 \\
\hline Hyaluronic acid & 2 & Dereure 2012a; Humbert 2013 \\
\hline $\begin{array}{l}\text { Hyaluronic acid }+ \\
\text { povidone iodine }\end{array}$ & 1 & Casoni 2002
\end{tabular}

\begin{tabular}{ll}
\hline Hydrocolloid & Backhouse 1987; Blair 1988a; Bowszyc 1995;Brandrup 1990; \\
& Caprio 1992; Charles 2002; Greguric 1994; Hanft 2006; Hansson \\
& 1998; Kalis 1993; Kucharzewski 2013; Leaper 1991; Meredith \\
& 1988; Moffatt 1992a; Nelson 2007; Norkus 2005; Ohlsson 1994; \\
& Rasmussen 1991; Scurr 1994; Senet 2003; Smith 1992; Smith \\
& 1994; Sopata 2016; Thomas 1997; Zuccarelli 1992 \\
\hline
\end{tabular}

\begin{tabular}{lll}
\hline Hydrofibre & 4 & Arenbergerova 2013; Armstrong 1997; Harding 2001; Kelechi \\
& 2012
\end{tabular}

\begin{tabular}{lll}
\hline Hydrogel & 6 & $\begin{array}{l}\text { Beckert 2006; De Araujo 2016; Luiza 2015; Senet 2011; Taddeuc- } \\
\text { ci 2004; Tumino 2008 }\end{array}$ \\
\hline $\begin{array}{l}\text { Ibuprofen } \\
\begin{array}{l}\text { Magnesium sul- } \\
\text { phate }\end{array}\end{array}$ & 2 & Fogh 2012; Gottrup 2008 \\
\hline
\end{tabular}

\begin{tabular}{ll}
\hline Nonadherent & Alvarez 2012; Arnold 1994; Backhouse 1987; Banerjee 1997; \\
& Blair 1988a; Blair 1988b; Callam 1992; Casoni 2002; Hansson \\
& 1998; Kelechi 2012; Leaper 1991; Moffatt 1992a; Moffatt 1992b; \\
& Meredith 1988; Nelson 2007; Robson 1995; Robson 2001; Rob- \\
& son 2004; Taddeucci 2004; Vin 2002 \\
\hline
\end{tabular}

\begin{tabular}{|c|c|c|c|}
\hline Non silver & 1 & Michaels 2009 & 208 \\
\hline No treatment & 1 & Hokkam 2011 & 104 \\
\hline Octenidine & 1 & Vanscheidt 2012 & 106 \\
\hline Ozonated oil & 1 & Solovastru 2015 & 29 \\
\hline Papain & 2 & De Araujo 2016; Luiza 2015 & 70 \\
\hline Paste bandage & 2 & Rubin 1990; Stacey 1997 & 149 \\
\hline Phenytoin & 1 & Hokkam 2011 & 104 \\
\hline Povidone iodine & 1 & Smith 1992; & 200 \\
\hline PMM & 4 & Meaume 2012; Petkov 1997; Romanelli 2015a; Vin 2002 & 400 \\
\hline PMM-silver & 2 & Hanft 2006; Lanzara 2008; & 79 \\
\hline Saline gauze & 3 & Humbert 2013; Ohlsson 1994; Stacey 2000 & 202 \\
\hline Shale oil & 1 & Beckert 2006 & 119 \\
\hline
\end{tabular}

Dressings and topical agents for treating venous leg ulcers (Review) 
Table 4. Interventions in the included studies (Continued)

\begin{tabular}{llll} 
Silica gel fibre & 1 & Brown 2014 & 120 \\
\hline Silver & 6 & $\begin{array}{l}\text { Dimakakos 2009; Ivins 2006; Jørgensen 2005; Kucharzewski } \\
\text { 2013; Michaels 2009; Senet 2014; }\end{array}$ & 663 \\
\hline SSD & 2 & Bishop 1992; Blair 1988b & 146 \\
\hline $\begin{array}{l}\text { Standard care/ } \\
\text { mixed treatments }\end{array}$ & 6 & $\begin{array}{l}\text { Arnold 1994; Brown 2014; Harcup 1986; Jull 2008; Lindsay 1986; } \\
\text { Steele 1986 }\end{array}$ & 715 \\
\hline Sucralfate & 1 & Tumino 2008 & 100 \\
\hline Suphadryl & 1 & Salim 1992 & 137 \\
\hline Tripeptide copper & 1 & Bishop 1992 & 86 \\
\hline Zinc oxide & 2 & Brandrup 1990; Solovastru 2015 & 72
\end{tabular}

Abbreviations: PMM: protease modulating matrix; SSD: silver sulphadiazine

anneligible intervention included in expanded base-case to improve network connectivity

Table 5. Comparison of NMA results for base-case and two sensitivity analyses

\begin{tabular}{|c|c|c|c|}
\hline NMA contrast & Base-case RR (95\% Cl) & $\begin{array}{l}\text { Narrow sensitivity } \\
\text { analysis } \\
\text { RR }(95 \% \mathrm{Cl})\end{array}$ & $\begin{array}{l}\text { Extended sensitivity analysis } \\
\text { RR }(95 \% \mathrm{CI})\end{array}$ \\
\hline Sucralfate versus hydrogel & 8.60 (3.66 to 20.2 ) & --- & 8.60 (3.68 to 20.1$)$ \\
\hline Sucralfate versus silver & $6.99(0.60$ to 82.0$)$ & --- & 2.80 (0.88 to 8.97$)$ \\
\hline Sucralfate versus foam & $14.83(1.30$ to 169$)$ & --- & 5.94 (1.96 to 18.0$)$ \\
\hline Sucralfate versus hydrocolloid & 16.24 (1.43 to 185$)$ & --- & 6.51 (2.17 to 19.6$)$ \\
\hline Sucralfate versus nonadherent & 17.15 (1.52 to 193$)$ & --- & $6.80(2.24$ to 20.7$)$ \\
\hline Hydrogel versus silver & 0.81 (0.08 to 8.19$)$ & $0.81(0.08$ to 8.20$)$ & 0.33 (0.15 to 0.72$)$ \\
\hline Hydrogel versus foam & $1.73(0.18$ to 16.9$)$ & $1.72(0.18$ to 16.9$)$ & $0.69(0.34$ to 1.41$)$ \\
\hline Hydrogel versus hydrocolloid & 1.89 (0.19 to 18.4$)$ & 1.88 (0.19 to 18.4$)$ & 0.76 (0.38 to 1.53$)$ \\
\hline Hydrogel versus nonadherent & $1.99(0.21$ to 19.3$)$ & $2.00(0.21$ to 19.4$)$ & 0.79 (0.39 to 1.62$)$ \\
\hline Silver versus foam & 2.12 (1.46 to 3.09$)$ & $2.12(1.45$ to 3.10$)$ & 2.12 (1.46 to 3.07$)$ \\
\hline Silver versus hydrocolloid & 2.32 (1.58 to 3.43$)$ & 2.32 (1.57 to 3.44$)$ & 2.32 (1.58 to 3.41$)$ \\
\hline Silver versus nonadherent & 2.45 (1.58 to 3.82$)$ & 2.47 (1.58 to 3.86$)$ & 2.43 (1.58 to 3.74$)$ \\
\hline Foam versus hydrocolloid & 1.10 (0.93 to 1.28$)$ & 1.09 (0.93 to 1.29$)$ & $1.10(0.94$ to 1.28$)$ \\
\hline Foam versus nonadherent & $1.16(0.91$ to 1.47$)$ & $1.16(0.91$ to 1.49$)$ & 1.15 (0.91 to 1.44$)$ \\
\hline
\end{tabular}


Table 5. Comparison of NMA results for base-case and two sensitivity analyses (Continued)
Hydrocolloid versus nonadherent
$1.06(0.84$ to 1.32$)$
1.06 (0.85 to 1.33$)$
1.04 (0.85 to 1.29$)$

Abbreviations: $\mathbf{C l}$ : confidence interval; RR: relative risk

Table 6. Ranks of treatments - base-case and two sensitivity analyses (ordered by mean rank)

\begin{tabular}{|c|c|c|c|}
\hline Treatment & $\begin{array}{l}\text { Base-case (rank of 22) } \\
\text { Mean rank (SUCRA) and maxi- } \\
\text { mum probability and its corre- } \\
\text { sponding rank }\end{array}$ & $\begin{array}{l}\text { Narrow sensitivity analysis } \\
\text { (rank of 17) } \\
\text { Mean rank (SUCRA) and } \\
\text { maximum probability and } \\
\text { its corresponding rank }\end{array}$ & $\begin{array}{l}\text { Extended base-case (rank of 25)\# } \\
\text { Mean rank (SUCRA) and maximum } \\
\text { probability and its corresponding } \\
\text { rank }\end{array}$ \\
\hline Sucralfate & ___ $91 \%($ rank 1) & --- & _93\% (rank 1) \\
\hline Silver & _-38\% (rank 3) & ___ $40 \%$ (rank 2) & $50 \%($ rank 2) \\
\hline $\begin{array}{l}\text { Hyaluronic acid } \\
+ \text { povidone iodine }\end{array}$ & $5.8(0.8) \_32 \%$ (rank 21) & --- & $21 \%($ rank 3$)$ \\
\hline Paste bandage & __19\% (rank 5) & $26 \%($ rank 3) & $22 \%($ rank 4) \\
\hline Hydrofibre & $14 \%($ rank 7$)$ & ___ $17 \%$ (rank 5) & _16\% (rank 6) \\
\hline Hydrogel & $8.9(0.6) \_$___ $39 \%$ (rank 2) & $39 \%($ rank 1) & $15 \%($ rank 20) \\
\hline PMM & $9.4(0.6) \_\_$_ $15 \%$ (rank 9) & ___ 19\% (rank 6) & __ $16 \%$ (rank 8) \\
\hline PMM silver & _12\% (rank 8) & __ $15 \%$ (rank 5) & $13 \%($ rank 7$)$ \\
\hline Film & ___ $9 \%$ (rank 5) & $10 \%$ (rank 3) & __ $9 \%$ (rank 5) \\
\hline Alginate & __ $17 \%$ (rank 10) & $20 \%($ rank 7$)$ & _16\% (rank 10) \\
\hline Octenidine & $11.4(0.5) \_$_ $7 \%$ (rank 7) & --- & $9 \%$ (rank 6) \\
\hline Foam & __ 18\% (rank 11) & $20 \%$ (rank 9) & $17 \%($ rank 11) \\
\hline Cadexomer iodine & ___ $9 \%$ (rank 19) & ___ $9 \%($ rank 4) & __ $8 \%$ (rank 19) \\
\hline Zinc oxide & _13\% (rank 20) & $\begin{array}{l}10.5(0.4) \_\_\_14 \% \text { (rank } \\
15)\end{array}$ & _ $8 \%($ rank 25) \\
\hline $\begin{array}{l}\text { Ibuprofen-releasing } \\
\text { foam }\end{array}$ & _12\% (rank 18) & --- & __a (rank 18) \\
\hline Hydrocolloid & __21\% (rank 15) & $\begin{array}{l}11.0(0.4) \_\_25 \% \text { (rank } \\
11)\end{array}$ & $18 \%($ rank 14) \\
\hline Nonadherent & $15.2(0.3) \_\_$_ $18 \%$ (rank 15) & $\begin{array}{l}11.8(0.3) \_\_\_25 \% \text { (rank } \\
13)\end{array}$ & $15 \%$ (rank 15) \\
\hline Povidone iodine & $15.2(0.3) \_$_ $14 \%$ (rank 17) & $\begin{array}{l}11.8(0.3) \_\_17 \% \text { (rank } \\
13)\end{array}$ & $12 \%($ rank 17) \\
\hline
\end{tabular}


Table 6. Ranks of treatments - base-case and two sensitivity analyses (ordered by mean rank) (Continued)

\begin{tabular}{|c|c|c|c|c|c|c|}
\hline Hyaluronic acid & $15.7(0.3)$ & _18\% (rank 4) & $12(0.3)$ & $38 \%($ rank 16) & $17.0(0.3)$ & _19\% (rank 22) \\
\hline Gentian violet & $17.4(0.2)$ & _19\% (rank 21) & --- & & $18.4(0.3)$ & _16\% (rank 25) \\
\hline SSD & $18.1(0.2)$ & $23 \%$ (rank 19) & $14(0.2)$ & $28 \%($ rank 15) & $18.8(0.3)$ & _16\% (rank 19) \\
\hline Saline gauze & $21.0(0)$ & $69 \%$ (rank 22) & $16.3(0)$ & -77\% (rank 17) & $23.0(0.1)$ & _33\% (rank 24) \\
\hline
\end{tabular}

Abbreviations:PMM: protease modulating matrix; SSD: silver sulphadiazine; SUCRA surface under the cumulative ranking curve \# ranks for extra treatments not reported 


\begin{tabular}{|c|c|c|c|c|c|c|c|c|c|c|}
\hline $\begin{array}{l}\text { Mixed treatment comparisons } \\
\Rightarrow \\
\text { Direct comparisons (risk of } \\
\text { bias) } \Omega\end{array}$ & $\begin{array}{l}\text { Silver vs } \\
\text { HC }\end{array}$ & HC vs NA & $\begin{array}{l}\text { Foam vs } \\
\text { NA }\end{array}$ & $\begin{array}{l}\text { HC vs } \\
\text { Foam }\end{array}$ & $\begin{array}{l}\text { Silver vs } \\
\text { foam }\end{array}$ & $\begin{array}{l}\text { Sucral- } \\
\text { fate vs HC }\end{array}$ & $\begin{array}{l}\text { Silver vs } \\
\text { NA }\end{array}$ & $\begin{array}{l}\text { Sucral- } \\
\text { fate vs NA }\end{array}$ & $\begin{array}{l}\text { Sucral- } \\
\text { fate vs sil- } \\
\text { ver }\end{array}$ & $\begin{array}{l}\text { Sucral- } \\
\text { fate vs } \\
\text { foam }\end{array}$ \\
\hline $\begin{array}{l}\text { Hyaluronic + povidone iodine } \\
\text { vs nonadherent (low) }\end{array}$ & & & & & & & & & & \\
\hline $\begin{array}{l}\text { Hydrocolloid vs nonadherent } \\
\text { (high) }\end{array}$ & 3.0 & 80.6 & 32.7 & 6.2 & 1.2 & 17.9 & 28.9 & 2.7 & 11.1 & 10.9 \\
\hline $\begin{array}{l}\text { Hyaluronic acid vs saline gauze } \\
\text { (high) }\end{array}$ & & & & & & & & & & \\
\hline $\begin{array}{l}\text { Hydrofibre vs nonadherent } \\
\text { (high) }\end{array}$ & 0.2 & 0.6 & 1.0 & 0.3 & 0.1 & 0.1 & 0.7 & 0.4 & 0.2 & 0.2 \\
\hline $\begin{array}{l}\text { Hydrogel vs nonadherent (very } \\
\text { high) }\end{array}$ & & & & & & 3.4 & & 5.2 & 2.6 & 3.4 \\
\hline PMM vs nonadherent (low) & 0.3 & 0.8 & 2.1 & 0.6 & 0.1 & 0.3 & 1.3 & 0.1 & 0.5 & 0.8 \\
\hline $\begin{array}{l}\text { PMM silver vs hydrocolloid } \\
\text { (high) }\end{array}$ & 1.0 & 0.1 & 1.2 & 2.2 & 0.4 & 0.1 & 0.4 & & 0.3 & 0.6 \\
\hline \multicolumn{11}{|l|}{$\begin{array}{l}\text { Hydrocolloid vs povidone io- } \\
\text { dine (very high) }\end{array}$} \\
\hline $\begin{array}{l}\text { Hydrocolloid vs saline gauze } \\
\text { (low) }\end{array}$ & & 0.2 & 0.1 & & & 2.7 & 0.1 & 1.9 & 1.8 & 1.9 \\
\hline Silver vs hydrocolloid (high) & 32.5 & 0.1 & 0.9 & 2.2 & 12.9 & 0.1 & 15.9 & & 7.2 & 0.5 \\
\hline \multicolumn{11}{|l|}{$\begin{array}{l}\text { Hydrocolloid vs zinc oxide } \\
\text { (high) }\end{array}$} \\
\hline SSD vs nonadherent (high) & & 0.1 & & & & 0.5 & & 0.9 & 0.4 & 0.5 \\
\hline $\begin{array}{l}\text { Cadexomer iodine vs nonad- } \\
\text { herent (high) }\end{array}$ & & 0.8 & 0.3 & & & 0.2 & 0.3 & & 0.1 & 0.1 \\
\hline Sucralfate vs hydrogel (high) & & & & & & 25.1 & & 32.4 & 18.7 & 21.4 \\
\hline
\end{tabular}




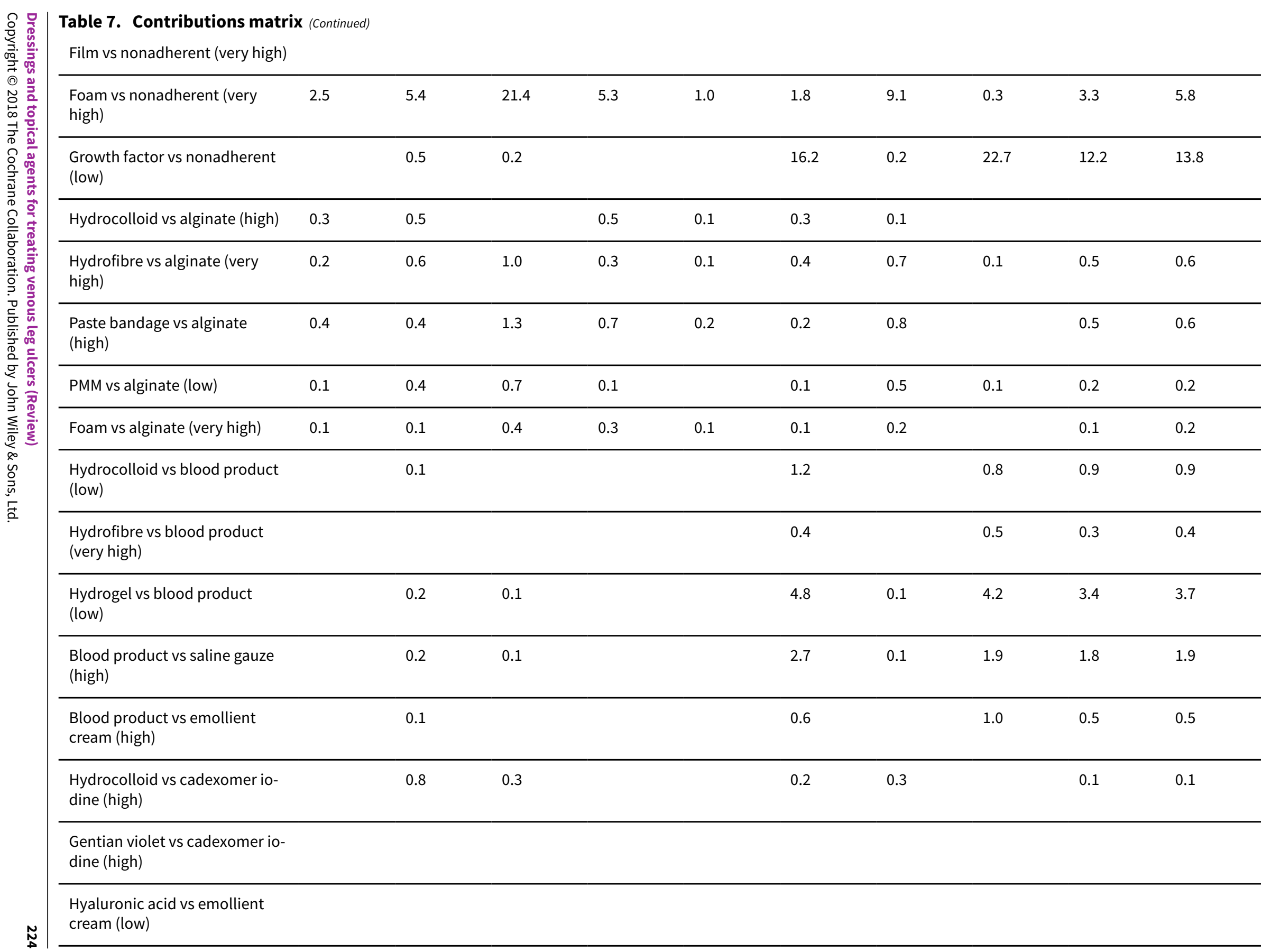




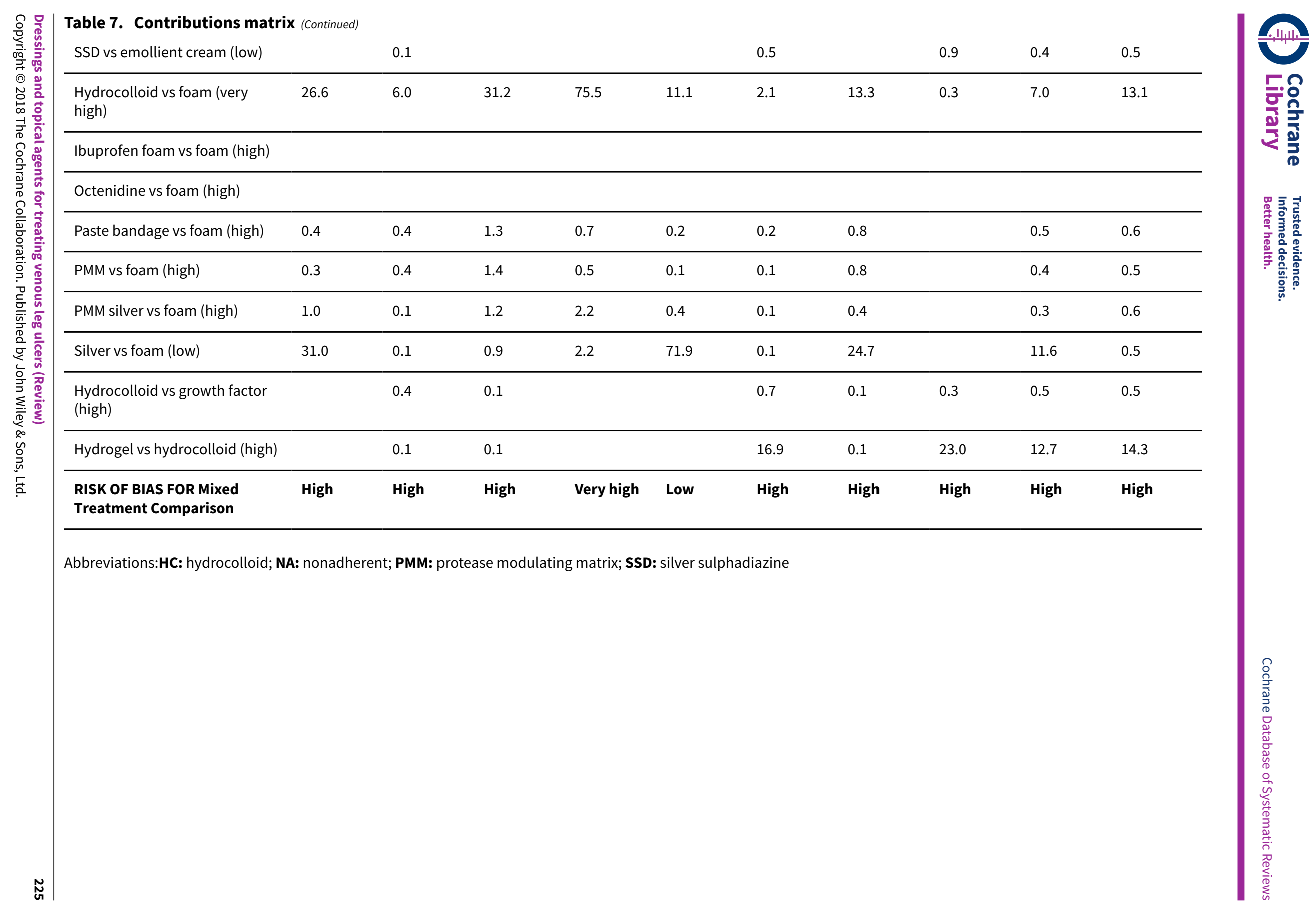


Table 8. Inconsistency factors - base-case and extended base-case

\begin{tabular}{|c|c|c|c|}
\hline Loop & RoRR and $90 \% \mathrm{Cl}$ & P value & $\begin{array}{l}\text { Loop heterogene- } \\
\text { ity } \\
\operatorname{tau}^{2} \text { (loop) }\end{array}$ \\
\hline Foam-hydrocolloid-silver & $2.44(90 \% \mathrm{Cl} 1.23$ to 4.84$)$ & 0.033 & 0 \\
\hline Nonadherent-alginate-foam & $2.28(90 \% \mathrm{Cl} 0.54$ to 9.67$)$ & 0.349 & 0 \\
\hline Alginate-foam-PMM & $2.26(90 \% \mathrm{Cl} 0.43$ to 11.94$)$ & 0.419 & 0 \\
\hline Nonadherent-cadexomer-hydrocolloid & $1.81(90 \% \mathrm{Cl} 0.25$ to 13.24$)$ & 0.625 & 0.104 \\
\hline Nonadherent-alginate-hydrocolloid & $1.66(90 \% \mathrm{Cl} 0.35$ to 7.74$)$ & 0.59 & 0.103 \\
\hline Foam-hydrocolloid-PMM silver & $1.60(90 \% \mathrm{Cl} 0.83$ to 3.08$)$ & 0.24 & 0 \\
\hline Alginate-foam-hydrocolloid & $1.40(90 \% \mathrm{Cl} 0.26$ to 7.39$)$ & 0.74 & 0 \\
\hline Nonadherent-alginate-PMM & $1.26(90 \% \mathrm{Cl} 0.72$ to 2.21$)$ & 0.503 & 0 \\
\hline Nonadherent-foam-PMM & $1.25(90 \% \mathrm{Cl} 0.43$ to 3.62$)$ & 0.73 & 0 \\
\hline Nonadherent-alginate-hydrofibre & $1.18(90 \% \mathrm{Cl} 0.61$ to 2.26$)$ & 0.684 & 0 \\
\hline Nonadherent-foam-hydrocolloid & $1.06(90 \% \mathrm{Cl} 0.55$ to 2.06$)$ & 0.878 & 0.042 \\
\hline Alginate-foam-paste bandage & $1.03(90 \% \mathrm{Cl} 0.23$ to 4.58$)$ & 0.974 & 0 \\
\hline \multicolumn{4}{|l|}{ Extended base-case only } \\
\hline Nonadherent-growth factor-hydrogel & $3.00(90 \% \mathrm{Cl} 0.40$ to 22.43$)$ & 0.370 & 0 \\
\hline Blood product-hydrocolloid-saline gauze & $2.78(90 \% \mathrm{Cl} 0.24$ to 31.92$)$ & 0.491 & 0 \\
\hline Nonadherent-growth factor-hydrocolloid & $2.23(90 \% \mathrm{Cl} 0.21$ to 23.65$)$ & 0.577 & 0.078 \\
\hline \multicolumn{4}{|l|}{ Quadratic loops } \\
\hline $\begin{array}{l}\text { Alginate-blood product-hydrocolloid-hydrofi- } \\
\text { bre }\end{array}$ & $7.34(90 \% \mathrm{Cl} 0.12$ to 460.27$)$ & 0.428 & 0.487 \\
\hline $\begin{array}{l}\text { Nonadherent-blood product-hydrofibre-hydro- } \\
\text { gel }\end{array}$ & $4.7(90 \% \mathrm{Cl} 0.15$ to 148.15$)$ & 0.461 & 0 \\
\hline $\begin{array}{l}\text { Nonadherent-blood product-hydrocolloid-hy- } \\
\text { drofibre }\end{array}$ & $4.09(90 \% \mathrm{Cl} 0.03$ to 493.5$)$ & 0.629 & 0.096 \\
\hline $\begin{array}{l}\text { Blood product-emollient cream-hyaluronic } \\
\text { acid-saline gauze }\end{array}$ & $3.68(90 \% \mathrm{Cl} 0.89$ to 15.16$)$ & 0.131 & 0 \\
\hline $\begin{array}{l}\text { Blood product-growth factor-hydrocolloid-hy- } \\
\text { drogel }\end{array}$ & $1.38(90 \% \mathrm{Cl} 0.07$ to 28.86$)$ & 0.862 & 0 \\
\hline $\begin{array}{l}\text { Nonadherent-blood product-hydrocolloid-hy- } \\
\text { drogel }\end{array}$ & $1.15(90 \% \mathrm{Cl} 0.02$ to 82.36$)$ & 0.957 & 0.096 \\
\hline
\end{tabular}


Abbreviations:Cl: confidence interval; PMM: protease modulating matrix; RoRR: ratio of relative risks

Table 9. Node splitting

\begin{tabular}{|c|c|c|c|}
\hline Comparison & Direct RR $(95 \% \mathrm{Cl})$ & Indirect RR (95\% Cl) & $\operatorname{RoRR}(\underline{90 \% \mathrm{Cl}})$ \\
\hline Alginate vs nonadherent & $1.08(95 \% \mathrm{Cl} 0.86$ to 1.36$)$ & $1.52(95 \% \mathrm{Cl} 1.07$ to 2.15$)$ & $0.71(90 \% \mathrm{Cl} 0.50$ to 1.02$)$ \\
\hline Foam vs nonadherent & 1.35 (95\% $\mathrm{Cl} 0.87$ to 2.08$)$ & $1.10(95 \% \mathrm{Cl} 0.83$ to 1.47$)$ & $1.22(90 \% \mathrm{Cl} 0.79$ to 1.89$)$ \\
\hline $\begin{array}{l}\text { Hydrocolloid vs nonadher- } \\
\text { ent }\end{array}$ & $0.94(95 \% \mathrm{Cl} 0.72$ to 1.23$)$ & $2.01(95 \% \mathrm{Cl} 0.56$ to 7.23$)$ & $0.47(90 \% \mathrm{Cl} 0.16$ to 1.39$)$ \\
\hline Hydrofibre vs nonadherent & $1.47(95 \% \mathrm{Cl} 0.84$ to 2.56$)$ & $1.35(95 \% \mathrm{Cl} 0.71$ to 2.56$)$ & $1.09(90 \% \mathrm{Cl} 0.53$ to 2.23$)$ \\
\hline Hydrogel vs nonadherent & $2.00(95 \% \mathrm{Cl} 0.21$ to 19.1$)$ & $0.76(95 \% \mathrm{Cl} 0.36$ to 1.64$)$ & $2.62(90 \% \mathrm{Cl} 0.35$ to 19.5$)$ \\
\hline PMM vs nonadherent & $1.46(95 \% \mathrm{Cl} 0.80$ to 2.67$)$ & $1.29(95 \% \mathrm{Cl} 0.85$ to 1.96$)$ & $1.13(90 \% \mathrm{Cl} 0.61$ to 2.11$)$ \\
\hline Foam vs alginate & $0.55(95 \% \mathrm{Cl} 0.10$ to 2.87$)$ & $0.95(95 \% \mathrm{Cl} 0.72$ to 1.27$)$ & $0.57(90 \% \mathrm{Cl} 0.14$ to 2.36$)$ \\
\hline Hydrocolloid vs alginate & $0.70(95 \% \mathrm{Cl} 0.24$ to 2.06$)$ & $0.87(95 \% \mathrm{Cl} 0.67$ to 1.14$)$ & $0.81(90 \% \mathrm{Cl} 0.31$ to 2.05$)$ \\
\hline Hydrofibre vs alginate & $1.18(95 \% \mathrm{Cl} 0.66$ to 2.10$)$ & $1.09(95 \% \mathrm{Cl} 0.57$ to 2.10$)$ & $1.08(90 \% \mathrm{Cl} 0.51$ to 2.29$)$ \\
\hline Paste bandage vs alginate & $1.22(95 \% \mathrm{Cl} 0.91$ to 1.63$)$ & $2.41(95 \% \mathrm{Cl} 1.28$ to 4.53$)$ & $0.51(90 \% \mathrm{Cl} 0.28$ to 0.91$)$ \\
\hline PMM vs alginate & $1.08(95 \% \mathrm{Cl} 0.76$ to 1.53$)$ & $1.07(95 \% \mathrm{Cl} 0.57$ to 1.98$)$ & $1.01(90 \% \mathrm{Cl} 0.55$ to 1.85$)$ \\
\hline Hydrocolloid vs foam & $0.92(95 \% \mathrm{Cl} 0.76$ to 1.12$)$ & $0.90(95 \% \mathrm{Cl} 0.64$ to 1.28$)$ & $1.02(90 \% \mathrm{Cl} 0.73$ to 1.42$)$ \\
\hline Paste bandage vs foam & $2.30(95 \% \mathrm{Cl} 1.29$ to 4.09$)$ & $1.17(95 \% \mathrm{Cl} 0.79$ to 1.72$)$ & $1.97(90 \% \mathrm{Cl} 1.10$ to 3.55$)$ \\
\hline PMM vs foam & $0.87(95 \% \mathrm{Cl} 0.30$ to 2.51$)$ & $1.19(95 \% \mathrm{Cl} 0.81$ to 1.74$)$ & $0.73(90 \% \mathrm{Cl} 0.28$ to 1.90$)$ \\
\hline PMM silver vs foam & $1.57(95 \% \mathrm{Cl} 0.83$ to 2.96$)$ & $0.96(95 \% \mathrm{Cl} 0.59$ to 1.57$)$ & $1.64(90 \% \mathrm{Cl} 0.83$ to 3.21$)$ \\
\hline Silver vs foam & $1.65(95 \% \mathrm{Cl} 1.08$ to 2.51$)$ & $4.12(95 \% \mathrm{Cl} 2.06$ to 8.22$)$ & $0.40(90 \% \mathrm{Cl} 0.20$ to 0.79$)$ \\
\hline PMM silver vs hydrocolloid & $1.07(95 \% \mathrm{Cl} 0.68$ to 1.7$)$ & $1.75(95 \% \mathrm{Cl} 0.91$ to 3.37$)$ & $0.61(90 \% \mathrm{Cl} 0.31$ to 1.2$)$ \\
\hline Silver vs hydrocolloid & $4.39(95 \% \mathrm{Cl} 2.23$ to 8.62$)$ & $1.76(95 \% \mathrm{Cl} 1.12$ to 2.75$)$ & $2.50(90 \% \mathrm{Cl} 1.26$ to 4.95$)$ \\
\hline $\begin{array}{l}\text { Emollient cream vs blood } \\
\text { product }\end{array}$ & $0.76(95 \% \mathrm{Cl} 0.54$ to 1.09$)$ & 2.78 (95\% Cl 0.53 to 14.62$)$ & $0.28(90 \% \mathrm{Cl} 0.07$ to 1.15$)$ \\
\hline $\begin{array}{l}\text { Hydrocolloid vs blood prod- } \\
\text { uct }\end{array}$ & $1.17(95 \% \mathrm{Cl} 0.09$ to 14.81$)$ & $2.39(95 \% \mathrm{Cl} 0.91$ to 6.32$)$ & $0.49(90 \% \mathrm{Cl} 0.05$ to 4.84$)$ \\
\hline Hydrofibre vs blood product & $0.33(95 \% \mathrm{Cl} 0.01$ to 7.82$)$ & $3.65(95 \% \mathrm{Cl} 1.31$ to 10.19$)$ & $0.09(90 \% \mathrm{Cl} 0.01$ to 1.5$)$ \\
\hline Hydrogel vs blood product & $2.13(95 \% \mathrm{Cl} 0.63$ to 7.25$)$ & $1.33(95 \% \mathrm{Cl} 0.33$ to 5.42$)$ & $1.6(90 \% \mathrm{Cl} 0.33$ to 7.69$)$ \\
\hline $\begin{array}{l}\text { Saline gauze vs blood prod- } \\
\text { uct }\end{array}$ & $0.93(95 \% \mathrm{Cl} 0.71$ to 1.21$)$ & $0.34(95 \% \mathrm{Cl} 0.1$ to 1.18$)$ & $2.71(90 \% \mathrm{Cl} 0.93$ to 7.85$)$ \\
\hline
\end{tabular}


Table 9. Node splitting (Continued)

\begin{tabular}{llll}
$\begin{array}{l}\text { Hyaluronic acid vs emol- } \\
\text { lient cream }\end{array}$ & $0.76(95 \% \mathrm{Cl} 0.18$ to 3.24$)$ & $2.78(95 \% \mathrm{Cl} 1.13$ to 6.8$)$ & $0.28(90 \% \mathrm{Cl} 0.07$ to 1.15$)$ \\
\hline $\begin{array}{l}\text { Hydrocolloid vs growth fac- } \\
\text { tor }\end{array}$ & $0.55(95 \% \mathrm{Cl} 0.06$ to 4.6$)$ & $1.11(95 \% \mathrm{Cl} 0.84$ to 1.46$)$ & $0.49(90 \% \mathrm{Cl} 0.08$ to 3.01$)$ \\
\hline $\begin{array}{l}\text { Hydrogel vs growth factor } \\
\text { Hyaluronic acid vs saline }\end{array}$ & $2.32(95 \% \mathrm{Cl} 1.06$ to 5.07$)$ & $0.64(95 \% \mathrm{Cl} 0.14$ to 2.89$)$ & $3.63(90 \% \mathrm{Cl} 0.87$ to 15.21$)$ \\
\hline $\begin{array}{l}\text { gauze } \\
\text { Hydrocolloid vs saline }\end{array}$ & $3.5(95 \% \mathrm{Cl} 0.87$ to 14.06$)$ & $1.91(95 \% \mathrm{Cl} 0.57$ to 6.39$)$ & $1.84(90 \% \mathrm{Cl} 0.39$ to 8.7$)$ \\
\hline
\end{tabular}

Abbreviations:Cl: confidence interval; PMM: protease modulating matrix; RoRR: ratio of relative risks; RR: relative risk

\section{AP P E N DICES}

\section{Appendix 1. Glossary of network meta-analysis (NMA) terms}

Arm-specific outcomes/arm-level data: raw outcome data (e.g. mean (SD) or risk) for each arm of the trial (see also treatment contrast).

Assumptions for NMA: in common with all meta-analysis, the true treatment effect across trials is assumed to be described by a fixedeffect or random-effects model. Additionally, transitivity is assumed and, concurrently, exchangeability and consistency.

Baseline risk: the absolute risk of the outcome in the 'control' group. This is affected by the presence of prognostic factors. Some authors have used the baseline risk as a proxy effect modifier, but in general the effect estimate (RR/OR/HR) is independent of the baseline risk; on the other hand, the absolute risk difference depends on baseline risk.

Bayesian approach: the explicit quantitative use of external evidence in the design, monitoring, analysis, interpretation of a healthcare evaluation. In the Bayesian paradigm, prior beliefs about parameters in the models are specified and factored into the estimation. Posterior distributions of model parameters are then derived from the prior information and the observed data. In NMA, it is common to use non-informative priors for effect estimates.

Coherence/consistency: the direct effect estimate (e.g. mean difference or log odds ratio) is the same as the sum of the indirect effect estimates.

Connected network: a group of linked interventions, such that every trial in the network has at least one intervention in common with at least one other trial. Sometimes individual comparisons are not connected to the rest of the network (disconnected network) and can sometimes be joined in by extending the network to include supplementary interventions.

Contour-enhanced funnel plot: contour-enhanced funnel plots show areas of statistical significance, and they can help in distinguishing publication bias from other possible reasons for asymmetry. In a network of interventions, each study estimates the relative effect of different interventions, so asymmetry in the funnel plot cannot be judged. To account for this, an adaptation of the funnel plot can be used, in which the standard error is plotted against an adjusted effect size for each study: the adjusted effect size for a comparison is the studyspecific effect size minus the mean for the meta-analysis for that comparison.

Contrast/study-level data: outcome data for the comparison (e.g. mean difference, odds ratio).

Decision space/decision set: the interventions in the decision set are the focal treatments of interest to systematic review authors.

Deviance Information Criterion (DIC): the DIC is a measure of the balance between model fit (the posterior mean deviance) and model complexity (the leverage) and calculated as the sum of these two; the smaller the DIC, the better the model. DIC is often used to compare models, for example, comparing fixed-effect and random-effects models. If there is an important difference in DIC between models, there is evidence of heterogeneity.

Direct evidence/direct comparison: head-to-head comparison of two treatments, for example, A versus B (see also indirect evidence).

Edge: line representing a direct comparison on a network diagram. 
Effect modifier: effect modification occurs when the effect of A versus B (as the RR/OR/HR for binary outcomes) is significantly different in two or more subgroups, and this leads to heterogeneity, either within trials or between trials, or both. Factors that give rise to subgroup effects are called effect modifiers, and it is important to identify potential effect modifiers and allow for them in the analysis. The identification of significant effect modifiers may lead to stratification (separate analyses for each subgroup) or to a decision not to combine data from different trials in a meta-analysis. In general, trials have different distributions of effect modifiers (e.g. proportion of people with and without diabetes), leading to inconsistency between trials in the treatment effect. This is often magnified when there is a network of different comparisons.

Exchangeability: it is assumed that treatments in a NMA are exchangeable, so, if treatment $B$ had been given to patients in the indirect $A$ versus $C$ trials and if $A$ had been given in the $B$ versus $C$ indirect trials, then the true $A B$ differences in these indirect studies would be identical to the true $A B$ difference in direct $A$ versus $B$ trials, or at least from the same common distribution. Furthermore, if patients in other trials within the wider linked network (e.g. D versus $E$ trials) were given $A$ and $B$, the $A B$ differences would also be the same or from the same distribution. This assumption breaks down when there are effect modifiers.

Fixed-effect: the true treatment effect is assumed to be constant across trials (fixed-effect) - see also random-effects and transitivity.

Global inconsistency: inconsistency across a network is described as global inconsistency. It can be evaluated statistically by fitting models that allow and do not allow for inconsistency. A 'leave-one comparison-out' approach, often called 'node splitting,' can also be applied, with each direct comparison being excluded from the network and then estimating the difference between this direct evidence and the indirect evidence from the network.

Heterogeneity in a NMA: patients are not randomised to different trials. Therefore, there may be systematic differences in study characteristics or the distribution of patient characteristics across trials. If these characteristics influence the treatment effects (i.e. are effect modifiers), then there are systematic differences in treatment effects across trials, which is called between-trial heterogeneity. There may also be within-trial heterogeneity if there are subgroups of an effect modifier for which results are reported separately. In a NMA, the term, 'heterogeneity' applies to variation in effect modifiers within a single comparison (e.g. A versus B); the term, 'inconsistency' refers to the imbalance in effect modifiers between comparisons.

Heterogeneity variance parameter $\left(\tau^{2}\right)$ : in a random-effects model we assume there is heterogeneity for each pairwise comparison (e.g. $A$ versus $B$ ) with variance $\left(\tau^{2} A B\right)$, but in a NMA we often assume that there is a common heterogeneity amongst all the comparisons in the network; this common heterogeneity has a variance $\left(\tau^{2}\right)$, which is called the 'heterogeneity variance parameter'. It can be compared with empirical distributions of heterogeneity values typically found in meta-analyses (Salanti 2014; Turner 2012).

Inconsistency/incoherence: this occurs when the effect estimate derived from an indirect comparison is not the same as the effect estimate derived from a direct comparison. For example, in a network of three interventions, there is inconsistency if $d_{A B}($ direct) $\neq$ $d_{A B}$ (indirect), where $d_{A B}$ (indirect) $=d_{A C}$ (direct) - $d_{B C}$ (direct); the effect estimates are given as mean differences or log (odds ratios/risk ratios/hazard ratios). Note that in order to investigate inconsistency there must be both indirect and direct evidence (loops in the network). See also global inconsistency.

Inconsistency factor: this is the absolute difference between the direct and indirect estimates on the log scale (or the logarithm of the ratio of the two odds/hazard ratios) for one of the comparisons in a loop. A statistically low-powered z-test and a $95 \% \mathrm{Cl}$ of the inconsistency is computed to determine whether this difference is significant.

Indirect evidence/indirect comparison: comparison of two treatments, for example, A versus B, obtained from combinations of other comparisons (e.g. trials comparing $A$ versus $C$ and trials comparing B with C) (see also direct evidence).

Indirect comparison meta-analysis: meta-analysis of a set of treatments that are linked via common comparator(s), but none are compared directly; evidence is combined in a single internally consistent model.

Leverage: this is the effective number of parameters of the model, which is calculated differently for fixed-effect and random-effects models, with the latter having greater complexity.

Likelihood (function): the likelihood function is a tool for inferring the underlying distribution of the observed data. To do this, we propose a model to represent the data - often a parametric distribution is assumed (e.g. binomial) - and unknown parameters of that distribution are determined, given the data, by maximising the likelihood (the larger the likelihood, the closer the model fit).

Loop (of evidence): combination of direct and indirect evidence, such that the interventions in the network diagram can be linked to form a closed loop.

Meta-analysis: a statistical synthesis of the results from two or more separate studies. Methods involve calculating a weighted average of effect estimates from the separate studies.

Mixed treatment comparison meta-analysis: another name for network meta-analysis. 
Model: a statistical model is a (simplified) mathematical representation of the system we wish to learn about, and which generates our observed data. The model will usually depend on some known factors, such as other variables measured alongside the data, and some unknown parameters that we wish to determine. Then having determined the unknown parameters, the model should be able to simulate data that are an approximation of the real data, allowing us to make inferences from the data.

Multi-arm trial: individual trial that compares more than two interventions. It is important to take into account correlations within these trials in the analysis.

Network: trials must be linked in a network of interventions, such that every trial in the network has at least one intervention in common with at least one other trial.

Network diagram: graphical representation of the interventions in the network. It consists of nodes representing the interventions and edges representing the comparisons. The amount of available information can be presented by 'weighting' the nodes and edges using different node sizes and line thicknesses according to the number of studies reporting that treatment or comparison respectively. Other types of weighting are discussed in Chaimani 2013.

Network meta-analysis (NMA): NMA is the simultaneous combination of data from randomised comparisons of multiple competing treatments (A versus B, A versus C, A versus D, B versus D, and so on), to deliver an internally consistent set of estimates while respecting the randomisation in the evidence. The use of indirect estimates can provide information on comparisons for which no trials exist. It can also improve the precision of the direct estimate by reducing the width of the Cls compared with the direct evidence alone.

Node: intervention represented on a network diagram, usually by a circle of weighted size.

Pairwise meta-analysis: meta-analysis of one or more trials of direct comparisons (e.g. A versus B) - see direct evidence.

Prognostic factors: population or study characteristics that affect the risk of the outcome. In a sufficiently large randomised trial that is free from bias, prognostic factors are distributed evenly between intervention groups and do not affect the effect estimate (RR/OR/HR for binary outcomes) unless they are effect modifiers, but they do affect the baseline risk and absolute risk difference.

Random-effects: trial-specific treatment differences are assumed to be from a common distribution - see also fixed-effect and transitivity.

Ranking: ordering of treatments according to their relative effectiveness.

Sparse data: data with wide confidence intervals because of few events as a consequence of small studies or short follow-up periods.

\section{Study-level data: see contrast.}

SUCRA: Surface Under the Cumulative RAnking. This is a measure of the probability that the given treatment is the best. Thus, a SUCRA would be 1 (or 100\%) when a treatment was certain to be the best and $0(0 \%)$ when a treatment was certain to be the worst.

Supplementary set (of interventions): interventions added to the network to provide additional evidence on relative treatment effects of the decision set. This may be to connect an otherwise unconnected network of treatments, to increase the precision of the treatment effect estimates or to help address between-trial heterogeneity.

Transitivity: NMA requires a transitivity assumption, such that there is no imbalance in the distribution of effect modifiers across the different types of treatment comparisons (see also exchangeability).

'Unadjusted' meta-analysis: meta-analysis of all the treatment arms for a particular treatment (e.g. all A arms). This breaks the randomisation and should not be done.

References include: Caldwell 2005; Caldwell 2014; Chaimani 2013; Cipriani 2013; Dias 2013; Dias 2014; Grant 2013; Jansen 2013; Lu 2004; Salanti 2008; Salanti 2011; Salanti 2014; Soares 2014; Spiegelhalter 2003; Thorlund 2012; Tu 2012; WinBUGS 2016.

\section{Appendix 2. Search strategies}

\section{Cochrane Specialised Wounds Register}

1 MESH DESCRIPTOR Bandages EXPLODE ALL AND INREGISTER

2 MESH DESCRIPTOR Alginates EXPLODE ALL AND INREGISTER

3 MESH DESCRIPTOR Hydrogels EXPLODE ALL AND INREGISTER

4 MESH DESCRIPTOR Honey EXPLODE ALL AND INREGISTER

5 MESH DESCRIPTOR Silver EXPLODE ALL AND INREGISTER

6 MESH DESCRIPTOR Silver Sulfadiazine EXPLODE ALL AND INREGISTER

7 MESH DESCRIPTOR Charcoal EXPLODE ALL AND INREGISTER

8 MESH DESCRIPTOR Silicones EXPLODE ALL AND INREGISTER 
9 MESH DESCRIPTOR Colloids EXPLODE ALL AND INREGISTER

10 MESH DESCRIPTOR Polyurethanes EXPLODE ALL AND INREGISTER

11 dressing* or pad or pads or gauze or tulle or film or bead or foam* or non-adherent or "non adherent" or hydrocolloid* or "sodium hyaluronate" or alginat ${ }^{\star}$ or hydrogel ${ }^{\star}$ or silver ${ }^{\star}$ or honey ${ }^{\star}$ or matrix or iodine* or "protease modulat " or "capillary action" or charcoal or silicon* or polymer* or polyurethane* or hydrocellular or hydropolymer* or carboxymethylcellulose or carboxymethyl-cellulose or gelatin ${ }^{\star}$ or NaCMC or "gel forming" or gel-forming AND INREGISTER

12 ((odour or odor) near3 absorb*) AND INREGISTER

13 primapore or curasorb or seasorb or sorbsan or advadraw or vacutex or tegaderm or opsite or allevyn or biatain or medihoney or activon tulle or granuflex or "nu derm" or aquacel or iodoflex or iodozyme or xeroform or carboflex or cutimed or sorbact or promogran or acticoat or "urgosorb silver" or mepitel or urgotul or activheal or alione or askina or comfeel or duoderm or flexigran or hydrocoll or nu-derm or "ultec pro" or mepilex or versiva or urgoclean or cutinova or tegasorb or dermafilm or replicare or signadress or algoplaque or varihesive or advasorb or copa or lyofoam or permafoam or polymem or suprasorb or transorbent or trufoam or urgocell or kendall or kerraboot or cavi-care AND INREGISTER

14 \#1 OR \#2 OR \#3 OR \#4 OR \#5 OR \#6 OR \#7 OR \#8 OR \#9 OR \#10 OR \#11 OR \#12 OR \#13 AND INREGISTER

15 MESH DESCRIPTOR Metronidazole EXPLODE ALL AND INREGISTER

16 metronidazole AND INREGISTER

17 MESH DESCRIPTOR Administration, Topical EXPLODE ALL AND INREGISTER

18 MESH DESCRIPTOR Anti-Bacterial Agents EXPLODE ALL AND INREGISTER

19 \#17 AND \#18 AND INREGISTER

20 (topical near2 (antibiotic* or antimicrobial* or antibacterial $\left.{ }^{\star}\right)$ ) AND INREGISTER

21 MESH DESCRIPTOR lodophors EXPLODE ALL AND INREGISTER

22 \#17 AND 21 AND INREGISTER

23 ((topical near2 iodin*) or "cadexomer iodine") AND INREGISTER

24 MESH DESCRIPTOR Collagenases EXPLODE ALL AND INREGISTER

25 \#24 AND \#17 AND INREGISTER

26 (topical near2 collagen*) AND INREGISTER

27 MESH DESCRIPTOR Phenytoin EXPLODE ALL AND INREGISTER

28 \#27 AND \#17 AND INREGISTER

29 (topical near2 phenytoin) AND INREGISTER

30 MESH DESCRIPTOR Zinc Oxide EXPLODE ALL AND INREGISTER

31 \#30 AND \#17 AND INREGISTER

32 (topical near2 zinc) AND INREGISTER

33 (iodosorb or actiformcool or aquaflo or flamazine or silvadene) AND INREGISTER

34 MESH DESCRIPTOR Ointments EXPLODE ALL AND INREGISTER

35 (ointment ${ }^{\star}$ or lotion* or cream* or powder* or gel or gels) AND INREGISTER

36 (topical near (agent ${ }^{\star}$ or preparation ${ }^{\star}$ or therap* ${ }^{\star}$ or treatment $\left.{ }^{\star}\right)$ ) AND INREGISTER

$37 \# 15$ or \#16 or \#19 or \#20 or \#22 or \#23 or \#25 or \#26 or \#28 or \#29 or \#31 or \#32 or \#33 or \#34 or \#35 or \#36 AND INREGISTER

38 \#14 or \#37 AND INREGISTER

39 MESH DESCRIPTOR Leg ulcer EXPLODE ALL AND INREGISTER

40 ((varicose next ulcer ${ }^{\star}$ ) or (venous next ulcer ${ }^{\star}$ ) or (leg next ulcer ${ }^{\star}$ ) or (stasis next ulcer ${ }^{\star}$ ) or (crural next ulcer ${ }^{\star}$ ) or (ulcus next cruris) or (ulcer next cruris)) AND INREGISTER

$41 \# 39$ OR \#40

42 \#38 AND \#41

\section{The Cochrane Central Register of Controlled Clinical Trials (CENTRAL)}

\#1 MeSH descriptor: [Bandages] explode all trees \#2 MeSH descriptor: [Alginates] explode all trees \#3 MeSH descriptor: [Hydrogels] explode all trees \#4 MeSH descriptor: [Honey] explode all trees \#5 MeSH descriptor: [Silver] explode all trees \#6 MeSH descriptor: [Silver Sulfadiazine] explode all trees \#7 MeSH descriptor: [Charcoal] explode all trees \#8 MeSH descriptor: [Silicones] explode all trees \#9 MeSH descriptor: [Colloids] explode all trees \#10 MeSH descriptor: [Polyurethanes] explode all trees

\#11 (dressing* or pad or pads or gauze or tulle or film or bead or foam* or non-adherent or "non adherent" or hydrocolloid* or "sodium hyaluronate" or alginat* or hydrogel* or silver* or honey* or matrix or iodine* or "protease modulat " or "capillary action" or charcoal or silicon* or polymer or polyurethane* or hydrocellular or hydropolymer* or carboxymethylcellulose or carboxymethyl-cellulose or gelatin ${ }^{\star}$ or NaCMC or "gel forming" or gel-forming):ti,ab,kw \#12 ((odour or odor) near/3 absorb*):ti,ab,kw 
\#13 (primapore or curasorb or seasorb or sorbsan or advadraw or vacutex or tegaderm or opsite or allevyn or biatain or medihoney or activon tulle or granuflex or "nu derm" or aquacel or iodoflex or iodozyme or xeroform or carboflex or cutimed or sorbact or promogran or acticoat or "urgosorb silver" or mepitel or urgotul or activheal or alione or askina or comfeel or duoderm or flexigran or hydrocoll or nu-derm or "ultec pro" or mepilex or versiva or urgoclean or cutinova or tegasorb or dermafilm or replicare or signadress or algoplaque or varihesive or advasorb or copa or lyofoam or permafoam or polymem or suprasorb or transorbent or trufoam or urgocell or kendall or kerraboot or cavi-care):ti,ab,kw

\#14 \{or\#1-\#13\}

\#15 MeSH descriptor: [Metronidazole] explode all trees

\#16 metronidazole:ti,ab,kw

\#17 MeSH descriptor: [Anti-Bacterial Agents] explode all trees

\#18 MeSH descriptor: [Administration, Topical] explode all trees

$\# 19$ and \#17-\#18\}

\#20 (topical near/2 (antibiotic ${ }^{*}$ or antimicrobial ${ }^{*}$ or antibacterial ${ }^{\star}$ )):ti,ab,kw

$\# 21 \mathrm{MeSH}$ descriptor: [lodophors] explode all trees

\#22 \{and \#18, \#21\}

\#23 ((topical near/2 iodin*) or ("cadexomer iodine")):ti,ab,kw

\#24 MeSH descriptor: [Collagenases] explode all trees

$\# 25$ and \#18, \#24\}

\#26 (topical near/2 collagen ${ }^{\star}$ ):ti,ab,kw

$\# 27 \mathrm{MeSH}$ descriptor: [Phenytoin] explode all trees

\#28 \{and \#18, \#27\}

\#29 (topical near/2 phenytoin):ti,ab,kw

\#30 MeSH descriptor: [Zinc Oxide] explode all trees

$\# 31$ and \#18, \#30\}

\#32 (topical near/2 zinc):ti,ab,kw

\#33 (iodosorb or actiformcool or aquaflo or flamazine or silvadene):ti,ab,kw

\#34 MeSH descriptor: [Ointments] explode all trees

\#35 (ointment* or lotion* or cream* or powder* or gel or gels):ti,ab,kw

\#36 (topical next (agent ${ }^{\star}$ or preparation* or therap* or treatment $\left.{ }^{\star}\right)$ ):ti,ab,kw

\#37 \{or \#15-\#16, \#19-\#20,\#22-\#23, \#25-\#26, \#28-\#29, \#31-\#36\}

\#38 \{or \#14, \#37\}

\#39 MeSH descriptor: [Leg Ulcer] this term only

\#40 MeSH descriptor: [Varicose Ulcer] explode all trees

\#41 (varicose next ulcer* or venous next ulcer* or leg next ulcer* or stasis next ulcer ${ }^{\star}$ or crural next ulcer ${ }^{\star}$ or ulcus next cruris or ulcer next cruris):ti,ab,kw

\#42 \{or \#39-\#41\}

\#43 \{and \#38, \#42\}

\section{Ovid MEDLINE}

1 exp Bandages/

2 exp Alginates/

3 exp Hydrogels/

4 exp Honey/

5 exp Silver/

6 exp Silver Sulfadiazine/

7 exp Charcoal/

8 exp Silicones/

9 exp Colloids/

10 Polyurethanes/

11 (dressing $^{\star}$ or pad or pads or gauze or tulle or film or bead or foam* or non-adherent or "non adherent" or hydrocolloid* or "sodium hyaluronate" or alginat ${ }^{\star}$ or hydrogel ${ }^{\star}$ or silver ${ }^{\star}$ or honey ${ }^{\star}$ or matrix or iodine* or "protease modulat " or "capillary action" or charcoal or silicon* or polymer* or polyurethane* or hydrocellular or hydropolymer* or carboxymethylcellulose or carboxymethyl-cellulose or gelatin ${ }^{\star}$ or NaCMC or "gel forming" or gel-forming).tw.

12 ((odour or odor) adj3 absorb*).tw.

13 (primapore or curasorb or seasorb or sorbsan or advadraw or vacutex or tegaderm or opsite or allevyn or biatain or medihoney or activon tulle or granuflex or "nu derm" or aquacel or iodoflex or iodozyme or xeroform or carboflex or cutimed or sorbact or promogran or acticoat or "urgosorb silver" or mepitel or urgotul or activheal or alione or askina or comfeel or duoderm or flexigran or hydrocoll or nu-derm or "ultec pro" or mepilex or versiva or urgoclean or cutinova or tegasorb or dermafilm or replicare or signadress or algoplaque or varihesive or advasorb or copa or lyofoam or permafoam or polymem or suprasorb or transorbent or trufoam or urgocell or kendall or kerraboot or cavi-care).tw.

14 or $/ 1-13$ 
15 exp Metronidazole/

16 metronidazole.tw.

17 exp Administration, Topical/

18 exp Anti-Bacterial Agents/

19 and/17-18

20 (topical adj2 (antibiotic ${ }^{\star}$ or antimicrobial ${ }^{\star}$ or antibacterial $\left.{ }^{\star}\right)$ ).tw.

21 exp lodophors/

22 and $/ 17,21$

23 ((topical adj2 iodin ${ }^{\star}$ ) or "cadexomer iodine").tw.

24 exp Collagenases/

25 and $/ 17,24$

26 (topical adj2 collagen ${ }^{\star}$ ).tw.

27 exp Phenytoin/

28 and $/ 17,27$

29 (topical adj2 phenytoin).tw.

30 exp Zinc Oxide/

31 and $/ 17,30$

32 (topical adj2 zinc).tw.

33 (iodosorb or actiformcool or aquaflo or flamazine or silvadene).tw.

34 exp Ointments/

35 (ointment ${ }^{\star}$ or lotion* or cream* $^{\star}$ or powder* or gel or gels).tw.

36 (topical adj (agent ${ }^{\star}$ or preparation ${ }^{\star}$ or therap ${ }^{\star}$ or treatment $\left.{ }^{\star}\right)$ ).tw.

37 or/15-16,19-20,22-23,25-26,28-29,31-36

38 or $/ 14,37$

39 Leg Ulcer/

40 exp Varicose Ulcer/

41 (varicose ulcer ${ }^{\star}$ or venous ulcer ${ }^{\star}$ or leg ulcer ${ }^{\star}$ or stasis ulcer ${ }^{\star}$ or crural ulcer $^{\star}$ or ulcus cruris or ulcer cruris).tw.

42 or/39-41

43 and $/ 38,42$

44 randomized controlled trial.pt.

45 controlled clinical trial.pt.

46 randomi?ed.ab.

47 placebo.ab.

48 clinical trials as topic.sh.

49 randomly.ab.

50 trial.ti.

51 or/44-50

52 exp animals/ not humans.sh.

5351 not 52

5443 and 53

\section{Ovid Embase}

1 exp "bandages and dressings"/

2 exp honey/

3 exp hydrogel/

4 exp Calcium Alginate/

5 silver/

6 charcoal/

7 silicone derivative/

8 exp colloid/

9 polyurethan/

10 (dressing* or pad or pads or gauze or tulle or film or bead or foam* or non-adherent or "non adherent" or hydrocolloid* or "sodium hyaluronate" or alginat* or hydrogel ${ }^{\star}$ or silver* or honey* or matrix or iodine* or "protease modulat*" or "capillary action" or charcoal or silicon $^{\star}$ or polymer ${ }^{\star}$ or polyurethane* or hydrocellular or hydropolymer* or carboxymethylcellulose or carboxymethyl-cellulose or gelatin* or NaCMC or "gel forming" or gel-forming).ti,ab.

11 ((odour or odor) adj3 absorb*).ti,ab.

12 (primapore or curasorb or seasorb or sorbsan or advadraw or vacutex or tegaderm or opsite or allevyn or biatain or medihoney or activon tulle or granuflex or "nu derm" or aquacel or iodoflex or iodozyme or xeroform or carboflex or cutimed or sorbact or promogran or acticoat or "urgosorb silver" or mepitel or urgotul or activheal or alione or askina or comfeel or duoderm or flexigran or hydrocoll or nu-derm or "ultec pro" or mepilex or versiva or urgoclean or cutinova or tegasorb or dermafilm or replicare or signadress or algoplaque 
or varihesive or advasorb or copa or lyofoam or permafoam or polymem or suprasorb or transorbent or trufoam or urgocell or kendall or kerraboot or cavi-care).ti,ab.

13 or/1-12

14 exp metronidazole/

15 metronidazole.ti,ab.

16 topical drug administration/

17 exp Antibiotic Agent/

18 and $/ 16-17$

19 (topical adj2 (antibiotic ${ }^{\star}$ or antimicrobial ${ }^{\star}$ or antibacterial ${ }^{\star}$ )).ti,ab.

20 exp cadexomer iodine/

21 and $/ 16,20$

22 "cadexomer iodine".ti,ab.

23 exp silver/ or exp sulfadiazine silver/

24 and $/ 16,23$

25 exp collagenase/

26 and/16,25

27 (topical adj2 collagen*).ti,ab.

28 phenytoin/

29 and $/ 16,28$

30 (topical adj2 phenytoin).ti,ab.

31 exp zinc oxide/

32 and $/ 16,31$

33 (topical adj2 zinc).ti,ab.

34 (iodosorb or actiformcool or aquaflo or flamazine or silvadene).ti,ab.

35 exp ointment/

36 (ointment ${ }^{\star}$ or lotion* or cream ${ }^{\star}$ or powder ${ }^{\star}$ or gel or gels).ti,ab.

37 (topical adj (agent ${ }^{\star}$ or preparation ${ }^{\star}$ or therap ${ }^{\star}$ or treatment $\left.{ }^{\star}\right)$ ).ti,ab.

38 or/14-15,18-19,21-22,24,26-27,29-30,32-37

39 or $/ 13,38$

40 exp leg ulcer/

41 (varicose ulcer ${ }^{\star}$ or venous ulcer ${ }^{\star}$ or leg ulcer* ${ }^{\star}$ or stasis ulcer ${ }^{\star}$ or crural ulcer ${ }^{\star}$ or ulcus cruris or ulcer cruris).ti,ab.

42 or $/ 40-41$

43 and $/ 39,42$

44 Randomized controlled trials/

45 Single-Blind Method/

46 Double-Blind Method/

47 Crossover Procedure/

48 (random $^{\star}$ or factorial ${ }^{\star}$ or crossover ${ }^{\star}$ or cross over $^{\star}$ or cross-over $^{\star}$ or placebo* or assign $^{\star}$ or allocat ${ }^{\star}$ or volunteer $\left.{ }^{\star}\right)$.ti,ab.

49 (doubl* adj blind $\left.^{\star}\right)$.ti,ab.

50 (singl $^{\star}$ adj blind $\left.{ }^{\star}\right)$.ti,ab.

51 or $/ 44-50$

52 exp animals/ or exp invertebrate/ or animal experiment/ or animal model/ or animal tissue/ or animal cell/ or nonhuman/

53 human/ or human cell/

54 and $/ 52-53$

5552 not 54

5651 not 55

5743 and 56

\section{EBSCO CINAHL Plus}

S55 S41 AND S54

S54 S42 OR S43 OR S44 OR S45 OR S46 OR S47 OR S48 OR S49 OR S50 OR S51 OR S52 OR S53

$\mathrm{S} 53 \mathrm{TI}$ allocat* random* or AB allocat* random*

S52 MH "Quantitative Studies"

S51 TI placebo* or AB placebo*

S50 MH "Placebos"

S49 $\mathrm{TI}_{\text {random }}$ allocat $^{\star}$ or AB random* allocat*

S48 MH "Random Assignment"

S47 TI randomi?ed control* trial $^{*}$ or $A B$ randomi?ed control* trial $^{*}$

S46 AB ( singl ${ }^{\star}$ or doubl ${ }^{\star}$ or trebl* or tripl ${ }^{\star}$ ) and AB ( blind ${ }^{\star}$ or mask ${ }^{\star}$ )

S45 TI ( singl ${ }^{*}$ or doubl* or trebl* or tripl ${ }^{*}$ ) and $\mathrm{TI}$ ( blind* or mask ${ }^{*}$ )

S44 TI clinic $^{\star} N 1$ trial $^{\star}$ or AB clinic ${ }^{\star} N 1$ trial $^{\star}$ 
S43 PT Clinical trial

S42 MH "Clinical Trials+"

S41 S37 AND S40

S40 S38 OR S39

S39 TI (varicose ulcer* or venous ulcer* or leg ulcer ${ }^{\star}$ or stasis ulcer ${ }^{\star}$ or crural ulcer ${ }^{\star}$ or ulcus cruris or ulcer cruris) OR AB (varicose ulcer* or venous ulcer ${ }^{\star}$ or leg ulcer ${ }^{\star}$ or stasis ulcer ${ }^{\star}$ or crural ulcer* or ulcus cruris or ulcer cruris)

S38 (MH "Leg Ulcer") OR (MH "Venous Ulcer")

S37 S13 OR S36

S36 S14 OR S15 OR S18 OR S19 OR S21 OR S22 OR S24 OR S25 OR S27 OR S28 OR S30 OR S31 OR S32 OR S33 OR S34 OR S35

S35 TI (topical N3 agent* or topical N3 preparation* or topical N3 therap* and topical N3 treatment*) OR AB (topical N3 agent* or topical N3 preparation* or topical N3 therap* and topical N3 treatment ${ }^{\star}$ )

S34 TI (ointment ${ }^{\star}$ or lotion ${ }^{\star}$ or cream ${ }^{\star}$ or powder ${ }^{\star}$ or gel or gels) OR AB (ointment* or lotion ${ }^{\star}$ or cream or powder $^{\star}$ or gel or gels)

S33 (MH "Ointments")

S32 TI (iodosorb or actiformcool or aquaflo or flamazine or silvadene) OR AB (iodosorb or actiformcool or aquaflo or flamazine or silvadene)

S31 TI (topical N2 zinc) OR AB (topical N2 zinc)

S30 S16 AND S29

S29 (MH "Zinc Oxide")

$\mathrm{S} 28 \mathrm{TI}$ (topical N2 phenytoin) OR AB (topical N2 phenytoin)

S27 S16 AND S26

S26 (MH "Phenytoin+")

S25 TI (topical N2 collagen*) OR AB (topical N2 collagen*)

S24 S16 AND S23

S23 (MH "Collagen")

S22 TI "cadexomer iodine" OR AB "cadexomer iodine"

S21 S16 AND S20

S20 (MH "lodophors+")

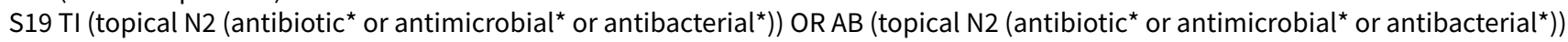

S18 S16 AND S17

S17 (MH "Antiinfective Agents+")

S16 (MH "Administration, Topical+")

S15 TI metronidazole OR AB metronidazole

S14 (MH "Metronidazole")

S13 S1 OR S2 OR S3 OR S4 OR S5 OR S6 OR S7 OR S8 OR S9 OR S10 OR S11 OR S12

S12 AB (primapore or curasorb or seasorb or sorbsan or advadraw or vacutex or tegaderm or opsite or allevyn or biatain or medihoney or activon tulle or granuflex or "nu derm" or aquacel or iodoflex or iodozyme or xeroform or carboflex or cutimed sorbact or promogran or acticoat or "urgosorb silver" or mepitel or urgotul or activheal or alione or askina or comfeel or duoderm or flexigran or hydrocoll or nuderm or "ultec pro" or mepilex or versiva or urgoclean or cutinova or tegasorb or dermafilm or or replicare or signadress or algoplaque or varihesive or advasorb or copa or lyofoam or permafoam or polymem or suprasorb or transorbent or trufoam or urgocell or kendall or kerraboot or cavi-care)

S11 TI (primapore or curasorb or seasorb or sorbsan or advadraw or vacutex or tegaderm or opsite or allevyn or biatain or medihoney or activon tulle or granuflex or "nu derm" or aquacel or iodoflex or iodozyme or xeroform or carboflex or cutimed sorbact or promogran or acticoat or "urgosorb silver" or mepitel or urgotul or activheal or alione or askina or comfeel or duoderm or flexigran or hydrocoll or nu-derm or "ultec pro" or mepilex or versiva or urgoclean or cutinova or tegasorb or dermafilm or replicare or signadress or algoplaque or varihesive or advasorb or copa or lyofoam or permafoam or polymem or suprasorb or transorbent or trufoam or urgocell or kendall or kerraboot or cavi-care)

S10 TI odor N3 absorb* or AB odor N3 absorb*

S9 TI odour N3 absorb* or AB odour N3 absorb*

S8 AB (dressing* or pad or pads or gauze or tulle or film or bead or foam* or non-adherent or "non adherent" or hydrocolloid* or "sodium hyaluronate" or alginat* or hydrogel or silver $^{\star}$ or honey ${ }^{\star}$ or matrix or iodine* or "protease modulat " or "capillary action" or charcoal or silicon $^{\star}$ or polymer ${ }^{\star}$ or polyurethane* or hydrocellular or hydropolymer* or carboxymethylcellulose or carboxymethyl-cellulose or gelatin* or NaCMC or "gel forming" or gel-forming)

S7 TI (dressing* or pad or pads or gauze or tulle or film or bead or foam* or non-adherent or "non adherent" or hydrocolloid* or "sodium hyaluronate" or alginat* or hydrogel* or silver* or honey* or matrix or iodine* or "protease modulat*" or "capillary action" or charcoal or silicon $^{\star}$ or polymer ${ }^{\star}$ or polyurethane ${ }^{\star}$ or hydrocellular or hydropolymer* or carboxymethylcellulose or carboxymethyl-cellulose or gelatin* or NaCMC or "gel forming" or gel-forming) S6 (MH "Silver") or (MH "Silver Sulfadiazine") or (MH "Colloids+") or (MH "Polyurethanes")

S5 (MH "Honey")

S4 (MH "Charcoal")

S3 (MH "Silicones")

S2 (MH "Alginates")

S1 (MH "Bandages and Dressings+") 


\section{Appendix 3. Assessing risk of bias}

\section{Was the allocation sequence randomly generated? (Part of 'Selection bias')}

\section{Low risk of bias}

The investigators describe a random component in the sequence generation process such as: referring to a random number table; using a computer random number generator; coin tossing; shuffling cards or envelopes; throwing dice; drawing of lots.

\section{High risk of bias}

The investigators describe a non-random component in the sequence generation process. Usually, the description would involve some systematic, non-random approach, for example: sequence generated by odd or even date of birth; sequence generated by some rule based on date (or day) of admission; sequence generated by some rule based on hospital or clinic record number.

\section{Unclear}

Insufficient information about the sequence generation process provided to permit a judgement of low or high risk of bias.

\section{Was the treatment allocation adequately concealed? (Part of 'Selection bias')}

\section{Low risk of bias}

Participants and investigators enrolling participants could not foresee assignment because one of the following, or an equivalent method, was used to conceal allocation: central allocation (including telephone, web-based and pharmacy-controlled randomisation); sequentially-numbered drug containers of identical appearance; sequentially-numbered, opaque, sealed envelopes.

\section{High risk of bias}

Participants or investigators enrolling participants could possibly foresee assignments and thus introduce selection bias, such as allocation based on: use of an open random allocation schedule (e.g. a list of random numbers); assignment envelopes without appropriate safeguards (e.g. envelopes were unsealed, non-opaque, or not sequentially numbered); alternation or rotation; date of birth; case record number; any other explicitly unconcealed procedure.

\section{Unclear}

Insufficient information provided to permit a judgement of low or high risk of bias. This is usually the case if the method of concealment is not described, or not described in sufficient detail to allow a definite judgement, for example if the use of assignment envelopes is described, but it remains unclear whether envelopes were sequentially numbered, opaque and sealed.

\section{Blinding - was knowledge of the allocated interventions adequately prevented during the study? (Performance bias for blinding of participants and caregivers; detection bias for outcome assessors)}

\section{Low risk of bias}

Any one of the following.

- No blinding, but the review authors judge that the outcome and the outcome measurement are not likely to be influenced by lack of blinding.

- Blinding of participants and key study personnel ensured, and unlikely that the blinding could have been broken.

- Either participants or some key study personnel were not blinded, but outcome assessment was blinded and the non-blinding of others unlikely to introduce bias.

\section{High risk of bias}

Any one of the following.

- No blinding or incomplete blinding, and the outcome or outcome measurement is likely to be influenced by lack of blinding.

- Blinding of key study participants and personnel attempted, but likely that the blinding could have been broken.

- Either participants or some key study personnel were not blinded, and the non-blinding of others likely to introduce bias.

\section{Unclear}

Either of the following.

- Insufficient information to permit judgement of low or high risk of bias.

- The study did not address this outcome. 


\section{Were incomplete outcome data adequately addressed? (Attrition bias)}

\section{Low risk of bias}

Any one of the following.

- No missing outcome data.

- Reasons for missing outcome data are unlikely to be related to true outcome (for survival data, censoring unlikely to be introducing bias).

- Missing outcome data are balanced in numbers across intervention groups, with similar reasons for missing data across groups.

- For dichotomous outcome data, the proportion of missing outcomes compared with the observed event risk is not enough to have a clinically relevant impact on the intervention effect estimate.

- For continuous outcome data, a plausible effect size (difference in means or standardised difference in means) among missing outcomes is not enough to have a clinically relevant impact on the observed effect size.

- Missing data have been imputed using appropriate methods.

\section{High risk of bias}

Any one of the following.

- Reason for missing outcome data are likely to be related to the true outcome, with either an imbalance in numbers or reasons for missing data across intervention groups.

- For dichotomous outcome data, the proportion of missing outcomes compared with the observed event risk is enough to induce clinically relevant bias in the intervention effect estimate.

- For continuous outcome data, a plausible effect size (difference in means or standardised difference in means) among missing outcomes is enough to induce a clinically relevant bias in the observed effect size.

- 'As-treated' analysis done with a substantial departure of the intervention received from that assigned at randomisation.

- Potentially inappropriate application of simple imputation.

\section{Unclear}

Either of the following.

- Insufficient reporting of attrition/exclusions to permit a judgement of low or high risk of bias (e.g. number randomised not stated, no reasons for missing data provided).

- The study did not address this outcome.

\section{Are reports of the study free of suggestion of selective outcome reporting?}

\section{Low risk of bias}

Either of the following.

- The study protocol is available and all of the study's prespecified (primary and secondary) outcomes that are of interest in the review have been reported in the prespecified way.

- The study protocol is not available but it is clear that the published reports include all expected outcomes, including those that were prespecified (convincing text of this nature may be uncommon).

\section{High risk of bias}

Any one of the following.

- Not all of the study's prespecified primary outcomes have been reported.

- One or more primary outcomes is/are reported using measurements, analysis methods, or subsets of the data (e.g. subscales) that were not prespecified.

- One or more reported primary outcomes was/were not prespecified (unless clear justification for their reporting is provided, such as an unexpected adverse effect).

- One or more outcomes of interest in the review is/are reported incompletely so that they cannot be entered in a meta-analysis.

- The study report fails to include results for a key outcome that would be expected to have been reported for such a study.

\section{Unclear}

Insufficient information provided to permit a judgement of low or high risk of bias. It is likely that the majority of studies will fall into this category. 


\section{Other sources of potential bias (Outcome reporting bias)}

\section{Low risk of bias}

The study appears to be free of other sources of bias.

\section{High risk of bias}

There is at least one important risk of bias. For example, the study:

- had a potential source of bias related to the specific study design used; or

- has been claimed to have been fraudulent; or

- had some other problem.

\section{Unclear}

There may be a risk of bias, but there is either:

- insufficient information to assess whether an important risk of bias exists; or

- insufficient rationale or evidence that an identified problem will introduce bias.

\section{Appendix 4. Summary of comparisons not included in the network}

\section{Comparisons for which there is only direct evidence}

\section{Standard care versus honey}

One trial compared honey with a range of other dressing types. Jull 2008 randomised 368 people to honey or standard care which included a number of different options. The risk ratio (RR) for complete healing was 1.12 (95\% confidence interval ( $\mathrm{Cl}) 0.92$ to 1.36$)$. This was very low-certainty evidence, downgraded twice for risk of bias and once for imprecision.

\section{Standard care versus cadexomer iodine}

Three trials compared cadexomer iodine with groups treated with a variety of other treatments. Harcup 1986; Lindsay 1986 and Steele 1986 randomised a total of 157 people to either cadexomer iodine or a range of other treatments which could be classed as standard treatment. The pooled random-effects RR for healing was $5.16\left(95 \% \mathrm{Cl} 1.56,17.10 ; \mathrm{I}^{2}=0 \%\right)$. This is low-quality evidence, downgraded twice for imprecision due to wide confidence intervals and low numbers of participants.

\section{Phenytoin versus no treatment}

One study Hokkam 2011 randomised 104 participants to phenytoin or no treatment (in addition to compression). The RR for complete healing was 1.25 (95\% Cl 0.90 to 1.74). There may be little or no difference between groups; this was low-certainty evidence, downgraded twice for low numbers of participants and events and wide confidence intervals which include the possibility of harm as well as benefit or no effect.

\section{Hydrocolloid versus either nonadherent or iodine}

One study randomised participants to either a hydrocolloid or a nonadherent or povidone iodine-based dressing. Arnold 1994 randomised 70 people. The RR was 0.79 (95\% Cl 0.42 to 1.48). This was very low-certainty evidence, downgraded twice for risks of bias and twice for imprecision.

\section{Sulphadryl versus inactive powder}

One study randomised participants to one of two sulphadryl powders or to a third inactive powder group. Salim 1992 randomised 168 participants. The RR was $1.31(95 \% \mathrm{Cl} 1.10$ to 1.56). This was low-certainty evidence downgraded once for imprecision and once for attrition bias.

\section{Silica gel fibre versus either mepitel or mepilex}

One trial randomised participants to either silica gel fibre dressing or to treatment with either nonadherent or foam dressings. Brown 2014 randomised 121 people. The RR was 0.63 (95\% $\mathrm{Cl} 0.31$ to 1.26). This is low- (or very low-) quality evidence, downgraded for lack of blinding (detection bias and maybe also performance bias) and imprecision.

\section{Comparisons which were considered to be partly relevant clinically and were not included in the network}

\section{Cellulose versus nonadherent}

One trial randomised 48 participants to either a cellulose dressing or a nonadherent dressing (Alvarez 2012). The RR was 0.92 (95\% Cl 0.38 to 2.22). This is very low-certainty evidence, downgraded once for risk of bias and twice for imprecision. 


\section{Shale oil versus hydrogel}

One trial randomised 119 participants to either shale oil or a hydrogel without the shale oil (Beckert 2006) The RR was 1.49 (95\% Cl 0.82 to 2.68). This is low-certainty evidence, downgraded twice for imprecision.

\section{Hydrocolloid versus collagen}

One trial randomised 96 participants to either a hydrocolloid dressing or a lyophilised collagen dressing (Caprio 1992).The RR was 0.77 $(95 \% \mathrm{Cl} 0.50$ to 1.18$)$. This is low-certainty evidence, downgraded twice for imprecision.

\section{Papain versus hydrogel}

Two trials randomised a total of 70 participants to either papain or hydrogel (De Araujo 2016; Luiza 2015). De Araujo was a three-arm trial with a total of 63 participants which also randomised 21 participants to an ineligible intervention, a blood product; the comparison between this and hydrogel was included in the expanded base-case sensitivity analysis. The RR for the comparison of papain with hydrogel was $0.94\left(95 \% \mathrm{Cl} 0.25,3.49 ; \mathrm{I}^{2}=16 \%\right)$. This is very low-certainty evidence, downgraded once for inconsistency and twice for imprecision.

\section{Hydrocolloid versus magnesium sulphate}

One trial randomised 110 participants to either hydrocolloid dressing or magnesium sulphate paste (Greguric 1994) The RR was 7.00 (95\% $\mathrm{Cl} 0.37$ to 132.40). This is very low-certainty evidence, downgraded once for risk of bias and twice for imprecision.

\section{Hydrocolloid versus dextranomer}

One trial randomised 108 participants to either hydrocolloid dressing or dextranomer treatment (Kalis 1993). The RR was 0.77 (95\% Cl 0.37 to 1.60). This was very low-certainty evidence, downgraded twice for risk of bias and twice for imprecision.

\section{Silver versus non silver}

One trial randomised 208 participants to either a silver-based or a non-silver-based dressing (Michaels 2009). The RR was 1.05 (0.94 to 1.16). This was low-certainty evidence, downgraded once for risk of bias and once for imprecision

\section{Cadexomer iodine versus dextranomer}

Two trials randomised participants to either cadexomer iodine or dextranomer treatments (Moss 1987; Tarvainen 1988).The RR was 1.33 $\left(95 \% \mathrm{Cl} 0.64\right.$ to $\left.2.75 ; \mathrm{I}^{2}=0 \%\right)$. This was very low-certainty evidence, downgraded twice for risk of bias and twice for imprecision.

\section{Ozonated oil versus emollient cream}

One trial randomised 29 participants to either ozonated oil or an emollient cream without the ozonated oil (Solovastru 2015). The RR was 10.31 (95\% $\mathrm{Cl} 0.62$ to 170.96$)$. This was low-certainty evidence, downgraded twice for imprecision.

\section{A. Pichinchensis versus alginate}

One trial randomised 34 participants to treatment with either A. Pichinchensis extract or an alginate topical treatment (Romero-Cerecero 2012). The RR was 1.67 (95\% Cl 1.03 to 2.70). This was low-certainty evidence, downgraded once for risk of bias and once for imprecision.

\section{Comparisons with tripeptide copper}

One three-armed study randomised participants to tripeptide copper, silver sulfadiazine (SSD) or an emollient cream without either active ingredient. The comparison between SSD and emollient cream is included in the expanded base-case network; the other two comparisons are summarised here.

\section{Tripeptide copper versus SSD}

Bishop 1992 randomised a total of 86 participants, of whom 57 were relevant to this comparison. The RR was 0.07 (95\% Cl 0.00 to 1.26$)$. This was low-certainty evidence, downgraded twice for imprecision.

\section{Tripeptide copper versus emollient cream}

Bishop 1992 randomised a total of 86 participants, of whom 58 were relevant to this comparison. The RR was 0.33 (0.01 to 7.86$)$. This was low-certainty evidence downgraded twice for imprecision.

\section{Appendix 5. Base-case and sensitivity analyses}

We conducted a network meta-analysis (NMA) for the base-case and then carried out sensitivity analyses; one examined risk of bias and the others investigated a restricted network and an extended network. For each network, we examined the results in two ways: as risk ratios (RR) with their $95 \% \mathrm{Cls}$ for each intervention compared with every other intervention in the network (NMA effect estimates); and for the network as a whole, giving the rank order for the interventions in the network and the probability that a particular intervention is the best, second best, etc treatment. 


\subsection{Base-case network}

The base-case NMA included 22 treatments (12 dressings: foam, hydrocolloid, hydrofibre, alginate, ibuprofen-releasing foam, nonadherent, paste bandage, protease-modulating (PMM), PMM-silver, silver-containing, film, saline gauze; and 10 topical agents: hydrogel, cadexomer iodine, gentian violet, hyaluronic acid, hyaluronic-acid with povidone iodine, octenidine, povidone iodine, SSD, sucralfate and zinc oxide) and generated results for 231 mixed treatment contrasts (i.e. all possible pairwise combinations of the interventions). There were 31 direct contrasts of which 24 were informed by only one study and the average number of events per mixed treatment contrast was around six (1479/231). Data were sparse and there was uncertainty around the estimates. The network diagram is shown in Figure 7.

Figure 7. Network diagram for the base-case, coded by risk of bias (3 categories) Key: green = low/unclear; yellow = high; red = very high overall risk of bias for the contrast. The number of studies for each contrast is given in Table 3

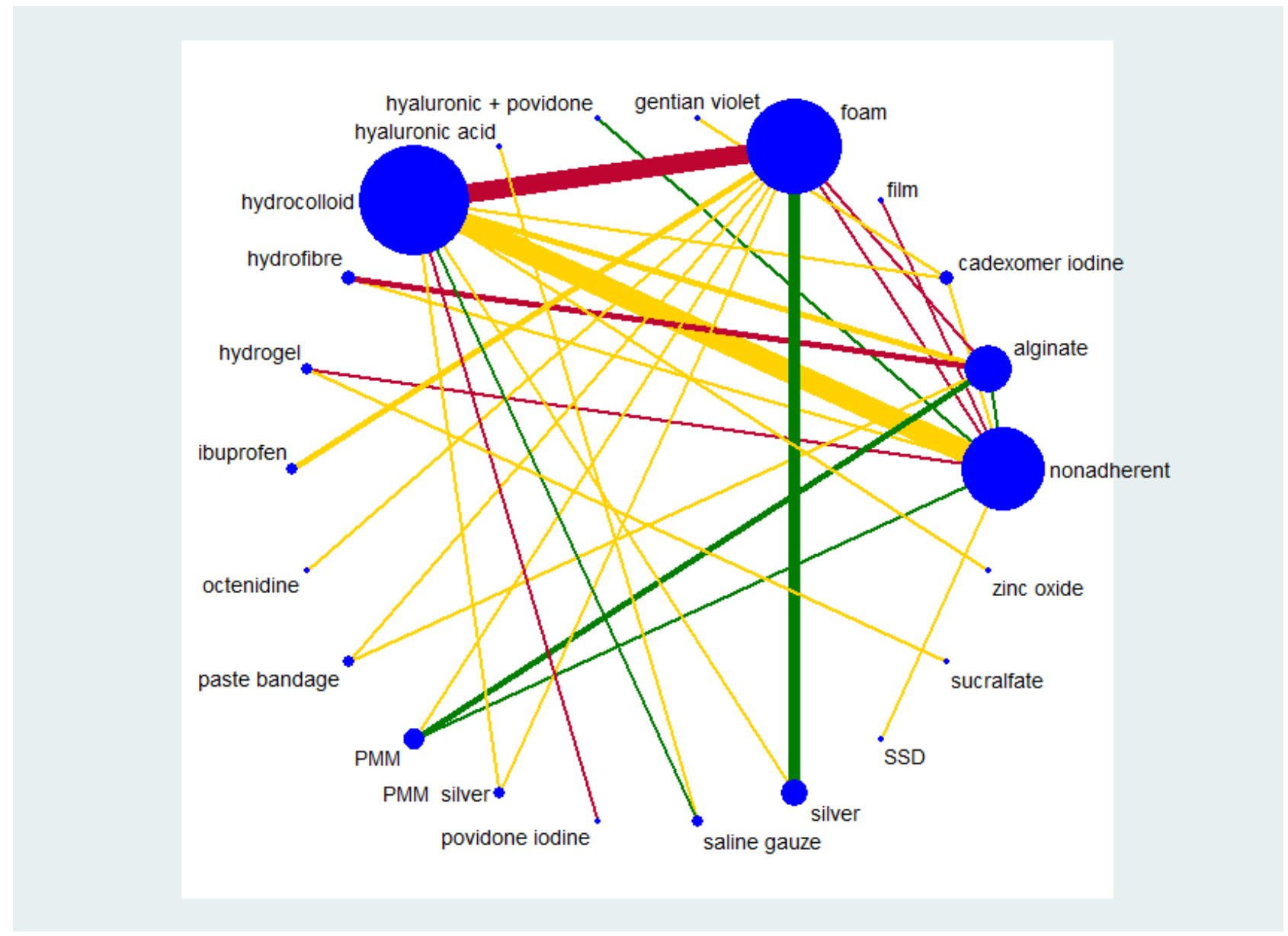

We summarised results for the base-case NMA as a whole using rankograms: data for each intervention are shown as the probability that each intervention is the best, second best, third best treatment, etc. These probabilities are based on uncertainty, reflecting the effectiveness from the network contrasts and the precision around the estimates. The closer the probability of a rank to $100 \%$ (or $0 \%$ ) and the narrower the distribution across different ranks, the greater the confidence in the ranking (see Figure 8 and Table 6). There was some overlap of the individual rankograms, illustrated in Figure 9, which shows both the confusion, together with some indication that sucralfate, hydrogel and silver dressings may be the best treatments and that the worst treatments may be saline gauze and hyaluronic acid. Across all treatments there was some uncertainty in the middle ranking of treatments, although the mean rank of one treatment (sucralfate) was close to 1 and the worst treatment was 21 (out of 22). Surface under the cumulative ranking curve (SUCRA) values were generally between 0.2 and 0.8 , but two treatments had a SUCRA value of 1 or 0 (sucralfate - 1 , and saline gauze - 0 ), with another treatment having values of 0.9 or 0.1 (silver 0.9 ). 
Figure 8. Rankograms for the base-case network showing the probability that each intervention is the best, second best, third best treatment, etc.

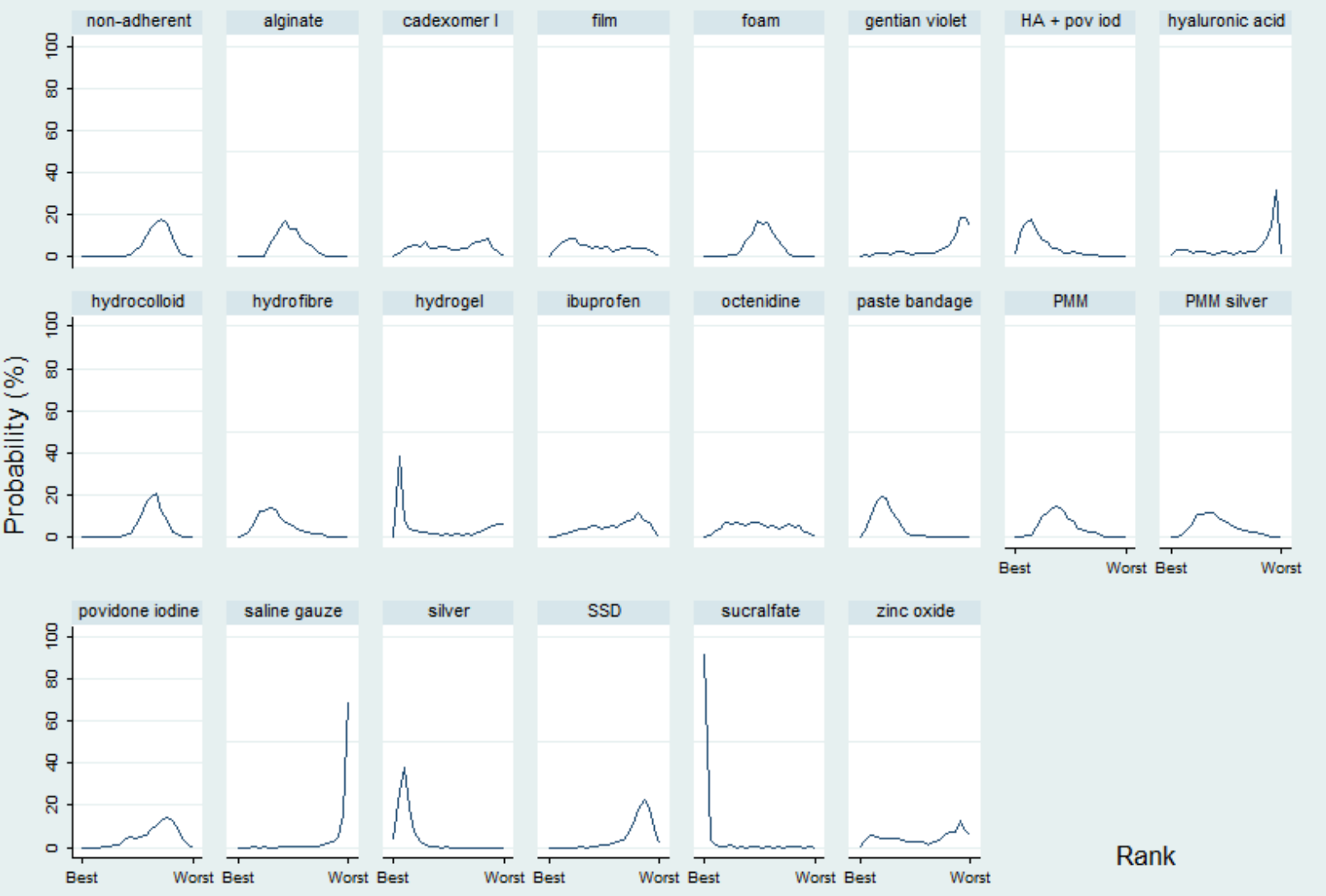


Figure 9. Rankograms for all treatments in base-case network showing the probability that each intervention is the best, second best, third best treatment, etc.

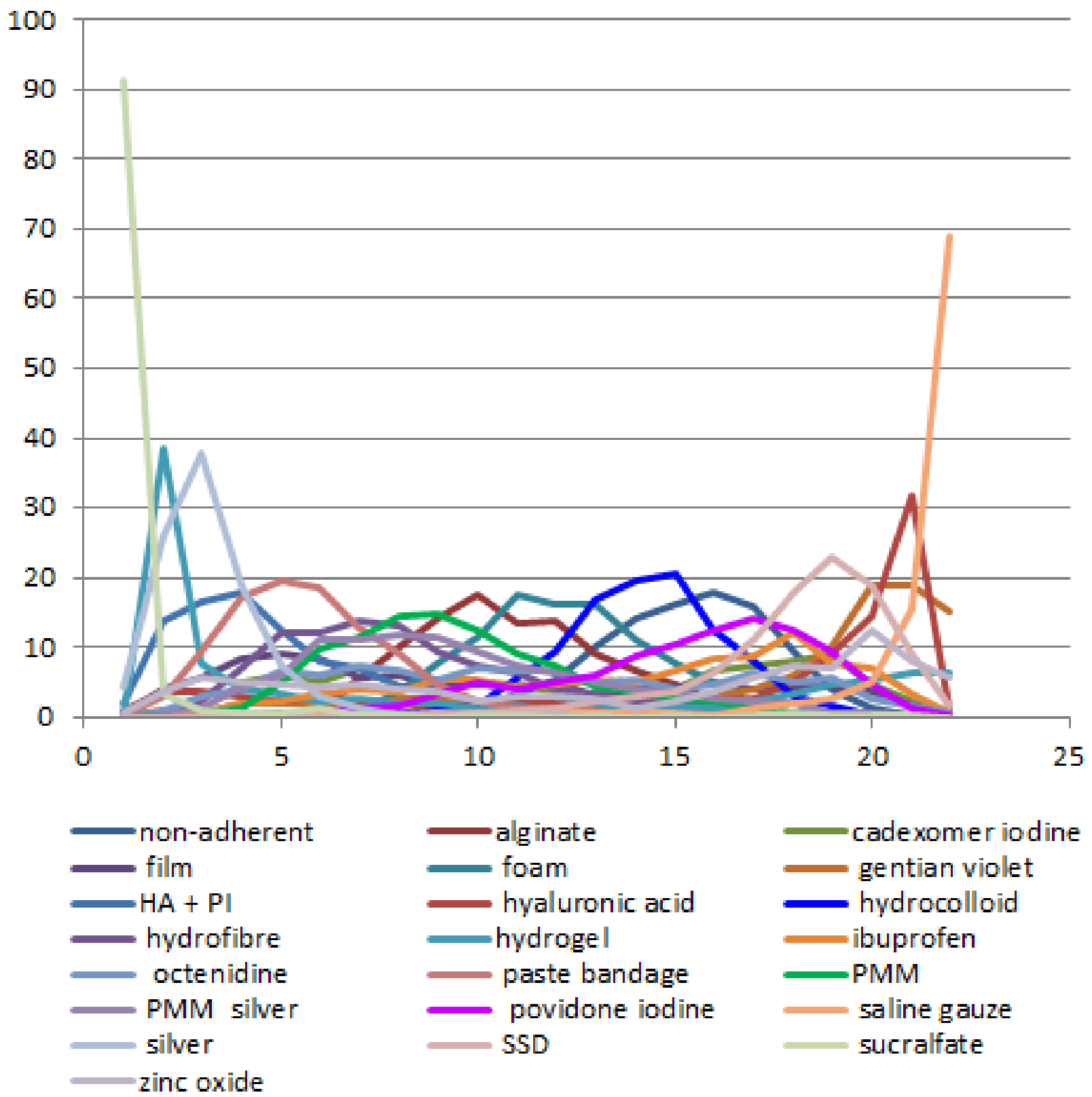

Numerically, sucralfate had by far the highest probability of being the best treatment (91\%), and saline gauze was most likely to be the worst treatment (69\%). However, the sucralfate ranking is likely to be artificially high: sucralfate is connected to the core of the network via hydrogel and the direct evidence for sucralfate versus hydrogel involves one study with 43 (of 50) healing events for sucralfate and five healing events for hydrogel. The comparison linking sucralfate to the core of the network (hydrogel versus nonadherent) has two and one events respectively in a very small study (24 participants). The NMA results for all comparisons with sucralfate have very wide Cls and large point estimates. Consequently, sucralfate (versus other interventions) has a finite probability of having a very large effect estimate (at the upper confidence limit), in turn leading to an artificially high probability of being the best treatment.

Examination of the results for each of the individual contrasts in the base-case NMA revealed that the majority of Cls were wide or very wide, often crossing at least one default minimally important difference (MID); i.e. the value of 0.75 or 1.25 was included in the $\mathrm{Cl}$ (see Sensitivity analysis, GRADE assessment). Results for a representative set of contrasts are given in Table 5, showing the three mostly highly-ranked treatments in the base-case network (sucralfate, hydrogel and silver dressings) and three commonly used treatments (foam, hydrocolloid and non-adherent dressings). Several of the contrasts with sucralfate and silver had the whole of the $\mathrm{Cl}$ above the default MID (i.e the whole 
confidence interval lay above 1.25). In the case of sucralfate, the relevant direct evidence also had small numbers of events in at least one arm, and was based on data from one direct study ('fragility').

We examined inconsistency in the base-case network as a whole, comparing consistency and inconsistency analyses. There was no significant inconsistency ( $\mathrm{P}=0.566$ ) (Appendix 7). There may be inconsistency at a local level for one loop (foam-hydrocolloid-silver) and for four contrasts: paste bandage versus alginate; paste bandage versus foam; silver versus hydrocolloid and silver versus foam (Appendix 7 ).

\subsection{Pre-specified sensitivity analyses}

We conducted the planned sensitivity analysis according to risk of bias, restricting the network to those studies at low or unclear risk of bias. Only 15 studies with eight interventions (nonadherent, alginate, foam, hyaluronic acid plus povidone iodine, hydrocolloid, PMM, saline gauze and silver dressings) remained, but they were joined in a network.

For most contrasts, the point estimates showed a smaller effect and the Cls were wider (data not shown). The exceptions to this were comparisons with nonadherent dressing, for which the point estimates were larger. Mean ranks were in the order (highest first): silver (mean rank 2.3), hyaluronic acid plus povidone iodine (2.7), PMM (4.0), hydrocolloid (4.2), foam (4.3), alginate (4.6), nonadherent (6.4), saline gauze (7.5). Rankograms were broad with the exception of saline gauze. The sensitivity analysis reinforced the findings of the basecase network, but with less precision, although effect estimates appeared smaller.

We did not conduct the second pre-specified sensitivity analysis (assuming an available case analysis rather than imputing no event for missing values) because more than two thirds (32/47) of studies were not judged to be at high risk of attrition bias, and few of those that were had differential missing data.

We then carried out two post-hoc sensitivity analyses, described below.

\subsection{Sensitivity analysis: narrow dataset}

The narrow dataset included 41 studies (of 47 in the base-case) in 3435 participants with 1331 events. This encompassed 17 different interventions (11 dressings: foam, hydrocolloid, hydrofibre, alginate, non-adherent, paste bandage, protease-modulating (PMM), PMMsilver, silver-containing, film, saline gauze; and six topical agents: hydrogel, cadexomer iodine, hyaluronic acid, povidone iodine, SSD, and zinc oxide) in 26 direct contrasts and these informed 136 mixed treatment contrasts; only six contrasts were informed by more than one study. There were 12 triangular loops.

Rankograms for the narrow dataset sensitivity analysis are shown in Figure 10 and the mean rank and SUCRA value, probability at the maximum and rank at the peak in Table 6 . There was slightly more of a distinction between interventions, but still overlap of rankograms and only saline gauze had a SUCRA value of 0 or 1 . Even in the absence of sucralfate, the mean rank order was the same as that for the base-case. 
Figure 10. Rankograms for the narrow sensitivity analysis showing the probability that each intervention is the best, second best, third best treatment, etc.

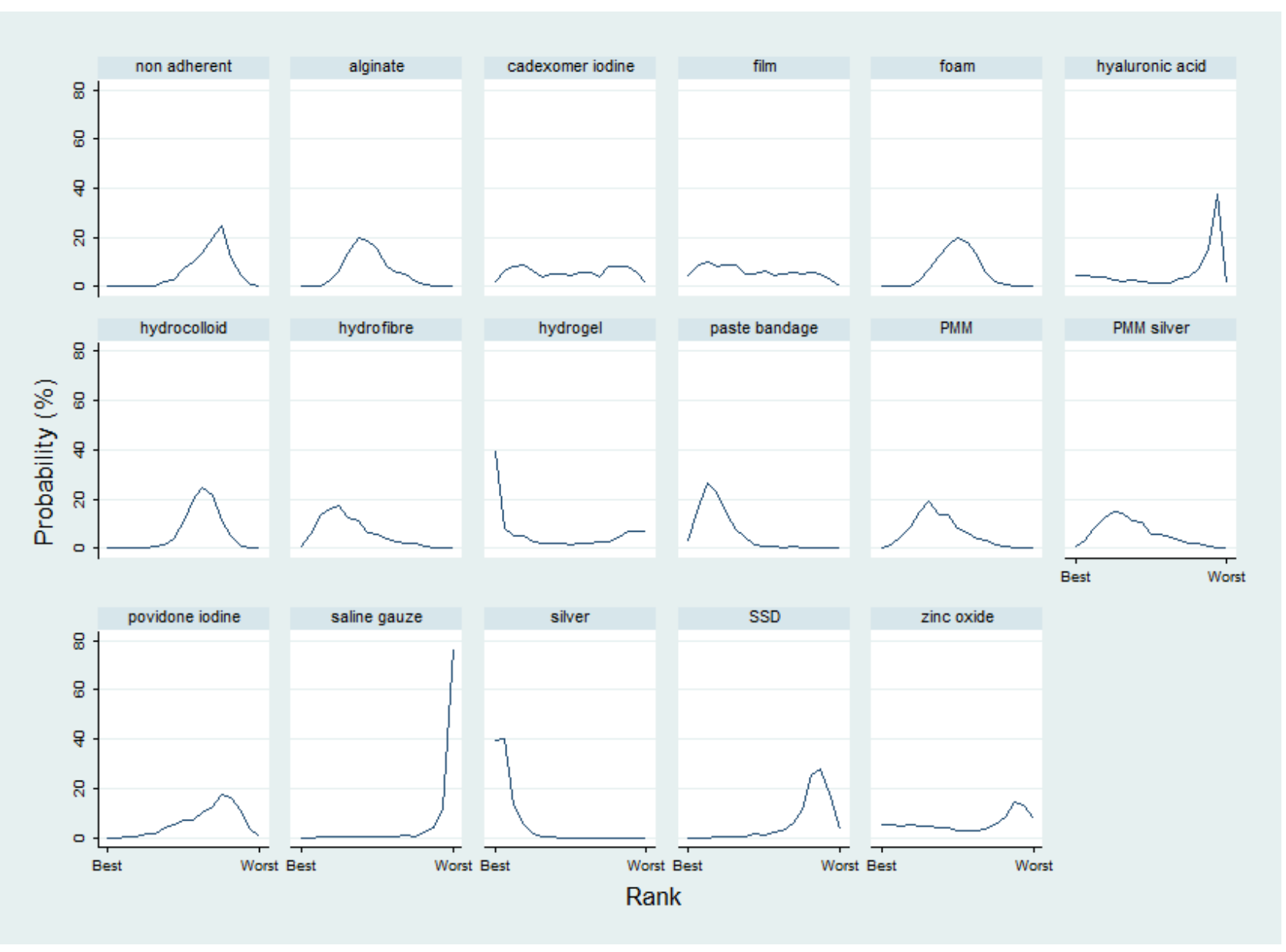

The results for the same set of individual contrasts as the base-case are given in Table 5. These are very similar to those for the base-case.

In the narrow network as a whole, there was no significant inconsistency (P-value 0.273, c.f. base-case 0.566). At the local level, the same four contrasts suggested inconsistency as in the basecase, with identical RoRRs. Again the foam-hydrocolloid-silver loop had inconsistency, with the same RoRR as the base-case (Appendix 7). There was little asymmetry in the funnel plot.

\subsection{Sensitivity analysis - extended base-case}

The extended base-case dataset included three additional treatments to give more links via ineligible and partly relevant interventions (blood product, emollient cream and growth factor), in order to convert 'hanging' treatments to 'core' treatments (especially hydrogel and saline gauze), thus reinforcing the network. The network diagram for the extended base-case, including 'Risk of bias' judgements is shown in Figure 3. There were 59 studies (c.f. 47 in the base-case) in 5156 participants with 1925 events. This encompassed 25 different interventions in 40 direct contrasts and these informed 300 mixed treatment contrasts; only eight contrasts were informed by more than one study. There were 15 triangular loops and six quadratic loops.

Results for individual mixed treatment contrasts in the extended base-case are shown in Figure 11; Figure 12; Figure 13; Figure 14; Figure 15; Figure 16; Figure 17; Figure 18; Figure 19; Figure 20; Figure 21. The results for the same set of contrasts as the base-case are given in Table 5 and some differences were found. In particular, all contrasts with sucralfate (except sucralfate versus hydrogel, which was unchanged) showed considerably smaller point estimates in the extended base-case and much narrower confidence intervals. Secondly, contrasts with hydrogel had point estimates favouring the comparator, rather than hydrogel as found for the base-case; the exception to this was the contrast hydrogel versus silver, which had a point estimate more in favour of silver in the extended base-case. Cls for contrasts with hydrogel were much smaller for the extended base-case. The other contrasts in Table 5 had very similar results for the extended base-case as the base-case. 
Figure 11. Comparisons of alginate with other treatments in the extended base-case network with risk of bias

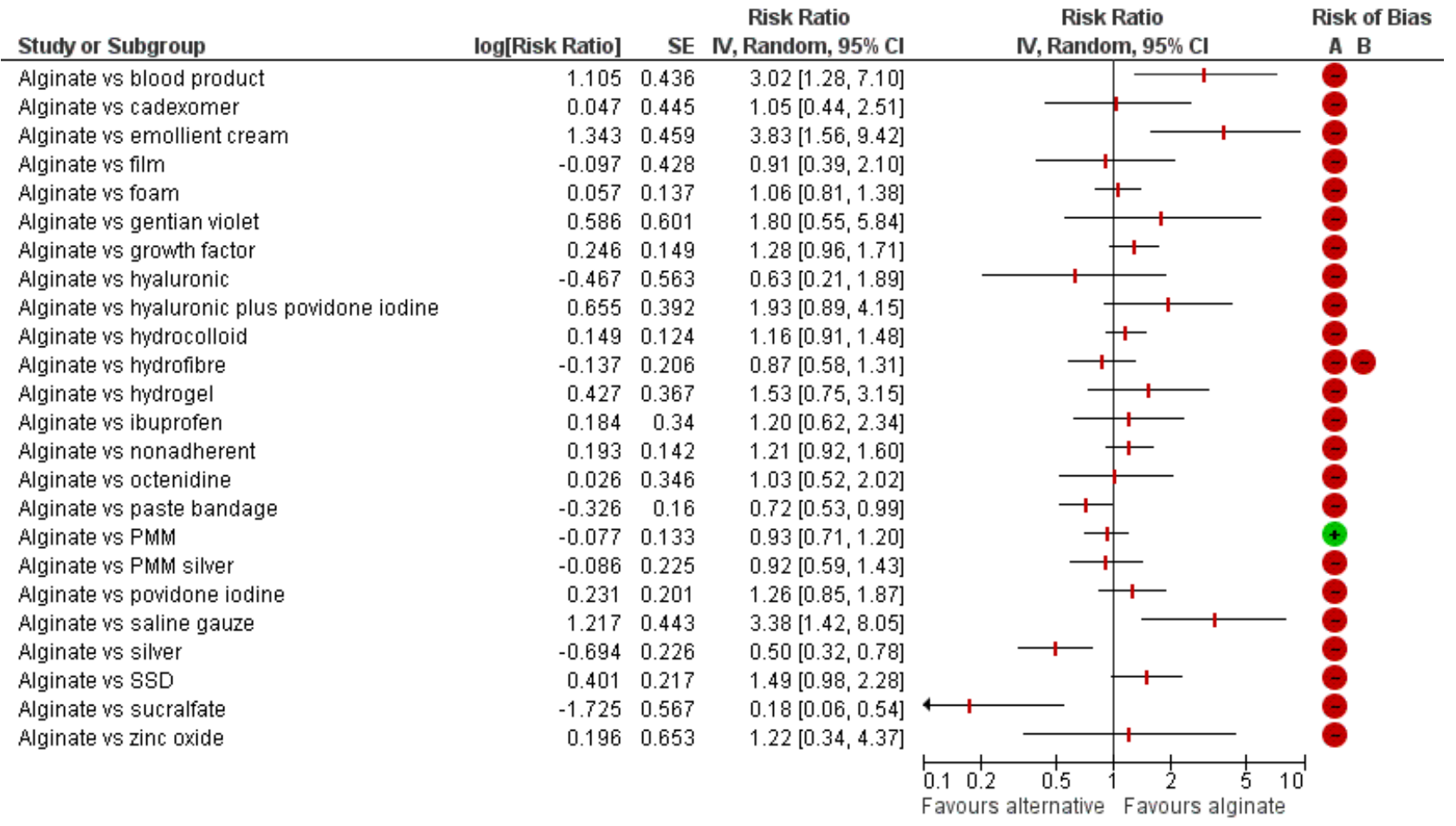

Risk of bias legend

(A) Overall risk of bias 1

(B) Overall risk of bias 2

Figure 12. Comparisons of cadexomer iodine with other treatments in the extended base-case network with risk of bias

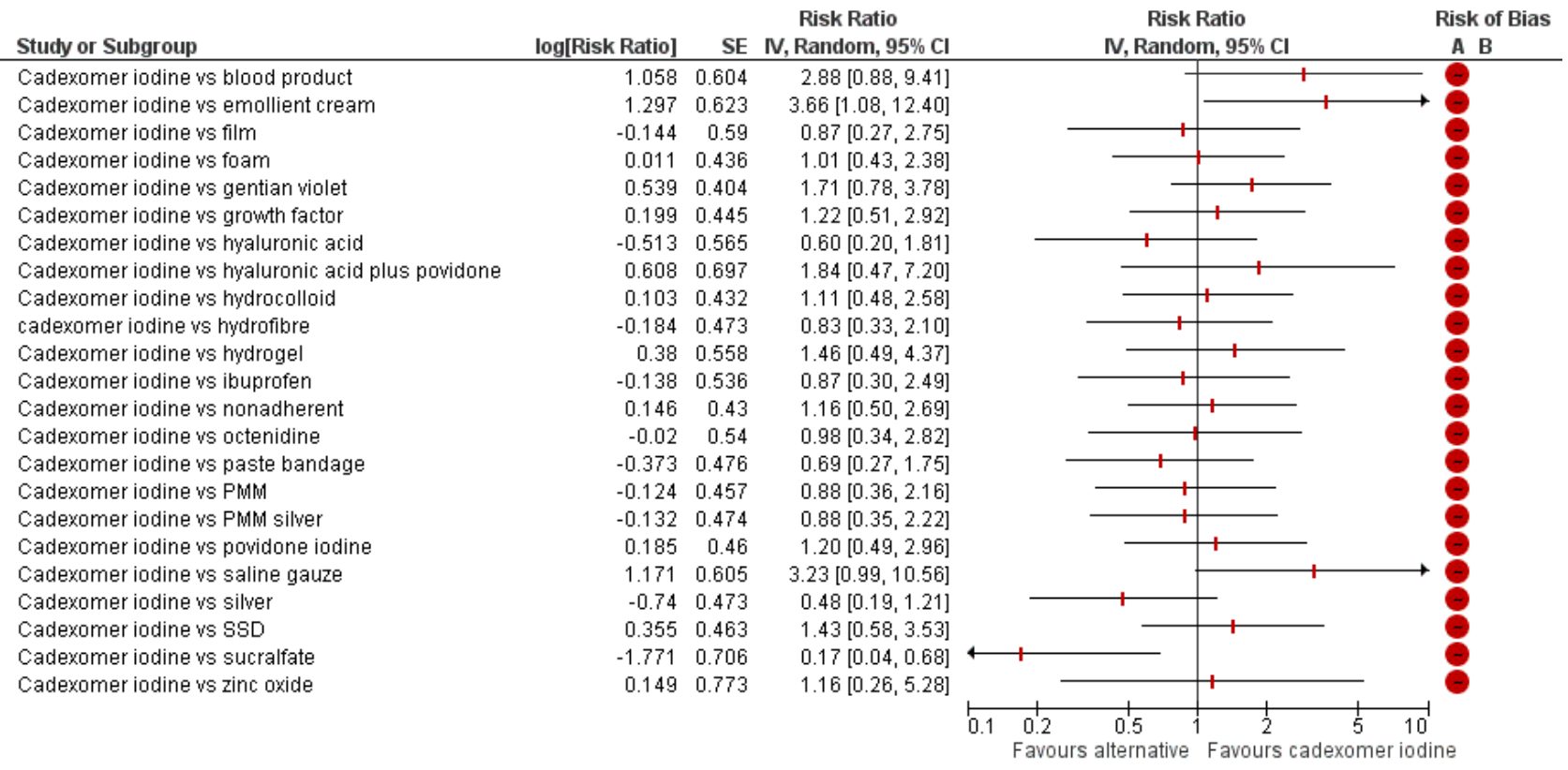

Risk of bias legend

(A) Overall risk of bias 1

(B) Overall risk of bias 2 
Figure 13. Comparisons of foam with other treatments in the extended base-case network with risk of bias

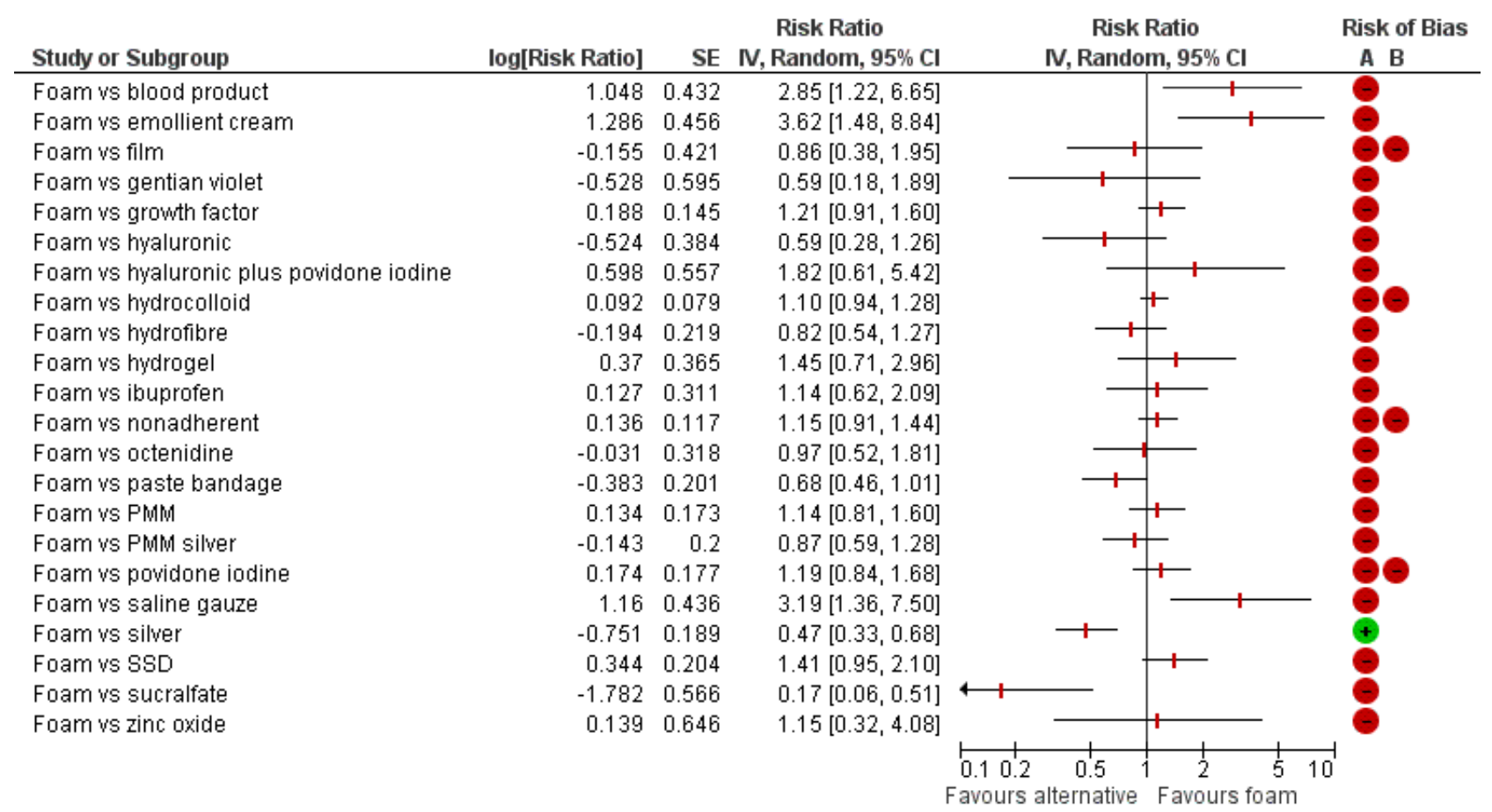

Risk of bias legend

(A) Overall risk of bias 1

(B) Overall risk of bias 2

Figure 14. Comparisons of hydrocolloid with other treatments in the extended base-case network with risk of bias

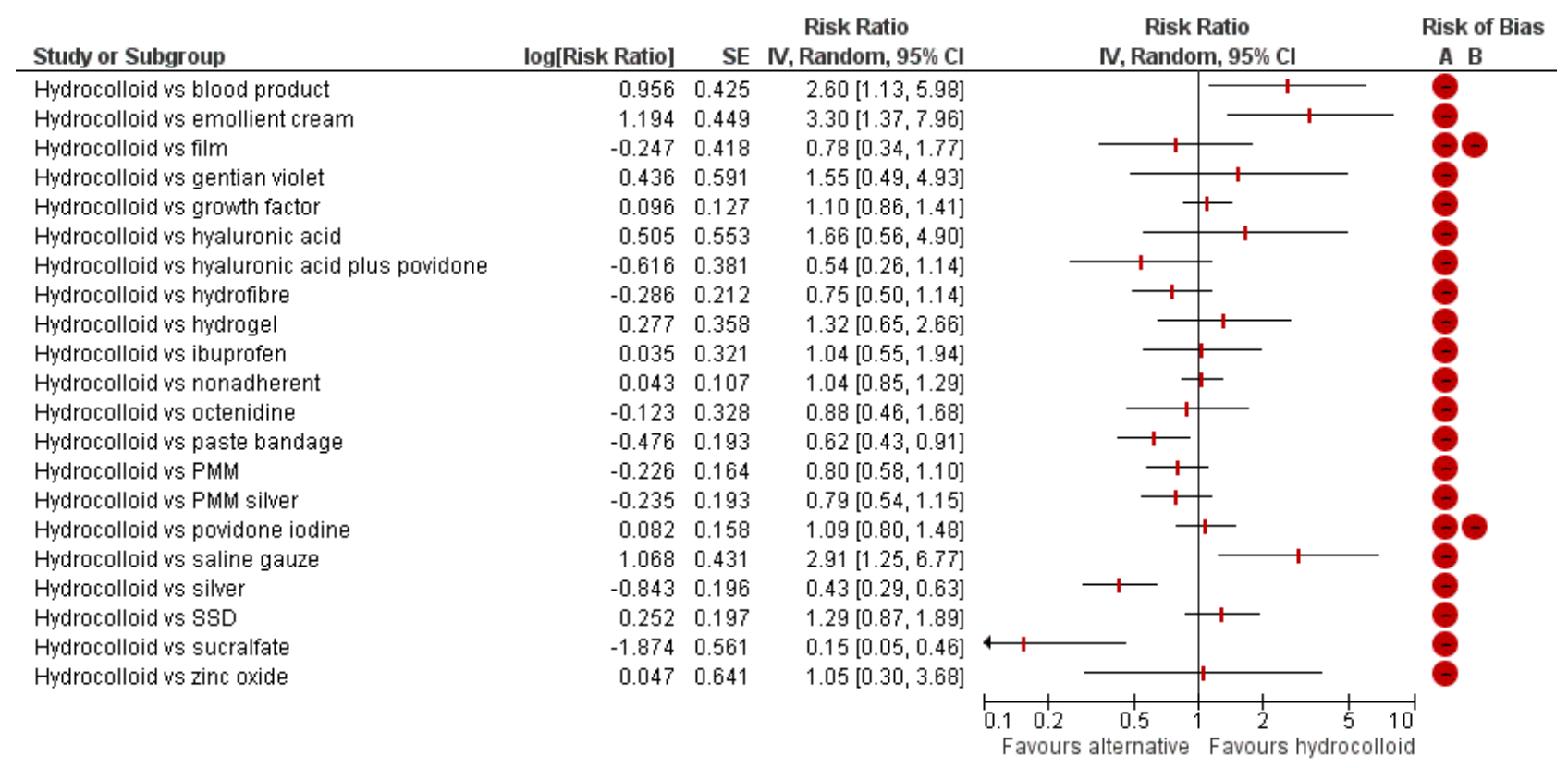

Risk of bias legend

(A) Overall risk of bias 1

(B) Overall risk of bias 2 
Figure 15. Comparisons of hydrofibre with other treatments in the extended base-case network with risk of bias

\begin{tabular}{|c|c|c|c|c|c|c|}
\hline Study or Subgroup & log[Risk Ratio] & SE & $\begin{array}{c}\text { Risk Ratio } \\
\text { IV, Random, } 95 \% \mathrm{Cl}\end{array}$ & $\begin{array}{r}\text { Risk } \\
\text { IV, Rando }\end{array}$ & $\begin{array}{l}\text { Ratio } \\
\mathrm{m}, 95 \% \mathrm{Cl}\end{array}$ & $\begin{array}{l}\text { Risk of Bias } \\
\text { A B }\end{array}$ \\
\hline Hydrofibre vs blood product & 1.242 & 0.465 & $3.46[1.39,8.61]$ & & & \\
\hline Hydrofibre ws emollient cream & 1.48 & 0.488 & $4.39[1.69,11.43]$ & & & \\
\hline Hydrofibre vs film & 0.04 & 0.454 & $1.04[0.43,2.53]$ & & & \\
\hline Hydrofibre vs gentian violet & 0.723 & 0.622 & $2.06[0.61,6.97]$ & & & \\
\hline Hydrofibre ws growth factor & 0.383 & 0.229 & $1.47[0.94,2.30]$ & & + & \\
\hline Hydrofibre vs hyaluronic acid & -0.33 & 0.42 & $0.72[0.32,1.64]$ & & - & \\
\hline Hydrofibre ws hyaluronic acid plus povidone & 0.792 & 0.582 & $2.21[0.71,6.91]$ & & & \\
\hline Hydrofibre vs hydrogel & 0.564 & 0.406 & $1.76[0.79,3.90]$ & & & \\
\hline Hydrofibre ws ibuprofen & 0.321 & 0.381 & $1.38[0.65,2.91]$ & & & \\
\hline Hydrofibre vs nonadherent & 0.33 & 0.206 & $1.39[0.93,2.08]$ & & + & \\
\hline Hydrofibre ws octenidine & 0.163 & 0.386 & $1.18[0.55,2.51]$ & & & \\
\hline Hydrofibre vs paste bandage & -0.189 & 0.267 & $0.83[0.49,1.40]$ & & & \\
\hline Hydrofibre vs PMM & 0.06 & 0.237 & $1.06[0.67,1.69]$ & & & \\
\hline Hydrofibre vs PMM silver & 0.051 & 0.287 & $1.05[0.60,1.85]$ & & & \\
\hline Hydrofibre us povidone iodine & 0.368 & 0.265 & $1.44[0.86,2.43]$ & & 1 & \\
\hline Hydrofibre vs saline gauze & 1.354 & 0.468 & $3.87[1.55,9.69]$ & & & \\
\hline Hydrofibre vs silver & -0.557 & 0.286 & $0.57[0.33,1.00]$ & & & \\
\hline Hydrofibre us SSD & 0.538 & 0.267 & $1.71[1.01,2.89]$ & & & \\
\hline Hydrofibre ws sucralfate & -1.588 & 0.593 & $0.20[0.06,0.65]$ & & & \\
\hline \multirow[t]{2}{*}{ Hydrofibre vs zinc oxide } & 0.333 & 0.675 & $1.40[0.37,5.24]$ & & & \\
\hline & & & & $\begin{array}{ccc}0.1 & 0.2 & 0.5 \\
\text { Favours alternative }\end{array}$ & \begin{tabular}{ccc|}
2 & 5 & 10 \\
Favours hydrofibre
\end{tabular} & \\
\hline
\end{tabular}

Risk of bias legend

(A) Overall risk of bias 1

(B) Overall risk of bias 2

Figure 16. Comparisons of hydrogel with other treatments in the extended base-case network with risk of bias

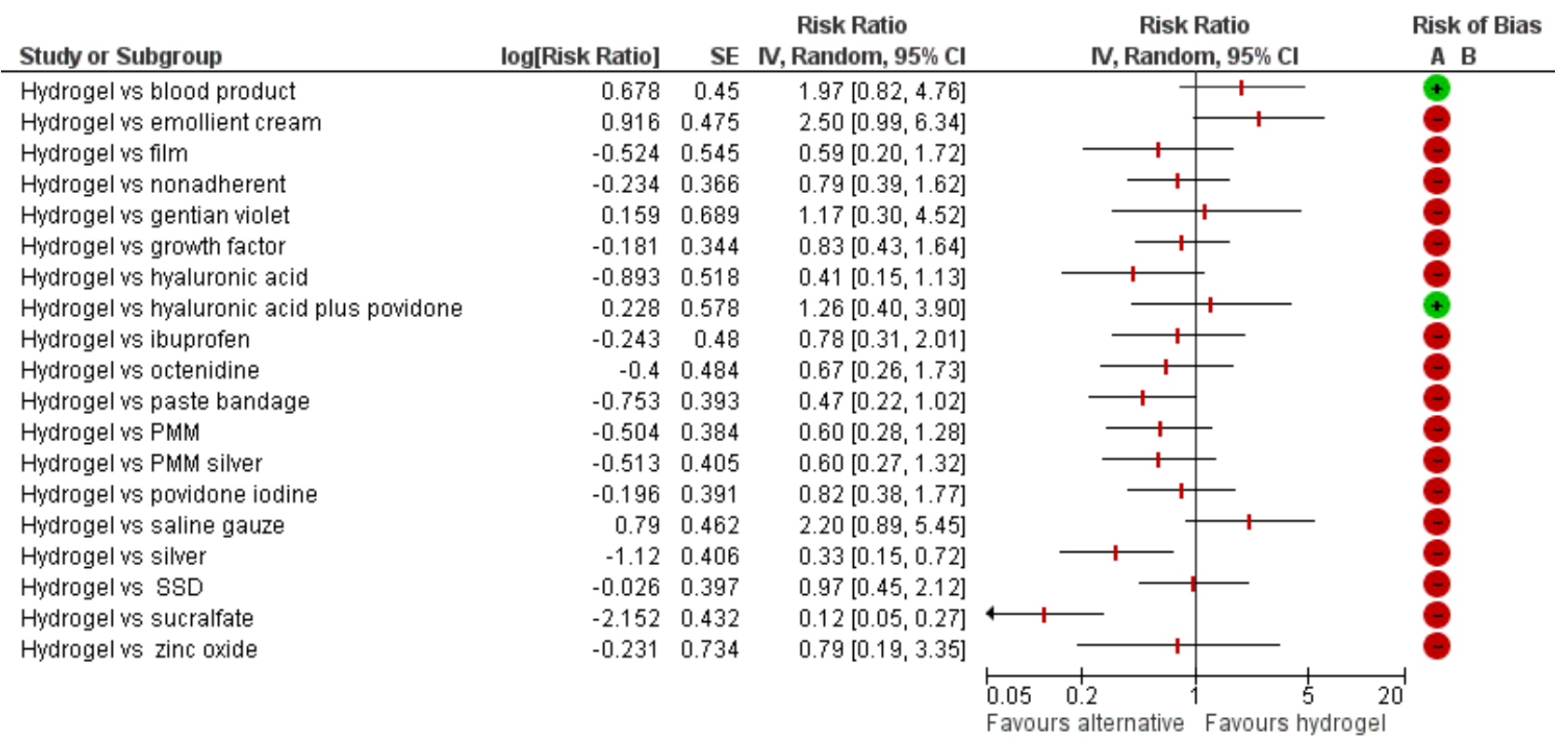

Risk of bias legend

(A) Overall risk of bias 1

(B) Overall risk of bias 2 
Figure 17. Comparisons of paste bandage with other treatments in the extended base-case network with risk of bias

\section{Study or Subgroup}

Risk Ratio

Risk Ratio

Paste bandage vs blood product

Paste bandage vs emollient cream

Paste bandage vs film

Paste bandage vs gentian violet

Paste bandage vs growth factor

Paste bandage vs hyaluronic acid

Paste bandage vs hyaluronic acid plus povidone

Paste bandage vs ibuprofen

Paste bandage vs nonadherent

Paste bandage vs octenidine

Paste bandage vs PMM

Paste bandage vs PMM silver

Paste bandage vs povidone iodine

Paste bandage vs saline gauze

Paste bandage ws silver

Paste bandage vs SSD

Paste bandage us sucralfate

Paste bandage vs zinc oxide

\begin{tabular}{rr} 
log[Risk Ratio] & SE \\
\hline 1.431 & 0.458 \\
1.669 & 0.478 \\
0.229 & 0.466 \\
0.912 & 0.624 \\
0.572 & 0.208 \\
-0.14 & 0.434 \\
0.981 & 0.588 \\
0.51 & 0.37 \\
0.519 & 0.233 \\
0.353 & 0.376 \\
0.249 & 0.209 \\
0.241 & 0.263 \\
0.558 & 0.249 \\
1.544 & 0.473 \\
-0.367 & 0.267 \\
0.727 & 0.279 \\
-1.398 & 0.585 \\
0.522 & 0.669
\end{tabular}

IV, Random, $95 \%$ Cl
$4.18[1.70,10.26]$
$5.31[2.08,13.54]$
$1.26[0.50,3.13]$
$2.49[0.73,8.46]$
$1.77[1.18,2.66]$
$0.87[0.37,2.04]$
$2.67[0.84,8.44]$
$1.67[0.81,3.44]$
$1.68[1.06,2.65]$
$1.42[0.68,2.97]$
$1.28[0.85,1.93]$
$1.27[0.76,2.13]$
$1.75[1.07,2.85]$
$4.68[1.85,11.84]$
$0.69[0.41,1.17]$
$2.07[1.20,3.57]$
$0.25[0.08,0.78]$
$1.69[0.45,6.25]$

IV, Random, 95\% Cl

0.5220 .669

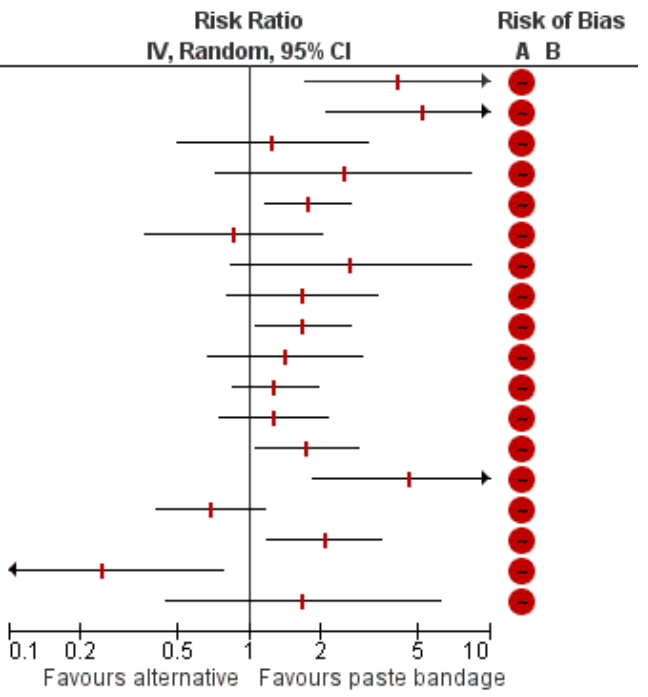

Risk of bias legend

(A) Overall risk of bias 1

(B) Overall risk of bias 2 
Figure 18. Comparisons of PMM and PMM silver with other treatments in the extended base-case network with risk of bias

\begin{tabular}{|c|c|c|c|c|c|c|}
\hline Study or Subgroup & log[Risk Ratio] & SE & $\begin{array}{c}\text { Risk Ratio } \\
\text { IV, Random, } 95 \% \mathrm{Cl} \\
\end{array}$ & $\begin{array}{r}\text { Risk } \\
\text { IV, Rando } \\
\end{array}$ & $\begin{array}{l}\text { Ratio } \\
\text { m, } 95 \% \mathrm{Cl}\end{array}$ & $\begin{array}{l}\text { Risk of Bias } \\
\text { A B }\end{array}$ \\
\hline \multicolumn{7}{|l|}{ 8.1.1 PMM } \\
\hline PMM us blood product & 1.182 & 0.45 & $3.26[1.35,7.88]$ & & & \\
\hline PMM vs emollient cream & 1.42 & 0.472 & $4.14[1.64,10.43]$ & & & \\
\hline PMM us film & -0.02 & 0.44 & $0.98[0.41,2.32]$ & & & \\
\hline PMM us gentian violet & 0.663 & 0.61 & $1.94[0.59,6.41]$ & & & \\
\hline PMM us growth factor & 0.323 & 0.186 & $1.38[0.96,1.99]$ & & 十 & \\
\hline PMM us hyaluronic acid & 0.732 & 0.573 & $2.08[0.68,6.39]$ & & & \\
\hline PMM vs hyaluronic acid plus povidone & -0.39 & 0.405 & $0.68[0.31,1.50]$ & & - & \\
\hline PMM us ibuprofen & 0.261 & 0.356 & $1.30[0.65,2.61]$ & & t & \\
\hline PMM us nonadherent & 0.27 & 0.173 & $1.31[0.93,1.84]$ & & 十 & \\
\hline PMM us octenidine & 0.103 & 0.362 & $1.11[0.55,2.25]$ & & & \\
\hline PMM vs PMM silver & -0.009 & 0.251 & $0.99[0.61,1.62]$ & & 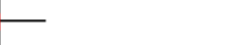 & \\
\hline PMM ws povidone iodine & 0.308 & 0.228 & $1.36[0.87,2.13]$ & & 十 & \\
\hline PMM us saline gauze & 1.294 & 0.456 & $3.65[1.49,8.92]$ & & & \\
\hline PMM us silver & -0.617 & 0.25 & $0.54[0.33,0.88]$ & & & \\
\hline PMM vS SSD & 0.478 & 0.239 & $1.61[1.01,2.58]$ & & & \\
\hline PMM vs sucralfate & -1.648 & 0.578 & $0.19[0.06,0.60]$ & $\longleftarrow$ & & \\
\hline PMM us zinc oxide & 0.273 & 0.662 & $1.31[0.36,4.81]$ & & & \\
\hline \multicolumn{7}{|l|}{ 8.1.2 PMM silver } \\
\hline PMM silver ws blood product & 1.191 & 0.465 & $3.29[1.32,8.19]$ & & & \\
\hline PMM silver vs emollient cream & 1.429 & 0.487 & $4.17[1.61,10.84]$ & & & \\
\hline PMM silver vs film & -0.012 & 0.463 & $0.99[0.40,2.45]$ & & & \\
\hline PMM silver vs gentian violet & 0.671 & 0.61 & $1.96[0.59,6.47]$ & & & \\
\hline PMM silver vs growth factor & 0.331 & 0.228 & $1.39[0.89,2.18]$ & & + & \\
\hline PMM silver vs hyaluronic acid & 0.74 & 0.587 & $2.10[0.66,6.62]$ & & & \\
\hline PMM silver vs hyaluronic plus povidone & -0.381 & 0.43 & $0.68[0.29,1.59]$ & & - & \\
\hline PMM silver ws ibuprofen & 0.27 & 0.37 & $1.31[0.63,2.71]$ & & + & \\
\hline PMM silver vs nonadherent & 0.279 & 0.226 & $1.32[0.85,2.06]$ & & + & \\
\hline PMM silver vs octenidine & 0.112 & 0.375 & $1.12[0.54,2.33]$ & & & \\
\hline PMM silver vs povidone iodine & 0.317 & 0.25 & $1.37[0.84,2.24]$ & & + & \\
\hline PMM silver vs saline gauze & 1.303 & 0.473 & $3.68[1.46,9.30]$ & & & \\
\hline PMM silver vs silver & -0.608 & 0.269 & $0.54[0.32,0.92]$ & & & \\
\hline PMM silverws SSD & 0.487 & 0.279 & $1.63[0.94,2.81]$ & & T & \\
\hline PMM silver vs sucralfate & -1.639 & 0.592 & $0.19[0.06,0.62]$ & $\longleftarrow$ & & \\
\hline PMM silver ws zinc oxide & 0.282 & 0.669 & $1.33[0.36,4.92]$ & & & \\
\hline
\end{tabular}

Risk of bias legend

(A) Overall risk of bias 1

(B) Overall risk of bias 2 
Figure 19. Comparisons of saline gauze with other treatments in the extended base-case network with risk of bias

\begin{tabular}{|c|c|c|c|c|c|c|}
\hline Study or Subgroup & log[Risk Ratio] & SE & $\begin{array}{c}\text { Risk Ratio } \\
\text { IV, Random, } 95 \% \mathrm{Cl}\end{array}$ & $\begin{array}{r}\text { Risk } \\
\text { IV, Rando }\end{array}$ & $\begin{array}{l}\text { Ratio } \\
\text { m, 95\% Cl }\end{array}$ & $\begin{array}{l}\text { Risk of Bias } \\
\text { A B }\end{array}$ \\
\hline Saline gauze ws blood product & -0.112 & 0.138 & $0.89[0.68,1.17]$ & T & & \\
\hline Saline gauze vs emollient cream & 0.126 & 0.222 & $1.13[0.73,1.75]$ & & & \\
\hline Saline gauze ws film & -1.315 & 0.591 & $0.27[0.08,0.85]$ & & & \\
\hline Saline gauze vs gentian violet & -0.632 & 0.728 & $0.53[0.13,2.21]$ & & & \\
\hline Saline gauze vs growth factor & -0.972 & 0.438 & $0.38[0.16,0.89]$ & & & \\
\hline Saline gauze ws hyaluronic acid & -1.684 & 0.566 & $0.19[0.06,0.56]$ & & & \\
\hline Saline gauze ws hyaluronic plus povidone & -0.562 & 0.355 & $0.57[0.28,1.14]$ & & & \\
\hline Saline gauze vs ibuprofen & -1.033 & 0.536 & $0.36[0.12,1.02]$ & & & \\
\hline Saline gauze vs octenidine & -1.191 & 0.54 & $0.30[0.11,0.88]$ & & & \\
\hline Saline gauze vs povidone iodine & -0.986 & 0.459 & $0.37[0.15,0.92]$ & & & \\
\hline Saline gauze ws silver & -1.911 & 0.473 & $0.15[0.06,0.37]$ & & & \\
\hline Saline gauze ws nonadherent & -1.024 & 0.432 & $0.36[0.15,0.84]$ & & & \\
\hline Saline gauze vs SSD & -0.816 & 0.454 & $0.44[0.18,1.08]$ & & & \\
\hline Saline gauze ws sucralfate & -2.942 & 0.633 & $0.05[0.02,0.18]$ & 1 & & \\
\hline \multirow{2}{*}{ Saline gauze vs zinc oxide } & -1.021 & 0.772 & $0.36[0.08,1.64]$ & & & \\
\hline & & & & $\begin{array}{ll}0.05 & 0.2\end{array}$ & & \\
\hline
\end{tabular}

Risk of bias legend

(A) Overall risk of bias 1

(B) Overall risk of bias 2

Figure 20. Comparisons of silver and SSD with other treatments in the extended base-case network with risk of bias

\begin{tabular}{|c|c|c|c|c|c|c|}
\hline \multirow{2}{*}{$\begin{array}{l}\text { Study or Subgroup } \\
\text { 10.1.1 Silver }\end{array}$} & log[Risk Ratio] & \multicolumn{2}{|r|}{ Risk Ratio } & \multicolumn{2}{|c|}{$\begin{array}{c}\text { Risk Ratio } \\
\text { IV, Random, } 95 \% \mathrm{Cl}\end{array}$} & \multirow[t]{2}{*}{$\begin{array}{l}\text { Risk of Bias } \\
\text { A B }\end{array}$} \\
\hline & & & & & & \\
\hline Silver vs blood product & 1.799 & 0.467 & $6.04[2.42,15.09]$ & & & \\
\hline Silver ws emollient cream & 2.037 & 0.489 & $7.67[2.94,19.99]$ & & & \\
\hline Silver vs film & 0.596 & 0.46 & $1.81[0.74,4.47]$ & & 1 & \\
\hline Silver ws gentian violet & 1.279 & 0.622 & $3.59[1.06,12.16]$ & & & \\
\hline Silver ws growth factor & 0.939 & 0.23 & $2.56[1.63,4.01]$ & & 千 & \\
\hline Silver ws hyaluronic acid & 1.348 & 0.586 & $3.85[1.22,12.14]$ & & & \\
\hline Silver ws hyaluronic acid plus povidone & 0.227 & 0.427 & $1.25[0.54,2.90]$ & & + & \\
\hline Silver ws ibuprofen & 0.878 & 0.364 & $2.41[1.18,4.91]$ & & 1 & \\
\hline Silver ws nonadherent & 0.887 & 0.22 & $2.43[1.58,3.74]$ & & 千 & \\
\hline Silver ws octenidine & 0.72 & 0.37 & $2.05[0.99,4.24]$ & & & \\
\hline Silver vs povidone iodine & 0.925 & 0.252 & $2.52[1.54,4.13]$ & & 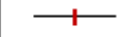 & \\
\hline Silver ws SSD & 1.095 & 0.275 & $2.99[1.74,5.12]$ & & 1 & \\
\hline Silver ws sucralfate & -1.031 & 0.593 & $0.36[0.11,1.14]$ & & & \\
\hline Silver ws zinc oxide & 0.89 & 0.67 & $2.44[0.65,9.05]$ & & & \\
\hline 10.1.2 SSD & & & & & & \\
\hline SSD ws blood product & 0.704 & 0.454 & $2.02[0.83,4.92]$ & & & \\
\hline SSD vs emollient cream & 0.942 & 0.477 & $2.57[1.01,6.53]$ & & & \\
\hline SSD ws film & -0.499 & 0.441 & $0.61[0.26,1.44]$ & & — & \\
\hline SSD ws gentian violet & 0.184 & 0.615 & $1.20[0.36,4.01]$ & & & \\
\hline SSD ws growth factor & -0.156 & 0.216 & $0.86[0.56,1.31]$ & + & - & \\
\hline SSD vs hyaluronic acid & 0.254 & 0.57 & $1.29[0.42,3.94]$ & & & \\
\hline SSD vs hyaluronic acid plus povidone & -0.868 & 0.406 & $0.42[0.19,0.93]$ & 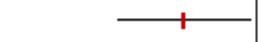 & & \\
\hline SSD vs ibuprofen & -0.217 & 0.372 & $0.80[0.39,1.67]$ & $\longrightarrow$ & - & \\
\hline SSD ws nonadherent & -0.208 & 0.177 & $0.81[0.57,1.15]$ & $\rightarrow$ & & \\
\hline SSD vs octenidine & -0.375 & 0.378 & $0.69[0.33,1.44]$ & + & - & \\
\hline SSD vs povidone iodine & -0.17 & 0.253 & $0.84[0.51,1.39]$ & $\longrightarrow$ & - & \\
\hline SSD ws sucralfate & -2.126 & 0.587 & $0.12[0.04,0.38]$ & $\longleftarrow 1$ & & \\
\hline SSD vs zinc oxide & -0.205 & 0.67 & $0.81[0.22,3.03]$ & & & \\
\hline
\end{tabular}

Risk of bias legend

(A) Overall risk of bias 1

(B) Overall risk of bias 2 
Figure 21. Comparisons of nonadherent with other treatments in the extended base-case network with risk of bias

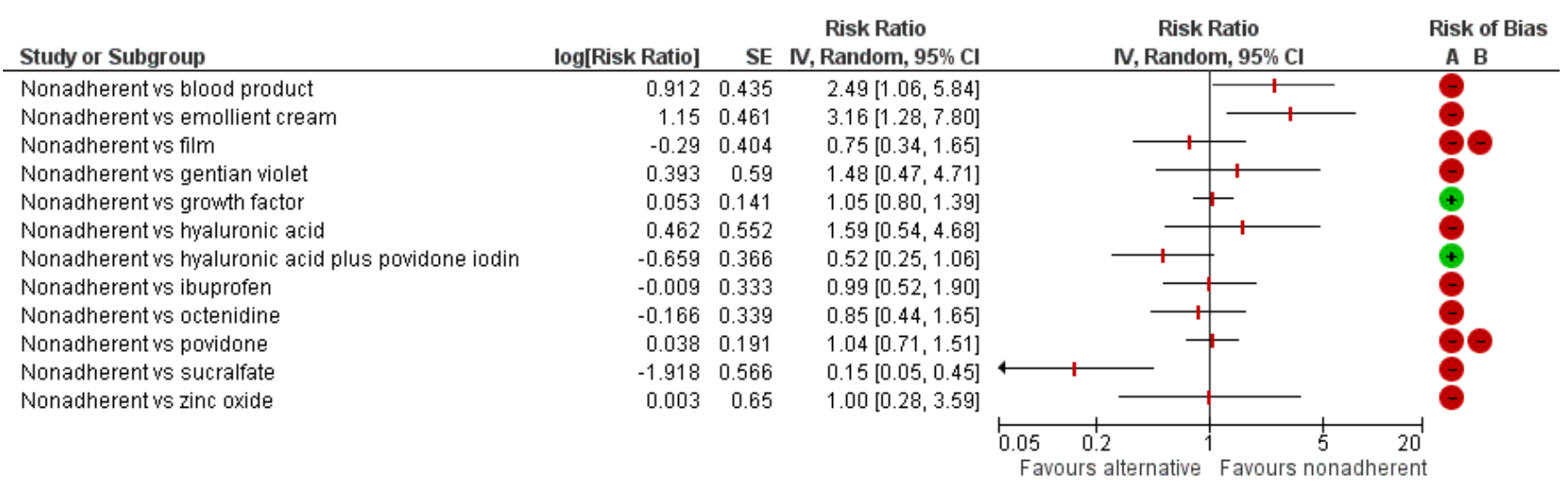

Risk of bias legend

(A) Overall risk of bias 1

(B) Overall risk of bias 2

Rankograms for the extended base-case sensitivity analysis are shown in Figure 4 and the mean rank, SUCRA value and peak probability and its rank in Table 6. The combined rankograms chart is shown in Figure 5: the distinction between interventions was similar to that of the base-case, but the silver treatment had a higher probability at the maximum (50\% versus $38 \%$ ) and saline gauze and hydrogel had approximately half the peak probabilities of the base-case ( $33 \%$ and $20 \%$ respectively). Sucralfate had a SUCRA value of 1 , but no other treatment had a value of 1 or 0 . Importantly, the extended base-case showed that the mean rank for hydrogel was considerably larger than for the base-case (16.9 compared with 8.9) and hydrogel no longer had a peak probability of being the second best treatment, instead it was most likely to be ranked 20th best. Otherwise the mean rank order was the same as that for the base-case. This instability for some treatments is likely to occur because in the base-case the direct evidence (from small studies) had an important contribution.

In the extended base-case network as a whole, there was no significant inconsistency ( $P$ value 0.326 , c.f. base-case 0.566 ). For nodesplitting, the same four contrasts suggested inconsistency as for the basecase, with very similar RoRRs. Again the foam-hydrocolloid-silver loop had inconsistency, with the same RoRR as the base-case (Appendix 7). There was little asymmetry in the funnel plot (Figure 6).

In view of the instability in the base-case network and its dependence on small studies in critical positions, we decided to report the results of the extended base-case sensitivity analysis in the main text and the 'Summary of findings' table.

\section{Appendix 6. Risk of bias in the network}

The percentage contributions to the mixed treatment contrasts from each direct contrast are shown in Table 7 for the extended base-case network contrasts comparing all combinations of silver, sucralfate, non-adherent, foam and hydrocolloid, these were obtained by applying the CINeMA web tool (CINeMA 2017).

We calculated the risk of bias for each contrast in the NMA (based on the direct evidence); risk of bias for each mixed treatment contrast is shown in the last row of Table 7 (see Assessment of risk of bias in included studies).

The contributions to the whole network from each direct contrast were not available from the web tool, but we estimated the risk of bias for the whole network to be high, based on a chart showing contributions to all the mixed treatment contrasts (Figure 22). 
Figure 22. Risk of bias contributions to each NMA comparison in the extended base-case network (vertical scale $0 \%$ to $100 \%)$

red = very high risk of bias, yellow = high risk of bias, green = low risk of bias
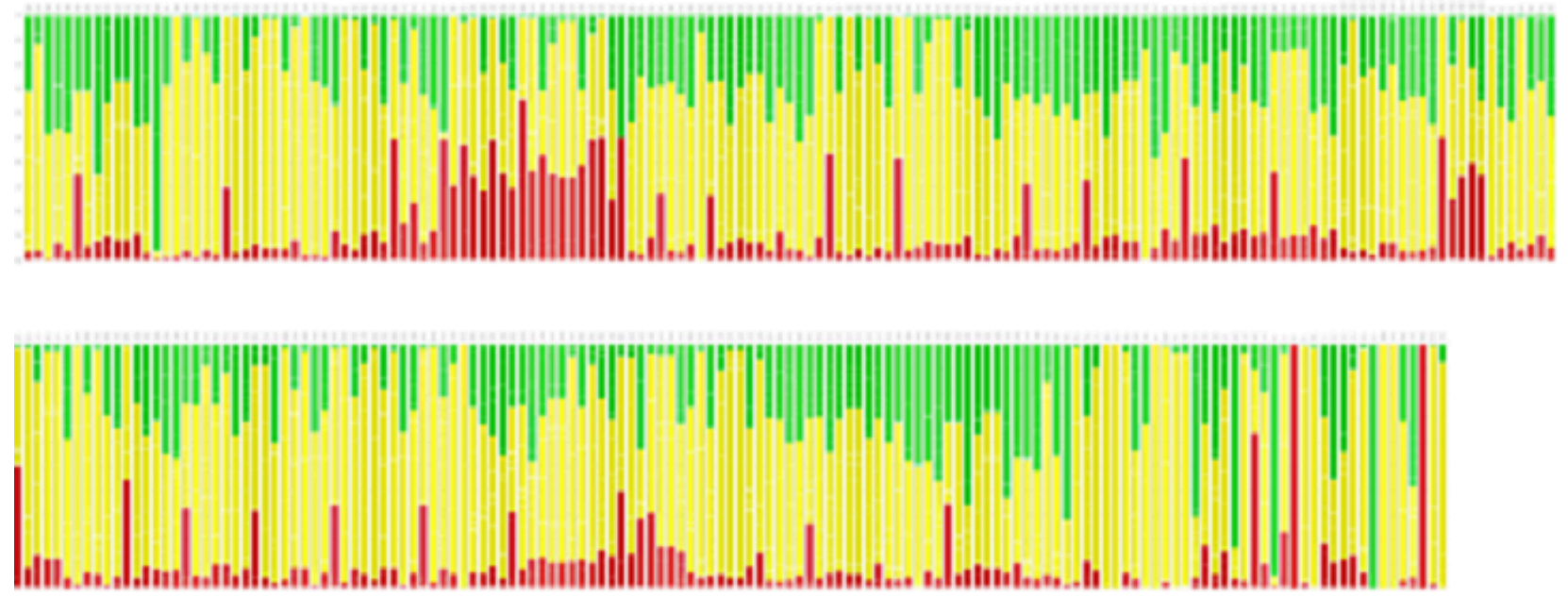

\section{Appendix 7. Inconsistency in the base-case network and sensitivity analyses}

\subsection{Inconsistency in the network as a whole}

We conducted both consistency and inconsistency analyses. The latter gave the following results for the base-case network and the two sensitivity analyses.

Base-case network: the $\mathrm{P}$ value for the 10 inconsistency parameters all being zero was 0.566 and $\mathrm{Chi}^{2}$ (10) was 8.64 (i.e. no significant inconsistency).

Restricted base-case network: the $\mathrm{P}$ value for the 10 inconsistency parameters all being zero was 0.273 and $\mathrm{Chi}{ }^{2}(10)$ was 12.19 (i.e. no significant inconsistency).

Extended base-case network sensitivity analysis: P value for 17 inconsistency parameters all being zero was 0.3259 and Chi (17) was 19.05 (i.e. no significant inconsistency).

\subsection{Inconsistency for each contrast in the extended base-case (local inconsistency)}

We report local inconsistency for the extended base-case only. Firstly, we examined inconsistency factors, comparing results from the direct evidence with those from the indirect evidence for each contrast informed by a loop. We report results as the ratio of risk ratios (RoRR), with its $90 \%$ confidence interval $(\mathrm{Cl})$ for the 15 triangular loops and six quadratic loops (Table 8), assuming a common heterogeneity estimate within each loop (the first set of results in Table 8 have the same values as the base-case). At the $90 \%$ significance level, there appeared to be inconsistency in the foam-hydrocolloid-silver loop (RoRR $2.44,90 \% \mathrm{Cl} 1.23$ to 4.84 ). The results also suggested some non-significant potential inconsistency in all other loops (because the $90 \% \mathrm{Cl}$ crosses 2 or 0.5 or both).

-Secondly, a node-splitting approach was taken. The results following node-splitting for indirect and direct NMA estimates for the extended network are shown in Table 9, together with the ratio of risk ratios (RoRR) (indirect/direct) with its $90 \% \mathrm{Cl}$ (the $90 \%$ significance level was chosen for this test because of its lack of power). The 'indirect' estimate is the result when the NMA is run in the absence of the direct evidence for that contrast. This is only meaningful if the two interventions in the contrast are joined indirectly through the rest of the network; therefore, we report node splitting results for only 28 (of 40) direct contrasts. We made the following observations:

- Results for four contrasts suggested inconsistency at the $90 \%$ confidence level: paste bandage versus alginate (RoRR $0.51,90 \% \mathrm{Cl} 0.28$ to 0.91 ); paste bandage versus foam (RoRR $1.97,90 \% \mathrm{Cl} 1.10$ to 3.55); silver versus hydrocolloid (RoRR $2.50,90 \% \mathrm{Cl} 1.26$ to 4.95 ) and silver versus foam (RoRR $0.40,90 \% \mathrm{Cl} 0.20$ to 0.79 ).

- There was potential for inconsistency for eight other contrasts (with the $\mathrm{Cl}$ including either 0.5 or 2, or both): hydrofibre versus nonadherent (RoRR 1.09, $90 \% \mathrm{Cl} 0.53$ to 2.23); protease-modulating dressing versus nonadherent (RoRR $1.13,90 \% \mathrm{Cl} 0.61$ to 2.11 ); foam versus alginate (RoRR $0.57,90 \% \mathrm{Cl} 0.14$ to 2.36); hydrogel versus nonadherent (RoRR $2.62,90 \% \mathrm{Cl} 0.35$ to 19.5 ); hydrocolloid versus alginate (RoR 0.81, $90 \% \mathrm{Cl} 0.31$ to 2.05); hydrofibre versus alginate (RoRR 1.08, 90\% Cl 0.51 to 2.29); PMM versus foam (RoRR $0.73,90 \%$ $\mathrm{Cl} 0.28$ to 1.90 ); PMM silver versus hydrocolloid (RoRR $0.61,90 \% \mathrm{Cl} 0.31$ to 1.19 ); PMM silver versus foam (RoRR $1.64,90 \% \mathrm{Cl} 0.83$ to 3.21 ); hyaluronic acid versus saline gauze.(RoRR $3.63,90 \% \mathrm{Cl} 0.87$ to 15.21 ) and hydrocolloid versus saline gauze (RoRR $1.84 .90 \% \mathrm{Cl} 0.39$ to 8.7). The contrasts linked to ineligible interventions also showed potential for inconsistency (see Table 9). 
However, all the Cls were wide and there was uncertainty around whether there was inconsistency or not.

\section{CONTRIBUTIONS OF AUTHORS}

Gill Norman: co-ordinated the review; extracted data; checked the quality of data extraction; analysed or interpreted data; performed statistical analysis; checked the quality of the statistical analysis; produced the first draft of the review; contributed to writing and editing the review; approved the final review prior to submission; and is a guarantor of the review.

Maggie Westby: designed the review; analysed or interpreted data; performed statistical analysis; checked the quality of the statistical analysis; produced the first draft of the review; contributed to writing or editing the review; approved the final review prior to submission; and is a guarantor of the review.

Amber Rithalia: extracted data; checked the quality of data extraction; checked the quality of the statistical analysis; and approved the final review prior to submission.

Nikki Stubbs: analysed or interpreted data; advised on the review; and approved the final review prior to submission.

Marta Soares: designed the review; analysed or interpreted data; advised on the review; performed previous work that was the foundation of the current review; and approved the final review prior to submission.

Jo Dumville: conceived and designed the review; analysed or interpreted data; contributed to writing or editing the review; secured funding; and approved the final review prior to submission.

\section{Contributions of editorial base}

Nicky Cullum (Co-ordinating Editor): edited the protocol and the review; advised on methodology, interpretation and content; approved the final review prior to submission.

Gill Rizzello (Managing Editor): co-ordinated the editorial process, advised on content; edited the protocol and the review.

Reetu Child and Naomi Shaw: (Information Specialists) designed the search strategy, ran the searches and edited the search methods section.

Ursula Gonthier (Editorial Assistant): edited the Plain Language Summary, tables and reference sections.

\section{DECLARATIONS OF INTEREST}

Gill Norman: my employment at the University of Manchester while completing this work was funded by the NIHR and focused on highpriority Cochrane reviews in the prevention and treatment of wounds.

Maggie Westby: my employment at the University of Manchester while completing this work was funded by the NIHR and focused on highpriority Cochrane reviews in the prevention and treatment of wounds.

Amber Rithalia: none known.

Nikki Stubbs: I have received consultancy payments from Cogora, a healthcare marketing agency, and expenses for conference attendance. Funding from pharmaceutical companies supports training and education events in the service and I have received payments for non product-related educational sessions. These have been unrelated to the subject matter of the systematic review and have never been in support or in pursuit of the promotion of products.

Marta Soares: none known.

Jo Dumville: I received research funding from the NIHR for the production of systematic reviews focusing on high-priority Cochrane reviews in the prevention and treatment of wounds.

Andrew Jull (peer reviewer): I was lead author of an excluded study. No other conflicts to declare.

Clifford Richardson (peer reviewer): I work at the University of Manchester and know some of the members of the author team, but do not work with them in any capacity.

\section{SOURCES OF SUPPORT}

\section{Internal sources}

- Division of Nursing, Midwifery and Social Work, School of Health Sciences, Faculty of Biology, Medicine and Health, University of Manchester, UK. 


\section{External sources}

- National Institute for Health Research, UK.

This project was supported by the National Institute for Health Research, via Cochrane Infrastructure and Cochrane Programme Grant funding (NIHR Cochrane Programme Grant 13/89/08 - High Priority Cochrane Reviews in Wound Prevention and Treatment) to Cochrane Wounds. The views and opinions expressed herein are those of the authors and do not necessarily reflect those of the Systematic Reviews Programme, NIHR, NHS or the Department of Health.

- National Institute for Health Research Collaboration for Leadership in Applied Health Research and Care (NIHR CLAHRC) Greater Manchester Centre, UK.

Jo Dumville was partly funded by the National Institute for Health Research Collaboration for Leadership in Applied Health Research and Care (NIHR CLAHRC) Greater Manchester. The funder had no role in the design of the studies, data collection and analysis, decision to publish, or preparation of the manuscript. However, the review may be considered to be affiliated to the work of the NIHR CLAHRC Greater Manchester. The views expressed herein are those of the authors and not necessarily those of the NHS, NIHR or the Department of Health.

- NIHR Biomedical Research Centre, UK.

This review was co-funded by the NIHR Manchester Biomedical Research Centre. The views expressed in this publication are those of the author(s) and not necessarily those of the NHS, the National Institute for Health Research or the Department of Health.

\section{DIFFERENCES BETWEEN PROTOCOL AND REVIEW}

The following decisions were made which represent differences between the review and the published protocol (Norman 2017).

Establishment of a narrower base-case of interventions for the main network: after mapping the network of eligible interventions we made the decision to restrict the network to interventions in use in clinical practice rather than primarily research contexts. This both increased the clinical relevance of the results of the analysis and rendered it more amenable to analysis. The number of included interventions remained high, and was further increased by a sensitivity analysis using an expanded data set to examine the stability of the network. Studies which were not included in the network remained in the review and are summarised by direct evidence. We additionally conducted a sensitivity analysis using a narrower set of interventions which were more widely used.

We also made the decision to treat as excluded studies those trials which included only one relevant intervention and which did not perform a linking function in the network; we had planned to list these as included studies with limited data extraction. This was a pragmatic decision made because of the large number of these studies; they are instead clearly identifiable in the list of excluded studies.

We had considered performing a grouped analysis which would have looked at wider groupings of dressing types. Experience (Westby 2017) suggested that this was unlikely to provide useful additional information so we did not conduct this.

We had planned for the potential to conduct various sensitivity analyses which were not in practice appropriate, full details of these are nevertheless provided in the methods.

We had planned to search trials registers and to contact review groups working on ongoing relevant reviews. Time constraints due to the very large number of identified studies meant that this was not undertaken; however a full update search was conducted and all other reference cross-checking was undertaken.

\section{N DEX TERMS}

\section{Medical Subject Headings (MeSH)}

*Bandages; *Wound Healing; Anti-Ulcer Agents [*therapeutic use]; Bandages, Hydrocolloid; Network Meta-Analysis; Randomized Controlled Trials as Topic; Sensitivity and Specificity; Silver [*therapeutic use]; Sucralfate [ ${ }^{\star}$ therapeutic use]; Varicose Ulcer [ ${ }^{\star}$ therapy]

\section{MeSH check words}

Aged; Aged, 80 and over; Female; Humans; Male; Middle Aged 